Wha

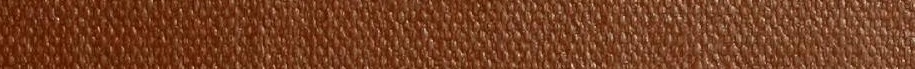

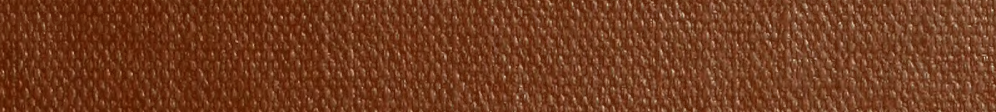

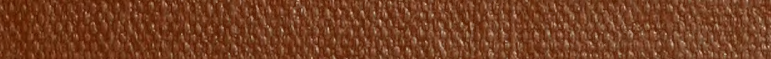

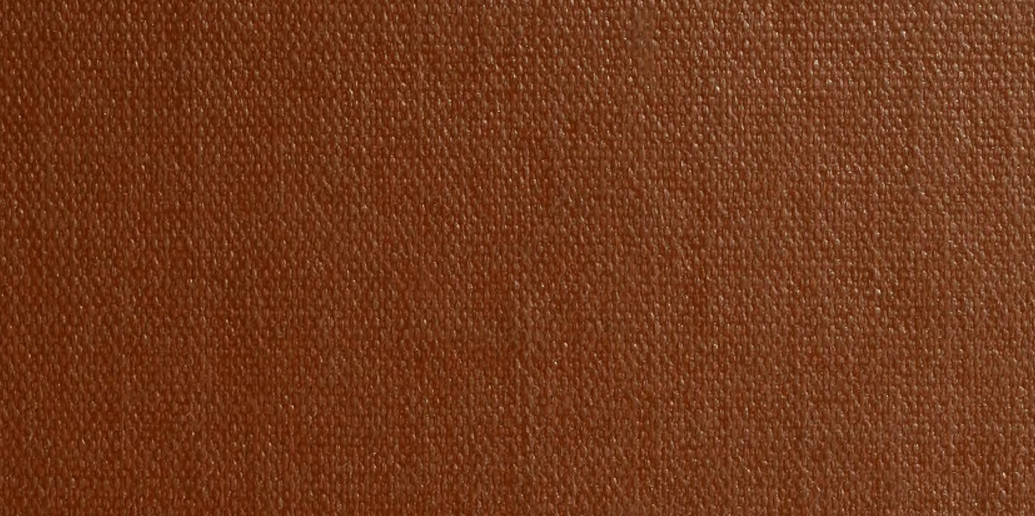



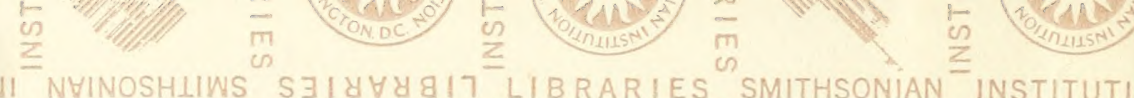

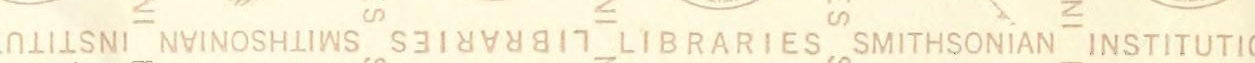

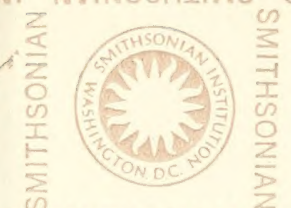

SMI

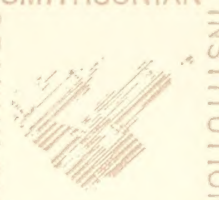

NHINOSHLIWS

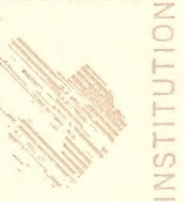

SMITHSONIAN

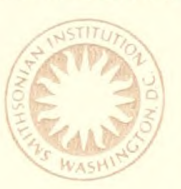

$\$$

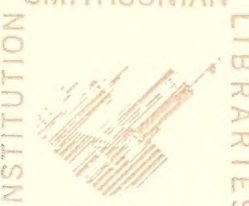

NHINOSHLIWS
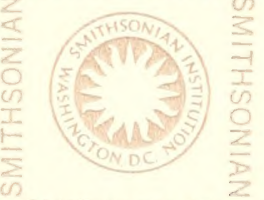

SMITHSONIAN

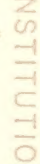

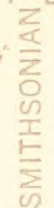
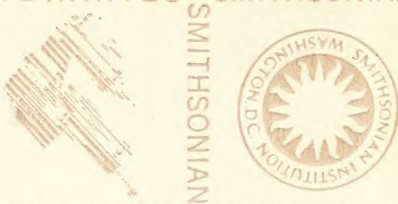

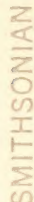

INSTITUTION
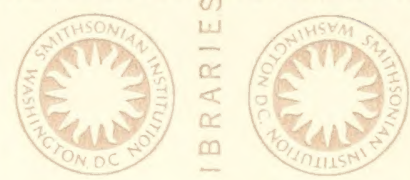

$\bar{z}$
on
-1
$=-1$
$c$
-1
0

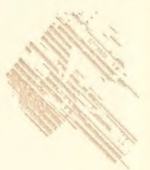

$\frac{\omega}{\alpha}$
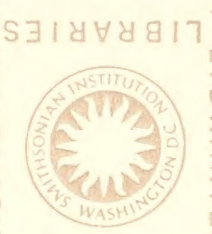

LIBRARIES

SMITHSONIAN

INSTITUTI
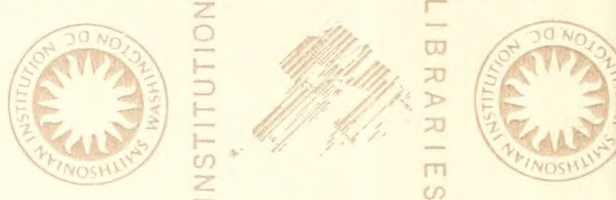

NSTITUTION

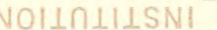

NYINOSHLIWS
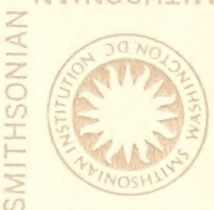

$\frac{0}{3}$

$\exists 18 \forall \forall \notin$
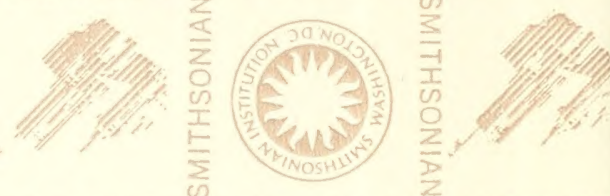

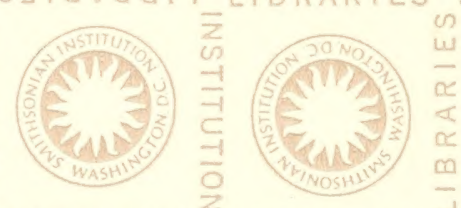

NOILNLILSNI
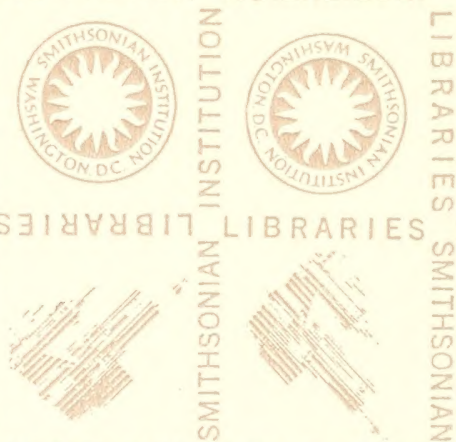

MINOSHHWS
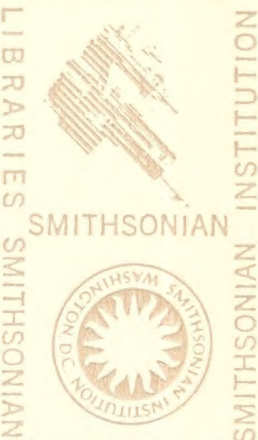

NHINOSHIINS
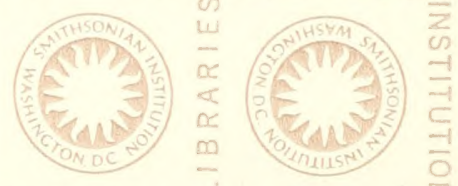
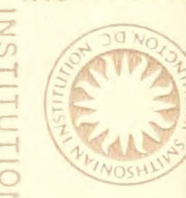

S $\exists \mid \forall \forall \forall \forall 8$

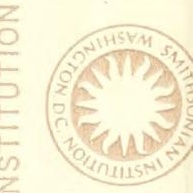


HSNI NHINOSHLIWS SAIBYY817'IBRARIES SMITHSONIAN

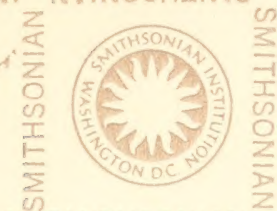

RIES SMITHSONIAN

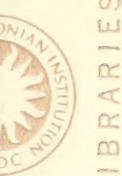

1 SSNI

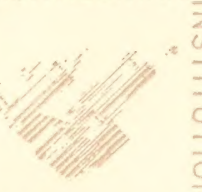

NHINOSHLIWS
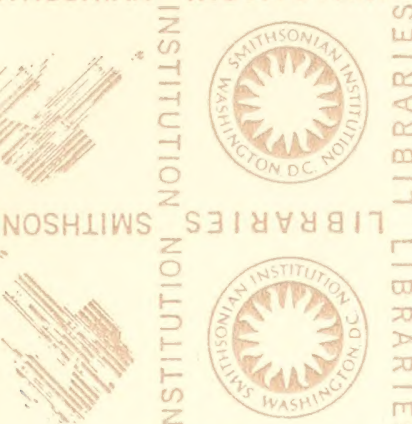

(6)

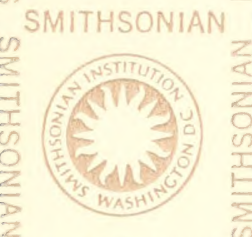

NVINOSHLIWS
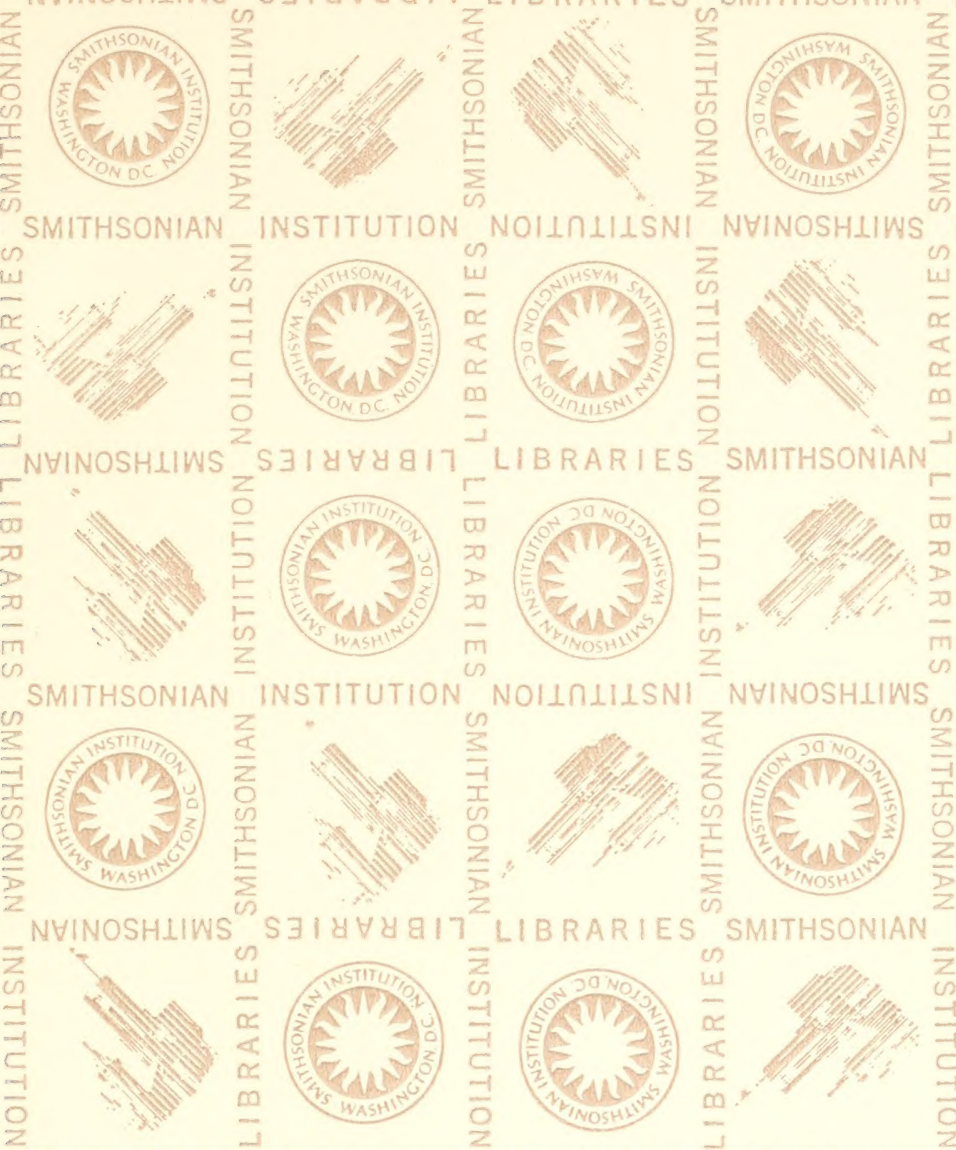

NVINOSHLIWS
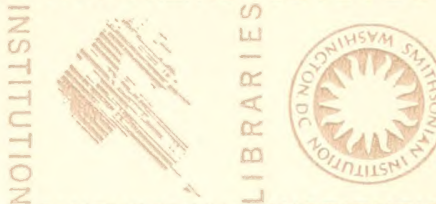

SMITHSONIAN

INSTITUTIC
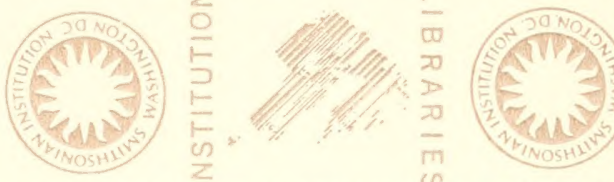

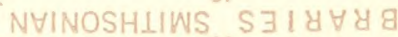
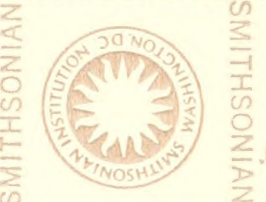

SMITHSONIAN
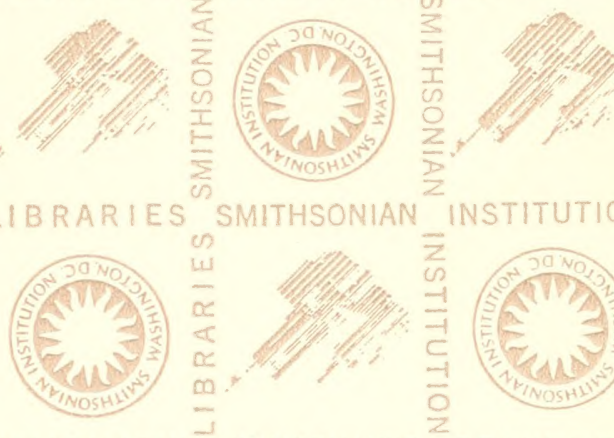

$R \mid E S$
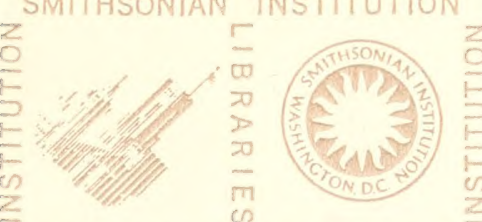

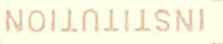
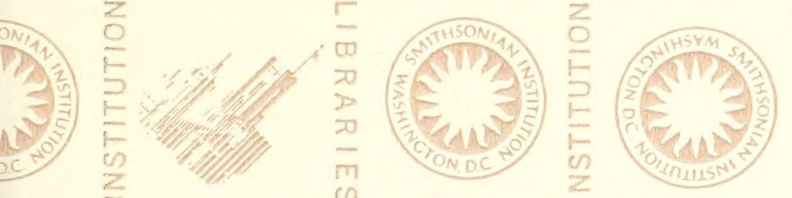

NYINOSHLIWS
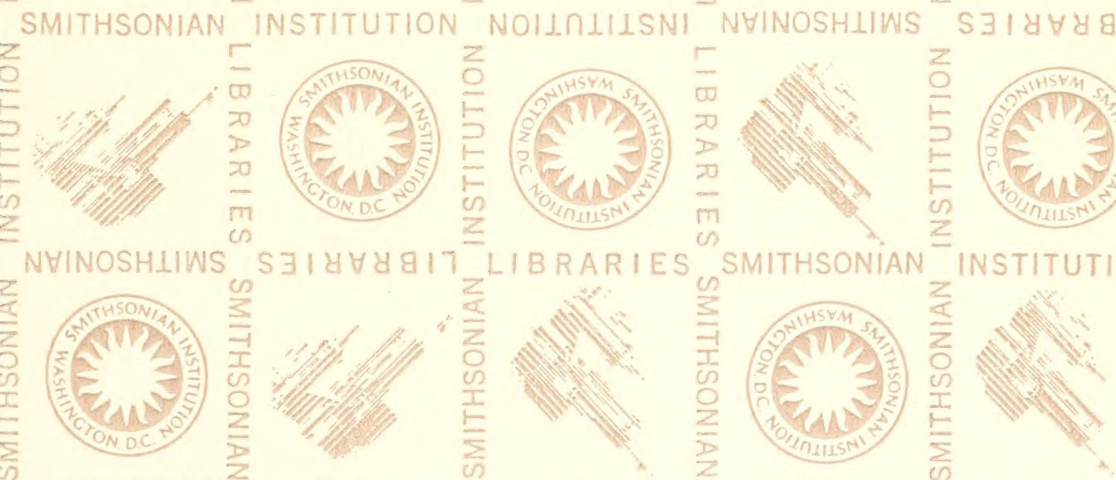

INSTITUTI

ARIES SMITHSONIAN

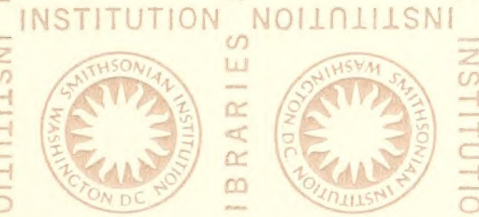

NVINOSHLIWS

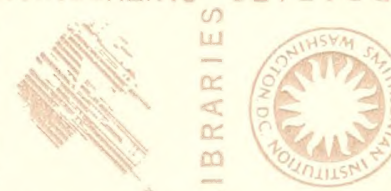





Versuch einer

\section{Avifauna der Provinz Schlesien.}

Von

\section{Dr. Curt Floericke,}

Assistenten am zoologischen Institut der Universităt Marburg.

I. Lieferung.

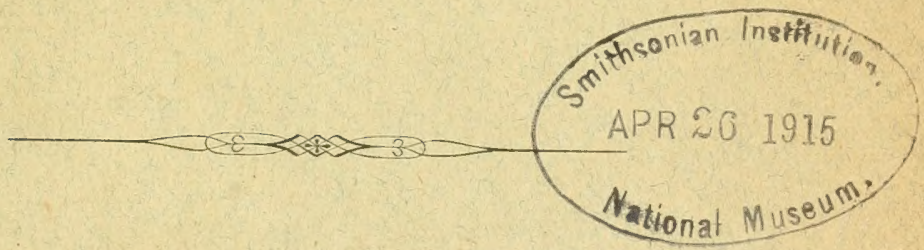

MARBURG.

Universitäts-Buchdruckerei (C. L. Pfeil).

1892.

Die verehrlichen Subskribenten werden hierdurch höflichst gebeten, lèn Subskriptionsbetrag in Höhe von Mark 9.- nach Empfang der Lieferung direkt an den Verfasser einzusenden. 


$$
\frac{03911 \%}{\frac{b}{m}}
$$




\section{Versuch einer}

\section{Avifauna der Provinz Schlesien.}

Von

\section{Dr. Curt Floericke,}

\section{Assistenten am zoologischen Institut der Universität Marburg.}

\section{Lieferung.}

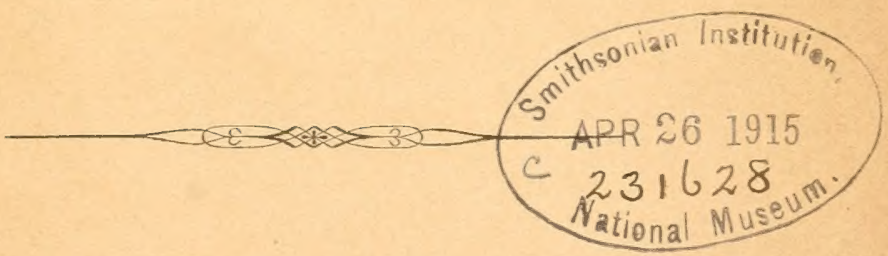

MARBURG.

Universitäts-Buchdruckerei (C. L. Pfeil). 1892. 

Dem Andenken seines teueren Lehrers

\author{
Herrn Geh. Reg.-Rat \\ Prof. Dr. Richard Greeff \\ zu Marburg
}

in aufrichtiger Dankbarkeit gewidmet

vom Verfasser. 



\section{A. Allgemeiner Teil. \\ I. Zur Einleitung.}

Nachdem die systematische und faunistische Ornithologie in der ersten Hälfte unseres Jahrhunderts ilıre grösste Blütezeit erreicht hatte, trat eine Periode entschiedenen Rückgangs ein, bis sich seit einem Decennium etwa ein erneuter Aufschwung in der ornithologischen Forschung bemerklich machte. Den Anstoss dazu gaben wohl hauptsächlich die grossartigen Theorieen Darwins, $\mathrm{zu}$ deren allseitiger Beleuchtung und Untersuchung sich kaum ein anderes Gebiet der Zoologie so sehr eignet als gerade die Ornithologie, wie denn auch die dem Reiche der Vögel entnommenen Beweise bekanntlich in den Werken Darwins einen ganz unverbältnismässig grossen Raum in Anspruch nehmen. Das ist vielleicht der Ornithologie grösstes und vornehmstes Verdienst, auf das sie stolz sein kann, für das sie den Dank aller Gebildeten verdient hat und mit vollem Rechte beanspruchen darf. Von diesen verallgemeinernden Gesichtspunkten aus gewann auch die genaue ornithologische Erforschung der einzelnen Gebiete unseres Vaterlandes erneutes Interesse, und die Ornithologie, die sich vorher fast ausschliesslich den exotischen Avifaunen zugewandt hatte, schenkte ihr jetzt eine verdoppelte Aufmerksamkeit. Musste es doch von grosser Wichtigkeit inbezug auf die Darwinsche Lehre erscheinen, einerseits die schon bekannten Lokalformen und Subspecies näher zu fixiren und ihre Verbreitungsbezirke genau kennen zu lernen und zu begrenzen, andrerseits aber neue aufzufinden. Die Einfülırung der Trinominalität in die ornithologische Nomenklatur wurde damit zur gebieterischen Notwendigkeit. Diese Bestrebungen haben einen ruhmreichen Vorläufer gehabt in der Person des Renthendorfer Pastors Chr. Ludw. Brehm, Vater des bekannten Alfr. Edm. Brehm, der uns noch heute in vieler Hinsicht zum Vorbild dienen kann. Aber dieser scharf blickende Forscher war seiner Zeit vorausgeeilt und wurde nicht von derselben verstanden. Es ist meine feste Ueberzeugung, dass heute eine seiner vielen Subspecies nach der andern eine glänzende 
Auferstehung feiern wird. Wie unendlich viel es in dieser Hinsicht auch bei den gewöhnlichsten und scheinbar allbekanntesten Vogelarten noch zu thum giebt, das hat erst ganz neuerdings wieder die geradezu verblüffende Auffindung zweier gut unterschiedener Lokalformen des gemeinen Staars durch Shar pe und des Eichelhehers durch Kleins ch midt gezeigt. Gute, genaue und ausführliche Avifaunen der einzelnen deutschen Provinzen sind deshalb ein dringendes Bedürfnis, wie dies ja auch die ${ }_{n} \mathrm{All}$ g e meine deutsche ornithologische Gesellschaft" 1890 in Berlin durch Einsetzung eines, $A$ usschuss zur Förderung der deutschen Vogelkunde" gezeigt hat, nachdem der "A usschuss für Beobachtungsstationender Vögel Deutschlands" an leicht vorauszusehenden Hindernissen und Zerwürfnissen gescheitert war. Ton dem genannten Gesichtspunkte aus bitte ich auch den folgenden anspruchslosen Beitrag aufzunehmen, der wenigstens den einen Vorzug hat, dass er mit grosser Lust und Liebe zur Sache geschrieben wurde. Mit einer wahrhaft leidenschaftlichen Begeisterung machte ich mich, als ich im März 1889 nach Breslau iibersiedelte, an die Erforschung der schlesischen Ornis, die mich einerseits durch ihre Eigenartigkeit und Reichhaltigkeit reizte und anzog, und die andererseits in den letzten Jahrzehnten von den Ornithologen fast auflällig vernachlässigt worden war, so dass ich dort ein besonders lohnendes Feld für meine mit jugendfrischem Mute aufgenommene Thätigkeit zu finden hoffen durfte. Auch als ich Schlesien im Herbst 1890 verliess, blieb ich noch bis zu diesen Augenblicke in reger Verbindung mit meinen dort mülssam gewonnenen Mitarbeitern und Beobachtern. Das eine glaube ich behaupten zu dürfen, dass ich keine Opfer an Zeit, Geld und Arbeit gescheut habe, um dem mir gesteckten Ziele wenigstens näher zu kommen. W Weun ich trotzdem meine Aufgabe nur höchst stümperhaft gelöst habe und den sachkundigen Leser um eine nachsichtige Beurteilung der folgenden Mitteilungen dringend bitten muss, so liegt dies einerseits in der Mangelhaftigkeit der ersten Untersuchungen cines jungen, unerfahrenen, umbemittelten und ganz allein dastehenden Anfänger's überhaupt begriindet, andrerseits aber auch zum nicht geringen Teil in den zahllosen und z. T. unüberwindbaren Schwierigkeiten und Hindernissen, die sich einem solchen Unternehmen an und für sich a priori entgegenstellen. Solche Lokalavifaunen haben aber auch noch einen weiteren nicht zu unterschätzenden Wert für die grosse Frage der Migration, die in der Hauptsache nur durch sie einer endgültigen Lösung näher gebracht werden kann. Deshalb wurde auch den Zugverhältnissen in dieser Arbeit eine ganz besondere Aufmerksamkeit geschenkt, obschon ich mir bewusst bin, dass gerade auf diesem Gebiete sich bei so beschränkter Zeit nur höchst schwierig positive Resultate gewinnen lassen. 
Was nun den speciellen Teil der Arbeit anbelangt, so glaubte ich mir, soweit nicht die subspecies inbetracht kommen, eine genaue Beschreibung der einzelnen Arten ersparen zu dürfen, sowohl um den Umfang der Arbeit nicht allzu sehr zu vermehren, als auch weil ja jeder Leser das darüber Nötige in den gebräuchlichen Hand- und Lehrbüchern findet. Dagegen habe ich die meiner Erfahrung nach sichersten Kennzeichen bei jeder Art angegeben. Dieselben wurden zwar zumeist anderen Autoren entnommen, aber an einem grossen Material von Bälgen auf das gewissenhafteste controllirt, und manches danach abgeändert. Grosse Sorgfalt habe ich darauf verwendet, an möglichst viel Exemplaren genaue Maasse zu nehmen, und glaube ich, dass das Vergleichen derselben mit solchen aus anderen Provinzen und Ländern und namentlich auch mit den von Pleske in sciner herrlichen Ornithographia Rossica angegebenen zu interessanten Resultaten führen dürfte. In biologischer Hinsicht wandte ich dem Brutgeschäft und der Wanderung besondere Aufmerksamkeit zu, weil diese beiden Punkte für eine Lokalornis wohl den grössteı Wert haben. Im übrigen teile ich von biologischen Beobachtungen nur solche mit, die entweder neu sein dürften oder aber lokale Abweichungen von dem allgemein Bekannten zeigen.

Es erübrigt nun noch, ein Wort über die angewandte Nomenklatur zu sagen. Mit Freuden würde ich mich in dieser Hinsicht ganz und gar an ein allgemein als gültig anerkanntes systematisches Verzeichnis deutscher Vögel angeschlossen haben; aber ein solches ist eben zur Zeit - ich schreibe diese Zeilen im Januar 1892 - leider noch nicht vorhanden, und so blieb mir nichts anderes übrig, als auch hierin einigermassen meinen eigenen Weg zu gehen und mich der Hoffinung hinzugeben, dass diese fühlbare Lücke recht bald durch die im Mai 1891 in Frankfurt a. M. von der ${ }_{n} \mathrm{Allgem}$. deutschen ornithol. Gesellschaftu zu diesem Zwecke eingesetzte Commission ausgefüllt werden möge. Im allgemeinen habe ich mich an Dr. Reichenows nSystematisches Verzeichnis der Vögel Deutschlands“ gehalten und also danach das Prioritätsprinzip als streng durchzuführende Grundlage anerkannt. Ebenso wie Reichenow damals, bin ich davon in dem Falle abgegangen, wo ein Linné'scher Speciesname von einem späteren Schriftsteller zum Gattungsnamen erhoben wurde. Dagegen konnte ich mich nicht entschliessen, die Dedikationsnamen klein zu schreiben, und endlich habe ich mir noch bezuiglich der Einteilung einzelner Familien in Gattungen in seltenen Fällen Abweichungen erlaubt, die aber jedesmal ausführlich begründet wurden. - Ein Verzeichnis schlesischer Trivialnamen hatte ich bereits früher (Ornithologisches Jahrbuch I1, p. 53-(61) veröffentlicht und habe dasselbe inzwischen nicht unbedeutend elweitert, teils durch eigene Wahrnehmungen, teils dureh dis 
freundliche Unterstützung des Herrn Forstmeister Schmidt in Ratiborhammer, der mir namentlich polnische, und des Herrn Custos Ba er in Niesky, der mir namentlich wendische Bezeichnungen zu übermitteln die Güte hatte. Seinen in der ${ }_{n}$ Allgem. deutsch. ornith. Gesellsch.“ zu Berlin am 23. April 1891 erhobenen Einwurf, dass ich Trivialnamen für niemals in der Provinz vorgekommene Arten angeführt hätte, hat Herr Schalow in der Sitzung vom 7. September 1891 auf die ihm brieflich von mir gemachten Mitteilungen hin wieder zurückgezogen. Ich führe anch diesmal wieder solche in der älteren Litteratur vorgefundene Trivialnamen mit an, deren Träger heutzutage nur noch selten in der Provinz vorkommen, weil sie immerhin philologisch-historisches Interesse haben; so z. B. die Namen für die verschiedenen Arten der Jagdfalken. Ferner hat mir Herr Kollibay (Ornith. Jahrb. II, p. 198-201) den Rat gegeben, dass ich bei den einzelnen Namen auch die Gegend, wo dieselben gebräuchlich sind, näher anführen solle. Ich habc dies nicht gethan, da das ius Endlose führen und den knapp zugemessenen Umfang meiner Arbeit weit überschreiten und ungebührlich vergxüsscrn würde, ohne irgend welehen erheblichen Nutzen zu schatten. Der in Schlesien arbeitende Ornitholog wird sich auch ohne dies sehr bald zurechtfinden. Sehr im Irrtum ist Herr Kollibay ferner, wenn er meint, dass ein beträchtlicher Teil der von mir gesammelten Trivialnamen der Vergangenheit angehöre und heute nicht mehr gebräuchlich sei. Her Kollibay kamn dies doch nicht aus seiner eigenen Unkemutnis derselben ohne weiteres folgern, da er doch nur einen verhältnismässig kleinen Teil Schlesieus kennen gelernt hat! Insofern bin ich trotzdem den Wünschen der Herren Schalow und Kollibay nachgekommen, als ich die wenigen lediglich historisehen Trivialnamen dureh cursiven Druck von den gegenwärtig im Gebrauch befindlichen unterschieden habe.

\section{Geschichte der ornithologischen Erforschung Schlesiens.}

Der meines Wissens erste, der eine vollständige Naturgeschichte der schlesischen Vügel zusammengestellt hat, ist wohl Cas par Schwenkfeld. In seinem 1603 in Liegnitz erscheinenen Teriotropheum Silesiae ist auch der Vogelwelt seiner Heimat ein umfangreiches Capitel gewidmet. Weunschon nach den Anschauungen der damaligen Zeit sich allerhand Aberglauben in seinen Beschreibungen breit macht, die Fledermäuse mit unter den Vögeln figuriren u. s. w., so zeugt doch andrerseits die Arboit 
von einer scharfen Beobachtungsgabe und einer überraschend guten und fortgeschritenen Kenntnis der Vogelwelt. Die meisten Arten sind kurz, aber gewöhnlich recht kenntlich beschrieben und in ihrem Vorkommen und Lebensweise ziemlich treu geschildert. Nur wenige species vermochte ich nicht genau zu identificiren. Danach ruhte die ornithologische Erforschung Schlesiens lange Zeit fast gauz, bis dieselbe gegen Ende des vorigen und Anfang dieses Jahrhunderts einen ungeahnten Aufschwung nahm. In rascher Aufeinanderfolge erschienen jetzt die Ilonographien vou Börner (1781), WVeigel (1806), Endler und Șcholz (1809), Kaluza (1810) und Gloger (1833). Die bei weitem bekannteste derselben ist die letztere, die meiner Ansicht nach beste und zuverlässigste dagegen ganz entschieden diejenige von Kaluza. Die Arbeiten von IV eigel und Börner haben kaum mehr als historischen Wert und leiden viclfach an Jvgenauigkeiten aller Art. Endler und Seholz geben weniger eine Lokalfauma als vichmehr Naturschilderungen und legen auf die biologische Seite das Hauptgewieht; ihr IV erk ist unfangreich und mit kenntlichen Buntbildern geziert.

Der berühmteste aller schlesischen Famnisten ist aber wie gesagt Dr. Coustantin Lud wig Gloger, der als Gymmasiallehrer in Breslau lebte und spiiter nach Berlin übersiedelte, wo er nach mehrjïhrigen schweren Leiden am 30. Dec. 1863 starb. Cab an is nemt ihn neinc'n vielseitigen, gemeinnützigen, echt dentschen Golehrten." Der von Ca ba 11 is (Journ. f. Ornith., $18(i t$, p. 30$)$ in Aussicht gestellte Nekrolog ist leider meines Wissens niemals erschienen, und mir sclbst ist es trotz vieler Beniilnungen nicht gelungen, Näheres über den Lebensgang Glogers in Erfahrung zu bringen. Gloger gehörte der naturwissenschaftlichphilosophischen Richtung an, die damals vicle Anhänger und Bewunderer fand und G. bei denselben eine hervorragende Stellung sicherte, uns heutzutage aber wenig sympathisch erscheinen will. Viele ornithologische Aufsätze Glogers leiden deshalb unter einem wenig verständlichen und zumeist recht überflüssigen Wust von weitschweifigen philosophischen Erörterungen und Betrachtungen. Am besten und zuverlässigsten sind Glogers Mitteilungen aus dem Riesengebirge, wo er sich mit Vorliebe aufhielt und namentlich über die vertikale Verbreitung der Vögel sehr genaue und wertvolle Aufzeichnumgen machte. Dagegen hat seine, Wirbeltierfauna Schlesiens" den grossen Nachteil entsetzlicher Unbestimmtheit; Ausdrücke wie „brütet vielleicht", „wahrscheinlich", „unter Umständen", "woht" oder "könnte" und noll vorkommen" u. s. w. sind an der 'Tagesordnung' und kümnen denjenigen, der auf' Glogers „Virbeltierfauna him weiter bauen will, schier zur Terzweiflung bringen. Schon aus diesem Grunde ist mir Kaluzas Werk, das ïbrigens Gloger sehr stark benützt hat, immer lieber gewesen, 
und habe ich dasselbe auch stets zuverlässiger befunden. Kaluza war übrigens glcichfalls als Gymnasiallehrer in Breslau thätig. Seit Glogers "Wirbeltierfauna Schlesiens" ist bisher keine allgemeine schlesische Ornis mehr erschienen, und da die rastlos fortschreitende und das Land verändernde menschliche Cultur inzwischen mannigfache Veränderungen in unserer Vogelwelt hervorgebracht haben wird, da die heutige Wissenschaft vieles unter ganz anderen Gesichtspunkten betrachtet, und da unsere Ornis seitlem um manche Art und um manche schöne Beobachtung bereichert worden ist, so war eine Neubearbeitung der schlesischen Ornis eine Notwendigkeit, welche mein Hervortreten mit dieser Arbeit verzeihlich und erklärlich machen möge.

Seit 1376 hatte der "Ausschuss f. Beob. Stat. d. Vögel Deutschl." auch in Schlesien cinige Beobachter angeworben, deren Zahl sich rasch steigerte (Auras, Deditius, Emmrich, Fritseh, Hirsch, Hosius, Kaiser, Kern, Kollibay, Kutter, v. Meyerinck, Mischke, Mohr, Müller, Peck, F. Richter, Schmiedehen, Spalding, 'Thiemann, Wagner, Weiss, Willimek, Wolf, Limmormann), ohne dass jedoch damit die Reichlaltigkeit, Güte und Zuverlässigkeit der Beobachtungen gleichen Sehritt hielt. Vichehr wurde wie in den meisten Gegenden Deutschlands so auch hicr - abgesehen von einigen rülımlichen Ausnahmen - durch diese tinrichtung wenig oder nichts gewonnen. Für den $A$ usschuss z. Förderung d. deutschen Vogelkundew, welcher die unterbrochene Arbeit vou neuem in verbesserter' Weise wieder aufnehmen soll, wurde von der ornithol. Gesellschaft $1890 \mathrm{Her}$ Rechtsanwalt Kollibay in Neisse als Vertreter Schlesiens gewählt, dem späterhin noch Verf. zur Seite trat. Einer zwischen uns getroffenen Verabredung zufolge wird künftighin Herr Kollibay den Regierungsbezirk Oppeln bearbeiten, wïhrend ich dic Regierungsbezirke Breslau und Liegnitz ïbernommen habe. Auch an dieser Stelle möchte ich die Herrn Beobachter bitten, dementsprechend ihre Einsendungen machen zu wollen.

Die Lausitz ist entschieden der ornithologisch bei weitem am besten erforschte Teil der Provinz. Die „Naturforschende Gesellschaft in Görlit ${ }^{6}$ hat von jeher der Vogelwelt ilurer Heimat eine ganz hervorragende Aufmerksamkeit zugewendet, and eine Reihe tüchtiger und wohlgeschulter Forscher hat vereint dazu beigetragen, die Ornis der Lausitz in einer WVeise klar zu stellen, wie dies nur in den wenigsten Gegenden Deutschlands der Fall ist. Schade, dass man dies nicht auch von den anderen Teilen der Provinz sagen kann! Den ersten Rang unter den lausitzischen Forschern nimmt wohl Rober t Tobias ein; namentlich in seinen Briefen an E. F. v. Homeyer tritt er uns als ein ebenso bescheidener und liebenswuirdiger wie kenntnis- und erfolg- 
reicher Ornithologe entgegen. Seine grösseren Arbeiten (Die Wirbeltiere der Oberlausitz 1849 , Verzeichnis der in der Oberlausitz vorkommenden Vögel 1851, Die Wat- und Schwimmvögel der Oberlausitz 1853) sind entschieden mit das Beste, was je uiber die schlesische Vogelwelt geschrieben worden ist. Schon vor ihm waren verschiedene Lokalavifaunen der Lausitz verötfentlicht worden, so von v. Uechtritz (1822), Starke (1823), J. G. Krezschmar (18.23), Brahts (18.7), Neumann (1823) und Fechner (1851). Anch die Herren v. Loebenstein und v. Zittwitz beteiligten sich eifrig an der ornithologischen Erforschung ihrer Heimat und legten bedeutende Sammlungen an, während das Museum der naturforschenden Gesellschaft in Görlitz" in ornithologiseher Hinsicht näehst dem UniversitïtsMuseum in Breslau wohl als die wichtigste und bedeutendste Sammlung in Sehlesien zu nennen ist. Gerade bei den lausitzischen Forschern tritt uns sodamn noch eine ammutende Erscheinung entgegen, die wir auch sonst vielfach verbreitet finden, dass nimmlich die Vorliebe und die Begeisterung für Ornithologie in bestimmten Familien sich vererbt und f'cstsetzt, so dass dieselben mehrere Forseher zu liefern imstande sind. So haben Robert Tobias und J. G. Krezschmar in Louis Tobias und Karl Robert Krezschmar würdige Epigonen gefunden. Später kam auch noch $A$. von $H$ omeyer nach Görlitz und neben ilım sind ans neuerer Zeit noch l'eck und Arthur Richter als lausitzische Ornithologen zu nennen, unter welehen gegnenwärtig wohl mein eifriger und glücklicher Mitarbeiter WV illiam Baer, Custos am Museum zu Niesky, die hervorragendste Stellung einuehmen dürfte.

Weit weniger gut sind wir iiber Nieder'schlesien unterrichtet. Einige der lausitzischen Forseher erstreckten allerdings ihre Thätigkeit teilweise auch mit über dieses Gebiet, so namentlich Arthur Richter und der jüngere Krezsehmar; ganz besonders schüne and wichtige Beobachtungen hat sodann der jüngere Tobias daselbst angestellt. 1. v. II o meyer beobachtete mit grossem Fleiss und vielem Glück mehrere Jahre bei Glogau, wo er ja bekanntlich auch 1 si:i Ardea egretta brïtend autfand. Ferner wiire noch als Erforseher der Gegend von Cauth und Neumark Forstmeister v. Meyerinck und als eifriger Beobachter in Bolkenhayn aus nenester Zeit wieder ciner meiner Mitarbeiter, Fabrikdirektor Sylender, zu nennen. Der in maneher Hinsicht so interessante Zobten endlich hat nenerdings in der Yerson von Karl Kna uthe gleichfalls einen gecigneten und rührigen „Vogelwä̈rter" gefunden.

In den Oderwaldungen Mitielschlesiens haben fast alle die in der allgemeinen Uebersicht genamnten Autoren zearbeitet, so namentlich Kaluza und Gloger. Lus nenerer Zeit wären Arlt und Graf' Roedern zu nennen, zwei ïusserst tüchtige und auf- 
merksame Beobachter, die leider beide viel zu wenig über ihre hervorragenden Forschungen veröffentlicht haben. A. v. Homeyer ist auch hier wieder hervorzuheben; daneben endlich noch zwei Conservatoreu des Breslauer Museums, Rotermund und Ti emanu. Auch ich selbst habe vornehmlich in der Breslauer Gegend beobachtet, so insbesondere in der ornithologisch ja schon längst durch Gloger und A. v. Homeyer zum locus classicus gewordenen Strachate, wo ich so unendlich schöne und glücklicheStunden verlebt habe, reich an reinen Forscher- und Jägerfreuden und so recht geeignet, mit mancher Enttäuschung und Verkennung wieder auszusöhnen.

Was nun die Sudeten und ihre Vorberge anlangt, so verdanken wir hier gleichfalls die genauesten und zuverlässigsten Nachrichten dem alten Gloger. Die höchst eigenartige und z. T. rein alpine Flora und Fauna des Riesengebirges insbesondere hat von jeher die Aufmerksamkeit der Naturkundigen auf sich gezogen und fesselt dieselbe auch noel heute in ganz hervorragenden Maasse, ohne doch darum in allen ihren Teilen so genau und gründlich bekannt zu sein, als es zu wïnschen und nach dem Gesagten eigentlich auch zu hoffen wäre. Wohl hat sich Gloger sehr sorgfültig und eingehend mit der vertikalen Verbreitung der einzelnen Vogelarten befasst, aber er war als leidenschaftlicher Gegner des älteren $\mathrm{Brehm}$ viel $z u$ sehr in seinen polemischen Anschauungen gegen den viel bekïmpften nArtzersplitterer" befangen, ais dass er die hervorragend interessanten Lokalvarietäten und Subspecies des Riesengebirges in ruhig-objektiver Weise hätte studieren und fixieren können, und auch keiner der folgenden Forscher hat in diese mit der "Zeit immer unklarer und verworrener" werdenden Verhältnisse volles Licht zu bringen vermocht. Es ist deshalb anzunchmen, dass ein längeres und sorgfültiges Beobachten im Riesengebirge - gegenüber den tlüchtigen 'Touristentouren der dasselbe bisher besuchenden Onithologen - zu ganz neuen und überraschenden, jedenfalls aber zu wissenschaftlich höchst wertvollen Resultaten fülıren würde. Hollen und wünschen wir im Interresse unserer schönen Wissenschaft, dass das Schicksal recht bald einen tüchtigen Ornithologen an jene reizvollen Berge fesseln möge. Von den lansitzischen Forschern haben Karl Rob. Krezschmar und beide Tobias wiederholt das Iser- und Riesengebirge besucht, Zacharias hat sich daselbst länger aufgehalten, einige der grössten deutschen Ornithologen, wie v on Ts chusi, A. v. Homeyer, A. E. Brehm und Rud. Blasius haben das Gebiet Rübezahls mehrfach durchstreift und Forstmeister II osius hat daselbst im Auftrage des ${ }_{n}$ A ussch. f. Beob. Stat. d. Vögel Deutschl." mit dem gesamten gräfl. Schaffgotsch'schen Forstpersonal Beobachtungen angestellt. Neuerdings ist man auch auf der österreichischen Seite rüstig vorgegangen, und müssen die Namen Capek, Eder und Michel hier rühmende Erwähnung 
finden. Ueber das Glatzer Gebirge hat v. Uechtritz näher berichtet. Jetzt ist dort mein Mitarbeiter Emmrich thätig.

Als ich von Thüringen nach Breslau übersiedelte, warf ich einen Blick auf die Specialkarte Schlesiens. "Sobald ich kann, geht's nach der Bartschniederung“, sagte ich dabei zu meinen Freunden, „das muss dic ornithologisch günstigste und interessanteste Gegend Schlesiens sein ". Und meine Erwartungen sollten nicht nur erfüllt, sondern noch weit übertroften werden! Es erscheint in der That sonderbar und auffallend, dass keiner der früher in Schlesien thätig gewesenen Ornithologen auf den Gedanken kam, der Bartschniederung einmal cinen Besuch abzustatten, obschon viele seltene Stäcke des Breslauer Museums von dort stammen, obschon die dort so zahlreich vorhandenen Brücher und Teiche von vornherein einen bevorzugten Brutplatz des Sumpf- und Wassergeflügels vermuten lassen, und obschon endlich - wie gesagt - ein flüchtiger Blick auf die Karte genügt, um sofort die Wichtigkeit der Bartschniederung für den Vogelzug zu erkennen. Nur durch Graf Roedern und Förster Spalding waren bisher einige spärliche Mitteilıngen über den Reichtum der dortigen Vogelivelt unter das oruithologische Publikum gedrungen.

Auch das viel verschrieene und doch in mehr denn einer Beziehung so interessante Oberschlesien müssen wir leider in ornithologischer Hinsicht grösstenteils noch als eine vollkommene terra incognita bezeichnen. A. v. Homeyer kam im Feldzuge 1866 dort an die Grenze und hat darüber auch ausführlich berichtet, und Kutter hielt sich von 1832-83 in Neustadt auf, woselbst ihm Kollibay zur Seite stand. Letzterer setzt jetzt noch seine Arbeit in Neisse allein fort und ist Berichterstatter für den Regierungsbezirk Oppeln im ${ }_{n}$ Aussch. z. Förderung d. deutsch. Vogelkunde." Ich selbst bereiste Oberschlesien im Frühjahr 1891. Neben Kollibay halten dort gegenwärtig noch Forstmeister Schmidt in Ratiborhammer und cand. theol. Uttend örfer in Gnadenfeld bei Kosel das ornithologische Banner aufrecht.

Während ich über die Biographien der älteren schlesischen Ornithologen trotz aller Bemühungen leider so gut wie gar nichts in Erfahrung bringen konnte, bin ich durch die Güte einiger Herrn wenigstens instand gesetzt, über den Lebensgang der folgenden noch lebenden schlesischen Ornithologen zu berichten. Ich lasse die betreffenden Mitteilungen hier folgen.

Alexander v. Homeyer, geboren am 19. Januar 1834 zu Vorland bei Grimmen in Neu-Vorpommern, evangeliscl, vom 11.-18. Jahre Cadett in Potsdam und Borlin, am 3. Mai 1852 als Portepeefühnrich ins Schlesische Füsilierregiment Nr. 38 versetzt. Während des Krieges 1866 wurde H. zum Hauptmann und 10 Jahre spïter zum Major im 2. Nassaulischen Infanterie- 
regiment $\mathrm{Nr}$. 88 befördert. 1878 nahm er seinen Abschied und zwar als Ganz-Invalide infolge der Nachwehen des afrikanischen Gallenfiebers. Von kleinauf beschäftigte sich H. mit Naturwissenschaften und besonders mit Zoologie. Schon als Potsdamer Cadett kannte er die wissenschaftlichen Namen der sämtlichen Vögel Europas und die meisten Vögel auch von Ansehı. Ein besonderes Interesse hatten für ihn von jeher die stimmen der Vögel, auf welchem Gebiete H. hente wohl umbestritten als die erste Autorität gilt. Von 1857 ab begam er im "Journal f. Ornithologie" seine Beobachtungen zu publiciren und machte wissenschaftliche Excursionen dureh Vorpommern, Rügen, an die Nosel und den Rhein sowie seine erste grössere Reise nach den Balearen, wobei er auch Catalonien und dis Ostpyreniien, Suidfrankreich und Algier bis in den Atlas hinein besuchte. 1Sti3-bt war er in der Provinz Posen an der russischen Grenze. Seme ornithologische Thätigkeit in Schlesien habe ich schon mehrfach hervorzuheben Gelegenheit gehabt. 1875 machte er als Expeditions-Chef mit Dr. Paul Pogge, Soyeaux und dem österreichischen Lieutenant Lux die CuanzaReise bis äber P'ungo Andongo hinaus. An dem letztgenamiten Punkte gründete er eine deutsche Station, erkrankte aber gleich darauf am Tula-Fieber und lag daselbst 7 Wochen lang mit geschwollenem Körper, gelähmt, unfïhig, die Reise fortzusetzen. Er übergab daher das Commando an Dr. Pogge, welcher im December des nächsten Jahres das Muatojambo-Centralreich er. reichte, waihrend $H$. nach Europa zurückkehrte. Er brachte von dieser Reise ca. $\$ 000$ Insekten, besonder's Lepidopteren, mit. Zur IIerstellung seiner Gesundheit hicht er sich 1566 im OberEngadin und 1878 in Südfrankreich und Norditalien auf. Von 1875, wo er krankheitshalber seinen Abschied nahm, bis 1883 wohnte H. in Wiesbaden, 1\$53-8t in Anklam, seit Ostern 1884 in Greifswald, woselbst er gegenwärtig gleichmässig Ornithologie und Lepidopterologie sowie etwas Botanik treibt. Seine Schmetterlingssammlung setzt sich aus ca. $3(0000$ Stück des paläarktischen Zonengebiets zusammen. Seit 1557 ist H. thätiges Mitglied der "Allgem. deutsch. ornith. Ges.", welcher er 1867 und 68 prïsidirte. In Frankfurt a. M. gründete er 1859 den ${ }^{2}$ Verein für naturwissenschaftliche Unterhaltung als intelektueller Urheber, hatte die wissenschaftliche Bestimmung der Vögel im zoologischen Garten und war auf Vorschlag des Dr. Rüppel Sektionär der Vögel des Museums der Senckenbergischen naturforschenden Gesellschaft. Eine besondere wissenschaftliche Thätigkeit entfaltete H. anch als Vortragender in der naturwiss. Gesellschaft zu Görlitz. 1591 wurde er zum Festrortrag des '2. internationalen ornithologischen Congresses in Budapest berufen und sprach dort mit grossem Erfolg iiber Vogelleben in Centralwestafrika, wurde Vice-Priisident des Congresses, Präsident der 
Congress-Abteilung Ornithologia oeconomica und Mitglied des permanenten internat ornith. Comités.

William Baer, geboren am 17. April 1867 in Herrnhut (Kgr. Sachsen), war von 1879-st Schüler und Pensionair des Progymnasiums und Pädagogiums in Niesky (Ober-Lausitz), das er krankheitshalber in P'rima verlassen musste. Seitdem leidet B. an hochgradiger Neurastheuie, die seinem unermüdlichen Eifer für die zoologische Erforsehung seiner Heimat bedauerliche Grenzen steckt. Seit 1887 ist B. mit der Ordnung der Sammlungen des Museums in Niesky beschäftigt.

Paul Kollibay wurde am 4. Juli 1863 zu Landsberg in Oberschlesien als Soln des Kreisichters Kollibay geboren. Seine frühzeitig hervortretende Liebe zu den Naturwissenschaften überhaupt lenkte unser verstorbener Dr. Kutter, damals in Neustadt, auf das Gebiet der Vogelkunde. Namentlich war es Kutters grossartige Eiersammlung, die den Jüngling mächtig anzog; er wurde Liersammler und auf diese Weise sehnell mit der Vogelwelt vertraut. Mit Kutter gemeinsam unternommene Ausflüge, seine Belehrungen und die Benutzung seiner Bibliothek vermehrten rasch eben so Kollibays Kenntnisse wie seine Liebe zur Ornithologie. Schon als Gymmasiast publicirte er einige biologische Beobachtungen, dann beteiligte er sich an den Arbeiten des Ausschusses für Beobachtungsstationen. Necessitate coactus wurde K. Jurist und liess sich nach Beendigung seiner Studien in Neisse nieder. Seine ornithologische Thätigkeit in Oberschlesien habe ich schon oben hervorgehoben; hier möchte ich nur noch hinzufügen, dass sich $K$. auch längere Zeit im Riesengebirge aufgehalten und daselbst interessante Beobachtungen gemacht hat, die er mir liebenswürdiger Weise für meine Arbeit zur Verfügung stellte.

Werfen wir endlich an dieser Stelle noch einen Blick auf die schlesischen Museen, so ist an erster Stelle natürlich dasjenige der Universität Breslau zu nemnen. Leider ist ron demselben dasselbe zu sagen wie von den weitaus meisten deutschen Universitäten: Ein schönes und reichei Material ist höchst mittelmässig conserviert und zur Geltung gebracht und rerkommt wegen Interesselosigkeit des dirigierenden Professors und Nachlässigkeit des zu wenig beaufsichtigten und zu viel anderweitig beschätigten Präparators. Ausserdem ist die Etiquettirung eine höehst mangelhafte, wodurch oft genug die interessantesten Stücke für den wissenschaftlich arbeitenden Ornithologen fast wertlos werden. Geschlecht, Fundort und Datum sind nur in den seltensten Fällen angegeben! Angesichts dieser Missstände erlahmte denn auch der Eifer derjenigen Freunde ornithologischer Forschung, welche die Sammlung mit Zusendungen bedachten und unterstützten, und das vorhandene Material stammt daher fast ausschliesslich aus 
älterer Zeit, deren Spuren sich nur zu deutlich an ihm bemerkbar machen. Das Breslauer Museum enthält viele schlesische Seltenheiten, Unica, zahllose wichtige Belegstiicke, und müsste deshalb unter ciner sorgfältigeren Pflege mit zu den besten und reich. haltigsten Lokalsammlungen Deutschlands gerechnet werden. Ich werde noch vielfach Gelegenheit haben, auf die Belegstücke des Breslauer Aluseums zurückzukommen, dessen sïntliche schlesische Exemplare ich übrigens genau untersucht und gemessen habe. Die Eiersammlung ist ganz unbedeutend nnd rollständig verblichen. Leitender Direktor ist gegenwärtig Herr Prof. Chun, Conservator F. Tiemann. Nächstdem nimmt die ornithologische Lokalsamm. lung der "Naturforschenden Gesellschaft“ zu Görlitz den hervorragendsten Rang ein, und zeichnet sich dieselbe auch dadurch sehr vorteilhaft aus, dass sie überall die Spuren einer liebevoll pflegenden Hand (augenblicklicher Direktor Dr. Peck) erkennen lässt. Von wichtigen Belegstïcken will ich hier nur Circaëtus gallicus, Numenius phaeopus, Totanus fuscus, Recurvirostra avocetta, Limosa rufa, eine sehr schöne Varietät von Gallinago maior, Phalaropus hyperboreus, Ortygometra minuta, Falcinellus rufus, Strix ulula, Anser erythropus, Eudromias morinellus pull., Muscicapa parva und die 3 Lestris-Arten hervorheben. Ferner wäre hier das Herrenhuter Museum in Niesky (Custos William Baer) zu erwähnen. Dasselbe enthält n. a. einen am 2. Jan. 188? erlegten Syrrhaptes paradoxus, weleher ganz den Eindruck eines vorjährigen Vogels macht. Herr Conservator Heydrich in Flinsberg besitzt eine interessante Sammlnug von Vögeln des Iser- und Riesengebirges. Wir finden hier u. a. Aquila clanga, Nyctea nivea, Surnia nisoria, Athene passerina, Nyotale Tengmalmi, Picoides tridactylus, Anthus cervinus, Phileremus alpestris, Linaria Holboelli, Carpodacus erythrinus, Corythus enucleator, Loxia rubrifasciata, Gallinula pygmaea, Phalaropus hyperboreus und Somateria mollissima. Auf die verschiedenen Schulsammlungen habe ich kein Gewicht gelegt, da man in denselben wegen der mangelhaften Etiquettirung die in den Naturalienhandlungen gekauften Exemplare gewöhnlich nicht von den in der Gegend selbst erlegten zu unterscheiden vermag. Dagegen findet der Ornithologe in den Schlössern der schlesischen Magnaten manches für ihn wichtige Stiick als Jagdtrophïe aufgestellt, so namentlich die grösseren Raub- und Wasservögel. Besonders schön und reichhaltig sind die Collektionen des Herzogs von Ratibor in Rauden und des Grafen Schaffgotsch in W'armbrumn. Die beste oder wenigstens wissenschaftlich wertvollste Eiersammlung besitzt wohl Herr Polizeirat Kuschel in Breslau; leider hat derselbe jetzt sein Interesse vorwiegend den exotischen Species zugewandt und darüber die einheimischen vernachliassigt. Auch Herr Kollibay sammelt Eier. Vielleicht darf ich an dieser 
Stelle auch noch meine eigene Sammlung erwähnen, welche gegenwärtig etwa 1200 Bälge umfasst, die zu $2 / 3$ aus Schlesien stammen und manche schlesische Unica in sich schliessen. Meine Eiersammlung ist sehr gering, enthält aber einige interessante Belegstücke für die schlesische Ornis.

\section{Bibliographia ornithologia Silesiaca.}

In meinen „Beitrïgen zur Ornis von Preuss. Schlesien“ konnte ich 100 Autoren mit 293 Arbeiten aufïühren. Dieses Verzeichnis habe ich inzwischen nicht unbeträchtlich vermehrt, nämlich auf 121 Autoren mit 371 Arbeiten. Einen Teil der neuen Citate und zwar insbesondere solche aus der älteren Litteratur verdanke ich der Güte meines belesenen Freundes Dr. Leverkühn in München; dieselben sind durch eiu Sternchen (*) kenntlich gemacht. Geschlossen wurde die folgende Liste Ende Februar 1892.

1882. Altum, Bernard, 1. Falco vespertinus in Menge in Oberschlesien. In: Orn. Centralblatt, 7. Jahrg. p. 86-87.

1890. - 2. Zum Vogelschutz (rufipes). In: Mitteilungen des ornithol. Vereius in Wien "Die Schwalbe“, 14. Jahrg. p. $259-260$.

1571. Arlt, Carl, Notizen über den Flussrohrsänger. In: Cabanis, Journal für Ornithologie. 19. Jahrg. p. 27-34. 1887. Auras, W., Beobachtungen aus der Umgegend von Gutmannsdorf, im 10. Jahresbericht (1 8 D) des Aussch. f. Bcob. Stat. d. Vögel Deutschl. In: ib. 35. Jahrg. p. $337-616$.

1891. Baer, William, 1. Ueber das Brüten von Mergus merganser bei Neusalz in Schlesien. In: Ornith. Monatsschrift d. deutschen Vereins z. Schutze d. Vogelwelt. 16. Jahrg. p. $320-321$.

1891. - 2. Ein Ausflug an den Nistort der "Birkente" in der preuss. Oberlausitz. In: ib. 16. Jahrg. p. 250-255. *13\%. Baunsdorfer, Ueber Vögel und Fischerei in Ostschlesien. In: Weidmannsheil, X. Bd. Nr. 10, p. 126-128.

1875. Blasius, Rudolf, 1. Skizzen aus dem Riesengebirge. In: Orn. Centralbl. 3. Jahrg. p. 121-122 u. 129-130.

1854. - 2. Naturhistorische Studien und Reiseskizzen ans der Nark und Pommern. I. In: Ornithol. Nonatsschrift d. deutsch. Ver, z. Schutze d. Vogelwelt. 9. Jahrg. p. 146-166. - Enthält Bemerkungen über schles. Stücke in der Samml. der Forstakad. zu Eberswalde. 1888. - 3. Ornithol. Nitteilungen. In: Verhandlg. des Ver. f. Naturw. in Braunschweig, Sitzung v. 2. XII. 1888. 
1851. v. Boenigk, Otto, 1. Bemerkungen über einige Vögel. In: Naumannia, 1. Jahrg., 4. Heft, p. 29-37.

1852. - 2. Ornith. Notizen. In: ib. 2. Jahrg. 4. H., p. 81-84. 1781. Boerner, Immanuel, Prodromus d. schlesischen Zoologie. In: Neue ökonomische Schriften der patriot. Gesellschaft in Schlesien.

1871. Borggreve, Bernard, Erster Nachtrag zu meiner Vogelfauna von Norddeutschland. In: Cab. Journ. für Ornithol., 19. Jahrg. p. 210-224.

1827. Brahts, F. C., Vögel, die in den Lausitzen vorkommen. In: Abhandlg. d. naturf. Ges. z. Görlitz. Bd. I, Heft 1, Nr. 4, p. 84-117. Heft 2, p. 22-56. Diese Arbeit umfasst nur die Raptatores, Scansores und einen Teil der Oscines. Vergl. J. G. Krezschmar. 1575. Brehm, Alfred Edmund, 1. Vogelleben der böhmischschlesischen Grenzgebirge. In: Cab. Journ. f. Orn. 23. Jahrg. p. 230-231.

1885. - 2. Aus dem Tierleben des Riesengebirges. In: Orn. Monatsschr. d. deutsch. Ver. z. Schutze d. Vogelwelt. 10. Jahrg. p. $220-228$.

1886. Capek, Viktor, Aus dem Riesengebirge. In: Mitt. d. ornithol. Ver. in Wien „Die Schwalbe", 10. Jahrg. p. $241-242$.

*1716. Joh. Bened. Carpzovii/ Analecta/ factorum Zittariensium/oder/ Historischer Schauplatz/ der lüblichen alten Sachsstadt des Marggratt'thums Ober-Lausitz/ Zittau.//. 1716. Folio. pg. 39. § 6. Cap. 9. über Steinadler, Trappen u. s. w.

1622. Ciichleri, Ottidis seu turdae in saltibus Gorlicensibus glande plumbea trajectae descriptio.

1535. Deditius, Beobachtungen aus der Umgegend von Lands. berg und Nendza, im 11. Jahresbericht (1886) d. Aussch. f. Beob. Stat. d. Vögel Deutschl. In: Cab. Journ. f. Orn. 36. Jahrg. p. 313-571.

*1750. Diedmann, Leue europäische Staats- und Reisegeographie. Dresden u. Leipzig 17500. Bd. IV. p. 876 .

158s. Ecks tein, Carl, Einige Drosselvarietäten aus der Samml. der Forstakademie Eberswalde. In: Der zoologische Garten, 29. Jahrg. p. 30-31.

1 sRi. Eder, Robert, 1. Die im Beobachtungsgebiete Neustadt b. Friedland vorkommenden Vogelarten. Nachtrag. In: Mitteil. d. orn. Ver. in Wien "Die Schwalbe, 12. Jahrg. p. 115. - Erwähnt auch ornithologische Vorkommnisse auf schlesischem Gebiet.

1890. - 2 Notizen über Muscicapa parva u. Lanius minor. In: Ornithol. Jahrbuch, 1. Jahrgang. p. 215-217. 
1891. Eder, Robert, 3. Ornithol. Notizen aus Preuss. Schlesien. In: ib. 2. Jahrg. p. 75.

1878. Emmrich, 1. Miscellen. In: Orn. Centralbl. 3. Jahrg. p. $46-47$.

1878. - 2. Beobachtungen a. d. Umgegend v. Goldberg, im 2. Jahresbericht (1877) d. Aussch. f. Beob. Stat. d. Vögel Deutschl. In: Cab. Journ. f. Orn., 26. Jahrg. p. $370-436$.

1880. - 3. Desgleichen im 3. Jahresbericht (1878). In: ib. 28. Jahrg. p. 12-96.

1809. Endler u. Scholz, Der Naturfreund oder Beiträge zur schlesischen Naturgeschichte.

1844. Fechner, 1. Einige Beiträge zur Naturgeschichte des Jahres 1843. In: Abhandl. d. naturf. Gesellsch. zu Görlitz, Jahrg. 1844, 1. Heft, p. 5-8.

1851. - 2. Versuch einer Naturgeschichte der Umgegend von Görlitz. In: Jahresprogramm d. höheren Bürgerschule in Görlitz.

1888. Fellbaum, Adolf, Notiz über Syrrhaptes paradoxus. In: Gefiederte Welt, 17. Jahrg. p. 215.

1870. Fickert, C., Notiz über Locustella naevia. In: Cab. Journ, f. Orn, 18, Jahrg. p. 439.

1889. Floericke, Curt, 1. Notiz über Syrrhaptes paradoxus. In: Orn. Monatsschr. d, deutsch. Ver, z. Schutze d. Vogelwelt. 14. Jahrg. p. 498.

1889. - 2. Notiz üb. Loxia bifasciata. In: ib. 14. Jalırg. p. 530.

1890. - 3. Beitrïge zur Naturgesehichte des gesprenkelten Sumpfhuhns. In: ib. 15. Jahrg. p. 177-187.

1890. - 4. Orn. Mitteil, aus Schlesien, I. In: ib. 15. Jahrg. p. $232-237$.

1890. - 5. Orn. Mitteil. aus Schlesien, II. In: ib. 15. Jahrg. p. $254-258$.

1890. - 6. Ein Ausflug in die Bartschniederung. In: ib. 15. Jahrg. p. $435-445$.

1890. - 7. Farbenvarietiten im Breslaner Museum. In: Cab. Journ, f. Orn. 38. Jahrg. p. 94-98.

1890. - §. Mitteil, über das Vorkommen seltener Vügel in Preuss, Schlesien, In: Orn. Jahrb. 1. Jahrg. p. 5 -8.

1890. - 9. Die Vogelwelt der Strachate bei Breslau. In: ib. 1. Jahrg. p. 191-199.

1891. - 10. Verzeichnis schlesischer Triviahnamen. In: ib. 2. Jahrg. p. 53-61.

1891. - 11. Ornith, Nitteil, aus Preuss, Schlesien, In: ib. 2. Jahrg. p. $201-204$.

1891. - 12. Beiträge z. Onnis v. Prenss. Sehlesicn. In: Cab. Journ. f. Orn. 39. Jahrg, p. 165-199. 
1891. Floericke, Curt, 13. Zur Ornis der Bartschniederung. In: ib. 39. Jahrg. p. 275-292.

1891. - 14. Reise nach Oberschlesien. In: Mitteil. d. orn. Ver. in Wien "Die Schwalbe“, 15. Jahrg. p. 202-204, $214-216,225-226,241-243$ und $254-256$.

1891. - 15. Zur Naturgesch. d. Taucher. In: Orn. Monatsschr. d. deutsch. Ver. z. Schutze d. Vogelwelt. 16. Jahrg. p. $23-24$.

1891. - 16. Nochmals Gallinula porzana. In: ib. 16. Jahrg. p. $42-45$.

1891. - 17. Ein zweiter Ausflug in die Bartschniederung. In: ib. 16. Jahrg. p. 96-99.

1891. - 18. Widerstreitende sociale Instinkte im Vogelgemüt. In: ib. 16. Jahrg. p. 482-483.

1891. - 19. Gänsejagd in der Bartschniederung. In: ib. 16. Jahrg. p. 293.

1892. - 20. Aus meinen Sommerferien. In: ib. 17. Jahrg. p. $103-108$ und $165-169$.

1892. - 21. Ueber den Gesang des Karmingimpels. In: ib. 17. Jahrg. p. 117-119.

1892. - 22. Zur Charakteristik der schlesischen Vogelwelt. In: Cab. Journ. f. Ornith. 40. Jahrg. p. 151-167. * 1768. Frenzel, MI., 1. Des unermüdlichen Forschers Fr. Historia naturalis Lusatiae. Hofm. I, 128. Cfr. auch Hist. Lus. sup. nat. Budissin 1768, 4. u. Kretsehmars Nachlese 1768, 81. Manuskript im Besitze d. naturf. Ges. in Görlitz u. Copie in d. Ratsbiblioth. zu Zittau.

$* \quad-\quad$ 2. Löftelgünse bei Hoyerswerda. Coll. Lus. Ms. S. III, 144. h.

* - 3. Schwäne bei Penzig. Coll. Lus. Ms. S. IlI, 166 b. 1586. Fritsch, A., 1. Beobachtungen aus d. Umgegend v. Radersdorf b. Leuthen, im 9. Jahresbericht (1884) d. Aussch. fo Beob. Stat, der Vögel Deutschl. In: Cab. Journ. f. Ornith. 34. Jahrg. p. 129-387.

1887. - 2. Desgleichen im 10. Jahresbericht (1885). In: ib. 35̃. Jahrg. p. 337-616.

1888. - 3. Desgleichen im 11. Jahresbericht (1886). In: ib. 36. Jahrg. p. 313-571.

*1720. Gerber, Anerkannte Wohlthaten Gottes in der Ober(u. Nieder-) Lausitz. Dresden 1720.

1827. Gloger, Constantin Ludwig, 1. Ueber den weissbindigen Kreuzschnabel. In: Okens Isis, Bd. XX, Heft 1, p. 411-420.

1.27. - 2. Ueber die auf dem Hochgebirge der Sudeten wïhrend des Sommers vorkommenden Vügel. In: ib. Bd. XX, Heft 1, p. 560-609. 
1828. Gloger, Constantin Ludwig, 3. Zur Naturgesch. des weissbindigen Kreuzschnabels. Breslau 1828.

1833. - 4. Schlesiens Wirbeltierfauna. Breslau 1833.

1853. - 5. Notiz über Falco aesalon. In: Cab. Journ. für Orn. 1. Jahrg. p. 300.

1853. - 6. Notiz über Ardetta minuta. In: ib, 1. Jahrg. p. 367.

1854. - 7. Späte Bruten. In: ib. 2. Jahrg. p. 69.

1854. - 8. Notizen über Bombycilla garrula und Gallinula chloropus. In: ib. 2. Jahrg. p. 172.

1854. - 9. Das Nisten von Seidenschwänzen in Deutschland. In: ib. 2. Jahrg. p. 344-348.

1854. - 10. Notiz über Strix nyetea. In: ib. 2. Jahrg. p. 356.

1856. - 11. Notiz über Actitis hypoleucus. In: ib. †. Jahrg. p. 377.

1856. - 12. Notiz über Cinclus aquaticus. In: ib. 4. Jahrg. p. 460.

1860. - 13. Charadrius morinellus auf dem Riesengebirge. In: ib. 8. Jahrg, p. 146.

1860. - 14. Notizen über Bombycilla garrula u. Loxia bifasciata. In: ib, 8. Jahrg. p. 369.

1864. Göller, Zahmheit eines frei lebenden Buchfinken. In: Der Tiergarten, Jahrg. 1864, p. 233-234.

1890. Grasnik, Zwergadler in Schlesien erlegt. In: Schles. Ztg. v. 26. VI. 1890.

1830. Gravenhorst, 1. Katalog des Breslauer Museums.

1832. - 2. Ueber den Zwergkauz. In: Okens Isis, Bd. XXV, p. 1292-1302.

1885. Groschupp, R., Besondere Leistung eines Kuckucks im Rufen. In: Ornith. Monatsschrift, 10. Jahrg. p. 215.

1714. Grosser, Samuel, Ornithologisches. In: Oberlaus. Merkwürdigkeiten V. p. 10 u. 25-27.

1863. Grube, 1. Ueber die Wanderungen des Fausthuhns. In: Jahresber. d. schles. Ges. f. vaterl. Cultur, 41. Jahrg. p. $66-68$.

1863. - 2. Ardea purpurea et comata und Carbo cormoranus in Schlesien. In: ib. 41. Jahrg. p. 68-69.

1863. -- 3. Die Zwergtrappe in Schles. In: ib. 41. Jahrg. p. 69.

1867. - 4. Ueber einen bisher noch nicht in Schlesien beobachteten Watvogel. In: ib. 44. Jahrg. p. 70.

1879. - 5. Das Brüten der Möven auf dem Kunitzer See. In : ib. 56. Jahrg. p. 118-120.

1890. Hartert, Ernst, 1. Ueber abweichende Nistplätze. In: Der zoolog. Garten. 31. Jahrg. p. 282.

1891. - 2. Notizen über Edelfalken. In: Ornith. Jahrbuch. 2. Jahrg. p. $100-103$. 
1892. Hartert, Ernst, 3. Trivialnamen u. Notizen aus Schles. In: ib. 3. Jahrg. p. 32-33.

*1681. v. H a ugitz, A dolf A ugust, Prodromus Lusaticus. Budissinae 1681.

1887. Hirsch, Beob. a. d. Umgeb. v. Hühnern bei Ohlau, im 10. Jahresbericht (1 555 ) d. Aussch. f. Beob. Stat. d. Vögel Deutschlands. In: Cab. Jou!n, f. Ornithol. 35. Jahrg. p. 337-616.

1889. Hirschenen, Ed., Notiz über Pastor roseus. In: Der Weidmann, Jahrg. 1889. p. 379.

*1719. Hoffmanu, Christ. Gottfr., Seriptores rertum Lusaticarum, inter quos Christophori Manlii conimentarii diu desiderati deprehunduntur. Leipzig 1719.

1890. Holtz, Ludwig, Das Steppenhuhn und dessen zweite Masseneinwanderung in Europa. Berlin 1890.

Enthält anderweitig nicht veröffentlichte Mitteilungen über das Vorkommen von Syrrhaptes in Schlesien auf p. $43-44$.

1863. v. Homeyer, Alexander, 1. Notizen über Strix nisoria, Muscicapa parva und Otis tetrax. In: Cab. Journ. f. Orn. 11. Jahrg. p. 223.

1863. - 2. Ardea egretta als Brutvogel Schlesiens. In: ib. 11. Jahrg. p. 440-447.

1864. - 3. Ueber das Brutgeschäft von Turdus pilaris bei Glogau, In: ib. 12. Jahrg. p. $289-296$.

1865. - 4. Notiz über Pratincola rubetra. In: ib. 13. Jahrg. p. 291 .

1865. - 5. Streifereien über die böhmisch-schlesischen Grenzgebirge. In: ib, 13. Jahrg. p. 355-367 u. in: Der zoolog. Garten, 6. Jahrg. p. 321-327, 361-367 u. $465-469$.

1866. - 6. Ueber das Vorkommen einiger z. T. seltener Vögel bei Glogau. In: ib. 14. Jahrg. p. 32-36.

1867. - 7. Briefe vom Kriegsschauplatz 1866. In: ib. 15. Jahrg. p. $46-55$.

1867. - S. Ruticilla titis überwinternd. In: ib. 15. Jahrg. p. 141.

1867. - @. Ueber Serimus luteolus. In: ib. 15. Jahrg. p. 287.

1867. - 10. Ornithol. Miscellen. In: ib. 15. Jahrg. p. 349.

1867. - 11. Zur Wanderung über das Riesengebirge. In: ib. 15. Jahrg. p. 420-422 u. in: Der zool. Garten, 8. Jahrg. p. 457-459.

1868. - 12. Ueber irreguläre Wanderungen und Haushalt einiger Vögel Europas. In: Der zoolog. Garten, 9. Jahrg. p. 121-127, 161-167, 199-204, 232-239, $269-273,336-341,401-405$. 
1869. v. Homeyer, Alexander, 13. Zur Verbreitung von Locustella naevia. In: Cab. Journal f. Ornithol. 17. Jahrg. p. 61-66.

1869. - 14. Notizen über Falco rufipes u. Ardea purpurea. In: ib. 17. Jahrg. p. 66.

1870. - 15. Borggreves Vogelfauna Norddeutschlands. In: ib. 18. Jahrg. p. 214-231.

1871. - 16. Briefl. Mitteil. In: ib. 19. Jahrg. p. 107-109.

1872. - 17. Erinnerungen aus meinem ornithol, Studienleben. In: Jahresber. d. schles. Gesellsch. f. vaterl. Cultur, 49. Jahrg. p. 45-47.

1873. - 18. Bemerk, üb. d. Vorkommen einiger Vögel Schles. In: Cab. Journ. f. Orn, 21. Jahrg. p, 145-148.

1873. - 19. Ueber einige Vögel des Hochwaldes In: ib. 21. Jahrg. p. 218-233.

1875. - 20. Biologische Beobachtungen über einige schles. Vögel. In: ib. 23. Jahrg. p. 111-113.

1885. - 21. Die Wachholderdrossel. In: Mitteil. d. ornithol, Ver, in Wien "Die Schwalbe“, 9. Jahrg. p. 8-9, $21,31-32,40-42,54-56$.

1885. - 22. Die drei europäischen Schwirrsänger. In: ib. 9. Jalurg. p. 281-283 u. 293-295.

1890. - 23. Tour dureh die böhmisch-schles. Grenzgebirge. In: Ornithol. Monatsschrift, 15. Jalurg. p. 429-435. 1871. v. Homeyer, Lugen Ferd in and, 1. Die Versamml. der deutschen Ornithologen in Gürlitz im Mai 1870. Stolp 1871.

1885. - 2. Ueber Turdus pilaris. In: Mitteil. d. orn. Ver. in Wien "Die Schwalbe“, 9. Jahrg. p. 245-247 u. $257-259$.

1889. Horn, Notiz über Adler. In: Deutsche Jägerzeitung. Jahrg. 1889, p. 495 .

1887. Hosius, 1. Beobacht, a. d. Riesengebirge, im 10. Jahresber. (1885) d. Aussch. f. Beob. Stat, d. Vögel Deutschl. In: Cab. Journ. f. Ornith. 35. Jahrg. p. 337-616.

1888. - 2. Desgl. im 11. Jahresber. (1886). In: ib. 36. Jahrg. p. $313-571$.

1865. J a h n, G. A., Notiz über Accentor alpinus. In: D. zool. Garten. 6. Jahrg. p. 473-474.

1885-89. Jahresberichte der forstlich-phänologischen Stationen. 1889. Jörge, H., Notiz über Steinadler. In: Deutsche Jägerztg. Jahrg. 1889, p. 850.

1887. Ka iser, Beob. a. d. Umgegend v. Schweidnitz, im 10. Jahresber. (1885) d. Aussch. f. Bcob. Stat. d. Vüge! Deutschl. In: Cab. Journ, f. Ornithol, 35. Jahrg. p. $337-616$, 
1810. Kaluza, A u gust, Ornithologia Silesiaca. Breslau 1810. 1887. Kern, F., 1. Beob. a. d. Umg. v. Breslau, im 10. Jahresber. (1885) d. Aussch. f. Beob. Stat. d. Vögel Deutschl. In: Cab. Journ. f. Orn. 35̆. Jahrg. p. 337-616.

1888. - 2. Desgl. im 11. Jahresber. (1886). In: ib. 36. Jahrg. p. $313-571$.

1828. Klöber, Ornithol. Mitteil. In: Okens Isis, Bd. XXI, p. $1105-1112$.

1887. Knauthe, Karl, 1. Notiz über Bartmeisen. In: Orn. Monatsschrift, 12. Jahrg. p. 231.

1887. - 2. Notiz über Schnärrdrosseln und Sporenstelzen. In: ib. 12. Jahrg. p. 255 .

1887. - 3. Tabelle über die Ankunft d. Zugvögel z. Schlaupitz am Zobten, nebst Bemerkungen dazu. In: ib. 12. Jahrg. p. 281-286.

1887. - 4. Notiz üb. d. Haussperling. In: ib. 12. Jahrg. p. 343.

1387. - 5. Der Schleierkauz im Taubenschlage. In: ib, 12. Jahrg. p. 202-203.

1887. - 6. Zu Wachtelfrage. In: ib. 12. Jahrg. p. 219-220.

1887. - 7. Vermehrung d. Hänflings. In: ib. 12. Jahrg. p. 208.

1888. - 8. Ornith. Beobacht, am Zobten im Jahre 1887. In: Gefiederte Welt, 17. Jahrg. p. 136-137 u. $146-147$.

1858. - 9. Die Vögel des Zubten. In: Cab. Journ. f. Orn. 36. Jahrg. p. $9-38$.

1890. - 10. Zur Nahrung der Elstern und Heher. In: Orn. Monatsschrift, 15. Jahrg. p. 425-426.

1890. - 11. Bartmeisen in Schlaupitz. In: ib. 15. Jahrg. p. 428

1890. - 12. Notiz über Hirundo rustica. In: ib. 15. Jahrg. p. 459.

1890. - 13. Tabelle über die Ankunft d. Zugvögel z. Schlaupitz a. Zobten im Frühjalı 1890. In: ib. 15. Jahrg. p. $475-481$.

1590. - 14. Notiz über Passer montanus. In: ib. 15. Jahırg. p. 483.

1s90. - 15. Schlafplatz vom Feldsperling. In: ib. 15. Jahrg. p. $371-372$.

1890. - 16. Zug der Elstern. In: ib. 15. Jahrg. p. 173-174.

1890. - 17. Nisten der Sperlinge auf Bïumen. In: Ornith. Jahrbuch, 1. Jahrg. p. 227-228.

1891. - 18. Absonderliche Nist- und Wohnstätten. In: ib. 2. Jahrg. p. 34-36.

1891. - 19. Geruchsinn der Vögel. In: Orn. Monatsschrift, 16. Jahrg. p. 22 .

1891. - 20. Eine Elster rüttelt. In: ib. 16. Jahrg. p. 87. 1891. - 21. Weitere Beispiele von der Frechheit d. Sperbers. In: ib. 16. Jahrg, p. 119. 
1891. Knauthe, Karl, 2.2. Notiz über Mehlschwalben. In: ib. 16. Jahrg. p. 151-15\%.

1891. - 23. Zur Schïdlichkeit der Krähen. In: ib. 16. Jahrg. p. $167-169$.

1891. - 24. Notiz über Steinadler. In: ib. 16. Jahrg. p. 183.

1891. - 25. Notiz üb. Rohrdommel. In: ib. 16. Jahrg. p. 237.

1891. - 26. Zur Wohnungswahl der Feldsperlinge. In: ib. 16. Jahrg. p. 261-262.

1891. - 27. Notiz über Elster. In: ib. 16. Jahrg. p. 263.

1891. - 28. Notiz über Haussperlinge. In: ib, 16. Jahrg. p. $292-293$.

1891. - 29. Blaukehlehen in der Umgebung von Schlaupitz. In: ib. 16. Jahrg. p. 325.

1891. - 30. Nebelkrähe u. Muschel resp. Schnecke. In: ib. 16. Jahrg. p. 389-390.

1891. - 31. Vögel als Fischdiebe. In: Mitteil, d, orn. Ver. in Wien "Die Schwalbe", 15. Jahrg. p. 50.

1892. - 32. Notiz über Grauwürger. In: Ornithol. Monatsschrift, 17. Jahrg. p. 44 .

1879. Kollibay, Pa u l, 1. Brütende Wachholderdrosselu. In: Ornithol. Centralbl., 4. Jahrg. p. 135-136.

1879. - ¿. Abnorme Nistweisen. In: ib. 4. Jahrg. p. 136-137.

1880. - 3. Ornithol. Mitteilungen aus Oberschlesien. In: ib.

5. Jahrg. p. 132-134 u. 154-155.

1880. - 4. Beob. a. d. Ungegend v. Neustadt, im 4. Jahresber. (1879) d. Ausseh, f. Beob. Stat, d. Vögel Deutschl. In: Cab, Journ, f, Orn, 28. Jahrg, p. 255-407.

1881. - 5. Notiz über Vultur cinereus u. Aquila fulva. In: Ornithol. Centralblatt, 6. Jahrg. p. 34.

1881. - 6. Ornithol, aus Oberschlesien. In: ib. 6. Jahrg. p. $132-134,161-163,185-187$.

1882. -- 7. Erwiderung. In: ib. 7. Jahrg. p. 57-58.

1882. - 8. Beob. a. d. Umgegend v. Neustadt, im 5. Jahresber. (1880) d. Aussch, f. Beob. Stat, d. Vögel Deutschl. In: Cab. Journ, f. Orn. 30. Jahrg. p. 18-109.

1883. - 9. Desgl, im 6. Jahresber. (1881), In: ib. 31. Jahrg. p. $13-76$.

1888. - 10. Desgl. f. d. Ung. v. Neisse, im 11. Jahresber. (1886). In: ib. 36. Jahrg. p. 313-571.

1891. - 11. Notiz über Löffler u. Adler, In: ib. Bericht über die Mai-Sitzung.

1891. - 12. Schlesische Trivialnamen. In: Ornithol, Jahrb. 2. Jahrg. p. $198-201$.

1823. Krezschmar, J. G., 1. Verzeishnis der oberlausitzisch. Vögel. Görlitz 1823. 
1823. Krezschma r, J. G., 2. Bemerkungen u. Berichtigungen zu der Arbeit von Starke (Cfr, diesen). In: Laus. Magazin. Jahrg. 1823, p. 349-351.

*1823. - 3. Notiz über Adler. In: ib. Jahrg. 1823, p. 349.

1826. - 4. Erster u. zweiter Beitrag system, Verzeichnisse der oberlausitzischen Vögel. Manuskript.

1826. - 5. Ueber den Zug der Vögel, Manuskript.

*1826. - 6. Vollständiger Vögelkalender für das ganze Jahr, für Liebhaber, Jäger pp. Manuskript.

1827. - 7. Ornithol. Bemerkungen. In: Abhdlg. d. naturf. Ges. z. Görlitz, Jahrg. 1827, 2. Heft, p. 148-15t.

*1827. - 8. Warum die Zittauer Gegend reicher an Vögeln sei. In: ib. II, p. 154.

1836. - 9. Lausitzische Tögel. (Forts, d. Arbeit v. Brahts.) In: ib. Jahrg. 1836, 2. Heft, p. 19-34.

1881. Krezschmar, Karl Robert, 1. Ornithologisehes aus dem Riesengebirge. In: Ornitholog. Monatsschrift, 6. Jahrg. p. $73-77$.

1881. - 2. Ueber die Zwergtrappe. In: ib. 6. Jahrgang. p. $164-165$.

188\% - 3. Ornithol. Beobachtungen aus der Gürlitzer Heide I. In: ib. 7. Jahrg. p. 31-39.

185\%. - 4. Dasselbe II. In: ib. 7. Jahrg. p. 226-230.

1582. - 5. Ornithol. Bericht aus der nïchsten Ungebung v. Görlitz. In: ib. 7. Jahrg. p. 144--146 u. 318-319.

188:3. -- 6. Ornithol. Beob. aus d. Görlitzer Heide. III. In: ib. 8. Jahrg. p. 157-163.

1sst. - - 7. Ueber d. Taucher d. Oberlausitz. In: ib. 9. Jahrg. p. $110-111$.

1584. - S. Die Wachholderdrossel. In: ib. 9. Jahrgang. p. $122-124$.

1845̃. - 9. Ornithol. Rückblick auf das Jahr 1884. In: ib. 10. Jahrg. p. $40-47$.

1886. - 10. Ornithol. Rückblick auf den Winter 1885/86. In: ib. 11. Jahrg. p. 158-160.

18s6. - 11. Ornithol. Mlitteilungen aus der Umgegend von Sprottau. I. In: ib. 11. Jahrg. p. 178-181.

1886. - 12. Dasselbe II. In: ib. 11. Jahrg. p. 228-232.

1887. - 13. Dasselbe III. In: ib. 12. Jahrg. p. 227-228.

1887. - 14. Dasselbe IV. In: ib. 12. Jahrg. p. 275-278.

1887. - 15. Ornithol. Beobachtuugen im Sommer u. Herbst 1886. In: ib. 12. Jahrg. p. 112-115.

1857. - 16. Notiz iiber den Sperlingskauz. In: ib. 12. Jahrg. p. 287.

1889. - 17. Abzug der Segler und Fliegenfänger im Herbst 1888. In: ib, 14, Jahrg, p. 75-76. 
1889. Krezschmar, Karl Robert, 18. Meine letzten Beobachtungen aus Schlesien. In: ib. 14. Jahrg. p. 136-135. 1882. Kutter, 1. Beob. a. d. Umg. v. Neustadt, in J. Jahresber. (1880) d. Aussch. f. Beob. Stat. d. Vögel Deutschl. In: Cab. Journ, f. Orn. 30. Jahrg. p. 18-109.

1883. - 2. Desgl, im 6. Jahresber. (1831). In: ib. 31. Jahrg. p. $13-76$.

* 1827. L a n ge, Verzeichnis der Vögel in der Zittanischen Gebirgsgegend. In: Laus. Nagazin. Jahrg. 1827. p. 205-24t0. *1785. Lesk e, Reise dureh Sachsen in Riücksicht der Naturgesch. u. Oekonomie. Leipzig 175ó. Nur d. I. Bd, erschienen. 1884. L everkühn, P a u l, Jagdergebnisse. In: Oru. Nonatsschrift, 9. Jahrg. p. 171-176.

1859. Liebe, Karl The od or, 1. Notiz über Steppenhühner. In: ib. 14. Jahrg. p. 50.

1890. - 2. Notiz über Goldregenpfeifer. In: ib. 15. Jahrg. p. $513-514$.

1891. - 3. Verbreitung des Zeimer in Deutschland. In: ib. 16. Jahrg. p. 323-324.

1892. - 4. Mandelkrähen im Nistkasien. In: ib. 17. Jahrg. p. $25-27$.

*Liefmann, Gänse von I3udissin mit Gold im Magen. In: Breslauer Sammlungen, Bd. XXXI, p. 153.

1877. Lineke, Der Girlitz bei Neisse. In: Oruithol. Centralblatt, 2. Jahrg. p. 166.

1890. Lindner, Friedrich, Notiz über Steppenweihen. In: Ornithol. Monatsschrift, 15. Jahrg. p. 458-459.

1834-54. v. Loebenstein, A. B., Briefe. In: E. F. v. Homeyer, Ornithol. Briefe, Berlin 1881.p. 189-201 u. $255-257$.

1854. Lübbert, H., 1. Notizen. In: Naumannia, 4. Jahrg. p. $105-106$.

1854. - ¿. Oruithol. Notizen. In: ib. 4. Jahrg. p. 398-399.

1855. - 3. Notiz über Cediencmus crepitans. In: ib. J. Jahrg. p. 109.

1887. Matschie, Paul, Versuch einer Darstelhung der Terbreitung von Corvus corone, cornix u. frugilegus. In: Cab. Journ, f. Orı. 35̃, Jahrg. p. 617-648.

M a yer u, seine Verdienste um die Laus. Zoologie. In: Laus. Monatsschrift.

* 1797. M e y e l's Vögelsammlung. In: ib. Jahrg. 17!7, p. 25! u. 280 u. Jahrg. 1799, p. 303.

1719. Meister, Martin, 1. Wasserrabe auf dem Görlitzer Neissturm. In: Hoftmann Scriptor. 1, 2, 85.

1719, - 2. Weisse Krähe in Görlitz. In: ib. p. 68. 
1719. Me ister, Martin, 3. Störche in ungewöhnlicher Menge in Görlitz. In: ib. p. 1, 2, 4, 7 .

1719. - 4. Eulen in ungewöhnlicher Menge in Görlitz. In : ib. p. 91 .

1868. M enzel, Physiographie des Isergebirges. Reichenberg 1868. Behandelt die Vogelwelt auf p. 102-105.

1578. v. Me yerinck, 1. Beob. a. d. Umgeg. v. Gr. Peterwitz bei Canth, im 2. Jahresbericht (1877) d. Aussch. f. Beob. Stat. d. Vögel Deutschl. In: Cab. Journ. f. Orn. 26. Jahrg. p. 370-436.

1ร7. - 2. Miscellen. In: Orn. Centralbl, 3. Jahrg. p. 107.

1879. - 3. Beobachtungen über die Ankunft der Zugvögel im Frühjahr 1879. In: ib. 4. Jahrg. p. 96-97.

1881. - 4. Frühjahrsbeobacht. a. d. Umgeg. v. Gr. Peterwitz bei Canth. In: ib. 6. Jahrg. p. 134-135.

185\%. - 5. Beobacht, über das Ankommen der Zugvögel im Frühjahr 1882. In: ib. 7. Jahrg. p. 100-101.

1587. - 6. Beob. a.d. Umg. v. Gr. Peterwitz b. Canth, im 10. Jahresbericht (1855) d. Aussch. f. Beob. Stat. d. Vögel Deutschl. In: Cab. Journ, f, Orn. 35̃. Jahrg. p. $377-616$.

1585. Michel, Julius, 1. Einige nordische Gäste im Iser-u. Lausitzer Gebirge. In: Mitteil, d. orn. Ver. in Wien „Die Schwalbe", 12. Jahrg. p. 168.

15!). - 2. Einige ornithol. Seltenheiten aus dem Iser- und Riesengebirge. In: Orn. Jahrb., 1. Jahrg. p. 25-30.

1591. - 3. Ueber Schwankungen in der Vogelwelt des Isergebirges. In: ib. 2. Jahrgs p. 91-99.

1587. Mitsehke, Cas imir, Beiträge z. 10. Jahresber. (1885) d. Aussch. f. Beob. Stat, d. Vögel Deutschl, In: Cab. Journ, f. Orn, 35. Jahrg. p. 377-616.

1877. Mohr, E., 1. Farbenvarietäten am Stieglitz und Sperling. In: Ornithol. Centralblatt, 2. Jahrg. p. 115.

1577. - 2. Beobacht, a. d. Umg. v. Breslau, im 1. Jahresber. (1576) d. Aussch. f. Beob. Stat. d. Vögel Deutschl. In: Cab. Journ. f. Orn, 25. Jahrg. p. 278-342.

185:3. Nüller, W. H., Wie Sperlinge subjektive Erfahrungen verwerten, In: Der zool. Garten, 24. Jahrg. p. 189. 1887. Müller, Beobacht. a. d. Umg. v. Straupitz bei Brockendorf, im 10. Jahresber. (1885) d. Aussch. f. Beob. Stat. d. Vögel Deutschl. In: Cab. Journ. f. Orn. 3ว. Jahrg. p. 377-616.

1821:. Neumann, J. G., 1. System. Verzeichnis der bisher entdeckten lausitzischen Vögel. In: Lausitz. Magazin, Jahrg. 1826, p. 352-364. 
*1826. Neumann, J. G., 2. Uebers. d. Vögel v. Braths. In: Abhdlg. d. naturf. Gesellsch, zu Görlitz. I, 84 u. II, 22. 1828. - Allgemeine Uebersicht d. laus. Vögel. Görlitz 1828. 1889. v. Nietesnewar, Notiz über Edelreiner. In: Dentsehe Jägerzeitung. Jahrg. 1889. p. 514.

1877. Peck, 1. Beobacht, a. d. Umg. v. Gürlitz, im 1. Jahresber. (1876) d. Aussch. f. Beob. Stat. d. Vögel Deutschl. In: Cab. Journ. f. Orn. 25. Jahrg. p. 278-342.

1878. - 2. Beobachtungsnotizen. In: Ornithol. Centralblatt. 3. Jahrg. p. 87.

1880. - 3. Notiz über Raubmöven. In: ib. 5. Jahrg. p. 14. 1880. - t. Beobacht, a. d. Umg. v. Gürlitz, im t. Jahresber. (1879) d. Aussch. f. Beob. Stat. d. Vögel Deutschl. In: Cab. Journ, f. Orn, 28. Jahrg. p. 35̃ō-407.

* 1791. P escheck, 1 . Uebersicht der in den Handel kommenden Naturprodukte. In: Laus. Monatsselır. Jahrrg. 1791. p. $36-50$.

*1823. - 2. Zittau und Umgebung. In: Lausitz. Magazin, Jahrg. 1823. p. $169-178$.

1842. - 3. Litteratur der Naturforschung in der Oberlausitz. In: Abhandl, der naturf. Gesellschaft zu Görlitz. Jahrg. 1842. 2. Heft, p. 101-128.

187t. Praetorius, A., Notizen iiber die Fortpflanzung der schlesischen Brutvögel. In: Der zoologische Garten. 15. Jahrg. p. 223-232.

1889. Reichenow, Anton, 1. Syrhaptes paradoxus in Deutschl. 1888. In: Cab. Jotirn. f. Orn. 37. Jahrg, p. 1-33.

1889. - 2. Systematisches Verzeichnis der Vögel Deutschl. Berlin 188!. - Enthält neue Mitteilungen iiber das Vorkommen seltener Arten in Schlesien auf p. 3, 29, $34,40,41,51$ u. 67.

1891. - 3. Circus macrurus in Oberschlesien erlegt. In: Cab. Journ. f. Orn, 39. Jahrg. Bericht üb. d. NovemberSitzung.

1885. Richter, Arthur, 1. Ornitholog. Beobacht. aus. Mittelschlesien, In: Ornitholog. Monatsschrift, 10. Jahrg. p. $50-58$.

1886. - 2. Beobachtungen über den Frühjahıss- u. Herbstzug sowie das Brutgeschäft der Vügel in Mittelschlesien. In: ib. 11. Jahrg. p. ว๊̄-60.

1886. - 3. Ein Rundgang durch meinen Garten. In: ib. 11. Jahrg. p. 269-279.

1886. - 4. Beobacht, a. d. Umg. v. Grossdorf bei Strehlen, im 9. Jahresbericht (18 8 t) d. Aussch, f. Beob. Stat. d. Vögel Deutschlands, In: Cab. Journ, f, Ornith. 34. Jahrg. p. 129-387. 
1887. Richter, Arthur, 5. Desgl. im 10. Jahresber. (1885). In: ib. 35. Jahrg. p. 337-616.

1887. - 6. Eine ornitholog. Merkwürdigkeit. In: Ornithol. Monatsschrift. 12. Jahrg. p. 115-116.

1889. - 7. Ornith. Bericht a. d. preuss. Oberlausitz, In: ib. 14. Jahrg. p. 258-267, 284-291 u. 308-313.

1887. Richter, Felix, Beobacht. a. d. Umg. v. Muskau, im 10. Jahresbericht (1885) des Aussch, f. Beob. Stat. d. Vögel Deutschlands. In: Cab. Journ. f. Ornith. 35̃. Jahrg. p. $337-616$.

1853. Graf Roedern, Erdmann, 1. Notiz ïber Strix flammea. In: Naumannia, 3. Jahrg. p. 223.

1853. - 2. Notiz über Sylvia cincrea. In: ib. 3. Jahrg. p. 224.

185̄3. - 3. Ornith. Notizen, In: ib. 3. Jahrg. p. 334-335.

1556. - t. Ueber die Lier der Ortygometra pygmaea. In: ib. 6. Jahrg. p. 402-404.

1876. - 5. Notiz über Gallinago gallinula. In: Cab. Journ. f. Orn. 24. Jahrg. p. 364 .

*1803. Roessig, Produkten-, Fabrik-, Manufaktur- u. Handelskunde von Kursachsen u. dessen Landen, 2 Thle. Forts, von Römers Statistik.

18bit. Rohnert, Kinige Beobachtungen über Fringilla serinus. In: Cab. Journ. f. Orn, 12. Jahrg. p. 396-398.

18\%8. Rotermund, Ueber 'Turdus aurorens. In: Okens Isis, Bd. XXI, p. $1036-1037$.

1857. Schüff, Ernst, 1. Notiz über Silberreiher. In: Gefiederte Welt, 16. Jahrg. p. 49.

1888. - 2. Ueber den diesjührigen Wanderzug der Steppenhühner. In: Der zool, Garten, 29. Jahrg. p. 168-177. 1890. - 3. Ornithol. Notizen. In: Cab. Journ. f. Ornithol. 38. Jahrg. p. 157-159.

*1795. Schmidt, Merkwürdige Naturprodukte der Weinlache am Neissefluss b. Görlitz. In: Laus. Monatsschr. Jahrg. 1795, p. $77 \mathrm{ff}$.

18st. Schmied chen, O., 1. Beob. a. d. Ung. v. Jïgerndorf b. Jauer, im 10. Jahresber. (1885) d. Aussch, f. Beob. Stat, d. Vögel Deutschl, In: Cab. Journ, f, Orn. 35. Jahrg. p. 337-616.

1s8s. - 2. Desgl. im 11. Jahresber. (1886). In: ib. 36. Jahrg. p. $313-571$.

18:2. Sch n eider, (x., Die Vogelwelt des Riesengebirges inbezug auf die Höhenlagen ihres Vorkommens. In: Der Wanderer aus dem Riesengebirge. XII. Jahrg. p. 6-9, $20-22,25-28$.

1809. Scholz, Cfr. Endler.

* Schumann, Lexikon von Sachsen. VII, 482 ff. 
1603. Schwenckfeld, Casp., Teriotropheum Silesiae. Lign. 1603. Abtlg. Aves. Bd. IV. p. 169-376.

1878. Sin ten is, Max, 1. Zur Naturgeschichte des Kuttengeiers. Anmerk. In: Ornithol. Centralblatt, 3. Jahrg. p. 147. 1878. - 2. Notiz über Cormorane. In: ib. 3. Jahrg. p. 181. 1880. Spalding, Beob. aus der Ung. von Trachenberg, im 3. Jahresber. (1878) des Aussch. f. Beob. Stat. der Vögel Deutschl. In. Cab. Journ. f. Orn. 28 Jahrg. p. $12-96$.

1823. Starke*", Statistische Beschreibung der Görlitzer Heide. In: Neues Laus. IIagazin. Görlitz 1823. II. Bd. 2. Abschnitt, Naturgesehichtl. Beschreibung, p. t-10 Vögel.

1881. Talsky, Josef, Mein Ausflug auf d. Schneckoppe. In: Mitteil. des ornithol. Ver. in Wien "Die Schwalbe", 5. Jahrg. p. 13-14 u. $21-22$.

1887. Thiemann, A., Beob. a. der Umg. von Ziegenhals, im 10. Jahresber. (1885) d. Aussch. für Beob. Stat. d. Vögel Deutschl. In: Cab. Journ. f. Orn. 35̃. Jahırg. p. $337-616$.

1877. Thienemann, Withelm, 1. Die Zwergtrappe in Schles. In: Ornithol. Centralblatt, 2. Jahrg. p. 31.

1882. - 2. Ueber die Zwergtrappe. In: Ornith. Monatsschr., 7. Jahrg. p. $27-29$.

1882. - 3. Die Zwergtrappe in Schlesien. In: ib. 7. Jahrg. p. $326-327$.

1865. Tiemann, Friedrich, 1. Ueber Syrrhaptes und andere seltene Vögel in Schlesien. In: Cab. Journ. f. Orn. 13. Jahrg. p. $217-219$.

1867. - 2. Notizen über Milvus ater u. regalis. In: Der zool. Garten, 8. Jahrg. p. 35̌̃.

1868. - 3. Ueber Albinismus. In: ib. 9. Jahrg. p. 255-256.

1870. - 4. Zur Vogelwelt der Strachate. In: ib. 11. Jahrg. p. $97-98$.

1850. Tobias, J., Ankunft der Tögel im J. 1843. In: Abhdlg. d. naturf. Gesellsch. z. Gürlitz. Jahrg. 1850). 2. Heft, p. 89 .

1848 Tobias, Lou is, J. Einige Bemerkungen im Jahre $1844 / 45$. In: ib. Jahrg. 1848. 1. Heft, p. 57-60.

1848. - 2. Abnorme Bildung am Schmabel einer Saatkrähe. In: ib. Jahrg. 1848. 1. Heft, p. 60-61.

185̃2. - 3. Ornitholog. Notizen. In: Naumamuia, 2. Jahrg. 1. Heft, p. 101.

1879. - 4. Einige Bemerk, über die Vogelwelt des Riesengebirges. In: Ornitholog: Centralblatt, to Jahrg. p. $40-42$. 
1879. Tobias, Louis, 5. Ornithol. Bemerkungen aus dem nordwestlichen Schles. In: ib. 4. Jahrg. p. 129-130, $137-138$ u. $141-145$.

1881. - 6. Orn. Bemerkungen. In: ib. 6. Jahrg. p. 118-119. 1836. Tobias, Robert, 1. Orn. Bemerkungen. In: Abhdlg. d. naturf. Gesellsch. z. Görlitz. Jahrg. 1836. 2. Heft, p. $35-45$.

1836. - 2. Tabelle über den Frühlingszug einiger Vögel in der Lausitz. In: ib. Jahrg. 1836. 2ँ. Heft, p. 46-47.

1842. - 3. Ornithol. Beobachtungen im Jahre 1834. In: ib. Jahrg. 1842. 1. Heft, p. 10-13.

1842. - 4. Ornithol. Beobachtungen im Jahre 1840. In: ib. Jahrg. 1812. 2. Heft, p. 31-33.

1842. - 5. Ornithol. Beobachtungen im Jahre 1841. In: ib. Jahrg. 1842. 2. Heft, p. 33-36.

1St4. - 6. Ornithol. Beobachtungen im Jahre 18t2. In: ib. Jahrg. 1844. 1. Heft, p. 1-4.

184t. … 7. Beitrïge zur Naturgeschichte einiger Vögel. In: ib. Jahrg. 1844. 1. Heft, p. 28-31.

154. - 8. Eine nene Drosselart. In: ib. Jahrg. 1844. 1. Heft, p. $32-34$.

1841. - @. Zur Naturgesch. des kinekucks. In : ib. Jahrg. 1844. 1. Heft, p. $34-36$.

1847. - 10. Ornith. Notizen. In: ib. Jahrg. 1847. 1. Heft, p. $56-58$.

1847. - 11. Orn. Excursion 17. d. Tafelfichte, hohem Iser- u. Riesenkamm. In: ib. Jahrg. 1847. 2. Heft, p. 41-46.

1847. - 12. Ornithol. Bemerkungen. In: ib. Jahrg. 1847. 2. Heft, p. $46-51$.

1845. - 13. Beiträge zur Naturgeschichte einiger Vügel. In: ib. Jahrg. 1848. 1. Heft, p. 47-57.

1849. - 14. Die Wirbeltiere der Oberlausitz. Görlitz 1849.

1851. - 15. Notiz über Vultur cinereus. In: Naumannia, 1. Jahrg. 2. Heft, p. 9 \%.

1851. - 16. Notiz üb. Mergus merganser. In: ib. 1. Jahrg. 2. Heft, p. 100-101.

1851. - i7. Notizen über Actitis hypoleucus und Totanus ochropus. In: ib. 1. Jahre. 2. Heft, p. 101.

1851. - 18. Verzeichnis d. in d. Oberlausitz vorkommenden Vögel. In: ib. 1. Jahrg. 4. Heft, p. 50-69.

1553. - 19. Notiz über Lanius rufus. In: ib. 3. Jahrg. p. $335-336$.

1853. - 20. Die Wat- und Schwimmvögel der Oberlausitz. In: Cab. Journ. f. Orn. 1. Jahrg. p. 213-218.

183s-4. - 21. Briefe. In: E. H. v. Homeyer, Oruith. Briefe, Berlin 1s81, p. 247-25்4. 
1869. v. Tsehusi zu S'ehmidhoffen, Viktor, 1. Ueber einige Vögel des Riesengebirges. In: Cab. Journ. f. Orn. 17. Jahrg. p. 2\%-23t.

1870. - 2. Ornithologische Mitteilungen. In: ib. 18. Jahrg. p. $257--278$.

15.2. v. Uechtritz, 1. Skizze der Oberlausitz. In: Okens Isis, Bit. XV, Heft 3.

1547. - 2. Die Vögel um Reinerz. In: Jahresher. d. schles. Gesellsch. f. vaterl. Cultur, Jahrg. 1847. p. $80 \mathrm{ff}$. 1586. Uttendörfer Otto, Ueber das Nisten des Rauchfussbussards. In: Gefiederte Welt, 17. Jahrg. p. 145-146. * - W agner, Joh. Caspar, Beschreibung der Lausitz in seiner Budissiner Chronik. In: Coll. Frenzelianae V1. 'Zittauer' Ratsbibliothek.

1S57. Wagner, Beob. aus d. Umg. von Reichenstein, im 10. Jahresber. (1855̃) d. Aussch. f. Beob. Stat. d. Vögel Deutschl. In: Cab. Jouru. f. Ornithol, 35. Jahrg. p. $377-616$.

1ss1. Walter, Ad,. Berichtung. In: Ornithol. Centralblatt, 6. Jahrg. p. 188.

1soi. Weigel, J. A. Y., Prodromus Fanae Silesiacae. Abtlg. Aves, p. 7 - 38.

1837. We iss, Georg, Beob. aus d. Umg. v. Lipine, im 10. Jahresber. (1885) d. Aussch. f. Beob. Stat. d. Vögel Deutschl. In: Cab. Jouru. f. Ornithol. 35. Jahrg. p. $377-6 i 6$.

1531. Willimek, Beob. a. d. Umg. v. Rauden bei Ratibor, im 9. Jahresber. (1884) d. Aussch. für Beob. Stat. d. Vögel Deutschl. In : ib. 34. Jahrg. p. 129-387.

1557. W olf, H., 1. Bewb. a. d. Umg. v. Muskau, im 10. Jahresber. (1885) d. Aussch. f. Beob. d. Vögel Deutschl. In: ib. 35. Jahrg. p. 377-616.

15s8. - 2. Desgl. im 11. Jahresber. (1886). In: ib. 36. Jahrg. p. $313-571$.

1s90. Wolf, Notiz über Adler. In: Schles. Ztg. v. 11. 3. 1390. 15(0). Zacharias, Otto, 1. Der Kuckuck im Rieseugebirge. In: ib. Sommer 1890.

1890. - 2. Die Vögel der Knieholzregion im Riesengelnirge. In: ib. November 1890.

1857. Zimmermann, 1. Beob. a. d. Umg. v. T'scheschkowitz b. Herrnstadt, im 10. Jahresber. (1885) d. Ausseh. f. Beob. Stat. d. Vögel Deutschl. In: Cab. Journ. f. Oru. 35. Jahrg. p. 377- 1316 .

1iss9. - 2. Notitz über Rotfussfalken. In: Deutsche Jägerztg. XIV. Bd. p. 32S. 
15.)-54. v. Kittwitz, Briefe. In: E. F. Tiomeyer, Ornithol. Briefe. Berlin 1881, p. 201-20う̃.

17.). II. v. F. P., Termisehte öknomische sammlungen, denen Landwirten zum besten aus den Breslatrer Naturu. Kunstansichten ausgezogen Leipzig 1750. Capitel VII. Von den Vögeln.

1882. A. G., Miscellen. In: Ornithol. Centralbl. 7. Jahrg. p. 94. 1737. Anonymus, Adler zu Gr. Schönau. In: Zittauer Wochenblatt, $1737,11$.

1738. - Keine Sperlinge zu Sohra u. Halbendorf. In: Sing. Lus. XVI, p. $240 \mathrm{ft}^{\prime}$

- Notiz über Geier. In: Schriften d. Laus. Gesellsch. d. Wissenschaften, Bd. I, p. 85 .

*15.7. - Mehrere seltene Vögel. In: Schriften der naturf. Gesellsch. z. Görlitz. Bd. I, p. 90 u. 149.

: - Oberlausitzer Arbeiten 1, p. 53-64. (Naturalien d. Laubaner Bibliothek.

* _ - Naturprodukte der Zittauer Gegend.

1s.4! - Notiz über Pelekan. In: Camenzer Wochensehrift, Jahrg. 1829, p. 716.

1Si-. - Eierproduktion am Kunitzer See. In: Ornithol. Monatssclrift, 7. Jahrg. p. 159.

1ธ่т. - Notiz üb. Goldadler. In: Gefiederte Welt, 16. Jahrg. p. 203.

1sit. - Notiz über Stein- u. Fischadler. In: ib. 16. Jahrg. p. 540 .

15s8. - Notiz über Syrrhaptes paradoxus. In: Schles. Ztg. Apr. 1888.

I sis. - Notiz iiber Tamnenheher. In: Deutsche Jägerztg. Bd. XIII, p. 23.

1888. - Notiz über Schnepfen. In: ib. Bd, XIII, p. 39.

1888. - Notiz über 'Tannenheher. In: ib. Bd. Xlli, p. 78 1888. - Notiz über Tannenheher. In: ib. Bd. XII, p. 97. 1835. - Notiz über Steinadler. In: ib. Bd. XIII, p. 110.

1888. Notiz über Tannenheher. In: ib. Bd. Xili, p. 129. 1888. - Notiz über Schnepfen. In: ib. Bd. XIII, p. 188.

1885. - Notiz über Schnepfen und Tannenheher. In: ib. Bd. XIII, p. $2: 8$.

lsis. -- Notiz über Tammenheher. In: Weidmann, Bd. XX, p. $66^{\circ}$

1s.5! - Notiz über Tannenheher. In: Deutsche Jägerztg. Bd. XIV, p. 409.

Ins! - Notiz über Sclmepfen. In: ib. Bd. XIV, p. 409.

1-2:1. Notiz über Patur rosar. In: Nitzsches lllustr. 1n!ii) Jagdztg. Bd. XVII, p. 516

Notiz üb. Schmepfen. In: Sehles. Ztg. v. 11. 21890. 
1891. - Hochtzeit der Vögel. In: ib. v. 28. 1. 1891.

18:1. - Erlegter Singsehwan. In: Nitzsches Illustr. Jagdzig: Bd. XVIII, p. 32t-325.

1591. - Erlegung cines Singschwans. In: ib. Rd. XVIII, p. 334;

\section{Verzeichnis der Beobachter und Mitarbeiter.}

1. A bukir, Forstsekretär in Carolath.

2. Asmus, Kgl. Oberförster in Henschener-Carlsberg.

3. Baer, William, Custos am Museum zu Niesky.

4. Bannowsky, Kgl. Forstsekretär in Friedrichsthal b. Oppehn.

5. Brothe, Prinzl. Oberförster zu Muskau.

6. Cusig, Kgnl. Oberförst r in Kuhbrück b. Franenwaldau.

7. v. Ehrenstein, Kgl. Oberförster in Grudschütz. b. Oppehn.

8. Emmrich, Amtsgerichts-Kassenrendant in Nenrode.

9. v. Fürsten mühl, Künigi. Forstsekretär in Ullersdorf bei Landeshut.

10. Fui er, Kgl. Oberförster in Woidnig b. Guhrau.

11. Gericke, Revierförster in Langenbrick, Grafschaft.

12. Grosser, Stiftsoberförster in Niederlinda b. Lauban.

13. Ha en el, Stält. Oherförster in Iagendorf b. Löwenherg.

14. Ha essler, Stiidt. Revierförster in Eichwalde b. Freiwaldau.

15. v. Hage 1 , Kgl. Oberfür'ster in s'chwammelwit\% b. Ottmachau.

16. Ha s s leutner, F., in Strehlen.

17. Helmich, Städt. Oberförster in Neurode b. Lüben.

18. Hornung, Joh., in Crascheow b. Oppeln.

19. Hubatsch, Jos., Conservator in Waldenburg.

20. Jaenisch, Furstreferendar in Tesselgrund b. Altheide.

21. Kirchner, Paul, Grfl. Revicrö̈ster in Gr. Iser b. Flinsberg.

2.. Klo p fer, Herzogl. Oberförster in Primkenau.

23. Knauthe, Karl, Oekonom in Schlaupitz a. Zobten.

24. Kollibay, Paul, Rechtsanwalt in Neisse.

25. Krabbe, Kgl. Oberförster in Klodnitz b. Kosel.

26. Kramer, Hein rich, Lehramtskandidat in Niesky.

27. Krueger, Oberförster in Hoyerswerda.

28. Kutzen, Kgl. Oberförster in Schelitz b. Oppeln.

29. Lange, Kgl. Oberförster in Alt-Reichenau.

30. Mally, Städt. Oberförster in Dittersdorf b. Sprottan.

31. Mïller, Kgl. Oberförster in Paruschowiz is. liybnik.

32. Morgenroth, Städt. Oberförster in Rietschen.

3:3. v. P a n $n$ w itz, Kgl. Oberförster in Kath. Hammer l,. Trebuity.

31. Ra ake, Herzogl. Oberförster in Sagan.

35. Graf v. d. Recke-Vulmerstein, Leopold, anf Crasehnit\% b. Militsch. 
36. Ruchel, Fürstl. Revierfürter in Nesigode b. Trachenberg. 37. Schmidt, A., Herzogl. Forstmcister in Ratiborhammer.

38. Simon, Oberlehrer in Breslau $\uparrow$.

39. Speth, Albert, Kgl. Revierförster in Strachate b. Breslau. 40. Sylaender, C., Fabrikdirektor in Bolkeuhayn.

41. Titz, Grfl. Oberförster in Mallwitz b. Sprottau.

42. Uttendörfer, Otto, cand. theol, in Crnadenfeld b. Kosel. 43. Vorw erk, Herzogl. Hegemeister in Nicier-Briesnitz b. Sagan. 44. Walikhoff, Kgl. Forstreferendar in Poppelau b. Oppeln. 45. v. Wallenberg, Kgl. Oberförster in Dembio b. Oppeln. 46. Zicmer, Städt. Oberförster in Guhlau b. Glogan.

47. Bormann, A., Gräll. Oberfürster in Peterstorf im Riesengebirge.

Die Wolmorte der einzelnen Beobachter sind auf ler beigegebenen Karte dureh rote Farbe hervorgehoben. Erwähnen will ich noch, das die eingesanten Nitteilungen unter Anwendung der schärfsten Kr:itik sorgfaltig gesichtei wurden, und dass ich die weitans grösste Zahl der oben genamnten Herren persönlich und viele unter ihnen sogar sehr genan kenne, was, wie jeder praktisch arbeitende Omithuloge weiss, für die riehtige Beurteilung und Würdigung des eingehenden Materials von hohem Werte isi.

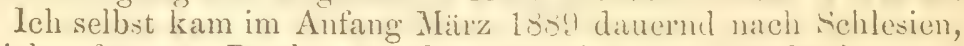
wo ich sofort von Breslan ans die ornithulogisohen Beobachtungen mit aller Energie aufuahm. Nit beanderer Vorlicbe richteten sich hier meine Exeursionen nach der den Ornithologen als Brutplatz des Flussrohrsänger's schnn seit Gluger' Zeiten wohl bekannten Strachate. Sodam zog mich die Bartschniederung mit ihrem aben si) reichen wie eigrnartigen Vogelleben unwiderstehlich an, die ich deshalb wiederholt und zu allen Jahreszeiteu besuchte. Auch anderen Gegenden der P'ruvinz wurlen flüchtigere Besuche abgestattet. In Frülijalı ls: bereiste ich zu ornithologischen Zweeken Obersehlesien und im Ineh...mmer deselben Jahres das Iserund Riesengebirge.

\section{Verzeichnis der seither in der Provinz nachgewiesenen Vogelarten.}

Fam. Sylviid a e.

* 1. Erithaeus philumela (Behst.) (* Ta. Ruticilla titis Cairii Gerbe.)

* 2. - luseinia (L)

* 3. - cyaneculis (Wolf).

*.
*. -
6. Ruticilla phocnicura (L.)

* 7. - titis (L.)

* 8. Pratincola rubicola (L.)

* 9. - rubetra (L.)

* 10. Saxicola oenanthe (L.)

* 11. Cinclus merula (J. C. Schäff.)

† 11a. - - melanogaster

$\mathrm{Br}$. 
* 11b. Cinclus merula albicollis (Vieill.)

12. Monticola saxatilis (L.)

* 13. Turdus musicus L.

14. - iliacus $\mathrm{L}$.

* 15. - viscivorus L.

* 16. - pilaris $L$.

17. - Naumanni Tem.

18. - ruficollis Pall.

19. - obscurus Gmel.

20. - varius Pall.

21. - atrigularis 'Tem.

22. - sibiricus Pall.

23. - merula L.

24. - torquatus L.

24a. -

Chr. L. Brehm).

25. Regulus cristatus Vieill.

* 26. - ignicapillus (Chr.

L. Brehm).

Phylloseopus superciliosus

(Gm.)

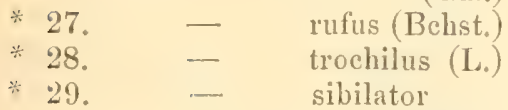

(Bchst.)

Bonellii

(Vieill.)

* 30. Hypolais philomela (L.)

* 31. Locustella naevia (Bodd.)

* 32. - luscinioides

33. - - fluviatilis

(Wolf).

* 34. Calamodyta aquatica (Gm.)

* 35. - sehoenobaena

* 36. Acrocephalus palustris

37.

(Bchst.)

*38, streperus

(Vieill.)

* 39. Sylvia atricapilla (L.)

* 41). - - curruca (L.)

* 41. - rufa (Bodd.)
42. Sylvia hortensis Behst.

43. - nisoria (Bchst.)

44. Accentor modularis (L.)

* 45. - collaris (Scop.)

Fam. Timeliidae.

* 46. Troglodytes parvulus Koch.

Fam. Parid a e.

* 47. Aegithalus pendulinus (L.)

* 4i. Panurus biarmicus (L.)

* 49. Acredula caudata (L.)

$\dagger 49 a$ - - rosea

* 50. Parus cristatus L.

(Blyth).

* 51. - caeruleus L.

52. - cyanus Pall.

53. - fruticeti Wallgr.

* 54. - ater L.

* 55. - maior L.

Fam. Certhiidac.

56. Sitta europrea L.

* 56a. - - caesia Wolf.

57. Certhia familiaris L.

57a. - - brachydactyla Chr. L. Brehm.

58. Tichodroma muraria (L.) Fam. A l a ud id a e.

$\dagger 59$. Otocorys alpestris (L.)

60. Alauda arvensis L.

61. - brachydactyla

Leisl.

- yeltoniensis Forst.

62. - arborea L.

(63). - cristata $\mathrm{L}$.

Fam. Motacillidac.

64. Budytes flavus (L.)

65. - citreolus (Pall.)

66. Liotacilla melanope Pall.

67. - alba L.

68. Anthus pratensis (L.)

69. - cervinus (Pall.)

70. - trivialis (L.)

71. - campestris (I.)

72. - spipoletta (L.)

Fam. Fringillidae.

73. Emberiza schoeniclus (L.)

pusilla Pall. 
74. Emberiza cia L.

\begin{tabular}{|c|c|c|}
\hline 75. & - & hortulana $L$. \\
\hline 76. & & cirlus L. \\
\hline 77. & & \\
\hline
\end{tabular}

79. Calcarius lapponicus (L.)

80. - nivalis (L.)

$\doteqdot$ 81. Loxia bifasciata (Brehm).

* s. - - curvirostra L.

* 83. - pityopsittacus Behst.

* 84. Pyrrhula europaea Vieill.

84a. - - rubicilla Pall.

* 85. Pinicola erythrinus (Pall.)

* 86. - cnucleator (L.)

* 87. Serinus hortulanus Koch.

* is. Carduelis elegans Steph.

albigularis Mad.)

* 59. Chrysomitris spinus (L.)

* 911 . Acanthis camabina (L.)

9. - - flavirostris (L.)

* 92. - linaria (L.)

92a. - - Holboelli

Brehm.

* 93. Chloris hortensis Brehm.

* 9 !. Fringilla coelebs L.

95. - montifringilla L.

$96 . \quad-\quad$ nivalis L.

* 97. Coccothraustes vulgaris Pall.

9.8. Passer petronius (L.)

* 99. montanus (L.)

*ilo. - domesticus (L.)

Fam. Sturnidae.

*101. Sturnus vulgaris L.

1112. Pastor roseus (L.)

Fam. Oriolidae.

*1113. Oriolus galbula L.

Fam, Corvidac.

Pyrrhocorax alpinus Koch.

11.L. Nucifraga caryocatactes L. $104 a$.

$$
\text { crorhyncha Brehm. }
$$

105. Garrulus glandarius (L.)

106. - infaustus (L.)

*107. Pica rustica (Scop.)
* 108. Colaeus monedula (L.)

* 109. Corvus frugilegus L.

*110. - cornix L.

*111. - corone L.

*112. corax L.

Fam. Lan iidac.

*113. Lanius collurio L.

*114. - senator L.

* 115. - minor Gm.

*116. - excubitor L.

116a. - - maior

Pall.

116b. - - Homeyeri

Cab.

Fam, Muscicapidac.

*117. Muscicapa parva Behst.

$\uparrow 118$. - collaris Behst.

*119. - grisola L.

*120. - atricapilla L.

* 121. Bombycilla garrula (L.)

Fam. Hirundinidac.

* 122. Hirundo urbica L.

*123. - rustica L.

* 124. Clivicola riparia (L.)

Fam. Cypselid a e.

* 125. Micropus apus (L.)

126. - melba (L.)

Fam, Caprimulgidae.

*127. Caprimulgus curopaeus L. Fam. Coraciidae.

*128. Coracias garrula L. Fam U pupidale.

*129. Upupa epops L.

Fam. Meropidae.

*130. Nlerops apiaster L.

Fam. Ale edinidac.

*131. Alcedo ispida L. Fam, Picidae.

*132. Picus viridis L.

*133. - viridicanus Wolf.

$\uparrow$ 134. Picoides tridactylus (L.)

* 135. Dendrocopus maior (L.)

* 136 .

medius (L.)

$\dagger 137$.

leuconotus

*138.

(Behst.) 
*139. Dryocopus martius (L.)

Fam. In dicat oridae.

* 140. Iynx torquilla L. Fam. Cu culid a e.

*141. Cuculus canorus L. Fam. Strigid a e.

* 142. Strix flammea L.

$\uparrow 143$. Carine passerina (L.)

*144. - noctua (Retz.)

* 145. Nyctale Tengmalmi (Gm.)

146. Nyctea ulula (L.)

147. - seandiaca (L.)

* 148. Syrnium aluco (L.) 149. - uralense (Pall.)

150. — lapponicum (Sparrm.)

†151. Pisorhina scops (L.)

*152. Asio accipitrinus (Pall.)

*153. - otus (Pall.)

*154. Bubo ignavus Th. Forst. Fam. Falconidae.

* 155. Falco vespertinus L.

*156. - subbuteo L.

*157. - aesalon Tunst.

*158. - tinnuneulus L.

*159. - - peregrinus T'unst.

160. - lanarius L.

161 - gyrfalco L.

162. Aquila pennata (Gm.)

*163. - pomarina Brebm.

164. - clanga Pall.

165. - melanaëtus (L.)

†166. - chrysaëtus (L.)

* 167. Archibuteo lagopus (Brüun).

* 168. Buteo vulgaris Leach.

desertorum

(Daud.)

* 169. Circaëtus gallicus (Gm.)

†170. Haliaëtus albicilla (L.)

* 171. Pandion haliaëtus (L.)

* 172. Pernis apivorus (L.)

*173. Milvus migrans (Bodd.)

*174. - ictinus Sav.

*175. Astur nisus (L.)

*176. - palumbarius (L.)
* 177. Circus aeruginosus (L.)

*178. - cyaneus (L.)

*179. - pygargus (L.)

180. - macrurus Gm.

Fam. Vulturidae.

181. Neophron percnopterus (L.)

182. Gyps fulvus (Gm.)

18\%. Vultur monachus L.

Fam. Tetraonidae.

* 184. Tetrao bonasia L.

*185. - tetrix I.

*186. - urogallus L.

(186a. - urogallo-tetrix).

Fam. Per dicid a e.

* 187. Coturnix communis Bomm. Caccabis saxatilis (Meyer)

188. Perdix cinerea Lath. Fam. P'hasianidae.

* 189. Plrasianus colchicus L.

Eam. Colu mbid a e.

* 190. Turtur communis Selby.

* 191. Columba palumbus L.

* 192. - oenas L.

Fam. Ardeidae.

193. Ardea garzetta L.

*194. - alba L.

*195. - purpurea L.

*196. - cinerea L.

197. - ralloides Scop.

* 198. Ardetta minuta (L.)

* 199. Botaurus stellaris (L.)

"2un. Nycticorax griseus (L.)

Fam. Ciconiidae.

*201. Ciconia alba J, C. Schäff.

*202. - nigra (L.)

Fam. Ibid a e.

203. Platalea lencerodia L.

*201. Plegadis falcinellus (L.)

Fam. Pteroclidae.

205. Syrrhaptes paradoxus (Pall.)

Fam. Rallidae.

*arki. Fulica atra L.

207. Gallinula chloropus (L.)

* 2(1s. Ortygometra pusilla (Pall.)

209. - parva (Scop.)

*210. - porzana (L.) 
*211. Crex pratensis Bechst.

*212. Rallus aquaticus L. Fam. Gruidae.

*213. Grus communis Bechst. Fam. Otididae.

*214. Otis tetrax L.

215. - Macqueeni J. E. Gray.

*216. - tarda L.

Fam. Scolopacidac.

*217. Scolopax rusticola L.

*218. Gallinago gallinula (L.)

*219. - caelestis

* 220 (Frenzel).

221. Numenius phaeopus (L.)

*222. - arcuatus (L.)

*223. Limosa aegocephala (L.)

224. - lapponica (L.)

*25. Totamus pugnax (L.)

*226. - hypoleucus (L.)

*227. - - calidris (L.)

228. - fuseus (L.)

229. - littoreus (L.)

*230. - ochropus (L.)

*231. - glareola (L.)

†232. - stagnatilis (L.)

233. Tringa minuta Leisl.

234. - Temmincki Leisl.

235. - subarcuata (Giild.)

236. - alpina L.

237. - Schinzi Brehm.

238. - canutus L.

239. - maritima Briun.

2.10. Limicolaplatyrhyncha('Tem.)

241. Calidris arenaria (L.)

242. Phalaropus hyperboreus (L.)

243.

fulicarius (L.)

244. Himantopus candidus Bonn.

245. Recurvirostra avocetta L.

Fam. Charadriidae.

*246. Oedicuemus scolopax (Gm。)

247 . Vanellus capella J. C. Michäfo.

248. - gregarius Vieill.

*249. Charadrius curonicus Gm.

†250. - hiaticula L.

alexandrinus $\mathrm{L}$.
*251. Chatradrius morinellus L. +252 . - pluvialis L. 253. - squatarola L.

254. Glareola pratincola (1.)

255. Cursorius gallicus (Gm.)

256. Ilacmatopus ostrilegus L.

Fam. Cyg n id a e.

257. Cygnus olor (Gm.)

258. - musicus Eechst.

259. - Bewicki Jarr.

Fam. Anseridac.

260. Anser finnmarchicus Gum.

261. - albifrons (Scop.)

262. - segetum (Gm.)

(262a. - - arvensis Brehim).

263. - brachyrhynchus

*264. - ferus Brïm.

265. - hyperboreus Pall.

266. Branta leucopsis (Bechst)

267. - bernicla (L.)

*268. Tadorna damiatica

Fam. An atidae.

Baill.

(Hasselqu.)

*269. Anas crecea L.

*270. - querquedula L.

*271. - acuta L.

*272. - penelope L.

*273. - strepera l.

*274. - clypeata L.

*275. - boschas L.

276 . Fuligula hyemalis (L.)

*277. - clangula (1.)

*278. - nyroca (Güld.)

*279. - rufina (Pall.)

*280. - ferina (L.)

281. - cristata (Leach.)

282. - marila (L.)

283. Oedemia nigra (L.)

284. - fusca (L.)

285. Aomateria mollissima (L.)

286. Erismatura leucocephala

Fam. Mergidae.

(Scop.)

287. Mergus albellus L. 
*288. Mergus merganser L.

289. - serrator L.

Fam. Pelecanidac.

290. Pelecanus onocrotalus L.

Fam. Sulida e.

291. Sula bassana (L.)

Fam. Phal a crocoracidac.

292. Phalacrocorax pygmaeus

$* 293$.

Fan. Sternidae. carbo (L.)

*294. Hydrochelidon nigra (L.) leucoptera

(Schinz).

*295. Sterna minuta L.

*296. - hirundo L.

Fam. Laridac.

297. Rissa tridactyla (L.)

* 298. Larus ridibundus L.

299. - canus L.

300. - fuscus L.

301. - marinus L.

302. - argentatus Brimm.
303. Larus glancus Brünn. 304. Stercorarius longicauda

Vicill.

305. - parasiticus (L.)

306. - pomatorhinus

(Tem.)

307. - catarrhactes

Fam. Procellariidae. 308. Thallassidroma pelagica (L.) Fam. Coly mbidae.

*309. C'olymbus fluviatilis Tunst. *310. - vigricollis

(Brehm).

†311. - auritus L.

*312. - griseigena Bodd.

*313. - cristatus L.

314. Urinator septentrionalis (L.)

315. - glacialis (L.)

316 - $-\operatorname{arcticus~(L.)~}$

Fam. Alcidac.

317. Uria lomvia (L.)

Geschlossen wurde diese Liste am 1. Mïrz 1892. Die mit cinem Sternchen (*) bezeichneten Arten sind zweifellos Brutvögel; die mit einem Kreuz $(\dagger)$ versehenen werden gleichfalls von einzeluen Beobachtern als Brutvögel angeführt, ohne dass aber bis jetzt absolut sichere Beweise für ihr Nisten vorliegen. Ohne Nummer habe ich solche Species aufgeführt, dic in der Provinz vorkommen oder vorgekommen sein sollen, bisher aber noch nicht mit vollkommener Sicherheit nachgewiesen sind. Dem Rate ornithologiseher Freunde Folge leistend habe ich bei Aufstellung dieses Verzeichnisses eine weit schärfere Kritik walten lasseì als bei meiner crsten Liste schlesischer Vügcel (Cab. Journ. 1891, p. 165 If.) und der aufmerksam vergleichende Leser wird deshalb bald finden, dass nicht nur die Zeichen des Brütens mehrfach verändert oder weggelassen, sondern dass sogar cinige Species (z. B. Alauda yeltoniensis) ganz gestrichen worden sind, weil die vorliegenden Daten meinen gesteigerten Anforderungen nicht mehr zu genügen vermochten. Dagegen sind andere Arten inzwischen briitend aufgefunden und einzelne (Circus macrurus, Phalaropus fulicarius, Cygnus Bewicki) gan\% neu für das Gebiet eonstatirt worden. Näheres über alle diese Verhältnisse wolle man im speciellen Teil bei den genannten Arten nachlesen. 


\section{Allgemeine Charakteristik Schlesiens und seiner Vogelwelt.}

Die preussische Provinz Schlesien erstreckt sieh zwischen dem $4 g^{\prime \prime} 49^{\prime}$ bis $2^{\prime \prime} t^{\prime}$ nürdlicher Breite und zwisehen dem $31^{0} 21^{\prime}$ und $31^{\circ} 56^{\prime}$ östlicher Länge und umfasst einen Fläeheninhalt von $\left.4(1) 28 !\right)$ g $\mathrm{km}$ (731,69 $\mathrm{qm})$. Durch dieselbe erstreckt sich das schlesische Längsthal, das zuerst längs der Malayane sich zur Oder hinzieht, alsdann dieser bis zur Mündung der Katzbach folgt und endlich weiter in westlicher Richtung üher Bober, Queiss und Lausitzer Neisse sich bis zur sehwarzen Elster erstreckt. Der Boden der Thalsenkung ist lïngs der Oder fruchthar, an rer Malapane und Elster sumpfig, zwischen Oder und Elster sandig und teilweise anch sumpfig. Nördlich von diesem Iängenthal zieht dureh die Provinz ein Landrücken; auf deniselben wheben sich zwlschen Bober und Oder die Katzenberge und der Frünberger Lantrücken $(200 \mathrm{~m})$, zwischen der Oder und her Thedaquelle der Trebuitzer Landrücken $(311 \mathrm{~m})$ und im Regierungsbezirk Oppeh endlich der

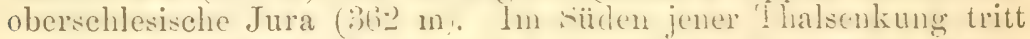
zunächst östlich ron der Oder las I'latealu ron Tarmowitz (Amnaberg $10(1 \mathrm{~m})$ mit dem oberschlesischen stemkohlengebirge als cin Ausläufer der Karpathen hervor. Anf' der linken Oderscite steigt das Land langsam an bis zur Febirgsmaner der Suleidn, welehe die Grenzen der l'rovinz in Oberschlesien nur mit dem F'usse der Bischofskuppe (s-6 $\mathrm{m}$ ) erreicht, dagegen durch Mittelsehlesien sich von Reichenstein bis Janer erstreckt. Tor dieser Gebirgsmancr erheben sich vereinzelt in der Ebrue der Zobten ( $72.5 \mathrm{~s}$ ), die Geiersberge (1579 m), dic Striegatuerberge u. a. Das Cebirge sclbst wird dureh den Pass von Lidbau an Puber (Landeshuter Pass) in 2 Teile gesehieden. Südüstlich erstreckt sich zunächst das Glatzer Gebirgssystem mit seinen vielfachen Terzweigungu, in denen der grosse Schneeberg (1 - 4 m) der lö̈chste Giptel ist, sodann das sandsteingebirge der Heuscheur, ferner das nienlerschlesische Steinkohlengebirge mit dem IIncinwald und endlich das Katzbachgebirge, von dem der Gröditzberg ein gegen das Tiefland vorgeschobener Posten ist. Im Nordwesten jenes Passes erhebt sich auf der Grenze gran Bühmen das Riesengebirge mit

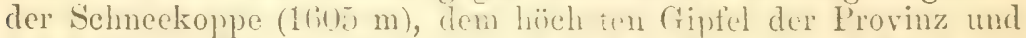
des deutschen Berglandes überhaturt, und als Fortsetzung das moorreiche Isergebirge. Tereinzolte Vurpusten des Berglandes gegen das Theftand siud weiter westich noch die Landskrone bei Cï̈litz und das Königshainer ficbirme. Imnerhalb des Gebirges bilden das Landeshuter und das Hirschberen Thal, beide am Bober, und das Glatzer Kesselthal imerhalb des Crlatzer Berglandes an- 
sehnliche Vertiefungen. Im allgemeinen ist die zum weitaus grössten Teile dem Stromgebiet der Oder angehörige Provinz sehr' wasserreich. Das Oderthal befiudet sich schon von der österreichischen Grenze an im Alluvium; es ist mehr oder weniger breit, in der Regel sehr fruchthar, oft auf weite Strecken mit einem Gürtel üppiger Auwaldungen eingefasst, aber nicht genügend gegen Ueberschwemmungen gesichert. Schlesien hat in den Gebirgen keine Seen, wohl aber eine Menge in den Niederungen im nördlichen Teile der Provinz und in dem W klein und flach und werden auch nur als Teiche bezeichnet. Im stumpfigen Thale der Bartsch liegen dieselben in 2 Gruppen neben einander; die östliche und grössere zwischen Militsch und Goschütz, die westliche zwischen Sulau und Trachenberg. Bei Schlawa unweit der Posenschen Grenze liegt der Schlawasee $(11 \mathrm{~km}$ lang, $3 \mathrm{~km}$ breit), das grösste Gewässer Schlesiens. Dann wären noch zu nemen die Lausitzisehen Seen und die Teichplatten von Oppehn und Falkenberg sowie die zahlreichen kleinen Teiche bei Pless. Das Klima ist am mildesten in der niederschlesischen Ebene, rauher in den Gebirgen und in Oberschlesien. Die jährliche Durchschnitts-

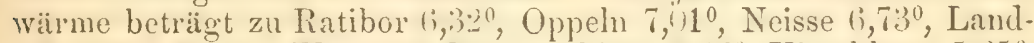
eck $5,40^{\circ}$, Kirehe 11 ang im Riesengebirge 3,5, $7^{\circ}$, Hirschberg 5,250, Görlitz $6,33^{0}$, Breslau $6,62^{\circ}$, Bunzlau $\overline{6,1} 8^{0}$. Die jährliche Regenmenge betrïgt in der Ebene $50-150 \mathrm{~cm}$, im Gebirge mehr. Der Boden ist längs des Gebirges sehr fruchtbar, ganz besonders aber in der Landschaft zwisehen Liegnitz und Oppeln, woselbst 70 bis $81 \% \%$ der Gesamtfliche dem Ackerland angehören. Am wenigsten fruchtbar sind die eigentlichen Gebirgskreise, solann der auf der rechten Oderseite gelegene Teil des Regierumgsbezirkes Oppeln, die Bartschniederung und mit Ausnahme des Kreises Görlitz auch der westlichste Zipfel der Provinz; in allen diesen Landstrichen sind die Ackerläudereien auch nur von geringem Umfang, die Waldungen dagegen sehr bedeutend. Der Proeentsatz der Bodenbenutzung stellt sich nach der Grundstenerregulirung überhaupt folgendermassen:

\begin{tabular}{ccccccccc} 
& & Acker Gärten & Wiesen & Weiden & Wald & Wasser Oedland \\
Kegierungsbez. Oppeln & 54,1 & 0,4 & 7,6 & 2,2 & 31,0 & 0,6 & 0,2 \\
" & Bresliıt & 61,8 & 1,3 & 9,2 & 1,5 & 21,2 & 0,9 & 0,2 \\
I.iegnitz & 46,1 & 0,8 & 10,0 & 1,8 & 36,6 & 0,8 & 0,1 \\
\hline Ganze Provinz Schlesien & 54,0 & 0,8 & 8,9 & 1,9 & 29,7 & 0,7 & 0,2
\end{tabular}

Dic holzueichen Gregenden Schlesiens bitten 3 Bezirke: Obersehlesien anf der rechten seite der Oder, die Gebirge längs der Grenze und die westliche Spitze der Provinz. In allen is Bezirken sind die Wraldungen grö̈stenteils im Besitze ron Privaten oder Gemeinden. In Uberschlesien hedecken die Wälder die Platte von Tarnowitz (das oberschlesische Steinkohlengebirge) und den 
nördlichen Jurazug, aber auch die versehicdenenen Einsenkungen und Flussthäler (Halapane) und die vom Oderthale ausgehenden Erweiterungen, selbst westlich von der Oler. Der Bodeu, den diese Wälder, in denen die Kiefer dominirt, bedecken, ist in den meisten Fïllen für eine andere Cultur nicht geeiguet. In den Gebirgskreisen erreichen dic Waldungen nicht ganz den Umfang derer von Oberschlesien, die Bodenverhältuisse sind aber durch Verwitterung der verschiedenen Gesteinsarten für den Holzwuchs recht günstig; die Fichte überwiegt, in klimatisch bevorzugten Lagen giebt es aber auch schöne Laubhölzer (Eiche, Buche). Im Riesengebirge umfasst die IValdregion (len Gürtel von 60)0-1:00 m Meereshöhe. Darüber hinaus her'seht die Knieholzregion, während die höchsten Teile ganz kahl und nur mit Geröllen bedeckt sind. Der Walddistrikt Westschlesiens schliesst sich aufs engste an die ansehnliche Waldregion des südlichen Braudenburgs an und entsendet auch geringere Ausläufer in das Königreich und die Provinz Sachsen hinein. Der Boden i:t wie in Brandenburg sandig und in der Regel für cine andere Cultur ganz ungeeignet, zuweilen anch sumpfig. In diesem Listrikte lisgt die über o qm grosse Görlitzer Heide. Von der Gesamtwallfliche der Provinz hat ime die Kiefer t5, die Kief'er in Mischung mit der Fichte 22 , Fichte und Tanne 20 , die Eiche 3 Procent. Das Laubholz ist im Regierungsbezirk Breslau noch am meisten vertreten, und zwar hauptsächlich längミ der Oder. Der Mineralreichtum Schlesiens ist bekannt, das Geflügel stark vertreten, dic Fischerei nicht unbedeutend und namentlich neucrdings inmer mehr in den Vordergrund tretend. Wildbret ist zahlecich verhanden, so besizt Sehlesien noch einen ungewöhnliehen licichtun an Ilirschen, Rehen, Wildschweinen, Hasen, Feld und Waldhühnern, Fasancu, Enten, Gänsen u. s. w. Charakteristiseh für die landwirtselıaftlichen Verhältnisse der Provinz ist endlich noeh das Torherrschen des Grosegrundbesitzes, dem iber $51 \%$ der Gesamtlaiche angehören.

Das Studium der schlesischen Ornis musste um so interessanter und lohnender erscheinen, als die Provinz cinerseits von dep ornithologischen Forschung in elen letzten bahrzelnten fiat andfaillig vernathliwigt wurde, und andererseits ms die dorige Vogelwelt in eincr Reichhaltigkeit und Mamnigfaltigkeit entgegen tritt wie kaum in einer, vielleicht in keiner anderen Bimnenperovinz Deutschlands. Bedingt wird dieser Reichtum an Formen und Arten erstlich dureh die cxtrem sülöstliche Lagge des Gebietes, welehes nach Osten hin in unumerbrochenem Zusammenhang mit den grossen russichen Ebenen steht und nach süden zu sich dureh die breite Mareh-Beczwa-Oder-Furehe zwanglos mit den oruithologiseh so gesegneten Auvaldungen der mittleren Donau und den ungarischen Steppen rerbindet. So mancher gefiederte Steppenbewohner wird deshalb dureh irgend welche Einfliisse der 
Witterung auf dem Zuge his nach den schlesischen Gefilden verschlagen, um dimn als ansugestopfte Soltenheit unsere Ornis zu bereichern. Hieher gehört z. B. das Vorkommen von Aquila imperialis, Cireus mantines, P'astor ros'us, Pratineola glareola, verschiedenen Lerehen und manchen andern. Ans den ungarischen süumpfen kommen der Purpur- und Edel-, seltener der prächtige Śeiden- und Löriblreiher zin uns, junge, noch nicht fortpflanzungsfïhige seeadler, seltene Rohrsinger 11. dergl. Die Karpathen liefern Stemadler und Uhus. Ein weiterer Vorzug, den Schlesien vor anderen (tegenten Deutschllanls besitzt, ist der Umstand, dass die höchsten Eirhebungen unseres Vaterlandes innerhalb seiner Grenzen liegen. Die höchst cigenartige und z. T. rein alpine Famna und Flora des Riesengebirges hat von jeher die Aufmerksamkeit der Naturkundigen in hohem Grade auf sich gezogen und beschäfligt dieselles auch hente noch in hervorragendem Maasse, ohne doch in allen ihren T'eilen so genau und griindlich bekannt zu sein, als man wünschen müchte und nach dem Gesagten eigentlich auch erwarten dürfte. Dies gilt ganz besonders von der Vogelwelt. Wohl hat Gloger dieselbe in ihrer Verteilung nach den Höhenlagen sehr snrgfältig studirt, aber er war als leidenschatilicher Gegrner des älteren Brehm viel zu sehr in seinen polemischen Anschaumugen gegen den vicl bekämpften "Artzersplitterer" befungen, als lass er die hervorragend interessanten Lokalvarietäten und subspecies des Riesengebirges in ruhigobjektiver Weise hä̈te studiren und fixiren kömnen. Wir müssen leider eingestehen, dass wir in dieser Hinsicht gerade bei den Sudeten uns noch über schr vieles im Unklaren befinden, und demgemaiss wärde wohl rin lïngeres und sorgfältiges Beobachten im liesengebiry. - gregentüber den flüehtigen 'T'ouristentouren rier dasselbe bisiner besuliehenden Ornithologen - zu ganz überrassehenden und jedenfalls zu wissenschaftlich höchst wertvollen Resultaten führen. Wünschen wir deshalb im Interesse unserer schönen Wissenschaft, dass clas Schicksal recht bald einen tïchtigen Ornithologen an jene reizvollen Berge fesselt! Das Riesengebirge führt der schlesischen Ornis mehrere Arten als Brutvögel zu, welehe sonst in Deutsehland zu den grössten Seltenheiten gehören; ich erimnere nur an den Alpenflüevogel, den Mornell, den Wasserpieper, die Ringdrossel. Auf dem Kuge kommt das Steinrötel, der rotkehlige Pieper und manche andere Raritit vor. Dor dritte Yunkt, dureh den sich die autiallende Reichhaltigkeit der schlesischen Oruis erkliaren liisst, ist das Vorhandensein ausgedehnter Sumpf- und Teichgebicte und prïchtiger, feuchter Anwaldungen, in weleh letzteren die linhirsinger cin erwünschtes IIeim finden, in weleh ersteren zahllose sumpf- und Wasservögel so mbehelligt wie sonst vielleicht nirgends in Dentsehlamel ihre Bruten gross ziehen. Die interessanten und für den Nenling so sehwierig zu 
beobachtenden Rohrsinger charakterisiren in erster Linie die üppigen mittelschlesischen Auwaldungen mit ihren schier undurchdringlichen Brombeer-, Brennessel- und Weidendickichten. Die Strachate bei Breslau ist schon seit Glogers Zeiten als einer der wenigen deutschen Brutplätze des Flussrohrsängers bekannt, und der Nachtigallrohrsänger wurle ganz neuerdings eben dort sowie in der vogelreichen Bartschniederung nachgewiesen. Diese enthält zugleich die meisten Teiche Sehleriens und weist ein Vogelleben auf, wie wir es sonst wohl num meh an wenigen Stellen Deutschlands finden werden. Man wird unwilliürlich an clie viel geschilderten und viel gerühmten ungrischen sümpfe crinnert, denen unsere Bartschniederung in mancher Beziehung nur wenig nachstehen mag. Wohl fehlen die sehimmeruden Gestalten der Edel, Seiden- und Löffelreiher, wohl die zierbichen Arosetten am Strande, die gewaltigen Pelekane aut' dem IV asserspiegel und die Schlangenlinion der Ibisse in hoher Luft, aber lafür siud die Crïnse und W $\mathrm{T}$ asserhühner, die Taucher und Enten, dic Müven und Seeschwalben in in so fabelhaften Mengen rertreten, dass ihr betiubendes Geschrei das Herz des Ornithologen höher sehlagen maeht, dass sie mit ihren bunten Gestalten, mit ihren mamigfachen Stimmen und Flugspielen vor seinen Augen ein bewegtes Bild cutrollen, wie es sich entziickender, lebensvoller und interessanter anch die aus. schweifendste Phantasie kaum atsmalen kam. Auch die Teich. systeme von Fallenberg, Oppehn, Görlitz, Pless und Ratibor sind reich an Togelleben, das aber duch an das der Bartschniederung bei weitem nicht beranreicht.

Als letzten Punkt, der bestimmend anf die Entwicklung der schlesischen Ornis einwirkt, möchte ich endlich noch die eigentümliche Gestaltung der lamb- und forstwirtschafilichen V erhältnisse hervorheben, deren Einfluss ant die Gruppirung und Verteilung der Vogelwelt sich vielleicint in keiner andern Provinz dentlicher und wirkungsvoller nachweisen lässt als gerade in Schlesien und ganz besonders in Oberschlesien. Schlesien ist das Land des Grossgrundbesitzes, das Dorado des deutsehen Jïgers. Dic Jagden befinden sich auf́ weite strecken hin in den Händen weniger Grossgrundbesitzer, die alle nur erdenklichen Nittel aufbieteu, ihren Rehbestand zu vergrössern oder ihre Fasanerien zu heben, um dann bei den grossen Jagden mögliehst hohe Strecken zu crziclen. Die hohen, auf die Erlegung ron Raubzeng ausgesetzten s'chussgelder und die indirekten Prämien, welche die Forstbeamten für jedes erlegte Stück Nutzwild beziehen, spornen dieselben den Raubrögeln gegenüber zu äusserster Thätigkeit an, und es ist deshalb nicht $z u$ verwunderr, wenn auf meilenweite Strecken hin trotz der günstigsten Terrainverhältnisse auch nicht ein cinziger lianbvogelhorst zu finden ist. Ebenso finden sich in solehen Gegenden die Eulen nur in sehr geringer Zahl, da auch 
ihre Fänge auf den meisten Iferrsehaften mit Geld ausgelöst werden, und sie in der That in tisaiterien anch manchen Schaden anrichten mögen. So paradiesisch dem Fasanjäger und dem sentimentalen Vogelschützleß diese Zustände auch erscheinen mögen, so kam doeh andrerseits der Ornithologe und wahre Naturfreund cine solch rücksichtslose Ausrottung aller Raubvögel ohne jeden Unterschieil der An nu tief beklagen Es muss ihn mit Schmerz erfüllen, zu sehen, wenu die Fuinge des Wespenbussards und Schlangenadlers mit demselben siohnssgeld prämiirt werden wie diejenigen des Wanterfalken oler Hühnerhabichts, welch letzterer in Oberschlesien sehl bezeichuend Fasanenmeister heisst. Sein Bedanern wird um so grö̈sser sein, als er sich sagen muss, dass gerade auf solch ausgerlehnten Jagrdgebieten sich eine mäissige und vernünftige sehonmug seltoner, interessanter und wenig schädlicher Raubrögel ohne bemerkenswerte Opfer mit Leichtigkeit durchführen liesse und damit dor. Onithologie kein geringer. Dienst goleistet würde. Bes:er liegen die Verhälnisse übrigeus da, wo sich grössere könimliche Wallknmplexe vorfinden, wie im Kreise Oppeln, weil hier die Suhussgelder viel niedrigner sind und nicht für alle Arten gezahlt werden, auch die dortigen Beamten bei ihrem höheren Fixum nicht so anf dieselben angewiesen sind. Hier ist $z$. $B$ der schüne Sureialler ein "elativ häufiger Brutvogel. Auf dem Znge sind übrigens die meisten Raubvögrel dafür desto besser vertreten, und die Krähenhütten liefern im Herbste oft sehr gute Resultate. So sind solbst See- und Steinadler keine allzu grossen Seltenheiten, sondern werden in jedem Jahre mehrfach gesehossen. Aehulich wie den Raubvögeh ist es den Fischdicben gegangen, wenngleich sich manche von ihmen durch ihre versteckte Lebensweise bisher all n Nachstellungen zu entziehen wussten und ihren Bestand als Brutvögel entschieden gewahrt haben, wie z. B. Botantus stelltris. Dagegen werden die grossen Colonicen der Fischreiloer von Jahr zu Jahr mehr cingeschränkt, und die der Nachtreilser und ícharben sehen in Kiirze völliger Vernichtung entgegen. Andrerseits aber hat die strenge Forstaufsicht, die rüeksiehtshose T'rertilgung alles Raubzeuges, die Anlage von Tiergärten und Remisen auch vieles Gute für die Vogelwelt im Gefolge gehabt. Der Wali ist von einer wahren Unzahl von Drosseln, Amseln, Grasmücken, Nachtigallen, Rotkehlehen, Finken, $\Lambda$ mmern und anderen singrö̈geln belebt, und die unter schärfster Controlle gehaltenen Fasanenremisen bieten den verschiedenartigsten Sänger'u gauz ungestörte, heimliche Brutplätze. Auf den während der Brutzeit ganz unbehelligt bleibenden Teichen ziehen die versehiedensten Entenarten, Möven, Seeschwalben, Taucher, Gänse, Teich-, Sumpl- und IVasserhühner in ruhiger Beschaulichkeit ihre Nachkommenschaft gross. Tom März bis Juni wird mit äusserster Strenge darauf gehalten, dass kein Unberu- 
fener die Teiche befährt - die Ruder der flachen Boote werden sorgsam verwahrt -, ja nicht einmal deren Ufer betritt. Kein Schuss darf in dieser Zeit an oder auf den Teichen fallen, und dem geschäftsmässigen Eiersammler, der hier freilich cine unendlich reiche Ausbeute machen würde, bleiben diese Paradiese glücklicherweise ganz verschlossen. Welcher Unterschied gegen andere Gegenden Deutschlands, wo vielfach die Jagd sich in len Händen roher, gewissenloser Aasjäger befindet, wo oft genug wildernde Hunde und Katzen dicjenigen Bruten vernichten, welehe dem mordlustigen Raubzeug oder den spähenden Augen jugendlicher Eiersammler entgangen waren! Das unter solchen Verhältuissen das nutzbare Federwild eine ganz cnorme Häufigkeit erreicht, ist wohl einleuchtend. So wurden, um nur ein Beispiel anzuführen, allein auf der Herrschaft Pless nach den officiellen Schlusslisten im Jagdjahre 18s9/90) erlegt: 33 Brachvögel, 2232 W' 280 Bekassinen, 1013 Enten, 39 Birkhähne, 24 Wachteh, 3081 Fasanen und 553̆ Rebhühner. Bezüglich der gefiederten Riuber wurden in demselben Zeitraume Schussgelder auf derselben Herrsehaft bezahlt für: 1 Uhu, 19 Adler, 57 Ealken, (is9 grosse, 3746 kleine Raubvögel und 1 $180: 3$ Krähen und Elstern. Solche Zahlen sprechen! Er'wägt man ferner, dass die 'Zahıl der angemeldeten Stüeke bei weitem nicht die der wirklich gesehossenen erreicht, so muss die Verwüstung, welche in Oberschlesien die „kleinen Raubvögel", also neben den schädlichen Sperbern und Lerehenfalken die tinnunenlus, rufipes und aesalon triftt, eine geradezt schreckbare genannt werden. Schade ist es, dass dic so massenhaft eingelieferten Vügel nicht von kundigen Angen controllirt werden; wie manche Seltenheit mag sich darunter befinden, die für immer der Wissenschaft verloren geht.

Jedermann weiss, wie sehr ferner dic Gestaltung der Vogelwelt eines Landes vou der ungebenden Landschaft abhängig ist, wie nüchtern und verstindnislos die Charakterisirung einer bestimmten Ornis ohne den landsehaftlichen liahmen erscheint. Es würde aber seine grossen Sehwierigkeiten haben, einen solchen im allgemeinen für ganz Sehlesien zu zeichnen und ihın die vorhandene Vogelwelt anzupassen; es lassen sich hier vielmehr if landsehaftlich grundversehiedene Gebiete auch bezüglich ihrer Avifauna ziemlich scharf aus einander halten; ich meine: die Lausitz, die niederschlesische Ebene, das Oderthal Mittelschlesiens mit seinen Auwaldungen, das ernste Oberschlesien, die Sudeten mit ihren Vorbergen und dem Itochgebirge und endlich das interessante Teich- und sumpfgebiet der Bartschniederung. Die Lausitz ist entschieden der landschaftlich verschiedenartigste und mulsestimmteste, zugleich aber auch der ornithologisch am besten erforsehte Teil der Provinz Schlesien, worïber ieh mich sehon oben niaher ansgesprochen habe. So erkliirt es sich, dass un- 
verhältnismässig viele der bisher für Śchlesien nachgowiesenen Seltenheiten auf die Lausitz entfallen, obwohl dieselbe meines unmassgeblichen Neinung nach keineswegs als das ornithologisch günstigste Gebiet der Provinz anzusehen ist. Weite Nadelholzwaldungeu, teils sandige Ilaiden, teils unterbrochen durch moorige W'iesen und kleine, nicht sehr' üppig bewachsene 'Teiche, kennzeichnen das Gebiet, dem aber auch fremdiche Ackerlandschaften und üppig begrünte Vorberge stellenweise eincu recht heiteren Charakter verleihen. Auf den jungen schwaryholzaaten treibt hier das seltene schwarkehlehen sem $1 \mathrm{Tesen}$, und aut (ien Teichen, welche der Rotschenkel mit seinem wuhllautenden I'tili belebt, finden wir auch im sommer seltene Enten, wie ja in diesem Jahre sogar Clangula glauivon durch Bacr und Kraner als Brutvogel nachgewiesen wurde. Die grrosse Gürlitzer Heide ist sehun seit lange als Brutplatz des prïclitigen Schlangenarllers bekamit; glücklicherwejse wird der sehr reducirte Bestand desselben jetzt auf das strengste geschont. Mitten dureh den schlesischen 'Teil der Lausitz zieht sich die Grenze zwischen Nebel- unl Rabenkrähe, und finden wir hier deshalb zahlreiche Terbastardirungeu zwisehen beiden vor. Die schluchtenreichen, tief eingeschnittenen Thäler des Queis, Bober und der Noisse bergen manche jeltenleit; ist

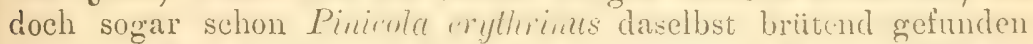
worden. Der im übrigen suhlesien nicht gerade häufige Triel ist Charaktervogel der zahlreichen Brachgegenden. Atuch im Vorjahre ist sehlesien durch die Lausiz wieder um cine nene Species bereichert worden; bei Nicsky wurde in den letzten Tagen des April ein junges Mäunchen von Curres mururus erlegt, das ich durch die Güte des Hrn. Bacr für meine collectir silesiaca erhich.

Niederschlesien ist wohl der ornithologisch am wenigsten bevorzugte Teil der ganzen P'rovinz. Die wcithin sich dehnende Ebene ist grösstenteils mit üppig prangenden Weizenfeldem berleckt, aus denen der Wachtel dakiylischer sculag hervordringi, während die Feldlerehe ihre schmetteruden sirophen in die Lüfte hinausjubelt und die schene Blaurake dals Auge durch ihr buntes Gefieder erfreut. Selten nur unterbricht ein Gehïlz, (rine Wirse das ewige Einerlei dieser dem Landmann als eim vahres Paradien, dem Naturfreunde aber höchst einfürnig exscheinenden Landschaft. Mehr Leben Lerrseht an den Utern dir Oder, wo iler Ginsesigger sein Heim hat, und der Fischreiher unter lautem Krïichzen zu Horste Hiegt, während das Braunkehlehen auf den Wiesen scin anziehendes Wesen treibt, und der Fitis seine munteren Strophen von den Bäumeis des Flussufer's herabsehallen lïsst. Am inter"essantesten für den Togelfremul aber ist in ganz Niederschlesien neben dem Kunitzer il̈̈rensee ier Primkenaner Bruch. Hier nisten z. B. die Brachvögel so zahtheich, das ihe Eier zu Siputtpreisen auf' dem dortigen Markte rerkanfi werden. Zur Kangeit 
stellen sich Strand- mo Wassonlinfer masenhaft ein, und im Sommer horsten der schwarze Storeh und der. Fischadler auf den höchsten Bäumen der weiten, wildreichen, dem hichwager unsere; Kaisers, dem Herzog Günther von Sehleswig - IJnlstein gehörigen Forsten. Ein ganz anderes Lanrliehafisbild biem che iuppigen Anwälder Mittelschlesiens dar, in denen ich hauptsitchlich benbachtet und in denen ich so muvergesslich glüklich. Stunten verlebt habe, reich an reinen Furscher. und Jighrfrenten. In fast ununterbrochenem Saume zielsen sich diise Wäller an der Oder entlang, mit dichten Weidenwerlern an den Fluss tretend, ïber welche uralte Eichen oder ricsige Sehvarzpappehn ihre ausdrucksvollen Kronen erheben. Ein T'eppich duftione Maiblïmchen bedecki im Frühjahr, eine Tafel köstlicher Erdbeeren in summer den überall feuchten Boden, während suhice molureldringliche Brombeerdickichte und mehr als mammshohe Bremmussehn las Vorwïrts. dringen hemmen, ja bisweilen znir Unmöglichkeit machen, zumal der an solchen Stellen stets mooratigge Bulen of trïgriseh nachgiebt und den darauf gesetzten Fus im sohlamm versinken lässl. Sumpfige Wiesen, ïppige Werler, zahllose [Mamme und Graben, tote Flussarme, trübe 11 asserlachen, sehilfbewachene Teiche und langgestreckte R hrdickichte unterbrechen fist fortwähend das

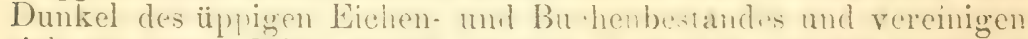
sich zu eunem Bilde, durch welches man sich unwilliürlich an die untere Donau versetz glanbt. Erol- und Rohrönger charakterisiren in erster Linie diese Wildnis. Dieselbe ist ein wahres Dorado für msere Sängerküniçin, die Nachtiganll. Wer nicht selbst einmal eimen lanen Aheme des Womnemonat in der surachate

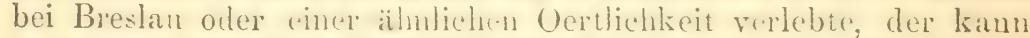

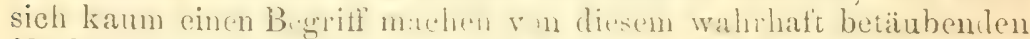

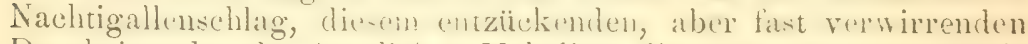

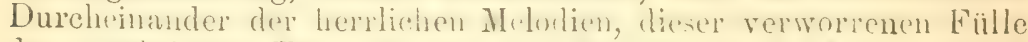
der prächtig-ten 'Töne, die ihm and Suhriu mul 'Tritt, aus jedem Busch, an jeter IFuke, ans jelem Graben entgonens:hallt. Ich habe thatwichlich dort of dus Nacht- nichi schlaten können; so laut, so anhaltend und so vielfach d"ang der" priehtige Schlag dureh die Fenster meines Zimmers. Anch das veizende Blankehlehen gehört zu den hïntigsten Vö̈gehn der schlesischen duwaldungen, und scin B.siant übertrift dort gun entschieden den seines rotbriastigen Vetters. Interessint dürte es ferner erscheinen, dass der Mittelspe ht hire minderence cuen so häutig ist als der grosse Buntspecht, und daw jeder anfmerkame. Förster den bunten Seidenschwanz, ja bisweilen selb-t die schöne Lasurmeise als seltene Gäste in strengen WTintern kennt. Einer der ersten Charakterrögel aber ist die Rohrotrossel, deren nurerliembares "Karre, karre, karra, kied, kied, kiets uns aus jolem Rolıdickicht entgegenschallt, die auch dam nicht schweigi, wem alle auderen 
Vögel während der Mittaghitze ermiihlet ruhen, und deren sonderbares Lied wie greschaten scheint für dicee ernsten, dem blossen Spaziergïnger ihres sumpfigen Beschatienheit wegen höehst unfreundlich erscheinenden $1 \mathrm{I}$ ail.ter. Das jentes Jahr ein-oder zweimal

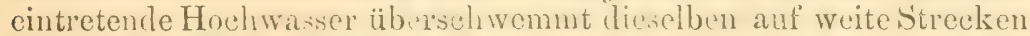
hin und fügt so lür den Menschen nene Ilinderni-se, für die Vogelivelt nene Torteile und Ammehmlichiseicen zu den schon

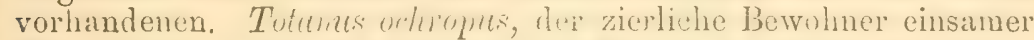
Waldlachen, erhält dann zahliechen Besuch ans seiner Verwandtschaft, und herumstreitende Finchather mul Reiher nehmen wochenlang hier ihren Aufenthalt, während die sumpt- mod Motthühnehen zwischen deu Seggnkufon ihr versicuktes Wosen treiben, und die Bekassinen auf den Zuge hier willkommene Ratst ma hen.

Noch ernster, mendlich viel einfömighr, bisweilen fast finster erscheinen die grossen Waldungen Oherechlesiens, die der stattliche Schwarzspecht durchiarmt, während die Iteidelerehe als cin lebender Spielball der Lïfte über die von der letzten Glıt der seheidenden Sonne ungoldeten Fichtenwipfel emporsteigt mul mit ihrem süssen Silberschlag dem von den würzigsten Limzitüten durehsehwängerten

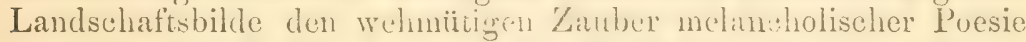
verleiht. Und doch besitzt anch diese Gegend ihne landschaftlichen Reize und für den On nitlolugen ein nicht geriuges Interesse. W Wem man im westlichen Weutsehand von Oberehlesien spricht, so verbindet man damit meistens die Torstellung von lärmenden Industriebezirken un: sehmutzigen Kihlenbergwerken ciner- und von öden, unfreundlichen Heilewaldungen andrerseits. Aber dem ist nicht so, und Obersehlesien ist entechieilen bessor als scin Ruf. Wohl dampten in den geriuschrollen Centren des Bergbaus und der industrie unzithlige schlote fist unanterbrochen gen Himmel, so dass dori, wie der Volkmund ohne allan gresse Uebretreibung sagt, nder silnee schwarz vom Ifimme! heruner homm," aber wenige stunden Fussmarch gienïgon anch schon, um uns wie mit einem Zauberschlage in dic tief-u Wralescinsumkeit za versetzen oder uns an die schilfigen Utier eines ron einer bunten Vogelwelt anf das schönste belebtein 'T'iches zu führen. Der erste Charaktervogel dieser Gugenden ist ents hicien der Fasan, um dessen Gedeihen sich der ganze Jagdochutz dreht. Ieh liann nicht recht begreifen, warum viele dutnen diesen Togel nicht mit in das Verzeichnio deutscher Arten auforenomen schen wollen; zählen doch anch die Botaniker anstandshos in inren Floren die aus fremden Ländern eingebiirgerten l'Hnzen nit anf, und wer da meint, dass etwa der asin lentiglich Cialturpoulukt sei, und dass er sich bei uns in freier Nittur nicht whe menschlichen Schutz halten köme, der ist sioherlich noch nichi in schelesien, diesem Fasanenlande emme il faut guwesen, wo wir zahlreiche Fasanen ohne die geringste Hegung, atleh auf von Lasjägern 
ganz erbarmungsios ausgepliiırlerten Jagden, ihre Bruten gross bringen sehen. Er gehört notgedrungen ebeu so zum oberschlesischen Charakterbilde wie der rauchende Sehlot des Berg'verks, wie die alte, abgestorbene Kiefer, wie das Rotwild aut saftig grinender Waldeswiese nnd wie die trillernde Heidelerche am blauen Himmelsdom. Die Zahl der auf den grossen Jagden an einem Tage erlegien Fasanen beirïgt anf manchen Ilerrschaften 1C ) und mehr. Se. Majestät der Kaiser schoss im Jahre 1890 an i) Tagen allein ca, 15, , Stück. Deshalb gelten auch für Oberschlesien ganz besonders die schon vorhin geschilderten jagdschutzlichen Verhältnisse. Wohl ist der farbenpräichtige Hahn ein gar stolzes Federwild, woll macht es clas Herz des IVeidmanns rascher schlagen, wem auf das Rufen und Lärmen der 'Treiber hin IIalın auf Hahn kröhlenr, polternd und surrend aufgeht, dass dem daran ungewohnten Jäger die sinne vergehen, wenn sie dann rasehen Fluges tahin ziehen, bis einer nach dem andern mit dem tötlichen Blei im Herzen wieder herunterstürzt, aber der Naturfeund kann trotzdem sein Herlauern darüber kaum unterdrücken, dass diesem einen bunten Fremolling so viele unserer einheimischen Vägct weichen mussten. Zux Zugzeit sind die Ranbvögel und die Drosseln sehr zahlreich vertreten, und zwar gilt dies besonders für die Mareh-Beezwa-Oderfurche. Unter den gewaltigen sich alsclann einstellenden brosselzïgen betiuden sich bisweilen auch recht scitene Gitste, die aber wohl nur in den wenigsten Fällen als solehe erkannt und für die Museen gerettet werden. Sicher nachäesiesen sind bisher: Turdus Naumanni, veficollis, obsumus, carius, atrigularis und sibivirus. Dancben werden alljahrlich seidensehwainze in grosscr Lahl und hin und wieder sperlings- und 'Zwergohreulen ir den oberschlesischen Dohnenstiegen gefangen.

Den ornithologischen Chatrakter der sudeten, welche übrigens für den Vogelzug eine nicht zu unterschätzende liolle sprichen, habe ich schon vorhin flüchigg getsmzeichnet und will hier nur noch hinzufügen, dass sich dic Urnis der wö̈stenteils mit herrlichen Wraldungen besetzten Vurberge ziemlich schart von der des Hochgebirges tremmen lässt. Granspecht, Bergistelze und Wasscramsel sind für erstere bezcichnemele Arten; auch erst sekundär eingewanderte species finden wir hier besonders häufig vertreten; so don niedichen Girlitz, so die birmende Wachholderdrossel. Das Hochgebirge, das anf den nicht etwa durch den Anblick des Alpen verwöhnten Dentschen cinen imposanten Lindruck macht, ist dureh sene scion vorhin genamiten alpinen Vogelarten fur den Ornithologen ron besonderem nnteresse. Wem es einmal vergünnt war, dori oben in Knichulz dit: lingdrossel und im Felseröll den $\mid 1$ anserpieper zu benbachten oder dem Flüevogrel an aen steilen ibisingen der ischneegruben nachzustellen, der 
wird sicherlich cinen unauslöschlichen Eindruck mit sich genommen haben.

Ich gehe nun zum letzten schlesischen Untergebiet über, zur Bartschniederung, welche dureh die in so zahllosen Mengen vertretenen Sumpf- und IVasservögel ein überaus charakteristisches Gepräge ertält. Schon ein Blick auf die Karte zeigt, dass die Bartschniederung mit ihren zahlreichen Teichen, Sümpfen und Forsten sowohl infolge ihrer natürlichen Beschaffenheit wie geographischen Lage eine vol'zugsweise reichlialtige und interessante Vogelivelt bergen muss; und in der That stellt dieselbe noch eiren der wenigen Zufluchtsorte fur unser durch die fortschreitende Cultur hart bedrängtes Wassergeflügel dar ${ }^{1}$ ). Dic Bartsch zeigt meist steile, aber niedrige Uferwandungen, seltener flache Kies- und Sandbänke. Bei Nesigode bildet sie eine sogenamnte "Luche", d. h. sie teilt sich in eine Unzahl sumpfiger Arme, welehe ein Gewirr von unergriudlichen Morästen, Erlenbrüchen, Rohr- und Schilfdickichten und üppigen Laubhölzern umschliessen: cin gecigneter Brutplatz für Reiher und Kraniche, wilde Gänse und allerlei Enten, ein Licblingsanfenthalt für das Schwarz-, Rot- und Damwild, ein ergiebiges Feld tur die Räubereien der Füchse und Fischotern. Die Wahlungen bestehen zum weit überwiegenden Teile aus langgedchuten Nadelhölzern; abel anch Laubwald ist vorhanden und in ihm oder an den Ufern der Teiehe riesenhafte, uralte, oft hohle oder dürre Fichen, die den Höhlenbrütern einen (rwiunsehten Anfenthalt bieten oder den zahlreich vorhandenen Raubvögeln zur IVarte dienen Lie Teiche sclbst, in denen cine crossartige Fischzucht betrieben wird, sind dicht mit Rohr und Schilf bestanden, so dass man ron dem eigentlichen Wasserspicgel oft herzlich wenig gewahr wird, und haben eine durchschnittiche Grösse von 150-100) Morgen. Brachfelder, öde Weideplätze und magere Wiesen fehlen eben so wenig wie fruchtbare, gut bebaute Strecken fetten Ickerbodens. Ja, schön sind wohl die märkischen Secu inmitten der ernsten Nadelwaldungen und sandigen Haiden, denen sie ein so fremdliches Gepräge anfzudrücken im stande sind, sehön sind auch die S'een P'ommerns und Necklenburgs mit ihre'n rauschenden Buchenvälderu und prangenden Weizenfeldern, aber unendlich vich sehöner fürwahr sind die Teiche Schlesiens an der Bartseh mit ihren undurehdringlichen Rohrwïhlern und sehilfdickichten, schöner sind sie vor allem wegen ihrer reichen, alles belebenden, alles umschwebenden, lämenden, spielenien, flatternden Vogelwelt!

1) Leider scheint man sich jetzt ernstlich an die liegulirung der Bartsch zu machen, und damit dürfte dem auch dieses ornithologisehe Dorado bald von der Bildfliche verschwinden. 


\section{Zugverhåltnisse.}

Im Jahre 1-7:) erschien unter dem Titel „Dic Zugstrassen lex Vögel" cine an-führliche Arbeit von Joan Axel P'almèn, Privatdocenten der Geologie an der Universitä zu Helsingfors, Ind iln folgte in Jalne $13-1$ ein Werk mseres bekannten, unlingst in holem Aler verstorbenen deutsehen Ornithologen Eugen Ferlinand von Ilomeyer, welches seinem ganzen Inhalte nach nichts als eine schnife Kritik und Polenik gegen das Palmènsche Buch ist. I'almin vertritt d? n Darwinismus, die Anpassung:theorie; cr liìst die Töscel auf schmalen Zngstrassen längs der Mecresufer mol Flïsse wamlers, bewregt sich zu viel auf dem grefähliehen febiete rep IIypothesen und geistreichen Theorien

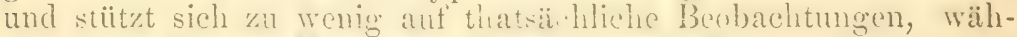

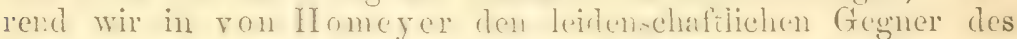
Darwinismus bor mus sehen, der desen sobwallen einer sehonungslusen, aber häufig lä̈chst ungerechen Krible untryieht, der die rögel in regelleser, breiter Front wandern lii--i nud als seharfer

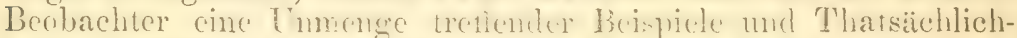

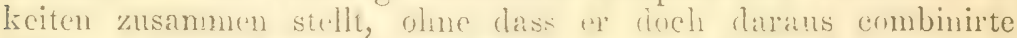

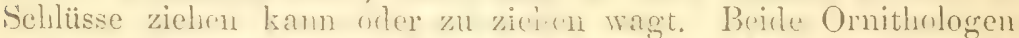
simel entschieden in iln'm Eifor für tie oigene nud in ihrer Polemik

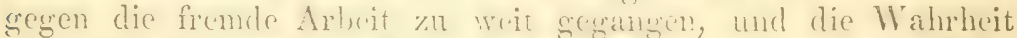
dürfte wic in so vichen Fällen so anch hien ungefialir in der Mitte zu suchen sein. In Ueluerinstimmung mit liadde muss auch ich vieles, was Palmin und vor ilm sehon Trallace und namentlich r. Middendonf aufstellten, mberlingt als richtig anertemnen und motersehreiben, obschm natülich unser sich immerhin nur in relativ hesehoidenen Grenzon haltendes liesengebirge bei weitem nicht so enume Teribrlerungen am Togelzuge zu bewirken rermag wie iler g(waltigu Querriegel des Kaukasus.

Und doch mör-hte ich anch dem Kamme der sudeten und namentlich dem liesengebirge nicht alle und jerle Bedentung für den Vngelz!n abspreclien, obwoll Alexander v. Homeyer und andere Foricher ersten lianges nicht glanben, dass dasselbe irgend welchen Einflus ant die Tíanderungen der Tögel ausübe. leh habe indesseri von allen meinen in den Torbergen wohnenden Mitarbeitern stets mit solelere Iiestimmtheit und mit solcher Ucberrinstimmung fiur den IIrlst die Zugriehtung so angegeben erhalten, das: ich doch sutzig geworlen bin, indem es scheint,

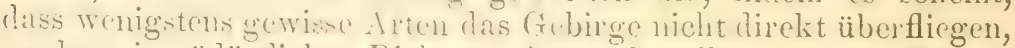

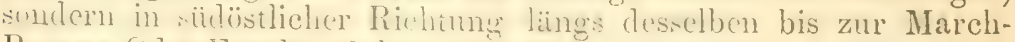
Beczwa-Oder-Furche dahin streichen. I)anchen werden wohl anch dic I'isse viel benutzt, von dienen der ron Landeshut ornitho- 
logiseh am stärksten frequentirt erseheint. Hören wir z. B. den Bericht meines dort beobachtenden Mitarbeiters v. Fürsten mühl: „Ich glaube mit Bestimmtheit annehmen zu kömnen, dass die Hauptstrasse des Vogelzuges im hiesigen Kreise nordwestlich von Landeshut her durch das breite Griissancer Thal über SchömbergAlbendorf bei schömberg nach Böhmen hineinführt. Dies entspricht auch der Bodengestaltung. Die Wandere haben hier keine bedeutendere Höhe zu ïh)rfliegen. Die ganze Zugrichtung der angenommenen Strasse ist $\mathrm{N} W \mathrm{P}-\mathrm{SO}$ und biegt dann etwas nach S um, resp. umgekehrt, doch habe ich rorwiegend den Zug in erster Richtung berbachten kömnen. Al*o erst NIV-SO, dann SSO-S. Als sehr beliebten Ruhepunkt möehte ieh jedoch andrerseits für die Drossehn die Tratutlicbersdorfer Heide bei Friedland erwähnen, welche ein ziemlich lioher $\mathrm{Berg}$ ist $(760-80(\mathrm{~m})$, von der genannten Strasse aus nach ONO gelegen. Doch vermute ich, dass diese Drossch einen anderen Weg bis dahin benützen, um danu vielleicht sich in der Richtung über Schömberg-Altendorf anzuschlieese'n. Das sind aber "ben nur Vermutungen." Es geht ans diescen Nittrilungen doch wohl bis zur Evidenz hervor, da:s das Gros der Herbstzugvögel durt in südüstlicher Richtung ankommt und erst beim Erblieken des tief eingesehnittenen Landeshuter Pas:es südlich nach Böhmen hineinbiegt, während ein anderer Teil auch jetzt noch in der alten Rinhtung seine Reise fortsetzt. (Chonia alba) Viche Vügel nehmen nach den übcreinstimmenden Berichten der dortigen Beobachter und namentlich des jüngeren Krezsehmar schum imstlichen Teile der Oberlausitz diese nach Südosten gerichtete Flugbahn an. Im Gegensatz zu deu bisher gemachten Ausführungen stehen num aber die Beobachtungeu A. v. Homeyers. Derselbe schreibt: „Das Riesengebirge ist den wandernden Tögehln kein wirkliches Hinderniss, und namentlich die von Norden nach süden gchenden Thäler machen wichtige Wanderstrassen aus ${ }^{1}$ ). Viele Tögrel sehenen sellost das Ueberfliegen des Kammes nicht, wenn anch Einsenkungen desselben den Vorzug erhalten und die höchsten Teile gemieden werden.

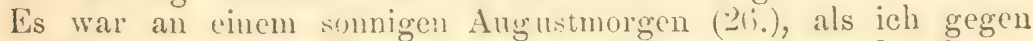
10 Uhr nach Seidorf an Fusse des Gebirges zuwandernd von Warmbrum her eine Schar siorrche ankommen sah, welche direkt dem Gebirge zustenerte. Als the schon an und für sich sehr hoch fliegenden Störehe an dem Fusse des Gebirge's angelangt waren, zugen sie etwas seitwärts schwenkend und dabei noch höher steigend nach dem höher lingenden Arndsitorf und Krummhübel zn. Hier fingen sie an zu kreisen und wandten sich in der kurzen Zeit von 7 Minuten so hoch, dass sie kanum noch zu

1) In diesem P'unkte stimme ich ganz mit A, vo. Horneyer überein. 
sehen waren. Jetzt hürte der Kreiselflug auf, die Schar breitete sich wie vorher in breiter Front aus und stenerte nun direkt dem Sehmicleberger Kamm zu, wm ihn faktisch zu überfliegen, wie ich es deutlich mit dem Fermrohr beobachtete. Wenn nun dieser Lramm anch betentend niedriger als der eigentliche Riesenkamm ist, so wird doch anch dieser äberflogen, wie das durch den Oberforster Bur")w beobachtet ist. Auf der Anuenkapelle crtuhr ich geregentlich ron - jungen Apothekern, welehe über den Landeshuter Kamm ${ }^{1}$ ) kamen, dass sie daselbst bein Gastwirt Frochlieh geschosene Sï̈rche gesehen hätten. Die Störche sullen sich gewöhnlich unweit seines Wohnhauses niederlassen, wobei alsolam oftmals ctliche erlegt werden. Fast als Merkwürdigkeit sehliesst sich hieran cine Mitteilung res Fürster's der Amakipuelle, wonach eine Fulier atia im Monat 1)ecember aut dem Iluchstein bei der Josefinenhüte dirreh seinen Hëhnorhund

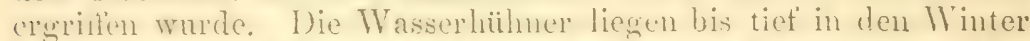
hincin anf den an Fusse des Gebirges getegenen Warmbrumer Teichen und versebwinden erst, went cirse getrieren. Ob vorstehender Fall dic liegel ansmacht oder nicht, bleibt dahingestellt, jedtufalls

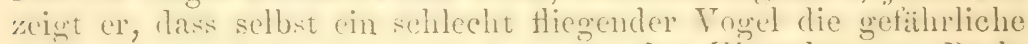
Gebirgswanderumg nicht selieut - In den II armbrumer Parkanlagen salı ieh wohl während $1+$ Tagen stets Pirole. Jeden

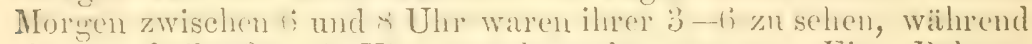
sic um beilïufig 10 Uhr verschwumen waren. Eine Balsampappledaller, welehe dem Gebirge zuführte, wurde namentlich vom ihne'n besteht. Ich beobachtete die Tö̈gel genauer und sah alsbald, wie sie llie Allee verliessen unt dem (rebirge zutlogen. Dies veranlasste meinerseits l'romenaden nath idem Itainfall, Ammakapelle, Kirehe Wang, linrz nach Orten, welehe ca. auf halber llühe dos Kammes liegen, und hicr faml ich meine Tögel wieder. Wenu ich nun anch wirlich nicht Pirole oben auf den Kamme sclbst antrat, an liegt es duch seln nahe, dass sic denselben überfliegen, indem nicht wohl anzunchmen ist, dass sie auf loalbem Wowe wieder umkehren sollten. I)asselbr gilt atueh ron einigen anderen Vögehn der Wiarmbrumer Allee, st ron Syleia loutensis und

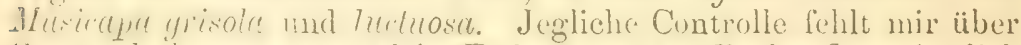
C'ynuerula lowruya, a, welehe Encie Iugust an Zackenfluss ziemlich hiiution war. Einmal ant dem Zuge mon Hirsehberger Thal, wo das Blankelehen nicht oder doch wohl nur äusserst selten brütet, kamm ich mir nicht denken, dass das Vügelchen des sich vorlageruden Gebirges wegen wierler umkelren sollte, um so mehr, als chen so zarte Tögel (S. lontrusis) das nicht thm." So sehr" diese dufülrungen des verehrten Forschers auch gegen meine 
auf die zahlreichen und übereiustimmenden Beobachtungen meiner Mitarbeiter gestützte Ansicht zu sprechen scheinen, so sind dieselben in Wirklichkeit doch kaum geeignet, selbige ernstlich zu erschüttern. Gerade bei Ciconia alba liegen mir so zahlreiche Bcobachtungen ïber den stets längs der Vorberge nach Südosten gerichteten Herbstzug vor, dass ich die einmalige Wahrnehmung v. Homeyers nur für einen Ausnahmefall ansehen kann. Die Fialle vom Landeshuter Kamm werden wohl mehr auf den Landeshuter Pass zu bezichen sein. Die auf dem Hochstein gefangene Fulica atra war augenscheinlich in durch widrige Winde, Stürme, Schneegestöber oder dergl. versehlagener Vogel. Dass sie dureh abnorme Anstrengungen übermület war, bewcist schon der Umstand, dass sie sich ohne weiteres vom Hunde greifen liess. Bci den Pirolen handelte es sich doch offenbar nur um kleine tägliche Ausflüge nach durch roichlichere Nahrung besonders anziehenden Punkten. Solehe kommen ja bei sehr vielen Vögeln vor, diirfen aber doch keinestalls zum Massstab für Zugverhältnisse gemacht werden! Ueber die kleinen Vögel ${ }^{1}$ ) habe ich weniger Nachrichten erhalten, habe aber dafür den Zug der Drosseln sehr eingehend sturlirt. Ieh verfuhr dabei derart, dass ich überall Erkundigungen über die Zahl der alljährlich an einer bestimmten Oertichkeit im Durchschnitt gefangenen Krammetsvögel einzog und danach berechnete, wie viel Krammetsvögel ctwa auf die Quadratmeile Landes kommen. Gegenden, in denen kein Krammetsvogelfang betricben wird, schätzte ich in gleicher Weise nach den benachbarten Landstrichen ab. Dann teilte ich eine Karte Schlesiens in entsprechende kleine Quadrate und bemalte dieselbe mit roter Farbe und zwar stufenweise um so dunkler, je grösser die Zahl der alljährlich gefangenen 1)rosseln war. Dahei stellte sich dann im grossen und ganzen das interessante Resultat heraus, dass sich ein dunkelroter Streifen von der Lausitz aus nach der March-Beczwa-OderFurehe durch die Vorberge längs der Sudeten in südüstlicher Richtung linzog, der nur nach dem Landeshuter Pass hin einen schwächeren Seitenzweig abgab. Jin zweiter nicht so intensiv gefürbter Streifen verlief von der Bartsehniederung aus siidwestlich über die Oder und die oberschlesische Teichplatte gleichfalls nach der March-Beczwa-Oder-Furche. Auf dieser zweiten, schwächer besuchten Strasse seheinen nach meinen Beobachtungen besonders die Amseln zu zichen. Alle anderen Particen des Landes blieben mit wenigen Ausnalımen verhältnismässig hell, auch das Oderthal, welehes demmach für di* Drossehn keine Zugstrasse darzu-

1) Mit den durch von IIomeyer beobachteten Grasmuicken dürfte es sich vielleicht ähnlich verhalten wie mit den erwähnten Pirolen. 
stellen scheint. Man wird num zwar gegen die Genauigkeit meiner Methode im eiuzelnen mit Recht mancherlei Einwäude vorbringen können, aber andrerseits dürfte es auch kaum zu leugnen sein, dass dieselbe immerhin geeignet ist, uns wenigstens einen ungefähren und allgemeinen Einblick in die Zngrerhältnisse jagdlich so bevorzugter Vogelarten zu verschatten. Deshalb verfuhr ich auch noch ähnlich mit den alljährlich geschossenen Enten, Schnepfen und Bekassinen, um auf diese Weise die Zugstrassen der Sumpf- und Wasservögel zu ermitteln. Das thatsächlich erbaltene Resultat liess sich hier allerdings schon voraussehen, denn die Natur hat ja den Sumpf- und Wasservögreh in Schlesien gewissermassen schon den IVeg vorgezeichnet, den sie auf ihren WVanderungen nehmen müssen. Wer vou Nordost liommende Vogelzug stösst zunächst auf die Bartschniederung mit ihren grossen Sümptin und Teichen, überquert dan die Oder in breiter Front und südwestlicher Richtung zwischen Breshau und Brieg orler folght auch wohl dem Laufe dersclben bis in die Gegend von Oppeln, besucht hierauf die grosse oberschlesisehe 'Teichplatte, um dam endlich dureh die Mareh-Beczwa-Oder-Furehe i: siillicher Richtung zwischen Karpathen und Sudeien hindurch der l)onan zuzueilen. Für einige grosse und der allgemeinen Beobatehtung selı zugängliche Vogelarten wie Stürche, Reiher, Schwine, Gïnse, Kraniche, Kiebitze 1. a. ist dieser. Wear schon mit ziemlicher sicherheit nachgewiesen. Die grosien nurdischen T'aucher dagegen seheinen der Oder zu folgen, und im Oderthale zicht anch woul das Gros der Rohrsänger, Laubrögel u. dergl. Doch sind hicr weitere bestätigende Beobachtungen noch dringend ü̈tig.

Gerade bei den Sumpf- und Wasservögeln lässt sich auch sehr deutlich das streichen von Raststation zu Raststation beobachten. Wohl hat uns erst vor kurzem wieder Gätke gezeigt, über welch ungehenre Schnelligkeit auch anscheinend so schlechte Flieger wie das Blankehlehen verfügen können, aber ich kann mir nach meinen in sichlesien gemachten Erfahrungen doch nicht gut denken, dass diese sehnelligkeit bei uns im Bimnenlande auf dem Herbstzug unter normaten V'rhältnissen voll und ganz zur Anwondung lommt. Es ist vielmehr schon mehrfach, namentlich auch dureh v. Middendor bis zur Evidenz nachgewiesen, dass die gefiederten Wanderer in Herbst keineswegs mit der Vollkraft ihrer stählenen Sehwingen dahin eilen, sondern vielmehr nur an jedem Tage cine rerhältuismäissig kleine Strecke zurücklegen, um dam an ciner gecegneten Raststation mehr oder minder lange zu pausiren. Für Schlesien kann ich mich dieser Ansicht r. Middendorfs nur ganz unl gar ansehlicssen und schmeichle mir, dass auch der unbefangen urteilende Leser dies thun wird, wenn er die im spreciellen Teile enthaltenen Zugtabellen einer näheren Prüfung unterzogen haben wird. Im übrigen muss 
ich inbezug auf alle die zahlreichen uns bei Betrachtung des in vieler Hinsicht noch immer so rätselhaften Vogelzuges entgegen tretenden Fragen auf die bei den einzelnen Arten beigefiigten Notizen im speciellen Teile dieser Arbeit verweisen.

Hier sei nur noch in aller Kürze erwähnt, dass auch die sog. "Rückzïge in Schlesien mehrfach wahrgenommen wurden. Ich selbst kounte solche Rückzüge 1859 bei Breslau in grossem Unfange constatiren; besonders deutlich traten dieselben bei Alauda arensis hervor. Ferner berichtet v. M e yer in ck: „Vom 1. April 1579 ab trat wieder kaltes, rauhes Wetter ein, abwechselnd mit schmeehuschen, und alle Morgen hatte es tüchtig gefroren. Alle Zugvögel waren wieder versehwunden, und kein Star, Kiebitz oder Krammetsrogel liess sich hören und sehen. Stare und Ziemer sah ich mehrfach nach Südosten ${ }^{1}$ ) zielıen. Wo waren nun die Zugvögel alle geblieben? Ich möchte doch glauben, dass viele bei der ranhen Witterung nach dem warmen Süden zurückwanderten. Als am 9. April wieder Südwind und warme Witterung eintrat, sah man plötzlich wieder im Waide und auf dem Felde alle möglichen Zugrögel und auch viele kleine Singrö̈gel.“ Vergl. anch hier im speciellen Teil die Beobachtungen v. MT eyerincks über Alauda arvensis.

Das Ziehen kleinerer Vögel in Gesellschaft grösserer hat namentlich $\mathrm{Kn}$ a ut he öfters beobachtet. Er ist der Ansicht, dass die kleineren Vögel stets dieht hinter den grösseren herfliegen und in ihnen eine vorziigliche Deckung gegen scharfe conträre Winde finden.

1) Also nicht nach Siidwesten iiber die Sudeten hinweg, sondern denselben parallel! 


\section{B. Specieller Teil.}

\section{Ordnung: Oscines, Sing vögel ${ }^{1}$ ).}

Kleine oder mittelgrosse (excl. Curtiture) Vügel mit einem mehr oder minder entwickelten Sïngmuskelapparat an unteren Kehllkopf. Die 1. Schwinge ist stets in verechiedenem Grade verkümmert oder kam anch ganz fehlen. Die Hinterseite der Lïufe ist meistens von einer ununterbrohelienen Horndecke bekleidet oder nur schwach getäfelt. Schwanz 12federig ${ }^{2}$ ).

Familie: Turdidae, Drosselvögel.

schnabel gerale, mässig dünn, seitlich ctwas zusammengedrüekt, mit seichtem Einselmitt vor der Śpitze des: Oberschmabels. Länfe hoch und durch grosse Schicnen bekleidet. Flügel ziemlich kurz bis mittelang. Die 3. Handsehwinge gewöhnlich am längsten.

Gattung: Erithacus Cuv. 1800. Erdsänger.

Schnabel dünn und pfriemförmig; ror den unbedeckten Nasenlöchern höher als breit. Ange gross. I.̈̈ufc hoch und gestiefelt. Flïgel ziemlich kurz. Kemnzeichuen sich noch besonders dureh würdevolles Wesen, aufrechte Stellung und eigentiumlich zitternde Schwanzbewegungen.

1. Erithacus philomela (Behst.) 175. - Sprosser.

Synonyma: Luicinia maior Schwenckf., Briss., Frisch., Klein. Motacilla luscinia maior $\mathrm{Gm}$. Motacilla philomela Buhis.,

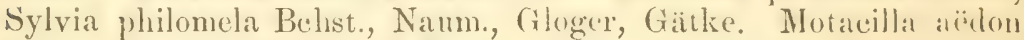
I'all. Curruea philomela Koch. I'hilomela maior C'hr. Brehm, Degl. Bonap. Iusciola philomela Kays. u. Blasius, Friedr. Lrythacus philomela Degl. Sylvia eximia Chr. Brehm; Luscinia philomela Chr. Brehm, Sund., A. Brelm, E. v. Homeyer, Mewes, Gicbel. Arumdinax aëdon Blyth., Daulias philomela Radde; Aëdon philomela Hartert.

1) Bei den gegebenen Diagnosen sind nur die mitteleuropäischen Formen beriicksichtigt, die exotischen dagegen der Einfachheit halber vernachlässigt.

$\left.{ }^{2}\right)$ Eine Ausnahme macht Cinclus merrara melanogaster. 
Trivialnamen: Sumpfnachigall, Rotvogel.

Kennzeichen der $\Lambda \mathrm{rt}$ : Die 2. Schwinge ist nur wenig kürzer als die 3. und viel lünger als die 5., die 1. nooh mehr verkümmert als bei der Nachtigall.

Das Brutgebiet des Sprossers erstreckt sich über Jütland, Dänemark, das untere schweden, Finnland, Polen, Ungarn, Russland und Turkestan. Für Deutschland ist er nur im Osten und zwar besonders im Nordosten (Ostpreussen und Pommern) als Brutvogel constatirt. Was nun schlesien anbetrifft, so gehört hicr der Sprosser zu denjenigen Arten, welche zu Beginu unseres Jahrhunderts nistend wie durehzichend ziemlich häufig anzutreffen waren, sich seittem aber mehr und mehr aus der Provinz zurückgezugen haben und gegenwärtig zu den selteneren Erscheinungen gezählt werden müssen. Die älteren Autoren fủhren den Vogel noch als Brutvogel für ganz Oberschlesien, die polnischen Grenzgegenden und selbst (Braths) fur einzelne Striche der Lausitz auf. Gegenwärig aber scheint der Sprosser als Brutvogel auf den östlichsten Teil des Kreises Militsch beschränkt zı sein. Bei Militsch selbst hörte ich einigremal sogenaunte "Zweischaller." Auch erhielt ich vou dort eine kleine Collektion Vogeleier, deren eines entschieden zu philomela gehört. Ferner wurden mir während der Brutzeit einige Stücke von dort eingeliefert. Während früher die Sprosser zahlreich durch Schlesien zrogen, scheinen sie etwa seit den Zeiten Al. v. II o m e yers ihre Wanderstrassen geändert zu haben, demn heutzutage triff't man sie auch zur Zugzeit nur selten und vereinzelt an. Schon der genannte Ornithologe hat wälrend seines Arfenthalies in Schlesien kein einziges Exemplar mehr in freier Natur beobachtet. Desto auffälliger erscheint die Nitteilung A. E. B i' e h m s, dass sich während des ganzen Sommers Sprosser im Kurgarieu von Warmbrum aufhielten. Da die Persönlichkeit des Autor's wohl jeden Ziveifel aussculiesst, möchte ich glauben, dass es sich um aus der Gefangenschaft entflohene Exemplare handelt. Im ganzen habe ich 7 schlesische Sprosser in IIiliden gehabt, welene alle den polnisehen Racen (E. puilomela m a i o r und h y brid a Bre h m) angehörter. Die kleine ungarische Form ist meines Wissens noch nicht in schlesien vorgekommen. Wahrscheinlich hat Giitke recht, wenn er diesem Vogel eine streng nord südliche Zugrichtumg zuschreibt, denn dadurch würde sich auch das seltene Vorkommen des im benachbarten Polen so zahlreich nistenden süngerkönigs bei uns in Schlesien leicht erklären lassen. Alle schlesischen Sprosser wurden auf dem Frülijahrszuge wahrgenommen; für den Ilerbstzug steht mir keine einzige Beobachtung zu Gebote, was sich aber vielleicht auch dadurch erklären lässt, dass sich der Vogel zu dieser Jahreszeit viel weniger bemerklich macht. Man triitt ihn noch am ehesten an den Ufern von Flïssen, besonders wo tiefes Holz mit dichtem 
Unterholz und Gebüseh vorhanden ist. Nach den Aufzeichnungen von R. 'Tobias war für die Jahre 15:2-1s35 der früheste Ankunftstermin der 1. , der späteste der 20 . und das Mittel am 17. Mai, al:o erineblich später als bei der Nachtigall.

2. Erithacus luscinia (L.) libs. - Na chtigall.

Synonyma: Motacilla luscinia L. Butr.; Sylvia luscinia Lath., Namm., Bchst., Gätke, Gloger; Currusa luscinia Koch; Philomela luscinia Selby, Degl.; Luncinia philumela Bunap.; Lusciola luscinia Kays, et Blasius, Friedr.; Luseinia vera sund. A. Brehm, Nowes; Erythaens luscinia Degl.; Luecinia minor Aldr., Schwenckf., Rezacz, Frisch, Klein, Chr. Brehm, E. v. Homeyer; Motacilla philomelar l'all; Danlias luscinia Radde; Aedon luscinia Hartert. Brehmeche Subspecies: megarhynchus, media, minor, Okeni, peregrina.

Trivialnamen: Deutsch: I örling, Nachtengall, Nachtingall. Polnisch: Slawik.

Kennzeichen der Art: Die -. Sulwiege bedentend kürzer als die 3. und von gleicher Lïnge mit der 5 .

$\mathrm{M}$ a asse von $2 \mathrm{U}$ schlesischen Exemplaren in $\mathrm{cm}$ :

$\begin{array}{lccc} & \text { maximum } & \text { minirumm } & \text { Durchschnitt } \\ \text { Länge: } & 16,8 & 15,6 & 16,1 \\ \text { Flügelspannung: } & 26 & 24,2 & 25,0 \\ \text { Schwanz: } & 6,8 & 6,3 & 6,6 \\ \text { Schnabellänge: } & 1,5 & 1,3 & 1,4 \\ \text { Fussrohr: } & 2,95 & 2,7 & 2,8\end{array}$

Das ganze südliche mol mittlere Eurpat ist als Brubberirk

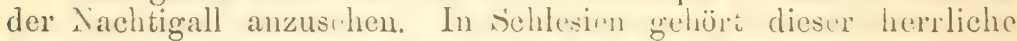
Togel glücklicherweise zu den allerhäufigsten Erscheinungen, und einen so enormen Reichtum an Nachtigallen wis die mittelschlesischen Auwälder dürften überhaupt woh! nur wenige Gegenden unseres engereu Vaterlaudes autzuweisen haben. Oestlich ron der Oder sowie in Oberschlesien wird sie zwar seltener, ist aber in wasserreichen Gegenden immer nuch recht häufig. Die niederschlesisehe Getreidecbene scheint ihr zu trocken zu sein, deun hier nimmt ihr Bestand merklich ab, um sich dann in den tieferen Teilen der Lausitz wieder zu heben. In len Vorbergen ist sie überall nur sparsam vertreten und dem eigentlichen Gebirge fehlt sie als Brutvogel gauz und kommt auch auf dem Zuge nur selten daselbst vor. In einigen Gegrenden wird den Nichtigallen von eigens aus Berlin, Dresden und anderwärts zureisenden Vogelfängern eifrig nachgestellt, olne dass jedoch deshalb eine Abnahme des Bestandes einträte, weil wahrscheinlich viel überzählige Männchen vorhanden sind. Knauthe meldet, dass die Vögel in scinem Beobachtungsgebiet stellenweise durch Ratten vertrieben worden seien. Uebrigens scheint sie sich neuerdings auch in 
einigen geschützten Gebirgskessehn mehr und mehr heimisch zu machen, so bei Glatz nach Hartert und im Hirschberger Thal nach Kollibay. Auf dem Zuge aber meidet sie das Gebirge, denn sonst müsste sie wenigstens im Frühjahı doch öfter dort wahrgenommen werden als dies thatsächlich geschieht. Wahrscheinlich geht auch bei ilı dre Hauptzug durch die MarchBeczwa-Qier-Furche, wis dem anch die dortige Gegend als das beste Fanggebiet gilt. R. To bi a s notirte von $1832-38$ als früliesten Ankunftstermin den 21i. April, als spätesten den 3. Mai, als durchschnittichen den 1. Mir. Seithem scheinen sich die Nachtigallen einen zeitigeren Frühjahrazug angewöhnt zu haben, und heute dürfte der Durchsehnitstermin für. Schlesien etwa auf den 25. April fallen. Ueber den Friblingszug liegen mir noch folgende Daten vor: 


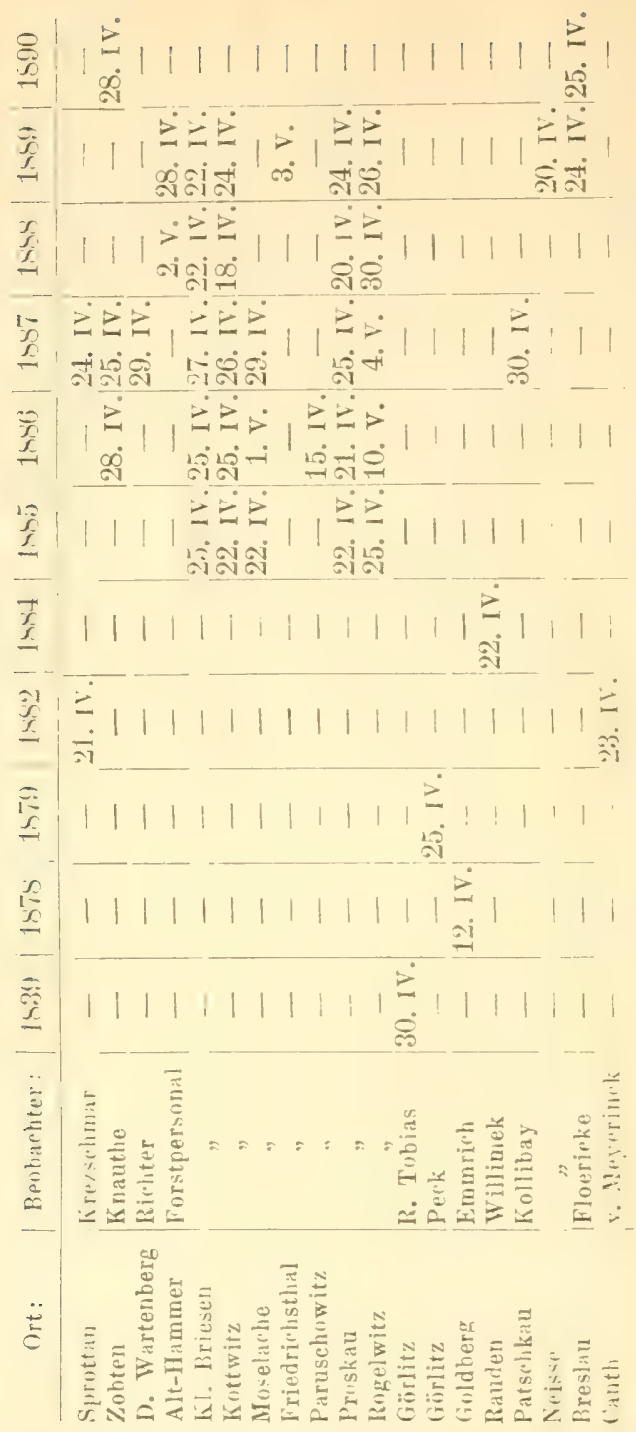

Der Wegzug erfolgt Anfang August und geht rasch und unmerklich von statten, da Schlesien mit Ausnalime der Grüneberger Gegend keine Weinberge besitzt, welche die Nachtigallen oft zu lïngerem Bleiben verlocken, und andrerseits das nahe Ungarn ja so sehr mit denselben gesegnet ist. Zum Brüten liebt 
die Nachtigall bei uns niederes Laubholz mit dichtem Gebiisch, in dem womöglich das vorjährige Laub noch liegen geblieben ist, und wo sich Gewässer oder wenigstens feuchter Boden in der Nähe finden Prätorius fand cin Gelege am 2). Nari, ich selbst am 18., 21. und 22. Nai, Kutter nackte Junge am (6. Juni. Alle Nester, die ich sah, standen dieht über dem Boden und bestanden änsserlich aus dlürrm Laub, in der Hauptsache aus dürren Grashalmen und Würzelehen und waren innen mit Haaren ansgelegt, buten also weder in der Anlage und Ausführung, noch in Grösse, Farbe und Form die t-G Fier Besonderes. Leider habe ich es versäimnt, die Nester zu messen. Durchschnittsmaasse von 22 schlesischen Eicrn: $21,9+15,1 \mathrm{~mm}$. Welcher der vielen Brehrnschen subspecies die schlesisehen Nachtigallen eigentlich angehören, habe ich nicht herausbekommen können. Diese Vügel seheinen mir überhaupt weniger den geographischen Breiten nach zu variiren als vielmehr nach der Beschaffenheit ihres lokalen Aufenthalts. II an findet oft sehr abweichende Tögel innerhalb ein und derselben eng begrenzten Oertlichkeit, weshalb sich die Brehm schen subspecies auch kaum werden aufrecht erhalten lassen. (Vergl, auch den dissbezuiglichen Passus bei Friderich). Was den Gesang anbelangt, so darf ich die schlesischen Nachtigallen wohl als gute Mittelvögel bezeichnen, unter denen diejenigen der Breslituer Gegend durch Weichheit, schmelz und Wohllaut der klagenden Partien und Mannigfaltigkeit der strophen wiederum besmuders hervorragen. In den "Breslauer simmlungen“ heisst es: "Lis hat schon mancher bundertmal mehr Mïhe und Sorgfalt gebrancht, die wunderbaren Veränderungen seiner Modulation mit Worten zu erklären als der Vogel zu seinem Gesange selbsi." Nach derselben Quelle soll die Süngerkönigin in den Lüchern der Bäume überwintern. 1698 wurde eine Geldstrafe von nicht weniger als 14, polnischen Gulden aut das F'angen, Kaufen und Verkiufen der Nachtigallen gesetzt.

Blaukehlchen.

3. Erithacus cyaneculus (Wolf). - Weissterniges kehlchen.

4. Erithacus suecicus (L.) - Rotsterniges Blau-

Meinen systematischen Anschanungen nach müsste eigentlich cyaneculus lediglich als subspecies zu sueciuts gezogen werdur, weshalb ich beide Blaukehlchen auch hier zusammen abhatuldele.

Synonyma: Cyanecula suecica Chr. Brehm, A. Brehm, Giebel, v. Hom., Newes, Radde; Motacilla suecica L., Butli, Gmel., Behst.; Cyanecula gilbratariensis Briss.; Sylvia suecica Lath., Behst., Naum., Gätlke; Sylvia cyanecula Meyer, Gloger; Cyanecula WVolfii Chr. Br.; Cyanecula lencocyana Chr. Brebm; Phoenicura suecica Sykes; Saxicola suecica Koch; Ficedula snecican 
Boie; Lusciola suecica Kays. und Blas., Friedr.; Lusciola cyanecula Schleg.; Erithacus cyanccula Degl.; Cyanecula longirostris, maior, minor, obscura Chr. Brehm; Motacilla coerulecula Pall.; Erithacus cyanus Rchw.; Cyanecula cyanecula und caerulecula Hartert; Sylvia leucocyana Gätke.

Trivialnamen: Blaukatel, Blookatel. Oberschlesisch-polnisches Idiom: Modro Raschka.

Kennzeichen der Art: Die 2. Schwinge steht an Grösse zwischen der 6. und 7. Die 3. ist gleich der t. und grösser als die כ. Die Geschlechter sind autfallend ungleich grefärbt.

Das rotsternige Blaukehlclien brütet lediglich im Nordosten Europas und ist in Schlesien auch auf dem Zuge eine höchst seltene Erscheinung, namentlich im Frühjahr. Ich besitze nur ein am 3. April is90 erlegtes Exemplar, und habe auch sonst keinerlei Kunde von dem Vorkommen dieser Art erhalten. Danach scheint es, als ob die nordischen Blaukehlchen wenigstens zu Beginn ihres Wanderfluges eine ausgesprochen ost-westliche F'lugrichtung inne hielten, womit auch ihr nach $G a ̈ t k e$ so zahlreiches Vorkommen auf Helgoland übereinstimmt.

Desto häufiger brütet die weisssternige Form bei uns in Schlesien. Man findet darunter nicht selten die Brehmsche E. Wolfi mit rein blauer Kehle und bisweilen auch Exemplare, welehe deutlich den Uebergang beider Formen in einander beweisen. Auch ich halte die Wol lisschen Blaukehlchen für besonders alte Männchen der weisssternigen Art, obgleich hier noch keineswegs alle Rätsel gelöst sein dürften. So fand z. B. auch ich stets die Walnuehmung $A \mathrm{l}$. v. Homeyers bestätigt, dass die gefangenen Exemplare von E. Wolfi stets schlechter sangen als diejenigen von $E$. cyancetulus, während man doch nach dem oben Gesagteu eigentlich das Ungekehrte erwarten sollte.

$\mathrm{M}$ a a s s e von 04 schlesischen Exemplaren in $\mathrm{cm}$ :

Totallänge:

Flügelspannung:

Schwanz:

Schnabellänge:

Tarsus :

$\begin{array}{ccc}\text { maximum } & \text { minimum } & \text { Durchschnitt } \\ 15,4 & 13,5 & 14,7 \\ 24,8 & 22,9 & 23,9 \\ 6,2 & 5,3 & 6,0 \\ 1,5 & 1,2 & 1,4 \\ 2,9 & 2,7 & 2,8\end{array}$

Im Oderthal seiner ganzen Länge nach und ganz besonders in den feuchten Auwäldern Mittelschlesiens ist das Blaukehlchen ein ganz gemeiner Brutvogel und stellenweise selbst zahlreicher vertreten als wie rubecula. Auch scheint es glüchlicherweise zu den. Arten zu gehören, welche sich veränderten Umständen rasch anzupassen ivissen und sich nicht durch die rastlos vorwärts schreitende und geeignete Brutplätze mehr und mehr zerstörende Cultur verdraingen lassen, weshalb ron einer Abnahme des Bestandes in schlesien vorläutig noch nichts zu spüren ist. Nach 
A. v. Homeyer nistet cyaneculus auch in den Oderwerdern bei Glogau sehr häufig, und auf der rechten Oderseite scheint es den Berichten meiner dort wohnenden Mitarbeiter zufolge ebenfalls überall gleichmïssig verbreitet zu sein. In der Bartschniederung ist es geradezu massenhaft vorhanden. Es findet sich dort nicht nur an den grossen Teichen, sondern eben so oft an ganz kleinen Wassertümpeln und halb oder ganz ausgetrockneten Gräben, wenn dieselben nur von recht dichtem und verworrenem Gebüsch eingefasst sind. In den Waldgegenden Oberschlesiens, im Hirschberger Thal und längs der ganzen Kette der Sudeten fehlt das Blaukehlchen als Brutvogel, ist aber auf dem Zuge eine regelmässige Erscheinung (Uttendörfer, A.v. Homeyer, Kirchner). In der Lausitz und in der linken Hälfte Nieder- und Mittelschlesiens ist der Vogel gleichfalls sparsamer vorhanden, zieht aber massenhaft durch und scheint sich neuerdings auch immer mehr auszudehnen und einzubürgern. So war cyaneculus nach $\mathrm{Kna}$ athe 1891 am Zobten sehr zahlreich, während es im Vorjahre noch vollkommen fehlte. Auf dem Frühjahrszuge trifft man es im niederen Gebüsch und Weidicht der Flussufer, ja selbst in den Gärten der Bauern, im Herbste dagegen besonders auf Kartoffeläckern und Gemüsebeeten. Ueber den Zug in Schlesien liegen nur folgende Daten vor:

\begin{tabular}{|c|c|c|c|c|c|c|c|c|c|c|}
\hline Ort: & Beobacht & : 1841 & $\mid 1842$ & & & 1552 & 1886 & 1889 & 1890 & 1891 \\
\hline & R. Tobias & 6.IX. & 16. IV & & - & & & - & - & \\
\hline$"$ & & - & - & 3.IV. & - & & & & - & \\
\hline Zobten & $\begin{array}{l}\text { Krezezchmar } \\
\text { Knauthe }\end{array}$ & = & $=$ & $\overline{-}$ & $\bar{z}$ & 10. -10 & $20 . \overline{\text { IIII. }}$ & $\overline{-}$ & $=$ & 6.1V. \\
\hline & & - & - & - & - & - & & - & - & 20. IX. \\
\hline & Mohr & - & - & - & $5.1 \mathrm{~V}$. & - & $14-$ & - & $\overline{-}$ & $=$ \\
\hline$"$ & Kern & - & - & - & - & - & 14. IV & & $4 \bar{v}$ & - \\
\hline$n$ & Floericke & - & - & - & - & - & - & 19. IX. & 24. IX. & - \\
\hline
\end{tabular}

Im allgemeinen lässt sich sagen, dass die Blaukehlchen in Schlesien in den ersten Tagen des April eintreffen und Mitte September wieder wegziehen, wenigstens soviel sich aus der allgemeinen Erfahrung und den wenigen Notizen schliessen lässt. R. To bias verzeichnete von 1832-38 als frühesten Ankunftstermin den 27. März, als spätesten den 11. und als Mittel den 4. April.

Nicht umsonst führt das liebreizende Vögelchen den Beinamen des „tausendzüngigen Sängers“, denn seine Nachahmungsgabe ist noch lange nicht genügend bekannt und geschätzt und kann in einigen Fällen einen geradezu bewunderungswürdigen Grad erreichen. Mit wahrem Vergnügen lauschte ich oft in der Strachate solchen Meisterspöttern, welche die verschiedensten Vogelgesänge 
ebenso täuschend wie lieblich nachzuahmen wussten; namentlich die Lieder der Dorngrasmücke und des Teichrohrsängers fehlten fast nie in diesem Potpourris. Auch den eigenartigen Balzflug des Blaukehlchens, wobei man den sonst so versteckt lebenden Vogel kaum wiedererkennt, konnte ich dort öfters beobachten, erspare mir hier aber eine nähere Beschreibung, da meine Wahrnehmungen in nichts von dem bereits Bekannten abweichen. Das Nest betindet sich gern an einem kleinen Abhang, auf einer Kaupe, unter einem grossen Rasenstück oder dergl., so dass es höhlenartig verdeckt steht. Der Vogel macht bei uns regelmässig 2 Bruten, die 1. zu 6 Eiern Mitte Mai, die 2. zu 5 Eiern Ende Juni oder Anfang Juli. Mohr fand das 1. Gelege am 10. und 22., Prätorius am 28., Baer am 17., ich selbst am 19. und 21. Mai vollständig. Die 6 Eier liegen zu 2 Reiben in Nest, mit den nach innen gerichteten Spitzen an einander stossend. (L. Tobias). Die Bebrütung dauert 13 Tage (Mohr). Ich selbst beobachtete einmal, wie ein verwaistes Geheck junger Blaukehlchen von einem gutmütigen Rotkehlchen, dem vielleicht die eigene Brut zu grunde gegangen war, gross gefüttert wurde.

Ma asse von 36 schlesischen Eiern in cm:

$\begin{array}{lccc} & \text { maximum } & \text { minimum } & \text { Durchschnitt } \\ \text { Länge: } & 2,2 & 1,9 & 2,05 \\ \text { Breite: } & 1,7 & 1,5 & 1,6\end{array}$

Die Form orientalis, welche ich aus verschiedenen ${ }^{1}$ ), hier nicht näher zu erörternden Gründen für hahnenfedrige Weibchen halte, ist meines Wissens noch nicht in Schlesien vorgekommen.

5. Erithacus rubecula(L.) 1758 . - Rotkehlehen.

S'ynonyma: Erithacus rubecula Cuv., Giebel, A. Brehm, Mewes; Sylvia rubecula Lath., Naum., Belist., Gloger, Gätke; Notacilla rubecula L., Buffon, Gmel., Behst.; Dandalus rubecula Boie, E. v. Hom.; Rubecula familiaris Blyth; Rubecula rubecula Bonap.; Rubecula pinetorum, R. septentrionalis, R. foliorum Chr. Brehm; Rubecula rufigularis Landb.; Lusciola rubecula Kays. und Blas., Friedr.; Erithacus rubeculus Radde, Hartert.

Trivialnamen: Rutkatel, Kätchen, Rottkälichen, -brüstlin, -kröpfelin, Winterrötelein, Waldrötelin. Oberschlesisch-polnisches Idiom: Raschka. Muskauer Wendisch: Sprosk.

Kennzeichen der Art: Die 2. Schwinge steht in der Grösse zwischen der 6. u. 7. Die 3. ist kleiner als die 4. und 5. M a asse von 55 schlesischen Exemplaren in $\mathrm{cm}$ :

Länge:

Flügelbreite:

Schwanz:

Schnabellänge:

Tarsus:

$$
\text { maximum }
$$

$$
13,9
$$

23,4

5,6

1,15

2,7 minimum

12,4

21,2

5,4

0,9

2,5
Durchschnitt

13,2

22,1

5,5

1,0

2,6

1) Dahin rechne ich namentlich auch das sporadisch zerstrente, ganz unregelmässige Vorkommen. 
Im Breslauer MIuseum steht eine Varietät, bei welcher Rückenseite und Schwanz fahl rostgelb, die Flügel schmutzig weiss, der Bauch rein weiss und schnabel und Füsse gelblich gefärbt sind. Im allgemeinen scheinen die Rotkchlchen wenig zu variiren, es sei denn, dass die östlichen Stiicke $u m$ ein weniges stärker sind wie die westlichen. Dagegen sind die Hochgebirgsvögel stets grösser und lebhafter gefärbt wie die Bewohner der Ebene oder Hügellandschaft und zeichnen sich vor diesen für das scharfe Ohr des Liebhabers namentlich durch den sehr zu ihrem Vorteile abweichenden Gesang aus. Wenn während derselbe bei den GartenRotkehlchen nur allzu oft ein blosses, leises Geleier vorstellt, enthält der Gesang der Gebirgsvögel meist einige laut pfeifende Strophen und höchst angenehme Wirbel- und Trillertouren, weshalb auch der Liebhaber einen solchen Vogel als "Wipfelpfeifer" bezeichnet und gern mit dem 3- und ffachen des gewöhnlichen Preises bezahlt. Ich bezweifle nicht, dass sich hicr bei genauerem Studium eines hinreichend grossen Materials eine gute subspecies würde aufstellen lassen. In seiner Verbreitung steht das Rotkehlchen im Gegensatze zu cyaneculus, denn es ist da besonders häufig, wo jenes nur sparsam vertreten ist oder ganz fehlt, und umgekehrt. In den Oderwaldungen, die ihm vielleicht zu feucht und sumpfig sein mögen, ist es nicht besonder's häufig, desto mehr aber in den Wälderu Oberschlesiens, der Lausitz, der Vorberge und in den Sudeten selbst. Hier bewohnt es die Waldregion bis zum Knieholzgürtel hinauf in grosser Zahl. Gloger giebt 4000 Fuss, $\mathrm{Kramer} 1400 \mathrm{~m}$ als oberste Grenze der vertikalen Verbreitung an. Eigentlich fehlt es nur dem hohen Kiefernwalde ohne Unterholz. Es macht überall in Schlesien regelmässig 2 Bruten zu $5-6$ und $t-5$ Eiern. Gelege wurden gefunden durch $\mathrm{Kutter}$ am 18., durch $\mathrm{Hosius}$ an 20, durch Kollibay am 23., durch mich am 16., 19. und 21. Mai. Doch fand Praetorius auch schon am 206. desselben Monats gefiederto Junge. Das 2. Gelege wird in der 2. Hälfte des Juni vollzählig.

$\mathrm{M}$ a a s e von 51 schlesischen Eiern in mm:

$\begin{array}{cccc} & \text { maximum } & \text { minimum } & \text { Durchschnitt } \\ \text { Länge: } & 19,6 & 19,3 & 19,4 \\ \text { Breite: } & 14,8 & 14,6 & 14,7\end{array}$

$\mathrm{K} \mathrm{n}$ a $\mathrm{u}$ the beobachtete ein Stück beim Fischfang, wie es einem kleinen Cyprinoiden schon ein Auge ausgehackt hatte. Ein Teil der alten Vögel bleibt auch im Winter bei uns. Sie ziehen sich dann in vor rauhen Winden geschütztere Thalsenkungen zurück, kommen auch vielfach an die menschlichen Gehöfte und sind bei strenger Witterung regelmässige Gäste der etwa angelegten Futterplätze, unterliegen aber trotzdem oft genug der Kälte und dem Nahrungsmangel. Ueberhaupt wintern in dem immerhin schon rauheren Schlesien bei weitem nicht so viele 
als etwa in Thüringen. Auf dem Zuge fangen sie sich bisweilen im Dohnenstiege. Sonst giebt über denselben folgende Tabelle Auskunft:

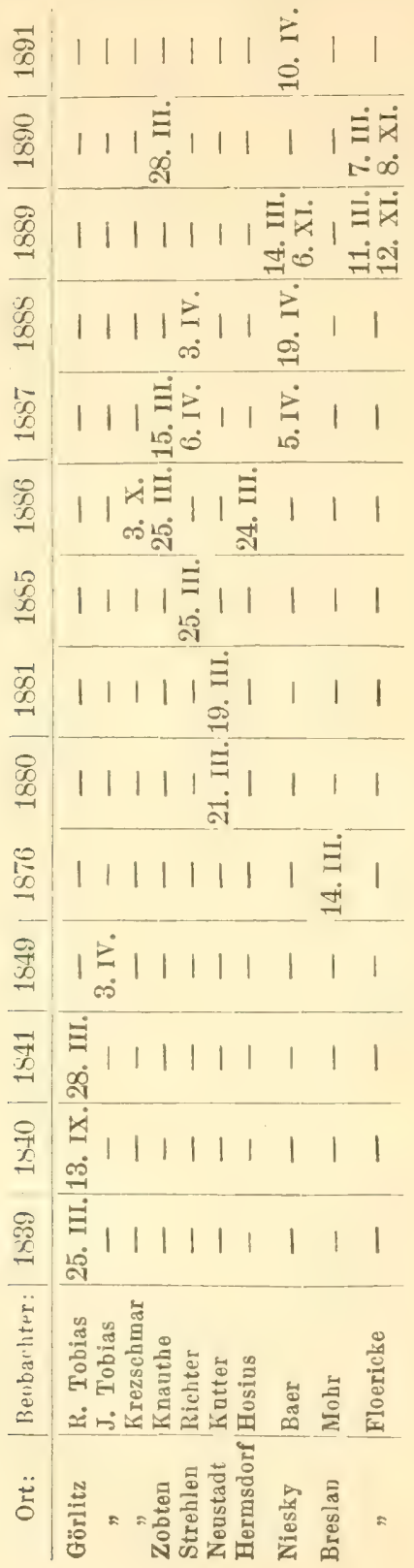


R. Tobias notirte von $1832-38$ als frühesten Ankunftstermin deu 30. März, als spätesten den 5 . April, als durchschnittlichen den 1. April. Gegenwärtig pflegen die Rotkehlchen schon Mitte März sich einzustellen.

Gattung: Ruticilla Briss. $17 t 0$. - Rotschwänzcheu.

Die Schwanzfedern sind fuchsrot, nur die beiden mittelsten braun. Obwohl sonst ein entschiedener Gegner der Zersplitterung unserer Vögel in allzu viele Gattungen, vermag ich hier doch nicht dem Beispiele Reichenows zu folgen und die Rotschwänzchen mit deu vorangegangenen Arten zu einem genus zu vereinigen. Bestimmend sind für mich dabei wesentlich auch biologische Gesichtspunkte, wie namentlich die Art und Weise der Nahrungsaufnahme und der Nestbau neben manchem anderen recht erhebliche Unterschiede bilden. Mit der Gattung Erithacus hat Ruticilla das eigentümliche Zittern mit dem Schwanze gemein, das hier noch ausgeprägter ist. $\mathrm{schwanz}$.

6. Ruticilla phoenicura (L.) 175s. - Garten-Rot-

Synonyma: Motacilia phoenicura L., Gm.; Sylvia phoenicura Lath., Bchst., Naum., Gloger, Gätke; Saxicola phoenicura Koch; Sylvia ruticilla Klein; Luscinia phoenicura Sund.; Fidecula phoenicura Boie, Cuv.; Phoenicura muraria Swains.; Ruticilla silvestris, R. arborea, R. hortensis Chr. Brehm; Phoenicura ruticilla Swains., Gould; Lusciola phoenicura Schleg., v. Schrenck, Kays. und Blas., Fridr.; Phoenicura albifrons Brandt; Erithacus phoenicurus Degl., Rchw.; Ruticilla phoenicura Griebel, A. Brehm, E. v. Hom., Mew., Radde, Hartert.

Trivialnamen: Rutschwanzel, Rutschwïnzel, Rotwistling, Rotwispel, Rotwistlich. Oberschlesisch-polnisches Idiom: Swisdek.

Kennzeichen der Art: Untere Flügeldeckfedern rostrot.

$\mathrm{M}$ a as se von 28 schlesischen Exemplaren in cm:

$\begin{array}{lccc} & \text { maximum } & \text { minimum } & \text { Durchschnitt } \\ \text { Länge: } & 14,0 & 13,7 & 14,1 \\ \text { Flügelbreite: } & 24,2 & 22,3 & 23 \\ \text { Schwanz: } & 6,2 & 5,8 & 6 \\ \text { Schnabellänge: } & 1,2 & 0,9 & 1,0 \\ \text { Tarsus: } & 2,8 & 2,3 & 2,5\end{array}$

Die Maasse sind im allgemeinen sehr constant.

Irgend welche Abänderungen sind mir nicht vorgekommen. Der Garteurotschwanz ist über ganz Schlesien ziemlich gleichmässig verbreitet, wennschon or in laubholzreichen Gegenden häufiger anzutreffen ist als in solehen mit reinem Nadelholz. Eine besondere Vorliebe hat er für einzeln stehende alte Kopf- 
weiden auf Viehtriften und dergl. Früher soll er noch ungleich hïufiger gewesen sein, und gegenwiirtig ist sein Bestand leider fast überall in entschiedenem Rïckgang begriften, was ja auch bei der modernen Forstkultur, die ihm seine Brutstätten mehr und mehr cntzieht, nicht wunder nehmen kann. Selbst die höhlenbewolnenden Meisen seheinen sich besser und leichter mit diesen Verlältnissen abzufinden als der Gartenrotschwanz. IVas nun dessen verticale Verbreitung anbetritft, so steigt er ziemlich hoch im Gebirge empor, so weit, bis auch das Nadelliolz zu verkrüppeln anfïugt, d. h. bis in eine Höhe von 3-00-3900 Fuss. v. Tschusi sah zur Brutzeit ein Männchen am Tannstein im Riesengebirge, A. v. II o mey er beobachtete den Vogel an allen Bauden der Koppenplane, und Talsky auf' dem Ziegenrüeken ander Grenze zwischen Wald-und Knieholzregion. Aus einigen Gegenden, wo der Gartenrotschwanz früher häufig war, ist er jetzt schon ganz verschwunden, so nach Auras seit 1 sis aus der Umgegend ron Gutsmammdorf. In anderen Strichen ist er aber immer noch häufiger wie titis, so namentich in den Vorbergen und gewissen Partieen Oberschlesicns (K ollibay). Ueberall licbt dieser Rotschwanz die Nïhe menschlicher Tohnungen. Er macht bei uns unter normalen Verhäluissen 2 Bruten, jede zn 5-7 Eiem, welche 1:2-13 Tage hebrütet werden (Molir). Die Anlage des Nestes ist bisweilen cine absonderliche; so fand Kollibay ein N'est, das nach Art von titis unter dem Dache einer Veranda angebracht war; A. v. II omeyer im botanischen Garten zu Breslau ein anderes, das ganz niedrig über der Erde in einem mit Sedum bepflanzten ficinhaufen stand. Kutter fand das volle Gelege am 12. Mai, Kulliba y am 21. desselben Nonats, Practorius selion flügge Junge am : (). Nai und i. Juni. Hahnenfedrige Weibchen sind nicht allzu selten; R. 'Tobias schoss cin solches am 19. April 18:3! Stellenweise wird der Gartenrotschwanz den Bienenstöcken schädlich.

Ma asse von 45 schlesischen Eiern in $\mathrm{cm}$ :

$\begin{array}{lccc} & \text { maximum } & \text { minimum } & \text { Durchschnitt } \\ \text { Länge: } & 2,0 & 1,55 & 1,8 \\ \text { Bl'eite: } & 1,5 & 1,25 & 1,35\end{array}$




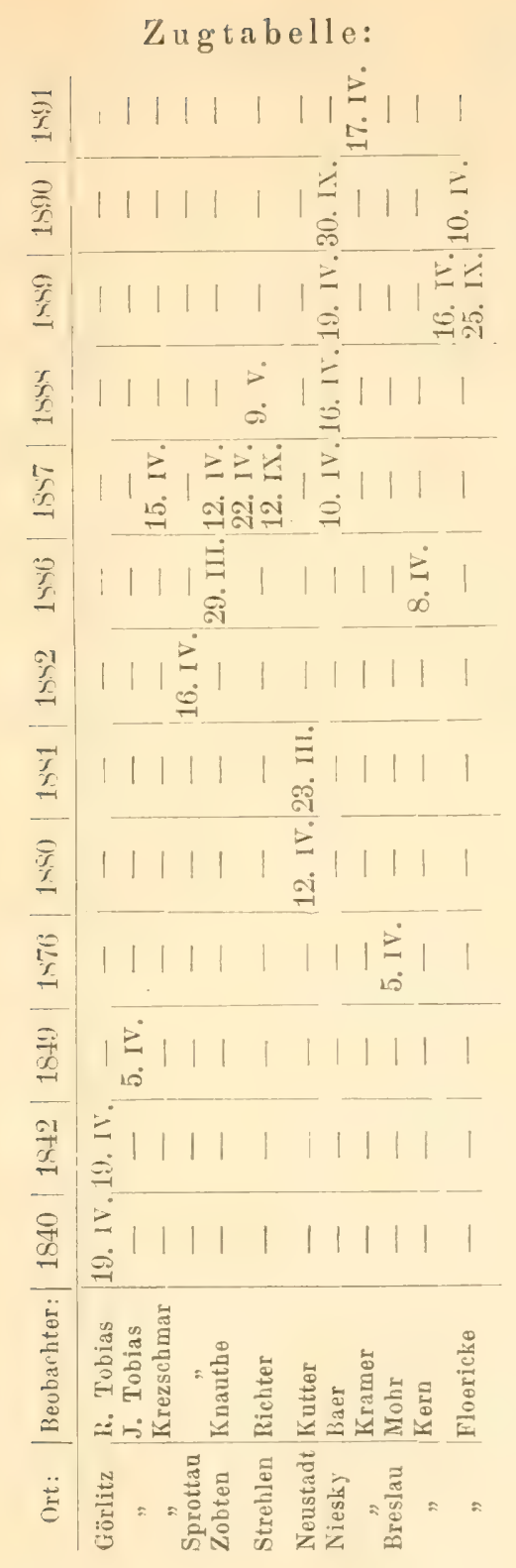


Rob. Tobias notirte von 1832-38 als frühesten Termin den 2., als spätesten den 17. und als mittelsten den 11. April. Im allgemeinen kommen die Gartenrotschwänze Anfang oder Mitte April in Schlesien auf den Brutplätzen an und verlassen uns wieder Ende September.

7. Ruticilla titis (L.) 1758. - Ha us rotsc hw a $1 \mathrm{z}$.

7a. Ruticilla titis Cairii Gerbe. 18ts. - Gebirgsrotschwanz.

Synonyma: Ruticilla gilbratariensis Briss.; Motacilla titis, M. erythacus L. Gm.; Sylvia gilbratariensis, S. atrata Lath.; Sylvia tithys Scop., Lath., Naum., Behst., Brehm, Glog., Gätke; Motacilla gilbratariensis, M. atrata Gmel.; Saxicola titis Koch; Phoenicura titis Jord.; Fidecula erythaca Less.; Lusciola titis Schleg., Kays. und Blas., Fridr.; Ruticilla Cairii Gerbe, Degl.; Erythacus titis Degl., Rehnw.; Ruticilla titis, R. atrata, R. gilbratariensis, R. montana Chr. L. Brehm; Ruticilla erythaca. Bunap.; Luscinia titis Sundew.; Ruticilla tilis Giebel, A. Brehm, Mewes, v. Hom., Hartert.

Trivialnamen: Rutschwanzel, Rutschwänzel, Rotzagel, Sommerrötele, Schwarzwistling, Schwarzwistlich, Schwarzwispel, Hauswistlich, Quabbelarsch. Oberschlesisch-polnisches Idion: Swisdek. ${ }^{1}$ ).

Kennzeichen der Art: Die Unter-Flügeldeckferlern sind schwarz und weiss geschuppt.

Mit der Besprechung der riesengebirgischen Rotschwänze begebe ich mich zagend auf ein viel umstrittenes Gebiet und muss dabei zu meiner grossen Beschümung gestehen, dass es mir in der immerhin ziemlich kurzen Zeit meines Aufenthaltes in Schlesien nicht möglich gewesen ist, ein ausreichendes Material zusammen zu bekommen, um über diese noch so unklare Frage selbstständig und entschieden urteilen zu können. Hören wir zunächst diejenigen Ornithologen, welche das Riesengebirge selbst besucht und den rortigen Hausrotschwanz beobachtet haben. Gloger fand den Vogel dort häufig bis zu einer Höhe von כ000 Fuss, äusserte sich aber weiter nicht über die etwa abweichende Färbung der Mämmchen. Nach v. Tschusi, $\mathrm{Krezschmar}$, A. v. Homeyer und R. Blasius ist titis auf allen Bauden des Gebirges Brutvogel und auf der Koppenbaude der einzige gefiederte Bewolner. A. v. Homeyer sah nur graue Exemplare, doch versicherten ihn die Baudenbewohner, dass auch schwarze vorkämen; auch weiter unten bei Schreiberhau und am Zackenfall fand derselbe nur die graue Varietät.

1) Eine sehr hübsche onomatopoetische Bildung ! 
Dagegen beobachtete R. Blasius am hohen Rad einige schwarze Stücke. v. Tschusi fand den Hauswistlich an der Spindelmühle im Neste der Mehlschwalhe brütend. Am ausführlichsten äussert sich Capek: „Neben dem Wasserpieper ist das Hausrotschwänzchen die häufigste Vogelerscheinung im Riesengebirge. Auf Steinhalden, auf isolirten Felsgruppen, zwischen dem Knieholze, namentlich am Ziegenrücken, auf der Koppe, den beiden Sturmhauben und dem hohen Rade, - überall bin ich diesem Vogel begegnet. Da Hr. v. Tschusi die Güte hatte, mich auf diesen Vogel aufmerksam zu machen, beobachtete ich alle Individuen mit dem Glase. Es waren junge und alte Exemplare, aber vergebens spähte mein Auge nach einem schwarz gefärbten Männchen, ob zwar jenes doch kein Vogel ist, der sich verstecken würde; immer gewahrte ich nur das schlichte, graue Kleid. Auch erschien der Vogel schon dem blossen Auge etwas kleiner als die typische Form des Flachlandes. Noch oberhalb Hohenelbe ist mir ein Pärchen mit etwa einer Woche alten Jungen vorgekommen; es war die grössere Form, das Männchen intensiv schwarz. Aus diesen Gründen halte ich es für unzweifelhaft, dass der im Gebirge vorkommende Hausrotschwanz die var. montana Br. oder Cairii $\mathrm{Gerbe}$ ist, die bereits in den Alpen und Karpathen nachgewiesen wurde." Ich selbst habe im Riesengebirge ebenfalls keine schwarzen Männchen beobachtet, wohl aber im lsergebirge dicht nebenan. Aus einem so verworrenen und sich vielfach direkt widersprechendem Material lassen sich nun freilich keine sicheren Schlüsse ziehen, aber man kann doch vielleicht mit einiger Bestimmtheit behaupten, dass die im Riesengebirge brütenden Rotschwänze zum weit überwiegenden Teile der grauen Varietät angehören, und dass dieselbe vielleicht das eigentliche Hochgebirge ausschliesslich bewohnt. Als eigentliche species wird wohl heutzutage kaum noch ein Ornithologe die $R$. Cairii auftassen, und selbst ihre Berechtigung als subspecies ist aus mehreren Gründen recht zweifelhaft, ja sie erschien fast vernichtet durch die Mitteilungen von LechthalerDimier, welcher an gefangen gehaltenen Exemplaren die Verfärbung von Cairii in titis beobachtete. Mir erscheint es freilich andrerseits auch nicht ganz sicher, dass die jung dem Neste enthaltenen Vögeln auch wirklich der echten Ruticilla Cairii angehörten. Wir stehen hier eben noch vor einem Rätsel, welches nur durch gute und zuverlässige Beobachtungen in den verschiedensten Gegenden unseres Faunengebietes $\mathrm{zu}$ lösen ist. Zunächst müsste überall festgestellt werden, wo eigentlich $R$. Cairii überhaupt vorkommt, und dann müssten möglichst oft und von versehiedenen Beobachtern in verschiedenen Gegenden junge Rotschwänzchen beider Bruten aufgezogen und im Käfig bezüglich ihrer Verfärbung beobachtet werden. So vieles auch gegen die Berechtigung von Cairii als subspecies zu sprechen 
scheint, so ist doch noch mancher wichtige Punkt unaufgeklärt. Warum kommt z. B. $R$. Cairii nur so zerstreut, nur in bestimmten Gegenden als Brutvogel vor? Wäre Cairii wirklich nur der junge Vogel von titis, so müssten wir doch überall, wo titis vorkommt, auch Cuirii finden. Und sonderbar wäre es doch im höchsten Grade, wem der Vogel in manchen Gegenden schon in der Jugend zur Fortpflanzung schritte, in anderen dagegen constant nicht. v. Tschus i äusserte brieflich die Vermutung, dass vielleicht die Jungen der ersten Brut schon im nächsten Frühjahr das Hochzeitskleid anlegten, die der 2. dagegen nicht, und dass letztere doch auch schon z. T. zur Fortpflanzung schritten und dann den $R$. Cairii darstellten. Kleinschmidt, welcher in Nierstein vielfach Gelegenheit hatte, beide Rotschwänze neben cinander zu beobachten, vermutet weiter, dass diese grauen Vögeln dann instinktiv sich mehr in felsigen Gegenden aufhielten, wo ihnen ihr unscheimbares Kleid den besten Schutz gewähre; wenigstens sei in seiner Heimat titis vorwiegend in deu Dörtern, Gärten und Wäldern, Cairii dagegen mehr an Abhängen, Felspartieen und dergl. anzutreften. Ich kann mich aber nicht der Ansicht verwebren, dass die Combination der Termutungen der beiden so scharf beobachtenden Forscher etwas Gekünsteltes mit sich bringe. Vielleicht findet man eine natürlichere Lösung des Rätsels, wenn man annimmt, dass in der That eine besondere und vorzugsweise in steinigen Gebirgsgegenden heimische subspecies $R$. Cairii existirt, welche ausser in anderen Merkmalen (geringere Grösse der Vögel und Eier, Nestbau, Aufenthalt, Färbung der Schwingenränder, Gesang etc.) sich namentlich dadurch von titis unterscheidet, dass die Männchen das graue Jugendkleid zwar nicht für immer, aber doch weit länger als die echten titis behalten. Es ist das aber eben auch nur eine Vermutung von mir, die ich zur Zeit durch keinerlei Beweise zu stützen vermag.

In der Sammlung des Conservators Heydrich in Flinsberg steht ein partieller Albino. v. Zit twitz beobachtete, dass ein und dasselbe typisch gefürbte Paar in 2 auf einander folgenden Jahren reine Albinos erzeugte. in $\mathrm{cm}$ :

Masse von 14 schlesischen Exemplaren (alles echte titis)

$\begin{array}{lccc} & \text { maximum } & \text { minimum } & \text { Durchschnitt } \\ \text { Länge: } & 15,0 & 13,0 & 14,2 \\ \text { Flügelbreite: } & 26,1 & 23,8 & 24,8 \\ \text { Schwanz: } & 6,8 & 6,4 & 6,6 \\ \text { Schnabellänge: } & 1,2 & 1,0 & 1,1 \\ \text { Tarsus: } & 2,6 & 2,1 & 2,4\end{array}$


Obschon der Hausrotschwanz natürlich auch in Schlesien zu den allgemein bekannten und stellenweise häufigsten Vögeln gehört, so ist er doch nicht in allen Teilen der Provinz von gleicher Häufigkeit. Zu den relativ seltenen Vögeln gehört er in den mit grossen Wäldern bedeckten Strichen Oberschlesiens sowie in der ilum wahrscheinlich z'l feuchten Bartschniederung. An beiden Oertlichkeiten steht sein Bestand sehr hinter dem von phoenicur' zuriick. Man findet ihn in solehen sonst für ihn wenig passenden Gegenden sehr regelmässig an den etwa vorhandenen Ziegeleien. Der Hausrotschwanz dürfte für Schlesien zu den Arten gehören, welche in firiheren Zeiten selten waren und erst in unserem Jahrhundert durch Einwanderung und Verschiebung ihres Verbreitungscentrums häufig geworden sind. Endler z. B. kannte weder Nest noch Eier unseres Vogels, dagegen nennt ihn vou Löbenstein $1 \checkmark 3 t$ schon einen nganz gemeinen Patron." Auch Gloger sagt von ihm: "Im Zunehmen."

Nach Kollib a y wird auch dieser Rotschwanz den Bienenstöcken schädlich. Bei Neustadt nistete ein Pärchen unter dem Dache eines bewohnten Bienenstockes, obwohl derselbe täglich von Menschenhand revidirt wurde. Obwohl Zugrogel, überwintert titis doch bisweilen, so nach A. v. Homeyer ein junges Männchen 1865/66 am Brückenkopfe von Glogau. Die Ankunft der Hausrotschwänze erfolgt in der zweiten Hälfte des März, der Wegzug Mitte Oktober. Nach R. To bias war von 15:32-38 der früheste Ankunftstermin der 8 ., der späteste der 2. .., und der mittelste der 19. März. Im übrigen dürfte über den Zug die folgende Tabelle wohl genügende Auskunft geben: 


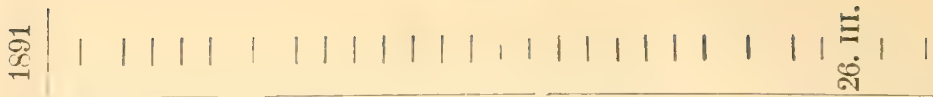

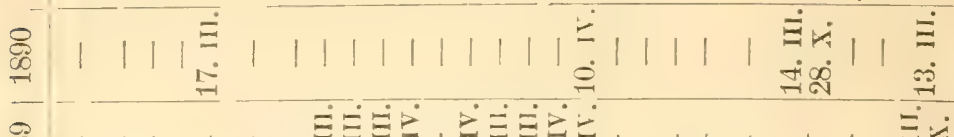

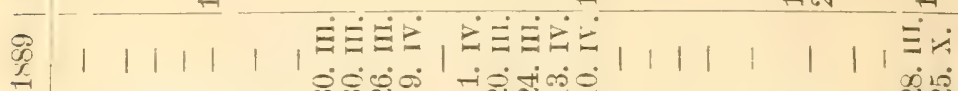

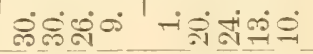

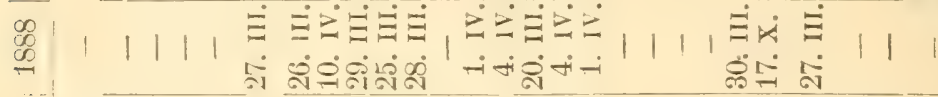

| | |

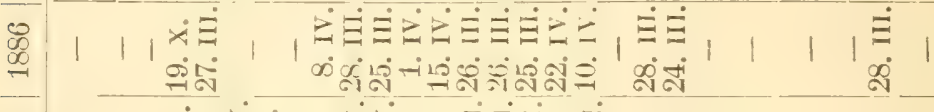

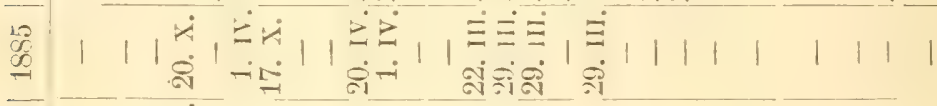

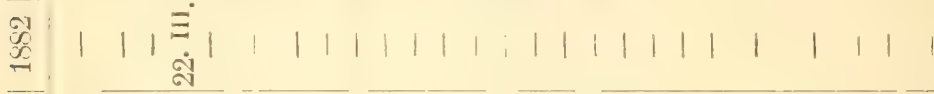

$\vec{\infty}$

要

是 $1|1| 1|1| 1|1| 1|1| 1|1| 1 \mid 1$ | 1

兽

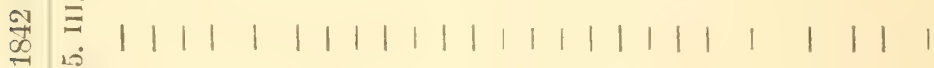

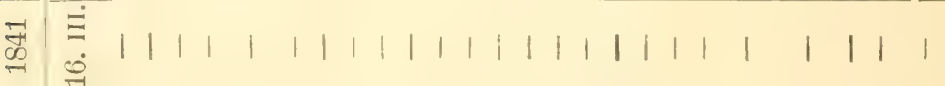

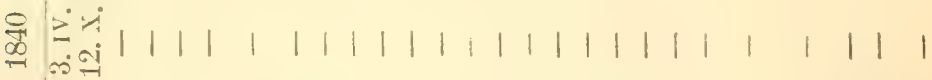

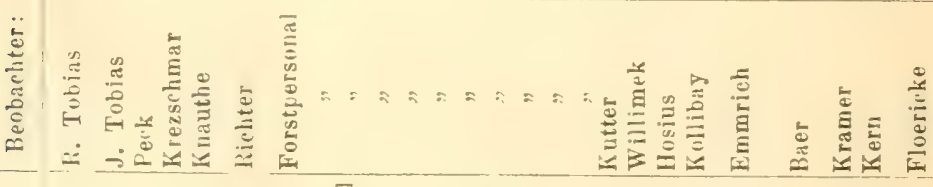

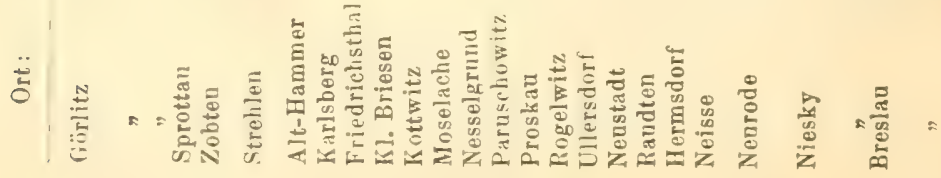


Die Weibchen kommen erfahrungsgemäss 4-8 Tage später als die Männchen. Titis brütet nicht nur auf Kirchen, hohen Gebäuden, Ziegeleien u. dergl., sondern auch in Steinbrüchen und den Felsspalten des Gebirges. Er macht regelmässig 2 Bruten und zeigt eine grosse Anhänglichkeit an den alten Brutplatz (Willimek). Kollibay beobachtete ihn am 13., ich am 16 . April beim Nestbau; Kutter fand denselben an 1. Mai vollendet. Volle Gelege fanden Practorius am 16. Kollibay am 28., ich am 27. und 29. April. Beim Füttern der Jungen traf R. Blasius diesen Rotschwanz am 19. Juni auf der Petersbaude. Flügge Junge sahen Kna the am 15. und Willimek am 19. Mai. Maasse von 52 schlesischen Eiern in $\mathrm{mm}$ :

$\begin{array}{lccc} & \text { maximum } & \text { minimum } & \text { Durchschnitt } \\ \text { Länge: } & 19,5 & 18,5 & 19,1 \\ \text { Breite: } & 14,7 & 14,2 & 14,5\end{array}$

Gattung: Pratincola K och 1816. - Wiesenschmätzer.

Schnabel verhältnismässig kurz und stark, mit starken Borsten besetzt. Läufe gestiefelt. Flügel kurz und r'und mit 19 Schwingen, von denen die 1. läuger als die Handdecken, die 3. und 4. die längsten sind. Sie bauen nicht in Höhlungen. Schwanz mittcllang.

8. Pratincola rubicola (L.) $1766 .-$ Schwarzkehliger Wiesenschmätzer.

Synonyma: Motacilla rubicola L., Gm., Bchst.; Sylvia muscipeta Scop.; Sylvia rubicola Lath.; Saxicola rubicola Bchst., Tem., Glog., Vieill., Naum., v. Schrenck, Gätke; Oenanthe rubicola Vieill.; Pratincola rubicola Koch, Degl., Kays. u. Blas., Fridr., A. Brehn, v. Hom., Newes, Radde, Hartert; Saxicola Hemprichi Ehr.; Saxicola saturatior Hodgs., Pratincola Hemprichi Cab., Bonap.; Pratincola var. indica Blyth, Swinh., Jerd.; Pratincola saturatior Horsf. u. Moore; Saxicola fruticeti, S. media, S. titis Chr. Brehm.

Kennzeichen der Art: Alle Schwanzfedern ihrem ganzen Verlaufe nach braunschwarz.

Diese Art ist mehr im westlichen Deutschland zu Hause und tritt jenseits der Elbe nur noch vereinzelt auf. Auf weite Strecken hin fehlt sie völlig, so nach $\mathrm{H}$ artert in ganz Ostpreussen. Ich schoss rubicola einmal bei Breslau, sonst aber berührt sie auch auf dem Zuge unsere Provinz nur höchst selten und ausnahmsweise. Mir wenigstens ist kein anderweitig erlegtes oder gefangenes Exemplar bekannt geworden. Auch dem Riesengebirge fehlt das Schwarzkehlchen gänzlich. Dagegen berichten schon die älteren Autoren von seinem Vorkommen in der Lausitz. R. Tobias beobachtete die Art 1 oder 2 mal auf dem Durchzuge, und Neumann, Brahts und Fechner führen sie als Seltenheit mit auf. 
Diese Angaben sind begreiflicherweise vielfach angezweifelt worden, aber sie haben in neuester Zeit eine erfreuliche Bestätigung erhalten durch meine beiden thätigen Mitarbeiter Baer und Kramer in Niesky, welchen es sogar glückte, rubicola als sicheren Brutvogel zu constatiren. Sie fanden am 22. April 1890 ein Gelege von is Stiick. Eins der Eier lag der Allgem. dentschen ornithol. Gesellsch. in Berlin auf der Oktobersitzung 1391 zur Begutachung vor und wurde von den anwesenden Oologen als zweifellose rubicola anerkannt. Der Togel hatte sich nach den genannten Beobachtern am 20. März cingefunden und war noch am 19. August auf dem Brutplatze. Im folgenden Jahre wurde er eben dort am 27. Mai, 10, und 2t. Juni beobachtet. Er liebt auch in der Lausitz die gebirgigen oder hügeligen Gegenden und treibt hier aut' steinigen Abliaingen, Halden und Triften, auf trockenen Wiesen und jungen Schwarzholzsaaten sein anzieheudes Wesen. Gloger neunt mubola sehr selten, erbringt aber eben so wenig Beweise für das thatsächliche Vorkommen wie $\mathrm{K}$ n a the, welcher den Togel als seltenen Durchzügler am Zobten aufführt.

9. Pratincola rubetra (L.) 1758. - Braunkehliger Wiesensch mätzer.

Synonyma: Motacilla rubetra L., Buff., Gmel., Bechst.; Sylvia rubetra Lath., Scop.; Saxicola rubetra Bechst., Naum., Temm., Glog., Gätke; Praticola rubetra Mewes; Oenanthe rubetra Vieill.; Fruticicola rubetra Macg.; Saxicola pratorum, S. septentrionalis, S. crampes Chr. Brehm; Pratincola rubetra Koch, Degl., Giebel, Kays, und Blas., Friell., A. Brehm, v. Hom, Radde, Hartert.

Trivialnamen: Kleine Steinfletsehe, Kraut- und Kohlvogel, Krautlerche.

K enuzeichender Art: Dic Schwanzfedern an der Wurzel weiss, mit Ausnahme der beiden mittelsten.

Ma asse von 21 schlesischen Exemplaren in $\mathrm{cm}$ :

$\begin{array}{lccc} & \text { maximum } & \text { minimum } & \text { Durchschnitt } \\ \text { Länge: } & 14,3 & 12,8 & 13,5 \\ \text { Flügelbreite: } & 26,4 & 24,6 & 25,6 \\ \text { Schwanz: } & 5,3 & 4,9 & 5,1 \\ \text { Schnabel: } & 1,1 & 0,9 & 1,0 \\ \text { Tarsus: } & 2,7 & 2,3 & 2,5\end{array}$

Die schlesischen Stücke sind im allgemeinen etwas grösser und in der Farbe etwas rötlicher als die westdeutschen und dürften darin mit den posenschen und ostprenssischen übereinstimmen, so dass sich vielleicht die $\mathrm{Brehm}$ sche subspecies septentrionalis 
darauf zurückführen und basiren liesse. Doch kann ich mir kein Urteil darüber erlauben, da mein Material nicht ausreicht. Friderich giebt als Totallïnge nur 1:3,1 und als Flügelbreite nur $25,0 \mathrm{~cm}$ im Durehsehnitte an und hat dabei wohl westdeutsche Exemplare im Auge gehabt.

Ruletra gehört im Gegensatze zu ler vorigen Art mehr dem östlichen Deutschland an. In Schlesion ist dieser Vogel meist recht zahlreich und in manchen Gegenden sogar gemein. So brütet er bei Breslan, in der Lausitz, sehr viel in Oberschlesien, an der östlichen Grenze, in Niederschlesien und in der Bartschniederung, wo er überall von allen Beobachtern angeführt wird. Wenn Gloger behauptet, dass rubelir dem Gebirge ganz fehle, so muss ich ihm dariu entschieden widersprechen, denn das Braunkehlchen meidet auch Wald- und Bergwiesen keineswegs, wemn dieselben nur nicht zu trocken liegen und sonst seinen Anforderungen entsprechen. So brütet unser Vïgelchen, wenn auch selten, nach Emmrich bei Nemrode, nach $\mathrm{K}$ a is er bei Warmbrum, nach Tobias sen. in allen Thälern des Isergebirges, nach Kollibay zahlreich auf den Wiesen des Hirschberger Thalkessels, um A. v. Hom c yer traf es sogar am Ziegenrücken an. Besonders häinfig soll rubetra in Obersehlesien sein. Es verlangt fenchte Wiesen, die mit cinigem Gebüsch durchsetzt sind. Dieser Schmätzer int weit weichlicher als sein schwarzkehliger Verwandter und tritt daher ziemlich spät im Frühahr bei uns ein, worüber die folgende Tabelle Auskunft giebt: 


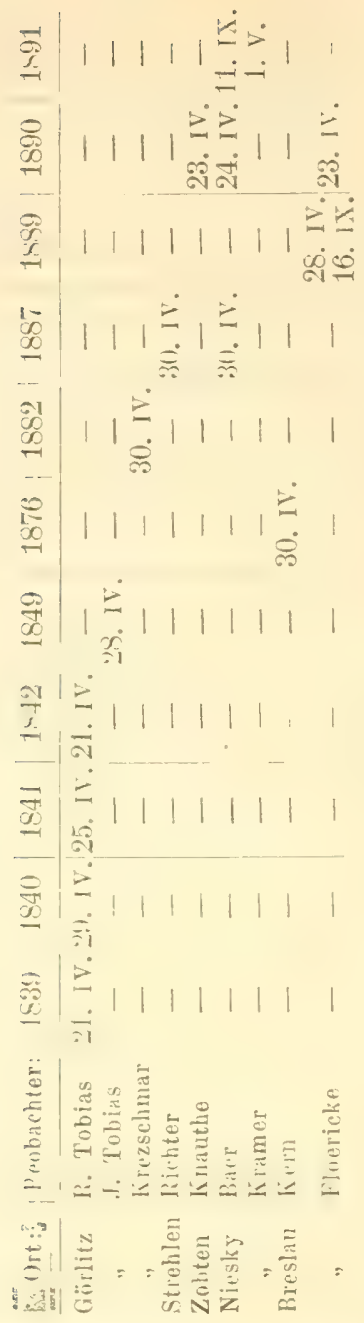

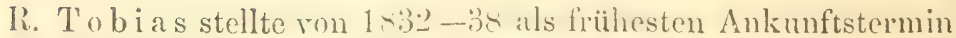
den ํ). April, als spätesten den 3. Mai und als durehsehnittlichen den 26 A pril fest. Im allgemeinen pflegt der Zug bei dieser Art sche regelmässig zu verlantin, weshalb sich dieselbe ganz besonders zu Zugbeobachtungen eignen dïrfte. Bei der Anlage seines Nestes scheut das Braunkehlchen die Nähe des Menschen keineswegs; mach Knathe nistete es sogar in Garten seines 
Dominiums. Kutter fand am 17. Mai das frische Gelege von 7 Stück, Kolliba y am 11. Juni eben ausgeflogene Junge.

$\mathrm{M}$ a as se von 15 schlesischen Eiern in $\mathrm{mm}$ :

$\begin{array}{lccc} & \text { maximum } & \text { minimum } & \text { Durchschnitt } \\ \text { Länge: } & 20,0 & 19,3 & 19,7 \\ \text { Breite: } & 14,2 & 13,8 & 14,0\end{array}$

Auch das Braunkehlchen gehört zu den Spöttern. A. v. H o m e y e r hörte bei Glogau ein MIIännchen ab, welches dic Gesänge von Anthus arborezs, Lullule arborea und Fringilla coelels imitirte. Gattung: Saxicola Buhst. 1 $\$ 02$. - Steinschmätzer.

Der breitfedrige, rein weisse Schwanz hat eine breite, schwarze Endbinde und fast ganz schwarze Mittelfedern.

10. Saxicola venanthe (L.) 1758. - S teinschmätzer.

S'ynonyma: Mrotacilla nenanthe L., Buff., Fab., Gmel., Bchst.; Ficedula vitiflora Briss, Sylvia oenanthe Lath., Bechst.; Motacilla vitiflora Pall.; Oenanthe cinerea Vieil.; Motacilla leucorrhoa Gmel.; Saxicola rostrata Elrbg:; Síxicola libanotica Ehrbg., Hompr.; Saxicola septentrinnalis, ș. grirea, s. cinerea Chr. Brehm; Saxicola oenanthoides Vigors; Vitiflora oenanthe, V. maior Chr. Brehm; Saxicola leucorrhoa IIartl.; Saxicola nenanthe Bechst., Naum., Temm., Glog., (xicb., Kays. und Blas., Fridr., v. Hom., Mewes, A. Br., Radde, Gätke, Hartert.

Trivialnamen: Steinfletsche, Steinsperling.

Kennzeichen der Art: Siehe die Gattungsmerkmale, da nur eine deutsche species.

Ma asse von 30 schlesischen Exemplaren in $\mathrm{cm}$ :

$\begin{array}{lccc} & \text { maximum } & \text { minimum } & \text { Durchschnitt } \\ \text { Länge: } & 15,5 & 14,4 & 15,0 \\ \text { Flügelbreite: } & 30,3 & 28,5 & 29,4 \\ \text { Sehwanz: } & 5,2 & 5,0 & 5,1 \\ \text { Schnabel: } & 1,55 & 1,3 & 1,4 \\ \text { T'arsus: } & 2,9 & 2,7 & 2,8\end{array}$

Authallend ist es mir, dass der Tarsus bei den schlesischen Stücken constant, wenn auch nur um eine Kleinigkeit, länger ist als es Friderich angiebt $(2,6 \mathrm{~cm})$.

In der Bartshuiederung und im fenchten Oderthale Mittelschlesiens ist der Steinschmaitrel als Brutyogel eine höehst seltene Erscheinung, die man hüehstens an den höher und trocken gelegenen Ziegeleien in Gesellschaft des Hausrotschwanzes antriftt. Am Zobten ist er mach k n a $u$ the auch nur sparsam vertreten und sogar in der Lausitz trotz der für ihn so günstigen Terrain- 
verhältnisse gar nicht häufig, obschon er auch nirgends ganz fehlt. 'Zahlreicher dagegen scheint der Steiuschmätzer in Oberschlesien vorzukommen, aber wahrscheinlich auch nur strichweise, da sich die Berichte der Beobachter z. T. widersprechen. Kiezschmar nemnt ihn einen Charaktervogel der Görlitzer Heide. Ein garz gemeiner Brutyogel aber ist er noch nach L. Tobias in den Weimbergen der Grïnberger Gegend und nach $\mathrm{Emmrich}$ in der Grafschaft, wie überhaupt wohl in allen Vorbergen der Sudeten, welehe ihm ja anch sehr güustige Daseinsbedingungen bieten. Ueber sein Vorkommen in Riesengebirge selbst sagt Gloger: „Nur dieser Schmätzer findet sich in Hochgebirge, wiewohl auch gar nicht häufig." Das tritl't hentzutage nicht mehr ganz zu, und es scheint, als ob sich oenunthe anch dem Hochgebirge mehr angepasst habe, dem er ist dort jetzt mit die häufigste Vogelerscheinung. Er findet sich bis zu einer IIöhe von t800 Fuss überall auf dem Kamm, wo Steinhaufen, trümmerreiche Halden und Felspartieen vorhanden sind, so namentlich an den Abhängen der Melzergrube und des Koppenkegels; ferner an der Renner- und Petersbande, an den s'shneegruben und Elbquellen, ja selbst am Koppenhause, $1610 \mathrm{~m}$ hoch. Hier hrütete im Sommer 1858 nach Zacharias ein TVeibehen. Das Nest stand in einer Fensternische, und der Voggel lins sich durch den lebhaften Verkehr nicht stören, bis er die Bente cines Marders oder Wiescls wurde. Wahrschenlich hatte hier die reichlich vorhandene Nahrung den Vogel angelockt, denu sonst ist er im Riesengebirge recht scheu. 


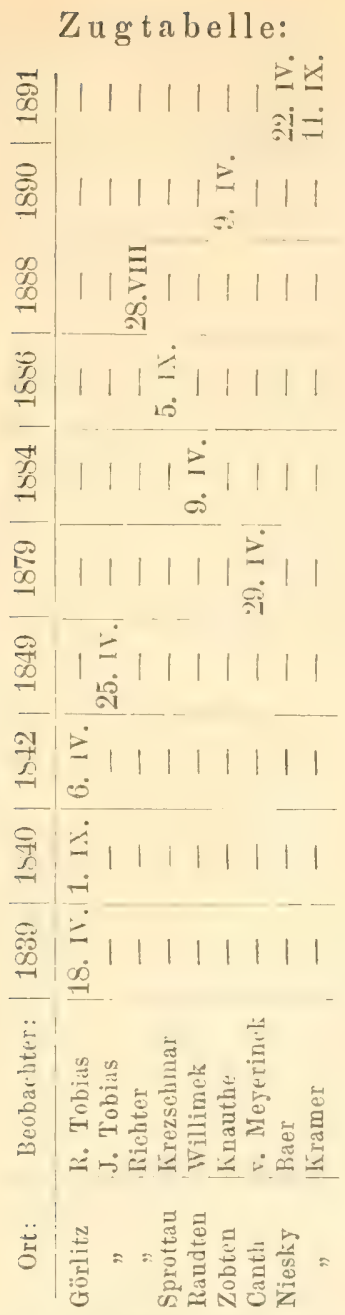

R. Tob i as notirte von $1832-38$ alis frühesten $\Lambda$ ukunftstermin den $\tilde{5}$., als spätesten den 18. und als durehsehnittlichen den 10 . April. Auf dem Herbstzuge zieht der Steinsehmätzer sehr zahlreich durch Fichlesien, die jungen Vögel zuerst. - Prätorius fand am 15. Mai ein Gelege bei Breslau, wo oendutlee sonst recht selten ist ${ }^{1}$ ). Ausgeflogene Junge sahen IV illimek am $b^{\prime}$. und

1) Ich selbst habe den Steinschmätzer während meines Breslauer Aufenthaltes nie zur Brutzeit bemerkt. 
Krezsehmar am 16 Juni. Ein mit dem vollen Gelege am 20. Nai $1 \$ 90$ aus Ziegenhals crhaltenes Nest war kreisrund und hatte einen äusseren Durehmesser von 11 und cinen inneren von $8 \mathrm{~cm}$ und eine Napftiefe von $3 \mathrm{~cm}$.

$\mathrm{M}$ a a s se von 26 schlesischen Eiern in $\mathrm{mm}$ :

$\begin{array}{lccc} & \text { maximum } & \text { minimum } & \text { Durchschnit } \\ \text { Länge: } & 20,9 & 20,4 & 20,6 \\ \text { Breite: } & 15,5 & 15,0 & 15,2\end{array}$

Glaubwürdigen Nachriehten zufolge benutzt anch der Kuekuek das Nest des Steinsehmätzers zum Ableyen scines Eies.

Gattung: Cinclus Behst. 102. - Wassersehmatzer.

Die ritzentörmigen Nasen]öeher sind mit einer buficelerten Ilaut verschliessbar. Füsse kräftig, mit kurzen, starken Niigchn. Flügel sehr kurz; die :). Sehwinge an längsten, librigens die :---1. fast gleich. Schwanz sehr kurz, sereade abogechnitten, aus breiten weichen Federn bestehend.

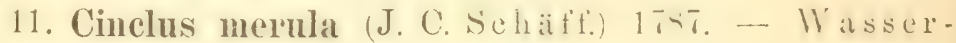
s ch mätzer.

11a. Cinclus merula albicollis (Vicill.) 1 14 . . Sïllieher IV a s serschmätzer.

11b. Cinclus merula septentrionalis Brohm lay. Nordischer Wasserschmëtzer.

Synonyma: Sturnus cinclus L., Bchst.; 'Turdus ayuaticus Gessn., L.; Motacilla cinclus Scop ; Turtus cinclus Lath.; Turdus gularis Lath.; Aquatilis einclus Nont, (inchus enropatens steph.;

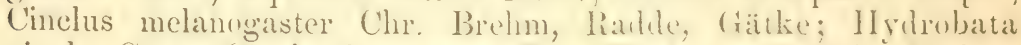
cinclus Gray; Cinclus leucueraster Ev; Cinchus medin Chr. Brehn; Cinclus aquaticus leucogaster liadde; Cinclus sepuntrionalis, Ć. peregrims, C. meridionalis, C. rufipeeturalis, ('. rupustris Chr. Brehm; Cinclus aguaticus Behst., Xatum., Chr. Brelim, Crloger, Giebel, Kays. und Blas, A. Brehm, Fribl.. Mrwe's, liadle', v. Hom., Hartert.

Trivialnamen: See- und Schildamsel, Wasserstar.

Kennzeichen der Art: Siehe die Ciatumgsmerlsmale, da nur eine Art bei uns.

Septentrionalis ist entehicelen cine sehr gute subspecies, die man fast als Art aufzufasen versuche ist. Sie hat nur lo Sichwanzfedern und weicht schon datureh sehr ron morula ab, ist aber auch der blossen Färlumg nach sofort leicht kenutlich, auch wem man keine suite, sondern nu ein einzelnes Exemplar vor sich hat. Septentrimalis mind we uld sind bei weitem nicht in dem Il a asso und in on mmerklicher Wreise Aureh Uebergänge verbunden, wie merula und a'binitis. IBisher war roch kein sicherer Fall des Torkommens der nördichen Varictit in Schlesien bekannt. Dieselbe schien selbst während der Zugzeit göinzlich zu 
fehlen, während die ostpreussischen Wasserstare durchgängig nordische sind. Da erhielt ich zu meiner freudigen Ueberraschung durch meinen Mitarbeiter Emm rich ein ca, am 15. März 1592 bei Neurode geschossenes Exemplar, weluhes sich als ein typischer septentrionalis erwies. Auffallend ist dabei auch noch besonders die Jahreszeit, da sonst die TVasserstare in günstigen Frühjahren in der zweiten IIälfte des März bereits gepaart zu sein pflegen. Allerdings behauptet auch schon $\mathrm{Glower}$, dass septentrionalis in Schlesien vorkommen, aber er bleibt uns den Beweis dafür schuldig, und die Exemplare der schlesischen Museen (auch diejenigen in Breslau, welche das ded. Gloger an der Etikette tragen) sind keine septentrionatis.

Weit schwieriger lasssen sich merula und allicollis auseinanderhalten. Die meisten meincr schlesischen Stücke sind derart, dass man nieht recht weiss, zu welcher der beiden Formen man sic stellen soll. Im allgemeinen aber prävalirt entschieden die helle Färbung der Batuchseite. Einige meiner schlesischen Stücke sind genau eben so licht als wie die von den Apenninen stammenden Exemplare meiner Sammlung, welehe doch ganz typische albicollis darstellen müssten. Ein Cinclus, den ieh kürzlich aus dem Erzgebirge erhielt, ist womöglich noch heller als die Italiener. Ueberhaupt lassen sich für beide Formen laum bestimmte Verbreitungsbezirke feststellen, sondern die Grenzen laufen hier ebenso durch einander wie diejenigen der Färbung. Diese Regellosigkeit der geographischen Verbreitung war es zuerst, die mich stutzig machte, und nachdem ich numehr ein zicmlich umfangreiches Material von Wassersehmätzern aus den versehiedensten Gegenden durchzusehen Golegenheit gehabt habe, bin ich jetzt zu der Ueberzengung gekommen, dass sich alhicollix keinentalls als Art, ja höchst wahrocheinlich nicht eimmal als subsprecies lalten liisst. Auch in den Maassen habe ich keine konstanten Untersehiede zwischen merula und albicollis aufiufinden vermocht.

Ma asse von 26 schlesischen Exemplaren in em:

$\begin{array}{lccc} & \text { maximum } & \text { minimum } & \text { Durchschnitt } \\ \text { Lange: } & 20,1 & 16,5 & 17,6 \\ \text { Flügelbreite: } & 31,8 & 26,9 & 29,3 \\ \text { Schnabel: } & 1,7 & 1,5 & 1,6 \\ \text { Schwanz: } & 5,0 & 4,6 & 4,8 \\ \text { Tarsus: } & 3,2 & 2,8 & 3,0\end{array}$

Wie man sieht, variiren die Maasse sehr, olme dass sich aber darin irgend welehe Regelmänsigkeit nachweisen liesse. Leider sind die Wasserstare in den sudeten schon so spärlich geworden, dass es schwer hält, für wissensehaftliche Untersuchungen das nötige Material zusanmen zu bringen, womit ich auch die Unvollkommenheit meiner Ausführungen zu cutschuldigen bitte. Gloger leuguet sonderbarer Weise das Vorkommen von allicollis 
in Schlesien ganz, während umgekehrt $\mathrm{R}$ eichenow riesengebirgische Stücke als echte albicollis bestimmte.

Bezüglich der Verbreitung rom Cinctus in Schlesien sagt Gloger: "An allen Gebirgsbächen," und R. Tobias: $I m$ Gebirge gemein, im Winter auch in rer Ebene." Wo sind die Zeiten hin! WVir dürfen es uns leider nicht verhehlen, dass gerade der muntere, anziehende Wasserstar in einem ganz rapiden und unaufbalisamen Rückgang seines Bestandes begritten ist. Viel tragen dazu die rücksichtslosen und mansgesetzten Nachstellungen der Forellenzüchter ${ }^{1}$ ) mit bei, gewiss viel melur nuch aber die stets zunehmende Verunreinigung der Crebirgsbäche durch Fabriken und Grubenwässer. Schon Gloger fängt darüber an zu klageu, und nach ihm stimmen fast alle Beobachter in dies Trauerlied mit ein. Heutzutage sind mir noch fulgende sichere Brut liatze des Wasserstars bekannt: Das Iserthal bis Flinsberg, Kochelfall, Zacken, Elbfall, Schreiberhan, II eistritz, Meiswasser, Juscfinenhütte, Aupathal, Spindelnühl, Landskrm, Ablä̈nge des Altvater, Heuscheucr, Wölfelsgrund, Neurode an den :; letztgenamuteu Lokalitäteu noch recht häufig), einigo striche in oberschlesischen Hüttenbezirk, Nesselgrund, NIuskan, Langenbrück, Sjurottan und Paruschowitz. Obwohl Ciebirsvogel, geht der Wasserstar doch nicht bis in das eigentliche Hocherebirge linanf, mul Gloger hat wohl recht, wenn er seine vertikale Terbrcitumg mit einer Höhe von 3000 -.;200 Fuss nach oben hin abgrenzt. Im IVinter kommt Cinclus anch in die Ebene herunter, aber immerhin nur selten; so erhielt ihn L. Tobias ron Is37-lic; in Grüneberg nur ein einziges Mal. v. Tschus i beobachtete am 7 . Juni beinahe flügge Junge.

Gattung: Monticola Boic 1, - Steindrossel.

Die Steindrossehn stehen zwischen den Drossehn, Rotschwänzen und Schmätzern mitten ime. Sehnabel riennlich lang, nicht ausgekerbt, vor den Nasculöchern dentlich singehuchtet, von der Mitte bis zur Spitze etwas abwirts gebogen. Fliggel ziemlich spitzig, die :3. Schwinge am länsten sehwanz ziemlich kurz, tast gerade, ohme eckigen Zuschnitt der velwwatedern. Farben des Gefieders rostrot und schieferblau.

Steinrötel.

12. Monticola saxatilis (L.) 176t. - Steindrossel,

Synonyma: Turdus saxatilis L., Buff, Gm., Behist, Lath., Glog., Gïtke; Mernla saxacilis Briss, Will. und Ray, Mb.; Petrophila saxatilis sirs. Suxienla montana Kuch; Lanius infaustus Cimel.; Petrocossyphns saxatilis Boic; Petrocincla saxatilis Vig., Degl., Radde; Sylvia saxitilis Savi; I'etrueichla saxatilis Kays.

1) Die wenigen Magenuntersuchungen, welche ich an Wasserstaren machen komte, sprachen stets für die IIarmlosigkeit des Vogels. 
und Blas.; Petrocossyplus Goureyi, P. polyglottus Chr. Brehm; Monticola saxatilis Boie, v. Heugl., Giebel, A. Brehm, v. Ilom., Mewes, Hartert.

Trivialuamen: Einsamer Spatz, Blaudrossel, Kleiner Blauziemer der Liebhaber.

Kennzeichen der Art: Siche Gattungsmerkmale, da nur diese eine Art in Deutschland.

Das Steinrötel gehört hauptsiichlich denGebirgen der Mittelmeerliunder an und ist auf denjenigen Deutschlands nur eine ausnahmsweise Erscheinumg. Sieht man die Berichte der älteren Beobachter durch, so gewinnt e; den Anschein, dass der Vogel damals zwar auch selten, aber doch öfters als jetzt clas Riesen-, Iser- und Lansitzer Gebirge auf dem Znge berührt, ja viclleicht auch daselbst gebrütet habe, wofür freilich keine Beweise vorliegen. Aus nenerer Zeit sind mir nur 2 Fälle seines Vorkommens bekannt

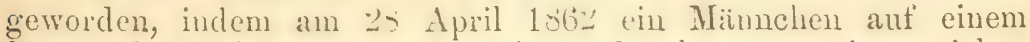
Damm bei Schleusig, einer sehr tief gelegenen, wicsenreichen Gegend (!) durch Hr. v. Ju u wig erlegt (T'obias) und um dieselbe Zeit 1st(k) cin anderes bei Flinsberg gefangen wurde. Jedenfalls ist hentzutage der Togel cine der gröisten Seltenleiten der schlesischen Ornis, und wem Z a charias sagt: „Damn und wamn in der Knieholzregion des Riesengebirges," so thut man gut, dies sehr cum grano salis zu nehmen, wie ich überhaupt den ornithologisehen Angaben dieses Forschers gegenüber Vorsicht empfehlen möchte.

\section{Gattung: Turdus L. 1758. - Drossel.}

Mittelgrosse Vügel mit siuftem, wichem Gefieler und ziemlich starken Füssen. Das 1. ( ielenk der Mittelzehe mit der äusseren verwachsen. Die schwingen bis zur b). alussen eingeschnürt, die 3. oder -t. am längsten. Sehwanztedern cekig zngespitzt. Sehmabel mittelmässig, scharfschneirlig, first grerade, an der byitze zusammengedriickt, lin'ste sanft geborgen, voi der spitze seicht gekerbt, an der Wurzel mit einigen Borsten.

\section{T'urlus musicus L. 175\%.-- singdros sel.}

Synonyma: Turdus pilaris Pall.; Sylvia musica Savi; Merula musica Selby; Tliacts musicus Inesm.; IJlocichla musicus Gray; Turdus philomelos, T'. minnr Chr. Brohn; 'Turhus musicus Sch wenckf., L., Frisch, Naum., (łmel, Behst., Chr. Brehm, Glog., Kays. und Blas, Fiebel, A. Prehm, v. Hom., Newes, Radde, Hartert, Gätke.

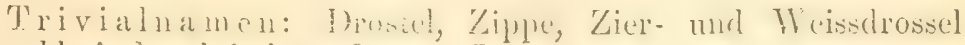
Oberschlesisch-poluisches Ldiom: Drost.

Kennzuichen der Art: Totalläne geringer als 2.2 cm. Unterflügeldeckfedern blass rostgelb. 
II a as vo von 55 schlesischen Exemplaren in $\mathrm{cm}$ :

$\begin{array}{lccc} & \text { maximum } & \text { minimum } & \text { Durchschnitt } \\ \text { Lainge: } & 21,8 & 19,2 & 20,9 \\ \text { Flïgelbreite: } & 35,7 & 34,3 & 34,8 \\ \text { Schwanz: } & 7,9 & 7,5 & 7,7 \\ \text { Schnabel: } & 1,5 & 1,25 & 1,4 \\ \text { Tarsus: } & 3,3 & 3,1 & 3,2\end{array}$

Im allgemeinen gehören die schlesischen Zippen zu den kleineren (T. mino Br.). Im Breslaucr Mluscum befinden sich folgende Abnormitiiten: a) Ganze Oberseite und Flügel schön licht isabcllfarben, Unterseite weiss mit rostfarbener Zeichnung, Schnabel und Füsse gelb. b) Tier weisse ichwanzfedern. c) Itic Grundfurbe der Brust ist dunkel rostfarben. Sehmabel sehwarz (spec. ?). d) Wie a) nur noch bedentend heller', namentlich auf den Flügeln. e) Ebenso. f) Rein wiss, Schmabel und Fisse hellgelb. In Eberswalde stehen nach lekstein 2 aus dem Eulengebirge stammende Exemplare mit weissen Federn am Kopte; sie finden sieh bei dem ainen nur and der rechten beite der S'irn sowic in der Ohrengegend, bei dem anderen ist der gamze Oberkopt rein weiss. Ein uoch viel merkwürdigners stück besehreibt. Sehwenckfeld, welehes 15!)! bei Liegnitz gefingen wurle: "Ceteris colore et magnitudine similis prater cristam, quam in vertice gerebat albida instar alauda et cireulum album, qui prona parte collum mediotenus cingebat."

Die singhrossel ist in ganz siehlesion encmein und in den grossen Nadelwaldungen Obersehlesions mod der Lansitz entechichen die am hä̈lfigsten, ja bisweilen die eduzige nistende 1)rossel. Sie seheint gerade den Nadelwald zu licben, namentich wemn derselbe Unterinoly aufzuweisen late und nicht zul trocken ist und äters von Wiesen, Sehlïgen nud jungen C'uluren unterbrochen wird. Anch in gemischten IValdungen und kleinen Feldholzern

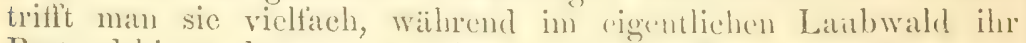

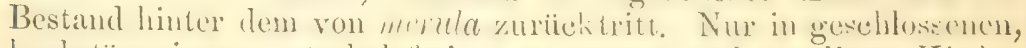
hochstimmigen, unterholztreien, trockenen und sandigen Kicferheiden ist sie wirklleh sulten. In Grobirge meht sie nach Gloger

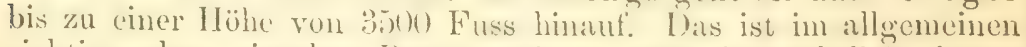
richtig, aber einzelne Paare steigen noch betrïchtlich höher empor. A. v. II om e y er beobachtete mesinte atut der 'Tafelfichte, Erlebach fand sie an der Fibfallbande briitend, R. Blasius sah sogar cinzelne auf dem Koppenplane. Im ganzen darf sie wohl als die im Reiesengebire am hä̈ufiesten rorkommende Drosscl-

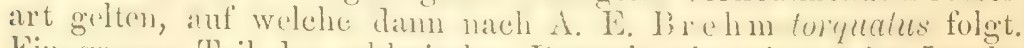
Ein grosser 'Teil der schlesischen I)rosschn äberwintert im Lande, namentlich alte Mämohen. Nitte März kehren auch die, welehe uns verlassen hatten, sehon wieder zuriiek. R. Tobias fand 
von 1832-38 als frühesten Ankunftstermin den 16., als spätesten den 20. und als durehschnittlichen den 18. März.

Im übrigen liegen nur noch folgende Daten vor:

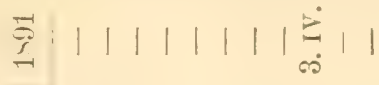

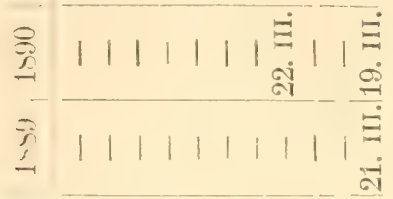

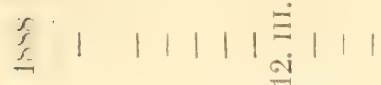

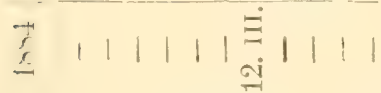

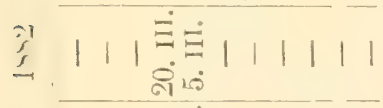

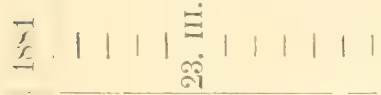

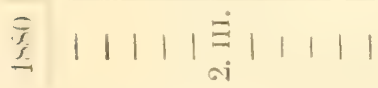

$$
\begin{aligned}
& \text { 穿 } 11 \text { 离 } 11111111 \\
& \text { is } 111111|1| \frac{1}{0 i}
\end{aligned}
$$

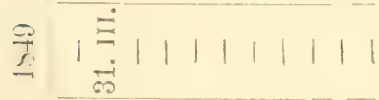

$$
\begin{aligned}
& \overrightarrow{\underline{z}} \underset{\overrightarrow{\mathrm{G}}}{\dot{\vec{\Xi}}}|||||||| \mid \\
& \text { 离 }
\end{aligned}
$$

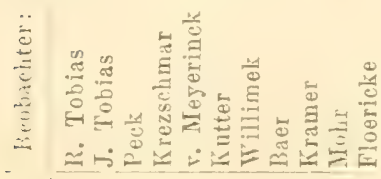

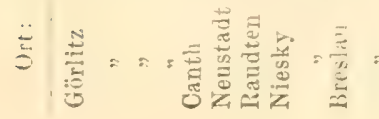


Die Zippe macht உ Bruten, Anfang April und Ende Mai zu (i) und $\&$ Eiern, welche je 15 Tigge bebrütet werden (Molrr). Volle Gelege fanden Practorius am 2, Kutter am 22., Flocricke am 6., 9., 15., 17, 23. April, Kollibay am 15. und 20. Mai. Einmal fand ich ein Nest, welches in eine Baumlöhllung hincin gebant war. Bei der Amsel kommt dies ja öfter vor, und werden solehe Tögel von dein Liebhabern "Stockamselu“ genannt und im Gevange besonders geschätzt, bei "musicus aber ist es meines Wissens noch nicht beubachtet. Die Gebirgsdrosseln singen auch hier regelmäs:ign besser als die der Ebene.

Ma asse von 118 schlesischen Eiern in mm:

$\begin{array}{lccc} & \text { maximum } & \text { minimum } & \text { Durchschnitt } \\ \text { Länge: } & 29,3 & 23,8 & 25,9 \\ \text { Breite: } & 21,3 & 18,6 & 19,9\end{array}$

\section{Turdus iliacus L. 1758 - Weindrossel.}

is ynonyma: Turdus illas Dall, Fylvia iliaca savi; Turdus manris Müller; Hylucicha musiea Giray; Turdus betulorum, T. pinetorum, T. gracilis Clur. Brehm; Thirdus iliacus L., Naum., Gmel., Behst, Chr. Brehm, Glog., Fays. und Blas, Griebel, A. Brehm, Fridr., v. Ilom., Nicwes, liadde, Hartert, Gätke.

Trivialnamen: Klein- umi Heideziemer, Wiesel, Heide-, Pfeif-, Bergdrossel, Gixerle, Rot- und Winddrossel.

Kennzeichen der Art: Grösse unter 22 om., Unterflügeldeckfedern lebhaft rostrot.

Im lireslauer Museum steht ein Exemplar, bei den die ganze Oberseite und die Fliggel sehön licht išabellitrben sind; dic Unter-

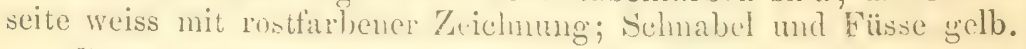

Diese hiubsche 1Yrossel, welehe in Yurd-skandinavien und Xord-Russland heimisch ist, berührt Sehlesien nur anf dem Zuge. Zawar habe ich auch Nachriehten chhalten, welehe ein vereinzeltes Briten von iliaens medten, konnte diesiben aben leider nieht genügend anf ihre Glanhwördigkeit hin pröfen. Unmöglieh wäre die Sache ja nichi, da bekammlich die Meindrossel schon in den Allgäner ilpen, in Ostprensen and in Thioringen brittend nachgewiesen white. Ueberhanpt ist es meine Uebrerengung, dass

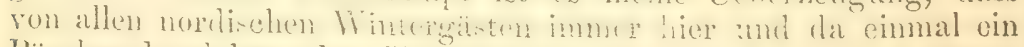

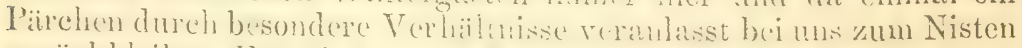

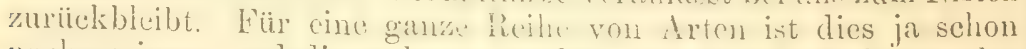

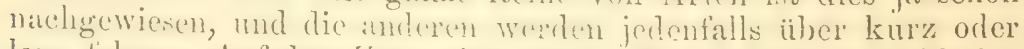

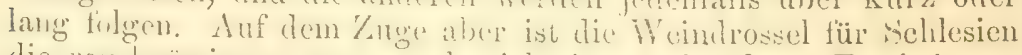
die regglmibsigste, wem inch niehn immer hiunfigste Erscheinung vols diesen Fremblingen ans dem hohen Norden, Die Itauptzangmonate sind Miirz und Olstuber. In dieser Zeit sieht man oft 
grosse Massen, vor- und nachicr mehr kleine Flüge oder auch ganz vereinzelte Individuen. Sie treiben sich gern fiee an Waldrä̈nderu herum, von wo sie dic IViesen absuchen können und üben bei schönem Winterweter schon fleissig ibren Gesang ein.

\section{Turdus viscivorus L. 175\%. - Misteldrossel.}

Synonyma: Turdus maior Briss, Buft.; Sylvia viscivora Savi; Ixocossylums viscivorus Kaup; Turdus Bmapartei Cab.; Turdus Ilodgsoni Iafresn,; Thedus anboreus, T. maior, 'T'. meridinnalis Chr. Irehm; T'urans riseivorus L., Naum., Gun., Behst., Chr. Brehm, (tlog, Kays. und blas, Gieb., A. Brehm, Rehw., v. Hom., Mewes, Fridr., Radde, Hart., Gätke.

Trivialnamen: Schnärre, Nistelziemer, Mistler.

Kennzeichen der Art: Grösse über $22 \mathrm{~cm}$. Unterflügeldcekfedern und die 3 ïussersten kehwanzfedern an der Spitzo weiss.

Im Breslaner Nhuseum brfindet sich eine Firbenvariotat. Das Exemplar zeigt dic Normaltirhung, aher mit sehe heller sohattirung. Die Schwungfedern siut schmutzig wanweiss, die schwanztedern ebenso gerändert und zwar die seitlichen am breitesten.

Die Misteldrossul ist als Brutrogel nicht selten, wemn sie auch stellenweise fehlt oder nur vereinzelt auftritt. Auf dem Zuge aber ist sie oft von ungehenre Hantigkeit, namentlich im Herbste. Nisdann halten sie sieh mehr im Luseren der Nadelwälder, wo sie den Beeren nachgehen, während man sie im Frühjahr anf den Niesen den hnsektenfang und anderweitige Jagd betreiben sieht. Am liebsien hith sich diese Drossel in dichten Nadelwälderu auf, doch versteht sie als kluger Vogel auch, verinderten Verhälnissen Rcehnung zu tragen und sich einer nenen Umgebmg anzupasion. So brüteten die Mistler bei Knathe noch 1359 in Narleholz, zogen aber im nächsten Jahre Laubbäume vor, weil inzwischen die Fichten durch Niederschlagen isolint worden waren. Das Nest ist stets in geschickter Weise der Umgebung angepasst und wird mit wirklich orhabenem Mnte gegen weit iaberlegene Feinde und namentlich gegen dic lüsternen Krähen verteddigi. Im Riesengebirge steigt viscicorus von allen echten Urosseln an hüehsten empor und kommt nach Gloger regelmaissig bis zu eincr Höhe von 3700 Fuss vor, wemmgleich sie in den Gebirgswaldungen nicht so häufig ist wie musirus. A. r. Homeyer fand sie bei Spindelmuihl, Errebach an der Elbfalltaude, R. T'obias auf der Tafelfichte und Kollibay auf dem Cavalierberge. Besonders häufig aber ist der Vogel in den grossen Nadelwaldungen Obersehlesiens, wo sich ihm ja auch die denkbar günstigsten Dascinsbedingungen bieten. 
Masse von 21 schlesischen Exemplaren in $\mathrm{cm}$ :

$\begin{array}{lccc} & \text { maximum } & \text { minimum } & \text { Durchschnitt } \\ \text { Länge: } & 28,6 & 25,5 & 27,0 \\ \text { Flügelbreite: } & 49,2 & 45,4 & 47,0 \\ \text { Schwanz: } & 11,2 & 10,6 & 10,9 \\ \text { Schnabel: } & 2,3 & 1,3 & 2,0 \\ \text { Tarsus: } & 3,5 & 3,2 & 3,3\end{array}$

Der Hauptzug, of in ungehenren Missen, findet Aufang Niarz und Ende Oktober statt. Tine dieser kräiftigen Drosseln harren aber auch den ganzen VInter bei uns ans und werden noch durch Zuzüge aus dem Norden verstälst, welche ebenfalls bleiben, so lange mildes Wetter herrscht. D) Togel macht regelmïssig ¿ Bruten, und zwar juflegt das 1. Gelege in den er'sten Tagen des April, das 2 . in den letzten Tagen des Juni vollzählig zu sein. Kna uthe fand das fertige Nest am 18 Marr, I'raetorius volle Gelege an 2. April und 3. Juli, ich selbst am t., 6., 7. und 24. (erst 2 Eier) April.

Masse von 38 schlesischen Eiern in mm:

$\begin{array}{lccc} & \text { maximum } & \text { minimum } & \text { Durehschnitt } \\ \text { Länge: } & 35 & 29 & 31 \\ \text { Breite: } & 24,5 & 20,5 & 22\end{array}$

Brutdauer 16 'l'age.

16. Turdus pilaris L. 175. - Wacholderdrossel.

Synonyma: Turdus musicus Pall., Buff.; Alauda calandretta Mü̈ller; Sylvia pilaris savi; Areenthornis pilaris Kaup; Merula pilaris selby; Planestictus pilaris Jerd.; Turdus subpilaris, 'T. juniperorum, T. fuscilateralis Chr. Brehm; Turdus pilaris L., Gm., Behst., Naum., Cur. Brehm, Gloger, Kays. und Blas., Gieb., A. Brehm, lichw., v. Hom., Mewes, Fridr., Radde, Hart., Gätke.

Trivialnamen: Grossziemer, 1)reck- und Zinmerdrossel, Kramet- und Weckholdervogel, schuiire, Schacker. Oberschlesischpolnisches Idiom: Pirskowiez.

Kennzeichen der. Art: Lä̈nge grösser als 22: em. Kopf und Bürzel aschgran. Unterflügeldeckfedern weiss. Am schwarzen Sehwanze hat nur die änsserste Feder ein weisses Bändehen.

Masse von 60 schlesischen Exemplaren in $\mathrm{cm}$ :

$\begin{array}{lccc} & \text { maximum } & \text { minimum } & \text { Durchschnitt } \\ \text { Cänge: } & 26,1 & 22,5 & 24 \\ \text { Flügelbreite: } & 49 & 45,3 & 47,4 \\ \text { Schwanz: } & 10,4 & 8,9 & 10,0 \\ \text { Schnabel: } & 1,9 & 1,65 & 1,8 \\ \text { l'larsus: } & 3,5 & 3,25 & 3,35\end{array}$




\section{Abnormitäten aus dem Breslater Museum:}

a) Nacken, Wangen und Hals licht grauweiss, Flügeldeckfedern mit breiten, weissen Kanten Am linken Flügel die 1. Schwungfeder, am rechteu die 1. und 3. weiss. Schnabel und Füsse normal.

b) Die ganze Rï̈ckenseite schön hell rostgrau, die Flügeldeckfedern isabellfarben. Die Unterseite zeigt reines Weiss mit blasser, verschwommener Zeichnung.

c) Schwanz- und Schwungtedem schwarzbraun, Flïgeldeckferlern teilweise mit breiten, zorschlissenen, weissen Kauten. Ebenso auf dem Rücken, Hals, Nacken und Kopf weisse Federn mit einzelnen braunen Rändern. Vorderseite normal.

d) Oberseite und Flügel wie bei b); Vorderseite weiss mit schwach angedeuteter Zeichnung:

e) Oberseite schmutzig. wriss, ins Rostfarbene spielend. Unterseite ähnlich, nur noch heller.

Heydrich besitzt cin stiick mit weissfleckigem Kopfe. Ein ähnliches Exemplar wurde nach sehwenck feld im Spätherbst 1602 bei Hirschberg crbentet. Turlus pilaris ist wohl neben dem Girlitz derjenige Vogel, über den die schlesischen Beobachter am allermeiston geschrieben haben, weil scine ron E. v. Home y er lebhaft bekimptte allmïhlige Einwanderung Jahrehnte lang das allgemeine Interesse in Anspruch genommen hat. Nach einer sorgtältigen Sichtung des vorhandenen masicnhaften Materials muss ich mich durchaus im Gegensatz zu dem genaminten ()nithologen und in Uebereinstimmung mit seinem Vetter A lex a nd $\mathrm{I}^{\circ}$ auf die Seite derjenigen Berbachter stellen, welche cinc allmihlige Ausdehnumg des Brutgebictes von piluris und in Verbindung damit eine sich noch bis in die neueste Zeit fortsetzende Cinwanderung des Vogels annehmen. Ein an Brutplatz so lebhafer und lärmender Vogel würde anch in den meisten Gegenden Deutschlands meiner Ansicht nach unmöglich so lange übersehen worden sein, als dies nach E. v. Homeyer mit pilaris der Fall gewesen sein müsste. Ich gebe zunächst ohne jeden Commentar die bezüglichen Daten in chronologischer Reihenfolge.

1816. Endler: Nur auf dem Lurchzuge. Kenut Nest und Brutgeschäft des Vogels gar nicht.

1818. Gloger findet bei Breslau die ersten Eier.

1821. Klöber schiesst bei Karlsruhe eineu noch sehr jungen, augenscheinlich dort ausgebrüteten Vogel.

1823. J. G. Krezschmar: Durcistreift in Herbst und Frühjahr in starken Zügen die Lansitz, brütet aber nicht.

1820. Gloger: Nistet bisweilen in Gesellschaften von 15-20 Paaren. 
1827. Klöber: Nistet bisweilen bei uns.

15:7. Brahts: In der Lausitz nur auf dem Durchzuge.

1832. R. Tobias: Zuerst als Brutrogel in der Lausitz bemerkt.

1533. Gloger: Iuf dem Durchzuge häufig, aber anch nistend. Im Winter selten.

1531. v. Boenigk: 4 brütende Pare in Zabelwitz bei GrossGlogau.

15:36. v. Loebenstein: Nistet hier überall zahlreich. (Hoyerswerda.)

153s. E. F. v. Homeyer besuchte mit v. Loebenstein und R. Tobias dic grösseren Brutplazize in der Lausitz. Alle Iörster sagten aus, dass dor Vugel rom jeher da gewesen sei. v. II ome yer bezwritile deshalb die allmähliche Ans. breitung. (Es erscheint mir sonderbar, dass dieser die Benbachitangen amberer somet stets so stirng und merbittlich kritisirende Forscher hier so viel auf eine durch nichts bewiesene föroteransage giebr, welche mit den Angaben aller früheren lausitzischen Forscher in 11 idersuruch steht.)

1839. R. Tobias: Auf dem Durchzuge in Massen, aber auch als Brutrogel nicht selten und hat sich als solcher in den letzten 7 Jahren inmer mehr angesiedelt. Brütet meist in

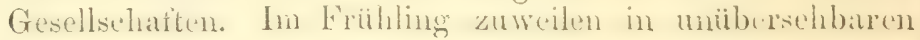
Scharen.

1847. v. Boenigk: $4-5$ brütende Paare in Niedermoyst bei Görlitz.

1848. - Junge im Posottendorfer Holz.

1849. - 10 Nester an Gr. Hennersiurfer Teich. Im Leopolishayner Walde 3 Brutpare.

1849. R. Tobias: Hat sich immer melr als Brutrogel cingebürgert.

1851. Fech ner: Zur Zugzcit bei Gürlitz bäufig. Einzelne nisten auch hier.

1864. A. v. Homeyer: Grosse Colonie bei Glogau, im Borkaner Eichenwald 15-20, im kleinen Kiefernwalde bei Kleutsch 3 und in den Vorwerker Kiefern 15 Nester.

1865. - Auf dem Cavalierberge bei Hirschberg grosse Colonieen. In den Vorhiohen des Riesengebirges überall Brutvïgel, so bei Sehweirhitz, Striegan, Liegnitz, Goldberg, Warmbiunn. Nach.v. Hahn auch bei Köben und Nilitsch. Bei Peterwitz (Grafschaft) ein vereinzeltes Paar, bei Tarnau 15 Paare. Im Winter selten.

1869. v. T'schusi: Im Riesengebirge auf dem Zuge zahlreich. 
1870. E. v. Homeyer: Bemerkenswerter Brutvogel am Rotstein bei Görlitz.

1872. Uttendörfer: Einmal bei Kosel nistend.

1876. Mohr: Brutvogel bei Breslau.

1878. R. Blasius: Zur Zugzeit am Zackenfall beobachtet.

1879. v. Meyerinck: Brutvogel bei Canth.

1879. Kollibay: Bei Neustadt ein durchaus nicht seltener Brutvogel, aber durch Eiersammler stark decimirt. Hat sich schon seit einem Menschenalter hier angesiedelt.

1880. - Bei Neustadt findet sich eine mehrere hundert Köpfe starke Brutcolonic, die sich vom Sassener Walde weit über die Kriwitzer Wiesen hinaus ausdehnt.

1881. Kutter: Starke Brutcolonie im Sassener Walde.

1884. Willimek: Bei Raudten nur durchziehend.

1885. Kaiser: Bei Sagan und Warmbrunn brütend.

1555. Richter: Bei Strehlen in einigen Paaren Brutvogel und im Zunehmen begriffen.

1887. - Gemein, namentlich in Parks.

1887. Kollibay: Häufig bei Hirschberg und Neisse, einzeln bei Patschkau brütend.

1858. Knathe: Am Zobten nur auf dem Durchzuge, iiberwintert aber bisweilen.

1890. Sperling: Als Brutvogel im Gürlitzer Stadtparke mehr und mehr sich einbürgernd.

1590. A. v. Homeyer: An den Sehneegruben beobachtet.

Ich selbst fand eine allerdings ziemlich zerstreut brütende Colonie von 12-15 Paaren in der Strachate bei Breslau; forner constatirte ich pilaris als Brutvogel in Oswitz, Masselwitz, Ransern und Pirscham bei Breslau, bei Trachenberg, Militsch, Kobier und Falkenberg. Von meinen Mitarbeitern führen folgende die Art als sicheren Brutvgel auf: B a er in Niesky, sylender in Bolkenhayn, v. Ehrenstein in Grudschütz bei Oppeln, Asmus in Heuschener-Carlsberg, Bannowsky in Friedrichsthal bei Oppeln, Abukir in Carolath, Hornung in Crascheow bei Oppehn, Brotke in Muskan, Gericke in Langenbrück, Fuier in Woidnig bei Guhrau, Haenel in Hagendorf bei Löwenberg, Hellmich in Neurode bei Lüben, Lange in Alt-Reichenau, Vorwerk in Nieder-Briesnitz bei sagan, Wallikhoff in Poppelau bei Oppeln, Ra ake in Sagan, Mally in Dittersdorf bei Sprottau, Müller in Paruschowitz bei Rybnik, Ziemer in Guhlau bei Glogau, Titz in Mollwitz bei Sprottau und v. Pannwitz in Hammer bei Trebnitz. Nur als Durchzügler wird pilaris erwähnt von Emmrich in Neurode und Cusig in Kuhbrück bei Frauenwaldau. Zieht man aus alledem das l'acit, so kann es doch wohl kaum einem Zweifel unterliegen, dass die Wachholder- 
Mrossel erst zu Begimu unseres. Jihrhumlerts ron Nordosten aus in Sehlewien eingerüekt ist, dass sie crot in der Mitte des Jahrhunderts als Brutrogel häufiger wurde, und dass sie bente endlich zu den yanz gewöhnlichen Vögehn gehört. Luteressunt ist es ferner, wie sie sich bei diesen Eimdringen nach den ihr anfangs doch noch neuen und ungewohnten Terhälnissen zn riehten wusste. Anfünglich brüteten die Tïgel den in ihrer nordischen Heimat angenommenen Sitten zufolge ïberall in grossen Culonien. Mit der

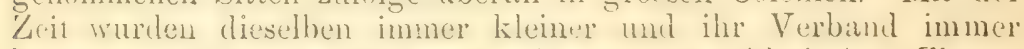
lockerer, und hente bräten wohl die meisten scinlesischen Ziemer in einzehen Paren, wenngleich die Brubrirke derselben nicht sehr gross und auch nicht so scharf abgregrenzt zu sein brauchen wie bei anderen Vogelarten, anch die Miimulen ans einer Gegend oft nach Art der siare des Abuds zusammenkommen, um einen gremeinschaftichen Lmbiss za nchmen, zu singe'n und zu lärmen. In dere ersten Zeit hielten sich dir Yögch streng an die ihnen vom Norden her rertrauten Birken, dam trat diese Vorliebe immer mehr zuriek ind hente ist vou derselben überhaupt kaum noch etwas zu beobachten. Die von Liebe mitgeteilte Beobachtung Krezselimars, dass die Wavhluhlerdrossel atas der Gegend von Gioblitz wieder versenwulden soi, steht mit den Mitteilumgen

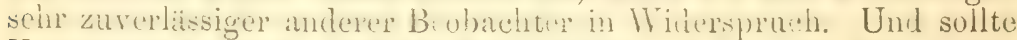
Irezsehnar arah wirklich liecht haben, so bin ieh doch nicht

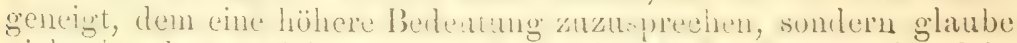
vichuelir, dass es sich nm eine lentiglich lokate Erscheinung haudelt,

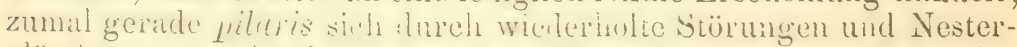
plünderungen sehr leicht ans einer tregend vertreiben lässt. Im Gegenteil ist anch nuch jotzt in len meisten Sirichen der Provinz eine fortdauernde Zunahine des Bestandes zil verzeichnen.

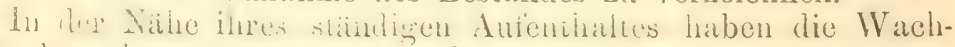

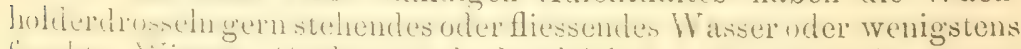

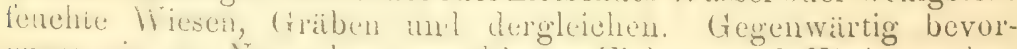

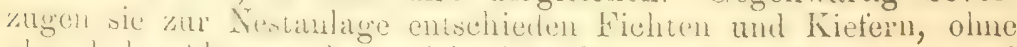
aber hohe, batt- und astreiche Laubbibume zu versehmähen und legen hier nach drt anderer brossehn ihr Heim anf einem anslantenten dste dichi am stamme an. 1. v. Ilomeyer giebt 7-3) Euss als Höhe des Standortes an. Wie weitaus meisten Nester aber fimle man schon in einer liöhe rou $(j-1)$, selten (2) Fun. Nach Sipcrling bancu sie in Görlitzer Stadtpark mit Vorliebe an die Sianme for alten italientsohen P'appeln, und so abudert das eben nach Ort unci Verhälnissen immer mehr oder

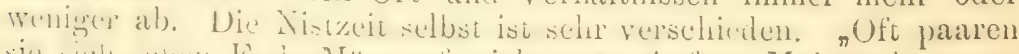

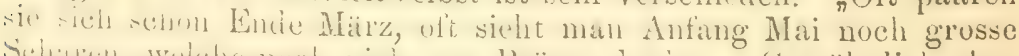
sehaph, welehe woch nichi ans brüten denken. Gowähnlich aber bezinn der Nesiban Ende April, so dass Ende Nai Eier in den Nistru siml." (A. r. Homeger.) Nach meinen in schlesien 
gemachten Erfahrungen kann man indess durchgängig schon Ende April auf volle Gelege rechnen; ich vermute unter den dureh v. Homeyer noch im Mai beobachteten grossen Schwärmen neue Einwanderer, die sich nicht gleich zum Brüten in der ihnen noch fremden Gegend entschliessen konnten. Wenn v. Homeyer sagt, dass ein zweimaliges Brüten nicht stattfinde, so muss ich auch darin diesem verdienstvollen Forscher widersprechen. Heutzutage wenigstens ist ein zweimaliges Brüten durchaus Regel, und stimmen darin auch die neueren Beobachter wie z. B. E. F. v. Homeyer mit mir übcrein. Gewöhnnlich bilden \& Eier das Gelege der 1. und 5 das der 2. Brut. Die Beobachtung von Holtz, dass innerhalb einer Colonie die Nester stets in gleicher Höhe stehen, fand A. v. Homeyer mit einer Ausnahme überall bestitigt. Das Nistmaterial beschreibt Wätzold folgendermaassen: „Die Nester zeigen im Material eine grosse Uebcreinstimmung. Vorherrsehend ist Galinm aparine und Agrostis stolontera, letzteres als feineres Bindewerk; dieses Gras wäehst ïberall an den Waldlachen. Ausserdem, jedoch nur in sehr geringer Menge, einige Holzreiser von Weiden und Ulmen, Phalaris arundinacea und Eiquisetum palustre. Aensserlich ist das Galinm, innerlich Agrostis mit einigen Poa (Waldrispengras) vorherrschend. Die meisten Nester haben cinen kleinen Bestandteil ron Astmoos (Hypmum)." Die Durehschnitsmaasse normaler Nester betragen nach A. v. Hom eyer:

Aeusserer Nestuntang am oberen Rande: $450 \mathrm{~mm}$.

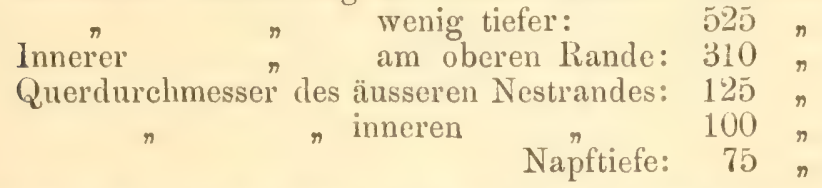

Häufig scheut der Vogel auch die Nähe des Menschen uicht, was namentlich neuerdings wiederholt beobachtet wurde. sin fand ich bei Breslan \& Nester an viel betretenen Wegen und Kollibay bei Hirschberg an 25. April ein Nest mit einem Li, welehes trotz anderweitiger Nistgelegenheit o F'uss hoch ant einer dümnen Fichte neben Gartenbänken stand. Ėbenso wie viscivorus ist auch pileris am Nistplatze sehr mutig und insbesondere stets bereit, mit den herumstrolehenden Krïhen und Eichelhehern anzubinden. Ganz regelmässig besuchen sic die dem Nistplatz zunïchst liegenden Wiesen, auf denen sie sich namentlich des Morgens stundenlang herumtreiben, um die noch nicht wieder in ihre Lüeher zurückgekrochenen Regenwürmer aufzunehmen. Trotz ihres Gelärms und ihrer ewigen Unruhe und ilhrer Kamptlust gegen grössere Vögel stören sie die in ihrer Nähe nistenden kleineren Vögel niemals auch nur im geringsten. In Gebirge geht diese Drossel brütend bis zu einer Hühe von 
$1170 \mathrm{~m}$ (neue schlesische Bande) cmpor. Volle Gelege fanden Kollibay am 21. und 2., April sowie am 26. und 27. Juni und 3. Juli, Mohr an 17. April, Kutter am 23. und 2x. April, v. Boenigk am 23. April, ich selbst am 24., 27., 29. April sowie am 28. und 30. Juni. Boenigk fand einmal in einem Neste dabei noch ein Ei von Fringilla coclebs. Kollibay erbeutete ein Gelege von (; Stück, bei welchem das letzte sehr gestreckt war und anf hell meergrüuem Grunde einige wenige rotbraune Punkte hatte.

Ma a s e von 74 schlesischen Eiern (davon 26 durch Ko llibay gemessen) in $\mathrm{mm}$ :

$\begin{array}{cccc} & \text { maximum } & \text { minimum } & \text { Durchschnitt } \\ \text { Länge: } & 30,2 & 25,4 & 28,3 \\ \text { Breite: } & 22,2 & 18,9 & 20,6\end{array}$

In milden, beerenreichen Wintern bleiben viele Wachholderdrosselu bei uns. Sonst ziehen sie im Norember fort, um schon sehr zeitig im Frïlijahr zurïekzukehren. Die folgende Tabelle bringt einige Hauptdurehzige : 


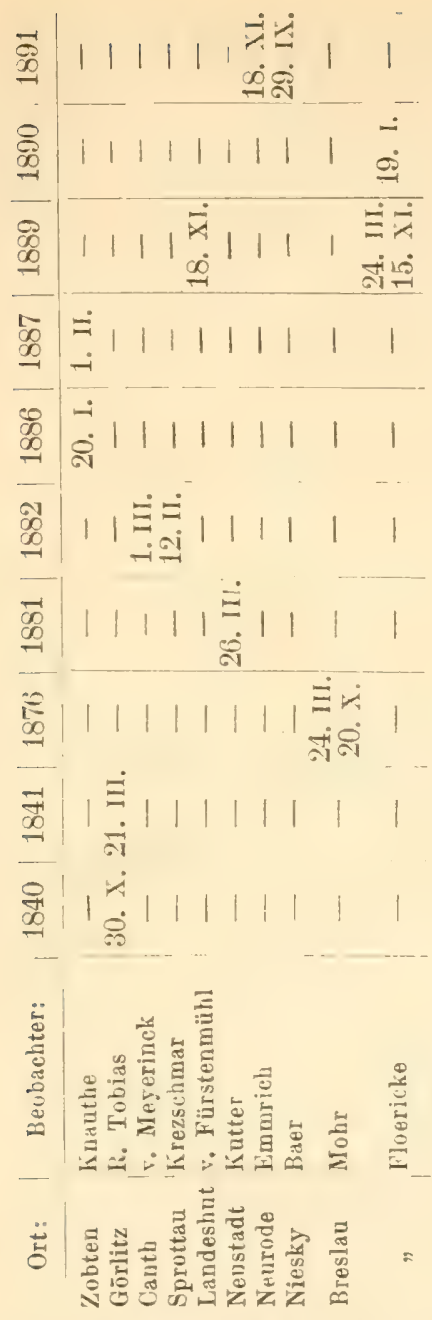

Der Krammetsvogelfang wird zwar noch vielfach und ganz besonders in den Gebirgsgegenden und in Oberschlesien betrieben, lässt aber auch hier mehr und mehr nach, zumal der Ertrag immer geringer wird. Doch kommen dabei immerhin ganz anständige Zahlen zu tage. So wurden z. B. im Jagdjahre 1885/84i allein in den königlichen Forsten der Provinz 71678 und im Jagdjahre 1889/90 75538 "Krammetsvögel" erbeutet. Pilaris stellt dazu oft nur einen geringen Procentsatz. Besonder's auffällig war 
mir unter den abgewürgten und in den Breslaner Delikatesshandlungen zum Verkauf ausgehängten Vögeln das oft fabelhaft zahlreiche Auftreten von merula, deren Zug dureh Schlesion überhaupt ein ungemein starker zu sein scheint. Wenn demnach der Vogelsehützler dem Krammetsvogelfang notgedrungen den Krieg crklären muss, so hat doch andrerseits die vissenschaftliche Ornithologie demselben manches interessante und wichtige Exemplar zu verdauken, wie die Aufzählung der nun folgenden Arten auch für Schlesien hinreichend beweisen dürfte.

17. Turdus Naumanni Tem. 1⒛ - Rotschwanzdrossel.

Synonyma: Turdus dubius Bchst.; Turdus ruficollis Gloner; Cychloscelus dubius Bonap.; Areenthornis Namami Gray; T'urdus Naumauni Blyth, Swinloe, Naum., A. Br., v. Hom., Mewes, Fridr., Jäickel.

Kennzeichen der Art: Friderich giebt dieselben folgendermassen: "Etwas grösser als die Singdrossel. Oberkopf dinkelbraun, alle Federn grau gesäumt; Nantel und Schultern rostbraun, Sïume graubraun; IBürzel und obere Schwanzdecken rostrot; ein breiter Augen- und Schlafenstreifen, Kopfseiten und Kehle weiss, ins rostrütliche ziehend; Zügel, Ohrgegend und ein doppelreihiger Fleckenstreifen neben der Kehle dunkelbraun; Kopfseiten und Oberbrust rostrot, mit schmalen weisslichen Säumchen; Unterflügeldecken cbenso; Unterleib weiss mit herzförmigen rostroten Sehafiflecken; Sehwingen dunkelbram, immen breit rostgelb gerandet; ebenso die grö̈ste Reihe der oberen Flügeldecken. Sohwanzfedern lebhaft rostrot, die beiden mittelsten und Aussenfalnen dunkelbraun, diese innen - gegen das Ende - ebenso verwaschen. Schnabel hombram, wurzelwarts gelb; Iris dunkelbraun, Füsse bräunlich. ${ }^{\text {" }}$

Nach R. Blasius steht in Eberswalde (in aus Schilesien stammendes Exemplar dieser für Deutschland seltenen Drossel, welche in Ostasien ihre Heimat hat.

1․ Turdus ruficollis P'all. 1776. - Rothalsdrossel.

s y 11 on y a: Turdus erythrurus Hodgs.; Planestictus ruticollis Bon.; Cichloides ruficollis Gray; Turdus ruficollis Blyth., Naum., A. Br., Reliw., v. Hom., Hewes, Fridr., Gätke.

Kennzeichender. Art nach Friderich: „Die Schwingen braun, an der Wurzel mit einem scharfen rostgelben, von aussen sichtbaren Fleck; die unteren Deckfedern der Flügel samt einem Teil der imueren Falne der Schwingen rötlich-rostgelb; der Schwanz immer, wenigstens an den Kanten, mit einem rötlichen oder roten Sehimmer; tiber dem Auge ein breiter, in der Jugend lichter, im Alter hell rostroter Streif. Der Oberleib olivengrau, auf Rücken 
und Flügeldeckfedern mit rostrot gemischt; von unten weiss, an den Seiten rostfarben gefleckt. Im höheren Alter wird der Schwanz zum grossen Teil rostrot."

Auch diese in Nord- und Mittelasien heimische Drossel kommt als grosse Seltenheit in Oberschlesien auf dem Durchzuge vur. Im Breslauer Museum befinclen sich 2 Belegexemplare, welche beide noch das Jugendkleid tragen. Lcider fehlen anch hier vicher alle näheren Daten auf der Etiquette. Nach G ätke kommt diese schöne Drossel am allerseltensten von: ilıen fern östlichen Verwandten nach Europa. Uebrigens liat Gïtke (Vogelwarte Helgoland, p. 258) das Vorkommen in Schlesien übersehen. Ich glaube, dass gerade in den oberschlesischen Dohnenstiegen sich noch manche Seltenheit nachweisen liesse. Leider ist aber niemand vorhanden, der die, dort gefangenen Drosseln daraufhin controlliren künnte.

19. Turdus obscurus Gm. 1785. - Blasse Drossel.

Synonyma: Turdus pallens Pall, Blas, Gätke; Turdus Seyflertitzii Chr. Brehm; Turdus pallidus Naum., Tem.; Turdus Davidianus Ed w.; Plancstictus obscurus Bon.; Geocichla obscurus Jerd.; Turdas obseurus Finsch, A. Br, Newes, Fridr., Hartert; Turdus illuminus v. Loeb.

Kennzeichen der Art nach Friderich: „Die Brustseiten mit rostgelbem Anstrich, Kropf und Unterumpf gainzlich ungefleckt; über den Augen cin weisser Streif; die Unterflïgceldeckfedern licht gelbgrau, gelblich weiss und grau gemischt; die äusserste Schwanzfeder am Ende mit einem verdeckten wcissen Streifchen."

Auch diese Art gehört zu denjenigen asiatischen Drosschn, welche hin und wieder auf dem Zuge als Seltenheit in Mitteleuropa gefangen werden. An 2! September 1s:39 wurde nach R. Tobias in Geisslitz bei Iloyerswerda cin stuek gefangen und nach v. Loebenstein im Herbst 1 int ein zweites auf dem Kynast.

20. Turdus varins $\mathrm{Pa} 11$. 1S1i. - Bergedrossel.

Sy 1 on yma: Turdus damma Lath., A. Brehm, Eridr, Crätke; 'Turdus aureus Holandre; Turdus Withei Eyton; Oreocinela aurea Bon.; Oreocincla dauma Blyth., sund.; Orencincla Vithei Blyth.; Oreocincla parvirostris Gould,; T. varius Rehw.

Kennzeichen der Art: Totallänge mehn als $26,5 \mathrm{~cm}$. Sehwanz 1tfechig. Diese grosse Lrossel bewohnt Ost- und Mitulasien. Dem einzigen in Schlesien erlegten mul im Breslauer Museum aufbewahren Fxemplar fehlen leider wieder alle näheren l)aten. Drosisel.

21. Turdus atrigularis T ('m, 1 ren). - Sichwarzkehlige Synonyma: Turdus Bechsteini Naum., Tob.; Turdus 
dubius Behst.; Sylvia atrogularis Savi; Cichloides Bechsteini Kaup; Turdus Naumanni Blyth; Merula atrogularis Bon. Hart.; Turdus atrigularis Natt., Tem., Gould, Giebel, Hart., Gätke, Jäckel, v. Hom,, Mewes, A. Brehm.

Kennzeichen der Art nach Friderich: "Alle oberen Teile hell olivengrau; der Unterleib bis auf die schwärzliche Oberbrust weiss mit spitzen Pfeilflecken; auf der Gurgel und Oberbrust ein breiter schwarzer Schild mit weissgrauen Rändern, das Schwarz etwas getrübt. Am Unterflügel die grossen Deckfedern schön ockergelb. Der Brustschild ist in Alter rein sehwarz, in der Jugend mit breiten weissgrauen Federchen verdeckt, welche graucn Ränder mit jedem Jahre schmäler werden und das Schwarz mehr hervortreten lassen.

$\mathrm{Da}$ atrigularis mehr im westlichen Asien zu hause ist, so besucht sie auf ihren Wanderungen Deutschland verhältnismässig öfter als die vorhergehenden Arten. Immerhin gehört auch sie zu deu grössten Seltenheiten unserer einheimischen Ornis. Sie ist nach Gloger und R. Tobias auch schon in schlesien erlegt, in neuerer Zeit aber daselbst meines Wissens nicht wieder nachgewiesen, wahrseheinlich allerdings nur aus Mangel an Beobachtern.

22. Turdus sibiricus Pa1l. 1776. - Sibirische Drossel.

Synonyma: Turdus lencocillus, T. auroreus Pall,; Turdus Bechsteini Naum.; Turdus atrocyancus v. Hom.; Turdus mutabilis T'm.; Cichloselys sibiricus Bon.; Cichloselys mutabilis Gray; Turdus sibiricus Sivinh., Blas., Gieb., v. Hom., Mewes, Fridr.

Kennzeichen der Art: Kleiner als $22 \mathrm{~cm}$. UnterHügeldeckfedern weiss. Die 2 iussersten Pare der schwanzfedern mit weissem Fleck an der Spitze.

Auch diese ostasiatische Drossel kamn ich zu meiner Freude

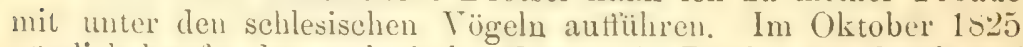
nimlich kaufte das zoologische Museum in Breslau cin Stück auf dem dortigen Wildpretmarkte auf, welehes der betreffende Händler mit mehreren hundert anderen Drossehn aus dem Eulengebirge erhalten hatte. Das Exemplar ist noch heute eine Zierde des Breslauer Museums.

\section{T'urdus merula L. 1758. - Amsel.}

S ynonyma: Turdus vulgaris Ray, Buff.; Merula vulgaris L.anch, v. Hom, Nerula merula Boie, Hartert; Sylvia merula Savi; Merula pinetorum, M. truncorum, M. alticeps, M. carniolica, II. maior Brehm; Turdus merula L., Gm., Bchst., Naum., Glog., Kays. und Blas., Gieb., A. Brelnm, Mewes, Radde, Jäckel, Gätke.

'T'rivialnamen: Omsel, Omstel, Amelze, Meerle. Oberschlesisch-polnisches Idiom: Kus. Muskauer wendisch: Kussak. 
Kennzeichen der Art: Die Männchen einfarbig schwarz, die Weibehen und Jungen einfarbig schwarzbraun mit Ausnalıme von Kehle und Vorderhals. Schwanz lang; im Flügel die to und 5. Schwinge am längsten.

M a asse von 78 schlesischen Exemplaren in $\mathrm{cm}$ :

$\begin{array}{lccc} & \text { maximum } & \text { minimum } & \text { Durelischnitt } \\ \text { Länge: } & 25,0 & 23,6 & 24,4 \\ \text { Flügelbreite: } & 40,1 & 37,9 & 38,8 \\ \text { Schwanz: } & 11,1 & 10,4 & 10,9 \\ \text { Schnabellänge: } & 2,0 & 1,7 & 1,8 \\ \text { Tarsus: } & 3,9 & 3,6 & 3,7\end{array}$

Dass die Amsel lokale Variationen aufweist, geht schon aus den vielen Brehm'schen subspecies hervor. Auch im Gesang benerkt man bei aufmerksamer Beobachtung bald manche Untersehiede, und dem wahren Liebhaber ist es durehatus nicht gleichgültig, woher scine Amscln stammen. Trotzdem vermag ich zur Zeit - vielleicht von der um ein weniges beträchtlicheren Grösse abgesehen - noch keine für unsere schlesischen Vögel constanten Charaktere anzugeben. Die Ansel ist zwar auch in Schlesien überall ein gemeiner Brutrogel, kommt aber doch nicht so massenhaft vor wie in den meisten Gegenden des mittleren und westlichen Dentschland. Schon Gloger sagt: „Als Nistvogel nicht so häufig wie in Thüringen." Am zahhlreichsten ist die Schwarzdrossel noch in der Lausitz und in Obersehlesien, wo sie in den Fasanenremisen ganz ungestörte Brutpliatze tindet und sich damn da in wenigen Jahren fabelhaft vermehrt. Im Oderthale Mittelschlesiens ist sie viel sparsamer, und jedenfalls steht ilı Bestand sehr hinter dem von musicus zurüek. Immerhin übertreibt Mo hr gewaltig, wemn er sagt: „Bei Breslau sehr selten." Im Gebirge, wo sie z. B. Erlebach an der Elbfallbaude brütend fand, geht die Amsel bis zu 3500 Fuss Höhe hinauf (Gloger), ist aber hier die seltenste Drossel (Brehm). Auch in Sehlesien hat sich das wunderbare Schanspiel vollzogen, dass dic Amsel aus einem seheuen Bewohner einsamer Waldungen ganz von selbst sich in einen steten Genossen menschlicher Ansiedlungen umwandelte. Dic Autoren vom Anfang unseres Jahrhunderts kennen merule nur als Waldvogel. Gegenwärtig brüten die meisten in Parks, Gärten, Anlagen, vicl seltener im Walde. Im letzteren Falle bevorzugen sie gemischte Bestände mit recht viel Gebüsch und Unterholz. Auch in den Gärten der grösseren Städte fehlen die Amseln nicht und sind z. B. in Breslau anch imnerhalb der Hanern zu finden. Von jeher hat ein Teil der Amseln in der Heimat überwintert, und dies scheint nenerdings in immer ausgedehnterem Maasse stattzufinden. Dic älteren Beobachter berichten übereinstimmend, dass nur alte Mämnchen den Winter über bei uns 
aushielten; Kollibay und ich haben dies aber auch mohrfach bei Weibchen gefunden. Der Amsclzug durch Schlesien ist namentlich im Herbste oft ein ganz ausserordentlich starker. Merkwürdiger Weise liegen mir aber nur schr spärliche Notizen über die Zeit desselben vor.

\begin{tabular}{|c|c|c|c|c|c|}
\hline Ort: & Beobachter: & 1581 & 1856 & 1889 & 1890 \\
\hline Neustadt & Kutter & 27. 111. & - & - & - \\
\hline Petersdorf & Vogt & - & 1. IV. & - & - \\
\hline Zobten & Knauthe & - & - & - & 15. IIJ. \\
\hline Alt-Hammer & Forstpersonal & - & - & 2. IV. & - \\
\hline Karlsberg & $"$ & - & - & 29. 111. & - \\
\hline K]. Briesen & $"$ & - & - & 20.111. & 一 \\
\hline Kottwitz & $"$ & - & - & 2. IV. & - \\
\hline Nesselgrund & $"$ & - & - & 20.111. & - \\
\hline Paruschowitz & , & - & - & 21. 111. & - \\
\hline Proskau & $"$ & - & 一 & 203. III. & - \\
\hline Ullersdorf & " & & - & $9 . \mathrm{IV}$ & - \\
\hline Breslau & Floericke & - & - & 21. III. & 7. 11. \\
\hline
\end{tabular}

Als harte Vögel schreiten die Amsehn schon sehr früh zur Brut. Kutter fand (immal schon am 25). April nackte Junge. Jährlich 2 Bruten. Gelege fanden Kuttel am 27. März, ̌․ und 19. April und 30. Mai, P'ractorius an S. April, Kolliba y am s. Juni, ich selbst am (i., 9., 11., 15. und 22. April sowie am 3. und 7. Juni.

Ma as ve von 70 sehlesischen Eiern in $\mathrm{mm}$ :

$\begin{array}{lccc} & \text { maximum } & \text { minimum } & \text { Durchschnitt } \\ \text { Länge: } & 28,6 & 27,5 & 28 \\ \text { Breite: } & 21,9 & 20,4 & 21\end{array}$

Das Breslauer Nuseum besitzt einen abnorm grefarbten Vogel. Einige Sulneitel-, Nacken-, Bauch- und Flügeldeckfedern sind weiss gekautet, wodurch in Nacken ein breites, weisses Band entstehi. Schwanz fast ganz weiss.

Nesträubereien der Amsel labe ich nie bemerken kömuen, obgleich ich in dieser Ilinsicht stets ein scharfes Auge auf sie gehabt Labe.

24. 'Turdus torquatus I. 1758'. - Ring d ros sel.

24a. 'Turdus torquatus alpestris (Brehm) 1831. Alpenamsel.

Synonyma: Merula montana Briss., Buft.; 'Turdus europaeus Mill.; Copsychus torquatus Kaup; Merula torquata Boic, v. Hom., Hart.; Sylvia torquata Savi; Thoracocincla torquata Reich.; Merula collaris, M. alpestris, M. vociferans, M. maculata Chr. Brehm; Turdus torquatus L., Gm., Behst., Naum., Chr. 
Brehm, Glog., Kays. u. Blas, Fridr., A. Brehm, Mewes, Radde, Gätke, Jäckel; Turdus alpestris Rchw. amsel.

Trivialnamen: Schilddrossel, Schnee-, Meer- und Ross-

Kennzeichen der Art: Grösse über 26,5 $\mathrm{cm}$. Das Gefieder mattschwarz mit weissgrauen Federrïndern. An der Oberbrust ein grosser, halbmondförmiger weisser (Männchen ad.) oder weisslichgrauer Fleck.

Wenn irgendwo, so ist hier die trinäre Benennung am Platze, denu alpestris bildet eine sehr gute subspecies, während mir es andrerseits zu gewagt erscheint, sie als vollgültige species aufzustellen. Für einen nur einigermaassen geübten Blick ist sie sofort von der typischen toryuatus zu unterscheiden. Es wäre von Wichtigkeit, numehr namentlich auf die biologisehen Eigentiimlichkeiten beider Formen recht genau zu achten, da sich hicr wahrscheisich ebenso wie bei den Baumläufer'n nicht unwesentliche Unterschiede herausstellen dürften. Als Brutvogel haben wir auf dem liesengebirge, wie ich auf das bestimmteste versiehern kann, nur alpestris; torquutus kommt nur auf dem Zuge vor.

N a asse von 13 riesengebirgischen Exemplaren (alle zu alpestris gehörig) in $\mathrm{cm}$ :

maximum minimum Durchschnith Typische torquatus

Länge:

Flügelbicite:

Schwanz:

S'chnabel:

Tarsus:

$\begin{array}{rl}27,5 & 26,6 \\ 41,3 & 40,0 \\ 10,5 & 10,1 \\ 2,0 & 1,75 \\ 3,6 & 3,35\end{array}$
nach Friderich:

Gloger giebt den von der lingdrossel in den Sudeten bewohnten Höhengütel auf 3700 _tho( Fuss an; ich glanbe in Ueberenstimnung mit R. Tobias, dass dies zu hoch gegriflen ist, und dass man etwa 2500 luss als mitere Grenze setzen kaun; die meisten Brutpare findet man äbrigens in einer Höhe von 3500 - 4000 Fuss. In eigentlichen Knieholz ist der Vogel viel seltener zu treften als in den obersten Regionen des echten Waldes, wo er namentlich feuchte Stellen mit Vorliebe aufsucht. ( $10 \mathrm{log}$ war es, der diese prächtige Drossel im Jahre $18: 26^{\circ}$ auf dem Riesengebirge als Brutvogel entdeckte und alsbald Nest, Eicr und Jugendkleid in der Isis beschreiben kointe. Seitdem haben alle das Riesengebirge besuchenden Ornithologen den Vogel mehr oder weniger eingehend beobachtet. Er verbreitet sich riemlich gleichmässig über das ganze Gebirge, ohne aber irgendwo eigentlich häufig zu sein, und wir dürfen e's uns leider nicht mehr verhehlen, dass der Bestand gegenwärtig aus mir unbekannten Gründen 
ganz rapide zurückgeht. Dasselbe ist nach Michel im Isergebirge der Fall, wo die Ringdiossel nach Tobias, Heydrich und Kirchner gleichfalls Brutvogel ist. Förster Göbel fand sie ferner auch auf dem Glatzer Schneeberg brütend. Von meinen Mitarbeitern führen sie als Brutvogel auf: Asmus für die Heuschener, Gericke für den Wölfelsgrund und Lange für die Landshuter Berge. Wie sparsam der Vogel im allgemeinen schon geworden ist, geht z. B. auch daraus hervor, dass ich ihn während cines 3wöchentlichen Aufenthaltes im Iser- und Riesengebirge nur vicrmal zu sehen bekam, obwohl ich besonders auf ihn Obacht hatte. Der Wasserpicper ist ungleich häufiger. Bezüglich des Aufenthalts der Ringdrossel sagt (Hloger: "Unter allen ihrer Familie ist sie am meisten Freundin freier Orte. Auch ihre am tiefsten gelegenen Brutpliitze, die obersten Fichtenwälder, müssen ausserdem, dass die Bäume klein und verkrüppelt und nicht über 3-1 Nanneslïngen hoch sein müssen, so licht aussehen, dass hüchstens der vierte oder fünfte Teil von dem IIolzbestand vorhanden ist, der vermöge des Raumes da sein könnte." Ich pflichte dem zwar bei, möchte aber in Uebereinstimmung mit A. v. Homeyer moch betoneu, dass der Togel sich vich weniger im Knieholz als vielmehr weiter unten im obersten Gürtel des cehten Waldes aufzuhalten pflegt. Wenn der Winter auf dem Gebirge seine Herrschaft mit ganzer Strenge entfaltet, ziehen sich die Ringdrosseh in geschützte Thäler zurück und verstreichen sogar bis in die ebenen Teile der P'rovinz. So beobachtete ich einmal cinen kleinen Schwarm im Winter 185T/Ss bei Breslau. Schon Ende März oder Anfang April rüeken sie aber wieder in die Gebirgswaldnugen ein, wenuschon rauhes Wetter sie of noch mehrmals wieder in die Thäler und Vorberge zurückwirft. Eutsprechend ihren rauhen Wohmplätzen machen sie nur eine Brut. Auch das Mänuchen brütet (A. v. II o m e y er). Bisweilen stehen mehrere Nester nahe bei cinander (Gloger). v. Homeyer fand ein stark bebrütetes Gelege an 2:3. Mai; das Nest stand 4 l'uss vom Boden in einer alten Rottanne. L. Tobias beob. achtete am 19.Juli im Riesengrund flügge Junge. Am ausführlichsten hat Gloger iiber das Brutgeschät dieses interessanten Vogels berichtet: "Hhre Nester legt sie auch in den Fichtenwaldungen nicht über 5 Fuss und nirgends unter 11/2 Fuss am Boden an, übrigens in den diehtesten Zweigen, gern auf armes- bis schenkoldicken, in der Regel horizontalen Aesten oder in den Z wiesehn, wo mehrere wenigstens fingerstarke deste es noch tragen helfen, viel seltener anf solchen selbst und stets am Stamme. Aeusserlich wird es ans feinen dürren Fichtenreischen, grobem, noch mit den Wurzeh versehenem Grase und elwas Moos gebaut; danu kommt eine ziemlich dümne Lage Mooserde und zur imnersten Ausfütterung Stengel der kurzen, dort uben wachsenden Grïser. Dic $3-\overline{0}$ 
Eier haben eine blass grünlichblane oder dunkelblauweissliche Grundfarbe und eine hellrötlichbraune oder braunrote und rote oder violette Zeichnung, die sich teils in mässig grossen Flecken, teils in feinen Strichelehen darstellt, bald sparsam, bald ziemlich dicht aufgetragen ist, zuweilon am spitzen Ende an häufigsten. Sie variiren von einer ovalen bis zu einer selır länglich birnförmigen Gestalt, gleichen in der Grösse denen von viscivorus nicht völlig, ähneln ihnen zuweilen ziemlich in der Farbe, oft aber auch sehr denen vou pilaris und merula." Es ist mir nicht bekannt, ob sich die so von Gloger beschriebenen Eier von denen der nordischen tortukatus unterscheiden lassen. Ich vermag dies nicht, was aber leicht in mangelnder Erfahrung und Uebung auf oologischem Gebiet begründet sein köunte. Ueber den Gesang lautet das Urteil sehr verschieden. F'rider ich rühmt denselben, andere sind weniger entzückt. Ich muss mich letzteren anschliessen, obschon ich sur in der Voggelstube Gelegenheit hatte, den Vogel zu belauschen. In romantischer Hochgebirgsuatur macht das Lied des frcien Sängers voraussichtlich einen ganz anderen Eindruck. Dic einzige alpestris, welche ich bisher im Käfig pflegte, sang wesentlich schlechter als die echten torruatus. A. v. Homeyer, wohl der grösste lebende Gesangs- und Vogelstimmenkenner, sagt: „Gesang ähnlich dem von viscicorus aber nicht einmal so mannigfaltig."

Die Linnésche T. torquatus, welche besonder's in Skandinavien britet, kommt in śchlesien, wic gesagt, nur auf dem Durchzuge vor und scheint hier ziemlich streng eine Strasse einzulhalten, welche von der Latusitz aus in südöstlicher Richtung längs der sudeten bis zur Mareh-BeczwarOder-Furehe dahin zicht, nicht als ob diese Vögel dem Passe zueilten, um hier durch die Gebirgslücke nach der lonau hin zu rücken, sondern weil sio wahrscheinlich auf ihren Vanderungen dem Gebirge an und für sich gern so lange als angängig folgen. Oestlich von dieser Strasse werden nur selten Ringdrosseln wahrgenommen, auf derselben aber bisweilen ziemlich zahlreich gefangen. Der Ilerbstzug ist viel stärker als der Frühjalırszug, geht übrigens auch ziemlich raseh und jedenfalls viel schneller als bei anderen Drossehn vorüber und drängt sich unter normalen Verhältnissen auf höchstens 14 Tage zusammen.

Familie: Sylviadae, Sänger.

Kleine, schlanke Vögel mit geradem, schr dünnem, echt pfriemenförmigem Schnabel, krältigen, mittelhohen Füssen und kurzen, ziemlich gerundeten Flügeln.

Gattung: Regulus Cuv. 1800. - Goldhähnchen.

Die kleinsten europäischen Vögel. Länge weniger als $9 \mathrm{~cm}$. Ueber jedem Nasloch ein steifes, kammartiges Federchen. Die 
mittellangen Flügel mit 19 schwachen Sehwungfedern, von denen die 3. und to am längsten. "Schwanzfedern an der Spitze am breitesten, das Ende nach aussen schräg zugestutzt." (Friderich).

25. Regulus cristatus Vi eill. 1s0\%. - G elbköpfiges Goldhähnchen.

Synonyma: Motacilla regulus L., Gm., Bchst., Butf.; Sylvia "egulus Lath., Behst.; Regulus flavicapillus Naum., Glog., Gäitle; Regulus vulgaris Steph.; Regulus himalayaus Blyth; Regulus septentrionalis, R. crococephalus, R. chrysocephalus Chr. Brehm; Regulus regulus Hart.; Regulus cristatus Koeh, Degl., Will. und Ray, Alb., L., Chr. Brehm, Kays. und Blas., Gieb., A. Brehm, Fridr., v. Hom., Newes, Radde, Jäckel.

Trivialnamen: MIcisen- uni sommerkönig, Ochsenäuglein, Tamenneislin, Goldhühmel, Strensslin, Waldzeislein.

Kennzeichen der Art: Augengegend gelblich granweiss. Masse von 22 schlesischen Exemplaren in $\mathrm{cm}$ :

$\begin{array}{lccc} & \text { maximum } & \text { minimum } & \text { Durchschnitt } \\ \text { Länge: } & 9,2 & 8,2 & 9,0 \\ \text { Flügelbreite: } & 15,7 & 14,5 & 15,4 \\ \text { Schnabel: } & 0,95 & 0,75 & 0,9 \\ \text { Tarsus: } & 1,65 & 1,55 & 1,6 \\ \text { Schwanz: } & 3,8 & 3,5 & 3,9\end{array}$

Sehon $\mathrm{N}$ a $u$ m a nu hat mit liecht hervorgehoben, dass dieses Goldhïhnehen ungemein in Kürpergröse, wie Schwanz- und Schmabellänge variirt. Ich habe bei nuscren sehlesisehen Stücken stets ungewöhnlich lange schwän\% und schuäbel gefunden, eine Erscheinung die auch bei ustpreussischen Exemplaren wiederkehrte, während die westrleutschen (xoldhähnehen das umgekehrte Verhältnis zcigen. Anch sind die östlichen lurehgängiy stärker. Leider habe ich, dnreh missliche Unstinde genötigt, einen nicht unbeträchtliehen T'eil der von mir in Schlesien zusammengebrachten Vogelbälge verïussern mïssen, wober anch meine schöne Goldhälnchensuite zerrissen und in alle W Velt zersplittert wurde, so dass ich jetzt keine nachtrïglichen Untersuchungen imehr vornehmen kann. Ich werde mich aber redlich bemühen, das Versäiunte wieder nachzuholen. Uebergänge aller Art und Verbastardirungen seheinen ïbrigens sehr hïufig zu sein und in Mitteldeutschland überhanpt zu überwiegen. Im Winter scheint die ïstliche Form auch z. T. westwïrts zu verstreichen; ich habe sie z. B. schon hier in Hessen getroffen.

Als Brutvogel ist diese Art in ganz Schlesien gemein, noch häufiger zur Strichzeit. Be'sonder's zahlyeich ist sie in den grossen Nadelwaldungen der Lausitz, der Sudeten und Oberschlesieus rertreten. Im Gebirge geht ristatus nach Gloger bis zu 3800 
Fuss Höhe empor. Kramer beobachtete ilın noch im Knieholz bei der Riesenbaude $(1400 \mathrm{~m})$.

M a ass e von 6 schlesischen Eiern (aus einem Gelege) in mm:

$\begin{array}{lccc} & \text { maximum } & \text { minimum } & \text { Durchschnitt } \\ \text { Länge: } & 14,0 & 13,0 & 13,5 \\ \text { Breite: } & 10 & 10 & 10\end{array}$

26. Regulus iquicapillus (Chr. Brehm, Tem.) 1820. Feuerköpfiges Goldhähnchen.

Symonyma: Sylvia ignicapilla Tem., Chr. Brehm; Regulus mystaceus Tieill.; Regulus pyrocephalus, brachyrhy nchus, Nilsonii Chr. Brehm; Regulus ignicapillus Lic'st., Naum., Glog., Kays. und Blas., A. Brehm, Gieb., Fridr., v. Hom., Mewes, Hart., Gätke, Jäckel.

Kennzeichender Art: Dureh die Augen ein schwarzer, über denselben ein weisser Strich.

Durchschnittsma asse von 2 schlesischen Exemplaren in $\mathrm{cm}$ : Länge $=8,2 ;$ Flugbreite $=14,4 ;$ Schwanz $=3,7$; Schnabel $=1,0 ;$ Tarsus $=1,5 \mathrm{~cm}$.

Dieses Goldhähnehen ist ein westlicher Vogel nnd in Schlesien sehr selten, worauf schon der Mangel an Triviahnamen hinweist. In Obersehlesien seheint es als Brutvogel granz zu fehlen; ich beobachtete es nur eimmal, am 17. April 1391, auf dem Zuge bei Kobier und erlegte zur ziveifellosen Feststellung der Art zwei Exemplare. In Mittel- und Niederschlesien ist es dagegen schon mehrfach brätend gefunden worden, so von A. v. Homeyer bei Glugan, von Krezsehmal in der Görlitzer Heide, von Tobias im Isergebirge mal ganz netuerdings wieder von Kuauthe am Zobten. Das Breslaner Museum besitzt zwei in der Nähe der Stadt erlegte Exemplare. Da ich die Art in Oberschlesien auf dem Durchzuge beobachtete, möchte man vermuten, dass auch sie von Süden aus durch die March-Beczwa-Oder-Furche im Frühjahr nach Schlesien zieht. Uebrigens scheut sie sonst hohe Gebirge keineswey's. Auch ignicapillus bevorzugt die Nadelwaldungen. Im Gegensatz zu der vorigen Art ist sie aber Sommervogel. Der Hauptzug fällt in die Monate März-April und AugustSeptember. R. 'Tobias notirte 1832-35 als frühesten Ankunftstermin den 31. März, als späitesten den 21. und als durchsehnittlichen den 15̃. April. Im Jahre 1840 sah er am t. April die ersten. Uebrigens scheint es öfter's vorzakommen, dass einzelne Exemplare sich auf dem Herbstzug ungebührlich verspäten. So fing Richter noch am 15. Oktober ein Exemplar bei Breslat und R. Tobias schoss ein anderes am 6. November 1 583 . Baer vollends schreibt mir: „Am 2. und 4. December 1890 ein einzelnes Stück, ohne dass eine Meisenschar oder dergl. in der Nühe war. Sonst hier 
noch nicht beobachtet." Wahrseleinlich handelte es sich in diesem Falle um ein kränkliches Exemplar. - A. v. Homeyer sah auf der Tafelfichte am 20. September diese Art.

Gatung: Phylloscopus Boie 1S26. - Laubsänger.

Von den 19 Schwingen sind die 3. und 5. am längsten. Auge klein, Füsse schwächlich; Schmabel dïm, aber hinten verbreitert. Ueber dem Auge ein heller Streifen.

Phylloscopus superciliosus (Gm.) 1788. - Goldhähnchen-Laubsänger.

Es ist zu verwundern, dass dieser asiatische Fremdling bei seinem relativ häufigen Vorkommen in Helgoland noch nicht öfters im Inneren Deutschlands nachgewiesen werden kounte ${ }^{1}$ ). Ich glaube sicher, ihn einmal 1ss!! in der Strachate auf 3 Schritt vor mir gehabt zu haben; leider komute ich nicht schiessen und den Beweis für meine Termutung liefern. Ein alter, sehr kundiger und wahrheitsliebenter Vogelfanger in Breslau versicherte mir auf das bestimmteste, dass er 2 uder 3 Mal einen sonderbaren Vogel, halb Goldhälnchen, halb Laubsänger, gefangen habe. Nach vorgezeigten Abbildumgen bezeichnete er sotort superciliosus als die in Frage stehende Art. Danach möchte man vermuten, dass auch der unbekanntẹ Reyulus, welehen Lübbert 1 soj zwischen ristatus und ignicapillus beobachtete, superiliosus gewesen sein möchte. Künftion in Schlesien beobachtende Ornithologen möchte ich bitten, ihr Augenmerk überhaupt besonders mit auf die dortigen Lanbsïnger zu richten, welche in clieser Hinsicht mit die lohnendsten Vögel sind, aber gewöhnlich viel zu wenig beachtet werden. sänger.

27. Phylloscopus rufus (Bchst.) 1802 . - W idenla ub-

Synonyma: Phyllopneuste rufa Chr. Brehm, Degl., Gieb., A. Brehm, v. IIom.; Curruca rufa Briss.; Sylvia rufa Lath., Gould, Behst., Naum., Gätke; Motacilla rufa Gm.; Ficedula rufa Bchst., Jäckel; Sylvia hippolais Leach; Sylvia collybita Vieill.; Sylvia Ioquax Herb.; Sylvia abietiua Nils., Glog.; Sylvia angusticauda Malh.; Phyllopneuste pinctorum, I'h. solitaria, Ph. mirabilis Chr. Brehm; Asilus rufus Gray; Ficedula acredula Kays. und Blas.; Muscipeta minima Frisch; Regulus einereus L.; Motacilla acredula L., Gm., Behst., Pall.; Sylvia nemorosa Baldust.; Phylloscopus collybita Newes; Phylluseopus rufus Kaup, Radde, Hartert, Pleske.

Trivialnamen: Backöfel, Kilpzalp, Schilpschalp.

1) Am 29. Soptember 1892 schuss ich ein Exemplar in Rossitten auf der Kurischen Nehrung. 
Kenuzeichen der Art: Füsse schwärzlich, die zweite Schwinge steht in ihrer Länge stets zivischen der 6. und 9., ist meist kürzer als die 7. und länger als die 8.

Mehrfach schon habe ich Laubsänger unter Händen gehabt, die ich trotz aller Mühe nicht bestimmen konnte, und die gewöhnlich in der Mitte zwischen rufus und trochilus standen. Meine Ansicht ist die, dass es sich hier um Bastarde zwischen beiden Arten handelt, und dass solche Verbastardirungen weit öfter vorkommen als man bisher anzunehmen geneigt ist. Auch hört man öfters Laubvögel, die dem geübten Ohr des Kundigen sofort durch ihren abweichenden Gesang auttallen. Es erscheint mir gar nicht unwahrscheinlich, dass sich bei genauerem Studium schliesslich doch noch der Phyllosropus silvestris Meisn. als eine gute, durch fortgesetzte Verbastardirung entstandene subspecies herausstellen dürfte. Der Gesang desselben soll aus dem der beiden feststehenden Arten zusammengesetzt sein und lautet nach Friderich wie: "Dididi diediedie diü diü dea dia hoida dimldelm dimldelm dilm." Aus dem Erzgebirge erhielt ich kürzlich einen Phylloscopus, der die Charaktere von rufus mit denen von trochilus und der Grösse von hypolais vereinigte! Deu $R$ addeschen obscurus (Ornis caucasica, p. 233) dagegen habe ich noch nie zu Gesicht bekommen, und wird $R$ adde wohl Recht haben, wenn er denselben nur als eine individuelle, zum Melanismus neigende Varietät ansieht. Es folgen einige Maasse in $\mathrm{mm}$ :

Mass e von 24 schlesischen Exemplaren:

\begin{tabular}{|c|c|c|c|c|c|}
\hline & $\max$ & $\min$. & Durchschn. & $\begin{array}{l}\text { Durehschnittsm. westdeutsch. } \\
\text { Exempl. (Friderich) }\end{array}$ & $\begin{array}{l}\text { Do. ron } 27 \text { russ. } \\
\text { Expl. ( } 1 \text { l } \theta \text { s ke) }\end{array}$ \\
\hline Totallänge: & 114,0 & 108,5 & 112,0 & 108,0 & - \\
\hline Flügelbreite: & 200,0 & 180,0 & 192,1 & $170-190$ & - \\
\hline Schuabel: & 11,3 & 9,7 & 10,6 & $6,0(9,0 \mathrm{Fl})$. & 11,8 \\
\hline T'arsus: & 20,2 & 17,0 & 19,7 & 16,0 & 20,3 \\
\hline Schwanz: & 53,9 & 49,0 & 528 & 45,0 & 54,7 \\
\hline
\end{tabular}

Im allgemeinen schwanken die Grössenverhältnisse bei rufus wie überhaupt bei allen Laubsängern sehr. Doch sehen wir unverkennbar, dass die schlesischen stücke den russischen und namentlich den polnischen Exemplaren näher stehen als den westdeutschen. Die östlichen Lanbvögel sind durchgängig stärker und haben längere schnäbel und schwänze! Ausserdem ist das Gesamtcolorit der nordüstlichen Stücke viel lichter, was namentlich auf der Bauchseite hervortritt. Auf den Durchzuge, aber auch nur dann, traf ich solche Exemplare auch in Hessen. Sie fallen dem Beobachter schon dureh stimme und Wesen auf. Ich glaube, dass eine solche nahe Verwand tschaf't mit der poluischen Avifauna sich für unsere schlesische Ornis in dieser TVeise bei den meisten als Brutvögel vorkommenden Arten wird nachweisen lassen. Schlesien zeigt darin nach meinen Erfahrungen mehr. Terwandtschaft mit 
Polen als selhst mit der benachbarten und uns durch die Forschungen Sich a low s schon gut bekannt gewordenen Mark; besonders dentlich tritt dies hervor, wenn wir bei solchen Vergleichen die mit Brandenburg sehr übereinstinmende Lausitz ausser acht lassen. Sehr auffallend erscheint in obiger Tabelle die kolossale Difterenz in der Schnabellänge. Ich vermute indessen, dass hier ein Irrtum Friderichs vorliegt, welcher übrigens auch nicht angiebt, in welcher Weise seine Schuabelmessungen ausgeführt wurden. Da nun die Pleskeschen Angaben sich durchgängig aut Culmen-Maasse beziehen, so habe ich auch noch einige westdeutsche Exemplare analogen Schnabelmessungen unterworfen und die oben in Klammern beigefügte Zahl erhalten. Bei dieser Gelegenheit möchte ich noch bemerken, dass alle meine Messungen genau nach der Methode von Reichenow ausgeführt wurden (Caban is Journal, 1891. p. 346 ff.)

Sollten weitere Untersuchungen bestätigen, dass wir es in der That auch hier mit einer östlichen und einer westlichen subspecies zu thun haben, so möchte ich für erstere den Namen Ph. rutus Plestiei vorschlagen, da wir erst durch Pleskes genaue Beschreibungen und exalste Messungen wieder auf die Varietäten der Laubsänger aufmer-ssam geworden sind. Es wäre von den Beobachtern künftig besonders auch auf Gesang, Brutgeschäft, Grösse, Form und Zeichnung der Eier zu achten, da sich wahrscheinlich auch hier nicht unbeträchtliche Differenzen herausstellen dürften. Die westliche Form, Ph. rufus occidentalis etwa, würde sich also zuuächst besonders durch ihre geringere Grösse und namentlich durch ihren kürzeren Schuabel und Schwanz sowie durch dunklere Färbung charakterisiren. In Mittel-Deutschland herrschen voraussichtlich Uebergänge vor ${ }^{1}$ ).

Der Zilpzalp ist in den meisten Gegenden Schlesiens ein gemeiner Brutvogel. Bei Breslau war er z. B. ausserordentlich zahlreich Stellenweise dagegen ist er aus mir unbekannt gebliebenen Gründen wieder recht sparsam, so nach $\mathrm{R}$ ichter bei Strehlen und nach Kna nthe am Zobten. Am häufigsten ist er im Mittelgebirge, so namentlich in der Grafschaft Glatz. Auch im Riesengebirge ist er gut vertreten. Gloger meint zwar, or ginge dort nicht hoch himauf, aber neuere Beobachtungen widersprechen dem. So fand Capek ein Pärchen mit Jungen am Ziegenrïcken im Knieholze $(1+20 \mathrm{~m})$ und liürte 2 singende Mäunchen bei der

1) Auch Herr v. Berlepsch hat, wie ich soeben erfahre, die ihm sofort ins Auge fallende grosse Form auf dem Zuge in Hessen erlegt. Skandinavische Exemplare, die ich sah, gehörten ebenfalls derselben an. 
Zugtabelle:

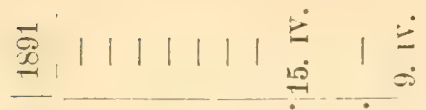

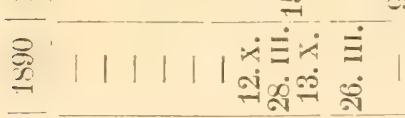

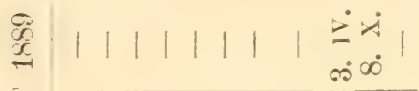

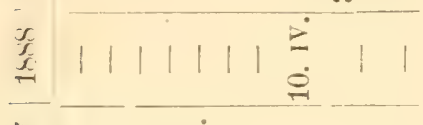

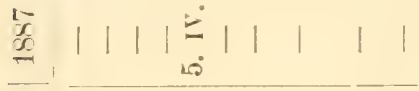

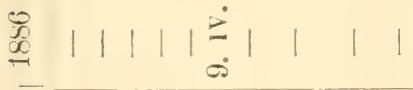

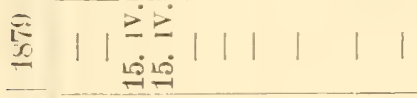

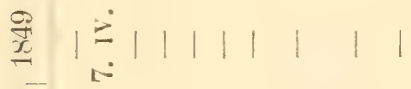

$$
\begin{aligned}
& \text { 学岕 }|1|||||||
\end{aligned}
$$

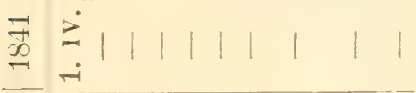

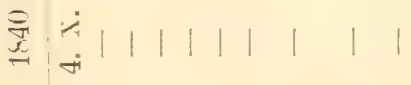

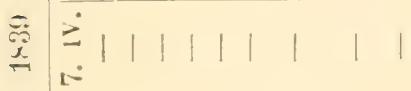

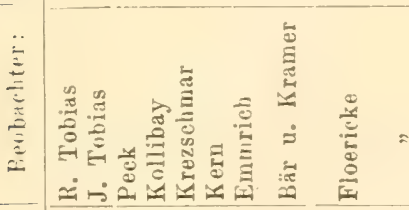

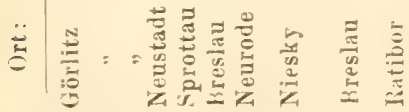


Spindlerbaude, $r$. Tsehusi enliteckte ein Nest in den Siebengründen und Kramer benbachtete nufus äberall im Kuieholz bis zu einer Höhe von 1410$) \mathrm{m}$. Sonderbarer Weise hörte dagegen R. Blasius 1sis auf einer Riesengebirgstour keinen einzigen. Auf der rechten Oderseite wird der Vogel uach der russischen Grenze zu immer seltener. An liebsten hat er gemischte Bestiinde, aber auch Fichtenwaldungen oder Laubhölzer; nur im reinen trockenen Kiefernwalde ist er wirkliei selten. Auf dem Zuge kommt er aber ïberall ror. Trotz seiues zärtlichen Aussehens ist dieser Laubsänger ein recht wetterhartes Vögelchen, das schon Ausgang März oler in deri ersten Tagen April bei uns ankommt und erst spät im Jahre wieder an den Wegzug denkt.

Dieser fleissige Siunger lässt bisweilen auch noch im Herbste sein eiufaches Liedchen erschallen; so hörte ihñ Emmrich noch am 12. Oktober singen R. Tobias fand von 1332-38 als frühesten Ankunftstermin den :30. Mïrz, als spätesten den 16. April, als mittelsten den 2. April. Ru/us macht in Sehlesien 2 Bruten. v. Tschusi fand das zweite Gelege am ?. Jumi, R. Tobias flïge Junge am 23. Mai, ich selbst volle Gelege am 23. und 29. April, 1. und 4. Mai und am 12. Juni.

$\mathrm{M}$ a asstabelle in $\mathrm{mm}$ :

\begin{tabular}{|c|c|c|c|c|c|}
\hline Länge : & $\begin{array}{l}\text { Maasse } \\
\text { max. } \\
15,9\end{array}$ & $\begin{array}{l}\text { von } 42 \\
\text { min. } \\
14,8\end{array}$ & $\begin{array}{l}\text { schles. Eiern } \\
\text { Durchsch. } \\
15,0\end{array}$ & $\begin{array}{c}\text { Durchschnittsm. mãrk. } \\
\text { Eier (s c ha l o w) } \\
14,78\end{array}$ & $\begin{array}{c}\text { Durchschnittsm, von } t 6 \text { poln. } \\
\text { Eiern }(\mathrm{T} \text { a czan ow } \mathrm{k} \text { i) } \\
15,1\end{array}$ \\
\hline ite : & 12,8 & 11,6 & 12,05 & 11,55 & 12,2 \\
\hline
\end{tabular}

Nach seebohm (Brit. birds and their eggs. I, p. 439) ist die Zeichnumg der Eier nach einem doppelten 'Typus ausgeprïgt. Entweder sind dieselben mit feinen bramen Piinktehen besetzt, die auf dem stumpfen Ende einen Kranz bilden oder über das ganz Ei verteilt sind, oller aber die Eier haben rerwaschene dunkelbrame Flecken, zwischen welehen auch violett-graue Felder zu Tage treten. Ich habe seither in Schlesien nu den ersten Typus vertreten gefunden, und möchte deshalb die Herren Oologen bitten, besnders auf diese Verhailtnisse achten zu wollen, da sie sich viclleicht zur Sonderung der subspecies verwerten lassen könnten.

25. Phylloscopus trochilus (L.) 175s. - Fitisla ubsänger.

synonyma: Regulus moncristatus Aldr., Will., Ray., Alb.; Motacilla trochilus L., Buli., Gm.; Ficedula asilus Briss.; Motacilla fiti.: lichst.; Regulus fitis Cur.; I'hylloserpus fitis Chr. Brehm; sylvia trochilus Lath. Naum., Clog., Cätke; Sylvia fitis Behst.; Trenchilas modius Forst, Sylvia melodia Blych, Curuca viridua Inmpl. und lihrbg.; Ihyllopuenste Eversmanni Bonap.; Phyllopneuste fitis Mayer; Ficedula fitis Kroch; Sylvia flaviventris Vieill; 
Sylvia silvestris Meisn.; Sylvia Meisneri Paessl.; Phyllopnenste maior Tristr.; Phyllopneuste icterina Bonap.; Sylvia angusticauda Gerbe; Sylvia tamarixis Cresp.; Phylloscopus Gaetkii Seebohm; Phyllopneuste citrina Menzbier; Asilus trochilus Gray; Phyllopneuste trochilus Blas. und Kays., Fridr., Jäck.; Phyllopneuste fitis, $\mathrm{Ph}$. arborea, $\mathrm{Ph}$. acredula, $\mathrm{Ph}$. septentrionalis, Ph. gracilis Chr. Brehm; Phylloscopus trochilus Boie, Mewes, Radde, Pleske, Hartert.

Trivialnamen: Backöfel, Weidenzeisig, Weidenblatt.

Kennzeichen der Art: Füsse hell. Die 2. Schwinge steht zwischen der 5 . und 6 , oder ist der 6 . gleich.

Masstabelle in $\mathrm{mm}$ :

Totallänge :

Flugbreite:

Schnabel :

Scluwanz:

Tarsus :
Durchschnittsm. westdeutsch.
Ex. nach Friderich 112
185
9
45
18

$\begin{array}{cccc}\text { Maasse von } 45 \text { schles. Ex. } & \text { Durchschnitsm. vou 5t } \\ \text { max. min. Durchschn. russ. Ex. nach Pleske } \\ 126 & 114 & 122,2 & - \\ 201 & 188 & 196 & - \\ 12,5 & 9,5 & 11,0 & 12,1^{\text {\% }} \\ 57 & 46 & 52,3 & 55,7 \\ 20 & 18 & 18,8 & 19,6\end{array}$

Auch hier sehen wir wieder dic interessante Erscheinung vor uns, dass sowohl die Gesamtgrösse wie diejenige des Schnabels und Schwanzes nach Osten hin zunelimen, und dass die schlesichen trochili den russischen näher stehen als den westdeutschen. Sollten künftige Forschungen auch sonstige biologische oder anatomische Unterschiede zwischen den östlichen und westlichen Fitislaubsängern darlegen, so würde auch lifer wohl eine subspecifische Trennung am Platze sein. Schon Gloger weist darauf hin, dass man bisweilen ganz abweichende Gevänge bei dieser Art vernimmt und giebt uns damit einen wertvollen Fingerzeig.

Auch dieser niedliche Laubsïnger belebt mit seinem anmutigen Trillergesang die unterholzreichen Laub- und gemischten Waldungen, die Vorhölzer und Feldbüsche sowie die Gärten und Anlagen von ganz Schlesien. Eine besondere Vorliebe seheint er fuir Birken zu haben. An den Flussufern ist er weniger als die vorhergehende Art. In Mittelschlesien ist er der gemeinste Laubsïnger. Obwohl in der Ebene kein Freund vom Nadelholz, scheut er dasselbe im Gebirge doch durchatis nicht und bewohnt namentlich die Knieholzwaldungen recht zahlreich. Nach ftloger geht er bis zu 4400 Fuss Höhe empor, Kramer beobachtete ihn bis $1400 \mathrm{~m}$ überall im Knicholz. v. Tschusi sah ihu noch oberhalb der Petersbande, Al. v. IJ o me yer am Elbfall im Birkenholz, Rud. Blasius an der neuen schlesisehen Bande (1172) und zahlreich am Elbfall, R. Tobias auf der Tafelfichte und Kern auf dem Kamme des Altvater-Gebirges, Kollibay an der Kirche Wang. Praetorius fand das Gelege am 2., ich 
selbst am 5., 7. und 11. Mai vollzählig. Ob trochilus in Schlesien eine oder zwei Bruten macht, ist mir unbekannt.

Maasse schles. Nester Maasse russ. Nester nach $\mathrm{Pleske}$
Aenssere Breite:
$90-115 \mathrm{~mm}$
$85-123 \mathrm{~mm}$
Innere Breite:
$60-80$
Höhe :
Tiefe:
$28-5 \overline{5}$
$43-67,5$
$48-82$
$32-70$

Leider habe ich die nicht zu entschuldigende Unterlassungssünde begangen, nur von wenigen Vogelarten die Nester zu messen. Doch ergiebt der Vergleich mit den Untersuchungen Pleskes, dass die deutschen Nester durchgängig dünnere Wände und geringere Tiefen haben, was in Westdeutschland noch mehr hei'vortritt und in der grösseren Rauhigkeit des russischen Klimas seine naturgemässe Erklärung finden dürfte.

Masstabelle in $\mathrm{mm}$ :

\begin{tabular}{|c|c|c|c|c|c|c|}
\hline & $\begin{array}{l}\text { Durchschnittsm. } \\
\text { märk, Eier nach } \\
\text { Schalow }\end{array}$ & $\begin{array}{l}\text { Maasse } \\
\text { max. }\end{array}$ & $\begin{array}{l}\text { v. } 35 \mathrm{~s} \\
\text { min. }\end{array}$ & $\begin{array}{c}\text { schles. Eiern } \\
\text { Durehschn. }\end{array}$ & $\begin{array}{l}\text { Durchsch. v. } 16 \\
\text { poln. Eiern } \\
\text { (T a czan.) }\end{array}$ & $\begin{array}{c}\text { Durchschn. v. } 22 \text { Eiern } \\
\text { aus Petersburg } \\
\text { (B } \mathrm{i} \text { a } \mathrm{n} \text { b } \mathrm{i})\end{array}$ \\
\hline & 15,4 & 16,5 & 14 & 15,6 & 15,6 & 16,1 \\
\hline & 11,6 & 13 & 11,5 & 12,5 & 129 & 12,2 \\
\hline
\end{tabular}

Also auch hier wieder eine geringe, aber regelmässige und unverkennbare Grössenzunahme nach Osten! Die Eier aus dem St. Petersburger Gouvernement erscheinen merkwürdig schlank. Die Hauptzugzeit fällt auf Anfang April und Anfang Oktober, worïber die folgende Tabelle nähere Auf'schlüsse giebt. 


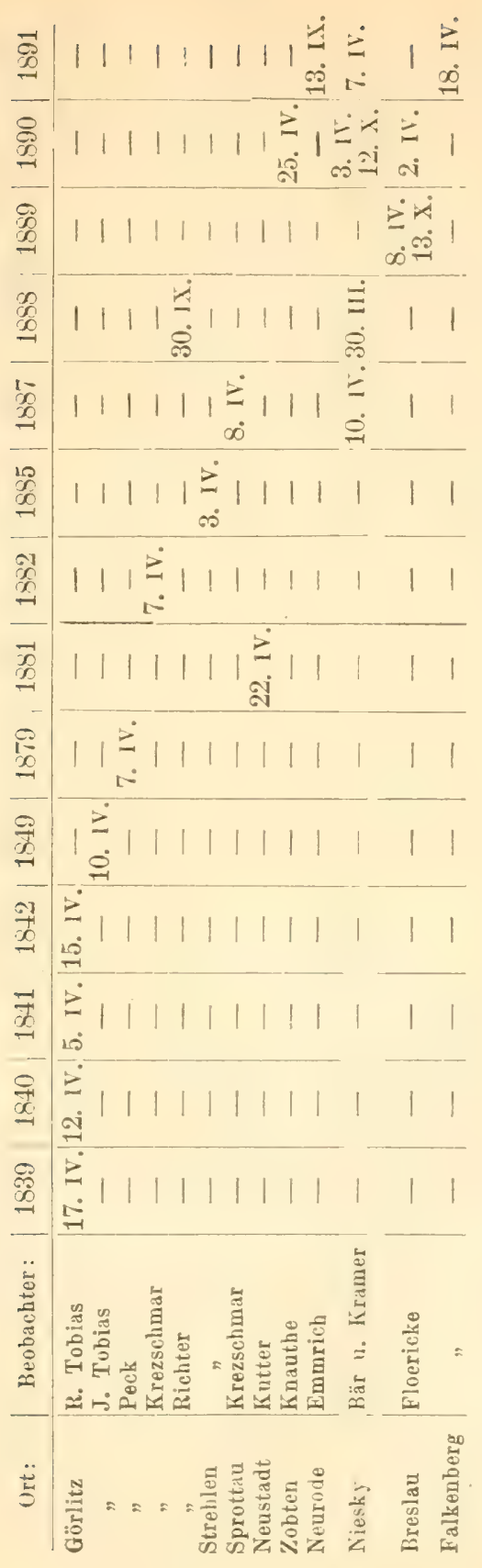


R. Tobias fand von 1832-33 als frühesten Ankunftstag den 31. März, als spätesten den 14 . und als mittelsten den S. April. Auch der Fitis singt noch auf dem Wegzuge. sänger.

Phylloscopus Bonellii (Vieill.) 1319. - Berglaub-

Gloger hörte im Jahre 1836 in einem Fichtenwäldehen des Riesengebirges einen ihm fremden Laubvogelgesang, hinter dem er $\mathrm{Ph}$. Bonellii vermutet. Sonst liegen keinerlei Nachrichten iiber das Vorhandensein dieser Art im Riesengebirge vor. Dieselbe würde aber wohl dem sangeskundigen Ohr eines Al. v. Homeyer kaum entgangen sein. Ich selbst konnte das Riesengebirge leider nur im Spätsommer besuchen, als die Vogelgesänge bereits verstummt waren.

29. Phylloscopus sibilator (Bchst.) 1793. - WaldLa u bsänger.

Synonyma: Motacilla sibilatrix Bchst.; Asilus sibilatrix Behst.; Sylvia Alavicola Vieill.; Ficedula asilus maior Briss.; Motacilla sylvatica Turt.; Trochilus maior Furst.; Sylvia sibilans Blyth; Sylvia prasina Rouill,; Sylvia sylvicola Lath., Mont.; Phyllopneuste sylvicola Chr. Brehm, Calb., Gieb.; Sylvia sibilatrix Beh̆st., Naum., Br., Glog., Gätle; Ficedıla sibilatrix Koch, Kays. und Blas., Fridr., Jäckel; Curruca sibilatrix Elem.; Sibilatrix sylvicola Kaup; Phyllopneuste megarhynchus Chr. Brehm; Phyllopneuste sibilatrix Chr. Brehm, Degl., A. Brehm, v. Hom.; Phylloscopus sibilatrix Blyth, Pleske; Phylloscopus sibilator Mewes, Hartert.

Auch dieser Laubvogel heisst beim schlesischen Volke nach der Bauart seines Nestes "Backöfchen."

Kennzeichen der Art: Bei sililator ist im Gegensatze zu den bereits besprochenen Pluylloscopus-Arten die 1. Schwinge kürzer als die Deckfedern der Primärschwingen. Die 2. Schwinge rangirt zwischen der 4. und 5. oder ist gleich der 4 .

Diese Art scheint viel weniger zu variiren als trochilus und rufus, und auch die Grössenverhältnisse erweisen sich als ziemlich constante. Zwischen den Messungen von Friderich, Pleske u. a. und den meinigen vermochte ich keinerlei Abänderungen aufzufinden. Nur die Schnabcllänge crscheint verschieden, indem die östlichen Vögel zumeist einen etwas längeren Schnabel besitzen als die westlichen und demnach vielleicht zu der $\mathrm{Brehm}$ schen subspecies megurhynuhs zu rechmen sein möchten. Friderich giebt $9 \mathrm{~mm}$, Ples ke dagegen $13 \mathrm{~mm}$ als die gewöhnliche Schnabellänge an, während meine schlesischen Exemplare im Durchschnitt $12,5 \mathrm{~mm}$ messen. 
Ma asse von 13 schlesischen Stücken in $\mathrm{mm}$ :

$\begin{array}{lccc} & \text { maximum } & \text { minimum } & \text { Durchschnitt } \\ \text { Länge: } & 125 & 115 & 120 \\ \text { Flügelbreite: } & 210 & 190 & 198 \\ \text { Schnabel: } & 12,0 & 14 & 12,5 \\ \text { Schwanz: } & 53 & 48 & \text { อ1 } \\ \text { Tarsus: } & 20 & 17,5 & 18,6\end{array}$

Auch die schwanzlïnge erscheint in Uebereinstimmung mit Pleske $(40,5-5 t \mathrm{~mm})$ ein wenig beträchtlicher als wie sie Friderich angiebt $(48 \mathrm{~mm})$.

Der Waldlaubsänger ist in Schlesien nicht gerade häufig, was besonders ron den ebenen und waldarmen Teilen Mittel- und Niederschlesiens gilt. Am häufigsten findet er sich noch in den Waldungen der Vorberge. Hier liebt er ausgedehnte Nadelhölzer, besonders wenn dieselben aus Fichten und Kiefern gemischt sind und eingesprengte Buchen enthalten, wo er lichte Stellen und das Stangenholz aufsucht, das dichte Gebüsch dagegen nach Möglichkeit vermeidet. In reinen Laubwäldern ist er viel seltener und in den sumpfigen Auwaldungen fehlt er fast ganz. Auf dem Zuge dagegen findet man ihn auch in kleinen Feldhölzern, selbst in Gïrten und einzeln stehenden Hecken und Gebüschen. Besonders häufig ist sililator als Brutvogel im Hochwald und bei Glogau (A. v. Homeyer) sowie in der Grünberger Gegend (Baer, L. Tobias). Ins eigentliche Hochgebirge seheint er nicht hinaufzugehen; doch beobachtete $A$. v. Home yer ihm noch cinzelu am Elbfall und R. 'T'obias auf dem lserkamm. Unter den echten Laubvögeln ist dieser der weichlichste, weshalb er erst in den letzten Tagen des April oder in den ersten des Mai auf den Brutplätzen eintritft, worüber die Tabelle das Niihere angiebt.

\begin{tabular}{|c|c|c|c|c|c|c|c|c|c|}
\hline Ort: & Beubacliter: & $1=41$ & 1879 & lim $\rightarrow+j$ & Iילt & 185. & 1ऽ৬! & $1 \leqslant 90$ & 108 \\
\hline & & $24 . \mathrm{IV}$. & 00 & & - & - & & & \\
\hline & & - & 29. IV. & - & $\sqrt{y}$ & $\sqrt{\mathrm{x}}$ & - & - & \\
\hline & & - & - & $22 . \mathrm{IV}$ & - - & 2.1 & - & $\begin{array}{r}20.11 \\
-\end{array}$ & \\
\hline & Floericke & - & - & - & -_- & - & 29. IV & $27.1 \mathrm{~V}$. & \\
\hline
\end{tabular}


R. Tobias notirte von 18:32-38 als frühesten Ankunftstag den 24. April, als spätesten den 3. und als durehschnittlichen den 1. Mai. I as [)atum des IVegzuges ist mir nicht näher bekannt geworden; doch dürfte derselbe zumeist schon Ende August erfolgen. In vielen Gegenden schlesiens kommt silnilator überhaupt nur auf dem Durchinge vor, so nach Knathe am Zobten. Nur eine Brut. L. Tobias fand bei Sedezyu einige Pärchen, die in reinen Kiefernwalde anf kahlen Plïtzen ohne Unterholz briiteten; ein von ihm entdecktes Nest stand ganz frei auf der Elde und war mit Nadelstreu bedeckt. R. Tobias fand am 16. Juni ein volles Gelege und am 1है. schon nackte Junge.

Maasse von 12 schlesischen Eiern in mm:

$\begin{array}{lccc} & \text { maximum } & \text { minimum } & \text { Durchschnitt } \\ \text { Länge: } & 17,5 & 15,0 & 16,1 \\ \text { Breite: } & 12,5 & 12,0 & 12,4\end{array}$

Gattung: Hypolais (Hipulais) Brehm 152s. - Gartensäuger.

Schnabel breiter und länger als bei Phylloscopus und mit starken Borsten rersehen. Bei der folgenten Art steht die 2. Sulnvinge ihrer Grösse nach zwischen der 4. und 5̇. Füsse ziemlich kräftig.

30. IIypolais philomela (L.) 175x. - Gartenlaubrogel.

Symonyma: Dotacilla hypolais L., Buff., Gm., Behst., Fischer; sylvia icterina Vieill., Giebel; Curruea arundinacen Briss., Sylvia hippolais Behst., Lath., Naum., Glog., Meyer, Güitke; Ifypolais salicaria Ghr. Brehm, v. Hom.; Ficedula septima Aldr., Ray; Ficedula hypolais Blas., Fridr., Jäckel; Ficedula hypolais fulvipes Schleg.; Sylvia obseura smith; Hypolais faniliaris Tacz.; Ilypolais icterina Gerbe, Ingl., Desm., A. Brelnn, Rchw., Mewes, Pleske; Hypolais albiceps, H. media, H. planiceps, H. hortensis, II. vulgaris Chr. Brehm; Ilypolais philomela Hart.

Trivialnamen: Gelber Sticherling, Ixlein, Sprachmeister, Spötterling. Oberschlesisch-pohnisches Idiom: Zaganiac\%.

Kennzeichen der Art: Siehe die Gattungsmerkmale, da nur diese eine Art in Dentschland. In Gesang, Grösse Nestbau und Eifirbming weicht Hypolais gleichfalls sehr von den Phylloscopus-Arten ab.

Masstabelle in $\mathrm{mm}$ :

\begin{tabular}{|c|c|c|c|c|c|}
\hline Lïnge : & $\begin{array}{l}\text { Maasse } \\
\max , \\
146\end{array}$ & $\begin{array}{l}\text { von } 58 \\
\text { min. } \\
134 \\
200\end{array}$ & $\begin{array}{l}\text { echles. Ex. } \\
\text { Durchischn, } \\
144,5\end{array}$ & $\begin{array}{c}\text { Durchschnittsm, westdeutsch. } \\
\text { Ex. (Frid erich) } \\
135 \\
000\end{array}$ & $\begin{array}{l}\text { Durchschnittsm, v. } 11 \\
\text { russ. Ex. nach Pleske } \\
-\end{array}$ \\
\hline Flugbreite: & 245 & 220 & 233 & 222 & \\
\hline Schnabel: & 17 & 14 & 15,4 & 12 & 16,8 \\
\hline Schwauz: & 59 & 52 & 56 & fast 50 & 57,1 \\
\hline Tarsus: & 22 & 21 & 21,9 & 22 & 21,7 \\
\hline
\end{tabular}


Auch hier wiedcr annälıernd dieselben Maassverhältnisse, wenn auch nicht in besonders ansgeprägtem Grade. Auch die Farbe der Beine scheint zu variren und im Westen im allgemeinen heller zu scin. Leider habe ich es unterlassen, darüber genaue Notizen zu machen und demgemïisse Untersuchungen anzustellen.

Hypolais ist einer unserer lräufigsten Vögel und so fabelhaft viel Bastardnachtigallen wie in den feuchten Awwäldern Mittelschlesiens habe ich noch in keiner anderen Gegend Deutschlands wieder gefunden. Bei Breslau kommen nach Mo hr durchschnittlich etwa 12 Pärchen auf den Morgen. Wenn man den Berichten der alten schlesischen Autoren glauben darf, so ist der Vogel früher nicht so häufig gewesen, und anch jetzt ist noch eine fortdamernde Lunahme zu verzeichnen. In manchen Gegenden ist Hypolais überhaupt erst ganz neuerdings cingewandert, so nach Knathe am Zobten und Geiersberge. Nach dem Gebirge zu wird der Bestand raseh dünner und in cien Sudeten selbst gehen die Gartensänger als Brutrögel nach $\mathrm{K} \mathrm{r}$ a $\mathrm{m}$ r nicht leicht über cine Höhe von $700 \mathrm{~m}$ hinauf. Sie halten sich hier an die geschützten Thäler und finden sich besonders in dem des Zacken wic überhanpt in ganzen Hirschberger Kessel ziemlich luäufig (A. v. Homeyer, Koll ibay). Bekauntlich ist dieser geschätzte Sünger eine Zierde unserer Anlagen und grösseren Gärten. Sonst findet er sich namentlich in feuchten Laubwaldungen, kleinen Feldhölzern, auch auf Hutungen und dergl. 
Zugtabelle:

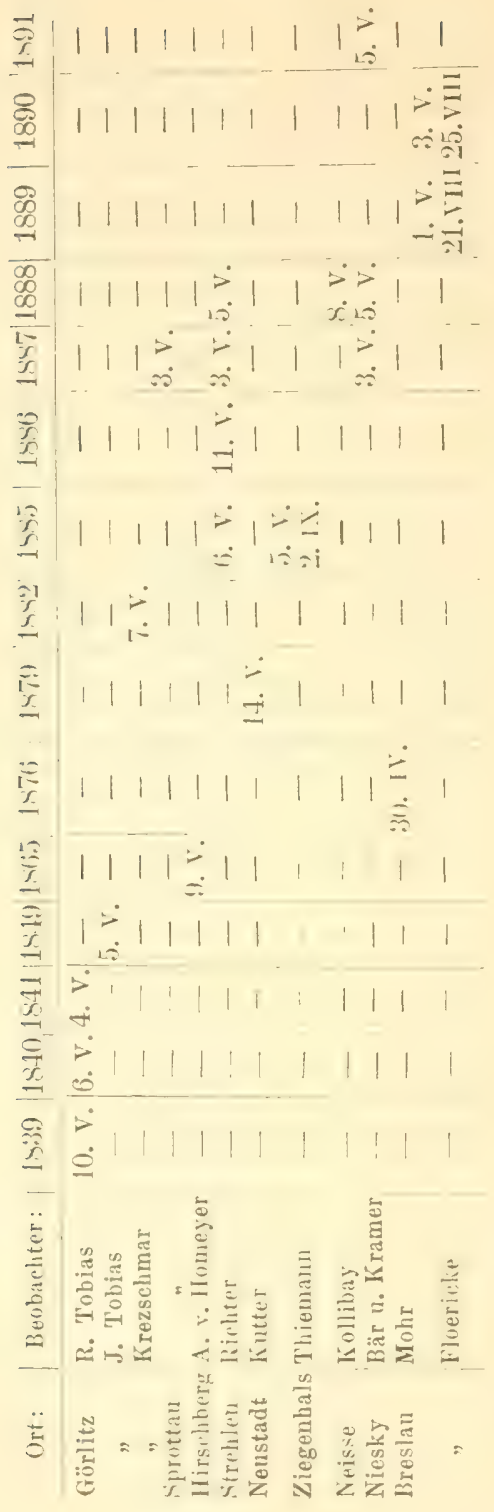


R. To b i as notirte von 183:- -38 als frühesten Ankunftstermin den 4 , als spiitesten den 14. und als mittelsten den 9. Mai. Die Weibchen tretfen ea. s-10 Tage später ein als die Männchen. Entsprechend seinem kurzen Sommeraufenthalte macht Hypolais, sofern er nicht gestïrt wird, nur eine Brut. Doch fand Praetorius auttallender Weise einmal noch am 18. Juli frische Eier. Brutdaucr 13 Tage. Das Nest steht gern auf jungen, dichten Fichten (MI $\circ \mathrm{r}$ ); ich fand es mehrfach auch auf ausschlagende Kopfiveiden aufgesetzt; Kollibay neunt Kopfrosen als den gewölnulichsten Standort. Es ist bekanntlich ein hübscher Bau und bei uns in sehlesien fast immer mit Birkenrinde durchwirkt, worauf zuerst L. Tobias hingewiesen hat.

M a asse von 38 schlesischen Liern in mm:

$\begin{array}{lccc} & \text { maximum } & \text { minimum } & \text { Durchschnitt } \\ \text { Länge: } & 19 & 17 & 18 \\ \text { Breite: } & 14,5 & 12 & 13,5\end{array}$
Eier.

A. v. Homeyer fand abweichend ammerartig gestrichelte

Volle Gelege entdeckten K utter am @. Juni und 30. Mai, Praetorius am 30. Mai, Kollibay am 11. und 16. Juni, ich selbst am 29. Mai, 2., 3., B., 14. und 17. Juni; nack te Junge fand Kutter am 15. Juli.

$\mathrm{M}$ a a s e von 6 schlesischen Nestern in mm:

$\begin{array}{cc}\text { Aeussere Breite: } 85-95 & \text { Höhe: } 55-75 \\ \text { Innere Breite: } 45-60 & \text { Tiefe }: 40-50\end{array}$

Gewöhnlich ('nthialt das Gelege schlesischer Gartensänger 5, seltener 4 oder (j) Eier. MIanche Imker behaupten, dass dieser Vogel den Bienenstöcken empfindlichen Abbruch thue, was ich aber nie wahrgenommen habe und anch nicht für wahrscheinlich halte.

Gattung: Locustella Ka up 1529. Heuschreckensïnger.

Die mittelsten Schwanzfedern verlaingert und sehr breit, Schwanzdeckfedern ganz ungewölınlich lang. Zehen lang. Flügel kurz und rund, Schivingen nicht eingeschnürt, die 2. und 3. am längsten. Eigentümlicher Schwirrgesang.

31. Locustella naevia (Bodd.) 1783. - HeuschreckenRohrsänger.

Synonyma: Sylvia locustella Penn., Lath., Naum., Gätke; Curruca cinerea naevia Briss,; Motacilla naevia Bodd.; Locustella acicula Ray; MIuscipeta locustella, MI. olivacea Koch; Acrocephalus fluviatilis Naum.; Calamoherpe locustclla Boie; Calamoherpe tenui- 
rostris Chr. Brehm; Calamodyta locustella Gray, Gieb.; Salicaria locustclla Suby; Loenstella Rayi Gould; Locustella vera, L. anthirostris, L. teninirostris Clir. Brehm; Loenstella locustella Bon.; Degl.; Lusciniola laneenlata (Xray; Acrocephalus locustella Rehw., Fridr.; Threnetria locustella Schaner; Locustella naevia Degl., A. Brehm, v. Hom., Mewes, Hartert.

'T' r i vi a l m a m en fülıren die so versteckt lebenden LocustellaArten in Suhlesien nicht und sind äberhaupt daselbst trotz ihrer relativen Häufigkeit und des autfallenden Sohvirrgesangs dem gemeinen Mann gänzlich unbekannt.

Kennzeichen der Art: Die 2, und 3. Schwinge sind grleich lang; der Rückes gefleckt. (1)a infolge des vielen HerumEriechens in dem scharfen und schueidenden Rohr das Gefieder und namentlich auch die grossen, beim Hüpten gelüfteten Schwungfedern der Rohrsänger häufig sehr abgenutzt und zerstossen sind, so verwischen sich bisweilen dic S'chwingenverhältuisse und erseheint es deshalb nicht angiingig, nach diesen allein zu bestimmen.)

Maase von 12 schlesischen Exemplaren in $\mathrm{cm}$ :

$\begin{array}{lccc} & \text { maximum } & \text { minimum } & \text { Durchschnitt } \\ \text { Länge: } & 14,0 & 12,5 & 13,4 \\ \text { Flugbreite: } & 21,4 & 19,2 & 20,1 \\ \text { Schwanz: } & 5,9 & 5,0 & 5,5 \\ \text { Schnabel: } & 1,0 & 1,3 & 1,5 \\ \text { Tarsus: } & 2,1 & 1,9 & 2,0\end{array}$

Lokalvarietäten dieses hohrsingers sind mir nicht bekannt geworden. Friderich giebt als sehnabeliänge ur $1,0 \mathrm{~cm}$ an. Vielleicht haben wir es demmach in suhlesien mit der $\mathrm{Br}$ ehmschen subspecies temirostic zu thun, was ich bei dem geringen Material, welehes mir zur Verfügung stand, nicht entscheiden kounte.

Der Heuschrcekensänger gehört zu denjenigen Vögelu, welche viel häufiger sind, als man gewö̀nlich annimmt, un die sich nur der Beobachtung vielfach zu entziehen pflegen. In Sehlesien ist ("r an manchen Oertlichkeiteu durchaus nicht selten, und man darf behaupten, dass sein Bestaur im Zunehmen begriften und er überhaupt bestrebt ist, seinen Verbreitungsbezirk zu vergrössern. Dies könnte von einem an einen so bestimmten Aufenthaltsort gewöhnten Togel wunderbar erscheiuen, weun ihm nicht sein ausserordentliches Anpassungsvernögen an veränderte Verhältnisse zul statten kïme. Gloger fiand 15.1; unseren Vogel bei Neisse ziemlich häufig auf und gleich darauf auch bei Breslau, wo er an der Oder die Standplätze von + Pärchen in geringer Entfernung von cinander constatirte. Namentlich zwischen Breslau und der Strachate mol in der letyteren selbst hat sich der Bestand dieses 
Rohrsängers seitdem stetig gehuben, was auch Tiemann 1565 betont. Deshalb kommte auch A. V. Home yer $181 ; 7$ schreiben: „Bei Breslau sehr häufig." Uebrigens schwankt der örtliche Bestand aller schwirrenden Rohrsainger von Jahr zu Jahr ganz atusserordentich. Die's gilt namentlich auch von fluvialitis. Yon naevia fand A. v. Homeyer 1s62 bei Glogau ea. 20) Brutpärchen, 181,6 dagegen nur 2 . i)erselbe Furseher constatirte naexia noch für Wilandsdorf und für Reindörfel in del Graf'schaft Glatz. In der Gegend von Neusalz i>t ier. Togel nach L. T'o bi as nieht selten, häutiger noch im L'rimekenauer Bruch. Während naevia also im ganzen Oderthale eine reguhniissige Erscheinnmg ist, ist er in der Lausitz auscheinend viel sparsamer vertreten. Nur R. Tobias erlegte ihn wiederholt im Herbste und einmal auch an 13. Mai 1831 abends 7 Uhr in einem Roggenfelde ein schwirrendes Männchen, ohne aber ein Nest zu entciecken. Nach A. v. Home yer hat der Heuschreckensinger aber doch einmal in der Lausitz genistet und zwar auf ziemlich freiem Terrain. Ich weiss nicht, worauf sich diese Angabe bezicht. Die neneren Latsitzischen Forscher erwähmen den Heuschreckensïnger überhaupt nicht mehr, und es scheint, als ob er sich auch auf dem Zuge ziemlich streng an das Oderthal hicle. Ich selbst fand ihn recht häufig bei Breslau und sparsaner in der Bartsohniederung. Inbezug auf seinen Aufenthaltsort ist dieser Sänger nicht allzu wählerisch, zeigt aber häufig eine gevisse Lamnenhaftigkeit. In feuchten, sumptigen Auwäldern mit Dornengestrüpp ist er gern und bevorzugt hier freie Wiesen lund Plätze mit einzeln stehenden Gebüschen. Nach A. V. II om y er liebt er noffene, mit hohem

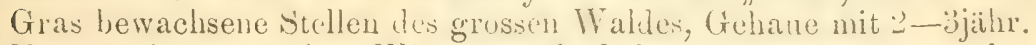
Nachwuchs, sumplige Wicsen un! Gebüsch." Stets muss das Terrain feucht seiu. Damn hudet man ihn aber auch in Getreideund Kleefeldern und auf' dem Zuge in Kraut- und Kartutfelä:keru. L übbert fand 1 s.j bei Breslau ein Nest in cinem Kleetelde, in dessen Nähe es weder ein Gestriuch, noch ein Geviusser, noch überhaupt sumpfiges Terrain gab. Auf dem Zuge ist der Henschreckensänger schon in den meisten Gegenden Schlesiens machgewiesen worden, so von R. Tobias für Görlitz, von Thiemann für Ziegenhals, von v. Me yerinek für Canth, von Kuauthe für den Zobten u. a. Bisweilen ist der I)urehzug (in ziemlich starker. So schoss Gloger eimmal bei Neisse :3 Stück nahe bei und gleich hinter einander. Dic Ankunft erfolgt Anfang Mai, der Wegzug während des september. Bei Breslau notirte ich die Ankunft am 1. Mai 1859 und am 3. Mai 18!10. Durehschnittsmaasse von 4 schlesischen Eiein - 16,9 $-12,0$ mm. Fridr. giebt an, dass naeviu 2 Bruten mache, was mir für schlesien wenigstens ziemlich unwahrscheinlich vorkommt. Charakteristisch für den Vogel ist nach I i k k r sein ausserordentlicher Speichel- 
überfluss. Der höchst eigenartige resang der schwirrenden Rohrsïnger, der dem, welcher ihn eimmal gehört hat, stets im Ohre liegen wird, ist schon oft genug geschildert worden, und besser, als ich es zu thm rermöchte. Am bezeichnendsten und prägnantesten drückt sich meine' Ansicht nach A. v. Homeyer aus, wenn er sagt: nutevia und hesinioles schwirren, resp. schmuren in ir und ar einsilbig, und flucratilis zittert in e und r zweisilbig."

3:. Locustella Inscinioides (Sa vi) 1824. - NachtigallRohr sänger.

Synonyma: Sylvia luscinioides Savi, Namm., Blas.; Calamodyta luscinioides Gray, Gieb.; Pscudoluscinia Sinvii Bon.; Salicaria luscinioides Kays, und Blasins; Lusciniopsis Savii Bon.; Potamoëdus luseinioides Bon., Newes; Cettia luscinioides Gerb.; Lusciniola Savii Bon.; Lusciniopsis luscinioides Degl.; Pseudoluscinia luscinioides Gray; Threnetria acheta Schaner; Acrocephalus luscinioides Fridr.; Locustella luscinioides Kaup, A. Br., v. Hom., Hartert.

Kennzeichen der Art: Die - Schwinge am längten. Oberund Unterseite ungefleckt, nur an den Halsseiten wenige, unscheinbare und sehr kleine Flecken.

Schon als ich als Obertertianer längere Zeit in Ostgalizien weilte, hatte ich ein resges Interesse für und in Verhältnis zu meinem Alter auch recht leillich Kemtuisse in der Vogelwelt. Damals hörte ich dort wiederholt den eigenartigen Schurrgesang eines Rohrsängers, den ich nach der Beschreibung in Brehms Tierleben für naevia hielt, aber nicht erlegte. Die unvergesslichen Töne blieben mir für immer im Ohr haften. Sjuäter kam ich dann nach Thüringen, wo ich überhaupt keine Gelegenlseit hatte, schwirrende Rohrsainger zu beobachten unl von da nach Breslau, wo sich mir dieselbe in reicherem Marase hot. Mit Wohlgefallen lauschte ich auch hier wieder den sonderbaren Liedern der interessanten Vögel, aber dieselben kamen mir doch anders vor als das schumeren, welches nir immer noch von Ostgalizien her im Ohre lag. Ich schoss und nutersuchte nun einige dieser mich in so holiem Grade f'sselnden linhrsänger, bestimmte sie als nacria und fluviatilis und lernte beide Arten näher kennen. Da höre ich am 5. Nai 1 s.y in der Strachate einen Vogel schwiren, bei dessen Lauten ich mir sofort sage: Das ist der Rohrsänger, den Du von Ostgalizien her kiennst. Nach endlosen Bemühungen bin ich so glücklich, ihm zu schiessen und den er'sten schlesischen ${ }^{1}$ ) lusrinioides in ihm zu coustatiren. Am 27 . Nai hörte ich dann ein zweites Männelseu bei Radziunz schwirem, opfterte es der Wissenschaft und entdeckte nachher auch noch das mit 4 weisslichgrauen, dunkler gewölkten Eiern belegte, dicht über dem Borten aus dïrren Schilfblätern crbaute. Nest. Seitdem habe ich

1) und auch wohl deutschen! 
den herrlichen Vogel nicht wieder beobachtet und auch keine weiteren Nachrichten über sein Vorkommen erhalten. Der Nachtigallenrohrsänger ist ein sïdeuropäischer Vogel, welcher aber noch in Galizien ziemlich häufig vorkommt und sich sogar in Holland angesiedelt hat. Im vorigen Herbst soll er auch in Ostpreussen erlegt worden seiu. Sein Vorkommen in Schlesien kann eigen tlich nicht allzusehr überraschen, zurnal luscinioides bekanntlich zu den am schwierigsten zu beobachtenden Vogelarten gehört und deshalb häufig übersehen werden mag. Als ich von Thüringen nach Breslau übersiedelte, sagte mir mein verehrter ornithologischer Lehrer, Prof. Liebe, noch beim Abschied: "Achten Sie besonders auf luscinioides; der'selbe mus meiner Ueberzeugung nach in Schlesien vorkommen." Die Ereignisse zeigten, wie sehr dieser scharf blickende Forscher auch hier wieder Recht behalten hat. Man kann sich nun das Vorkommen des Vogels in Schlesien auf zweierlei Weise erklären. Entweder ist ein Trupp dieser Rohrsänger im Frühjahr 1890 auf dem Zuge durch irgend welche Einflüsse der Witterung nach Schlesien verschlagen worden und hat sich z. T. daselbst auch hïuslich niedergelassen, oder aber luscinioides gehört zu denjenigen Arten, welche ständig und erfolgreich bestrebt sind, die Grenzen ihres Verbreitungsbezirkes weiter hinauszuschieben. Mir will die letztere Erklärung als die wahrscheinlichere erscheinen. Wie dem aber auch sein mag, so rechne ich jedenfalls den erstmaligen Nachweis des brütenden luscinioides in Schlesien und damit auch wohl zum ersten Male in Deutschland stets zu meinen schönsten ornithologischen Erinnerkingen. lch möchte übrigens fast vermuten, dass luscinioides auch schon an anderen Punkten über die deutschen Grenzen vorgedrungen ist und bisher nur durch seine so überaus versteckte Lebensweise der Aufmerksamkeit der ohmebin zu dünn gesäten Beobachter entgangeu ist. Meine beiden schlesischen Exemplare zeigten folgende Maasse: Totallänge $=13,9 \mathrm{~cm}$; Schwanz $=$ $6,5 \mathrm{~cm} ;$ Flugbreite $=22 \mathrm{~cm} ;$ Flügellänge $=7 \mathrm{~cm} ;$ Schnabel -. $1,3 \mathrm{~cm}$; Tarsus $=2,2 \mathrm{~cm}$. Maasse von $t$ schlesischen Eiem = $20+16 \mathrm{~mm}$.

33. Locustella fluviatilis (IV o lf.) 1810. - Flussohrsänger.

Synonyma: Sylvia fluviatilis Mayer und Wolf, Naum, Glog., Gätke; Acrocephalus stagnatilis Naum.; Acrocephalus fluviatilis Naum., Rchw., Fridr.; Calamodyta fluviatilis Gray, Gieb.; Calamoherpe fluviatilis Chr. Bıehm; Salicaria fluviatilis Kays. und Blas.; Lusciniopsis fluviatilis Bon.; Potamoëdus fluviatilis Gray, Mewes; Threnetria gryllina Schauer; Locustella strepitans Chr. Brehm; Locustella cicada Hausm.; Locustella fluviatilis Gould, A. Brehm, v. Hom., Radde, Hartert. 
Kennzeichender Art: Rücken ungefleckt. Kehle und Kopf dentlich gefleckt. Die sehr verlängerten unteren Schwanzdeckfedem mit breiten weissen Enden. Die 2. Schwinge am längsten. Grösse über $14 \mathrm{~cm}$.

Maasse von 6 schlesischen Exemplaren in $\mathrm{cm}$ :

Länge:

Flugbreite:

Schwanz:

Schnabel:

Tarsus: maximum

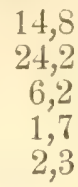

minimum

14,1

23,0

$\overline{5}, 4$

1,5

2,1
Durchschnitt

14,4

23,6

5,7

1,6

2,2

Die Strachate bei Breslau ist schon seit lange als einer der wenigen deutschen Brutplïtze des Flussrohrsïngers bekannt. Gloger erlegte hier im Frïhjahr 1520 das erste schlesische Exemplar, ein Männchen von ansgezeichnet dïsterer Farbe. 1331 hörte er mehrere schwirrende Männchen an der Oder und Glatzer Neisse. Dann fehlt es an Nachrichten über unseren Vogel bis zum Jahre 1865 , wo ihm Arlt wieder in der Strachate aufiand; $1866^{2}$ und 1367 fehlten sie daselbst; dafür beobachtete Ar lt im letzteren Jahre 2 Stiick im Ottwitzer Holz. 1 slis waren 2)-3, 1869 dagegen wohl 10 Pärchen in der Strachate. Dieser Bestand hiclt sich, und A. v. Homeyer schrieb 1571 ,vielfach in der Strachate" und 1886 ,ist in schlesien recht häufig!" Ich selbst beobachtete 1859 in der Strachate nur 3-4, 1 S. stens 12 Paare. Der Bestand scheint also auch bei dieser Art sehr zu schwanken. Ausser bei Breslau beobachtete A. v. Homeyer unseren Vogel auch noch I:2 Meilen südwestlich davon bei Schweidnitz in dem nördlich davon gelegenen Walde von Königszelt uud zwar auf cinem Platze des Waldes in cinem 2-3jährigen Gehau. Es waren zwei singende Hämnchen, die derselbe dort, ohne das Nest zu fiuden, wochenlang fast täglich hörte. Keru bemerkte den Flussrohrsänger im sommer 1835 an der Glatzer Neisse und deren Nebenarmen unil Kollibay hörte cbendaselbst im Mai 1Ssti 3-t stiick und ebenso in den folgenden Jahren. Am 12. Mai $15 y$ erlegte er bei Neisse ein schwirrendes Männchen, welches leider im Sumpte verloren ging. Sonst sind mir keine weiteren Brutplätze des Flussrohrsängers in Schlesien bekaunt gevorden, loch stimme ich durehaus A. v. Home e er bei, wenn er sagt: rischeint seinen Verbreitungsbezirk auszudehnen und ist viel häufiger als man gewöhnlich amnimmt. Er gehört eben zu den Vügehn, welche häufig ïbersehen und überhïrt werden." Bei Breslau ist er übrigens nicht nur in der Sirachate zu finden sonderu auch vis it vis auf dem anderen Oderufer und ziemlich zahlreich bei KJ. Tschensch an der Ohle und deren Verzweigungen. Ueppig feuchte Auvaldungen bilden 
den bevorzugten Aufenthaltsort des Flussrohrsängers während der Brutzcit, dock meidet er nach A. v. Homeyer den eigentlichen inneren Wald und namentlich die Stellen, welche dureh alte Eichen beschattet werden, und bevorzugt die lichteren, dicht mit Untergebüsch durchwachsenen Saumpartien. Hier liebt er die Nachbarschaft von kleinen, offenen, nassen oder auch feuchten Plätzen und treibt im Busche selbst unfern des Saumes sein Wesen. Seinen absonderlichen Gesang trägt das Männchen gewölnnlich von einem bestimmten, dicht von Gestrüpp umsponnenen Lieblingsbaum, meist einer Birke oder Weide, aus vor und steigt dabei, wenn es sich ungestört glaubt, immer höher, so dass es sich bisweilen den Blicken in einer Höhe von 5-7, nach A. v. Homeyer selbst 15 Fuss ziemlich frei zeigt. Bei dem geringsten Anzeichen von Gefahr lässt es sich dann freilich wie ein Stein ins Dickicht herabfallen, entschlüpft hier mit wahrhaft mäuseartiger Behendigkeit und bleibt nun auf längere Zeit spurlos verschwunden. Dasselbe Manöver macht es anch nach einem fehl gegangenen Schusse, so dass der mit diesem Benehmen noch unbekannte Beobachter meint, sein Sehuss habe den Vogel getötet und sich nun vergeblich in dem Dickicht müde sucht. Die Ankunft von fluviatilis erfolgte bei Breslau nach meinen Beobachtungen 1889 am 1. und $189 J$ am 5. Mai. Das Nest findet man selten in der Nähe des Flussufers sondern meist melı binnenwärts. Arlt und Graf R o e d e r n versorgten von Breslau aus die Sammlungen der deutschen Oologen regelmässig mit den kostbaren Eiern von fuviatilis, leider aber haben beide fast gar nichts über ilure dabei gemachten Erfahrungen veröffentlicht. Ausführlicher äussert sich A. v. Homeyer über das Brutgeschäft: „Das tief unten im Gras oder im durchwachsenen Niedergestrüpp auf oder wenige Zoll über dem Boden stehende Nest ist selir schiver zu finden. Die Eicr kennzeichnen sich durchans als Schwirrsänger-Eier mit ihren feinen, glasigen, rötlichen Tinten, variiren aber doch bedeutend." Wohl nur eine Brut von 5 -li Eiern. Arlt fand das volle Gelege schon am 11. Mai und am 12. Juni bereits flügge Junge. Trotzdem ich gerade bei fluviatilis unendliche Mühe auf die Nestersuche verwendet habe, war ich doch nur einmal, am 21. Juni 1890, so glücklich ein Nest mit fast flüggen Jungen zu entdecken, die, als ich Miene machte, sie zu ergreifen, aus dem Neste schlüpften und spurlos im Gestrüpp verschwanden. Wenn Arlt die Ansicht äussert, dass sich das Männchen gar nicht an der Aufzucht der Jungen beteiligt, so muss ich das stark in Zweifel ziehen, denn die Auffindung des eben erwälnten Nestes wurde mir gerade im Gegenteil nur dadurch möglich gemacht, dass ich das MIännchen erst schwirren und dam mit Futter im Schnabel zum Neste Aliegen sah. Durchschnittsmaasse von $\overline{5}$ schlesischen Eiern = $21,5+17,5 \mathrm{~mm}$. 
Gattung: Calamodus Ka up. 182?. - Schilfsänger.

Hier vermag ich ansnahmsweise nicht, mich an Reichenow anzuschliessen, denn die Schilfsänger weichen von den echten Rohrsingern doch vielfach und namentlich auch in ihren biologischen Eigentümlichkeiten so wesentlich ab, dass ich sie nicht mit diesen unter einen Hut bringen möchte. Wollte man consequent sein, so müsste man entweder alle Rohrsängergruppen zu der einen Gattung Acrocephalus vereinigen, oder aber man muss sich eben der von mir durchgeführten Drei-Teilung anbequemen. Bei Calamulus ist dic Oberseite gefleckt, dic Unterseite ungefleckt, die Flugel lang, der Seheitel zweifarbig, der Schnabel verhältnismässig schlank und mit Borsten an der Basis versehen. Die 2. Schwinge länger als die 4. s än ger.

34. Calamodus aquaticus $(\mathrm{Gm}$.) 17s's. - Binsenrohr-

Synonyma: Notacilla aquatica L., Gm.; Sylvia aquatica Lath., Tem., Naum., Gätke; sylvia schnenobaenus scop.; Silvia salicaria Bechst.; Sylvia paludicola Vicill.; Sylvia striata Chr. Brehm; Sylvia carioeti Nanm., Glog.; MInseipeta salicaria Koch; Calamodyta aquatica Gray, Giebel; Calammherpe anuatica, C. cariceti, C. limicola, U. striata Chr. Brehm; Sialicaria aquatıea, S. cariecti Kilys. und Blas., Jiickel; Arundinaceus aquaticus Less.;

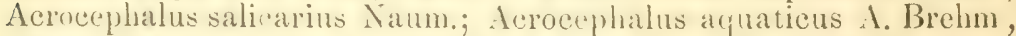
Rehw., Fridr., Pleske; Calamodus ayuaticus, C. salicarius Cab., Newes, Hartert.

Kennzeichen der Art: Die oberen ichwanzleckfedern haben dunkle Schaftflecken.

Ausser dem gewöhılılichen rötlichgelben Vogel kennt man noch ein mehr grauliches Kileid, welehes i a C. carireti als eigene Art beschrieb und abbildete. Die meisten neueren Oruithologen unter Führung E. F. v. Ho meyers sind indessen der Ansicht, dass man es hier nur mit versehiedenen Altersstadien ein und desselben Vogels zu thun habe. Wenn ich mir nach dem allerdings geringfiggigen Material, welches durch meine Hände gegangen ist, ein Urteil erlauben darf, so möchte ich mich diesen Forschern anschliessen und dadurch mit in Gegensatz zu unserem grössten schlesischen Ornithologen, zu Gloger, treten, welcher cariveti für cine nördliche Lokalvarietät von aquatime hiäl. Aus der Breslaner Gegend wenigstens habe ich beide Formen nebst Uebergangsstalien ganz regellos dureh einander crhalten, ja arruticus sogar in stark überwiegender Mehrzahl, waihrend man doch sunst dort eigentlich nur cariceti erwarten miisste, da dieser Rohrsänger bekamitlich ein mehr süalicher Vogel ist und nicht sehr weit nach Norden und Nordosten geht. Auch in der Latusitz kommen nach R. Tobias beide formen vor. 
Welche derselben eigentlich das jüngere Kleid darstellt, vermag ich nicht genau zu sagen. Nach E. v. Homeyer ist die graue Form das Sommer und die rötliche das Winterkleid.

Masse von 7 schlesischen Exemplaren in $\mathrm{cm}$ :

$\begin{array}{lccc} & \text { maximum } & \text { minimum } & \text { Durchschnitt } \\ \text { Länge: } & 12,8 & 12,5 & 12,7 \\ \text { Flügelbreite: } & 18,9 & 18,4 & 18,7 \\ \text { Schwanz: } & 4,6 & 4,3 & 4,4 \\ \text { Schnabellänge : } & 1,1 & 0,8 & 1,0 \\ \text { Tarsus: } & 2,0 & 1,7 & 1,9\end{array}$

Obgleich im allgemeinen in Schlesien selten, ist der Binsenrohrsänger stellenweise an geeigneten Oertlichkeiten verhältuismässig häufig; wach Art anderer Rohrsänger schwankt aber auch hier sein Bestand sehr beträchtlich. Auf dem Zuge erscheint er in manchen Jahren reeht zahlreich, wird aber meist übersehen oder verkannt. So beobachtete Bacr am 3. Oktober 1s8? an einem Teiche bei Niesky 12 Stück in kurzer Zeit, wovon r ' erlegte. Gloger crhielt 1819 mehrere Nester mit Eiern aus der Gegend von Neisse. Bei Breslau ist der Binsenrohrsänger im Riedgras der Sümpfe und Teiche gar nicht selten, und fand ich ihn \%. B. bei Kl. Tschansch unerwartet zahlreich. In den grossen Brüchen und Mloräste'n der Bartschniederung fundet er sich gleichfalls und für die Gegend von Saabor hat iln L. Tobias als seltenen Brutvogel nachgewiesen. In der Lausitz hat ihn R. Tobias zwar wiederholt zur Zugzeit (apuaticus = Winterkleid!) als auch 2mal in Mai (rariceti = Sommerkleid!) erlegt, doch fehlte noch bis auf die neneste Zeit ein vollkommen sicherer Beweis für das thatsächliche Brüten, bis denselben nummelı B a er erbracht hat. Derselbe fing an den Uhyster T'eichen cinen jungen Togel und bekam dabei den Alten so nahe zu Gesicht, dass bei der Geubtheit des Beobachters cine Verwechslung mit jhraymitis vollkommen ausgeschlossen erscheint. Am 13. Mai 1s!ll stellten sich die Vügel wieder an den dortigen Teicheu cin; bei Breslau ersehicnen sie 1859 an 1. Mai und 1890 am 26. April. Maasse von 5 schles. Eiern $=16+11 \mathrm{~mm}$.

rohrsänger.

35. Calamodus schoenobaenus (L.) 1758. - Schilf.

Synonyma: Motacilla schoenobaenus L., Gm., Belist.; Motacilla yvica Hass.; Motacilla salicaria Tunst., Don.; Sylvia phragmitis Behst., Naum., Glog., Gätle; Sylvia schoenobanus Vieill.; Sylvia salicaria Lath., Forst.; Curruca salicaria Flem.; Curruca silvestris Briss.; Calamodyta schoenobaenus Giebel; Calamodyta phragmitis Neyer u. Wolf, Degl; Calamolrerpe phragmit is Boie, v. Hom,; Calamoherpe tritici, C. subsphragnitis Chr. Brehm; 
Caricicola brachyrhynchus, C. danubialis, C. phragmitis, C. schocnobacnus, C. subphragmitis, C. tritici Chr. Brelım; Muscipeta phragmitis Koch; Salicaria phragmitis Selby; Acrocephalus schoenobaenus Rchw., Radde, Fridr.; Calamodus phragmitis Kaup; Calamodus schoenobaenus Gray, Mewes, Hartert.

\section{Trivialnamen: Kleiner Weidenzeisig.}

Kenuzeichen der Art: Die oberen Schwanzdeckfedern sind einfarbig (Pleske).

Trotz der vielen subspecies, die Brehm aufgestellt und trotz der Verschiedenheit der Eier, welche Seebohm betont hat, glaube ich doch, dass gerade bei sihoenobnems sich sehr schwer gültige Lokalformen werden auffinden lassen, da alles zu sehr durch cinander geht, und diese Vögel auch individuell stark zu variiren scheinen. Auch die Vergleichungen der Maasse meiner sehlesischen mit solchen westdeutscher und russischer Exemplare ergeben keine constanten Unterschiede.

Maasse von 19 schlesischen Exemplaren in $\mathrm{cm}$ :

$\begin{array}{lccc} & \text { maximum } & \text { minimum } & \text { Durchschnitt } \\ \text { Länge: } & 14,0 & 12,8 & 13,3 \\ \text { Flügelbreite: } & 21,3 & 19,1 & 20,0 \\ \text { Schwanz: } & 5,4 & 4,9 & 5,1 \\ \text { Schnabellånge: } & 1,4 & 1,0 & 1,3 \\ \text { Tarsus: } & 2,0 & 2,2 & 2,1\end{array}$

Diese Art ist in Schlesien weit häufiger vertreten als die vorige und findet sich an allen Teichen, die nicht vollständig von Schilf- und Rohrdickichten oder WVeidengestrüpp entblösst sind; so ist schoenobaenus nach Hosius selbst an den Giersdorfer Teichen bei Warmbrunn keine Seltenheit. An den weidenreichen Ufern der Ohle, Oder, Bartsch, Weistritz und anderer Flüsse Mittelschlesiens ist er ïberall zu finden, wo schilfige Uferstellen vorhanden sind. In den Sehilf- und Erlenbrüchen von Primckenau, Trachenberg und Oberschlesien ist er einer der ersten Charaktervögel. Auch sein Bestand ist ein sehr schwankender. A. v. Homeyer constatirte ilın für Glogau, Baer für Niesky und Kutter für Neustadt als Brutvogel. Der Durchzug von schoenobaemus ist in manchen Gegenden Schlesiens, so namentlich auch bei Breslau und in der Bartschniederung, besonders im Herbste oft ein ausserordentlich starker. Den Gesang des Schilfrohrsänger's habe ich sehr schiitzen gelernt und seinem schon oft genug geschilderten Balzflug stets mit Yergnügen zugeschen. Sehr bemerkenswert dürfte es erscheinen, dass diese Rohrsänger in Schlesien bisweilen ganz nahe bei einander, ja oft in förmlichen Colonieen brüten, während Naumann und fast mit deuselben Worten auch noch Fride. 
rich in der nenesten Anflage seines Lehrbuchs besonders betonen, dass sich diese Vögel einen relativ grossen Nistbezirk scharf abgrenzen und eifersüchtig gegen andere P:irchen verwahren. Dieses colonieweise Brüten findet mit Vorliebe statt, wo die Vögel im jungen Weidengestrüpp nisten, ohme dass ich cinen völlig stichhaltigen Grund dafür anzugeben wïsste. Bei Kl. Tschansch beoachtete ich auf etwa $1 / 2$ Morgen allerdings sehr günstigen Terrains mindestens 20, wahrscheinlich ca. 25 Paare. R. Tobias zählte in den t0er Jahren in einjährigen Weiden mehrfach 8 Pare auf $1 / 4$ Morgen. Er fand die Art in der Lausitz, L. Tobias bei Saabor brütend. Letzterer fand gleichfalls eine Colonic in einem 2jährigen Weidenwerder, wo die Nester ganz nahe zusammen standen. Die Nester dieser Art sind übrigeus oft auffallend schlecht und liederlich gebaut. Da dieser Rohrsänger schon verhältnismässig früh im Jahre bei uns eintritt't, so wäre es möglich, dass er '2 Bruten macht, worüber mir indessen keine Erfahrumgen zu Gebote stehen. Ich fand am 16. und 27. Mai volle Gelege.

$\mathrm{M}$ a a s e von 21 schlesischen Eiern in $\mathrm{mm}$ :

$\begin{array}{lccc} & \text { maximum } & \text { minimum } & \text { Durchschnitt } \\ \text { Länge: } & 19 & 17 & 18,2 \\ \text { Breite: } & 14 & 12 & 13,25\end{array}$

Maasse von 3 Nestern in $\mathrm{mm}$ :
Aeussere Breite: $100-130$
Innere Breite: $60-75$
Höhe: $50-90$
Tiefe: $40-55$

Ueber den Zug liegen nur sehr spärliche Daten vor:

\begin{tabular}{|c|c|c|c|c|c|c|c|c|}
\hline Ort: & Reobachter: & 1839 & 1842 & 1876 & 1879 & 1889 & 1890 & 1891 \\
\hline & $\begin{array}{l}\text { R. Tobias } \\
\text { v. Meyerinck }\end{array}$ & 26. IV. & 23. IV. & - & 3. V. & $\overline{-}$ & - & \\
\hline Niesky & Bär u. Kramer & 一 & - & - & - & - & 8.1 & 3. V. \\
\hline Breslau & Mohr & - & - & 19. IV. & 一 & - & - & - \\
\hline alkenberg. & Floericke & - & - & - & $\begin{array}{l}- \\
-\end{array}$ & 20. IV. & 19. IV. & 23. \\
\hline
\end{tabular}

Gattung: Acrocephalus Naum. 1811. - Rohrsänger.

Selmabel verhältnismässig breit und an der Basis abgeflacht. Rücken und Scheitel ungefleckt. Die 2. und 3. Schwinge am längsten; die Schvingen bis hüehstens zur 4. auf der Aussenfahne verengt. sänger.

36. Acrocephalus palustris (Behst.) 1802. -- Sumpfrohr - 


\section{3tia. Acrocephalus palustris horticolus ( $\mathrm{N}$ a u m.) 1840.} - Gartenrohrsänger.

Synonyma: Sylvia palustris Bchst., Naum., Glog., Gaitke; Sylvia strepera Vieill.; Sylvia agricola, ¿. montana Jerd.; Sylvia fruticola, S. horticula Naum.; Calamodyta palustris Gray; Gieb., Newes; Calamodyta strepera Gray; Calamodyta agricola Gray; Calamoherpe palustris, C. arbustorum Boie, Degl.; Calamoherpe pratensis Jaub.; Calamoherpe agricola Blyth, Acrocephalus agricola Blyth; Salicaria palustris Kays, und Blas., Jäekel; Acrocephalus palustris Naum. sen., Cab., A. Brehm, v. Hom., Radde, Fridr., Hartert.

Trivialnamen: Sprachmeister, Schwarzblättcl, Rohrzeisig.

Kenuzeichen der Art: Flügellïnge unter $72 \mathrm{~mm}$. Die 2. Schwinge gleich der 3. Die 3. aussen nicht verengt. Unterleib mit ockergelbem Anflug. Die kleinen unteren Flïgeldeckfedern blass gelblichweiss (Letzteres nach Friderich).

Ma ass e von 42 schlesischen Exemplaren in $\mathrm{mm}$ :

$\begin{array}{lccc} & \text { maximum } & \text { minimum } & \text { Durehschnitt } \\ \text { Länge: } & 143 & 130 & 136 \\ \text { Flügelbreite: } & 202 & 184 & 193 \\ \text { Schwanz: } & 59 & 52 & 55,5 \\ \text { Schnabellänge : } & 16 & 13 & 14 \\ \text { Tarsus : } & 24 & 21 & 22,5 \\ \text { Flügellänge: } & 70 & 63 & 67\end{array}$

Naumamn's horticulus, welcher sich hauptsäehlich durch dunklere Färbung der Oberseite unterscleidet, loummt auch in Schlesien vor. Leider habe ich nur wenige Stuicke in Händen gehabt und diese wenigen wieder fortgegeben, da dies zu liegimmener ornithologischen Thätigkeit in Schlesien war und ich damals noch nicht hinreichend auf derglcichen Feinheiten achtete. Doch möchte ich, olwwohl ich mich dadureh wahrseheinlich in Gegensatz zu der Mehrzahl der heutigen Ornithologen stelle, die Vermutung aussprechen, dass wir es hier mit einer guten subspecies zu thun haben, welche eben durch die veränderte und einem neuen Aufenthalt angepasste Lebensweise entstanden ist. Die Stimme z. B. ist ander's; leider habe ich es wie gesagt damals unterlassen, sofort Notizen zu machen und aus der Erimnerung wage ich nicht, dergleichen feine Unterschiede wiederzugeben. Künttige Beobachter werden iln Augenmerk namentlich auf biologische Eigentünlichkeiten beider Formen zu lenken haben. Erfahrene Eiersammler behaupten, dass auch die Eier verschieden seien u. s. w.

Dieser ausgezeichnete Spötter ist mit Ausnahme der Sudeten und der Lausitz in gauz Sehlesien ein gemeiner Brutvogel, oft sogar ungemein häufig und in den üppig feuchten Auwaldungen Mittelsehlesiens mit der erste Charakterrogel. Dabei nimmt sein 
Bestand immer noch zu und wandert er in stetig grösser werdender Zahl auch in Gegenden ein, denen er bisher ganz oder grossenteils fehlte. In ganzen Oderthale und in der Bartschniederung ist palustris gemein, ebenso an fast allen Nebenfüssen der Oder, sobald sie das Gebirge verlassen haben, und ihr Lauf ein trägeres Gefälle annimmt. Besonder's häufig scheint er, was schon Gloger hervorhebt und neuerdings wieder Kollibay bestiitigt hat, an den Ufern der Glatzer Neisse zu sein. Bei Breslau schoss Gloger einmal im Frühjahr 1820 i bis 6 Uhr morgens \pm Stück. Auch bei Neustadt ist die Art nach $\mathrm{K} u t t e r$ sehr gut vertreteu. In den Vorbergen geht er für einen Rohnsinger recht hoch hinauf. Am Zobten ist palustris nach Knauthe ein zwar sparsamer, aber im Zunehmen begriffener Brutrogel. A. v. IIomeyer fand ihn häufig au kleinen Feldteichen bei Glatz, Frankenstein und Reiudörfel, ja als vereinzelten Brutvogel sogar auf feuchten Stellen des Hochwaldes. Relativ selten ist dieser Sangeskïnstler dagegen in der Lausitz, wemigleich er auch dort jetzt vordringt ind zunimmt. Von 1832-36 fand der cifrige R. T'obias nur 3 Nester, spricht aber bereits 1839 von einer deutlich erkembaren Zunalme des Vogels in den ebenen Teilen der Lausitz. „Lirst unterhalb Görlitz, wo die Ufer der Neisse flacher werden und auf den Wiesen mit Gesträuch umgebene Lachen sind, brütet er rcgelmässig." Bei Zittau ist er nach dem jüngeren Krezschmar noch jetzt eine Seltenheit, und für Niesky constatirte ihn erst Kramer 1891 als einen für die Gegend neuen Brutvogel. Auwälder, weidenreiche Flussufer, sumpfige, mit niederem Gebüsch bewachisenen Wiesenflächen bilden seircon Aufenthalt; ferner nach Kollibary mit besouderer Vorliebe „die mit Nesseln, Hopten und W'inden durchwachenen Weiden der Ufer kleiner. Bäeme, die dureh tiefer gelegenes Ackerland fliessen." Auf $1 \mathrm{~cm}$ Herbstzuge findet man die Sumpfrohrsänger vidfach in Kartutfilackern. Dic Zugmonate sind Mai und August. Bei Breslau kam palustris 1859 am 1. uud 1890 am t. Nai an. Iels liörte dort vielfach ganz allsgezeichnete Spötter. Das Nest steht wohl stets noch über truckenen Boden, nie direkt über dem Wasserspiegel (R. 'T'obias). Doch werden diese stellen bäufig übersehwennt, und lieben die Vügcl überhaupt Fenchtigkeit in der Nähe. Kutter und Kolliba y finden die Nester gewöhnnlich in hohen Nessehn, ca. $1 \mathrm{~m}$ über dem Boden, L. Tobias dagegen in Weiden, wo sie meist antfallend schlecht befestigt wareu. Gelege nach Kollibay stets mur zu 4 Stieck, was ich bestatigen kann. Kutter fand am t., Kollibay am 8 . und 18 ., ich an 3., 12. und 14. Juni volle Gelege. Am 7. Juni stiess Kutter auf ein Nest, welches 1 Ei und 1 sparei enthelt. Nur eine Brut.

Maasse von 4 tsehlesischen Liem (wovon $1+$ durch Kollibay gemessen) in $\mathrm{mm}$ : 


$\begin{array}{lccc} & \text { maximum } & \text { minimum } & \text { Durchschnitt } \\ \text { Länge: } & 19,6 & 16,4 & 18,555 \\ \text { Breite: } & 14,3 & 12,4 & 13,4\end{array}$

Die Bauart der Nester ist übrigens, wie auch schon Pleske hervorgehoben hat, nach einem zweifachen Typus. Die in Weiden erbauten gleichen denen des Teichrohrsängers, die in Nesseln und Hopfen crrichteten dagegen denen der 1)orngrasmücke. Vielleicht ist uns damit ein nencr Fingerzeig für dic subspecifische Sonderung von palustris und horticulus gegeben!

37. Acrocephalus streperus (Vieill.) 1s17. - Teichrohrsänger.

Synon y ma: Notacilla arundiuacea $\mathrm{Gm}$.; Motacilla salicaria L., Gm., Behst.; Sylria arundinacea Lath., Behst., Naum., Glog., Gätke; Sylvia strepera, S. bacticata Viejll, Sylvia attinis Mardy; Sylvia salicaria Lath., Behst.; Curruca fusca Hempr. u. Ehrbg., Salicaria Gessneri Wil. und Ray; Luscinia salicaria Klein; Salicaria arundinacea Selby, Jickcl; Calamodyta arundinacea Gray, Giebel; Calamodyta baeticula Gray; Calamodyta strepera Mewes; Calamoherpe arundinacea Boie, Degl., Blyth, Brehm; Calamoherpe salicaria, C. Brehmi, C. hydrophilus, C. piscinarum, C. alnorum, C. arbustorum, C. pinetorum, C. latirostris, C erassirostris Chr. Brehm; Calamolerpe obscuricapilla l)ub; Acrocephalus arundinaceus Naum., Cab., A. Brehm, v. IIom.; Acrocephalus salicarius Fridr.; Acroeephalus streperus Radde, l'leske, Hartert.

Trivialnamen: Ixcl, kleiner Rohrsperling, lileiner liohrspatz.

Kennzeichender Art: Flügellänge unter 7: $\mathrm{mm}$. Die 2. Schwinge kürzer als die 3 ; letztere anssen verengt. Unterleib mit hell rostgelblichem Anflug. Unterflügcldeckfedern licht rostbräunlich.

$\mathrm{N}$ a asse von $2 t$ schlesischen Exemplaren in $\mathrm{cm}$ :

$\begin{array}{lccc} & \text { maximum } & \text { minimum } & \text { Durehschnitt } \\ \text { Länge: } & 13,5 & 13,0 & 13,25 \\ \text { Flügelbreite: } & 19,6 & 18,9 & 19,2 \\ \text { Schwanz: } & 5,8 & 5,2 & 5,35 \\ \text { Schnabel: } & 1,8 & 1,6 & 1,7 \\ \text { Tarsus: } & 2,4 & 2,1 & 2,25\end{array}$

Auch der 'Teichrohrsänger ist für die uneisten Gegenden Sululesirns ein gemeiner Vogel. Er findet sich in den Rohrpartien aller, anch dor kleimsten T'eiche, ferner in Weidicht und Röhricht der Flüsse und Auwiilder, sowie anch an überwachsenen Gräben und fonchten Stellen der Aulagen und Parks. Wr scheut dabei keinswwegs die Nähe des Menschen; so hörte ich ihn wiederholt im botanischen Garten zu Breslau. Ueberhaupt weiss er sich in 
veränderte Verhältnisse zu schicken und bringt sein Nestehen auch gern auf einer wagerechten Astgabel an, wenn es an palssenden Rohrstengeln fehlt (R. Tobias). Sehr häufig lebt er in den Ausschachtungen zu seiten der Bahndämme, wie dies nach den schönen Untersuchungen von $\mathrm{Licbe}$ auch in 'Thüringen der Fall ist. Auch auf den T'eichen der Vorberge ist dieser Rohrsänger zu finden, so bei Hirsehbeig und nach A. v. Ho meyer auch bei Cudowa. Der Bestand schwankt übrigens wie bei allen Rohrsängern sehr erheblich. Der Durchzug ist sehr lebhaft und findet in den Monaten April und september statt. Viel bestimmte Daten über die Ankunft liegen freilich nicht vor. R. Tobias fand von 1832-38 als frühesten Ankunftstermin den 27. April, als spätesten den S. Mai und als mittelsten den 1. Mai. Ferner' notirt er den 26. April 183! als Ankunftstermin für Görlitz, Krezschmar den 10. A pril 1582 für ebendort, Kern den 14. April 1886 für Breslau und ich den 23. April 1889 und den 25. April 1890 für dieselbe Gegend Zur Anlage scines Neste's wählt sich streperus bekanntlich hohrpartien, auch wenn dieselben von noch so kleinem Umfange sind, und bringt hier seinen Lau an den Stengeln über oder ummittelbar neben dem Wrasser an. Doch erleidet auch diese Regel ihre Ausnahmen. So fand v. Bocnigk die Nester ofters neben dem IVasserspiegel, aber freilich meist au solchen Orten, wo das WVasser noch kurz zuvor gestanden hatte. Einmal aber stand das Nest in einem Weidenwerder, mindestens 20 Schritte rom Ufer eines toten Flussarmes entfernt, auf einer $\Lambda$ stgahel. Ich erhielt am $:$ und 11. Juni frisehe Gelege. Nach meinen Erfahrungen macht streperus in sehlesien regelmässig 2 Bruten, was schon der ailtere Tobias im Gergensatze zu Na u m a n hervorgehobeu hat. Lie Erklärung, welche der Görlitzer Ornithologe hierfür giebt, will mir treilich weuiger einleuchten. Nach R. Tobias soll nïmlich das Mänchen allein die ausgetlogenen Jungen füttern, während das Weibchen sich zu einem bis dahin noch ungeparten Männchen gesellt und mit diesem Ende Juli eine zweite Brut macht.

Ma ase von 6 schlesischen Nestern in $\mathrm{mm}$ :

$\begin{array}{lll}\text { Aeussere Breite: } & 60-90 & \text { Höhe: } 50-75 \\ \text { Innere Breite: } & 40-50 & \text { Tiefe: } 35-40\end{array}$

Ma as e von 32 schlesischen Eiern in $\mathrm{mm}$ :

$\begin{array}{lccc} & \text { maximum } & \text { minimum } & \text { Durchschnitt } \\ \text { Länge: } & 20 & 16 & 18,1 \\ \text { Breite: } & 14 & 13 & 13,5\end{array}$ drossel.
33. Acrocephalus armblinacens (L). 175\%. - Rohr. 
Synonyma: Turdus arundinaceus L., Briss., Gm., Behst, Fisch.; Turdus junco Pall.; T'urdus palustris Klein; Sylvia turdoides Meyer, Tem., Cuv., Tyz., Naum., Gätke; Sylvia turdella Ratt.; Sylvia turdina Glog., Schleg.; Muscipeta lacustris Koch; Calamoherpe turdoides Boie, Bon., Degl., Tacz.; Calamoherpe media IIalm; Calamoherpe lacustris, C. stagnatilis, C. maior, C. longirostris Chr. Brehm; Arundinaceus turdoides Less.; Salicaria turdoides Kays, u. Blas., Meyer, Schwed., Jäckel; Salicaria turdina Schleg.; Acrocephalus arabicus Hengl.; Acrocephalus fulvolateralis Sharpe; Acrocephalus lacustris Naum.; Acrocephalus turdoides Cab., A. Br., v. Hom., Radde, Pleske; Acrocephalus arundinaceus Gray, Fridr., Hartert.

Trivialnamen: Rohrspatz, grosser Rohrsperling:

Kennzeichen der Art: Flügellinge über $85 \mathrm{~mm}$. Die 2. Schwinge steht in ihrer Länge zwischen der 3. und $t$.

Ma asse von 40 schlesischen Exemplaren in $\mathrm{cm}$ :

$\begin{array}{lccc} & \text { maximum } & \text { minimum } & \text { Durchschnitt } \\ \text { Länge: } & 22,2 & 19,8 & 21 \\ \text { Flügelbreite: } & 30,1 & 27,4 & 28,7 \\ \text { Schwanz: } & 8,8 & 7,9 & 8,4 \\ \text { Schnabel: } & 2,3 & 2,1 & 2,2 \\ \text { Tarsus: } & 3,0 & 2,8 & 2,9\end{array}$

Das sonderbar knarende Lied der Rohndrossel ist es, das auch dem Laien in den sehlesischen Auwaldungen und Teichgebieten autiallt, das vor allem mit zur statliage dieser Landschaften gehört, und das man dort wilklich bis zum Ueberdrusse zu hören bekommt. Der Vogel fehlt in solchen Gegenden wohl nirgends, ist in manchen, wie bei Breslau, Glogau, Neusalz und der Bartschnickerung ansserordentlich gemoin, in anderen aber auch in entschiedenem Rïickgange oder gar in Ansiterben begriften. So ist er nach Kna uthe seit lsco: bei siprottau völlig ausgerottet und anch ron den Schilaupitzer Tejehen neuerdings ganz versehwunden. In der Lausitz scheint "r nach den übereinstinmenden Berichten der dortigen Forscher überhaupt nicht so häufig zu sein wie in Mittel- und Oberschlesien, und in den Gebirgsgegenden fehlt er fast ganz, geht jedenfalls nicht so hoch wie streperus. Emmerich beobachtete ihm bei Neurode nur einmal, im Mai 1891. R. Tobias notirte von 18.j. .. is als friiliesten Ankunftstermin den 27. April, als spätesten den 7 . und als durehschnittlichen den 3. Mai. 
Zugtabelle:

\begin{tabular}{|c|c|c|c|c|c|c|c|}
\hline Ort: & Beobachter: & 1840 & 1876 & 1582 & 1559 & 1590 & 1891 \\
\hline iiirlitz. & R. Tobias & 29. IV. & - & & - & - & - \\
\hline & Krezschmar & - & & 3. V. & - & & - \\
\hline Zobten & Knauthe & 一 & - & - & 一 & 19. V. & - \\
\hline Niesky & Kramer & - & - & - & - & - & 3. V. \\
\hline Breslau & Mohr & - & 28. IV. & - & - & - & - \\
\hline " & Floericke & - & - & - & 1. V. & 2. V. & - \\
\hline
\end{tabular}

Der WVegzug erfolgt schon im August. Man findet den Togel dann nicht nur im Röhricht, sondern anch in allem möglichen Gesträuch, vorausgesetzt, dass Wasser in der Nähe ist. Nur eine Brut zu t-ó Eiern, welche 15 Tage lang bebrütet werden. Bei Breslau benutzt der Kuckuck die Nester des dort selı häufigen Drosselrohrsängers zum Ablegen seines Eies. Auch diese Art zeigt beim Nestbau mancherlei Abnornitaiten. So nistete arundinaceus nach A. v. Hom ey er bei Glogan ziemlich zahlreich, während das Wasser fast gianzlich fehlte und die Oder wohl 30, , -1000 Schritt entfernt war. L. Tobias fand, noch ehe das Rohr gewachsen war, ein nicht angeheftetes Nest auf einem abgehauenen Weidenstocke. H. Lübbert erhielt am 20. Nai 1554 ein Nest mit 5 Eiern, die abwichend gefarbt, hell weissgrau mit einem kaum bemerkbaren Stich ins Grünliche waren. Drei davon hatten nur sehr bleiche aschgraue, die beiden andern daneben auch noch wenige bleicholivenfarbene Flecke. L. Tobias fand das volle Gelege am 17., ich selbst am 11), 12., 13., 21., 22. und 27. Juni.

II a as e von 68 schlesischen Eiern in $\mathrm{mm}$ :

$\begin{array}{lccc} & \text { maximum } & \text { minimum } & \text { Durchschnitt } \\ \text { Länge: } & 25 & 21 & 23,2 \\ \text { Breite: } & 17 & 15 & 16,3\end{array}$

Durchschnittsmaasse vou 11 schlesischen Nestern in mm:

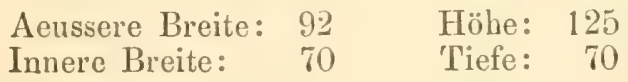

Gattung: Sylvia Scop. 1769. - Grasmücke.

Schnabel ziemlich stark und pfriemförmign mit breiten, ritzenförmigen und von Borstenfederchen umkleideten Nasenlöchern. Der Schwanz ist ungebïndert und kürzer als die Filügel. In diesen ist die 3. Schwinge am längsten, die 1. erreicht nie die Hälfte der 2.

39. Sylvia atricapilla (L.) 175s. - Mönchsgrasmücke. Synonyma: Motacilla atricapilla L., Tengm., Gm., Buff., Bchst.; Motacilla moschita Gm.; Curruca atricapilla Briss., Curruca 
Heincckeni var. Jard.; Curruca nigricapilla, C. pileata, C. ruficapilla Chr. Brehm; Monachus atricapillus Kaup; Philomela atricapilla Sws.; Epilais atricapilla Cab.; Sylvia moschita Lath.; Sylvia ruficapilla Naum.; Sylvia Naumanui v. Müll.; Sylvia rubicapilla Landb.; Sylvia atricapilla Klein, Penu., Lath., Behst., Namm., Glog., Gieb., Kays. und Blas., 1. Br., v. Hom., Mewes, Fridr., Radde, Pleske, Hart., Gätke, Jäckel.

Trivialnamen: Schwarzplatte, Schwarzblättehen, Schwarzkopf, Crasespatz, Kolostervogel, Kilosterwenzel, Mönchlein. Polnisch heissen alle Grasmücken Piegsa.

Kennzeichen der Art: Die 1. Schwinge überragt die Deckfedern der Armschwingen, die 2. ist kürzer als die 5. Füsse blaugrau. Kopfulatte schwarz (Mäunchen) oder rostbram (Weibchen und Junge).

Ma as e von 57 schlesischen Exemplaren in $\mathrm{cm}$ :

$\begin{array}{lccc} & \text { maximum } & \text { minimum } & \text { Durchschnitt } \\ \text { Länge: } & 14,7 & 14,0 & 14,5 \\ \text { Flügelbreite: } & 24,0 & 22,9 & 23,6 \\ \text { Schwanz: } & 6,7 & 6,0 & 6,5 \\ \text { Schnabel: } & 1,4 & 1,2 & 1,3 \\ \text { Tarsus: } & 2,2 & 2,0 & 2,1\end{array}$

Die Weibehen haben durchgingig kiirzere Schnäbel. Die Schwarzplittchen im Gebirge sind ersichtlich stärker und pflegen sich auch durch besseren Gesang auszuzeichnen.

Der Plattmönch ist keineswegi in allen Teilen der Provinz in gleicher Häufigkeit vertreten. In der niederschlesischen 'Tiefebene und in den ebenen Teilen Nittelschlesiens sowie auf der ganzen rechten Uderseite ist er keineswegs hailufig, und es scheint sogar Gegenden zu greben, wo el ganz fehlt. So hat ihn L. To b i a s bei Grüneberg nie benerkt. Bei Breslau, in der Lausitz und in ganz Oberschlesien ist dageg'n der Plattmönch gemein, am allerhäufigsten aber in den Vorbergen und in der Grafschaft, wohin eigens die Berliner Togelfiunger und -Händler reisen, um ihren Bedarf an gut singeulen Schwarzplaittchen zu decken. Die guten Siinger unter denselben werien aber dadurch immer rarer, und der Licbhaber kann hentzutage schon lange herumlaufen, ehe er ein Sehwarzplattel zu hïren bekommt, welches sein verwöhntes Ohr zu befriedigen vermag. In den armen Weberdörfern des Eulengebirges und der Gratschatt ist der Mönch der beliebteste Stubenrogel. Trotz dicsur Liebhaberei ist in seinem Bestande keine Abnalime zn spüren, sondern vielmehr in manchen Gegenden eine hïchst erfreuliche Zunahme zu constatiren, so nach $\mathrm{K} n$ a $u$ the am Zobten. Bei Flinsberg gab es nach Hosius 1874 nur $3-4$ Brutpare, 1s5\% deren bereits ea. 30. Der Vogel geht übrigens 
im Gebirge ziemlich hoch empor. Im Hirschberger Thal und bei Schreiberhan ist er schr häufig und zieht sich von hier aus überall am Gebirge empor, wo gesehïtztere Stellen sich finden, soweit der Wald reicht. Ja, cinzelne gehen sogar bis ins Knieholz. So fand Gloger diese Art an den Räuderu des kleinen Teiches (3700 Fuss), wo Pinus nuilio mit verkrüppelten Stämmchen von P. picea, Sorbus auruparia, Prums padus, Riles petracum, Betula carpathica, Salix silesiace, $S$. arenaria, Lonicera nigra etc. unter einander wachsen, und die Zwischenrïume mit üppigen Farrenkräutern, Veratrum Lobriumun, Lilium, Aconitum multifidum, Sonchus alpinus und anderen wuchernden Pflanzen überzogen sind. Capek hörte cin singendes Nämnchen im Knieholz des "Kessels" $(1350 \mathrm{~m})$. Gemischte Waldungen, die reich an niederem Gebüsch sind, hat der Schwarzkopf am liebsten; doch ist er bezüglich seines Aufenthaltortes nicht allzu wählerisch und anspruchsvoll. Er findet sich auch in grossen Gärten und fast regelmässig in den Anlagen der schlesischen Städte. Nach den Beobachtungen von $\mathrm{R}$. Tobias traf atricapilla bei Görlitz von 1832-38 frühestens am 17 ., späitestens am 2!. und durchschnittlich am 20. April ein. Sonst liegen über den Zug nur noch folgende Daten vor:

\begin{tabular}{|c|c|c|c|c|c|c|c|c|}
\hline Ort: & Berobachter: & 1881 & 1882 & 1855 & 1887 & 1889 & 1890 & 1891 \\
\hline Gürlitz & Richter & - & -1 & - & - & 18. IX. & - & - \\
\hline 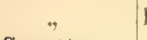 & Krezsihmar & - & 23. IV. & - & - & - & - & - \\
\hline prottau & " & - & - & - & 23. IV. & - & - & - \\
\hline ten & linantlie & - & - & - & 16. IV. & - & 一 & - \\
\hline Nenstadt & Kutter & 21. IV. & - & - & - & - & - & - \\
\hline Flinsberg & Hosins & -1 & - & 28. V. & - & - & - & - \\
\hline Breslau & Floericke & - & - & - & - & $23 . \mathrm{IX}$. & 18. IV. & - \\
\hline Falkenberg & $"$ & - & - & - & - & & - & 21. IV \\
\hline
\end{tabular}

K utter hat beobachtet, lass der Plattmönch mit Vorliebe an Maulbeeren nascht. In der Ebene macht atrirapilla regelmässig '2 Bruten, im Gebirge wohl nu1 eine. Das Nest legt el mit Vorlicbe in Fichtenstranchwerk an (Mohr). Es ist sorgfältiger gebaut als dies sonst bei den Nestern der Grismücken der Fall zu sein pflegt und zwar besonders, wem Moos als Baumaterial verwendet wurde. Das Männchen löst das Weibchen in den Mittagsstunden beim Brüten ab, und beide sitzen so fest anf den Eiern, dass mann sie mit Händen greifen kann. Mls Ko ll i ba y einmal den Versuch machte, das brütende Weibchen zı ergreifen, stürzte sich dasselbe mit wütendem Geschrei auf seine Iland und biss ihn in den Daumen. Volle Gelege fanden Kollibay am 24. Mai, 1. und 9. Juni, Practorius an 16. Mai und ?. Juli, ich selbst am 15., 18., 23. Mai, sowie am 8. Juli. 
Masse von 17 sehlesischen Eiern (davon 5) durch Kollibay gemessen) in $\mathrm{mm}$ :

$\begin{array}{lccc} & \text { maximum } & \text { minimum } & \text { Durchschnitt } \\ \text { Länge: } & 22 & 18 & 19, \overline{5} \\ \text { Breite: } & 15 & 14 & 14,7 \overline{5}\end{array}$

40. Sylvia curpuca (L.) $175 \%$ - Z Z a ung ras m ü cke.

Synonyma: Curruea garrula Brisis, Degl.; Motacilla curruca L., Buff., Gm., Bchst.; Motacilla garrula Retz; Motacilla dumetorum Gm.; Notacilla sylvia l'all.; Stoparula curruca Bon.; Sylvia dumetorum Lath.; Sylvia garrula Belst., A. Br.; Sylvia dumetorum, s. molaria, s. septentrionalis, s. superciliaris Chr. Brelm; Sylvia affinis Blyth; Sylvia curruca Lath., Naum., Glng., Kays. u. Blas., Crieb., Frill., v. Hom., Raulde, Pleske, Hartert, Gätke, Jäckel.

Trivialnamen: Weisskehlehen.

Kennzeichen der Art: Die 1. Schwinge überragt die Deckfedern der Armschwingen. Die -2. steht ilner Länge nach zwischen der 5. und 6., seltener zwisehen der 6. und 7. (三 var. aftinis Blyth). Die 3. bis .). Schwinge anssen verengt. Die beiden äussersten sehwanzfedern grösstenteils weiss, die beiden nächsten mit enem weissen budfleck. Füsse blaugrau. Kopt' grau.

Die var. ufinis, bei welcher die shwingenverhialtnisse etwas abweichen und die eine istliche Art oder subsjecies darstellen soll, habe ich in sichlesien nie gefunden. Alle stücke, welche ich unter Händen hatte, erwicson sich als echte rurvera. Uebrigens ist ja jetzt durch Pleske sclbst der subspecifische Wert von affinis äusserst zweifelhaft geworden.

Ma asse von 27 schlesischen Exemplaren in $\mathrm{cm}$ :

$\begin{array}{lccc} & \text { maximum } & \text { minimum } & \text { Durchschnitt } \\ \text { Länge: } & 12,9 & 12,2 & 12,75 \\ \text { Flügelbreite: } & 20,0 & 18,9 & 19,4 \\ \text { Schwanz: } & 6,1 & 5,3 & 5,75 \\ \text { Schnabel: } & 1,3 & 1,1 & 1,25 \\ \text { Tarsus: } & 2,0 & 1,9 & 1,9\end{array}$

Ganz fehlt diese Grasmücke wohl nirgends in Sehlesien, aber in manchen (xegenden ist sie uicht allzuhäutig (Bartschniederung), während sie in anderen wicder die gemeinste Art der ganzen Gattung ist. Dies gilt z. B. fur den Kobten ( K n a u the) und für cinen grossen Teil vou Oberschlesien. Dabei ist der Vogel daselbst moch in weiterem Zunehmen begrifien. In den Vorbergen ist curvace überall gemein, geht aber im eigentlichen Gebirge nicht so hoch empor wie der Schwarzkopf. Im Isergebirge lebt 
er überall in den Hausgïrten ( $\mathrm{Menzel}$ ). El liebt weitläufigte Gärten und parkartige Gegenden mit viel Gebüsch, dichten Hecken und Zäunen, weshalb er auch in den städtischen Anlagen nirgends zu fehlen pflegt. Doch kommt er auch tief im Nadelwalde in den Fichtendickichten, in grossen Laub- und Auwäldern und im Gebirge auf reinen Fichten- und Tannenschlägen vor. In der grossen Görlitzer Heide ist "urruca sogar nach dem jüngeren $\mathrm{Krez}$ schmar die einzige dort brütende Grasmücke. Eine ganz besondere Vorliebe scheint dieser Vogel für die Stachelbeerbüsche zu besitzen. Nach R. To bias kam er von 1832-38 frühestens am 8., spätestens am 20. und durchschnittlich am 13. April bei Görlitz an.

Diese Grasmücke macht bei uns 2 Bruten zu je 4-6 Eiern, welche 13 Tage lang (nach $\mathrm{Mohr}$ ) bebrütet werden. Das Nest steht mit Vorliebe in jungen Fichten. Richter beobachtete den Nestbau am 24. April und 1. Juni und ausgeflogene Junge am 29. Mai und 3. Juli; Kollibay an 12. Mai und 4. Juni, ich am 14. Mai.

$\mathrm{M}$ a asse von 26 schlesischen Eiern in $\mathrm{mm}$ :

$\begin{array}{lccc} & \text { maximum } & \text { minimum } & \text { Durchschnitt } \\ \text { Länge: } & 18 & 15,5 & 17,3 \\ \text { Breite: } & 14 & 12 & 12,9\end{array}$


146

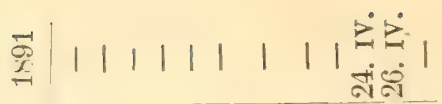

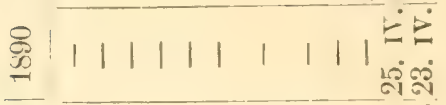

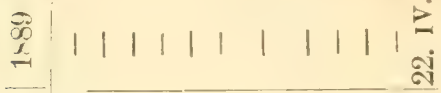

$$
\begin{aligned}
& \text { 舟 } 11|1| 1 \geq|1|
\end{aligned}
$$

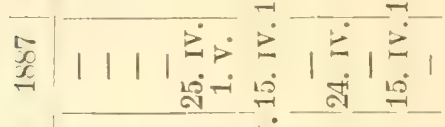

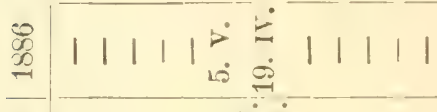

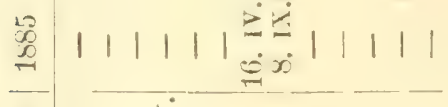

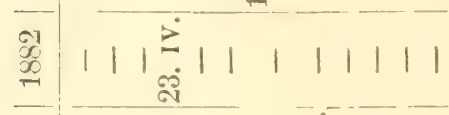

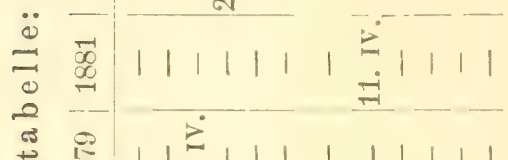

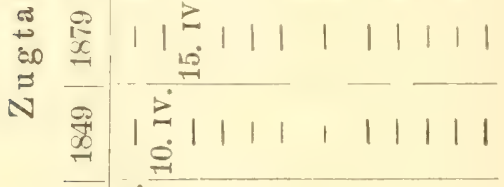

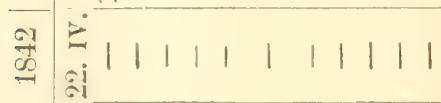

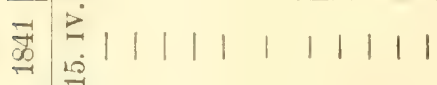

$$
\begin{aligned}
& \text { 通 }
\end{aligned}
$$

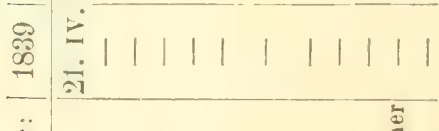

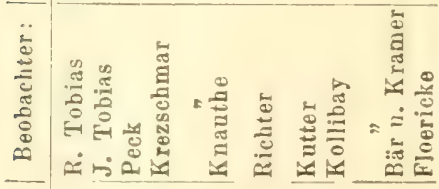

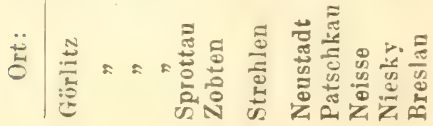




\section{Sylvia rufa (Bodd.) 1783. - D orngrasmücke.}

Synonyma: Motacilla sylvia L., Buff,, Gm., Bchst.; Motacilla cineraria L.; Motacilla dumetorum Gm.; Stoparola cinerea Bon.; Curruca cinerea Briss., Koch; Curruca sylvia Steph.; Curruca cineracea, C. fruticeti, C. caniceps Chr. Brehm; Sylvia fruticeti, S. cineraria Behst.; Sylvia cinerea Lath., Naum., Glog., Behst., Chr. Brehm, Kays. u. Blas., Gieb., A. Br., Rehw., Fridr., v. Hom., Radde, Pleske, Gätke, Jäckel; Sylvia sylvia Steph., Hart.; Sylvia rufa Bodd., Steph., Meves.

Trivialnamen: Fliegenstecher, Grasemische, Dornschmetzer.

Kennzeichen ler Art: Die Bastardschwinge ist kürzer als die Flügeldeckfedern. Die S'chwanzdeckfedern zeigen keine Spur von Querstreifung. Die grossen Flügeldeckfedern sind rostbraun gesäumt. Füsse gelblich fleischfarben.

Es scheint, als ob diese Grasmücke zum Variiren neige, worauf schon das Vorkommen einer constanten östlichen Form, $S$. cinerea fuscipilea Pleske, hinweist. Die letztere kommt in Schlesien auch auf dem Zuge nicht vor, da sie eine südliche Wanderrichtung hat und deshalb in Ostindien überwintert. Die grossen und je nach der Oertlichkeit constanten Unterschiede in Nestbau und Beschalfenheit der Eier lassen es rätlich erscheinen, dieser Art künftig ein besonderes Interesse zuzuwenden, da vielleicht noch besondere Lokalformen von ilır existiren. Leider bin ich zu spät auf diese Verhältnisse aufmerksam geworden und habe viel zu wenig Material durchgesehen, als dass ich auch nur Vermutungen darüber äussern könnte.

Ma asse von 51 schlesischen Exemplaren in cm:

$\begin{array}{lccccc} & \text { maximum } & \text { minimum } & \text { Durchschnitt } & \text { Friderich } & \text { Pleske } \\ \text { Länge: } & 15,4 & 13,9 & 14,7 & 14,3 & - \\ \text { Flügelbreite: } & 23,6 & 22,1 & 22,7 & 22,1 & - \\ \text { Schwanz: } & 7,0 & 6,2 & 6,5 & 6,0 & 6,3-7,0 \\ \text { Schnabel : } & 1,4 & 1,2 & 1,3 & 1,0 & 1,2-1,5 \\ \text { Tarsus: } & 2,1 & 1,9 & 2,0 & 2,0 & 2,0-2,2\end{array}$

Einigermassen bestehen auch hier die schon mehrfach erwähnten Grössenunterschiede zwischen östlichen und westlichen Exemplaren, wenngleich nicht in sehr frappanter Weise.

Sylvia rufa ist gleichfalls einer der gemeinsten schlesischen Vögel und z. B. bei Breslau in den Auwäldern sowie in der Bartschniederung die bei weitem häufigste Grasmücke. Doch hört man neuerdings mehrfach Klageu, dass sie sehr merklich abnehme (Knauthe), was sich mit Riucksicht auf die Wahl ihrer Brutplätze ja auch leicht erklären liasst. Im ganzen Oderthal und in den Teichgegenden ist sic ausserordentlich häufig, weniger in dem 
trockenen Teil der schlesischen Ebene. Im Gebirge geht sie von allen Grasmücken am höchsten empor, ohne jedoch dort gerade besonders hänfig zu scin. Capek hörte ein Männchen im Knieholz des ${ }_{n} K_{\text {essels }}$ (1350 m) singen, und Gloger traf $2-3$ Pärchen an Rande des grossen Teiches (3300 Fuss) an einem wie bei atricapilla geschilderten Platze. Diese Grasmücke liebt stets freie, sonnige Lokalitäten (R. Tobias) und bewohnt demgemäss nie den tiefen Wald, sondern mehr einzeln liegende Strauchpartien, junge Schläge, Weissdornhecken, das Gebüsch an Flussufern, Bahndämmen u. dergl. und die Ränder der Feldgehölze. Nach R. Tobias hält sie sich auch in toten, von Gebüsch geflochtenen Zäunen, nach Fechner viel im Grase auf, und nach L. Tobias brütet sie bei Grüneberg sogar im Getreide. Was die Zugverhältnisse anbetrifft, so notirte $R$. Tobias von $18: 32-38$ als frühesten Ankunftstermin den 20. April, als spätesten den 2. Mai und als mittleren den 27. April.

Das Nest findet man besonder's in Weissdornhecken oder in Brombeerranken. Kutter fand das volle Gelege am 27. Mai, Kollibay am 17. Mai, 8. und 9. Juni, ich am 19., 23., 24. Mai und 3. Juni. Nackte Junge traf Kollibay in einem Neste am 7. Juni an. Sehr interessante Aufschlüsse über die Färbung der Eier giebt uns Graf Roedern: „Die bekanntlich sehr variirenden Eier sind nach dem Standort des Nestes verschieden, d. h. nach der Beschaffenheit der Lokalitat. Die Nester mit Eiern von grünlicher Farbe habe ich stets nur in feuchtem, bruchigem Terrain und zwar nabe am Erdboden oder ganz auf der Erde, zuweilen tief unten in einem Binsengebüsch gefunden. Nester mit Eiern von gelblicher Färbung standen fast nur in Dornhecken, gewöhnlich an Feldwegen. Nester endlich mit Eiern von olivenbräunlicher Grundfärbung fanden sich meist in trockenem, ausgedehntem, gewöhnlich etwas hoch gelegenem Gebüsch und zwar besonders im Birkenholz."

II a asse von 57 schlesischen Eiern (davon 14 durch Kollib a y gemessen) in $\mathrm{mm}$ :

$\begin{array}{lccc} & \text { maximum } & \text { minimum } & \text { Durchschnitt } \\ \text { Länge: } & 20 & 16 & 17,9 \\ \text { Breite: } & 15 & 13 & 13,9\end{array}$

Kolllibay fand auch bei dieser Art Kuckuckseier im Neste. 


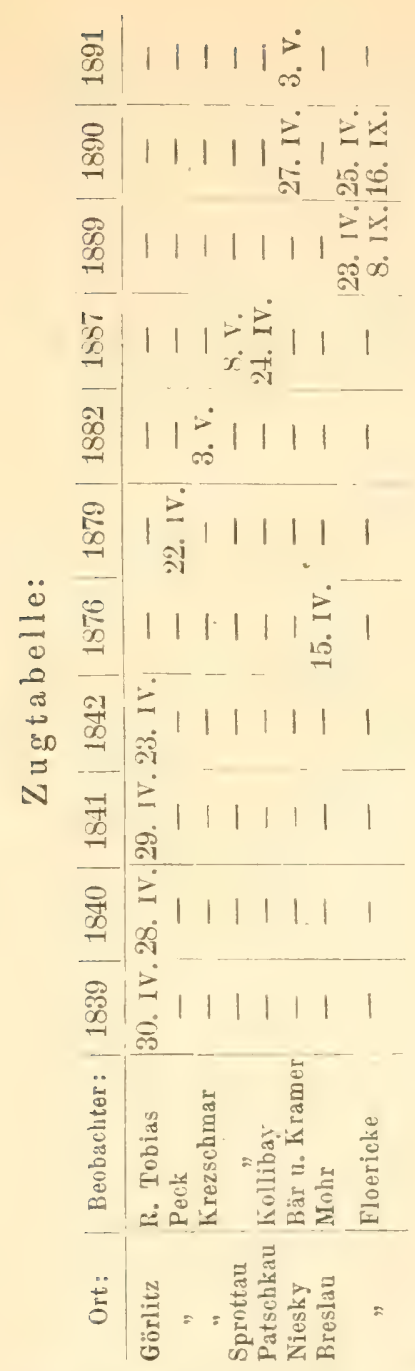

42. Sylvia hortensis Bchst. 1802. - Gartengrasmücke. Synonyma: Motacilla hortensis Gm., Bchst.; Motacilla salicaria L.; Curruca hortensis Koch; Curruca hortensis, C. brachyrhynchus, C. grisea Chr. Brehm; Epilais hortensis Kaup; Adornis hortensis Gray; Sylvia aedonia Vieill.; Sylvia hortensis Lath., Penn., Behst., Naum., Glog., Gieb., Kays. und Blas., A. Brehm, v, Hom., Radde, Hart., Gätke, Jïckel, Pleske. 


\section{Trivialnamen: Grasemische, Graukehlchen.}

Kennzeichen der Art: Dic Bastardschwinge kürzer als die Deckfedern; Schwanzdeckfedern nicht quergestreift und Elügelfedern ohne rostbraune Säume. Die '. - chwinge ist gleich der 4. und grösser als die 5 .

Maasstabelle in $\mathrm{mm}$ :

\begin{tabular}{|c|c|c|c|c|c|c|}
\hline Dure & $\begin{array}{l}\text { tsm. westdeutsch, } \\
\text { h Friderich }\end{array}$ & $\begin{array}{l}\text { Maasse } \\
\text { max. }\end{array}$ & $\begin{array}{l}\text { von } 25 \\
\text { min. }\end{array}$ & $\begin{array}{l}\text { schles. Ex. } \\
\text { Durchschn. }\end{array}$ & $\begin{array}{l}\text { Durchsehr } \\
\text { russ. Ex. }\end{array}$ & $\begin{array}{l}\text { nittsm, ron } 26 \\
\text { nach } P \text { leske }\end{array}$ \\
\hline Totalläıgø: & 143 & 157 & 146 & 153 & & - \\
\hline Flngbreite: & 227 & 244 & 231 & 239 & & - \\
\hline Schwanz: & 54 & 64 & 57 & 60 & & 63 \\
\hline Schuabel : & 10 & 14 & 11 & 12,5 & & 13,6 \\
\hline Tarsus: & 22 & 22 & 20 & 21 & & 20,9 \\
\hline
\end{tabular}

Bei hortensis sehen wir wieder einmal die Grössenzmmahme nach Osten hin recht deutlich, besonders auch an Fligel und Schwanz. Der Tarsus scheint sich daran nach allen von mir angestellten vergleichenden Messungen nicht zu beteiligen, soudern cr pflegt im Gegenteil bei den östlichen Exemplaren um ein weniges kleiner zu sein.

Obwohl in einzelnen Gegenden (Glogau, Bolkenhayn) recht läufig, ist die Gartengrasmücke im allgemeinen in Schlesien doch bei weitem nicht so gemein wie im mittleren Deutschland, ja in manchen Strichen fast die seltenste Grasmïcke (Bartschniederung). Dabei wird auch vielfach über rasche Abnahme ihres Bestandes geklagt ( $\mathrm{K}$ n a u th e-Zobten), ohne dass die Gründe dafür eigentlich recht ersichtlich wären. Am zahlreichsten und gleichmässigsten scheint sie den übereinstimmenden Berichten der dortigen Forscher zufolge noch in der Lausitz vertreten zu sein. R. Tobias nennt sie sogar die häufigste Grasmücke. Im Grbirge geht sie nicht sehr hoch aufwärts. Kramer giebt bereits 7,0 m (Schreiberhau) als die höchste von ihm beobachtete Höhenlage ihres Vorkommens an. Sie liebt Laubwald und lichte Feldhölzer nit einzelnen grossen Iäumen (R. Tobias) und bewuhut auch gern weitläuftige Obstgiirten und Parkanlagen, worauf ja selum ihr Name hindeutet. Im Fichtenwalde ist sie sehr selten, fehlt aber doch nicht yainzlich (R. Tobias). Als frühesten Ankunftstermin notirte R. Tobias von $1832-35$ den 2 , als spätesten den 16. und als durchschnittlichen den 9. Mai.

Nach Emmrich siugt hortensis bisweilen auch noch beim Wegzuge. Nur eine Brut Lnde Mai zu 5-(; Eiern, welche 14 Tage lang bebrütet werden (Mohr). Bisweilen schmuggelt der Kuckuck seine Eier in die licherlich gebauten Nester ein (Kutter). Volle Gelege fanden K ut er am 25.). Mai, 1. md 12. Juni, Praetorius am 30. Mai, Kollibay am 1.. Mai, 7. und ؛. Juni, ich selbst am 2. Juni. Flügge Junge traf R ichter am 20. Juni und 30. Juli. 
Zugtabclle:

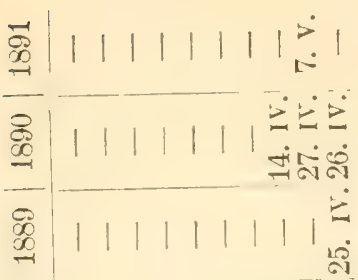

$\underset{\infty}{\infty}|1| \frac{j}{0}|1| 1\left|\frac{1}{0}\right|$

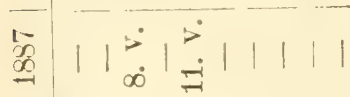

镨! 11110

超! $1111111=111$

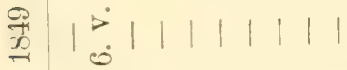

巽安111111111

至定 1111111111

糔安

|c

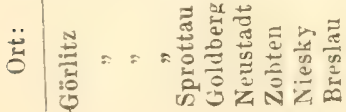


Maasse von 43 schlesischen Eiern (davon 15 durch Kollibay gemessen) in $\mathrm{mm}$ :

$\begin{array}{lccc} & \text { maximum } & \text { minimum } & \text { Durchschnitt } \\ \text { Länge: } & 22 & 19 & 20,1 \\ \text { Breite: } & 16 & 14 & 15,2\end{array}$

Märkische Eier messen nach Schalow im Durchschnitt $19,3+14 \mathrm{~mm}$, polnische nach Taczanowski $20,1+15,3$. Also auch hier die Eier im Osten grösser, also auch hier Śchlesien näher an Polen als an West- und Mitteldeutschland angeschlossen.

43. Sylvia nisoria (Bchst.) 1795. - Sperbergrasmücke.

sy non y a: Motacilla nisoria Behst.; Curruca nisoria Koch, Degl.; Curruca undata, C. undulata Chr. Brehm; Philacantha nisoria Glog., Heugl.; Adophanes nisorius Kaup; Nisoria undata Bon.; Sylvia nisoria Bchst., Naum., Glog., Kays. und Blas., Gicb., A. Br., v. Hom., Mewes, Fridr., Pleske, Hart., Gätke, Jäickel.

Kennzeichen der Art: Die Afterschwinge kürzer als die Deckfedern. Die Schwanzdeckfedern erscheinen quer gestreift. Die 3-4 äussersten Schwanzdeckfedern haben auf der Innenseite einen weissen Endfleck.

Ma asse von 20 schlesischen Exemplaren in $\mathrm{cm}$ :

$\begin{array}{lrcc}\text { Länge: } & 16,8 & 16,5 & 16,65 \\ \text { Flügelbreite: } & 27,0 & 26,1 & 26,3 \\ \text { Schnabel: } & 7,6 & 7,1 & 7,4 \\ \text { Schwanz: } & 1,7 & 1,4 & 1,55 \\ \text { Tarsus: } & 2,5 & 2,3 & 2,4\end{array}$

Dieser mehr östliche Vogel ist in Schlesien naturgemäss häufiger anzutreffen als im westlichen oder mittleren Deutschland, doch ist seine Verbreitung eine höchst unregelmässige, vielfach unterbrochene, ich möchte sagen inselartige. In einzelnen Gegenden ist sie sehr häufig, in anderen selten und in wieder anderen fehlt sie beinahe gïnzlich. So kommt sie nach Kaiser bei Sagan und nach Knauthe am Zobten nur auf dem Durchzuge vor, und bei Kosel brütet sie nach Uttendörfer nur vereinzelt und nicht in allen Jahren. Bei Breslau und in der Bartschniederung gehört nisoria zwar zu den regelmässigen Brutvögeln, ist aber keineswegs häufig. Dies muss dagegen in der Umgebung von Ziegenhals in holiem Grade der Fall sein, von wo die Breslauer Vogelhändler den grössten Teil ihres Bedarfes beziehen. Im Nordwesten der Provinz scheint diese Art am besten vertreten zu sein. In der Lausitz ist sie nicht selten und an der Oder sogar sehr häufig, so z. B. wach L. Tobias bei Grineberg. A. v. Homeyer fand bei Glogau allein 25 Nester. Derselbe Forscher constatirte die 
Sperbergrasmücke vereinzelt bei Salzbrunn und zahlreich bei Münsterberg und Neisse, K utter in der Grafschaft bei Lomnitz, Richter bei Strehlen, Kaiser bei Schweidnitz. Bei Neustadt ist sie nach $\mathrm{Kutter}$ die seltenste Grasmïcke. Im allgemeinen lässt sich sagen, dass sie in erfrenlicher Zunahme begriffen ist. Die Nähe des Menschen scheut auch diese Art keineswegs, und sie siedelt sich deshalb oft auf den ihr einen günstigen Aufenthalt bietenden Kirchhöfen selbst grösserer Stïdte (Breslau, Görlitz) an. Sonst liebt sie Hutungen mit viel Buschwerk und Dornengestruipp, dicht überwachsene Gräben und Dïmme, fenchte Laubholzwaldungen mit lichten Beständen und viel Unterholz, auch das Weidicht der Flussufer. Dem Gebirge und dem Nadelivald scheint sie gäuzlich zu fehlen. - In gesanglicher Beziehung wird diese Grasmücke vielfach unterschätzt. Ich habe wahrhafte Meistersänger unter ilnen gehört, deuen man mit Entzücken lausehen komnte, und die z. T. auch ein gar nicht geringes Nachahmungstalent besassen. Die Zugmonate sind Mai und August. Volle Gelege fanden Kutter am 25. und Praetorius an 21. Mai, Kollibay am 5. und 9. Juni, ich selbst am 6. Juni (mit 1 Ei von Cuculus).

Ma as se von 22 schlesischen Eiern (davon 4 durch Kollibay gemessen) in $\mathrm{mm}$ :

$\begin{array}{lccc} & \text { maximum } & \text { minimum } & \text { Durchschnitt } \\ \text { Länge: } & 22,0 & 20,0 & 20,5 \\ \text { Breite: } & 16,5 & 14,0 & 15,3\end{array}$

Kollibay fand in einem Neste, welehes die Jungen bereits verlassen hatten, ein taubes $\mathrm{Ei}$ von auffallender Grösse und länglicher Form mit am stumpfen Ende kranzförmig zusammentretenden Flecken; es war gewissen Eiern von collurio sehr ähnlich.

Gattung: Accentor Bchst. 1502. - Flüevogel.

Schnabel ziemlich stark, an der Wurzel sehr dick, mit lïnglich ritzenförmigen Nasenlöchern. Hinterzehe mit cinen grossen, stark gekrümmten Nagel. Die 3. und t. Schwinge am längsten. Hauptfarbe ein rostiges Braun. Der Magen ist sehr muskulös und erinnert mehr an den der Körnerfresser als an den der Sylvien. Aeussere und Mittelzehe am Grunde verbunden.

4t. Accentor modularis (L.) 1758. - Heckenbraunelle.

Synonyma: Passer canus L., Sylvia gula plumbea Klein; Motacilla modularis L., Gm., Bechst.; Curruca fusca Frisch; Curruca sepiaria Briss.; Sylvia modularis Lath.; Tharraleus modularis Kaup; Accentor pinetorum Chr. Brehm; Accentor modularis Bchst., Naum., Gould, Koch, Glog., Kays. und Blas., Gieb., A. Br., v. Hom., Mewes, Fridr., Hart., Gätke, Jäckel.

Trivialnamen: Graukehlchen. 
Kennzeichen der Art: Grösse unter $15 \mathrm{~cm}$. Die 4. Schwinge am längsten.

Ma as e von $1 t$ schlesischen Exemplaren in $\mathrm{cm}$ :

Länge :

Flugbreite:

Schwanz:

Schnabel:

Tarsus: maximum

14,8
22,1
5,9
1,3
2,3

minimum

14,1

21,2

5,3

1,1

2,1
Durchschnitt

14,6

21,8

5,7

1,2

2,2

In den feuchten Auwaldumgen Mittelschlesiens und in der sumpfigen Bartschniederung, wahrscheinlich auch an der oberschlesischen Teichplatte, gehört die Heckenbraunelle zu den grössten Seltenheiten. Ein alter und sonst sehr gut in der heimischen Vogelwelt bewanderter Breslaner Vogelfänger teilte mir cimmal voller Freude mit, dass er einen seltenen und ihm günzlich unbekannten Vogel gefangen luabe. Als ich num das Wundertier nähes besichtigte, entpuppte es sich als einfache Braunelle. In Obersehlesien dagegen bieten ihr die grossen Nadelwaldungen und uamentlich die ron allem Raubzeng frei gehaltenen Fasanenremisen ganz ungestörte Brutpläze, so dass sie dort ziemlich lüutig ist. Von meinen Mitarbeitern wird sie uur wenig erwähnt. Knathe sagt, dass sie am Zobten keineswegs häufig sei und obendrein im Abnehmen begriffen. In der Lausitz ist sie zahlreicher, auf dem Durchzuge oft massenhaft vertreten. Das cigentliche Gebiet dieser Art aber bildrn die Vorberge und ebenso auch das eigentliche Gebirge mit seinen Nadelwaldungen. Bei Hlinsberg ist sie ungemein liänfig, im Hochwald nach A. v. Hom e yer ziemlich luäufig. Sic liebt hier die an Unterholz reichen Nadelwaldungen und bevoryugt die Iiichtendickungen beim Brutgeschäft. Im Riesengebirge kommt sie nach Gloger bis zu cincm IHölsengürtel von 4600 Fuss im Nadel- und gemischten Wald sowie im Knnie. und Krummholz vor. "Man hört und sieht modularis im Kinieholz ganz gewöhnlich. Er liebt besonders die zusammenhängenden Wälder desselben, mögen sic auch sehrsumpfig scin, felilt aber anch da, wo auf den trockensten Bergen die Kiefer nur noch in einzelnen grossen sträucher'n gredeiht, nicht. Er trifft daher immer mit dem Fitis zusammen,“ A. v. Homeyer sah modularis zahlreich am Elb. und Kochelfall, v. 'T's chus i beobachtete eiu Pärchen im Krummlolz, Capek traf ein Weibchen in Fichtendickicht bei der letersbaude und ein altes Männehen im Knicholz bei den Aupaquellen $(1+20 \mathrm{~m})$; R. Tobias beobachtete den Vogel auf der 'Tafelfichte und im obersten Knieholz des Riescnkammes. Die Braunelle zeigt sich dort übrigens ziemlich selieu und lebt versteckt. $\Lambda$ v. Hom eyer hörte ein singendes Mïmnehen die Lieder des l)isteltinken und Wasserpiepers nach- 
ahmen. Der Zug fällt in die Monate Mïrz und Oktober. Es bleiben aber auch sehr viele Vögel dieser Art regelmässig bei uns, selbst in den strengsten Wintern. Ueber das Brutgeschäft liegen mir leider gar keine Nachrichten aus Schlesien vor.

\section{t5. Accentor collaris (Scop.) 1769. - Alpenflüevogel.}

Synonyma: Motacilla Kyburgensis Gesn.; Motacilla alpina Gm., Buff.; Sturnus moritanus Gm.; Sturnus collaris Scop., Gm.; Fringilla gularis Sprüngl., Storr; Fringilla collaris Lath.; Turdus minor Baldac.; Accentor maior, A. subalpinus Chr. Brehm; Accentor alpinus Behst., Namm., Glog., Gould, Chr. Br., Kays. und Blas., Gieb., A. Br., Fridr., Rehw., v. Hom., Mewes, Radde, Gätk.; Accentor collaris Hartert.

\section{Trivialnamen: Schnee- und Alpenlerche.}

Kennzeichen der Art: Grösse über $16 \mathrm{~cm}$. Die 3. Sehwinge am längsten.

Durchschnitts- MI a a s e von 3 schlesischen Exemplaren: Länge $=16,8 \mathrm{~cm} ;$ Flugbreite $=29,8 \mathrm{~cm}$; Sehwanz $-6,4 \mathrm{~cm}$; Schnabel $=1,7 \mathrm{~cm} ;$ Tarsus $=2,4 \mathrm{~cm}$.

Der Alpenflïevogel bewohnt die Hochgebirge von süd- und Mitteleuropa und ist eine der Hauptzierden unserer schlesischen Ornis. Das Riesengebirge ist der einzige Platz in Preussen, wo dieser interessante Alpenbewohner brütet. Im Anfange unser's Jahrhunderts scheint er dort übrigens nach Endler und R. 'T'obias läufiger gewesen zu sein als jetzt. Den gegenwiirtigen Gesantbestand des ganzen Riesengebirges glaube ich mit 10-12 Pairehen resp. Familien nicht zu gering zu schätzen. Dieselben verteilen sich ziemlich gleichmässig auf die Schneekoppe, die Schneegruben und das hohe Rad. Doch hören wir in zeitlicher Reihenfolge die Berichte derjenigen Autoren, welche das Glück hatten, persönlich mit collaris bekannt zu werden: Cloger sehreibt 1826: „Findet sich anf der fast ganz mit Sohollengeröll bedeckten Koppe, selbst auf den benachbarten Felspartien des Riesengrundes, diesem gegenüber an dem sehr steilen Abfall des Brunnenberges, an den obersten Rändern des kleinen Teiches, auf dem felsigen, nach Böhmen hinschauenden Teile des Ziegenrückens, damn vorzugsweise wieder in den Schneegruben, wahrselieinlich auch in der Nähe des Elbfalls am sog. Rochlitzer Ziegenriek, aber nirgends in bedeutender Anzahl, sondern höchstens in etwa 3 Pärchen oder Familien. Die trockensten, felsigsten, steinigsten, vom Hol\% entblïssten Orte zicht er allen andern ror." Das lireslauer Museum besitzt ein junges Männchen, das wohl auch noch aus ( R. Tobias fand unsern Vourel im Juni 1, ti am grossen Teich, kleinen Teich und im Riesengrund, äberall ziemlich zahlreich. 
Heydrich erlegte 1869 ein Exemplar in den Schneegruben. v. T'schusi beobachtete in den Schneegruben 2 Pärchen und am Brunnenberge ein Weibchen. A. v. Homeyer fand 1865 an den Schneegruben 5-8 Pärchen und beobachtete Ende August 1867 ein junges singendes Männchen am kleinen Teich. Den Gesang nennt dieser Forscher "nicht sehr bedeutend". Nach meinen an gefangen gehaltenen Exemplaren gemachten Beobachtungen muss ich dem aber entschieden widersprechen und befinde mich dabei im Einklang mit den meisten andern Beobachtern. Gloger sagt ausdrücklich: „Sein herrlicher, lauter Gesang und die schönen Locktöne hallen zwischen den hohen Felswänden und in den tiefen Schluchten ganz vortreflich wider. Am Koppenkegel sah v. Homeyer den Vogel auffälliger Weise gar nicht. Krezschmar dagegen traf ihn an der Koppenbaude und $\mathrm{T}$ a lsky sah ebendasolbst 1 altes und 3 junge Exemplare. $\mathrm{Capek}$ beobachtete bei Somnenaufgang auf dem Gipfel der Schneekoppe 9 sehr zutrauliche Individuen, welche in Gesellschaft von Ruticilla titis und Anthus upuatirus ihrer Nahrung nachgingen. Der zweite Ort, wo er die Alpenbraunelle antraf, war der nordwestliche Abhang des mit Steinblöcken bedeckten hohen Rades mit den oberen Partien der anliegenden Schneegruben. "Hier bemerkte ich 3 alte Vögel, die während der Mittagsstunden auf den Felsblöcken oder in einem Versteck unter denselben ausruhten, dam cin Weibchen, welches 2 nachfliegende Junge fütterte. An diesen beiden Stellen haben höchstens je 3 Parre genistet. ${ }^{*}$ A. E. Brehm bemerkte Alpenflüevögel am Koppenkegel, IIohen Rad und in den Schneegruben, und R. Blasius entdeckte 157 in letzteren ein Nest. Kollibay sah 1887 ebenfalls bei Sonnenaufgang einen kleinen Flug auf dem Gipfel der Schneekoppe, Kramer und ich 1891 je 15 resp. 8-9 Stück an den steilen Wänden der Schneegruben. Ich fand den Togel dort nicht so zutraulich wie die Besucher der Koppenbaude. Nach Kollibay vertritt er daselbst vollständig die Stelle des Haussperlings, sucht zwischen den Dachziegeln der Baute und unter den Fïchenabfällen seine Nahrumer u. s. w. Wie aus dem Vorhergehenden er'sichtlich, ist der Alpenflïevogel im Riesengebirge auf einen Höhengürtel von t- J000 Fuss beschrïnkt. Im Wintẹ. kommt er niedriger herab und streift auch in das benachbarte Isergebirge hinüber, wo ihn R. 'Tobias anf' der 'Tafelfichte beobachtete. Ganz vereinzelt kommt er nach Luchs ins Hirschberger Thal. R. Blasius crbeutete am 19. Juni 187 's mit Lebensgefahr an der Sehneegrubenbaude ein Nest mit 2 ca. 10 Tage alten Jungen. "Es stand mach Norden in einer kleinen Vertiefung unter dem Felsen unmittelbar auf verwittertem Granitgrunde. Der Vertiefung entsprechend ist die Form eiue kurz-ovale, 17, resp. $14 \mathrm{~cm}$ breit, $6 \mathrm{~cm}$ hoch, 8 , resp. $7 \mathrm{~cm}$ weit und $6 \mathrm{~cm}$ tief. Die iussere, dicht dem Felsen aufsitzende Schicht besteht aus Moos, 
trockenen Stengeln und Wurzelfasern, die innere Sehicht aus feinen Grashalmen, die zuletzt mit einer dünnen Lage von Schweinsborsten und 4-5 kleinen Hühnerfederchen ausgekleidet ist. Die Jungen zeigen eine ganz charakteristische, dicke, kurz-konische Schnabelwurzel und starke, stämmige, kurze Läufe; an den eben vorsprossenden Mittelschwingen und deren Deckfedern sind die hellen Spitzen dentlich zu erkennen, ebenso die hervorspriessenden rostbräunlichen Enden der seitlichen Brustfedern." 


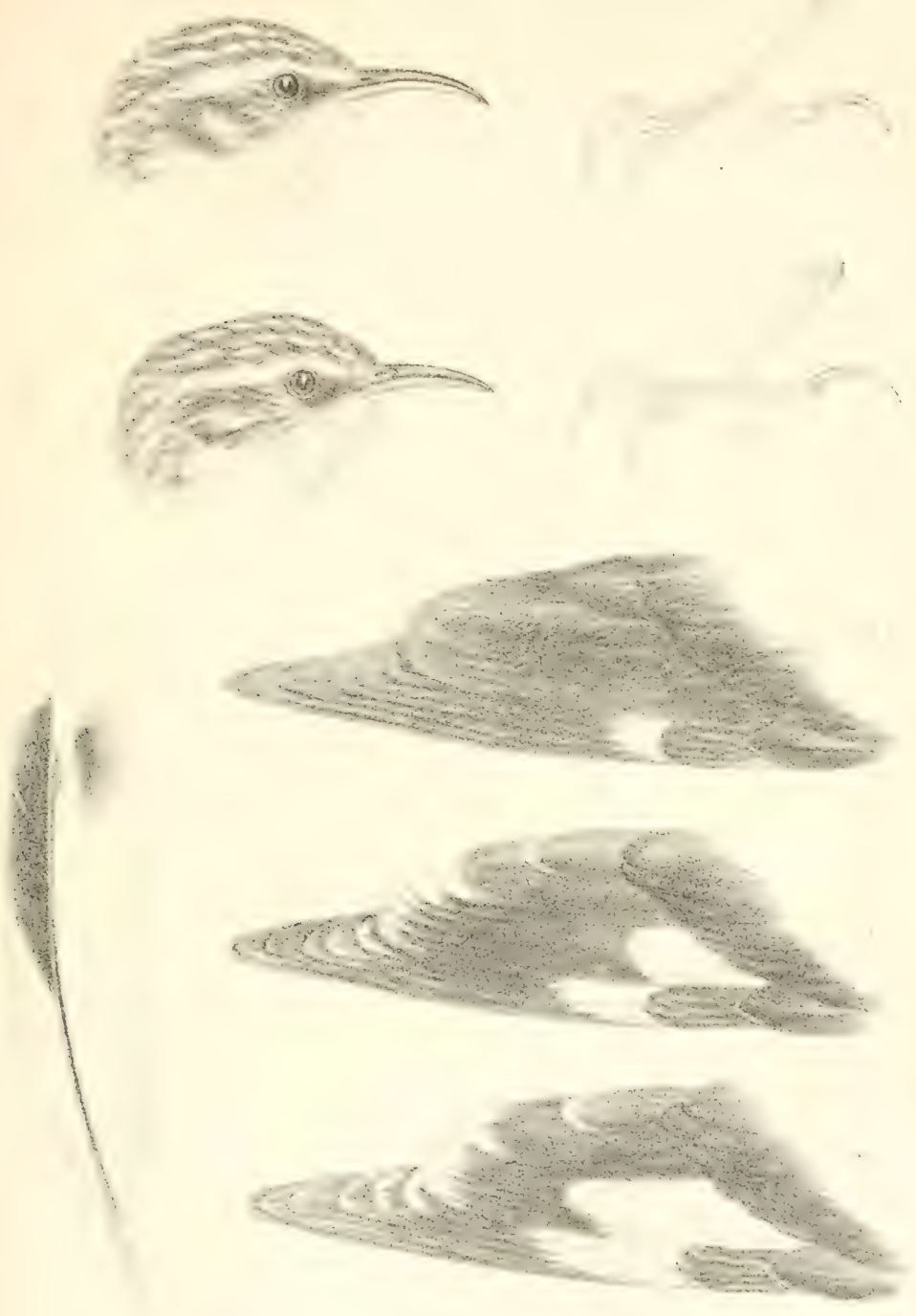



Versuch einer

\section{Avifauna der Provinz Schlesien.}

Ton

Dr. Cure Hloericke.

Assistenten am zoologischen Institut der Lniversitit Marburg.

II. Lieferung.

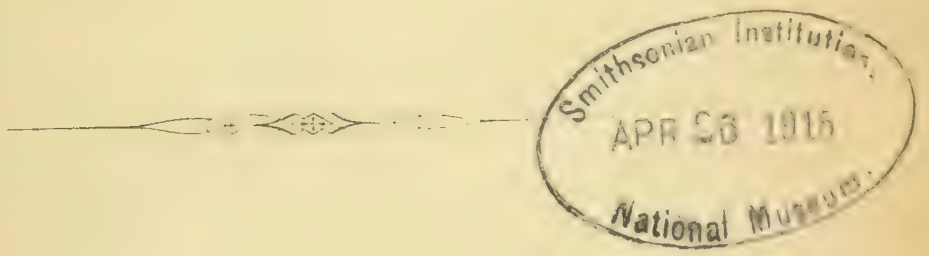

MARBURG.

Universitäts-Buchdruckerei (C. L. Pfeil).

1893. 



\section{Versuch einer}

\section{Avifauna der Provinz Schlesien.}

Von

\section{IDr. Craxt Hloericke,}

Assistenten am zoologischen Institut der Universität Marburg.

II. Lieferung.

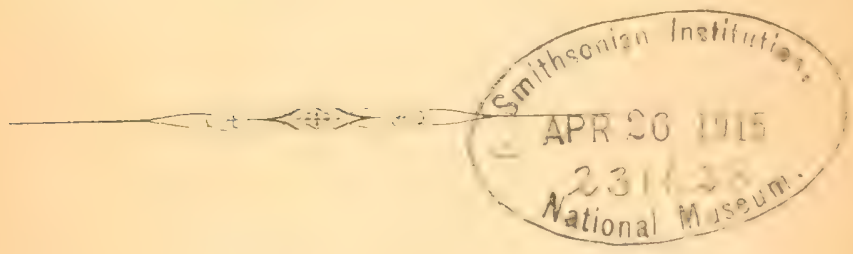

MARBURG.

Universitäts-Buchdruckerei (C. L. Pfeil).

1893. 

Familie: Timeliidae, Timalien.

Gattung: Troglodytes Vieill. 1807. - Z a un s chlüpfer. Kleine Vögel mit gebogenem, dünnem und pfriemförmigem Schnabel, welcher die Länge des Kopfes nicht erreicht. Nasenlöcher sehr schmal. Fusswurzel auf dem Spann mit 4 grossen Schildern. An den kurzen runden Flïgeh sind die t. und 5 . Schwinge am längsten, die 1. halb so lang als diese, alle vorderen Schwingen säbelförmig. Der keilfürmige Schwanz ist kurz abgerundet.

46. Troglodytes parvulus Koch 1816. - Z a unkünig.

Synon yma: Passer troulodytes alte Autoren; Regulus Briss.; Motacilla troglodytes L., Buff., Gm., Behst.; Sylvia troglodytes Lath., Behst.; Anorthura enmmunis Reun., Reich.; Anorthura troglodytes Hart.; Troglodytes europaeus Vieill., Cuv.; Troglodytes regulus Meyer; 'Troglodytes punctatus Boie; Troglodytes vulgaris Tem.; Troglodytes troglody tes S'chleg.; Troglodytes Naumami, Tr. sylvestris, Tr. domesticus Chr. Brehm; Troglodytes nepalensis Hodgs., Gould, Blanf.; Troglodytes subhimalayanus Hodg.; ; Truglodytes parvulus Koch, Naum., Glog., Kays. und Blas., Gieb., A. Brehm, v. Hom., Hewes, Radde, Fridr., Gätke, Jäekel.

Trivialnamen: Schnec-, Dorn-, Winter-, Mäuse- und Nesselkönig, Zaunschlipflein.

Muskauer Wendisch: Seischek.

Kennzeichen der Art: Siehe die Gattungsmerkmale, da nur diese eine Art in Deutschland.

Ma a s e von 15 schlesischen Exemplaren in $\mathrm{cm}$ :

$$
\text { maximum minimum Durchschnitt }
$$

$\begin{array}{lrrr}\text { Länge: } & 9,9 & 9,1 & 9,5 \\ \text { Flügelbreite : } & 15,2 & 14,0 & 14,6 \\ \text { Schwanz: } & 3,2 & 2,9 & 3,0 \\ \text { Schnabel: } & 1,2 & 1,0 & 1,1 \\ \text { Tarsus: } & 2,0 & 1,6 & 1,8\end{array}$

Wie man sieht, variiren die Zaunkönige in der Grösse ziemlich bedeutend, ohne dass sich aber hierin irgend welche (iesetz- 
mässigkeit nachweisen licsse. Vielmehr ist der individuellen Ausbildung der weiteste Spielraum gegeben. Nach $R$ adde sind seine kaukasischen Exemplare um eine Kleinigkeit dunkler wie westdeutsche; in Schlesien habe ich davon noch nichts wahrnehmen können.

Am 8. III. 1890 beobachtete ich in der Strachate ein Exemplar, welches partiellen Albinismus zeigte, konnte es aber leider nicht erlegen.

In der schlesischen Ebene ist der Zaunkönig eine ziemlich seltene Erscheinung, wenigsteus bei weitem nicht so häufig als in den meisten anderen Gegenden Deutschlands. Im Winter sieht man ihn zahlreicher, weil dann die Standvögel noch dureh Zuzug aus dem Norden verstärt werden. Ich habe einmal cinen ganzen Trupp auf der IVanderschaft begriftener Zaunkönige in der Strachate gesehen. In Oberschlesien ist der Vogel schon zahlreicher vertreten, denn hier bicten ihm namentlich die vielen Fasanenremisen prichtige Brutplätze. Aueh am Zobten ist der Zaunkönig nach Kna ut he ziemlich hitutig. In den grossen Brüchen Ostschlesiens ist er gemein und nistet auf den Erlenstöcken. In der Lansitz finden sich zwar im Whinter viele Zaunkönige ein, aber als Brutvögel sind sie auch hier nicht allzu zahlreich. Die Wintergäste haben stets ihre bestimmten Lieblingspluatze, die sie jedes Jahr mit grosser Regelmässiglieit und oft it bedeutender Menge aufsuchen. Die meisten Zaunkönige Sublesiens aber beherbergen die Vorberge der Sudeten wie auch diese selbst. Alte, wiste Gubirgswaldungen mit recht sparrigen und verworenem Unter. holz scheint dals muntere Vö̈gelchen ganz besonders zu lieben. Wetterhart, wio der '/aunkünig ist, geht er auch vertikal ziemlich weit in die Ilöhe. Kr a mer tral ihu im Knieholz bis äber $1400 \mathrm{~m}$ an und vermutet, dass er dort brüte. R. Blasius sah Zaun-

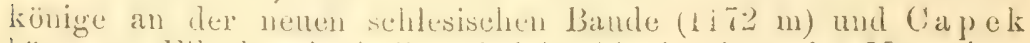
hörte am Elbufer wberhalb sjpindehüihl ein singendes Männchen. R. Tob ias beobachteie den Troyludytes anf dem Iserkamm, und bei linsberg ist das Vögelehen ausserordentich gemein. Schattige Wähder nit vielen dichten Gebiisch wählt er am liebsten zum Standquartier, aber auch ganz einzeh stehende lebende oder tote Hecken und Züunn, wenn sich diesclben in der Nähe von Ge. wässern befinden.

Der Zalunkönig veruchet sich seler stark. Er macht bei uns in schlesien regehmässig 2 Bruten zu je $\succ$ Eiem. Moh $\mathbf{r}$ giebt sugar 12 Lier für das erste Gelece an. Wie in Schlesien gemachten Beobachtungen über das Brutgeschät dieses Vogels sind im übrigen recht dürtig. L. T'o bias beobachtete, dass Zaunkïnige in Mauselöchern brüteten. I Itter fand am 20. Juli nackte Junge. 
Maasse von 17 schlesischen Eiern in mm:

$\begin{array}{lccc} & \text { maximum } & \text { minimum } & \text { Durchschnitt } \\ \text { Länge: } & 16 & 14 & 15,48 \\ \text { Breite: } & 12,5 & 11,5 & 12,0\end{array}$

Die alte Behauptung, dass der Zaunkönig im Herbste nochmals ein Nest baue (wohl zum Uebronahten für die kalten Wintermonate) erscheint mir gar nicht so unwahrscheinlich, demn mancherlei Beobachtumgen weisen daranf hin. Jedenfalls bedürfen anch diese abgeliärteten Vügelchen an recht rauhen Abenden eines wärmenden Nachtquartiers. So erzahlt Knauthe, dass sich an einem Decemberabend des Jahres 1sg( drei Zaunkönige vor der grimmen Kälte in ein Feldsperlingsnest flüchteten, aber nach hartem Kampfe voì den rechtmïssigen Inhabern wieder herausgebissen wurden. Manche sehliefen auch auf dem Kornborlen, wohin sie durch die sog. Luftessen gelangten. Ein andermal will derselbe Bcobachter gesehen haben, wie sich ein vorwitziger Zaumkönig der Hauskatze auf den Kopf setzte.

Familie: Paridae, Meisen.

Schmabel gerade, kurz, hart, stark, kegelförmig, seitlich zusammengedrückt, mit scharfen Sehneiden. I)ic kleinen, runden Nasenlöeher sind mit Borstenfederehen bedeckt. Zunge nit Borstenpinseln. Krallen sehr gekrimmt, Fusssohlen breit. Lauf rorm getäfelt, hinten über drei Viertel ler Lünge geschient. An den kurzen Flügeln ist die 1. Schwinge liürzer als die Hälfte der ־.., die 4. und 5. am längsten. Gefieder zerschlissen.

Gattung: Aegithalus Boie 182:. - Beutelmeise.

Schnabel vorn sehr dümn und spitzig, da vou der Mitte: an zusammengedrückt. Schwanz kuxz. Die 3., 4. und 5. Schwinge am längsten.

47. Aegithalus pendulinus (L.) 170̃. - Beutelmeisc.

Synonyma: Motacilla pendulina $\mathrm{L}_{\text {. }}$; Parus pendulinus L., Bufi., Behst, Gm., Namm., Glog., Gieb., Fridr.; L'ar'us narbonensis Gm.; Parus polonieus Briss.; Paroides pendulinus Cray; Pendulinus polonicus, P. medius, P. macrurus Chr. Brehm; Aegithahus medius, Ae. macrurus, Chr. Brehm; Acuithalus pondulinus Vign., Jard. u. Selby, Boic, Degl., Kays. u. Blas., A. Brehm, v. Hom., Newes, Jitckel, Radde, Tartert; Aegithalus pendulinus castaments Sevz.; Aegithalus pendulinus caspius Poelz.

Kennzeich en der. Art: biehe die Cxattmernerkmale, da nur diese eine Art in Deutschland.

Frïher hat die Beutehneise in śchlesien g(t)riitet, jetzt ist dies wohl kanm noch der Fall. Insbesondere war rer Togel in der Bartschniederung nicht allzu suten, obschon we seines versteckten 
Lebens halber auch dort wenig bekannt war. Im Breslauer Muscum steht ein von dort stammendes Nest mit 4 Jungen und ein altes Exemplar. Auch in der Heydrichschen Sammlung befindet sich ein Stïck, welches 1870 aus einem Fluge von drei Individuen geschossen wurde. Nach v. H a hn hat die Beutelmeise früher in den Rohrteichen Guhraus genistet, nach $\mathrm{K}$ a I u z a anch bei Nimkau. Jetzt zeigt sie sich noch hin und wieder auf dem Durchzuge. Ich selbst beobachtete sie einmal in der Bartschniederung bei Craschnitz und $\mathrm{K} n$ a $u$ the sah am 3. Februar 1890 6 Stiick in seinem Garten am Zobten. Dagegen muss ich es als sehr übertrieben bezeichnen, wenn Mohr die Beutelmeise einen nunbedingten Wintervogel bei Breslau“ nennt. In der Lausitz soll sie nur einmal, im Jahre 1823, vorgekommen sein.

\section{Gattung: Panurus Koch 1816. - Schilfmeise.}

Schnabel hell, Nasenlöcher länglich eiförmig. Die 1. Schwinge verkürzt, die t. und 5. am längsten. Die äusseren Schwanzfedern halb so lang als die mittleren. Die Mämuchen besitzen einen sehr charakteristischen schwarzen Schnurrbart, welcher bei den Weibchen von den Kehlfedern überdeckt ist.

48. Panurus biarmicus (L.) 1758. - Bar tmeise.

Synonyma: Parus biarmicus L., Bchst., Vieill., Naum., Gieb., Fridr., Gätke; Parus russicus Gm.; Parus beardmanicus Albin; Lanius ninimus Edw.; Paroides biarmicus Gray; Parus barbatus Briss., Scop., Glog:; Callimophilus biarmicus Selby; Calamophilus biarmicus Leach; Calamophilus barbatus Kays. u. Blas, Leach, Radde, Jäckel; Calamophilus russicus, C. arundinaceus, C. dentatus Chr. Brehm; Mystacinus biarmicus Boie; Mystacinus rusicus, M. arundinaceus, M. dentatus Chr. Brehm; Aegithalus biarmicus Boie; Panurus barbatus Saund.; Panurus biarmicus Koch, Degl., A. Brehm, v. Hom., Hewes, Hartert.

Kennzeichen der Art: Siehe die Gattungsmerkmale, da nur diese eine Art in Deutschland.

Von der Bartmeise gilt im wesentlichen dasselbe wie von der vorigen Art. Während sie früher nach den übereinstimmenden Berichten der alten Autoren in der Bartschniederung sogar nistete, ist sie jetzt auch auf dem Zuge eine höchst seltene Erscheinung geworden. Kna uthe war so glïcklich, sic zweimal zu beobachten. Am 1. April 1887 sah er einige Exemplare in einem grösseren versumpften Gehölz. Ferner berichtet er: ${ }_{n} \mathrm{Am}$ 1. IX. $1890 \mathrm{kam}$ bei ganz flauer Brise aus Süden ein kleiner Trupp vou Westen her nach dem Dorfe gepilgert, verteilte sich in die verschiedenen Gärten (in unserem Gehöft zählte ich 5 Stück, in den Obstpflanzungen angrenzender Rusticalgüter z, 3 und 4), weilten hier bis gegen $8 \mathrm{Uhr}$ und zogen dann den ${ }_{n}$ Schwarzen 
Graben" entlang - an seinem Ufer stchen auf schlanpitzer F(biet noch dicht gedrängt li eiden und Erlen - gen Osten, der Lohe zu, weiter." Nach meinen Erfalrungen ziehen die Meisen (namentlich Adertulu coututa) vieffach planlos lireuz und quer und berühren dabei Gegenden, in denen sic sonst nicht rorkommen. Einem solchen sich zigeunerartig herumtreibenden Trupp mögen auch die von Knathe beobachteten Barmeisen angehürt haben.

Gattung: Acredula Koch 1,11; - Sehwanzmeise.

Schmabel sehr kurz und schwach. Nasenluch punktförmig. Der Schwanz ist sehr lang mul sicht intolge rerschiedener Liinge der einzelnen Federpare stufenförmig aus.

Schwanzmeise.

49. Acredula candata (L.) 176s. - W Dissküplige

taa. Acredula caudata rosea (Blyth.) 1436. - II istliche Schwanzmeise.

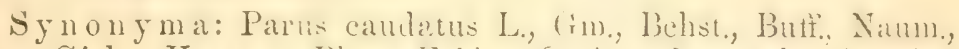
Glog., Gieb., Kays. 1. Mlas, Frielr., Caitse; Parus longicamdus Briss,; Orites candata Möhr, sund., Mend.; Orites cambatus lichw., Mewes; Orites rosens Gray; Mecistura ragan- Leneh; Mecistura

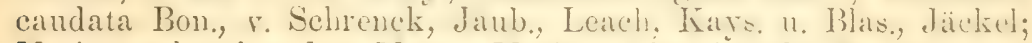
Mecistura lougicaudata Macg.; Mecistura Lnnicaula, M. pinetorum Chr. Brehm; Necistura rosea Blyth; l'aroifes cautatus, 1'. pinctorum Chr. Brehm; icredula caindata Luch, Sharpe, A. Brehm, v. Hom., Radde, Hartert.

Trivialnamen: Zahl- unl Bergmeislein, Pannenicle -stieglitz, -stösser.

Kennzeichen der Art: Siche die Gattungsmerkmale, dat nur diese eine Art in Deutschland.

Wohl allgemein untersebeidet man jetzt bei dex sehwanzmeise zwei subspecies, nämlich die rein weissküptige östliche Form un die westliche rosed mit breiten sehwar\%en Kropifstreifen, Audentum

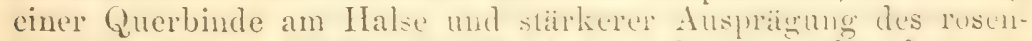
rötlichen Tones. Ueber den Wirt ron subspecies aber kommen diese beiden Formen nicht hinans, mol ich remay mich deshalh hier nicht an Reichenow anzuschliessen, welcher rosea als selbstständige Art mit aufziblı!. I) (na! in Mitteldentsohland finden sich alle nur denkbaren Ucbereainge, und Terbastardirumgen

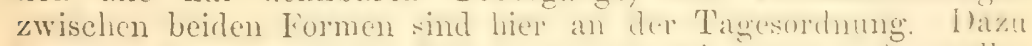

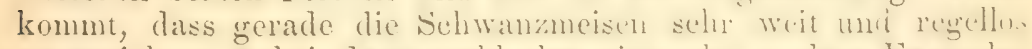
verstreichen, wobei dand wolnl das cine whe amlere Exemplail eimmal ans irgend welelien Grïnden im Grbeve ler anderen sub. species zurückbleibt und hier anch zur Fontlanzung schreitet.

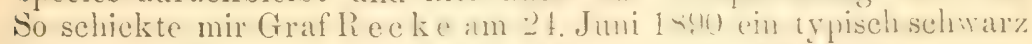
gestreiftes Eexemplar, das sich als cin altes Mäminchen erwies, 
aus Craschnitz. Der Fall ist zweifellos, da ich, um ganz sicher zu gehen, das Geschlecht sogar auf listologischen Querschnitten mikroskopisch untersuchte. Zur Brutzeit haben wir in Schlesien sonst nur die echte caudata, aber auf dem Zuge scheint auch rosea bisweilen vorzukommen; wenigstens habe ich sie schon einmal in Schleibitz bei Hundsfeld geschossen.

M a asse von 36 schlesischen Exemplaren (alles echte caudata) in $\mathrm{cm}$ :

$\begin{array}{lcccc} & \text { maximum } & \text { minimum } & \text { Durchschnitt } & \text { Nach } \\ \text { Lärideriche: } & 15,9 & 14,8 & 15,1 & 14,5 \\ \text { Flägelspannung: } & 20,2 & 18,5 & 19,0 & 18,5 \\ \text { Schwanz: } & 10,6 & 9,3 & 9,6 & 8,7 \\ \text { Schnabel: } & 0,5 & 0,5 & 0,5 & 0,5 \\ \text { Tarsus: } & 1,7 & 1,5 & 1,6 & 1,6\end{array}$

Hieraus ist ersichtlich, dass der Vogel nach Osten zu an Grösse zunimmt, zumal auch $\mathrm{R}$ ad d e viel beträchtlichere Maasse als Friderich angiebt.

In ten Laubwäldern der schlesischen Ebene ist die Schwanzmeise überall ein gemeiner Brutvogel; so fand ich sie bei Breslau schr haiufig. Doch wird an manchen Orten über ihre Abnahme geklagt, so \%. B. von L. Tobias für die Gegenden von Görlitz und Grüneberg. Im Gebirge findet sie sich nur spärlich, weil dort meist Nadelholz vorhanden ist, welehes sie nach Möglichkeit vermeidet. Deshalb muss sie für das Glatzer- und Isergebirge nach Emmrich und Michel als die seltenste Meise bezeichnet werden, und anch in Oberschlesien ist sie aus demselben Grunde nicht eben häufig. Im Riesengebirge fand sie Kollibay öfter in der Thal- und Valdregion. Am Zobten ist sie mach $\mathrm{Knau}$ the selten. Laubhölzer, Parks und auch grosse, zusammenhärngende Obstgärten bilden die bevorzugten Aufenthaltsplïtze der Schwanzmeise. Den Menschen scheut das zutrauliche Tögelchen ganz und gar nicht. Ki nathe constatirte sie als Brutvogel auf der Promenade von Schweidnitz, und auch ich habe sie wiederholt anf den schönen Promenaden von Breslau gesehen, vermag aber nicht mit Sicherheit anzugcben, ob sie dort auch brütet. Volle Gelege fanden Emmrich am 23. April, Thieman am 3. und ich am 4. Nai. v. Boen ig k erbeutete eimmal ein Nest mit ganz weissen Eicrn. Nach Kollibay fängt sich die Schwanzmeise auch bisweilen im Dohnenstieg.

Masse von 14 schlesischen Eiern in mm:

$\begin{array}{lccc} & \text { maximum } & \text { minimum } & \text { Durchschnitt } \\ \text { Länge: } & 14,5 & 13 & 13,65 \\ \text { Breite: } & 11 & 10 & 10,45\end{array}$


Gattung: Parus L. 1758. - Waldmeise.

Typische Meisen mit mittellangem Sehwanze und starkem kegelförmigem Schnabel. Die 2.. Schwinge ist kürzer als die 6. Höhlenbrüter und gelegentliche Samenfresser.

50. Parus cristatus L. 175s. - H a u benme is e.

Synonyma: Lophophanes cristatus Kaup, Newes, Radde; Lophophanes mitratus, L. capistriatus, L. rufescens Chr. Brehm; Parus mitratus Chr. Brehm; Parus cristatus L., Buff., Gm., Bchst., Naum., Glog., Gieb., Kays. und Blas., A. Br., v. Hom., Gätke, Hartert, Jäckel.

Trivialnamen: Strauss-, Kobel-, Heubel- und Heidemeise, Koppmeese. Im oberschlesisch-polnischen Idiom heissen alle Waldmeisen Siekora.

Kennzeichen der Art: Auf dem Kopfe eine deutliche Federhaube,

M a a s e von 31 schlesischen Exemplaren in $\mathrm{cm}$ :

$\begin{array}{lccc} & \text { maximum } & \text { minimum } & \text { Durchschnit } \\ \text { Länge: } & 12,7 & 11,7 & 12,1 \\ \text { Flügelbreite: } & 20,8 & 19,3 & 19,9 \\ \text { Schwanz: } & 4,5 & 4,2 & 4,4 \\ \text { Schnabel: } & 0,8 & 0,8 & 0,8 \\ \text { Tarsus: } & 1,5 & 1,4 & 1,4\end{array}$

Die Brehmsche suhspecies mescens, welche sich durch rostgrauen Oberkörper und rostgraue Seiten anszcichnet, kommt auch in Schlesien vor. Ia sich aber daneben eben so zahlreich die gewölnhliche cristatus findet, so ist nicht ersichtlich, ob rufescens eine constante Lokalvarietït oder nur eine individuelle Abweichung darstellt.

In all den zahllreichen Nadelwäldern Schlesiens, so insbesondere in der Lausitz, im Gebiete der Sudeten und in Oberschlesien, ist die Haubenmeise eine gewöhnliche Erscheinung. Da, wo sich der Nadelwald ohne Unterbrechung meilenweit ansdehnt, darf man sie wohl als die gewöhnlichste NIeise bezciehnen; das gilt z. B. für die Görlitzer Heide. Freilich verringert unsere moderne Forstwirtschaft die Brutbïume immer mehr, und die Klagen über das Abnehmen dieser und anderer Meisenarten sind daher fast allgemein. Am Zobten ist cristutus nach Kna uthe nur spairlich vorhanden. Als vertikale V'erbreitungsgrenze giebt Gloger eine Höhe von 3800 Fuss an. Die Haubenmeise bewohnt die ganze Waldregion des Riesengebirges bis zum Knicholzgürtel. A. v. Homeyer traf sie im Aupathal und bei sehreiberhau, Kollibay auf dem Cavalierberge, R. Blasius am Zackenfall und R. Tobias auf dem Iserkamm, Fechner bomerkte eine auf- 
fallende Vorliebe des Vogels für Wachholdersträucher. Praetorius fand am 16. Mai das volle Gelege. Kollibay beobachtete am 19. Mai ein Pärchen, welches Nestjunge fütterte. ${ }_{n} A l s$ sie mich zuerst bemerkten, thaten sie sehr ängstlich und legten sich zeitweise in eigentümlicher. Weise der Länge nach mit gespreizten Flügeln auf einen Zweig."

Masse von 12 schlesischen Eiern in $\mathrm{mm}$ :

$\begin{array}{lccc} & \text { maximum } & \text { minimum } & \text { Durchschnitt } \\ \text { Länge: } & 17 & 15 & 16, \check{0} \\ \text { Breite: } & 12,5 & 11,5 & 12,0\end{array}$

\section{Parus caeruleus L. 1758. - B la um e ise.}

Synonyma: Cyanistes caeruleus Kaup, Mewes, Radde; Cyanistes caerulescens, C. salicarius, C. violaceus Chr. Brehm; Parus coerulescens Chr. Brehm; Parus coeruleus L., Gm., Bchst., Naum., Glog., Giebel, Fridr., Kays. und Blas., A. Brehm, v. Hom., Hart., Jäckel, Gätke.

Trivialnamen: Bloomeese, Mehl, Bien- und Pimpelmeise.

Kennzeichen der. Art: Schcitel blau, bei jungen Vögeln grünlich. Unterlkörper gelb.

Masse von 64 schlesischen Exemplaren in $\mathrm{cm}$ :

$\begin{array}{lccc} & \text { maximum } & \text { minimum } & \text { Durelischnitt } \\ \text { Länge : } & 12,1 & 11,7 & 11,8 \\ \text { Flügelbreite: } & 20,6 & 19,7 & 20,1 \\ \text { Schwanz: } & 5,4 & 5,1 & 5,3 \\ \text { Schnabel: } & 0,8 & 0,6 & 0,7 \\ \text { Tarsus: } & 1,8 & 1,8 & 1,8\end{array}$

Die Blaumeise ist in Schlesien nirgends selten und fehlt nur dem reinen Kieferwald. In Gegenden, wo das Nadelliolz selne überwiegt, triftt man sie weniger häutig, so z. B. in der Grafschaft Glatz; anch in der Görlitzer Ileide brütet sic nur spärlich. In Anlagen und grossen Gärten gehört sie zu den regelmässigen Brutvögeln, und im Winter kommt sie zutraulich auch in die belebtesten Städte und holt sich die für sie hingestreuten Hanfkörner von den Fensterbrettern. 1)as Abnehmen der Meisen kann man leider gerade bei dieser bunten und hübschen Art am deutlichsten beobachten. Mohr beobachtete eine eigentümliche Vorliebe der Blanmeisen für blühende Pappelu, an denen sie sich oft zu hunderten ansammeln sollen. Caeruleus macht in Schlesien regelmässig 2 Bruten, so dass man die Eicr in 2 Perioden zu Mitte Mai und Ende Juni finden kann. Ieh sah cinmal schon am 5. April in der Strachate ein brütendes Weibchen, welches von seinem Männchen fleissig gefüttert wurde. Practorius fand 
volle Gelege am 16. Mai und 10. Juli, sowie am 2. Juni ein Nest mit nackten Jungen. Kutter beobachtete die Blaumeise am 16 . April beim Nestbau. Am 22. Mai entdeckte er zwischen 2 fast parallel laufenden Acsten ciner Abies alba in Höhe von $3 \mathrm{~m}$ ein Nest mit zwei Eiern und am 15. Juni ein anderes mit 4 Eiern $5 \mathrm{~m}$ hoch auf einer Eiche. Bratclauer 13 Tage (Mohr).

Masse von 19 schlesischen Eiern (davon 5 durch $\mathrm{Kutter}$ gemessen) in $\mathrm{mm}$ :

$\begin{array}{lccc} & \text { maximum } & \text { minimum } & \text { Durchschnitt } \\ \text { Länge: } & 15 & 13 & 13,9 \\ \text { Breite: } & 11,5 & 10 & 10,9\end{array}$

Die Eicr sind etwas kleincr als märkische Stücke, welche nach Schalow 14,77 + 11,46 mm messen.

52. Parus cyanus I'all. 1770. - Lasur'meise.

Synonyma: Cyanistes cyanus Kaup, Mewes; Cyanistes elegans Chr. Brehm; Parus indicus Aldr.; Parus cyaneus Falk; Parus elegans Chr. Brelım; Parus cocruleus naaior Briss.; Parus saebyensis Sparrm., Belst.; Parus kujaescik; Parus cyanus Pall., Gm., Bchst., Chr. Brehm, Glog., Gieb., Kays. u. Blas., A. Brehm, v. Hom., Hartert.

Kennzeichen der Art: Scheitel und Unterleib weiss.

Diese prachtrolle Meise kommt nur als seltener Gast in strengen Wintern zu uns. Gloger, Kaluza und Endler erwähnen, dass sie früher wiederholt bei Breslau erlegt worden sei. W e is schoss im Winter 1879/80 bei grosser Kälte ein Exemplar in dem Wachower Forst bei Rosenberg. Ich selbst beobachtete am 22. Februar 1890 ein Stïck unter cinem Schwarm Kohlmeisen bei Schleibitz. Der Vogel war nicht gerade schen, aber sehr flüchtig. Leider war der Park gerade sehr von Menschen belebt, so dass ich nicht gleich schiessen komte, und währenddem empfahl sich der herrliche Vogel auf Nimmerwiedersehen. Mehrfach lernte ich auf der rechten Oderseite kundige und aufmerksame For'stbeamte kennen, welche die Lasurmeise als besondere Seltenheit strenger Winter recht wohl kannten.

53. Parus fruticeti Wallgr. 1s5t. - Sumpfmeise.

sy yonyma: Parus palustris I., Gm., Bchst., Naum., Chr. Brehm, Gloger, Gieb.. Kays. u. Blas, A. Br., Fridr., Gätke, Hart., Jäckel; Poecile subpalustris, P. sordida, P. stagnatilis, P. salicarius Chr. Brehm; Parus cinereus communis Bald.; Poekile communis Degl.; Poecile palustris Kaup, v. Hom., Newes, Radde.

Trivialnamen: Mur-, Asch-, Kot- und Rindmeise.

Kennzeichender. Art: Kopfplatte schwarz ohne weissen Nackenfleck. Untere Seite rostweisslich. 
Meinen systematischen Anschaumgen nach muisste man die deutsche Sumpfmeise eigentlich als subspecies zu der schwedischen palustris ziehen, welche der Beschreibung Liune's zu grunde lag, und demgemäss trinär $P$. palustris fruticeti benennen. Im Winter ist die Sumpfmeise in Schlesien entschieden häufiger als im Sommer, was durch den Zuzug nördlicherer Vögel bewirkt wird. Es ist sehr leicht möglich, dass auch die echte palustris sich zuweilen bis nach Schlesien verstreicht, doch ist mir noch kein Belegexemplar dafür unter die Hände gekommen.

$\mathrm{M}$ a asse von 52 schlesischen Exemplaren in $\mathrm{cm}$ :

$\begin{array}{lccc} & \text { maximum } & \text { minimum } & \text { Durchschnitt } \\ \text { Länge: } & 12,5 & 11,4 & 11,75 \\ \text { Flügelbreite : } & 20,2 & 19,0 & 19,4 \\ \text { Schwanz: } & 5,0 & 4,8 & 4,9 \\ \text { Schuabel: } & 0,85 & 0,8 & 0,5 \\ \text { T'arsus: } & 1,7 & 1,7 & 1,7\end{array}$

Ob auf dem Riesengebirge die Alpeumeise ( $P$. alpestris Baill.), welche ich ebenfalls nur als subspecies aulfassen und trinair benennen möchte, vorkommt, ist leider noch nicht genïgend festgestellt. Ich möchte es aber beinahe vermuten. Einmal schoss ich in der Nähe der Schneegruben ein Stück, welches ich beim ersten Anblick für alpestris hivelt; leider aber ging das interessante Exemplar verloren, che ich es rräjarieren konnte. Neuerdings schreibt Michel, dass er die alpine Tarietät im Iscrgebirge angetrofion habe. Künftigen Beobachtern empfehle ich, den Sumpfmeisen der Sudeten ihre ganz besondere Aufmerksamkeit zuzuwenden.

Die Sumpfmeise ist in Schlesien keineswegs gleichmässig verbreitet; stellenweise ist sic vichmehr zicmlich selten, olme dass ich einen stichhaltigen Grund difür anzugeben wüsste. Dies ist z. B. bei Breslau und nach Perrin anch bei Ruhland der Fall. In anderen Gegenden ist sie wieder sehr gemein. Reinen Kicferwald liebt sie nicht. Laubhölzer mit feuchtem Boden, in deren Nähe sich Gewäisser befinden, beherbergen sie dagregen sehr regelmässig. Im Gebirge ist sie hïufig und in allen Fichtenwäldern bis zu deren oberer Grenze anzutreffen.

Bei der herrschenden Wohnungsnot nehnen die brütlustigen Sumpfmeisen vielfach zı Mäusclöchern ihre Zuflucht. Hartert fand bei Breslau ein Nest in dem durchbrochenen Boden eines Singdrosselnestes, in den die sumptimeisen eine Menge von Niststoffen eingetragen hatten. Kollibay berichtet: ${ }_{n} \mathrm{Am}$ 19. Mai wurde cin frisehes Ei auf dem Rasen in der Nähe einer mit vielen Astlöchern versehenen starken Birke aufgefunden. Der Vogel, 
welcher es nicht in die durch Regen gefüllten Nisthühlen legen kounte, hatte es wahrscheinlich auf dem Rasen abgelegt."

$\mathrm{M}$ a a s se von 16 schlesischen Eiern in $\mathrm{mm}$ :

$\begin{array}{lccc} & \text { maximum } & \text { minimum } & \text { Durchschnitt } \\ \text { Länge: } & 16 & 15,5 & 15,75 \\ \text { Breite: } & 12,5 & 11,5 & 12,1\end{array}$

54. Parus ater L. 1758, - Tannenmeise.

Synonyma: Poecile atra Kaup; Parus brittanicus Sharpe; Parus atricapillus Briss.; Parus carbonarius Pall.; Parus abietinum, P. pinetorum Chr. Brehm; Parus ater L., Shaw, Gm., Bchst, Naum., Glog., Kays. u. Blas., Gieb., Fridr., A. Brelım, v. Hom., Mewes, Hartert, Gätke, Jäckel.

Trivialuamen: Busch-, Hunds- und Tschätschmeise, Sichelschmied.

Kennzeichen der Art: Kopfplatte schwarz mit weissen Nackenstreifen. Unterleib weisslich.

Ma asse von 31 schlesischen Exemplaren in $\mathrm{cm}$ :

$\begin{array}{lccc} & \text { maximum } & \text { minimum } & \text { Durchschnitt } \\ \text { Länge: } & 11,2 & 10,6 & 10,9 \\ \text { Flügelbreite: } & 18,7 & 17,5 & 18,1 \\ \text { Schwanz: } & 5,0 & 4,7 & 4,8 \\ \text { Schnabel : } & 0,9 & 0,9 & 0,9 \\ \text { Tarsus: } & 1,8 & 1,8 & 1,8\end{array}$

Die Tannenmeise fehlt keinem Nadelwalde Schlesiens und ist in der Ebene wie im Gebirge in gleicher Häufigkeit anzutrelfen. In den grossen Forsten Oberschlesiens, der Sudeten und der Lausitz ist sie sogar ansserordentlich gemein. Krezschmar nennt sie geradezu nden häufigsten Vogel im waldigen Teile des Riesengebirges." Sie geht dort nach Gloger bis zu einer Höhe von 3500 Fuss empor. A. r. Hom e yer traf sogar noch an deu Schneegruben Taunemmeisen. Auf dem Iserkamme findet sie sich nach R. T'obias und auf der Hetschener (28v0) nach Kutter' ebenfalls sehr zahlilreich. Sehon im August beginnt der Strich, dessen Lobhaftigkeit bald durch zuziehende nordische Schwärme erhöht wird. Die Vügel (namentlich die nordischen) kommen dann auch in die Laubhölzer, Anlagen und Gärten, selbst in die der grossen Städte. Auch diese Meise nistet vielfach in Mäuselöchern, selbst ohne Not, da ihr jecle Nisthöhle recht ist.

$\mathrm{M}$ a a s se von 8 schlesischen Eiern in $\mathrm{mm}$ :

$\begin{array}{lccc} & \text { maximum } & \text { minimum } & \text { Durchschnitt } \\ \text { Länge: } & 15,5 & 14,5 & 14,9 \\ \text { Breite: } & 12 & 11 & 11,6\end{array}$


55. Parus maior L. 1758. - Ko hlmeise.

Synon yma: Parus fringillago Pall; Parus robustus Brehm; Parus perniciosus, P. cyanotus, P. intercedens Chr. Brehm; Parus maior L., Gm., Behst., Buff., Naum., Glog., Gieb., Kays. u. Blas., A. Brehm, Fridr., v. Hom., Mewes, Radde, Hart., Gätke, Jäckel. schmidt.

Trivialnamen: Spiegel-, Brand- und Schlossermeise, Feil-

Kennzeichen der Art: Scheitel schwarz, Unterseite gelb mit einem schwarzen Mittelstreifen.

Masse von 70 schlesischen Exemplaren in $\mathrm{cm}$ :

$\begin{array}{lccc} & \text { maximum } & \text { minimum } & \text { Durchschnitt } \\ \text { Länge: } & 14,0 & 13,5 & 13,7 \\ \text { Flügelbreite : } & 22,5 & 21,2 & 21,7 \\ \text { Schwanz: } & 6,2 & 5,9 & 6,0 \\ \text { Schnabel: } & 1,0 & 1,0 & 1,0 \\ \text { Tarsus: } & 2,0 & 2,0 & 2,0\end{array}$

Die Kohlımeisen sind in der Grösse ausserordentlich constant. Bei vielen ostdeutschen Stücken ist das Gelb der Unterseite ein wenig intensiver und der schwarze Bruststreifen etwas breiter und weiter herabreichend, aber auch diese geringfügigen Unterschiede zeigten sich nicht durchgängig.

In den meisten Gegenden Schlesiens zählt die Kohlmeise zu den gemeinsten Tögehn, doch ist auch sie unverkennbar im Abnehmen begriffen. In Mittelschlesien ist sie nach Richter stellenweise sogar schon recht spärlich geworden, weil es ihr eben zu sehr an geeigneten Brutstitten fehlt. Auch in der Görlitzer Heide ist sie nach $\mathrm{Krezschmar}$ nur wenig vertreten. Laubholz zieht sie den Nadelwaldungen vor, ohne aber die letzteren gänzlich zu meiden. So findet sie sich nach v. Ts chusi in allen Fichten. waldungen des Riesengebirges. A. v. Homejer traf sie noch in der Nähe der Schneegruben. In den Aulagen und Gürten ist sie ebenfalls eine allbekannte Erscheinung. Im september und Oktober stellen sich auch zahlreiche nordische Schwärme ein, um bei uns zu überwintern. In der Grafschaft Glatz werden nach Emmrich immer noch alle Meisenarten massenhaft auf den Meisenhütten gefangen. Kn a uthe hörte zweimal Kollmeisen, welche täuschend Stücke aus dem Gesange von Emberiza citrinella nachahmten. In Schlesien werden regelmaissig zwei Bruten gemacht, Richter beobachtete den Nestban 1887 am 25 . April und 1888 am 24. desselben Monats; die Jungen flogen am 8. bezgl. 10. Juni aus. Auch sah er, wie Blaumeisen durch Kohlmeisen aus ihrem Nistloch vertrieben wurden. Praetorius fand am 2. Mai und 5. Juli volle Gelege, ich selbst am 30. April und 28. Juni. 
Ma asse von 27 schlesischen Eiern in mm:

$\begin{array}{cccc} & \text { maximum } & \text { minimum } & \text { Durchschnitt } \\ \text { Länge: } & 18 & 16,5 & 17,42 \\ \text { Breite: } & 13,5 & 12,5 & 13,08\end{array}$

Familie: Sittidae, Spechtmeisen.

Ich mag die Spechtmeisen nicht nach dem Vorgange Reichenows mit den Certliirlae in eine Familie vereinigen, sondern ziehe es vor, sie von diesen völlig zu sondern, weil beide Vogelgruppen in ihrem Leibesbau und der Ausrüstung zu dem von beiden geübten Klettergewerbe doch gar zu wenig Gemeinsames haben. Die Sittidae charak terisiren sich dureh den geraden, harten, pfriemförmigen und spitzigen Schnabel, durch die vorn in 4 Fasern zerschlissene Zunge und die kurzen, kräftigen und breitsohligen Füsse, an denen die Hinterzehe durch ihre Grösse hervorragt. Die Mittel- und Aussenzehe sind fast bis zum ersten Gelenk, die Nittel- und Imnenzehe dagegen nur wenig verwachsen. Die 1. Schwinge ist sehr klein, die 2. kürzer als die 3., die 4. am längsten. Der l2fedrige Schwanz ist kurz und weich und kamn beim Klettern nicht als s'tütze benützt werden.

Grattung: Sitta L. 175s. - Kleiber. Siehe die Familienmerkmale, da nur diese eine Gattung.

56. Sitta europaea L. 1758. - Nordischer Kloiber.

כfia. Sitta europaea caesia Wolf 1810. - Mittelenropäischer Kleiber.

Synonyma: Piens einerens Gesin.; Ditta sericea Tem.; Sitta asiatica Bon.; Sittat uralensis Glog., Pall.; Sitta affinis Blyth; Sitta sibirica Pall.; Sitta roscitia Blak.; Sitta advena, S. pinetorum, S. foliorum, s. suecica, s. septentrionalis Chr. Brehm; Sitta eaesia Noyer, Degl., (Uicb., Radde, Hart.; Sitta curopaea L., Gm., Behst., Lath., Butf., Chr. Br., Naum., Glog., Gieb., Kays. u. Blas., v. Hom., Fridr., Jäckel; Sitta europaea uralensis Hart.

Trivialnamen: Schwarzplätel, Blauspecht, Maispecht.

Kennzeichen der Art: Siehe die Gattungsmerkmale, da nur diese eine Art in Deutschland.

Der Kleiber ist für den Systematiker einer der interessantesten und lehrreichsten Vögel, da er nach der geographischen Lage wie nach der natürlichen Beschattenheit seines Aufenthaltortes sehr bedeutend variirt. Was den letzteren Punkt anbelangt, so kommt namentlich die verschiedene Länge, Stärke und Ausbildung des Schnabels inbetracht, welche je nach der Holzbeschatfenheit der von dem Vogel bewohmten Wialder abändert. Meine Untersuchungen über diesen P'unkt sind noch nicht abgeschlossen, und muss ich mir deshalb einen eingehenden Bericht über diese inter- 
essanten Verhä̈ltnisse für später vorbehalten. Sonst sind die Kleiber noch in ihrer Grösse und dem helleren oder dunkleren Colorit der Unterseite verschieden. Die grossen hellen Tögel gehören dem Norden an, lagen der Beschreibung Linne's zugrunde und stellen deshalb die typische europaea dar. Die dunkleren und kleineren Kleiber Deutschlands sind derselben meiner Anffissung wach subspecifisch unterzuordnen und trinär als $S$. europaea caesia zu benennen. Nur diese subspecies brütet in Schlesien. Im Winter dagegen kommen auch die hellbäuchigen Nordkleiber zu uns, aber uicht allzu häufig, da diese Vögel überhaupt nur ungern weitere Wanderungen auszuführen ptlegen. Vou den im Winter gesammelten Stückeu gehörten etwa $90 \%$ zu caesia und nur $10 \%$ zu europaca. Die subspecies uralensis hat sich meines Wissens noch nicht nach Schlesien verstrichen. in $\mathrm{cm}$ :

II a asse von tl schlesischen Exemplaren (lauter coesia)

$\begin{array}{lccc} & \text { maximum } & \text { minimum } & \text { Durchschnitt } \\ \text { Länge: } & 14,1 & 12,9 & 13,6 \\ \text { Flügelbreite: } & 27,9 & 26,4 & 27,3 \\ \text { Schwanz: } & 4,6 & 4,5 & 4,55 \\ \text { Schuabel: } & 2,1 & 1,5 & 1,8 \\ \text { Tarsus: } & 2,1 & 1,6 & 1,8\end{array}$

Leider geht es auch dem hübschen lileiber wie den meisten anderen Höhlenbrütern: er ist in anfialtender und sehr merklicher Abnalume begriffen. Alle alten schlesischen Famisten bezeichnen ihn als sehr gemein, während er heute in vielen Gegenden bereits zu den seltenen Brutvögeh gehört und in auderen überhaupt nur noch auf dem Zuge vorkommt. Das Letztere ist nach $\mathrm{K} n \mathrm{au}$ the am Zobten der Fall. Nach Perrin ist er bei Ruhland, nach Krezschmar bei Gürlitz, nach Emmrich bei Neurode und nach Sylender bei Bolkenhayn bereits ziemlich selten geworden. In den Oderwaldungen der Breslauer Gegend aber traf ich ihn zu meiner Freude noch recht zahlreich an. Der Kleiber fehlt zwar dem Nadelholze auch zur Brutzeit nicht ganz, zieht abel Laub- und gemischte Waldungen mit mögliclist alten Beständen entschieden vor. Doch geht Krezschmar zu weit, weun er sagt: nan Laubbäume gebuuden." Auf dem Zuge kommen die Spechtmeisen auch in die Gürten und rutschen selbst an günstig gelegenen Häusern herum. Als vertikale Verbreitungsgrenze des Vogels giebt Gloger für das Riesengebirge eine Höhe von 3800 Fiss an. Kolliba y erhielt eimmal eim Exemplar lebend aus dem Dohnenstiege. Ich schoss im Januar 1890 ein Mänıchen mit verkümmertem Schnabel, welches von seinem Weibchen gefüttert wurde. Volle Gelege fanden Praetorius am 30. April und ich am 9. Mai. 
Ma as e von 18 schlesischen Eiern in mm:

$\begin{array}{lccc} & \text { maximum } & \text { minimum } & \text { Durchschnitt } \\ \text { Länge: } & 19,5 & 18,5 & 19,1 \\ \text { Breite: } & 14,5 & 13,5 & 14,0\end{array}$

F a milie: Certhiidae, Ba u m läufer.

Der lange, dünne Schnabel ist sanft gebogen, besitzt einen kantigen Rücken und eine scharfe Spitze. Die Zehen sind lang und tragen sehr grosse Krallen. Von den 10 Handschwingen ist die 1. sehr verkürzt, die 4. und 5. am längsten. Die Zunge ist lang, schmal und spitzig. Der Singmuskelapparat ist nur schwach entwickelt.

Gat tung: Certhia L. 1758. - B a umläufer.

Die Zunge läuft vorn in einen unmerklichen Fortsatz aus und besitzt keine um den Hirnschädel herumlaufende Zugbänder, ist deshalb auch nicht vorschnellbar. Der Lauf ist etwas kürzer als die Mittelzehe, vorn schwach getäfelt und hinten mit einer Hornplatte bedeckt. Die Hinterzehen der schwächlichen Füsse tragen besonders grosse und krumme Kirallen. Der schmale, keilförmige Schwanz läuft in zwei Spitzen aus; er hat sehr starre Federschäfte und wird deshalb beim Klettern als Stützorgan benutzt. Die 4. Schwinge ist am längsten.

57. Certhia familiaris L. 1758 . - Baumlä ufer.

57a. Certhia familiaris brachydactyla Chr. L. Brehm. 1831. - Kurzzehiger Baumläu fer.

Synonyma: Certhia Turneri Gessn.; Motacilla scolopacina Norske; Certhia scandulaca Pall.; Certhia minor, C. maior Erisch; Certhia brachydactyla, C. macrodactyla, C. septentrionalis, C. megalorhynchus, C. rufidorsalis, C. brachyrhyuchus, C. paradoxus Chr. Brehm; Certhia Costae Bailly; Certhia Nattereri Bon.; Certhia longicauda Brandt; Certhia brachydactyla v. Hom.; Certhia familiaris L., Gm., Behst., Naum., Glog., Gieb., Kays. und Blas., A. Brehm, Fridr., v. Hom., Mewes, Raldde, Hart., Jäckel, Gätke.

Trivialnamen: Kleiner Baumhacker, -rutscher, -kletterer, -kletterlin, -heckel, Hirngrille, Sichelschnäbler, Rindenkleber, Kletterspechtel. Oberschlesisch-polnisches Idiom: Bargel.

Kennzeichen der Art: Siehe Gattungsmerkmale, da nur diese eine Art in Deutschland.

Die graurückigen Baumläufer mit lïngerem Schnabel und kürzeren Zehen stellen eine ständlige Abänderung dar, welche Vater Brehm als brachydartyla bezeichnete. (Tafel I, 1 und 1b). Fast wïre man versucht, diese Form als selbststiundige Art aufzufassen, zumal sie ein geübter Beobachter namentlich an der 
Stimme auch in freier Natur mit Sicherheit zu unterscheiden vermag. Doch habe ich schon Uebergänge zwischen beiden gefunden, wenn auch nur selten und undeutlich und glaube deshalb nicht, dass die kurzzehige Form über den Wert einer subspecies hinauskommt. Die typische familiaris (Tafel I, 2 und $2 \mathrm{~b}$ ) charakterisirt sich im Gegenteil durch kürzeren Sichnabel, längeren Zehen und gelben Rücken. Die bei beiden Arten abweichende Schädelform, welche $\mathrm{Brehm}$ angiebt, ist im allgemeinen für dieselben constant und deshalb auch auf unserer Tafel wiedergegeben worden. Augenscheinlich hat sie sich in Anpassung an die Schnabellänge und die dadurch bedingte verschiedene Haltung des Kopfes herausgebildet. Brachydactyla dominirt im allgemeinen in Westeuropa.

Auf Grund der sorgfältigsten Untersuchungen, welche ich gerade den Baumläufern in sehr eingehender Weise widmete, kann ich mit Bestimmtheit behaupten, dass beide Formen in Schlesien brütend neben einander vorkommen, und zwar bewohnt familiaris hauptsächlich den Nadelwald, brachydactyla dagegen Laubgehölze, Parks, Gärten, Alleen und dergl. Auch die Lier beider Formen sollen nach L. Tobias verschieden sein.

Maase von 44 schlesischen familiaris in $\mathrm{cm}$ :

$\begin{array}{lccc} & \text { maximum } & \text { minimum } & \text { Durchschnitt } \\ \text { Länge: } & 12,8 & 12,2 & 12,6 \\ \text { Flugbreite: } & 20,0 & 19,0 & 19,4 \\ \text { Schnabel: } & 1,9 & 1,6 & 1,8 \\ \text { Schwanz: } & 6,3 & 6,0 & 6,2 \\ \text { Tarsus: } & 1,6 & 1,5 & 1,55\end{array}$

Maasse von 19 schlesischen brachydactyla in $\mathrm{cm}$ :

$\begin{array}{lccc} & \text { maximum } & \text { minimum } & \text { Durchschnitt } \\ \text { Länge: } & 12,3 & 11,9 & 12,2 \\ \text { Flugbreite: } & 19,6 & 18,6 & 19,1 \\ \text { Schnabel: } & 1,4 & 1,2 & 1,3 \\ \text { Schwanz: } & 6,2 & 5,9 & 6,0 \\ \text { Tarsus: } & 1,5 & 1,4 & 1,5\end{array}$

Im allgemeinen wiegt familiaris in schlesien vor und die grossen Nadelwaldungen der Lausitz, der Sudeten und Oberschlesiens bewohnt sie wohl ausschliesslich. In einigen Gegenden fehlen die Baumläufer ganz; so sollen sie nach Knauthe am Zobten nur auf dem Striche vorkommen. Sonst finden sie sich wohl überall, wenn auch nirgends häufig. Bei Breslau sah ich ihrer im IVinter viele, darunter öfters auch brachydactyla. Die harmlosen Vögel kamen auch in die Anlagen und Gärten der Stadt. Im Gebirge sind die Baumläufer überall zu Hause und gehen nach Gloger bis zu einer Höhe von 3800 Fuss empor. 
Ich fand bei Breslau am 8. April das volle Gelege; J. Tobia s traf schon am 26. April flïgge Junge an. Zwei Bruten.

$\mathrm{M}$ a asse von 14 schlesischen Eiern in mm:

$\begin{array}{lccc} & \text { maximum } & \text { minimum } & \text { Durchschnitt } \\ \text { Länge : } & 16,5 & 15 & 15,6 \\ \text { Breite: } & 12 & 11,5 & 11,7\end{array}$

Gattung: Tichodroma Ill, 1s11. - Mauerläufer.

Die sehr lange Zunge besitzt zwei um den Hirnschädel herumlaufende Zugbänder; sie ist mit Widerhaken besetzt und kann in einer inneren Rinne des Schnabels hin- und hergeschoben werden. Die Aussenzehe ist zum Teil mit der Mittelzehe verwachsen. Läufe ringsum gestiefelt. Die breiten und kurzen Schwanzfedern sind weich und dienen deshalb beim Klettern nicht zur Stütze.

\section{Tichodroma muraria (L.) 1766. - I a u erla ufer.}

Synonyma: Picus murarius alte Aut.; Certhia muraria L., Gm., Behst.; Certhia muralis Briss.; Petrodroma muraria Vieill.; Tichodroma alpina Koch; Tichodroma phoenicoptera Tem., Glog.; Tichodroma europaea Steph.; Tichodroma subhimalayana Hodgs.; Tichodroma nepalensis Bon.; Tichodroma brachyrhynchus, T. megarhynchus Chr. Brehm; 'Tichodroma muraria Illl, Naum., Kays. u. Blas., Gieb., A. Brehm, v. Hom., Mewes, Fridr., Radde, Hart., Jäckel.

Trivialnamen: Mur-und Klettenspecht.

Kennzeichen der Art: Siehe die Gattungsmerkmale, da nur diese eine Art in Deutschland.

Wenn man schwenckfeld Glauben schenken darf, so ist der Mauerläufer in früheren Jahrhunderten in den schlesischen Gebirgen keine allzu grosse Seltenheit gewesen. Auch Gloger, Kaluza und W eigler führen ihn als seltenen Irrgast mit auf. Endler erwähnt ein an den Felsen der Grafschaft Glatz geschossenes Exemplar. In neuerer Zeit aber ist der prächtige Alpenvogel in Schlesien meines W issens nicht wieder nachgewiesen worden, und man wird gut darun thm, ihn ginzlich aus der Liste schlesischer Vögel zu streichen, falls nicht noch in dem Reste unseres Jahrhunderts wieder ein Stück erlegt werden sollte. Ausgeschlossen ist dies freilich keineswegs, da der Mauerläufer in der sächsischen S'chweiz noch öfters vorkommt.

Familie: Alaudidae, Lerchen.

Schnabel schmal und walzenartig, aber ziemlich kräftig. Die 1. Schwinge ist verkümmert, die $1 t$. viel kürzer als die $1 i$., die 3. und 4. an lïngsten. Die Hinterschwingen sind von beträchtlicher Länge. Die Läufe sind auf der Hinterseite getäfelt. Der lange 
Nagel der Hinterzehe ist gerade. Das Gefieder zeigt in der Hauptsache ein erdfarbiges "Lerchengrau." Die Geschlechter sind äusserlich nicht verschieden.

Gattung: Otocorys Bp. 133\%. - Ohrenlerche.

Am Hinterkopfe zwei dentliche Federohren. Der Kropf mit bunter Zeichnung.

59. Otocorys alpestris (L.) 1758 - Alpenlerche.

Synonyma: Alauda nivalis, Pall, Frisch; Alauda flava Gmel.; Alauda hiemalis Frisch; Alauda virginiana Briss; Alauda cornuta Wils.; Alauda alpestris L., Gm., Behst., Chr. Brehm, Naum., Glog., Gieb., Gould, Fridr., Giatke; Alauda albigula Brandt; Phileremos alpestris Chr. Brehm; Kays. und Blas, A. Brebm, v. Hom., Jäckel; Phileremos rufescens, Ph. striatus Chr. Brehm; Otocorys alpestris Gray, swinhoe, Mewes, Hart., Radde.

Trivialnamen: Schneelerche, Priestergürtel.

Kennzeichen der Art: Siche die Gattungsmerkmale, da nur diese eine Art in Deutschland.

$\mathrm{Ma}$ asse von 4 schlesischen Exemplaren in $\mathrm{cm}$ :

$\begin{array}{lccc} & \text { maximum } & \text { minimum } & \text { Durchschnitt } \\ \text { Länge: } & 17,6 & 16,8 & 17,1 \\ \text { Flugbreite: } & 33,4 & 32,5 & 32,8 \\ \text { Schwanz: } & 7,8 & 7,2 & 7,5 \\ \text { Schnabel : } & 1,2 & 1,1 & 1,1 \\ \text { Tarsus: } & 2,2 & 2,2 & 2,2\end{array}$

Welcher der vielen anfoestellten Alpenlerchensubspecies, von denen ich übrigens nach $R$ addes Vorgang wenig halte, die in Schlesien vorkommenden Tügel angehöreu, vermag ich nicht zu sagen, da ich zu wenig Naterial unter den Händen gehabt habe.

Die Alpenlerche gehört zu denjenigen nordischen Wintergästen, welche in Schlesien nur unregelmässig und im ganzen ziemlich selten erscheinen. In manchen Jahren ist sie verhältnismässig häufig und kommt dam in kleinen Scharen mit den Sperlingen auf die Gehöfte, um dort Futter zu suchen. Im IVinter 1s38/39 und dam wieder $1841 / 42$ war sie nach R. Tobias besonders häufig. Kaluza sah sie mehrere Herbste hinter einander bei Neisse vielfach und erlegte daselbst einige Exemplare. Gloger sagt, dass die Alpenlerche namentlich im Gesenke vorkomme und iiberhaupt auf dem Zuge in den Torbergen nicht gerade selten sei. Braht s erwilhnt, dass 1524 einige bei Hermhut geschossen wurden. R. Tobias erbertete die Alpenlerehe am 3. und 7. Jamuar 1025 bei Görlitz, L. 'T'obias $16+2$ zwischen Görlitz und Ebersbach und $r$. Lo ebens te in $15+7$ ebendaselbst. Ausnehmend tiefer schneetall ist augenscheinlich auf das Erscheinen dieser rögel von Linfluss, da die betreffenden Jahre stets sehr schnee- 
reich waren. Wichtiger noch sind für uns die Bebachtungen aus der neueren Zeit. Das Breslauer Museum besitzt 5 schlesische Exemplare (leider ohme alle näheren Daten!) und in Görlitz steht ein am 10. Juni (!) 1866 erlegtes Stück. Bei Görlitz selbst wurde nach A. v. Homeyer am 2t). Januar 1868 eine Alpenlerche geschossen. Nach Dr. Luchs erscheint dieselbe alljährlich bei Hirschberg, ist aber im allgemeinen sehr selten. Heydrich erlegte im August 1866 ein anscheinend gepaartes Pirchen zwischen der Koppe und der Spindlerbaude. Am 10. Januar 1568 vurde ein Männchen bei Gr. Briesuitz am Fuss del Landskrone von Baron Bodeuhausen erbeutet. R. Blasius beobachtete am 19. Juni 1878 am Koppenkegel flüchtig zwei Vögel, in denen er alpestris vermutete. Ich selbst sah im VVinter $155 \% / 90$ wiederholt bei Breslau Alpenlerchen unter den Schwirmen der Schneeammeru und Bergfinken und war auch so gliicklich, ein Belegexemplar zu schiessen. In demselben Winter erhielt ich 3 weitere Stiicke aus der Gegend von Ziegenhals zugeschickt. - Noch jetzt steht die Frage offen, ob die Alpenlerehe bisweilen auf dem Riesengebirge brütet oder nicht. Wie wir oben sahen, sind wiederholt daselbst Alpenlerchen auch im Sommer beobachtet oder erlegt worden. Auch der Unstand, dass in jedem Winter Alpenlerchen bei Hirschberg erscheinen, legt die Vermutung nahe, dass wir es hier mit riesengebirgischen Exemplaren zu thun haben, welche vor den Unbilden des winterlichen Hochgebirges in den geschützten Thalkesseln Zuflucht suchen. Einen wertvollen Beitrag zu der strittigen Angelegenheit licferte mir mein Mitarbeiter Simon, der in früheren Jahren ein sehr eifriger Eiersammler war und 30 Jahre lang regelmässig oologische Excursionen ins Riesengebirge gemacht hat. Derselbe schrieb mir: "Von der "Alpenlerche* (ich meine aber die richtige Alaula alpestris und nicht etwa den von deu Baudenbewohueru ebenfalls ndlpenlerche" genannten Anthus aquaticus) erbeutete ich nur eimmal Eier; sie ist jedenfalls als Brutvogel sehr selten. In demselben Jahre fing ich ein eben Alügge gewordenes Junges. Ferner fand ich im Juni 1847, als der Kamm teilweise noch mit grossen Schmeelagern bedeckt war, in der Gegend der Altschlesischen Baude unter einem Wachholderstrauche ein Nest mit 4 jungen Alpenlerchen." Die Simousche Eiersammlung, in der sich vicle für die Ornis Schlesiens wertvolle Stücke befunden haben sollen, wurde leider später aufgelöst und in alle Winde zerstreut, wie das ja das Schicksal vieler derartiger sammlungen zu sein pflegt, wemn ihre Besitzer keine Zeit mehr haben, sich ihnen zu widmen. Ich schrieb sofort an Herrn Oberlehrer Simon, ob er sich nicht mehr crimuern kömne, wo die Alpeulereheneier hingeraten seien. Der Brief blieb zunächst umbeautwortet, und bald darauf erhicht ich die traurige Nachricht, dass mein alter, lieber Lehrer in dic besseren Jagdgriunde hinüber- 
gewandelt sei. Somit bin auch ich leider nicht in der Lage, den vollgültigen Beweis für das oft behauptete Brüten der Alpenlerche auf dem Riesengebirge zu erbringen. Es wäre aber eine der dankenswertesten Aufgaben für späterhin die Gefilde Rübezahls besuchende Ornithologen, dieser Angelegenheit ihre ganz besondere Aufmerksamkeit zu widmen.

\section{Gattung: Alauda L. 1758. - Feldlerche.}

Lerchen mit dem oben geschilderten Familiencharakter, aber ohne Federobren und ohne lebhafte Kehlfärbung.

60. Alauda arvensis L. 1758. - Feld lerche.

Synouyma: Galerita arenicola Tristr.; Alauda vulgaris Ol. Will.; Alauda canora Aldr.; Alauda arvorum Frisch; Alauda italica Gmel., Buff.; Alauda candida Briss.; Alauda coelipeta Pall., Klein; Alauda longipes Lath.; Alauda dulcivox Hodgs.; Alauda moreotica v. d. Mühle; Alauda Duponti Vierth.; Alauda segetum, A. montana, A. agrestis, A. campestris, A. crassirostris, A. robusta, A. galeritana, A. bugiensis, A. pratorum, A. albigularis, A. tenuirostris, A. minor Chr. Brehm; Alauda arrensis L., Gm., Lath., Behst., Naum., Gould, Chr. Brehm, Glog., Gieb., Kays, und Blas., A. Br., v. Hom., Newes, Fridr., Radde, Hart., Gätke, Jäckel.

Trivialnamen: Himmels-, Korn-, Saat- und Singlerche, Lirche, Lärke. Oberschlesisch-polnisches Idiom: Skowronek. Muskauer Wendisch: Skrobränk, Schkorentschk.

Kennzeichen der Art: Deckfedern des Unterflügels rötlich-grauweiss. Auf dem Kopfe kein Federhäubchen. Die 1. Schwinge kürzer als die unteren Deckfedern. Die äusserste Schwanzfeder jederseits bis auf einen schmalen braunen Längsstreif der Innenfahne weiss, ebenso die Aussenfahme der 2 . und der Saum der 3. Schnabel oben schwärzlich, unten hell.

Im Breslauer Museum stehen folgende Farbenvarietäten:

a. Grundton ein fahles Gelbweiss mit lichter, aber ziemlich deutlicher Zeichnung.

b. Achnlich, aber fast ganz ohne Zeichnung.

c. Ohne Zeichnung, das Gesamtcolorit melir ins Rostfarbene spielend.

d. Wie a. Mit sehr deutlicher Zeichnung. Rückenfedern weiss gerändert.

e. und fo iuv. Rein weiss.

Heydrich besitzt ein Exemplar mit ausgesprochenem Albinismus und ein anderes mit ausgesprochenem Melanismus in seiner Sammlung. Endler berichtet von einem 1819 bei Breslau gefangenen Männchen, welches an den äussereu Schwung- und Steuerfedern sowie an der Kehle weisse Farben zeigte. 
Ma as e von 72 schlesischen Exemplaren in $\mathrm{cm}$ :

$\begin{array}{lccc} & \text { maximum } & \text { minimum } & \text { Durchschnitt } \\ \text { Länge: } & 18,0 & 16,5 & 17,3 \\ \text { Flugbreite: } & 35,7 & 34,5 & 35,1 \\ \text { Schwanz: } & 7,4 & 6,9 & 7,1 \\ \text { Schnabel: } & 1,4 & 1,2 & 1,3 \\ \text { Tarsus: } & 2,5 & 2,4 & 2,4\end{array}$

Die Lerchen variiren bekamntlich sehr in der Grösse. IIeine sçlesischen Vögel sind im Verhältnis zu anderen deutschen Feldlershen ziemlich stark, reichen in dieser Hinsicht aber doch nicht an die Kaukasier Raddes heran. Wie bei den letzteren sind die Flecken auf der Brust schmal und scharf abgegrenzt.

Die Feldlerche ist einer der ersten Charaktervögel der schlesischen Ebenen, soweit in denselben nicht der Nadelwald dominirt. Im Mittelgebirge wird sie grösstenteils durch die Heidelerche ersetzt, aber im Hochgebirge geht sie weiter hinauf und ist auch entschieden häufiger als diese. Die fruchtbaren Ackerländereien der niederschlesischen Ebene sind für unseren Vogel wie geschaffen. Während man im allgemeinen die Beobachtung macht, dass die Gebirgsvögel bessere Sänger sind als die der Ebone, verhält es sich bei den Feldlerchen nach meinen Erfahrungen geradezu umgekehrt. Auch von Tsehusi nennt die Feldlerchen des Riesengebirges, die er sehr scheu fand, ausnehmend schlechte Sänger. In der Görlitzer Heide ist arrensis nach $\mathrm{Krezschmar}$ nur sparsam vertreten. Im Gebirge geht sie bis zur oberen Grenze des Knieholzes. Gloger giebt eine Höhe von $4600 \mathrm{Fuss}$ als oberste Verbreitungszone für sie an. Er sagt: „Nur diese Lerche geht so weit, dass sie den Namen cines Alpenvogels noch verdient. Sie ist auf den unter einem Niveau von 4400 Fuss liegenden höchsten Wiesen sehr gewöhnlich; ich habe sie aber auch auf 4600 Fuss holien kahlen, grasigen und steinigen Bergen noch nistend gefunden." R. Tobias traf sie als zahlreichen Brutvogel im Isergebirge, A. v. Homeycr nicht selten am Elbfall, den Elbquellen und Schneegruben und ziemlich häufig auf dem Koppenplan, v. Tschusi ebenso auf der weissen Wiese und dem Brunnenberg. R. Blasius und Capek hörten singende Männchen an den Elbwiesen. Noch viel häufiger als während der Brutzeit ist aber die Feldlerche in Schlesien auf ihren Wanderungen, und der Durchzug dieser Vögel durch unsere Provinz muss ein ausserordentlich starker sein. Derselbe hält im Herbste mehrere Wochen hindurch an und erstreckt sich bis tief in den Winter hinein, da immer noch Nachzügler durchpassiren. In milden Wintern bleiben einzelne Trupps auch ganz bei uns. So harrten nach Peck 1879 bei Görlitz viele den ganzen Winter durch aus; am 11. Januar wurden in der Nähe der Stadt zwei Züge von 12 und 8 Stück 
beobachtet, ebenso 2 cinzelne Exemplare an 2. December. Auch $\mathrm{K} n \mathrm{authe}$ sal wiederholt im December noch diese Lerche. Im Frühjahr treffen die Feldlerchen meist sehr zeitig ein und werden dann oft vom Nachwinter überrascht, wobei sie viel Not auszustehen haben. Gewölınlich treffen erst einzelne Vorläufer ein, welche sich bei eintretendem Schneewetter wieder zurückziehen, noch ehe die Hauptmasse erschienen ist. Dies konnte ich z. B. im Winter 1889/90 sehr schön bei Breslau constatiren. Dort fand ich auch mehrfach Exemplare, welche sich zum Uebernachten in Fahrgeleise gedrückt hatten und dabei eingefroren waren. Krähen und sperber wussten das bald für sich auszunützen. Dieselbe Beobachtung hat $\mathrm{Klopfer}$ bei Primkenau gemacht. v. Me yerinck schreibt: „Vom 24.-23. Februar 1879 lag 1 Zoll hoch Schnee. Da erschienen plötzlich Lerchen in solcher Menge, dass sie die ganzen Felder bedeckten. Auch einige Ilaubenlerchen waren dazwischen. Bisweilen sassen die Lerchen so dicht, dass man t-5 Stück mit einem Schuss hätte erlegen können. Sie flatterten fortwährend sehr eifrig niedrig über dem Erdboden hin, natürlich keine singend, sondern blos nach Nahrung suchend. Es war in den Tagen vorher im süden Deutschlands, im Königreich Sachsen, Provinz Sachsen und der Mark viel hoher Schnee gefallen und wahrscheinlich waren die Lerehen von dort abgezogen, weil sie dort gar keine Nahrung finden kounten, und hice in Schlesien nur wenig Schnee lag. Ich beobachtete diese Massen von Lerchen, welche man nur nach Hunderttausenden ansprechen komnte, auf einem Raum von ca. 11/2 Quadratmeilen. Am meisten sassen sie auf Kleestoppeln." R. Tobias fand von 1832-35 als frühesten Ankunftstermin den 26. Januar, als spätesten den 24. und als durchschnittlichen den 12. Februar. Dic übrigen Zugdaten finden sich in der nebenstehenden Tabelle.

Die Feldlerche macht in Schlesien regelmässig zwei Bruten zu Anfang April und Ende Juni. Die 1. enthält 4-5, die 2. gewölnnlich nux 3 Eier, welche 14 Tage lang bebrütet werden. (Mohr.) Volle Gelege fanden Pratorius am 15. Mai, Kutter am 1. Juli, ich selbst am 29. April und 26. Juni.

Maasse von 24 schlesischen Eiern in mm:

$\begin{array}{lccc} & \text { maximum } & \text { minimum } & \text { Durchschnitt } \\ \text { Länge: } & 23 & 21,5 & 22,55 \\ \text { Breite: } & 16 & 15 & 15,45\end{array}$

61. Alauda brachydactyla Leisl. 131t. - Is a bell-Lerche.

Symonyma: Alauda calandrella Bonell., Bon.; Alauda testacea Pall., Glog.; Alauda arenaria Steph.; Alauda dukhunensis Sylies; Alauda pispoletta Pall.; Alauda Kollyi Tem.; Melanocorypha moreotica v. d. Murs; Melanocorypha brachydactyla, 
M. itala, M. graeca Chr. Brehm; Melanocorypha arenaria Bon.; Baggeyra lark Lath, Emberiza bagheira Frankl., Emberiza olivacea Tick.; Corypha bagheira Blyth; Coryphidea bagheira Blyth; Coryphidea calandrella Horsf.; Calandrella brachydactyla Blyth, Kaup, v. Hom., Radde, Hart.; Calandrella arenaria, C. bagueira Bon.; Phileremos brachydactyla Kays. u. Blas., A. Br.; Phileremos moreotica v. d. Mühle; Calandritis brachydactyla Cab., A. Br., Mewes; Alauda brachydactyla Leisl., Naum., Fridr., Gätke.

Kennzeichen der Art: Zehen kurz. Die längste Hinterschwinge reicht bis ans Ende der 4. Schwinge.

Diese Lerche bewohnt Süderropa und kommt nur als grosse Seltenheit in Deutschland vor. In Schlesien ist sie bis jetzt erst zweimal erlegt worden, nämlich 1 \&1 nach Gloger bei Breslau und 1838 mach R. Tobias bei Görlitz. Tielleicht kommt sie öfters vor, wird aber ibres unscheinbaren Gefieders wegen keiner Beachtung gewuirdigt.

Alauda yeltoniensis Forst. 1767. - Mohrenlerche.

Im Frühjahr 18-! wurde nach $R$. Tobias eine Mohrenlerche auf dem Görlitzer Markte verkauft. E. v. Ho meyer bezweifelt das und meint, dass es sich wohl un einen Mrelanismus der Feldlerche gehaudelt habe. Da sonst weiter keine Nachrichten über das Vorkommen dieser schönen Lerche rorliegen, und ich nicht in Erfahrung bringen kunnte, was aus dem Exemplar von Tobias geworden ist, so habe ich sie einstweilen aus der Liste der schlesischen Vögel gestrichen.

Im Gegensatz zu Reichenow tremme ich die Heide- nnd Haubenlerehe nicht als besondere Gattung Galerita $a b$, sondern ziehe sie mit zu Alumla. Das Reich enow sehe Verfahren erscheint mir inkonsequent, den entweder muss man wie ich alle deutschen Lerehen zu einer Gattung vereinigen oder aber, wenn man sich für die Zersplitterung entseheidet, drei Gruppen, Álaula, Lululla und Galeritu bilden, da die Hauben- und Heidelerehe ebenso setr von einander abweichen, wie die Feldlerchen von diesen beiden.

62. Alauda arborea L. 1758. - H eidelerehe.

s ynonyma: Chorys arborea Reichb; Galerita anthirostris Landb.; Galerita arbor'a Boie, Rchw., Newes; Galcrita nemorosa, G. musica, G. arborea Chr. Brehn; Lullula arborea Bon., Kaup, v. Hom., Ralde, Hart.; Alauda nemorosa Gm., Briss.; Alauda cristata minor Ray; Alauda cristata 1'all.; Alauda cristatella Lath.; Alauda arborea L., Gm., Behst., Naun., Gould, Chr. Br., Kays. u. Blas., Gieb., A. Br., Fridr., Jäckel.

Trivialnamen: Mittel-, Wald-, Busch- und Steinlerche. Oberschlesisch-polnisches Idiom: Lesne Skowronek. Wendisch: Schkorentschk. 
Kennzeichen der Art: Auf dem Kopfe eine sehr kleine, abgerundete Federhaube. Alle Schwanzfedem besitzen cinen weissen Endfleck.

Ma as e von 16 schlesischen Exemplaren in $\mathrm{cm}$ :

$\begin{array}{lccc} & \text { maximum } & \text { minimum } & \text { Durchschnitt } \\ \text { Länge: } & 15,2 & 14,8 & 15,04 \\ \text { Flugbreite: } & 30,5 & 29,7 & 30,2 \\ \text { Schwanz: } & 5,4 & 5,1 & 5,2 \\ \text { Schnabel : } & 1,1 & 1,0 & 1,06 \\ \text { Tarsus: } & 2,1 & 2,1 & 2,1\end{array}$

Die Heidelerehen sind in den Maassen und besonders in der Schattirung des Gefieder's viel constanter als arcensis und cristata.

Die Heidelerche gehört den grossen Nadelholzwaldungen an, besonders wem dieselben reich an mit Heidekraut bedeckten Blössen sind. Demgemäss finden wir sie nirgends häufiger als in Oberschlesien, wo sie mit ilırem süssen lullenden Gesang dem öden Landschaftsbilde zur grössten Zierde gereicht. Auch in den sandigen Kieferheiden der Lausitz ist sie stellenweise sehr zahlreich und auf manchen trockenen, unfruchtbaren Waldblössen neben dem Triel der einzige Vogel. Ilır drittes Verbreitungsgebiet in Schlesien endlich bilden die Sudeten, in denen sie aber nur bis zu einer Höhe von 3200 Fuss hinaufsteigt. In den geschützten Thälern sicdelt sie sich am licbsten an und ist auch hier wegen ihres Gesanges der Liebling der Gebirgsbewolner. L. 'Tobias hat sie aber auch noch bei Johamnisbad in einer Höhe von 4000 Fuss beobachtet. Sonst kommt arborea in Schlesien nur vereinzelt und nirgends sehr häufig vor. L. Tobias fand sie bei Grünberg, meine Mitarbeiter an viclen Punkten auf der rechten Oderseite. Knauthe beobachtete den ganzen Sommer über Heidelerchen am Zobten, vermochte aber ihr Brüten nicht mit Sicherheit zu constatiren. Vielfach wird auch uber ein sichtliches Abnehmen des lieblichen Vogels geklagt, so von Krezschmar für die Gegend vou Sprottau. l'er Durchzug der Heidelerehen durch Schlesien p flegt ein sehr starker zu sein und vollzieht sich besonders in den Mlonaten Miï'z und Oktober. R. Tobias notirte in 7 Jahren als frühestes Datum der Ankunft den t., als spätestes den 17. und als durchschnittliches den 15. März.

\begin{tabular}{l|l|c|c|c|c|c|c}
\multicolumn{1}{c|}{ Ort: } & Beobachter: & 1840 & 1842 & 1884 & 1886 & 1890 & 1891 \\
\hline Görlitz & R. Tobias & 27. IX. & $11 . \mathrm{X}$ & - & - & - & - \\
Rauden & Willimek & - & - & 26. II. & - & - & - \\
Hermsdorf & Hosius & - & - & - & 21. III. & - & - \\
Niesky & Bär u. Kramer & - & - & - & - & 15. II. & 4.III,
\end{tabular}


Auch diese Lerehe macht bei uns stets 2 Bruten; nur im Gebirge erleidet diese Regel vielleicht eine Ausnahme. Wolf fand das Gelege am 21. April, Hosius am 15. Mai.

$\mathrm{M}$ a asse von 11 schlesischen Eiern in $\mathrm{mm}$ :

$\begin{array}{lccc} & \text { maximum } & \text { minimum } & \text { Durchschnitt } \\ \text { Länge: } & 21,5 & 20 & 20,5 \\ \text { Breite: } & 15,5 & 15 & 15,2\end{array}$

63. Alauda cristata L. 175̌s. - Ha u benlere he.

Synonyma: Heterops cristatus Hodgs.; Certhilauda chendula Blyth; Mirafra Hayi Jerd., Bon.; Spizalanda Hayi Bly th; Spizalauda deva Horsf.; Lullula cristata Kaup; Galerita eristata Boie, A. Br., Rehw., v. Hom., Mewes, Radde, Hart.; Galerita abyssinica, G. chendula, G. Boysi, G. isabellina Bon.; Galerita maior, G. viarum, G. altirostris, G. carinthiaca, G. abysininica, G. rufescens, G. Hava, G. lutea, G. Theklac Chr. Brehm; Alauda undata Gm.; Alauda galerita Pall., Frisch; Alauda matutina Bodd.; Alauda chendula Fraukl.; Alauda gulgula Sykes; Alauda deva Jerd.; Alauda cristata L., Briss., Scop., Gn., Bchst., Naum., Pall., Br., Glog., Gieb., Kays, und Blas., Fridr., Gätke, Jäckel.

Trivi a In a men: Kupp-, Kopp-, Heubel-, Kobel-, Wege-, Schopf-, Mist- und Kotlerche, Lïrle, Lürle, Lärke. Oberschlesischpolnisches Idiom: Swigotuschka. Wendisch: Schkorentschk.

Kennzeichen der. Art: Auf dem liopfe eine grosse spitze Federhaube.

Ma asse von to schlesischen Exemplaren in em:

$\begin{array}{lccc} & \text { maximum } & \text { minimum } & \text { Durchschnitt } \\ \text { Länge: } & 17,7 & 15,6 & 17,2 \\ \text { Flugbreite: } & 35,4 & 31,6 & 34,5 \\ \text { Schwanz: } & 7,2 & 5,9 & 6,8 \\ \text { Schnabel: } & 2,0 & 1,6 & 1,7 \\ \text { Tarsus: } & 2,6 & 2,3 & 2,5\end{array}$

Die IIaubenlerchen variiren in der Grösse und Schnabellänge sowie im Grundton des Gefieders ganz ausserordentlich; ich vermochte aber an meinen schlesischen Stücken keine besonderen Lokalformen an der Hand dieser Nerkmale nachzuweisen. Im allgemeinen war der Grundton ein erdiges Hellbraun ohne Neigung zum Gelblichen oder Rötlichen, und die Fleckung auf demselben eine wenig scharf ausgesprochene. Einige der von mir untersuchten Stücke gehörten der Schnabellänge nach zu der subspecies macrorhyncha, ohne aber deren charakteristische Färbung im Gefieder zu zeigen. Im Breslauer Museum stehen zwei Farbenvarietäten. Bei dem ersten Exemplare ist die Grundfarbe weissgrau mit 
deutlicher Zeichnung, der Schwanz braun, aber mit breiten weissen Rändern an den ïussersten Federn. Bei dem anderen Exemplar ist die Grundfarbe hell isabellfarben und die Zeichnung darauf kaum bemerklich.

Die Haubenlerche gehört zu denjenigen Vögeln, deren Verbreitung durch das Vorwärtsdringen der menschlichen Cultur stetig gefördert wird. Zı Anfang unseres Jahrhunderts war sie in Schlesien noch verhältnismässig selten. So sagt $\mathrm{Br}$ a hts: nals Standvogel ziemlich selten" und Fechuer: nim Winter auf den Strassen, im Sommer nur vereinzelt vorkommend." Aber bereits Gloger nennt sie ngewölnnlich." Immerhin giebt es auch heute noch Gegenden in Schlesien, wo die Haubenlerche keineswegs zu den gewöhnlichen Vögehn gehört. So schreibt mir Ernmrich:

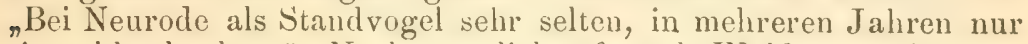
einmal beobachtet." Nuch ängstlicher fast als Wälder und Gebirge meidet die Haubenlerehe tief gelegene feuchte Landstriche. Aus diesem Grunde traf ich sie auch in der Bartschniederung nur spärlich an; sie findet sich hier nur an breiten Sandwegen oder bei den Ziegeleien, dort dann gewöhnlich in der Gesellschaft des Hausrotschwanzes. In die grossen Waldungen dringt sie längs der Fahrstrassen ein und bleibt auch auf deren nächste Umgebung beschränkt. Chausseen- und Eisenbahmbauten fördern ihre Vermehrung, und an hoch gelegenen, unfruchtbaren und trockenen Plätzen ist ihr liebster Aufenthalt. Die Nähe des Menschen scheint ihr geradezu angenehm zu sein; sie kommt nicht nur im Winter aus Hunger auf die Strassen der Städte, sondern nähert sich auch im Sommer zutraulich dem Menschen, wenn sie hier einen geeigneten Brutplatz ausfindig machen kam. Ich fand sie z. B. auf grossen Bauplätzen mitten in Breslau nistend. Nach Willimek übernachten die Haubenlerchen gern gesellschaftsweise in den Fahrgeleisen oder am Fusse der Strassenbäume. 2 Bruten zu 5 und 4 Eieru. Gelege, die ich entdeckte, waren am 27. und 30. April vollständig.

Ma as e von 14 schlesischen Eiern in mm:

$\begin{array}{lccc} & \text { maximum } & \text { minimum } & \text { Durchschnitt } \\ \text { Länge: } & 23 & 22 & 22, \overline{5} \\ \text { Breite: } & 17 & 16 & 16,4\end{array}$

\section{Familie: Motacillidae, Stelzen.}

Der längliche Spitzkopf hat eine flache Stirn und trägt einen dünnen und gestreckten Schnabel. Der ausgespannte Flügel hat zwei Spitzen, was dadurch entsteht, dass die drittletzte Armschwinge (Schultersehwinge) sehr beträchtlich verlängert ist. Die Abortivschwinge fehlt vollständig. 


\section{Gattung: Budytes Cuv. 1817. - Kuhstelze.}

Der Schwanz ist kürzer als die Hälfte der Gesamtlänge, aber immer noch von beträchtlicher Länge. Die 2 mittelsten Federn sind etwas grösser als die übrigen. Der lange Nagel der Hinterzehe ist nur sehr wenig gekrümmt.

64. Budytes flavus (L.) 1753. - Kuhstelze.

Synonyma: Parus luteus Gm.; Sylvia flava Klein; Motacilla flava L., Gm., Behst., Naum., Glog., Gieb., v. Heugl., Sund., Kays. u. Blas,, A. Br., Fridr., Gätke; Motacilla verna Briss.; Motacilla chrysogastra Behst.; Motacilla boarula L.; Motacilla flaveola Pall.; Notacilla neglecta Gould; Budytes atricapilla, B. paradoxa, B. pygmaea, B. fasciata, B. cinereicapilla, B. caniceps, B. neglecta Chr. Brehm; Budytes flava A. Br., v. Hom., Jäekel; Budytes flavus Radde, Hartert.

Trivialnamen: Geele Bachstelze, Kuhscheisse, Kuh- und Viehbachstelze.

Kennzeichen der Art: Kopf grau. Die 2 äussersten Schwanzfedern grösstenteils weiss. Keine weissen Flügelbinden.

Maasse von 53 schlesischen Exemplaren in cm:

$\begin{array}{lccc} & \text { maximum } & \text { minimum } & \text { Durchschnitt } \\ \text { Länge: } & 16,2 & 15,3 & 15,75 \\ \text { Flugbreite: } & 26,4 & 25,1 & 25,9 \\ \text { Schwanz: } & 7,3 & 7,0 & 7,1 \\ \text { Schnabel: } & 1,2 & 1,1 & 1,1 \\ \text { Tarsus: } & 2,5 & 2,3 & 2,4\end{array}$

Bekanntlich hat die Kulıstelze den Systematikern schon die grössten S'chwierigkeiten gemacht und bildet von jeher für die Kampfhähne unter denselben ein beliebtes streitobjekt. Wir haben in Schlesien nur die typische flaveus; ich habe eifrig nach cinereocapillus gefahndet, denselben aber auch auf dem Zuge niemals erhalten. Ich kann es mir deshalb ersparen, hier näher auf die verschiedenen Formen des Vogels einzugehen. Nach meiner Ueberzengung hat keine derselben Artberechtigung, sondern sie stellen alle (auch melanocephatus) sehr gute subspecies ein und derselben Art dar. Das Breslauer Museum besitzt ein männliches Exemplar, bei dem Schnabel und Füsse gelb, Kopf, Rücken, Flügel und Schwanz trüb weiss nnd die Kehle rein weiss gefärbt ist. Die Brust ist schwach, Bauch und Bürzel lebhaft schwefelgelb überflogen.

Die Kuhstelze ist in den schlesischen Ebenen noch immer recht häufig, soweit dieselben wasserreich sind und schweren Boden haben, aber ihr Bestand ist doch gegen früher sehr zurückgegangen und auch noch weiter im Abnehmen begriffeu. Sie ist an ganz bestimmtes Terrain gebunden und meidet z. B. leichten 
Sandboden nach Möglichkeit; so kommt sie nach Willimek bei Rauden auf Sandboden nicht vor, wohl aber $1 / 2$ Meile weiter östlich, wo Lehm beginnt. 1)ie Gebirgsthäler scheint sie ordentlich zu scheuen und fehlt z. B. an den ansehnlichen Sümpfeu bei Warmbrunn gänzlich (Gloger), während sie bei Breslau auf viel beschränkterem Terrain recht häufig ist. Die feuchten und sumpfigen Wiesen des Oderthals bewohnt sie anch heute noch zahlreich: ferner findet sie sich vorzüglich auf Vich weiden zwischen Rindern und Schafen, auch an den Rïndern der Bäche, Teiche und Wassergräben. In der Bartschniederung ist sie gemein, in Oberschlesien weniger und in der Lausitz stellenweise nur spärlich vorhanden. Allerorts hört man lebhafte Klagen über das Abnehmen dieser zierlichen und schmucken Vögel. So schreibt L. Tobias für die Umgegend von Grïneberg: "War bis 1860 sehr häufig und brütete fast auf jeder Wiese, wahm von da an auftallend ab und ist jetzt als Brutvogel beinahe gianzlich verschwunden. Krezschmar nenut flacus für die Gegend von Sprottau die seltenste Stelze. Andrerseits constatirte erfreulicher Weise Knauthe für sein Beobachtungsgebiet, dass die Kuhstelze erst 185i als Brutvogel am südrande des Geiersberges eingewandert ist. Auf dem Zugre kommt die Kuhstelze abgesehen von den Gebirgsgegenden iiberall sehr" häufig vor und treibt sich dann namentlich auf den Kraut- und Kartoffeläckern sowie zwischen den Schafherden in grossen Schwärmen umher. Der Hauptzug vollzieht sich im April und September und scheint der grossen Zugstrasse der Wasservögel (Bartsch-Oder-Falkenberger T'eichplatte-Lücle zwischen sudeten und Karpathen) zu folgen. R. Tobias fand von $1592-38$ als frühesten Ankunftstermin den 9., als spätesten den 20. und als mittelsten den 11i. April.

\section{Siehe umstehende Tabelle!}

Kna uthe beobachtete, wie sich Schafistelzen an einem abgeschlemmten Graben wertluse Fischchen fingen. Praetorius fand das volle Gelege an 16., ich selbst am 20. und 25. Mai. Dagegen traf Kollibay schon am 11. Nai eben ausgekrochene Junge an. Walter meinte, dass es sich wohl um Junge der Motacilla alba gehandelt habe, indessen hat Kollibay diese Angriffe zurückgewiesen.

$\mathrm{Ma}$ as e von 31 schlesischen Eiern in $\mathrm{mm}$ :

$\begin{array}{lccc} & \text { maximum } & \text { minimum } & \text { Durchschnitt } \\ \text { Länge: } & 18 & 17 & 17,6 \\ \text { Breite: } & 14 & 13 & 13,50\end{array}$

65. Budytes citreolus (Pall.) 1666. - Zitronen-Stelze.

Synonyma: Hotacilla scheltobriusk Lep.; Mutacilla citrinella Pall.; Motacilla aureocapilla Less, Motacilla citreola Pall., 


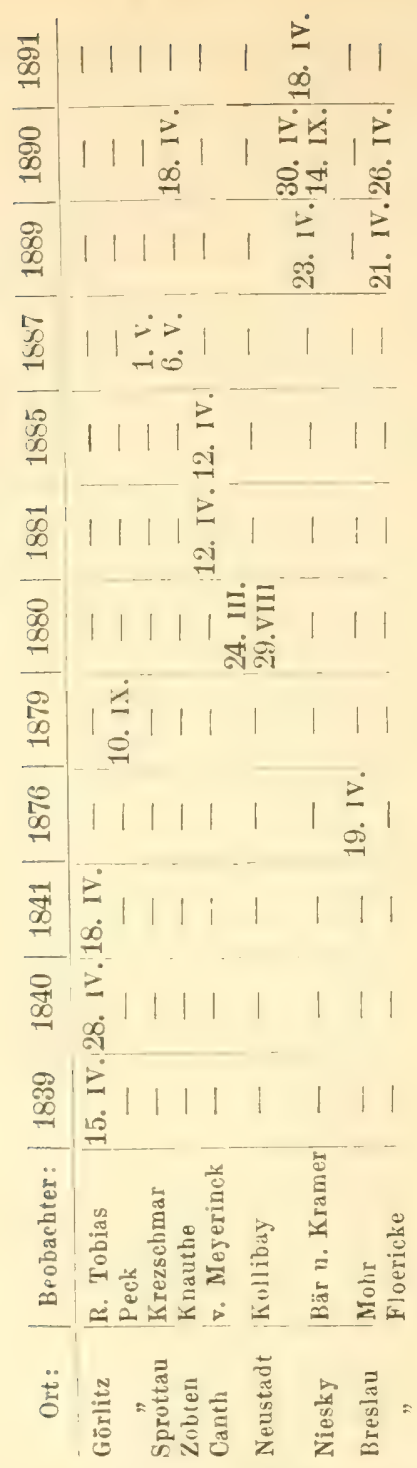

Kays. u. Blas,, A. Br., Fridr., Gätke; Budytes calcaratus, B. citreoloides Hodgs.; Budytes citreola Blyth, Degl., Cuv., Brehm, Rchw., Newes, Hart.; Budytes citreolus Radde. binden.

Kennzeichender Art: Kopf gelb. Zwei weisse Flügel- 
Diese in Ostasien heimische und für Deutschland sehr seltene Bachstelze kann ich zu meiner Freude auch für Schlesien mit anführen, da K na uthe vom 21.-23. März 1857 zwei zu dieser Art gehörige Stelzen an seinem Teiche bei Schlaupitz eingehend beobachtete.

\section{Gattung: Motacilla L. 1758. - Bachstelze.}

Der lange Schwanz nimmt die Hälfie der Gesantlänge ein. Der kurze Nagel der Hinterzehe ist stark gekrümmt. Die zwei mittelsten Schwanzfederu sind etwas verlängert.

\section{Motacilla melanope Pall. 1776. - Gebirgsstelze.}

Synonyma: Calobates sulphurca Kaup; Pallenura sulphurea Bon.; Motacilla sulphurea Behst., Naum., Chr. Br., Glog., Gieb., Landb., A. Br., v. Hom., Fridr., Gätke; Motacilla flava, M. javensis Briss.; Motacilla boarula Pen., Bchst., Kays. u. Blas., Radde, Hart, Jäck.; Motacilla grisea Muill.; Motacilla tschutschensis Gmel.; Motacilla montium Chr. Br.; Motacilla melanope Pall., Gray, Mewes.

Trivialnamen: Wedelschwanz.

Kennzeichen der Art: Bürzel gelbgrün.

Maasse von 12 schlesischen Exemplaren in $\mathrm{cm}$ :

$\begin{array}{lccc} & \text { maximum } & \text { minimum } & \text { Durchschnitt } \\ \text { Länge: } & 19,6 & 17,8 & 18,9 \\ \text { Flugbreite: } & 27,1 & 26,1 & 26,6 \\ \text { Schwanz: } & 10,6 & 10,0 & 10,4 \\ \text { Schnabel: } & 1,2 & 1,2 & 1,2 \\ \text { Tarsus: } & 2,1 & 2,1 & 2,1\end{array}$

Im Gegensatz zu den Sehafstelzen sind die Gebirgsbachstelzen sehr constant; nur die Länge des Schwanzes ist mehr oder minder grossen Schwankungen unterworfen.

Die Gebirgsstelze liebt die gebüschreichen Ufer der Bäche und kleinen Flüsse in gebirgigen und hügeligen Gegenden. In grosser Höhe ist sie nicht so gewöhnlich als alba, weil sie kalıle Gegenden meidet und nur an mit Wald bekränzten Baichen sich gern und dauernd aufhält. Gerade an den Gewiissern des Hochgebirges wird sie durch das Vergiften derselben mehr und mehr vertrieben und zieht sich deshalb neuerdings in die hügeligen Vorlandschaften der Sudeten, während sie der eigentlichen Ebene fehlt oder nur im Winter sich einstellt. Als oberste Grenze inrer Verbreitung giebt Gloger eine Höhe von 1300 F'uss an. IVie weitaus meisten Pärchen aber findet man in einer Meereshöhe von 7-s00 Meter. In deu Thälern des Kochel, Queis, Zacken, der Elbe, Neisse, Aupa und anderer Bergwïsser ist sic noch immer ziemlich häufig, obschon stellenweise unverkenubar im Abnehmen begriffen. Zacharias beobachtete sie sogar üter's 
am grossen Teich $(1217 \mathrm{~m})$. Die Grafschaft Glatz entspricht so recht den Anforderungen des Togels, weleher deshalb mit zu ihren ersten Charakterrögehn zïhlt. In den Vorbergen mehrt sich die Zahl der Gebirgsstelzen, welehe auch mehrfach an Oertlichkeiten einwandern, wo sic frïhcr noch nicht ansüssig waren. So erschienen nach Knathe $15 s i$ die ersten am Geiersberge, wo sie rasch zmahmen: 1 s90 briteten zwei Pärchen bei Schlaupitz selbst. Auch bei Sprottau constatirte Krezschmar cine Zunalime. Die Gebirgsstelze ist cin larter Togel, der in milden Wintern vielfach bei mus bleibt und damn in die geschützten Thäler sich zurückzicht oder nach der Elone verstreicht. Diejenigen, welche fortgezogen waren, stellen sich auch schon im März wieder anf ilıen Brutplätzen ein, woriber die folgende Tabelle Auskunft gicbt.

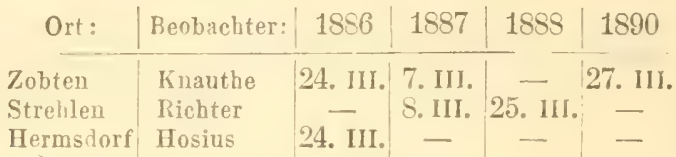

R. Tobias notirte von 15:3:-1 - 53 s als frühesten Ankunftstermin den 14. Februar, als spaitesten den 7. und als durchschnitlichen den t. Mä̈\%. Thiemann traf am 14. und Kollibay

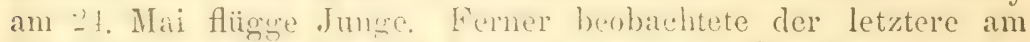
18. Juli eine Familie mii Jungen in rinem Garten mitten in Schmiedobery. Sonst sind dir resengebirgischen Graustelzen ziemlich seheu. Am : 11 . April fund $\mathrm{K}$ ollib a y im Festungsgraben von Neisse cin Nest in einem Hanerloch ibber dem Wasser mit 3-4 Tage alten Dunenjumgen.

\section{Motacilla alba L. 175. Wr Tse B a chstelze.}

syounyma: Mnscienua alba sparm.; Mrotacilla cincrea Briss, Butí,; Motarilla albulia I'all.; Motacillat albida Gm., Jaequ, ; Motacilla lugubris Tirill.. 'T'on.; Mlotacilla melanura Vieill.; Motacilla dukhumenis sike; Mutacilla septentrionalis, M. brachyrhynchus, M. fasciata, M. corvicalis, M. silvestris Chr. Brehm; Motacilla perwnata Gudd; Notacilla alba L., Gm., Lath., Bchst., Naun., Chr. Br., filur., Gieh., Kays. u. Blas, v. Heugl, A. Br., v. Hom., Mewes, Radde, Hart., Gä̀tke, Jäckel. .

Trivialnamen: IVaserstelze, schwarzehlige Bachstelze, Queclisterze, Klosterfialuin. Oherrechlesisch-polnisches Idiom: Ptuskwa. Wendisch: Schuiraplischka.

Kennzeichen der Art: Bürzel schwarzgrau. 
Ma asse von 32 schlesischen Exemplaren in $\mathrm{cm}$ :

$\begin{array}{lccc} & \text { maximum } & \text { minimum } & \text { Durchschnitt } \\ \text { Länge: } & 18,5 & 17,7 & 18,2 \\ \text { Flugbreite: } & 29,7 & 28,6 & 29,1 \\ \text { Schivanz: } & 8,6 & 8,4 & 8,5 \\ \text { Schnabel: } & 1,2 & 1,1 & 1,1 \\ \text { Tarsus: } & 2,5 & 2,3 & 2,45\end{array}$

Wir haben in Schlesien nur die typische alba. Nicht eimmal Anklänge an andere Formen vermochte ich festzustellen, auch nicht bei den Zugexemplaren. Nur sind die schlesischen Bachstelzen um eine Kleinigkeit stärker als westdeutsche.

Die weisse Bachstelze ist in ganz Schlesien ein allbekannter Vogel und im Gebirge wie in der Ebene, auch in den Walddistrikten, in gleicher Häufigkeit anzutreffen. So sehr das zierliche Vögelchen sonst auch die Nähe des Nenschen liebt, scheinen ihr doch Fabrikanlagen, Grubenwasser und Kohlenstaub nicht zu behagen, weshalb sie sich aus den grossen Industriebezirken immer mehr zurückzieht. Auch an anderen Orten ist sie im Schwinden begriffen, ohne dass man einen stichhaltigen Grund dafür anzugeben wüsste; so brütete im Beobachtungsgebiet $\mathrm{K} n$ a u th es 1890 nur noch ein einziges Pärchen. Im Riesengebirge geht die Bachstelze nach Gloger so weit hinauf, als es menschliche Ansiedlungen giebt, überfliegt während ihrer täglichen streifereien oft die höchsten Gipfel und erscheint sogar zuveilen auf der Koppe. Im allgemeinen giebt Gloger eine Höhe von 4300 Fuss, $\mathrm{K} o l \mathrm{i}$ b a y 4000 Fuss und $\mathrm{Kr}$ a mer $1400 \mathrm{~m}$ als obere Verbreitungsgrenze an. v. Tschusi sah zwei Pärchen an der Spindelmühle, ein Männchen bei der Schneegrubenbaude und fand bei st. Petel 4 Eier. Sim on und Zacharias trafen alljülırlich Bachstelzen bei der Wiesenbaude $(108 t \mathrm{~m})$. Kolliba y beobachtete alba im Juni $1857 \mathrm{am}$ kleinen Teiche unter der Hampelbaude, wo ihr die von den Baudenbewohnern aus Geröllsteinen errichteten Steinmauern als Brutplätze zu dienen schienen. A. v. Homeyer sah den Vogel auf dem Koppenplan. Auch diese Art beobachtete $\mathrm{K} n \mathrm{a} u \mathrm{th}$ e beim Fange klciner Fischchen. Der Zug geht hauptsächlich in den Monaten Mäirz und OAt. von statten, indessen kommt es öfters vor, dass vereinzelte Lxempl. den Winter über bei uns ausharren. Dies war $z_{0}$ B. nach L. Tobias im Winter 1873/74 bei Grüneberg der Fall. Auch A. v. Homeyer sah noch den 22. November 1862 cin altes Männchen an einer Quelle bei Glogau. Immerhin geschieht dieses Ueberwintern weder so häufig noch so regelmässig wie bei der Gebirgsbachstelze, sondern ist stets als eine Ausuahme zu betrachten und kommt gewöhulich nur in milden Jahren vor. Nach 
R. Tobias war von 1532-33 für Görlitz der früheste Aukunftstermin der 23. Februar, der späteste der ?. und der durchschnittliche der 3. März.

Siehe nebenstehende Zugtabelle!

Auch die weisse Bachstelze scheint der bei Burlytes angegebenen Zugstrasee längs der schlesischen Gewässer zu folgen und nicht durch die Pïsse der Sudeten einzubrechen. Denn sonst müsste sie z. B. hei Ullersdorf (Lamleshuter Pass) mit zuerst auftreten, während sie in Wirklichkeit nach unserer Tabelle dort gewöhnlich sehr spät erscheint, weil die Bachstelzen eben erst langsam von der Ebene aus in die Gebirgslandschaften einrücken, sobald dort der Winter nachzulasson beginnt. - Es finden jährlich 2 Bruten statt, zu Mitte April und Mitte Juni. Die erste enthält 6 , die zweite 4 -1; Eier, welche 1:3 Tage lang bebritet werden (Mohr). Dic Parmug fundet noch im März statt (Kutter). Den Bau des ersien Nestes benbachtete Richter am 20. Mai, den des zweiten am J. Juli; llic Jungen wurden aus denselben am 24. Juni uml \&. August flïgge. Pratorius fand ein Grege am 2. Hai, aus dem die Jungen am 6. Juni flïgge wurden; am 21. enthielt das Nesi wieler lrische Eier. Jeh selbst fand volle Gelege am 1. Mai, 24. und 28. Juni.

Maasse yon 44 schlesischen Eiern in $\mathrm{mm}$ :

$\begin{array}{lccc} & \text { maximum } & \text { minimum } & \text { Durchschnitt } \\ \text { Länge: } & 19, \overline{5} & 18, \overline{5} & 19,2 \\ \text { Breite: } & 15 & 14 & 14,2\end{array}$

Gattung: Anthus Bchst. 1807. - Pieper.

Der pfriemförmig gestreekte Schmabel ist an der Spitze ein wenig abwäris gebogen uni sticht ansgeschniten. Die Zehen sind schlant; thic Hinter\%hen haben versehiedenartig gekrümmte sponartige Nägel. Ler mur mittellange sehwanz ist sehwach ausgeschnituen. Das Gufied zeigt cinfache lerehenartige Farben.

6s. Anthus pratensis (L.) 1700 . - Viesenpieper.

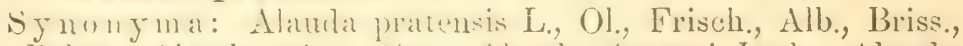

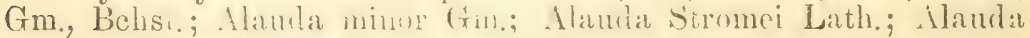
sepiaria Briss; Alanda brumalis Seopl; Leimoniptera pratensis Kaup; Parus ignotu. Sirine; Sinipola pratensis Gray; Anthus sepiarius Vicill,; Anthus tristis Batll.; Anthus palustris Neisn.; Authus Bertheloti Bolle; Anthus staguatilis, A. danieus, $\Lambda$, pratorum, A. palusiris, A. alticeps, A. temairostris, $A$ musicus, $A$. viresens, A. Lichtensteini, A. iesertorum, A. montanellus, A. hydrophilus, A. rufigularis Chr. Brehm; Ałthus pratensis Behst, Namm., Chr. Br., Crlog., Cricb., Kays. und Blas., A. Br., v. Hom., Mewes, Radde, Gätke, Hart., Jäckel. 


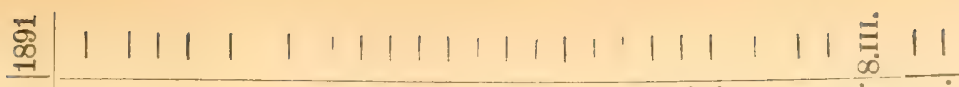

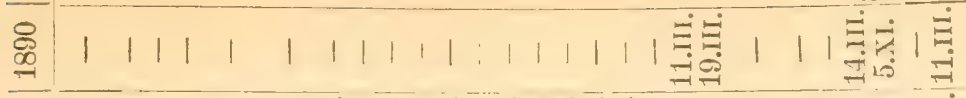

舟 11111 |

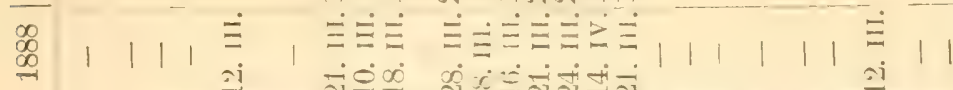

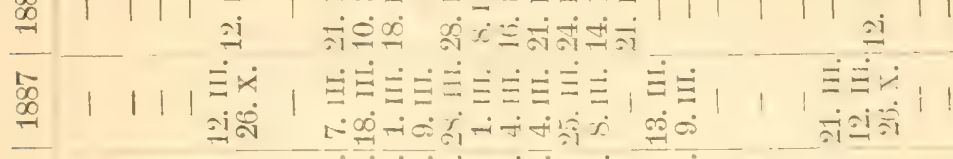

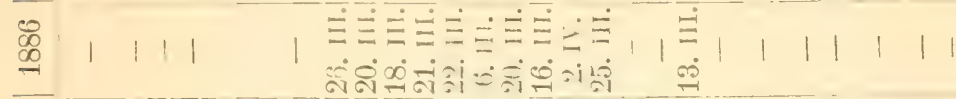

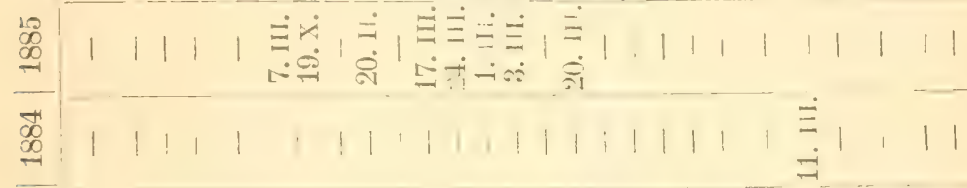

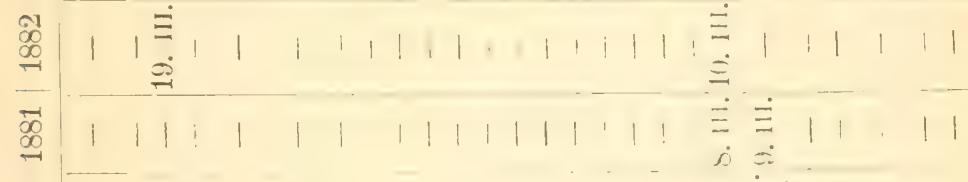

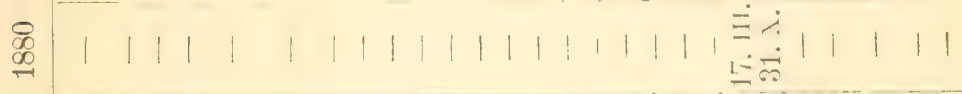

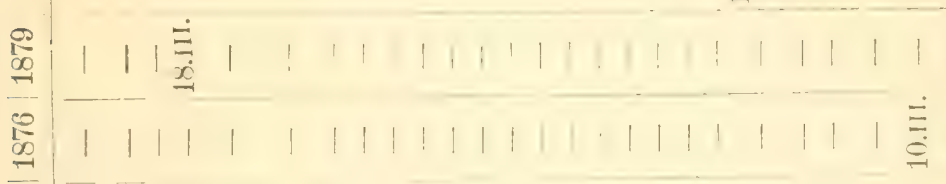

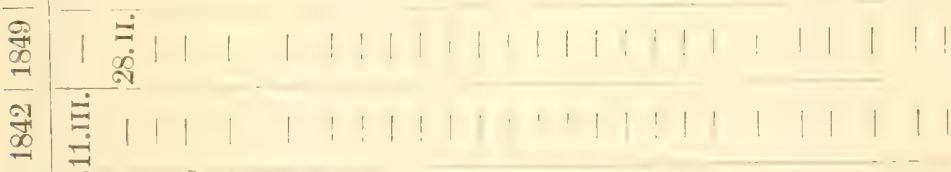

雷

윰

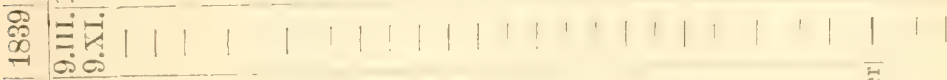

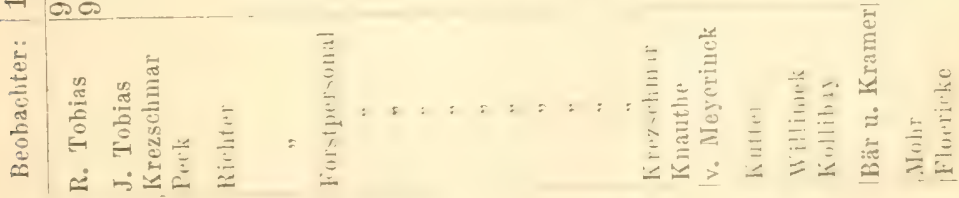

草| 
Trivialnamen: Grienvögelin, Greinerlein, Gückerlin, Hiester, Spiesslerche, Stoppelvogel, Stöpling, Wiesen- und Pieplerche.

Kennzeichen der Art: Der Nagel der Hinterzehe ist länger als diese und nur sehr wenig gebogen. Die vier ersten Schwingen sind ziemlich gleich. Füsse bräunlich.

II a as se von 16 schlesischen Exemplaren in cm:

$\begin{array}{lccc} & \text { maximum } & \text { minimum } & \text { Durchschnitt } \\ \text { Länge: } & 14,3 & 13,8 & 14,0 \\ \text { Flugbreite: } & 25,9 & 24,7 & 25,2 \\ \text { Schwanz: } & 6,2 & 5,9 & 6,0 \\ \text { Schnabel: } & 1,1 & 1,1 & 1,1 \\ \text { Tarsus: } & 2,2 & 2,2 & 2,2\end{array}$

In den Maassen sind die Wiesenpieper sehr constant, bezügrlich der Zeichunng aber kommen die maunigfaltigsten Abweichungen vor, namentlich imbezug auf die weissen Keilflecken der äussersten Schwanzfedern und auf die Fleckung der Kehle und Unterscite. Daher rühren auch die vielen subspecies des alten Brehm. Ton denselben hat wohl montanellus die meiste Berechtigung, und auch die im Riesen und Isergebirge so zahlreich vorkommenden Wiesenpieper scheinen dieser Gebirgsform anzugehören. R. Tobias constatirte diese gut ausgeprägte subsjecies als Brutrogel auf dem Gipfel der Tafelfichte (34ð3 Fuss) und dem in das Iserthal sich senkenden Abhang derselben sowie am grosen Teich. Ueberhaupt ist der Wiesenpieper in den Sudeten sehr zahlreich vertreten. Er findet sich hier insbesondere an moorigen Wiesen und feuchten Waldstellen, namentlich zwischen dem Höhengürtel von 2500 und 4000 Fuss, wo man ihn wohl den gemeinsten Vogel des Riesengebirges nemnen kann. Ueber 1000 Fuss geht er nur an besonders günstig gelegenen Stellen linaus und mit 4300 Fuss erreicht seine Terbreitung als Brutvogel im allgemeinen ihre äusserste Grenze. Krezschmar traf ihn häufig auf den Elb-, L. Tobias und Michel auf den Iserwiesen, A. r. Homeyer auf dem Koppenplan, A. Bxehm an der liesenbaude, R. Blasius nungeheuer häufig“ in der ganzen Krummholzregion. Hosius klagt darüber, dass die Zahl der Wiesenpieper' im Riesengebirge neuerdings rasch abnehme. Auch in den übrigen Teilen der sudeten sowie in den Vorbergen findet sich der Trigel vielfach, so nach Kutter sehr zahlreich auf den Bergwiesen des Glatzer Schneeberges (4400 Fuss). In der Ebene licbt er moorige Heidegegenden, wie sie sich in der Lausitz finden, Sümpfe und Brücher, auch die Wiesen der Auwaldungen. Im Primkenauer Bruch und in der Bartschniederung ist er sehr gemein. In ïbrigen fehlt er, vorausgesetzt dass die Gegend nicht zu trocken ist, fast nirgends völlig, ist aber doch in der Ebene nicht so 
gleichmässig und zahlreich verbreitet wie im Gebirge. Auf dem Zuge ist er viel häufiger und treibe sich dann in glossen Trupps, die aber nicht eng zusammenhalten (IR. Tobias), auf den Feluem herum. In milden Wintern bleiben anch cinzelne dieser wetterharten Vögelehen bei uns. Nach li. Tohias kamen die Wiesen-

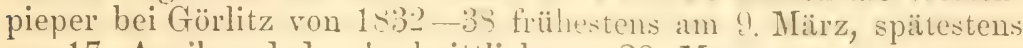
am 17. April und durchschnittlich am 20. März an.

$$
\text { Zugtabelle: }
$$

\begin{tabular}{|c|c|c|c|c|c|c|c|c|c|c|c|}
\hline Ort : & Beobariter: & $1-39 !$ & 1-411 & $1 \sim+1$ & 15.12 & $1=4 ! ?$ & lnat & Lur; & lang! & {$[n ! 11)$} & -1 \\
\hline Görlitz & R. Tobias & 25.11 & $\frac{20.11}{16.11}$ & 14.II & & & - & - & - & - & - \\
\hline Neustadt & $\begin{array}{l}\text { J. T'obias } \\
\text { Kutter }\end{array}$ & - & - & $=$ & $=$ & 25.111. & $25 . \overline{1 x}$. & - & - & $=$ & - \\
\hline Niesky & Bär u. Kramer & - & - & - & - & ! & - & - & - & & 19.III. \\
\hline Breslau & Kern & - & - & - & - & - & - & 28.111. & - & - & - \\
\hline , & Floericke & - & - & - & - & - & - & - & 31.III. & $\frac{24.11 \mathrm{I}}{7 . \mathrm{I} .}$ & - \\
\hline
\end{tabular}

R. Blasius fing an 1?? Juni im Riencugebirge Aligge gewordene Junge. Volle Gelege faml ioh am -7. April und li. Mar.

II a s s e von 22 schlesischen Eiern in $\mathrm{mm}$ :

$\begin{array}{lccc} & \text { maximum } & \text { minimum } & \text { Durchschnitt } \\ \text { Länge: } & 19 & 15 & 18,5 \\ \text { Breite: } & 14,5 & 13 & 13,8\end{array}$

Wenig bekaunt düfte es scin, dars ateh bei den Picperm ähnlich wie bei Drosseh. Finken und Grasmïcken sich die Bewohner der Ebene gesanglich ganz betrichtlich zu ihrem Nith-

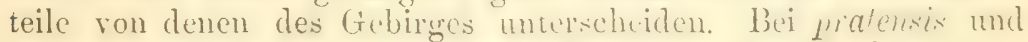
trivialis t:itt dies am dentlich:sen hervor, mut vielleicht ist uns damit ein weiterer Hinweis zur sulspecitischen bonnlerung von montanellus gegeben.

(i). Anthus cervinus ( Pall.) 1s11. - Rotkehliger Pieper.

Synonyma: Mrtacillat cerviua l'all. Alatal cervina fould;

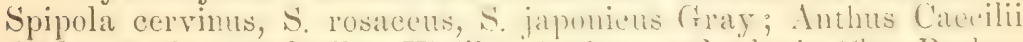
Aud.; Anthus ruticollis Tieill.; Anthun rufigularis Chr. Brehm,

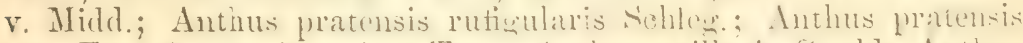
var. Ev.; Anthus japonicus 'Tem.; Animus axillaris (ronlel; Anthus

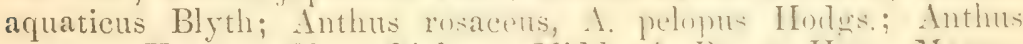

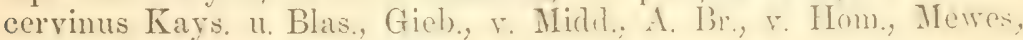
Fridr., Radde, Hart., Gätke.

Kennzeichen der Irt: Längo umwe 15) (em. Der Nagel der Hinterzehe ist lïnger als diese mol nur sehr weng gekriummt. 
Die 4. Schwinge ist beträchtlich kleiner als die 1, die 2.-4. aussen verengt.

Diescr nordische Pieper ist für Schlesien eine Seltenheit, mag aber auf dem Zuge auch öfters übersehen werden, da er sich für den Laien nur schwer im Jugendkleide von dem ihm dann sehr ähnlichen Wiesenpieper unterscheiden lässt. In der Lokalsammlung Heydrich's in Flinsberg steht ein Stück, welches auf den Steiner Feldern geschossen wurde. R. Tobias traf ein Pärehen im Kuieholze anf einer 'Torfwiese des Isergebirges, verlor zwar das krank geschossene Weibchen, erhielt aber das Männchen. Er meint, dass der Vogel im Isergebirge brüte. M i chel bemerkt hierzu: "Falls bei Tobias nicht ein Irrtum vorliegt (das ist bui den mediegenen ornithologischen Kenntnissen dieses höchst verdienstlichen Forscher's wohl gänzlich ausgeschlossen C. F.), ist "s sicher nur ein merkwürdiger Einzelfall." Ich selbst habe bei meinem Aufenthalt im Isergebirge auch nichts mehr von dem rotkehligen Pieper zu entdecken vermocht.

7). Anthus trivialis (L.) 1758. - Ba u m p eper.

S'ynon yma: Alanda trivialis L., Gm., Buff.; Alauda mincr Lath.; Alauda arborea, $A$. pratensis, $A$. sepiaria Briss.; Alauda minima W'ill., Ray, Frisch; Alauda arborea Behst,; Alauda brumalis, A. turdina Scop.; Cichlops thermophilus Hodgs.; Dendronanthus trivialis Blyth; Motacilla spipola Pall.; Pipastes arboreus Kaup; Pipastes trivialis Mewes; Anthus arboreus Behst., Naum., Glog., Gieb., Kays. und Blas., A. Br., v. Hom., Radde, Gätke, Jäckel; Anthus foliorum, A. juncorum, A. herbarum, A. luteogularis, A. saxorum Chr. Brehm; Anthus trivialis Blyth, Webb u. Berth., Licht, Hartert.

Trivialnamen: Spitz- und Baumlerche.

K cunzeichen der Art: Nagel der Hinterzehe kürzer als diese und halbmondförmig gebogen. Füsse fleischfarben.

II a asse von 35 schlesischen Exemplaren in em:

$\begin{array}{lccc} & \text { maximum } & \text { minimum } & \text { Durchschnitt } \\ \text { Länge: } & 16,0 & 15,3 & 15,6 \\ \text { Flugbreite: } & 27,7 & 26,5 & 27,0 \\ \text { Schwanz: } & 6,8 & 6,5 & 6,65 \\ \text { Schnabel: } & 1,2 & 1,1 & 1,1 \\ \text { Tarsus: } & 2,2 & 2,1 & 2,1\end{array}$

Im Tone des Gesamtcolorits ist der Baumpieper Abänderungen untcrworten, soust aber doch viel constanter als der Wiesenpieper. Im Breslauer Museum befindet sich ein reiner Albino mit gelblichem Zügel und gelbem Sehnabel und Füssen. 
Der Baumpieper ist in Schlesien wohl die häufigste Art sciner Gattung. Nur im Riesengebirge steht sein Bestand entschieden hinter dem von spipolettu und pratensis zurück und auch in den übrigen Teilen der Sudeten sowie in den Vorbergen pllegt der Wiesenpieper meist läufiger zu sein als er. Nach Kramer nehmen die Baumpieper schon bei $400 \mathrm{~m}$ Meereshöhe merklich an Zahl ab. Gloger giebt 4100 Fuss als oberste Verbreitungsgrenze an. Nach ihm geht der Baumpieper , eben so weit, auch wohl noch 100 Fuss weiter aufwärts als der Buchfink und findet sich also bis zu den unteren Grenzen der Knieholzregion, doch nie innerhalb dieser; viehmehr verlässt er die lichten Wälder verkrüppelter Fichten uiemals". v. Tsch usi beobachtete den Baumpieper zahlreich am 'Tannstein, Capek hörte ein singendes Männchen an der Petersbaude $(121) 0 \mathrm{~m})$. Thicmann giebt an, Baumpieper regelmässig bis zu $1400 \mathrm{~m}$ Meereshöhe gesehen zu haben. R. Tobias traf viele Bampieper aut' der 'Tafelfichte (3 453 Fuss). In der Ebene bevorzugt unser in manchen Gegenden ausserordentlich gemeiner Pieper die lichten Waldungen. In dichten Forsten siedelt er sich regehmässig auf den Schlägen an, zumal wemn noch Birkengesträuch und einzelne hohe Bäume dazwischen stehen und sich Wasser in der Nähe befindet. Sandigen Boden meidet er und wird in Gegenden, die an solchem sehr reich sind, durch den Brachpieper vertreten.

\section{Zugtabelle:}

\begin{tabular}{|c|c|c|c|c|c|c|c|c|}
\hline Ort: & Beobachter: & 1839 & 1849 & 1886 & 1857 & Iss!! & 1590 & 1891 \\
\hline & & 20. IV. & - & - & & - & & - \\
\hline & $\mathrm{T}$ & - & 10. IV. & & & & & - \\
\hline & är & - & - & - & 24. IV. & - & 26. III. & .22 .11 \\
\hline 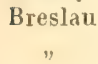 & $\begin{array}{l}\text { Kern } \\
\text { Floericke }\end{array}$ & - & - & 22. IV. & - & 18. & 5. IV. & - \\
\hline
\end{tabular}

Nach R. Tobias erfolgte die Inkunft bei Görlitz von 183.)-33 frühestens am 5., spätestens am 2:3. und im Lurchschnitt am 15 . April. Fechner notirte stets die Zeit vom 8.--16. April als Ankunftstermin, April und September sind die Hauptzugmonate. Kutter fand volle Gelege am 1!). Mai und 2u. Juni, ich selbst am 14., 19., 22., 23. und 27. Mai, alle in der Strachate, wo der Baumpieper ungemein häufig ist.

Ma as e von 6:2 schlesischen Eiern in mm (davon 10 durch Kollibay gemessen):

$\begin{array}{lccc} & \text { maximum } & \text { minimum } & \text { Durchschnitt } \\ \text { Länge: } & 23 & 18 & 20,8 \\ \text { Breite: } & 17 & 14,5 & 16,0\end{array}$


Schalow giebt als Maasse märkischer Eier $18,76+14,8 \mathrm{~mm}$ im Durchschnitt an, wonach die schlesischen Eier von arboreres im allgemeinen etwas grösser zu sein scheinen.

71. Anthus campestris (L.) 1758. - Brach pieper.

Synonyma: Alauda campestris L., Gm., Bechst., Briss.; Alauda novalium Frisch; Alauda grandior Pall.; Corydalla arenaria Brehm; Agrodroma campestris Swains., Hartl., v. Hom.; Anthus rufescens Tem.; Anthus rufus Vieill.; Anthus striatus Blyth; Anthus gracilis, A. arvensis, A. septentrionalis, A. striatus, A. agrorum, A. subarcuatus, A. flavescens Chr. Brehm; Authus campestris Bchst., Naum., Gieb., Kays. u. Blas., A. Br., Mlewes, Fridr., Radde, Hart., Gätke, Jäckel.

Kennzeichen der Art: Länge über $15 \mathrm{~cm}$. Der Nagel der Hinterzehe ist länger als diese und flach gebogen. Die 4. Schwinge ist merklich kleiner als die 1.

Trivialnamen: Brachlerche, Feldpieper.

Masse von 9 schlesischen Exemplaren in $\mathrm{cm}$ :

$$
\text { maximum minimum Durchschnitt }
$$

$\begin{array}{lrrr}\text { Länge: } & 16,7 & 16,0 & 16,4 \\ \text { Flugbreite: } & 28,3 & 26,5 & 27,6 \\ \text { Schwanz: } & 7,3 & 6,9 & 7,1 \\ \text { Schnabel : } & 2,0 & 2,0 & 2,0 \\ \text { Tarsus : } & 2,6 & 2,6 & 2,6\end{array}$

Als Durchzugsvogel ist der Brachpieper in Schlesien fast überall ziemlich häutig, als Brutrogel aber kommt er nur vereinzelt vor. Am zahlreichsten findet er sich noch als solcher in den Odergegenden Nicderschlesiens. Bei Glogan z. B. ist er nach A. v. Homeyer sehr häufig vertreten, so auf den Sehiessiänden und den sandigen Gehanen des Stadtwaldes. Nach L. Tobias ist er in den Sandgegenden bei Neusalz und Grüneberg sogar del gemeinste Voged. Seit dem Aufhören der Brachfelderwirtschaft hat sein Bestand aber auch dort sehr abgenommen. A. v. Homeyer fand ihn ferner bei Kreisau, dem Sitze Molukes, sowie bei Kohlfurt nistend. Nach Ba er brüted er auch bei Niesky, nach R. 'Tobias überhaupt in allen nieleren Sandgegenden der Lausitz. Sandboden ist ihm ein Bedürtinis, und er fundet sich deshalb hauptsächlich aut trockenen Feldern und Triften, an Brachen, Waldrändern und öden Mlätzen mit Sandboden. D)as Gebirge meidet er gïnzlich. Der Zug geht in den Monaten April und September von statten.

\section{Anthus spinoletta (L.) 1758. - Wasserpieper.}

Synonyma: Spinoletta florentinis Will., Ray; Alauda spinoletta L., Gm.; Alauda testacea Pall.; Alauda Coutelli And.; Anthus aquaticus Bechst., Naum., Tem., Glog., A. Br., v. Hom, Gätke; 
Anthus montanus Kneh; Anthus nigripes Hempr. u. Ehrbg.; Anthus aquaticus, A. hiemalis, A. alpinus Chr. Br.; Anthus spinoletta Bon., Zand., Degl., Kays. u. Blas., Gieb., Mewes, Fridr., Radde, Jäckel, Hartert.

Trivialnamen: Schneevogel, Schneelerche, Alpenlerche.

$\mathrm{K}$ ennzeichen der $\Lambda \mathrm{rt}$ : Nagel der Hinterzehe länger als diese und ziemlich stark und weit gebogen. Liinge über $15 \mathrm{~cm}$. Füsse dunkelbraun bis schwarz.

M a a s e von 10 schlesischen Exemplaren:

$\begin{array}{lccc} & \text { maximum } & \text { minimum } & \text { Durchschnitt } \\ \text { Länge: } & 16,7 & 15,5 & 16,2 \\ \text { Flugbreite: } & 28,6 & 27,5 & 28,1 \\ \text { Schwanz: } & 7,4 & 6,9 & 7,2 \\ \text { Schnabel : } & 1,4 & 1,3 & 1,3 \\ \text { Tarsus : } & 2,6 & 2,4 & 2,5\end{array}$

Vielleicht darf man den Wasscrpieper mit Zacharias als "den ersten Charaktervogel des Ricsengebirges" bezeichnen, sicherlich aber gilt dies wenigstens für die Knieholzregion. Im allgemeinen deckt sich seine Terbreitung mit der des Knieholzes, obschon er sich an einzelne'n Stellen auch auf dem noch höher gelegenen Geröllgürtel der hö̈hsten Berge angesiedelt hat, wie z. B. auf dem Koppenkegel und in den schmeegruben. Gloger sagt hierüber: "Er bewohnt nur das Knicholz und lebt nirgends wo dieses ganz fehlt. Er geht so weit hinanf, als es irgend gedeiht, und steigt ebenso da tiefer mit hinab, wo es sich auch 3-400 Fuss unter seiuem eigentlichen Standurte vorfindet." Die Verbreitung des Vogels wird im grosseu und ganzen dureh den Höhengürtel von $1000-1500 \mathrm{~m}$ begrenzt. Innerhalb dieser Höhe aber ist er ungemein häufig und findet sich an all den schon of t genannten und den Touristen woblbekamnten l'lätzen. Auf dem Kamme zwischen den Schneegruben und der alten schlesischen Baude sah ich den Wasserpieper geradezu massenhaft. Merkwürdig muss es erscheinen, dass der Vogel so wenig in das benachbarte lsergebirge himüber geht, wchch's ihm doch stellenweise sehr passende Aufenthaltsplätze bietet. leh habe den WVasserpieper dort nie gesehen und M i ch el bezweifelt stark, dass er überhaupt im Isergebirge vorkommt. Dagegen beobachtete ihn R. Tobias Ende Juni 1846 auf' der 'T'afelfichte und traf auf cinem ausgedehnten 3jährigen Schlage des angrenzenden hohen lserkammes ein Pärchen, welches Junge fütterte. Auch auf den Bergwiesen des Glatzer Schnecberges und besonder's an und auf den Gebäuden daselbst kommt der IVasserpieper nach Ku t ter ziemlich häufig vor. Im Winter verstreicht sich der Vogel in die Ebene, kehrt aber stets so bald als möglich zu seinen gelicbten Bergen zurück. 
v. Meyeriuck will ihn noch am 29. April bei Canth beobachtet haben. Als kluger Vogel weiss sich der Wasserpieper recht wohl in die Umstände zu schicken. Während er sich in Knieholze, falls man nicht etwa seinem Neste zu nahe kommt, recht scheu zeigt, beweist er an den Bauden grosse Zutraulichkeit, weil er erfahrungsgemäss von den dort sich aufhaltenden Menschen nichts zu fürchten hat und im Gegenteil auf manchen Leckerbissen rechnen kann. Jeder Tourist wird den munteren Pieper ohnchin bald lieb gewinnen, dem er belebt auch die ödesten Stellen mit seinem anmutigen Wesen. In seinem Benehmen ähnelt er nach R. Blasius sehr dem arborus; nur ist der Gesang nicht so melodisch, sonder'n etwas härter und schrillender. Oft lïsst er denselben von den Dächern der Bauden herunter ertönen oder von den Steindämmen, mit denen die Hochgebirgsbewohmer ihr Anwesen eingefriedigt haben. Kollibay sagt bezüglich des Gesanges: „Der Gesang, welcher häufir im Sitzen begomnen, sodann fliegend fortgesetzt und nach dem Niederlassen vollendet wird, gehört zu den einfachen; besonder's deutlich treten in demselben ein mehrmals schnell hinter einander herror gestossenes „Sehirr, schirr, schirr" sowie cin klagendes "Swid, swid" hervor." In freier Natur habe ich den Gesang des Wasserpiepers leider noch nicht gehört; derjenige meiner gefangen gehaltenen Exemplare aber vermochte mich nicht zu begeistern und stand jedenfalls weit hinter dem von arboreus zuruick. In geschlechtlicher Ekstase geberdet sich der Wasserpieper nach A. v. Homeyer wie ein Blaukehlehen, stellt den Fichwanz senkrecht, legt den Kopf zurück, lässt die Flügel hängen, tanzt, sprringt und singt. Trotz der Kürze des Hochgebirgsommers macht unser Vögelchen nach den ïbereinstimmenden Berichten aller Beobachter regelmässig zwei Bruten. „Die Nester findet man am Rande der Knieholzsträucher und unter deren Wrurzeln, auch zwischen Steinen, im Grase und an abhängigen Bachufern so in IIöhungen gebaut, dass sie von oben eine sichere und vollkommene Decke gegen Regen und schnee haben." (Gloger.) Die Eier sind in ihrem Colorit mannigfaltigen Abweichungen unterworfen. Durchschnittsmaasse von 4 schles. Eiern $=20$ in 15 . Ausuahmsweise scheint der Wasserpieper auch bisweilen in den Vorbergen zu bleiben und dort zu brüten, wo er überwinterte. So fand $W_{\text {olf }}$ bei Muskau in der Nähe der Görlitzer Neisse ein Nest von spinoletu mit einem Gelege von 3 Stiick, welches nicht vervollstiundigt wurde. Die "Naturforschende Gesellschaft" in Görlitz erklärte die Eier für zweifellos echt.

Familie: Fringillidae, Finkenvögel.

Schnabel stark, dick und kegelförmig. Nasenlöcher rundlich und von Borstenfederchen bedeckt. Die 1. Handschwinge ist vollständig verkümmert, so dass der Flügel deren nur ! ent- 
hält. Magen muskulös und zum Zerreiben von Körnernahrung geeignet.

\section{Gattung: Emberiza L. 1758. - Ammer.}

Der kleine, kurz kegelförmige, spitze Schnabel ist an der Wurzel dick und mit einem knochigen Gaumenhöcker versehen. Die runden Nasenlöcher liegen am Schnabelgrunde. Die 2. und 3. Sohwinge sind an längsten und nebst der 4. und teilweise anch der 5 . aussen verengt. Flug bogenförmig. Eier charakteristisch geädert.

73. Emberiza schoenichus (L.) 1758. - Rohrammer.

Synonyma: Fringilla sehocniclus L.; Passer arundinaceus Briss.; Buscarla arundinacea Bp.; Schoenicola arundinacea Bp.; Sichoenicola schocnichus Bly., v. Ifom.; Cynchramus schoeniclus Boie, Cab., Newes, Radde; Cynchramus stagnatilis, C. alnorum, C. septentrionalis, C. lacustris, C. lapponicus, C. limieola, C. mierorhynchus, C. phragmitis, C. riparius Chr. Brehm; Emberiza arundinacea Gmel.; Emberiza paserina Pall.; Emberiza palustris Chr. Br.; Emberiza sehoeniclus L., Gm., Behst., Butf., Naum., Chr. Br., Glog., Gieb., A. Br., Fridr., Hart., Gätke, Jäckel. chen.

Trivialnamen: Rohrsperling, Rohrspatz, Rohrspar, Schieb-

Kennzeichen der Art: Die 1. Schwinge kürzer als die 5. Schnabel dunkelgrau. Bürzel grau mit schwärzlichen Stricheh. Ein weisslicher Streifeu zicht vom unteren Schnabelwinkel neben der Kehle entlang.

Ma as e von 15 schlesischen Exemplaren in cm:

$\begin{array}{lccc} & \text { maximum } & \text { minimum } & \text { Durchschnitt } \\ \text { Länge: } & 14,5 & 13,0 & 13,5 \\ \text { Flugbreite: } & 25 & 23,5 & 24 \\ \text { Schwanz: } & 6,8 & 6,0 & 6,2 \\ \text { Schnabel: } & 0,9 & 0,8 & 0,8 \\ \text { Tarsus: } & 1,0 & 1,0 & 1,0\end{array}$

Die Rohrammern variiren bekauntlich in ihrer Grösse sowie in den Schnabelverhïtnissen sehr bedeutend. Leider habe ich den Abweichungen dieses Vogels in Schlesien zu wenig Aufmerksamkeit geschenkt. Soviel abri glaube ich mit Bestimmtheit versichern zu können, dass aile ron mir untersuchten schlesischen Exemplare die typische kleinwiiehsige Stammform darstellten, wemmleich einige schon ziemlich grosse Miarsse zeigten.

An Teichen und sumpfigen Wiesen ist der Rohrammer in Schlesien eine gewöhnliche Erscheinung, obschon er nur an wenigen besonders günstigen Oertlichkeiten geradezu als gemein bezeichnet werden kamn. Niederes Gestränch ist durchans Bedingung, wenn er sich fest ansiedeln kann. Rohr entbehrt er schon eher, obgleich er es 
sehr liebt und sich gern an den Rändern der Rohrdickichte herumtreibt. In den Vorhergen kommt er auch vor, ins eigentliche Gebirge aber geht er meines Wissens nicht hinauf. Im März kommen die Rohrammern bei uns an, um im Oktober wieder zu verschwinden. In milden Wintern bleiben aber die alten Vögel oft auch bei uns, so nach A. v. Homeyer $1 \$ 6 \varsigma / 69$ am Leopoldshainer Teich bei Görlitz, 1872/73 bei Schweidnitz und nach meinen eigenen Beobachtungen 1889/90 bei Breslau. Es folgen einige Ankunftstermine: 24. III. 1 \$39 bei Görlitz (R. Tobias), 6. IV. 1876 (bezgl. 13. X.) bei Breslau (Kern), 10. IV. 1882 bei Görlitz (Krezschmar), 23. 11I. 1891 bei Niesky (Baer und Floericke), 31. III. 1889 und 21. 1II. 1890 bei Breslau (Floericke). Praetorius fand das volle Gelege am 11. Mai und am 30. nackte Junge.

Maasse von 12 schlesischen Eiern in mm:

$\begin{array}{lccc} & \text { maximum } & \text { minimum } & \text { Durchschnitt } \\ \text { Länge: } & 19,5 & 18,5 & 19,0 \\ \text { Breite: } & 15 & 14,5 & 14,75\end{array}$

Emberiza pusilla Pall. 177i. - Z w er g a m mer.

Zu den Zeiten ron Weigler und Ender soll der Zwerg. ammer in Schlesien vorgekommen sein, wie beide Autoren übereinstimmen berichten. Leider fehlen aber alle näheren Daten, so dass man gut thun wird, diesen Ammer vorläufig nicht mit in das Verzeichnis der schlesischen Vögel aufzunehmen.

\section{Emberiza cia L. 1766. Z i p a m mer.}

Synonyma: Cirlus stultus Aldr.; Buscarla cia Bp.; Hylaespiza cia Blas.; Luspiza cia Blyth; Cia cia, C. meridionalis Gray; Emberiza pratensis Briss.; Emberiza notata Miull.; Emberiza barbata Scop.; Emberiza lutharingica Gm.; Emberiza cioides Tem.; Emberiza ciopsis Bp.; Emberiza meridionalis Cab.; Emberiza hordei, E. canigularis Chr. Brehm; Emberiza cia L., Gm., Behst., Naum., Chr. Brebm, Glog., Gieb., Kays. u. Blıs., A. Br., Fridr., v. Hom., Mewes, Radde, Hart., Gätke, Jäckel.

Kennzeichen der Art: Die 1. Schwinge ist kürzer als die 5. Die Schwingen an der Aussenfahme bis zur 5 . verengt. Schnabel bläulich. Bürzel rostrot.

Gloger vermutet bereits, dass der Zippammer bisweilen in Schlesien vorkomme, sagt aber nur in seiner unbestimmten Weise „vielleicht an der mährischen Grenze", weiss also jedenfalls nichts Bestimmtes. Zu meiner grossen Freude war ich selbst so glücklich, den thatsüchlichen Beweis für das Vorkommen dieses hübschen Vogels zu erbringen, indem ich im Frühling (März) bei Breslau ein Männchen erlegte, welches sich jetzt in meiner Sammlung 
befindet. Es scheint, als ob im Frühjahr junge und ungepaarte Mänuchen auf der Suche nach einer Lebensgefährtin sich bisweilen weit mach Osten und Norden verstrichen. Auch auf Helgoland ist diese Art schon zweimal nachgewiesen worden. Immerhin ist ihr Vorkommen in Sehlesien als ein durchaus ungewöhnliches und sehr seltenes zu betrachten, und jedenfalls schreitet sie bei uns nie zur Brut. Im südwestlichen Dentschland ist dies dagegen der Fall.

Emberiza leucocephala Gm. 17io. - Fichtenammer.

Eben lese ich in cinem Aufsatze Michels in der "Schwalbe", dass in Isergebirge ein Fichtenammer gefangen worden und durch meinen vor wenigen Tagen leider verstorbenen Mitarbeiter K ir chner der Grätl. Schaffgotsch'schen Sammlung in Warmbrunn einverleibt worden ist. Da aus dem Artikel Michels nicht zur genüge hervorgeht, ob diese rara avis auf preussischem oder böhmischem Gebiete erbentet wurde, so muss ich sie hier vor!äufig noch ohne Nummer aufführen. Sollte ersteres der Fall sein, so würde damit nicht nur Schlesien, sondern meines Wissens auch das deutsche Festland (in Helgoland ist lencocephala schou vorgekommen) um eine neue Art bereichert werden.

\section{Emberiza hortulana L. 1758. - Ortolan.}

Synonyma: Citrinella hortulana Kaup; Euspiza hortulana Blyth; Glycospiza hortulaua Cab., Mlewes; Émberiza Tunstallii Lath.; Emberiza matelbeyensis Sparm.; Emberiza badensis, E. chlorocuphala Gmel.; Limberiza pinguescens, E. delicata, E. antiqnorum, E. intercedens Chr. Brelnm; Limberiza hortulana L., Buff., Gmel., Behst., Naum., Chr. Br., Glog., Gieb., Kays. u. Blas., A. Br., v. Hom., Fridr., Radde, Hart., Gätke, Jäckel.

Trivialnamen: Urtlan, Utlan, Klitscher, Windsche, Wendische Goldammer, Korntinke.

Kennzeichen der Art: chmabel fleischfarben. Bürzel braungrau mit dunklen Schaftstrichen. Der Keilfleck auf den 2 äussersten ذ'chwanzfedern geht nicht bis zur. Nitte derselben.

$\mathrm{M}$ a asse von 8 schlesischen Exemplaren in $\mathrm{cm}$ :

$\begin{array}{lccc} & \text { maximum } & \text { minimum } & \text { Durchschnitt } \\ \text { Länge: } & 16,0 & 15,4 & 15,7 \\ \text { Flugbreite: } & 26,8 & 25,9 & 26,4 \\ \text { Schwanz: } & 6,2 & 6,0 & 6,1 \\ \text { Schnabel: } & 1,0 & 1,0 & 1,0 \\ \text { Tarsus: } & 1,8 & 1,8 & 1,8\end{array}$

Die schlesischen Ortolane erscheinen in der Färbung etwas verwaschener und schmutziger als aus südlichen Lündern stammende Stücke. Die Verbreitung des Gartenammer's in Deutsch- 
land ist eine sehr eigentümliche, vielfach unterbrochene und unregelmässige, ich möchte sagen, insclartige. Das gilt auch für Schlesien. Uebrigens ist der Vogel dem gewöhnlichen Manne wenig bekanut und mag sich deshalb auch vielfach der Beobachtung entzichen. "Die eigentliche Heimat", sagt A. v. Homeyer, ndürfte der Südosten sein. Vou hier verbreitete er sich nordwärts bis zur Nord- und Ostsee, doch auch mit der Eigentümlichkeit des Girlitz, dass einige Distrikte gestlcht, andere gemieden wurden. In Schlesien ist er stellenweise recht häufig." Und R. Tobias bemerkt geradezu: „Bei uns vielleicht lüufiger als in jeder anderen Provinz Deutschlands." Sehr treffend charakterisirt A. v. Homeyer die Lieblingsplätze des Vogels: „Lange Strassen mit alten Bäumen, welche durch üppiges Fruchtand, namentlich durch Klee-, Rapsund Rübenfelder führen, woran ïppige, aber nicht nasse WVeideplätze mit wenig Gebüseh und (inzehen Bäumen sich anschliessen, sind die Lieblingsplitze. Der Boden darf nicht feucht und auch nicht allzu schwer sein; ein milder warmer Lehm- oder Fruchtboden, mit sind durchschoben, sind ihm am liebsten." Auch in buschreichen Flussniederungen siedelt er sich an, und selbst öde Gegenden meidet er nicht völlig. Immer aber ist es die Ebene, welche er bewolnt; im Gebirge kommt er nur in seltenen Ausnahmefällen vor, von denen ich weiter unten einige anführen werde. Im ganzen haben wir in Schlesien 7 verschiedene Verbreitungsbezirke zu unterscheiden, nimmlich 1. der ebene und sandige Teil der Lausitz, speciell die Umgebung von Daubitz (Bär), Sprottau (Krezschmar), Niesky (Bär und Kramer) und Hoyer'swerda (Fechner). Bei Görlitz wird der Vogel nach R. Tobias schon seltener, und weiter nach rem Gebirge zu kommt er gar nicht mehr vor. 2. Wer nördliche Ziplel von Niederschlesien. Hier ist der Ortolan wirklich gemein und muss mit zu den ersten Charaktervögeln gezählt werdeu. Śpeciell gilt dies für die Gegenden von Glogau (A. v. Homeyer), Grüneberg, wo er nach L. T'obias sehr häufig in den Weinbergen getrotten wird, Sagan (Kaiser), Carolath (Sachse) und Neusalz. 3. Wie trockenen Teile der Bartschuiederung, soweit auf denselben der intensive Ackerbau reicht. Selten. t. Das IIigelland und die Ebene westlich von Breslau, also namentlich der Ḱreis Neumarkt. Doch ist der Ortolan daselbst jetzt überall in raschem Abnehmen begriffen; so constatirte z. B. v. Me y er in ck für Canth den stetigen Rückgang des Vogels und schliesslich sein völliges Verschwinden. 5. Das Hügelland südwestlich von Breslau. Hier kommt der Vogel nach $\mathrm{Richter}$ bei Strehleu vor und ist nach $\mathrm{Kern}$ bei Ottmachau häufig. 6. Einige gut angebaute Distrikte Oberschlesiens, wie die Gegenden von Kosel (Utteudörfer) und Nendza (Deditius). 7. Ver grosse rings von Gebirgen eingeschlossene Thalkessel der Grafschaft Glatz, wo A. v. Homeyer den Ortolan 
bei Glatz und Camenz auffand. Emmerich nennt ihn für Neurode sehr selten und hat ihn daselbst nur einmal, im Mai 1856 , beobachtet. Das führt uns zu den seltenen Ausnahmefällen, wo der Ortolan in ausgesprochenen Gebirgsgegenden brütend gefunden wurde. Das ist in Schlesien meines IVissens bisher erst zweimal der Fall gewesen. Nach M i chel brütete 1850 ein Paar im Steinbacher Thal bei Flinsberg, während sonst dort nie Ortolane vorkommen. Ein Stück davon befindet sich in Heydrichs Sammlung. Den anderen Fall constatirte A. v. Homeyer, welcher ein brütendes Pärchen auf den Bleichen von Polsnitz unweit des Fürstensteiner Grundes antraf. Der Zug scheint eben so sehr seine Eigentümlichkeiten und Unregelmässigkeiten zu haben als die Verbreitung. Denn während die meisten schlesischen Ankunftsdaten erst auf den Mai entfallen, wurden mehrfach schon im April brütende Ortolane gefunden. Einzelne bleiben auch den Winter über bei uns. So schoss R. Tobias 1841 ein überwinterndes Männchen. Der Herbstzug vollzicht sich hauptsächlich während des September; doch beginnt das Streichen schon im August. Das Nest ist schwer zu finden, weil es der Vogel gewöhnlich mitten in die Fruchtfelder baut. Perrin fand ein solches im Roggen am 25. April mit vollem Gelege. Durchschnittsmaasse von is schlesischen Eieru: $19+1$ j mm.

76. Emberiza cirlus L. 1766. - Z a un ammer.

Synonyma: Cirlus cirlus Gray, Kaup; Emberiza sepiaria Briss., Buff.; Emberiza elaeothorax Behst.; Emberiza cirlus L., Gm., Bchst., Naum., Glog., Gieb., Kays. u. Blas., A. Br., v. How., Mewes, Radde, Hart., Gätke, Jäckel.

Kennzeichen der Art: Die 1. Schwinge steht der j. nïher als der 4. Die Schwingen sind bis zur 5 . aussen verengt. Bürzel graugrün. Der Keilfleck auf der Innenfahne der 1. Schwanzfeder geht bis über die Mitte derselben.

Von dieser Art gilt ganz genau dasselbe, was ich oben über cia gesagt habe. Auch hier dürfte mein im Frühjanr bei Breslan erlegtes und in meiner Sammlung anfbewahrtes Exemplar das einzige sein, welches bisher mit Sicherheit in Schlesien nachgewiesen wurde. Auch der Zaunammer brïtet vereinzelt im siidwestlichen Deutschland.

\section{Emberiza citrinella L. 1753. - Gold a m mer.}

S y nony ma: Citrinella citrinella Gray; Emberiza flava Briss., Buff.; Emberiza maior, E. longirostris, E. brachyrhynehus, E. septentrionalis, E. planorum, E. silvestris, E. erythrogeny's Chr. Brehm; Emberiza citrinella L., Gm., Behst., Naum., Glog., Gieb., Kays. u. Blas., A. Brehm, v. Hom., Mewes, Radde, Hart., Gütke, Jäckel. 
Trivialnamen: Goldalmer, Goldutsche, Golditsche, Embritz, Emmeritz, Amritz, Gelbling, Grünschling, Gaulammer, Gaalammer, Geelgerst, Golitschke. Polnisch: Sternadel.

Kennzeichen der Art: Die 1. Schwinge ist gleich der 4. Die 1. Schwinge ist weiss, die übrigen gelb gesäumt.

II a asse von 73 schlesischen Exemplaren in $\mathrm{cm}$ :

$\begin{array}{lccc} & \text { maximum } & \text { minimum } & \text { Durchschnitt } \\ \text { Länge: } & 17,9 & 16,0 & 17,5 \\ \text { Flugbreite: } & 28,2 & 25,9 & 27,7 \\ \text { Schwanz: } & 7,6 & 7,0 & 7,4 \\ \text { Schnabel: } & 1,3 & 0,8 & 1,1 \\ \text { Tarsus: } & 2,2 & 2,0 & 2,1\end{array}$

Wie man sieht, schwanken die Grössenverhältnisse ausserordentlich. Wahrscheinlich kommt dies daher, dass wir in Schlesien zwei ziemlich heterogene Subspecies dieses Vogels vertreten haben, eine im Gebirge und eine in der Ebene. Die letztere ist ebenso geartet wie meine aus Posen und Ostpreussen stammenden Goldammern und zeichnet sich vor den westlichen aus durch auffallend grosse Maasse, eine eigentümlich bleich-grünlichgelbe Grundfärbung und teilweise auch durch einen etwas verkürzten Unterschnabel. Bei den im Winter hinzukommenden Goldammern treten alle diese Merkmale deutlicher hervor, während sie sich bei den Standvögeln viel mehr verwischen. Die Goldammern aus dem schlesischen Gebirge hingegen sind sehr lebhaft gelb, kleinwüchsig und langschnablig. Ob diese meine Vermutungen richtig sind oder nicht, müssen erst spätere Untersuchungen beweisen, zu denen ich hiermit angeregt haben möchte. Im Breslauer Museum stehen 2 abnorme Exemplare, deren Körper sehr licht graugelb mit schwach angedeuteter rostfarbener Zeichnung ist. Schwingen und Schwanz sind fast weiss, Schnabel und Füsse gelb.

Ich brauche wohl kaum zu sagen, dass auch in Schlesien der Goldammer ein gemeiner und allbekannter Vogel ist. Er folgt iiberall den Spuren und Ansiedlungen des Menschen oder richtiger vielleicht noch den l'ferden, weshalb der Trivialname "Gaulammer" sehr berechtigt erscheinen muss. Auf Gr. Iser z. B. hat er sich nach Kirchner erst seit 15 Jahren angesiedelt, nachdem Pferde statt der Ochsen daselbst als Zugtiere eingeführt wurden, und ist jetzt in raschem Zunehmen begriffen. In der Görlitzer Heide ist er nach Krezschmar der einzige dort brütende Ammer. Während seine Gattungsverwandten mit Recht als Charaktervögel der Ebene geltun, übersteigt er allein die Grenzen des Mittelgebirges, aber anch nur um kaum 200 Fuss. Ueber 3200 Fuss Meereshöhe geht ('1 nach Gloger nicht empor. Ausnahmsweise wird der Goldammer auch zuin Höhlenbrüter. Kna u the traf ihn 1886 in einem Maucrloche brütend und fand 1890 am ${ }_{n}$ Schwarzen Graben" nicht 
weniger als ein halbes Dutzend Wohnungen in ausgehöhlten Weidenstämmen, obwohl passendere Nistplaitze rings vorhanden waren. Der brütende Vogel sitzt sehr fest, wovon $\mathrm{Kollibay}$ ein hübsches Beispiel berichtet: ${ }_{n} \mathrm{Am} 5$. Juni $1388 \mathrm{ging}$ ich in einem Weidicht über eine kleine nur mit Hopfen überzogene Fläche, als plötzlich dicht hinter mir ein Vogel aufschwirrte. Ich blickte mich um und bemerkte am Boden eine grosse Menge von Rückenfedern der Goldammer. Bei weiterem Suchen entdeckte ich das Nest, dessen aus 4 Eiern bestehender Inhalt vollständig zerdrückt war. Ich war also direkt auf den brütenden Vogel getreten." Richter beobachtete den Nestbau am 23. April und 1\%. Juni. Kollibay fand einmal ein Nest auffallend Loch $(3 \mathrm{~m})$ in einer Tanne; sonst baut der Vogel niedriger. Aus den zahlreichen Daten, welche mir meine Mitarbeiter über gefundene Gelege zusandten, aus der Litteratur und aus eigenen Beobachtungen geht in Verbindung mit der Richterschen Notiz hervor, dass der Goldammer bei uns in schlesien regelmässig ¿2 Mal, gestört 3 Mal im Jahre brütet.

Maasse von 69 schlesischen Eiern (davon 19 durch Kollib a y gemessen) in $\mathrm{mm}$ :

$\begin{array}{lccc} & \text { maximum } & \text { minimum } & \text { Durchschnitt } \\ \text { Länge: } & 23,5 & 19,5 & 21,6 \\ \text { Breite: } & 17,5 & 15,0 & 16,5\end{array}$

Die gemessenen Eier stammten fast alle aus der Ebene. Da Friderich nur $1,9+1,4 \mathrm{~mm}$ angiebt, so scheint es, als ob auch die Eier der grossen und bleichen östlichen Form constant grösser wären.

78. Emberiza calandra L. 1758. - Gr a u a m mer.

Synonyma: Miliaria cana Frisch; Miliaria cana, MI. germanica, M. valida, M. septentrionalis, M. peregrina, M. meridionalis, M. minor Chr. Brehı; Niliaria europaea Swains., v. Hom.; Cynchramus miliaria Bp.; Spinus miliarius Gray; Crithophaga miliaria Cab., Mewes, Radde (et var. ninor); Emberiza caspia Mén.; Emberiza miliaria L., Gm., Bchst., Chr. Br., Naum., Glog., Gieb., Kays. u. Blas., A. Brehm, Fridr., Hart., Gïtke, Jiickel; Emberiza calandra L.

Trivialnamen: Klitscher, Gerstling, Gerstrogel, Gersthammer, welscher Ammer.

Kennzeichen der Art: Grösse über $18 \mathrm{~cm}$. Schnabel schmutzig gelb. Seitenfedern des Schwanzes olme weissen Keilfleck. 
Matase von 18 schlesischen Exemplaren in $\mathrm{cm}$ :

$\begin{array}{lccc} & \text { maximum } & \text { minimum } & \text { Durchschnitt } \\ \text { Länge: } & 19,2 & 18,5 & 18,8 \\ \text { Flugbreite: } & 30,3 & 29,8 & 29,9 \\ \text { Schwanz: } & 8,8 & 7,5 & 8,1 \\ \text { Schnabel: } & 1,4 & 1,3 & 1,35 \\ \text { Tarsus: } & 2,7 & 2,5 & 2,6\end{array}$

Am meisten scheint bei den typischen Grauammern die Schwanzlänge $\mathrm{zu}$ variiren. Der Grundton im Gefieder meiner schlesischen Exemplare ist stets ein trübes Graubraun, nie mit einem Stich ins Roströtliche. Die Subspecies minor, welche $R$ adde beschreibt, und die nur $14,6-16,5 \mathrm{~cm}$ Totallänge erreicht, kommt in Schlesien wohl nicht vor. Die Priorität inbezug auf die Auffindung dieser Form gebührt übrigens dem alten $\mathrm{Br}$ eh m.

Das Breslauer Museum besitzt folgende Farbenvarietäten:

a. Kopf schmutzig weiss mit sparsamer Zeichnung; Rücken, Flügeldecken und Steiss weiss ohne Zeichnung. Die Schwanzund Schwungfedern teils ganz weiss, teils weiss gekantet. Vorderseite rein weiss mit spärlicher Zeichnung.

b. Rein weiss mit einigen vereinzelten Streifen auf dem Bauche. c. Ganz weiss.

In den fruchtbaren Teilen der schlesischen Ebene ist der Granammer sehr gemein, in weniger bebauten Gegenden aber nur spärlich anzutretlen. Saudgegenden und das Gebirge meidet er giinzlich, doch ist er wach Kollibay noch im Hirschberger Thal uul uach Emmrich uoch bei Nearode als vereinzelter Brutvogel anzutreiten, und nach A. v. Ho meyer bei Frankenstein. Der Gratumme licbt tief liegende Ebenen mit recht fettem Boden, Getreidefeliter, Wiesen und Bruchränder; eine ausgesprochene Vorlicioe zeigt or nach Brahts für Rapsfelder. Ungeheuer häufig traf ich diesen Trogel bei Hundsfeld, östlich von Breslau, welche Gegend tür ihn wie gesehatfen erscheint. Im Winter kommen auch noch nordische Grauammern zu uns. Die bei uns nistenden bleiben entweder auch die ranhe Jahreszeit hindurch da oder rerstrcichen nur wenig. Mehmals fiel mir an diesem Vogel seine grosse Lebenszahigkeit auf. I'ractorius fand am 21. April das Gelege vervollständigt.

Masse von 11 schlesischen Eiern in $\mathrm{mm}$ :

$\begin{array}{lccc} & \text { maximum } & \text { minimum } & \text { Durchschnitt } \\ \text { Länge: } & 23 & 22 & 22,7 \\ \text { Breite: } & 17,5 & 16,5 & 17,1\end{array}$

(i a t tung: Calcarius Behst. 1802. - Spornammer. 
Der spornartige Nagel der Hinterzehe ist grösser als diese und nur wenig gebogen. In dem langen spitzen Flïgel sind die 1. und 2. Schwinge am längsten. Im übrigen Ammerncharakter.

79. Calcarius lapponicus (L.) 175\%. - Spornammer.

Synonyma: Fringilla lapponica L., Gm., Bchst.; Fringilla calcarata Pall.; Fringilla montana Briss.; Carduelis lapponica Rudb.; Emberiza lapponica Bp., Swains., Aud., Naum., Gieb., Nils., Fridr., Gätke: Emberiza calcarata Tem., Glog.; Plectrophanes calcaratus Meyer; Plectrophanes lapponicus Selby, Kays. u. Blas., A. Br., v. Hom., Jäckel; Plectroplianes groenlanlicus Chr. Br.; Passerina lapponica, P. montana Vieill.; Centrophanes lapponica Kau1., Mew.; Centrophanes calcaratus Gray; Calcarius lapponicus Hartert.

Trivialnamen: Lerchenfink.

Kennzeichen der Art: Die unteren Flügeldeckfedern sind grau mit weissen Rändern, die am Flügelbug auflicgenden oberen Deckfedern graubraun mit fahlen Säumen.

Der Lerchenammer gehört zu unseren seltensten Wintergästen; nach Gloger mischt er sich gewöhnlich unter die Schwärme der Feldlerchen und mag deshalb auch öfters übersehen werden. Im Februar 1811 trieb sich nach Endler eine Gesellschaft Spornammern bei Breslau herum, und wurde ein Stiick ans derselben erlegt. R. Tobias erwähnt ein bei Herrenhut vorgekommenes Exemplar. Nach Krezschmar wurde 1830 ein weiteres auf dem Felde bei Gr. Schönau geschossen.

80. Calcarius nivalis (L.) 175\%. - Schneeammer.

Synonyma: Emberiza nivalis L., Gm., Behst., Wils., Naum., Glog., Gieb., Fridr., Giitke; Emberiza mustelina, L. montana Gmel.; Emberiza glacialis Lath.; Emberiza borealis Vieill.; Avis nivis Mart.; Hortulanus nivalis Briss, Leach; Hortulanus glacialis Leaci; Passerina nivalis, P. glacialis Vieill.; Plectrophames nivalis II.yer, Aud., Chr. Br., Kays. u. Blas, A. Br., v. Hom, Mewes, Radde, Hart., Jäckel ; Plectrophanes borealis, P. montanus, P. mustelinus, P. hiemalis Chr. Brehm.

Trivialnamen: Schneevogel, Winterling, Neuvogel, gescheckter Emmerling.

Kennzeichen der Art: Die unteren Flügeldeckfederu weiss, die am Flügelbug aufliegenden oberen Deekfedern schivarz.

Der Schneeammer fehlt wohl in keinem Jalne gänzlich, ist aber nur in strengen und schneereichen Wintern wirklich häutig; wo er dann in grossen Flügen hoch gelegene und von Wald und Gebüsch möglichst entfernte Felder aufsucht. Sonst finden sich diese nordischen Gäste nur in kleiuen Trupps oder auch einzehn und unter den Schwärmen verwandter Vögel ein. Bei grosser 
Not kommen sie auch bis in die Dörfer, sonst aber nicht. Das Breslauer Museum besitzt 7 ausgestopfte Exemplare, und jede grössere Privatsammlung enthält deren einige. Sie erscheinen gewöhnlich Ende November und ziehen zu Anfang des Februar wieder fort, kehren aber bisweilen im März wieder zurück, wenn ein Nachwinter eintritt. Besonder's häufig waren sie 1838/39, $1840 / 41,1841 / 42,1875 / 76,1880 / 81,1884 / 85$ und $1888 / 89$. Im März 1889 beobachtete ich noch grosse Schwärme auf den Feldern siidlich von Breslau.

Gattung: Loxia L. 1758. - Kreuzschnabel.

Die Spitzen des starken und dicken Schnabels sind kreuzförmig über einander weg gebogen. Die 1. Schwinge ist am längsten. Die Federn des kurzen und gabelförmig ausgeschnittenen Schwanzes sind nach aussen schief zugestutzt.

81. Loxia bifasciata (Chr. Brehm) 1327. -- Bindenkreuzschnabel.

Synonyma: Crucirostra bifasciata et leucoptera Chr. Br.; Loxia falcirostra Lath.; Loxia taenioptera Glog.; Loxia leucoptera Nils., v. Schrenck, Gmel., Mew., Fridr., Jäckel; Loxia bifasciata de Sel., Bp., Schleg., Degl., Gieb., A. Br., v. Hom., Mewes, Hartert, Gätke.

Trivialnamen: Finkenflügel.

Kennzeichen der Art: Flügel mit zwei weissen Querbinden.

Wir haben in diesem Jahrhundert zwei Jahrgänge gehabt, in welchen die sonst sehr seltenen Bindenkreuzschnäbel plötzlich in grosser Menge in Schlesien auftraten, nämlich 1826 und 1889. Letztere Invasion habe ich selbst mit erlebt, dabei den Vogel mehrfach in freier Natur gesehen und viele Exemplare monatelang im Käfig gehalten und hier auf das eingehendste beobachtet. Trotzdem vermag ich der vorzüglichen Schilderung Glogers kaum etwas neues hinzuzufügen, da derselbe schon alle Gewohnheiten lind Eigentümlichkeiten des interessanten Vogels sehr genau behandelt hat. Nur möchte ich hier die Vermutung aussprechen, dass es für einen geübten Vogelpfleger und -züchter nicht allzu schwer sein wird, den Bindenkreuzschnabel in einer entsprechend ausgestatteten Vogelstube zur Brut zu bringen, was vom höchsten wissenschaftlichen Werte sein würde. Die Vögel zeigen sich, wenn man erst cinmal richtige Paare herausgefunden und zusammengesetzt hat, äusserst anhänglich und liebenswürdig zu einander. Ein Weibchen ging mir leider während meiner Abwesenheit an einem legereifen Ei zu grunde. - Schon im Jahre 1816 erhielt Klöber ein grünes Weibchen zugeschickt. 1826 wurden bei Carlsruhe bei Oppeln mehrere auf Leimruten gefangen, darunter auch ein ganz schwarzes Exemplar mit weissen Binden. Gloger 
vermutet, dass dasselbe der Gefangenschaft entflohen ist. Der letztgenannte Forscher erhielt seinen ersten Bindenkreuzschnabel im Herbst 1826 lebend, gleich darauf noch 3 tote und von mindestens 15 anderen sichere Nachricht. In der Lausitz erschienen die Bindenkreuzschnäbel um dieselbe Zeit nach den übereinstimmenden Berichten der dortigen Forscher massenhaft, und wurden ihrer viele gefangen. Die Vögel blieben auch noch den ganzen Sommer 1827 im östlichen Deutschland zahlreich, um dann erst wieder zu verschwinden. So konnte $\mathrm{Glog}$ er noch viel lebendes und totes Material sammeln und seine berühmte Monographie des Bindenkreuzschnabels schreiben. Dann liegen mir keinerlei Nachrichten über das Vorkommen dieses Kreuzschnabels in Schlesien mehr vor bis zum Jahre i 889. Im September dieses Jahres sah und erlegte ich in der Bartschniederung die ersten. Als ich von Craschnitz nach Breslau zurückkehrte, fand ich eine ganze lieihe von Nachrichten über das Vorkommen der Bindenkreuzschnäbel vor und ersah daraus zu meiner Freude, dass wieder eine grössere Invasion derselben im Gange sei. In den Breslauer Vogelhandlungen erschienen die "Finkenflügel“ von da an massenhaft. Meist stammten dieselben aus Oberschlesien und insbesondere aus der Gegend von Ziegenhals, wo sie in ganzen Schwärmen von den dortigen Vogelfängern erbeutet wurden. Bei Beginn des Winters verschwanden diese Massen, während vereinzelte und versprengte kleine Gesellschaften noch in den Gebirgswaldungen zurückblieben. So kam es, dass auch während des Winters sowie im Sommer 1890 immer noch ab und zu einige gefangen wurden und auf den Breslauer Vogelmarkt kamen. Ja höchst wahrscheinlich hat der Bindenkreuzschnabel 1890 sogar in der Gegend von Ziegenhals gebrütet. Wenigstens sah ich in einer Breslauer Vogelhandlung mehrere von dort stammende junge Exemplare, die ihrer Befiederung nach kaum seit 8 'Tagen das Nest verlassen und jedenfalls noch nicht die weite Reise aus ihrer nordischen Heimat zu uns zurückgelegt haben konnten. Sehr gern hätte ich diesen hochinteressanten Fall näher untersucht, aber die Verhältnisse machten es mir damals leider unmöglich, nach Ziegenhals zu reisen. Im Herbst 1890 und im Winter 18.90/91 hörte ich nichts mehr von den "Finkenflügeln", aber am 17. April 1891 traf ich wieder 2 Stück im Nadelwalde bei Kobier und erlegte das eine. Im Breslauer Museum stehen 2, in der Sammlung Heydrichs 4 Stück. schnabel.

82. Loxia curvirostra L. 1758. - Fichtenkreuz-

Synonyma: Loxia concifera Klein; Loxia crucirostra Pall., Buff.; Crucirostra abietum Meyer, Nils.; Crucirostra maior et pinetorum Chr. Br.; Loxia curvirostra L., Gm., Behst., Naum., Bp., 
Schleg., Glog., Gieb., Kays. u. Blas., A. Br., v. Hom., Mew., Fridr., Radde, Hart., Gätke, Jäckel.

Trivialnamen: Kreuzvogel, Krummschnabel, Krimass, Krienitz, Griens. Oberschlesisch-polnisches Idiom: Krziwenos.

Kennzeichen der Art: Ohne weisse Flügelbinden. Grösse unter $1 \mathrm{~s} \mathrm{~cm}$. Schnabel verhältnismässig dünn und schwach.

II a asse von 80 schlesischen Exemplaren in $\mathrm{cm}$ :

$\begin{array}{lccc} & \text { maximum } & \text { minimum } & \text { Durehschnitt } \\ \text { Länge: } & 17,9 & 17,2 & 17,5 \\ \text { Flugbreite: } & 28,6 & 27,8 & 28,2 \\ \text { Schwanz: } & 5,7 & 5,3 & 5,5 \\ \text { Schnabel: } & 1,3 & 1,2 & 1,23 \\ \text { Tarsus: } & 1,9 & 1,7 & 1,8\end{array}$

Fast wäre man versucht, curvirostra und pityopsittacus subspeeifisch neben einander zu stellen. Aber diese beiden Formen sind im Laufe der Zeit doch schon zu sehr aus einander geraten und stellen jetzt bereits verschiedene Arten dar, ebenso wie corone und cornix. Sie sind also schon über den Wert der subspecies hinaus gekommen, welchen die Formen der Kleiber, Baumläufer, Sumpfmeisen und Dompfafien eben erreicht haben, während die der Raubwürger (maior und Homeyeri) und anderer noch im Entstehen begriffen sind und sich ihm erst nähern.

Der Bestand der Kreuzsehnäbel wechselt auch in Schlesien sehr, was mit dem unruhigen zigeunerartigen Naturell der Vögel zusammenhängt. Ganz fellen sie unserer Provinz aber wohl nie. In den südwestlichen Gebirgen und wahrscheinlich auch in der Waldregion des Riesengebirges sind die Kreuzschnäbel Brutvögel, wennschon sich die vollgültigen Beweise dafür sehr schwer erbringen lassen. A. v. Homeyer beobachtete brütende Kreuzschnäbel bei Görlitz und Glogau und vermutet, dass sie auch im Ifochwalde nistet. L. To bias erhielt in der Grüneberger Gegend cin elsen ausgeflogenes Junges, und Heydrich fand im Januar 1847 ein Nest mit 4 ziemlich ausgefiederten Jungen bei Gr. Iser. Emmrich schreibt mir: ${ }_{\text {n}}$ Brütet in den Waldungen des Eulengebirges und streicht von hier aus in die Grafschaft." Ferner fuihren folgende meiner Mitarbeiter noch den Fichtenkreuzschnabel als Brutvogel auf: Asmus, Raake, Gericke, Mally und Brotke. Eier freilich hat wohl keiner von ihnen gefunden. In den Tannenwïldern unserer Gebirge trifft man Kreuzschnäbel den ganzen Sommer über. Nirgends aber sind sie so massenhaft vertreten wie in der Gegend von Ziegenhals, von wo aus ein grosser Teil der deutschen Vogelhandlungen seinen Bedarf an Kreuzschnäbeln zu decken pflegt. 
83. Loxia pityopsittacus Bchst. 1802. - Kiefernkreuzschnabel.

Synonyma: Crucirostra pinetorum Meyer, Nils.; Crucirosta pityopsittacus, C. subpityopsittacus Chr. Brehim; Loxia curvirostra maior Gmel.; Loxia pityopsittacus Bchst., Naum., Bp., Schleg., Glog., Gieb., Kays. u. Blas., A. Br., v. Hom., Mew., Fridr., Radde, Hart., Gätke, Jäckel.

Kennzeichen der Art: Grösse über $18,5 \mathrm{~cm}$. Schnabel sehr dick, hoch gewölbt und kräftig. Kopf auffallend breit. Ohne weisse Ellügelbinden.

Ma asse von 5 schlesischen Excmplaren in cm:

$\begin{array}{lccc} & \text { maximum } & \text { minimum } & \text { Durchschnitt } \\ \text { Länge: } & 19,3 & 18,7 & 19,1 \\ \text { Flugbreite: } & 29,4 & 28,7 & 29,2 \\ \text { Schwanz: } & 6,7 & 6,4 & 6,5 \\ \text { Schnabel: } & 1,4 & 1,4 & 1,4 \\ \text { Tarsus: } & 2,2 & 2,0 & 2,1\end{array}$

Der Bestand der Kiefernkreuzschnäbel ist noch grösseren Schwankungen unterworfen als wie derjenige der vorigen Art. In manchen Jahren sind sie recht häufig, und dann sieht man wieder jahrelang keineu einzigen. Doch lïsst sich im allgemeinen sagen, dass pityopsittacus weit seltener ist als curvirostra. Ueber das Brutgeschäft gilt dasselbe, was ich schon bei curvirostra gesagt habe. A. v. Hom eyer hat auch den Kiefernkreuzschnabel bei Glogau und Görlitz brütend beobachtet, sonst aber liegen nur wenige bestimmte Nachrichten dariiber vor. In Breslaner Museum stehen 3 aus Schlesien stammende und zu dieser Art gehörige Kreuzschnäbel.

Gattung: Pyrrhula Briss. 1760. - Gimpel.

Schnabel kurz und dick, oben mit einem kleinen Haken. Nasenlöcher von den Stirnfedern verlorgen. Schwanz gerade. Die Geschlechter sind ungleich gefärbt. 2, - t. Schwinge am längsten. scher Gimpel.

84. Pyrrhula europaea Vieill. 1816. - Mittele uropäi-

84a. Pyrrhula europaea rubicilla Pall. 1811. - Grosser Gimpel.

Syn onyma: Fringilla sanguinea Schwenckf.; Fringilla rubecula Frisch; Fringilla pyrrhula Aleyer, Gloger; Lmberiza coccinea Sand.; Loxia pyrrhula L., Buff., Gm., Behst., Fridr:; Pyrrhula rubicilla Pall., Kays. u. Blas., Gieb., Radde, Jäckel; Pyrrhula rufa Koch; Pyrrhula europaea Vieill., A. Br., v. Hom,, Hart.; 
Pyrrhula vulgaris Naum., Bp., Degl., Briss., Tem., Chr. Br., A. Br., Gätke; Pyrrhula pileata Nacg.; Pyrrhula germanica, P. peregrina Chr. Br.; Pyrrhula minor Chr. Br., Schleg.; Pyrrhula coccinea Selys; Pyrrhula maior Chr. Br., A. Br., v. Hom., Mew., Hart., Gätke; Pyrrhula Cassini Baird, Cab., Dyb., Radde.

Trivialnamen: Gümpel, gelehriger Kernbeisser, Blut-, Luh- und Lohfinke, Rotvogel, Bollenbeisser, Thumherr, Thumpfaffe. Polnisch: Gil.

Kennzeichen der Art: Siehe die Gattungsmerkmale, da nur diese eine Art in Deutschland.

Die nordöstlichen Gimpel sind ständig grösser und haben auch lebhaftere und reinere Farben, weshalb man sie mit Recht als besondere subspecies aufgestellt hat. Schon im Freien sind sie leicht von den beträchtlich kleineren mitteleuropäischen Vögeln zu unterscheiden. Auch im Schnabel kommen Differenzirungen vor und ebenso in den weissen Flügelspiegeln, welch letztere aber keineswegs constant sind. Die meisten neueren Autoren machen aus diesen beiden Formen zwei verschiedene Arten. Ich kann dem nicht beistimmen, da schon Radde im Kaukasus Uebergänge zwischen beiden gefunden hat, und mir in Schlesien ebenfalls solche aufgestossen sind. Ueber den Wert von guten subspecies kommen beide Formen entschieden nicht hinaus. P. Cassini vollends kann ich nicht einmal als subspecies anerkenuen, denn die weissen Streifen und Keilflecken auf der Innenseite der ersten Schwanzfeder finden sich sowohl bei europaea wie bei rubicilla und zwar in der allerverschiedensten Ausdehnung aber keineswegs bei allen Individuen. Irgend welche Gesetzmässigkeit ist dabei absolut nicht zu erkennen. Ganz dieselben Beobachtungen hat schon vor mir R adde gemacht. Es geht aus alledem wohl zur Genüge hervor, dass der Cassinische Streifen etwas rein individuelles und zufälliges ist. Verhältnismässig häufig kommt Melanismus, seltener Albinismus vor. Im vorigen Sommer erhielt ich durch Emmrich ein Exemplar, welches in seltsamer Weise beide Aberrationen vereinigte. Der sonst am ganzen Körper gleichmässig kohlschwarze Vogel hatte blendend weisse Flügelspiegel, welche weit über das gewöhnliche Maass ausgedehnt waren. Das Breslauer Museum besitzt 3 Farbenvarietäten. Bei a., einem Weibchen, sind die Stirn-, Scheitel- und Flügeldeckfedern mit breiten weissen Kanten versehen und die ersten Schwungfedern hellbraun gefärbt. Die Unterseite ist weiss, schwach rosa angebaucht. Bei b., einem Männchen, ist der ganze Körper gleichmässig schwarz gefärbt. Die Vorderseite weist hier und da zerschlissene rote Federkanten auf. Am linken Flügel befinden sich 2 und am rechten 4 weisse Schwungfedern. Exemplar c. ist gleichfalls ein Männchen und gleichfalls ganz schwarz; nur 
einige Schwanz- und Schwungfedern sind an der Wurzel weiss. Schon Schwenckfeld beschreibt eine var. alba: „colore prorsus candido paucis in dorso nigriusculis plumulis elucentibus." in $\mathrm{cm}$ :

Ma asse von 65 schlesischen Exemplaren (lauter europaea)

$\begin{array}{lccc} & \text { maximum } & \text { minimum } & \text { Durchschnitt } \\ \text { Länge: } & 15,1 & 13,8 & 14,5 \\ \text { Flugbreite: } & 25,8 & 24,9 & 25,2 \\ \text { Schwanz: } & 7,3 & 6,1 & 6,8 \\ \text { Schnabel : } & 0,9 & 0,8 & 0,85 \\ \text { Tarsus: } & 1,7 & 1,5 & 1,59\end{array}$

Rubicilla kommt nur als Wintergast nach Schlesien, ist aber dann mitunter recht häufig und wird namentlich in den Vorbergen massenhaft für die Vogelhandlungen gefangen. Als Brutvogel haben wir bei uns nur europaet, aber auch diese Form ist auf dem Striche weit zahlreicher wie während der Brutzeit. Die grossen Gimpel kommen zu Ende des Oktober und verschwinden damn wieder während des Februar. Die Brutgimpel liegen dem Nistgeschäfte hauptsächlich in den Waldungen der Vorberge ob, sind aber auch hier nur in wenigen Gegenden eigentlich liäufig, sondern meist nur ziemlich dünn gesäet. Dies ist $z$. B. nach A. v. Homeyer im Hochwalde der Fall. Am liebsten suchen die Dompfaffen bergige Buchenwälder auf, sind auch gern im Nadelwald, meiden aber den reinen Kieferhochwald. Nach $K$ na u the sind die Dompfaffen in den Bögenbergen bei Schweidnitz sehr gemein und nisten dort massenhaft. Bei Breslau fand ich den schönen Vogel während der Brutzeit nur sehr vereinzelt. Von meinen Mitarbeitern führen ihn folgende als Brutvogel auf: Baer, Bormann, Kirchner, Asmus, Schmidt, Raake, Gericke, Hänel, Sylaender, Walikh off, Jaen isch und Brotke, die meisten von ihnen aber mit dem Zusatze relten." Sonst wird er stets nur als Wintergast aufgezählt. In der Waldregion des Riesengebirges ist der Gimpel gemein und geht nach $\mathrm{K} r \mathrm{amer}$ bis $\mathrm{zu} 1100 \mathrm{~m}$ Meereshöhe hinauf. A. v. Home yer beobachtete einmal im Herbste ein Pärchen auf dem Koppenplane. Pra etorius fand in einem Garten bei scheitnig am 14. Mai 1872 ein Nest mit 4 frischen Eiern.

Masse von 9 schlesischen Eiern in $\mathrm{mm}$ :

$\begin{array}{lccc} & \text { maximum } & \text { minimum } & \text { Durchschnitt } \\ \text { Länge: } & 22 & 20,5 & 21 \\ \text { Breite: } & 15 & 15 & 15\end{array}$

Gattung: Pinicola Vieill. 1807. - Rosengimpel. 
Schnabel kurz und dick mit hakig übergebogenem Oberschnabel. Schwanz ziemlich lang und etwas ausgeschnitten.

\section{Pinicola erythrinus (Pall.) 1770. - Karmingimpel.}

Synonyma: Fringilla flammea L.; Fringilla cristata Briss.; Fringilla erythrina Meyer, Naum.; Fringilla incerta Riss.; Loxia erythrina Pall., Gm., Fridr.; Loxia obscura Gm.; Loxia cardinalis Bes.; Loxia rosea Vieill.; Loxia erythraea Endl. u. Scholz; Coccothraustes erythrina Vieill.; Linaria erythrina Boie; Erythrothorax rubrifrons Chr. Br.; Erythrospiza rosea Blyth; Erythrospiza erythrina Bp.; Haemorrhous roseus Jerd.; Pyrrhulinota rosacea Hodgs.; Erythrinus roseus A. Br.; Pyrrhula erythrina Tem., Naum., Kays. und Blas., Gätke; Carpodacus erythrinus Kaup, Schleg., Gieb., v. Hom., Mewes, Radde, Hartert.

Kennzeichen der Art: Länge unter $18 \mathrm{~cm}$. Keine weissen Flügelbinden.

Der Karmingimpel wurde zuerst 1790 durch Endler im Mai bei Breslau erlegt. 1809 schoss Drescher ein Pärchen cbenfalls bei Breslau, und 1810 nistete daselbst der Vogel nach Gloger im sumpfigen Gebüsch. 1836 erhielt R. Tobias ein Nest aus dem Queissthale. Dasselbe stand am Ufer des Flusses in einem Eichenstrauche etwa 3 Fuss über dem Erdboden; von aussen war es dem Neste des Bluthänflings ähnlich, doch loser und weniger kunstvoll, innen mit Haaren und Wolle ausgefüttert, und enthielt + Eier. Das erste, prächtig ausgefärbbte Männchen wurde erlegt, worauf sich ein zweites jüngeres zu dem verlassenen $W^{\prime}$ eibchen gesellte. 1827 und 1836 wurde der Karmingimpel auch bei Hirschfelde durch den älteren $\mathrm{K} r \mathrm{e}$ z s ch ma r nachgewiesen. Auch Heydrich hat den Vogel bei Flinsberg melirfach beobachtet und ein Männchen für seine Sammlung erlegt. 1850 wurde bei Flinsberg ein Nest gefunden, welches unweit des Queissflüsschens auf einer Gartenmauer in einem dichten Weidenstrauche stand. R. Tobias schrieb damals: „Vielleicht gar nicht selten, wird aber nicht erkannt,“ Seitdem müssen sich die Karmingimpel ziemlich rasch aus Schlesien zurückgezogen haben. Schon A. v. Homeyer fand im Queissthal keine mehr vor, und heutzutage brütet wohl kaum ein Karmingimpelpärchen innerhalb der Provinz, weshalb auch die Bemerkung Frideriehs ${ }_{\text {Brütet bei }}$ Breslau“ sehr cum grano salis zu nehmen ist.

86. Pinicola enucleator (L.) 1758. - Hakengimpel.

Synonyma: Fringilla enucleator Meyer, Glog.; Strobilophaga enucleator Vieill.; Pyrrhula enucleator Tem., Naum., Chr. Br., Kays. und Blas., Gätke; Loxia enucleator L., Gm., Bchst., Fridr.; Loxia flamengo Sparrm.; Loxia psittacea Pall.; Corythus enucleator Cuv., Bp. und Schleg., Degl., Kays. u. Blas,, v. Hom., 
Hart., Jäckel; Corythus angustirostris et minor Chr. Brehm; Pinicola enucleator Cab., Gieb., A. Br., Mewes.

Kennzeichen der Art: Lünge über $18 \mathrm{~cm}$. Zwei weisse Flügelbinden.

Erst in einem einzigen Falle hat man den Hakengimpel in Schlesien nistend angetroffen. Chr. Brehm berichtet uns, dass im Jahre 1832 bei Breslau ein Nest dieses nordischen Vogels gefunden wurde. Sonst ist der Hakengimpel nur Wintergast und zwar ein höchst unregelmäissiger. Gloger behauptet zwar, dass er in den meisten Jahren zu uns kïme, aber ich möchte das doch stark in Zweifel ziehen. In der zweiten Hälfte unseres Jahrhunderts haben sich die Hakengimpel vielmehr nur in den allerwenigsten Jahren bis nach schlesien verstrichen, dann aber allerdings massenhaft. Man kanu bei diesem Vogel ebenso wie bein Steppenhuhn von förmlichen Einwanderungen reden. Die Hakengimpel zeigen sich dabei höchst vertraut, ja förmlich dummdreist und geraten deshalb zahlreich in die Hände der Vogelfänger und -händler. Uebrigens pflegen die schönen roten Mänuchen den unansehnlichen Weibchen gegenüber stets bedeutend in der Minderzahl zu sein. Mit Vorliebe halten sich die bei uns einrückenden Hakengimpel in den Gebirgsgegenden auf. 1797 fand nach Endler eine grosse Einwanderung statt. Dann sind die Jahre $1821-23$ als besonders reich au Hakengimpeln zu bezeichnen. 1825 durchzogen nach Heydrich tausende das Iser-und Riesengebirge. $1876^{\circ}$ erschienen sie nach Peck an der Landskrone. 1380 erbeutete Heydrich ein IVeibchen bei Neuwiese am Südkamme des Gebirges, und im Februar 1890 beobachtete ich ein singendes Männchen bei Suhleibitz. Eine grosse Invasion der Hakengimpel aber brachte uns ganz neuerdings der streuge Winter 1892/93, wo ihrer viele in den verschiedensten Gegenden der Provinz im Dohnensticge gefangen und unter den Krammetsvögeln mit auf den Markt gebracht wurden. He ydr i ch besitzt 2, das Breslauer Museum うे Belegexemplare.

\section{Gattung: Serinus Kuch 1816. - Girlitz.}

Schnabel sehr kurz und dick. Die 1. Schwinge grüsser als die 4., aber kleiner als die 2 . und 3. Alle 4 verengt. Die äussere und mittlere Zehe hinten zusammengewachsen.

87. Serinus hortulanus Koch 1816. - Girlitz.

Synonyma: Loxia serinus Scop.; Pyrrhula serinus Degl., Kays. u. Blas.; Fringilla serinus L., Gm., Behst., Briss., Buff., Sand., Naum., Glog., Fridr., Gätke; Fringilla islandica Fabr.; Crithagra seriuus Sws.; Uryospiza serinus Cab., Kays. u. Blas., Jäckel; Serinus serinus Hart.; Serinus luteolus Landb.; Serinus flavescens Gould; Serinus brumalis Strickl.; Serinus meridionalis, 
S. islandicus, S. orientalis Chr. Brelım; Serinus hortulanus Koch, Gieb., A. Brehm, v. Hom., Mewes.

Trivialnamen: Niesel-, Meer- und Rübenzeisig, Goldhahn, Hirngritterl, Görlitzer Würgengel.

Kennzeichen der Art: Siehe die Gattungsmerkmale, da nur diese eine Art in Deutschland.

Maasse von 52. schlesischen Exemplaren in cm:

$\begin{array}{lccc} & \text { maximum } & \text { minimum } & \text { Durchschnitt } \\ \text { Länge: } & 12,3 & 11,4 & 11,9 \\ \text { Flugbreite: } & 20,8 & 20,1 & 20,5 \\ \text { Schwanz: } & 5,2 & 4,8 & 5,0 \\ \text { Schnabel : } & 0,9 & 0,8 & 0,8 \\ \text { Tarsus: } & 1,3 & 1,1 & 1,2\end{array}$

Die Girlitze sind im allgemeinen sehr constante Vögel.

A. v. Homeyer hat das Verdienst, zuerst darauf aufmerksam gemacht zu haben, dass der Girlitz seinen Verbreitungsbezirk in nordöstlicher Richtung auszudehnen bestrebt sei. Kürzlich (Orn. Monatsberichte I, 1.) hat W. Hartwig gezeigt, dass sich das Vögelchen dazu dreier Ausfallpforten bediente, von deneu die für Schlesien inbetracht kommende die March-Beczwa-Oderfurche ist. Als die ursprüngliche Heimat des Girlitz haben wir Nordwestafrika und das südwestliche Europa anzusehen. Am besten werden wir uns das allmähliche Vordringen des Girlitz veranschaulichen, wenn wir ebenso wie bei Turdus pilaris die Berichte der einzelnen Eorscher in chronologischer' Reihenfolge überblicken.

1828. Neumann erwähnt den Girlitz noch gar nicht.

1830. Gloger: Brütet sehr selten.

1837. Uttendörfer: Ein alter Vogelfänger bei Kosel will den Girlitz seit diesem Jahre kennen.

1840. Rohnert: Zwischen Oder und Oppa noch nicht vorhanden.

1842. Moeschier: Die ersten bei Herrnhut beobachtet.

1846. A. v. Home yer: Fehlt bei Breslau.

1851. Fechner: Selten in der Gegend von Zittau.

1851. R. Tobias: Wohl nur sehr einzeln, doch scheint er die Vorberge alljährlich zu bewohnen. Da er im Mai oft paarweise gefangen wurde, mag er wohl brüten.

1857. Luchs: Zahlreich bei Hirschberg, Hermsdorf u. Petersdorf.

1857. Peck: Fehlt bei Görlitz. Dasselbe berichten Müller für Liegnitz und v. Hahn für Guhrau.

1858. Rohnert: Tritt bei Ustron a. d. Weichsel auf.

1850. He ydrich findet bei Flinsberg die ersten Eier.

18(i2. Auras: Von jetzt ab in der Gegend von Gutmannsdorf Brutvogel. 
1863. A. v. Ifome yer: Die ersten Vorläufer zeigen sich bei Glogau.

1864. Rohnert: In jedem Dorfe des südöstlichen Oberschlesien. An der nördlichen Abdachung des Riesengebirges selten.

1864. L. Tobias: Zum ersten Male in Saabor.

1865. A. v. Homeyer: Zahlreicher Brutvogel in der Grafschaft Glatz und im Eulengebirge. Bei Reinerz häufiger, nach Glatz zu seltener, bei Salzbrunn vereinzelt. Fehlt bei Reichenbach und Liegnitz. Bei Löwenberg und nach Hirschberg zu wird er immer häufiger. Bei Glogau nur auf dem Striche. Bei Frankenstein, Neisse und Münsterberg ziemlich häufig. In Ober- und Mittelschlesien überhaupt und namentlich um das Riesengebirge herum, in dessen Vorbergen überall recht zahlreich. Von hier dehnt er sich immer weiter nach Norden aus.

1866. A. v. Homeyer: Bei Breslau ziemlich häufiger Brutvogel, bei Liegnitz einzelne Paare, bei Glogau bisweilen ein singendes Männchen.

1866. $\nabla$. H a hn: Bei Militsch und Köben einzeln nistend.

1867. L. Tobias: Brütet in grossen Mcngen in allen Obstgärten aIn Fusse des Riesengebirges. Bei Grüneberg erst seit kurzem heimisch und nicht häufig.

1868. Pe ek: In kleiner Anzahl regelmässiger Brutvogel bei Gör litz. Dasselbe berichten Müller für Liegnitz und v. Hahn für Guhrau.

1869. v. Tsehusi: Auf spindelmühl drei und bei St. Peter zwei Paare.

1870. E. F. v. Hom e y er: Bei Görlitz und am Fusse des Riesengebirges häufig.

1870. Michel: Der Girlitz soll in diesem Jahre zuerst im Isergebirge aufgetreten sein.

1875. A. E. Brelim: Im Gebirge im Abnehmen. Kommt hoch oben gar nicht vor.

1875. A. v. Homeyer: In der Lausitz wird er von Jahr zu Jahr häufiger.

1877. Emmrich: Bei Goldberg nur selten durchziehend.

1877. Lincke: Bei Neisse bäufiger Brutrogel.

1878. R. Blasius: Bei Hirschberg häufiger Brutvogel.

1880. Kutter: Bei Neustadt sehr gemein.

1881. L. Tobias: Hat sich in den letzten Jahren bei Grüneberg sehr gemehrt.

1882. Krezschmar iun.: In den Anlagen von Sprottau ein nicht häufiger Brutvogel.

1885. Richter und Wolf: Bei Muskau sparsamer Brutrogel. 1885. W e iss: Bei Lipine häufig, desgl. nach Mo hr bei Breslau. 1885. Rich ter: Brutvogel in den Gärten von Strehlen.

1886. Kollibay: Bei Neisse gemein, auch im Gebirge. 
1887. Kollibay: Bei Patschkau, Hirschberg und Schmiedeberg sehr bäufig.

1888. Deditius: In Nendza gemein, selbst auf dem Marktplatz.

1890. Knauthe: In diesem Jahre sehr sparsam; nicht ein einziges Nest gefunden.

18:0. Michel: In den Vorbergen des Isergebirges sehr häufig; in geringer Menge auch im Gebirge selbst.

1891. Floericke: Brutvogel bei Breslau und in der Bartsciniederung. Von meinen Mitarbeitern tühren die meisten den Girlitz als Brutvogel an. Besonders interessant erscheinen in dieser Hinsicht die Angaben für Niesky (B a e r), Oppeln (v. Ehreustein), Bolkenhayn (Sylender), Sagan (Raake), Löwenberg (Ha enel), Carolath (A bukir) und Lüben (Hellmich).

Aus alledem geht wohl zur genüge hervor, dass der Girlitz während der toer und joer Jahre durch die Mareh-BeczwaOderfurche in Schlesien eingerückt ist, und dass diese Einwanderung zu Beginn der b0er Jahre ihren Iöhepunkt erreichte. Die Vögel fluteten nicht auf einmal in die sich vor ihnen ausbreitende schlesische Ebene, sondern hielten sich vielmehr anfangs streng an den Rand und die Vorberge der Sudeten, in denen sie rasch bis zur Lausitz vordrangen, um dam erst ganz langsam und allmählig in die Tiefebene des Oderthals hinabzusteigen und dann auch dieses selbst zu überschreiten und sich noch weiter nordöstlich in dem Flachlande auszubreiten. Jetzt ist die Invasion in ihren Hauptziigen vorüber, und es darf uns deshalb nicht Wunder nehmen, wenu der Bestand der Girlitze hier und da bereits wieder abzunehmen beginnt. "Grosse weite Ebenen" liebt der Girlitz nach A. v. Homeyer nebenso wenig wie das hohe Gebirge oder den geschlossenen WVald. Das Hügelterrain, namentlich das sich dem Mittelgebirge vorlagernde, ist besonders bevorzugt." Nach den übereinstimmenden Berichten von A. E. Brehm, R. Blasius und Kollibay ist der Girlitz im eigentlichen Hochgebirge nicht mehr anzutreften; Kollibay fand schon bei Brückenberg in ¿̇ou Fuss Meereshöhe keine mehr vor. Für Anlagen, Obstgïrten, Alleen und Parks hat das harmlose Vögelchen eine grosse Vorliebe, namentlich die Birnbäume sucht es sehr gern auf. Der Girlitz ist für unsere Gegenden ein Zugvogel, der im April ankommt und im Oktober wieder verschwindet. 
Zugtabelle:

\begin{tabular}{|c|c|c|c|c|c|c|c|c|c|}
\hline Ort: & Beobachter: & 18.31 & 1885 & 1886 & 1857 & 1585 & 1559 & 1890 & 1891 \\
\hline prottau & Krezschmar & 3. $x$. & - & - & - & - & - & - & 一 \\
\hline Streblen & Richter & 一 & $\begin{array}{l}\text { 9. IV. } \\
5 . \mathrm{X} \text {. }\end{array}$ & 6. IV. & $\begin{array}{l}\text { 15. IV. } \\
\text { 4. } \mathrm{X} \text {. }\end{array}$ & 18. IV. & - & 一 & - \\
\hline & & - & - & 21. IV. & - & - & - & - & - \\
\hline & & - & - & - & - & - & - & 8. IV. & - \\
\hline iesk & Bär u. Kramer & - & - & - & 15. IV. & $\begin{array}{r}\text { 10. I1 } \\
4 . \mathrm{X}\end{array}$ & 一 & $\begin{array}{l}\text { 8. X. } \\
\text { 8. }\end{array}$ & 9. IV \\
\hline & & - & 一 & 一 & 7. IV. & $1-$ & 一 & - & - \\
\hline & & 一 & - & 一 & - & - & - & - & 16. $\mathrm{X}$. \\
\hline reslau & Thiema & - & $\begin{array}{l}\text { 11. III. } \\
10 . \text { XI. }\end{array}$ & - & - & 一 & 一 & 一 & - \\
\hline$"$ & & - & - & 3. IV. & - & 一 & - & - & - \\
\hline tube & Floericke & - & $=$ & - & - & - & 10. IV & 29. III. & - \\
\hline
\end{tabular}

Ihre Nahrung nehmen dic Girlitze gewöhnlich vom Boden auf. Kollibay sah auch das Weibchen auf einer Mauer sitzen und dem Kalk derselben eifrig zusprechen. Derselbe Forscher hat den Vogel beim Balzen beobachtet: ${ }_{n}$ Der Parungstlug des Girlitz ist ein so eigentümlicher, dass der Vogel dem Nichtkenner zunächst ganz fremd erscheint. Während sonst der Girlitz in schwachen Bogenlinien mit ziemlicher Schnelligkeit dahineilt, erhebt er sich zur Paarungszeit von einem frei gelegenen Sitzpunkte aus mit kurzem Aufschwunge in die Luft empor und beschreibt mit flatternden, gaukelnden, fledermausartigen Schlägen der weit gespreizten Flügel unter eifrigem Gesang einige mehr oder minder regelmässige Kreise, um nach kurzer Zeit auf seinen ursprünglichen Platz zurückzukehren oder zu dem irgendwo in der Nähe anscheinend emsig beschäftigten WVeibchen zu eilen." Nach Kollibay besorgt das Weibchen allein den Nestbau. A. Richter behauptet freilich gerade das Gegenteil. Nach den Erfahrungen Wolfs wird fast stets Schafwolle zur imneren Ausfütterung des Nestes benutzt. Ein Nest, welches $K u t t e r$ erbeutete, bestand ausser den üblichen Hälmchen z. T. auch aus starken Fäden und Streifen von Leinewand; im Innern war es mit Pferdehaaren und Federn recht warm ausgefüttert. Kollibay machte die Beobachtung, dass der Girlitz besonder's gern am Wasser auf Rosskastauien brütet. Das Nest ist nach ihm nicht eben schwer zu finden, weil das Weibehen selbst unter den Augen des Beobachters darauf geht, obwohl unruhig mit dem vollen Lockton des Kanarienvogels rufend. Einmal, am 8. Juni 1589, fand er bei Patschkau ein Nest mit $t$ frischen Eiern 7 Fuss hoch über dem Boden in einer sog. Kopfweide, sonst aber uie an einem solchen Orte. Die eben angegebene Höhe scheint die gewöhnlichste zu sein. Auch ein am 26. Mlai 1858 von Kolli b a y gefundenes Nest stand 6 Fuss 
hoch auf einem Lebensbaum und enthielt 4 frische Eier. Praetorius dagegen sammelte am 25. April 1872 bei Breslau ein Gelege, welches sich in einem nur 6 Zoll über der Erde auf einem Kirschbaum befindlichen Nest befand. Der Nestbau vollzieht sich nich $\mathrm{Kollibay}$ in 4-5 Tagen; er beobachtete einen solchen vom 14.-17. Mai, dem vom 21.-25. das Legen der Eier folgte. Tolle Gelege fand er ferner noch am 20. und 24. Mai, sowic am 11. Juni; ich selbst am 15. Nai. R. Blasius beobachtete am 18. Juni eben ausgeflogene Junge. Kollibay entdeckte am 22. Mai auf einer Linde ein Nest mit noch nackten Jungen, die das Weibchen vor seinen Augen fütterte; am 30. fand er ¿ Nester 4 Fuss hoch auf Cypressen; das eine enthielt zerschlagene Eier, das andere 3 eben ausgeschlüpfte Junge und $1 \mathrm{Ei}$, welches am anderen Tage auch noch ausfiel. K $u$ t ter fand am 12. Juni nackte Junge. Es werden regelmässig 2 Bruten gemacht, zu denen der Togel nach $A$. Rich ter ein und dasselbe Nest benutzt.

Ma asse von 27 schlesischen Eiern in $\mathrm{mm}$ :

$\begin{array}{lccc} & \text { maximum } & \text { minimum } & \text { Durchschnitt } \\ \text { Länge: } & 17 & 15 & 16 \\ \text { Breite: } & 13 & 10 & 12\end{array}$

G a t t ung: Carduelis Briss. 1760. - Stieglitz.

ben schwarzen Flügel ziert ein hochgelbes Feld, die schwarzen schwauzfedern besitzen weisse Spitzen. Șchuabel echt kegelförmig, aber schlank.

3?. Carduelis elegans Steph. 1826. - Stieglitz.

(Carluelis elegans albigularis Mad. 1882. - W IV isskehliger Stieglitz.)

synunyma: Fringilla carduelis L., Gm., Bechst., Naum., (Elogg, Chr. Br., Gieb., Kays. u. Blas., Fridr., Gätke; Fringilla ochracen Cxm.; Linaria carduelis Boie; Chrysomitris carduelis Iichw.; l'aser carduclis Pall.; Spinus carduelis Koch; Acanthis carduelis Kays, 11. Blas, Jiak.; Carduelis vulgaris L.; Carduelis carduclis Less.; Hart.; Carluelis nobilis Alb. Magnus; Carduelis albida, C. candiula, C. nigra Briss.; Carduelis alboochracea Jacqu., Carduelis auratus Eyt; Carduelis germanicus, C. septentrionalis, C. ascedens, C. atrantipemnis, C. meridionalis Chr. Br.; Carduelis elegans Degl., A. Br., v. Hom., Mewes, Radde.

Trivialnamen: Stiegelitz, Stieglitzke, Distelvogel, Rottkogel. Polnisch: Sczygiol. Wendisch: Stieglitza.

Kennzeichu der Art: Siehe die Gattungsmerkmale, da $n u r$ diese eine Art in Deutschland.

Ilic Licblaber unterscheiden Garten-, Wald- und Alpenstirglize und haben darin vollkommen recht. Diese 3 Formen sind hicht geographisch schart von einander abgegrenzt, sondern 
kommen vielfach neben einander vor, bewolnnen aber dann stets für sich die ihnen schon durch den Namen vorgeschriebencu Oertlichkeiten. Der Alpenstieglitz scheint allerdings mehr dem Südosten anzugehören und kommt hauptsächlich in den Gebirgen des Karpathensystems vor; in dem flachen oder hügeligen Teil Nord-, Mittel- und Ostdeutschlands fehlt er anseheinend vollständig; ob er in Skandinavien vorkommt, weiss ich nicht. Es erscheint auffallend, dass noch kein Ornithologe die obige Dreiteilung der Vogelliebhaber näher und wissenschattlich untersucht hat. Russ gebührt das Verdienst, zuerst 1892 in der neuesten Auflage seines "Handbuch" diese 3 Formen richtig auseinander gehalten und ihre wichtigsten Kennzeichen angegeben zu haben. Ich habe mich gerade mit der Stieglitzfrage viel beschäftigtt und ein ziemlich reiches Material unter den Händen gehabt. Nunmehr bin ich zu der Ueberzeugung gekommen, dass wir es in der That hier mit guten Subspecies zu thun haben. Im Norden prävalirt im allgemeinen der Wald-, im Westen und südwesten der Garten- und im Südosten der Alpenstieglitz. In Schlesien kommen alle 3 Formen vor; alpestris im Riesengebirge und vielleicht auch noch in anderen Teilen der Sudeten, silvestris in der Lausitz, Oberschlesien und der Bartschniederung, hortensis hauptsächlich in der Ebene und dem Hügellande von Nieder- und Mittelschlesien. Ich stelle im folgenden die hauptsächlichsten Naasse und Kennzeichen zusammen. Im ganzen habe ich 130 schlesische Exemplare untersucht. Bei den Maassen führe ich nur den jedesmaligen Durchschnitt in cm an.

\begin{tabular}{lc}
\multicolumn{1}{c}{ Carduelis } & elegans hortensis \\
Totallänge: & 12,35 \\
Flügelspannung: & 23,74 \\
Schwanz: & 4,97 \\
Schnabel: & 1,09 \\
Tarsus: & 1,48 \\
Flügelspiegel: & hellgelb \\
Rot des Kopfes: & ohne seidenartigen \\
& Glanz
\end{tabular}

Von den Schwanzfedern haben weisse Spitgelflecke:

Spitzen der Schwung - schmutzig weiss, und Steuerfedern: bisweilen fehlend Unterleib :

Brustflecke: schmutzig weiss gross und nicht scharf begrenzt, dunkelbraun mit schwach gelblichem Grund

Schwingen น. Schwanz: schwarz Gesang :

nicht sehr laut, hastig, zwitschernd
C. elegans silvestris

$$
\begin{array}{r}
14,12 \\
25,07 \\
5,29 \\
1,16 \\
1,56
\end{array}
$$

tiefgelb

ohne seidenartigen Glanz

$$
2-4(6)
$$

rein weiss, stets vorhanden

rein weiss

klein und scharf begrenzt, sehr dunkel mit lebhaft gelblichgrünem Grund

tief schwarz

laut, langsam, sehmetternd
C. elegans alpestris

$$
\begin{array}{r}
14,04 \\
25,04 \\
5,25 \\
1,15 \\
1,52
\end{array}
$$

tiefgelb mit einem Stich ins Orangefarb. mit seidenartigum

Glanz

$$
\text { (2) } 4-8
$$

rein weiss, stets vorhander blendend weiss klein und siharf begrenzt, dunkel, mit lebhaft gelbl.-grünem Grund und ebenso schwach gesäumt sammetartig schwarz sehr laut, glockenhell, trillernd 
An Uebergängen aller Art fehlt es natürlich nicht; dieselben finden sich aber mehr inbezug auf die Farbentöne als inbezug auf Stimme und Grössenverhältnisse. Silvestris und alpestris stehen sich viel näher als hortensis diesen beiden. Doch ist die letztere die bei uns bei weitem am häufigsten vorkommende Form. M a d arasz hat endlich noch einen weisskehligen Stieglitz, $C$. elegans albigularis, aufgestellt, welcher eine rein weisse Kehle und 6 weisse Schwanzspiegel hat. Ich bin mir über diesen Vogel noch nicht recht klar, glaube aber, dass die weisse Kehle nur ein Zeichen hohen Alters ist und deshalb keine subspecies, sondern lediglich eine individuelle Abändertung darstellt. Auf die weissen Spiegelflecke der Schwanzfedern, welche sehr schwanken, gebe ich ohnehin nicht viel. Sie sind auch von den oben angeführten Kennzeichen die bei weitem unsichersten. Die weisskehlige Form ist uach zuverlässigen Berichten schon mehrfach im nordwestlichen Teile der Provinz, im Hügellande der Oder und Bober gefangen worden. Auch die Berichte s'chalows aus der Mark stimmen damit überein. In Heydrichs Sammlung befindet sich ein schwarzer Stieglitz. Nach Mohr wurde 1375 bei Breslan ein Exemplar gefangen, dessen nganzer Kopf schwarz war, welche Farbe auf Hals und Rü̈ken in cin dunkies Brann überging. Das Hochgelb der Fliigel war mit kleinen, feinen, aber dichten braunen Punkten iibersizet, die Brust gelblichbraun, die W eichen ebenso, der Schnabel blei- oder silberweiss mit umfangreicher schwarzer Spitze. Vor Jahren wurde schon ein ïhnlicher gefangen, der aber ganz braunschwarz war, bis auf deu normalen Schwanz.

1)er Stieglitz ist in gannz Schlesien ein gewöhnlicher und von jedermann gern gesehener Brutyogel. Er li bt namentlich parkund auenartige Gegenden, Vor- und Feldhölzer, Alleen und Banmgirten. Die Nïhe des Mensehen scheut er so wenig, dass er sich bis,weilen sugar in betebten Gesellschafts- oder Restanrationsgiarten der Stälte niederliasst, wovon mir u. a. Emmrich ein Beispind mitteilte. In der Lausitz scheint der schöne Vogel verhältnismässig an seltensten zu sein. K. Tobias sagt: ${ }_{n}$ Ausser der Zugzeit keineswey genein und nur zu wenigen Paaren in der Nähe von (⿳亠丷冖̆litz brïtend." Seitdem haben sie zwar mit der Vermehrung der Chausseen und Anlagen entschieden zugenommeu, sinci aber anch heute noch nicht allzu häufig. Bei Breslau ist der Dieglitz sein zahlreich, und ebenso ist dies nach den übereinstimmenlen Berichten der dortigen Beobachter in ganz Oberschlesien der Fall. Bei Neusalz brütet er nach L. Tobias iì jeder Allee. Vereinzelt wird über seine Abnahme geklagt; so schreibt K 11 at u the: "War früher ungemein zahlreich. In unserem 1 Morgen grossen Obstgarten standen if Nester. 1590 dagegen fehlte er in schlaupitz ganz und war auch in der Umgegend selten," im Siäitherbst sieht man die Stieglitze oft in sehr grossen 
Flügen von 800-1000 Stïck umherstreichen. Im März pflegen sie sich wieder auf ihren Brutplätzen einzustellen. Sehr gern baut der Stieglitz auf Rosskastanien. Wohl 2 Bruten. Praetorius f'and das volle Gelege am 16. Mai und 6. Juli, ich an 12. Mai. Kolliba y beobachtete am 30. Nai die Fütterung der Nestjungen, und Emmrich fing am 22. Juli eben flügge gewordene Junge. Ueber die Verbreitung des Stieglitz im Riesengebirge habe ich leider gar nichts erfahren können. Ob sich anch bei den Eiern lokale Abweichungen geltend machen, weiss ich nicht. Doch sind sie in Form nnd Grösse oft ziemlich verschieden.

Masse von 18 schlesischen Eiern in $\mathrm{mm}$ :

$\begin{array}{lccc} & \text { maximum } & \text { minimum } & \text { Durchschnitt } \\ \text { Länge: } & 18,5 & 15 & 17 \\ \text { Breite: } & 13,5 & 11 & 12,5\end{array}$

Gattung: Chrysomitris Boie 1828, - Zeisig:

Schnabel sehr schlank kegelförmig und fein zugespitzt. Dic langen, spitzen Flügel reichen bis über die Mitte des Schwanzes himab. Die 2. Schwinge am lüngsten. Der kurze Schwanz ist leicht ausgeschnitten. Die Dammenkralle ist an Länge gleich der vorderen Mittelkralle und die Innenzehe gleich der Aussenzehe.

89. Chrysomitris spinus (L.) 1758. - Erlenzeisig.

Synonyma: Passer spinus Pall.; Fringilla spinus L., Gm., Bchst., Chr. Br., Naum., Glog., Fridr., Gïtke; Fringilla spinoides Tem.; Fringilla fasciata Müll.; Spinus viridis Koch; Spinus alnorum, S. medius, S. betularum, S. obscurus Chr. Brehm; Carduelis spinus Steph., Macg.; Linaria viridis Frisch; Linaria spinus Leach; Acanthis avicula Gessu.; Acanthis spinus Kays. u. Blas., Jäckel; Chrysomitris spinus Boie, Gieb., A. Br., v. Hom., Mewes, Radde, Hartert.

Trivi aln a men: Zeis, Zeisel, Zeisker, Zeischen, Zissle, Zenske, Erlfink. Wendisch: Zeisk. Polnisch: Czicza.

Kennzeichen der Art: Die 1. Schwinge nur wenig kleiner als die 2., die 1.-3. verengt; am Fliigel eine gelbe Querbinde.

Auch beim Zeisig giebt es ganz entschieden eine östliche und westliche Varietät, die weniger durch plastische Verhältnisse als durch verschiedene Verteilung, Nuancirung und Intensitiat der Färbung von einander abweichen. Leider muss ich bestimmte Angaben darüber auf später verschieben, weil ich durch die Unstände gezwungen war, meine Zeisigsuiten wegzugeben und dieselben noch nicht wieder genügend ersetzen komnte. Sehw enckfeld erwähnt einen Fall von Melanismus. Im Breslauer Mluseum befinden sich 3 Bastarde zwischen Zeisig und Girlitz. 
Ma as se von 60 schlesischen Exemplaren in $\mathrm{cm}$ :

$\begin{array}{lccc} & \text { maximum } & \text { minimum } & \text { Durchschnitt } \\ \text { Länge: } & 12,0 & 11,2 & 11,8 \\ \text { Flügelbreite: } & 21,9 & 20,6 & 21,5 \\ \text { Schwanz: } & 4,6 & 4,2 & 4,4 \\ \text { Schnabel: } & 0,9 & 0,8 & 0,8 \\ \text { Tarsus: } & 1,5 & 1,3 & 1,4\end{array}$

Auf dem Zuge ist der Zeisig in ganz Schlesien eine selır gewölunliche Erscheinung, als Brutvogel dagegen nur stellenweise häutig. Am zahlreichsten findet er sich in den Schwarzwäldern der Torberge wie auch in der Waldregion des eigentlichen Gebirges. Auch bei lins ist er der Liebling der armen Gebirgsbevölkerung, und fast in jeder Weberhütte findet man einen Zeisig im Käfig. In das Knicholz kommt er wohl nur auf dem Striche. Kramer hat ihn bis zu $1400 \mathrm{~m}$ Meereshöhe beobachtet, v. Tschusi traf' iln bei śpindelmiihl, Capek an der Petersbaude, an der weissen Wiese und auf dem Ziegenrücken, L. Tobias an der neuen schlesischen Baude und R. Tobias auf der Tafelfichte. Sylaender fühnt ihn als sicheren Brutvogel für Bolkenhayn, Emmrich für Goldberg und $\mathrm{K} n \mathrm{n} u \mathrm{th}$ e für die Umgebung des Zobten aut. In der Ebene wählt sich der Zeisig grosse Kiefernund Fichtenwälder zum Aufenthalte aus; so nistet er nach A. v. Homeyer im Görlitzer und im Gloganer Forst. Im Winter wird der Bestand del einheimischen Vögel noch durch grosse Schwärue aus dem Norden verstärkt. Kollibay traf Ende Juli in den Gärten von Schmiedeberg junge Vügel an. IV olf beobachtete bei Muskau den Bau eines Nestes im höchsten Gipfel ciner schwanken Kiefer. Tiermal bestieg er es mit Lebeusgefahr, doch wurden keine Eier hineingelegt. Nach seiner Ansicht war es ein Spiegelnest.

Gattung: Acanthis Bchst. 1802. - II änfling.

Scluabel kurz, gerade, zugespitzt, von der Basis aus zusammengedrückt. Zehen und Nïgel kurz. Schwanz und Flügel lang und spitz.

\section{Acanthis camnabina (L.) 1758. - Bluthänfling.}

Synonyma: Fringilla cannabina L., Gm., Bchst., Naum., Glog., Gieb., Kays. u. Blas,, Fridr., Gätke; Fringilla linota, F. argentoratensis Gm.; Fringilla fusca Müller; Fringilla miuima Bodd.; Linaria rubra maior Briss.; Linaria cannabina Boie; Passer cannabina, P. papaverina Pall.; Ligurinus cannabinus Koch; Cannabina maior, C. minor, C. pinetorum, C. arbustorum Chr. Brehm; Cammabina linota Gray, v. Heugl., Degl., Chrr. Br., A. Br.; Cannabina sanguinea Landb., v. Hom.; Linota cannabina, L. fringilli- 
rostris Bp. u. Schleg.; Linota cammabina Newes, Raddr, Jäckel; Chrysomitris cannabina Rehw; Acgiothus fringillirostris riray; Acanthis cannabina Blyth, Hartert. hänflich.

Trivialnamen: Hanferle, Hänflick, Krantlıänfling, Rut-

Kennzeichen der Art: schnabel grau, Füsse Heischfarbig. Die 9 grossen Schwingen mit weissem Aussensaum. Keine weissen Flügelbiuden. Die Schwanzfedern sind mit Ausnahme der mituleren am Schafte entlang schwarz, zu beiden seiten weiss.

Masse von 53 schlesischen Exemplaren in $\mathrm{cm}$ :

$\begin{array}{lccc} & \text { maximum } & \text { minimum } & \text { Durchschnitt } \\ \text { Länge: } & 14,9 & 13,3 & 14,4 \\ \text { Flugbreite: } & 26,1 & 23,9 & 25,4 \\ \text { Schwanz: } & 6,0 & 5,4 & 5,8 \\ \text { Schnabel: } & 1,0 & 0,8 & 0,9 \\ \text { Tarsus: } & 1,7 & 1,5 & 1,6\end{array}$

Die Hänflinge variiren in der Grösse sehr, und zwar gehören die schlesischen Stücke durchgängig zu den grosswïchsigen. Friderich giebt nur $13,5 \mathrm{~cm}$ als durchschnittlehe Totallinge an.

Auch der Hänfling ist in den Vorbergen besonder's hïutig, geht aber im eigentlichen Gebirge höher hinauf als der Zeisig, da er in Knieholz noch ziemlich gewöhulich nistet. Gloger giebt 4700 Fuss als vertikale Verbreitungrgrenze an. v. Tsulh us i fand bei Spindelmühl ein brütendes Pärchen, Krezsehmar ilurer viele an den Bibersteinen. In der Ebene ist der Hänfling zwar auch ein allbekannter Vogel, aber keineswegs überall gemeill; bei Breslau z. B. ist el ziemlich selten. Dazu kommt, dass sein Bestand grossen Sehwankungen unterworfon, dass er an ein mud demselben Orte in dem cinen Jabr ungehener häutig; in lem nächsten aber plötzlich nur höchst sparsam vertreten ist. Veränderungen, die an seimen Brutplätzen vorgenommen werden, sint stets auf ihn von Einfluss, sei es nun anziehend vder abstossend. K na uthe hat ihn z. B. erst dureh Anpflanzen ron Nadellolz in das Dorf Schlaupitz gelockt. Nach Richuer fellen die Hänflinge in Strehlen ganz. Dieser geschätzte Sänger lebt sowohl im Laub- wie im Nadelwald, bevorzugt aber kleine Feld- und Torhölzer und kommt auch gern in die Aulagen und Gärten. Er trifft im März bei uns ein und zieht in Oktobor wioder ab; häufig überwintern die Hänflinge aber auch. Practoris fand am 14. April 1872 ein Nest am Rande eines Fusswerges in cincm Bunch der Strachate nur 6 Zoll über dem Boden. An 12. Juni wurden die Jungen flügge und am 1. Juli war das zweite Gelege vollständig. Kollib a y entdeckte am 1. Mai 1858 ein Nest mit 5 Eicru i Fuss hoch in einer Fichte. $t$ der Eier waren mehrere Tage 
bebrütet, während das 5. nur wenig Blutstreifen zeigte. Ein anderes Gelege aus der Sammlung Kollibays stammt vom 16. Juni. Kutter traf am 16. Mai auf nackte, Richter am 20. Juni auf eben flügge gewordene Junge.

M a a s e von 22 schlesischen Eiern in $\mathrm{mm}$ :

$\begin{array}{lccc} & \text { maximum } & \text { minimum } & \text { Durchschnitt } \\ \text { Länge: } & 18 & 16,5 & 17,5 \\ \text { Breite: } & 13,5 & 12 & 13\end{array}$

91. Acanthis flavirostris (L.) 1758. - Berghänfling.

Synonyma: Fringilla fusca Rudb.; Fringilla flavirostris L., Gm., Bchst., Glog., Gieb., Kays. u. Blas., Fridr.; Fringilla montium Gmel., Naum., Gätke; Linaria montana Briss., Will.; Linaria montium Leach; Cannabina flavirostris, C. montium, C. media Chr. Brehm; Cannabina flavirostris A. Brehm, v. Hom; Linota montium Bp.; Linota flavirostris Kays. u. Blas., Mewes, Radde, Jäckel; Chrysomitris flavirostris Rehw.; Acanthis montium Blyth.; Acanthis flavirostris Hartert.

Trivialnamen: Rotbürzel.

Kennzeichen der Art: Schnabel gelb, Füsse schwarz. Keine weissen Flügelbinden. Die 4 ersten Schwingen schmutzig weiss, die $t$ nächsten hellweiss gesäumt. Die 3. ragt bis zur Flügelspitze.

Der Berghänfling erscheint keineswegrs in allen Wintern bei uns und auch nie in sehr grosser Zahl, so dass er mit zu den selteneren unter den nordischen Gästen gehört. Gewöhnlich mischt er sich dann unter die Schwärme der Leinzeisige und treibt sich mit diesen auf den kahlen Feldern umher. In der Lausitz scheint er noch seltener zu sein. Der ältere Krezschmar erhielt nur 1 Stück. R. Tobias erlegte ihn zweimal, am 1ㄹ. December 1830 bei Görlitz und dann wieder 1836 an einem verlassenen Steinbruch. Wald und Gebirge meidet er im Winter. Das Breslauer Museum besitzt 2 von Rotermund stammende Belegexemplare. Im Winter $1859 / 90$ war der Berghänfling ziemlich zahlreich. Ich traf einmal zwischen Breslau und der Strachate 3 ziemlich ermattete Exempl., erhielt mehrere lebend und tot zugeschickt und sah ihrer viele in den Breslauer Vogelhandlungen. Im nächsten Jahre waren keine da, und ich habe den Vogel auch von meinen Correspondenten seitdem nicht wieder erhalten.

92. Acanthis linaria (L.) 170๊ - Birkenzeisig.

92a. Acanthis linaria Holboelli (Brehm) 1831. - Grosser Birkenzeisig.

Synonyma: Fringilla linaria L., Gm., Bchst., Buff., Naum., Glog., Gicb., Fridr., Gätke; Fringilla vitis Müller; Fringilla 
borealis Vieill.; Linaria rubra Briss, A. Brehm; Linaria borealis Degl.; Linaria alnorum v. Hom.; Linaria Holboclli, L. alnorum, L. betularum Chr. Brehm; Passer linarius Pall.; Spinus linarius Koch; Cannabina linaria Rüpp.; Chrysomitris linaria Rchw.; Linota linaria Bp., Rarlde; Aegiothus linarius et Holboelli Cab.; Acanthis linaria Bp. u. Schleg., Kays. u. Blas., Hart., Jiickel.

Trivialn a men: Tschätscher, Zötscherlin, Tschïtscherling, Schösserle, Mäusevogel, Totenvogel, Stockhänfling; Bergzeisig:

Kennzeichen der Art: Ueber den Flügel, dessen Schwingen schmal hellbraun gesäumt sind, verlaufen ¿ weissliche Streifen. Kehle braunschwarz.

Der niedliche Birkenzeisig tritt in manchen Winteru in ungeheuren Schwärmen auf, in anclern zeigt cr sich nur vereinzelt, und in manches Jahrgängen scheint er ganz zu fehlen. Wiederholt sind Birkenzeisige auch sehon im Sommer vorgekommen, ja sie haben sogar receinzelt in Schlesien gebritet. Gloger berichtet, dass auf dem Breslauer Markte ein junger Vogel verkauft wurde, welcher augenscheinlich in der Nähe ausgebriitet worden war. Lübbert traf Birkenzeisige während des ganzen Sommers pärchenweise im Riesen- und Glatzer Gebirge an und erhielt 1854 von da 2 Eier, die $\mathrm{B}$ ald a m us für zweifellos echt erklärte. R. Tobi as erwälnt das Jahr 1830 als besonders reich an Birkenzeisigen. Nach v. Loebenstein waren sie in dem gelinden Winter 185\%/53 ausserst zahlreich. Krezschmal beobachtete sie $1581 / 32$ bei Görlitz, ebenda Peck 1ş!! und Kutter 1881 bei Neustadt. Uttendörfer erhielt 1859,20 - und $1890 / 915$ Exmplare. $\mathrm{K}$ na uthe und $\mathrm{Emm}$ rich rerzcichnen linaria ebenfalls tür den letzten Jahrgang. Ich selbst habe namentlich 1 ss! $/ 90$ zahlreiche Birkenzeisige bei Breslan geseherl, und die dortigen Togelhandlungen waren monatelang fömmlich überfült mit ilmen. Holloelli, welcher sich durch bedeutendere Grösse und einen stärkeren orargegelben Schnabel aluzeichnet, ist nach $\mathrm{Nlichel}$ lisio in 2 Exemplaren bei Flinsberg gefangen worden.

\section{Gattung: Chloris Cuv. 1800. - Grünling.}

Unterschnabel an der II nrzel breiter wie der Uberschmabel. In den bis zur Hälfte des zicmlich kurzen und sehwach ausgeschnittenen Schwanzes reichenden Flügeln ist die 1. Schwinge kleiner als die 3., die 2.-4. deutlich verengt. Hauptfarbe gelbgrün.

93. Chloris hortensis Chr. Brehm 18:31. - Grï in fin.

Sy nonyma: Fringilla chloris L., Tem., Meyer, Naum, Glog., Gieb., Gätke; Loxia chloris L., Gm., Behst., Fridr.; Coecothraustes chloris Pall.; Ligurimus chloris Koch, Degl., A. Brelım, Rchw., v. Hom., Mewes; Serimus chloris Boie; Linaria chloris, 
L. pinetorum, L. hortensis, L. septentrionalis Chr. Brehm,; Chloris Alavigaster Sivains.; Chloris chrysoptera Landb.; Chloris vulgaris Cab.; Chloris chloris Gray, Hart.; Chlorospiza chloris Bp., Kays. u. Blas., Radde, Jäckel.

Trivialnamen: Grünvogel, Grünhanferl, Grünhänfling, grüner Kernbeisser, Grünitz, welscher Hanfling, Hirschvogel, Hirschfink. Wendisch: Konopatschk.

Kennzeichen der Art: Siehe die Gattungsmerkmale, da nux diese eine Art in Deutschland.

M a asse von 30 schlesischen Exemplaren in $\mathrm{cm}$ :

$\begin{array}{lccc} & \text { maximum } & \text { minimum } & \text { Durchschnitt } \\ \text { Länge : } & 15,9 & 15,1 & 15,6 \\ \text { Flugbreite : } & 27,8 & 26,5 & 27,2 \\ \text { Schwanz: } & 6,0 & 5,7 & 5,9 \\ \text { Schnabel : } & 1,2 & 1,2 & 1,2 \\ \text { Tarsus: } & 1,9 & 1,7 & 1,8\end{array}$

In systematischer Hinsicht giebt mir der Grünling keine Veranlassung zu irgend welcher Bemerkung.

Für die ganze Provinz ist der Grünling eincr der gemeinsten Vögel, obschon er in manchen Jahren in bestinmten Gegenden auch nur spärlich auftritt. Vor allem muss das T'errain reich an Gebïsch sein und darf auch nicht zu trocken liegen, wenn es ihn in grösserer Zahl beherbergen sol]. Kleine Fcldhölzer, Parkanlagen, Promenaden, Alleen, Kirehhöfe und weitläufige Obstgärten pflegen besonders reich an Grünfinken zu sein. In den Vorbergen ist der Vogel überall häufig, abcr im eigentlichen Gebirge scheint er nicht eben hoch hinauf zu gehen; merkwürdigerweise fehlt es bezüglich seiner vertikalen Verbreitung fast gänzlich an positiven Nachrichten. R. '1'ob ias beobachtete kleine Züge auf der Tafelfichte, allerdings zur Strichzeit. Nirgends ist der Grünfink aber so massenlaft vorhanden wie in den schönen Auwaldungen des Oderthales. Die Nähe des Menschen scheut er nirgends und ist auch im Winter auf den Futterplätzen unter den Finkenvögeln mit der dreisteste. K n a u the fand z. B. 1890 ein Nest, welches nur einen Schritt von einem Bahnwärterhäuschen sich in einer Coniferengruppe befand, an der ein seln belebter Weg vorüber fülrte. Die Grünfinken sind für Schlesien teils vollständig Stand-, teils aber auch Strichrögel. Die letzteren stellen sich aber schon in den arsten Tagen des März wieder auf ihren Brutplätzen ein. Die Nester werden mit Vorliebe auf Pappeln, Cypressen, Lebensbiumen und Fichten angelegt. Sehr eingehend hat Kollibay den Nestbau beobachtet. Derselbe vollzieht sich zu den verschiedensten Tageszeiten, am eifrigsten und anhaltendsten aber 
frühmorgens. Das Männchen beteiligt sich nicht an der Arbeit, begleitet und umfliegt aber fortwährend unter verliebten Geberden das Baustoffe suchende IVeibchen. Am ersten Tage (10. IV.) wurden nur Grashalme und Moos, an zweiten feine Wurzeln und am dritten dargebotene Wollfïden eingetragen. Am 30. April war das Gelege mit 5 Eiern vollzäblig. Ein anderes Nest mit ebenfalls 5 frischen Eiern erbeutete Kollibay am 16. Mai. Einige Tage vorher hatte er, da er sich anders von dem Inhalt nicht überzeugen konnte, das Nest herunter genommen und hierauf wieder an seinen Platz gestellt, weil es erst ein Ei enthielt. Der Vogel hatte sich aber dadurch nicht stören lassen, sondern ruhig weiter gelegt. Gewöhnlich stehen die Nester in Mannshöhe oder etwas niedriger; in grossen dichten Waldungen erblickt man sie viel seltener als an den oben geschilderten Lokalitäten. Es finden 2 Bruten statt, von denen die erste zu Anfang Mai vor sich geht.

$\mathrm{M}$ a a s e von 33 schlesischen Eiern in $\mathrm{mm}$ :

$\begin{array}{lccc} & \text { maximum } & \text { minimum } & \text { Durchschnitt } \\ \text { Länge: } & 20 & 19 & 19,65 \\ \text { Breite: } & 15 & 14 & 14,6\end{array}$

Gattung: Fringilla L. 1758. - Edelfink.

Die 2. und 3. Schwinge am längsten. Die äussere und mittlere Zehe sind hinten etwas verwachsen und tragen sehön gekrümmte spitzige Nägel.

\section{Fringilla coelebs L. 1758. - Buchfink.}

Synonyma: Passer spiza Pall.; Struthus coelebs Boie Coelebs coelebs Less.; Fringilla sylvia Scopr.; Fringilla nobilis Schrank; Friugilla hortensis, F. silvestris, F. nobilis, F. alpestris F. minor, F. maior Chr. Brchm; Fringilla coelebs L., Gm., Bchst., Buff., Naum., Chr. Brelım, Glog., Gieb., Kays. u. Blas., A. Brelım, v. Hom., Mewes, Radde, Fridr., Hart., Gätke, Jäckel.

Trivialnameu: Rotte Finke, Busch- und Gartentink. Wendisch: Säba.

Kennzeichen der Art: Der schwan ist gabelig ausgeschnitten und hat schwärzliche Federn, von denen dic zwei äussersten Paare einen weissen Keilfleck tragen. Die 1. Schwinge ist kürzer als die 4.

Von den Brehm'schen Varietäten hat meines Erachtens minor die meiste Berechtigung und zwar stellt diese kleinere subspecies die nordische Form der Buchfinken dar. Yon den in strengen Wintern in Schlesien crhaltenen Buchfinken gehörten etwa $25 \%$ zu minor, von den in Ostpreussen von mir erbenteten aber wohl $80^{\circ}, 0$. Die bei uns brütenden Buchfinken sind stäudig und erheblich grösser und stellen deshalb vielleicht die Brehm'sche 
subspecies maior vor. In Schlesien wenigstens habe ich zur Brutzeit die kleinwüchsige Form niemals erhalten.

Ma asse von 75 schlesischen Exemplaren (alle zu maior gehörig) in $\mathrm{cm}$ :

$\begin{array}{lcccc} & \text { maximum } & \text { minimum } & \text { Durschschitt } & \text { Maasse von minor } \\ \text { Länge: } & 16,3 & 15,2 & 15,85 & 13,8-14,0 \\ \text { Flugbreite: } & 27,1 & 25,8 & 26,5 & 24,5-25 \\ \text { Schwanz: } & 7,2 & 6,8 & 7,0 & 6,5-6,6 \\ \text { Schnabel: } & 1,1 & 0,9 & 1,0 & 0,9 \\ \text { Tarsus: } & 1,9 & 1,6 & 1,7 & 1,5\end{array}$

In milden Wintern kommt minor viel seltener oder gar nicht bis zu uns herab. Die nordische Natur dieser Vögel erkennt man auch daran, dass sie gegen die Kälte und andere Unbilden des Winters ausserordentlich widerstandsfähing sind und in dieser Hinsicht weit über den bei uns brütenden Buchfinken und selbst über den gleichfalls aus dem hohen Norden stammenden Bergfinken stehen. Die Liebhaber unterscheiden ferner unter unseren Brutrögch noch Garten- und Waldfinken. Ich habe nicht ermitteln können, ob dieselben subspecifischen Wert haben, möchte aber hiermit zu diesbezüglichen Untersuchungen anregen. In Heydrieh's Sammlung befindet sich ein Albino; auch $\mathrm{Schw}$ enckfeld erwähnt bereits einen solchen.

Gute Schläger findet man unter den schlesischen Buchfinken jetzt leider nur noch höchst selten. Früher war das anders, und namentlich die riesengebirgischen Reitzugfinken wurden von den Liebhabern sehr geschätzt. Aber bereits v. Tschusi und A. v. Homeyer hoben ausdrücklich hervor, dass sie im Riesengebirge nur schlechte Schläger gehört hätteu. Das systematische und schonungslose Wegfangen der guten alten Vorschläger hat sich also auch hier empfindlich gerächt. Der Buchfink ist in Schlesien überall häufig und auch ziemlich gleichmässig verteilt, wennschon der Bestand der verschiedenen Gegenden zeitweise starken Schwankungen unterworfen ist. Als vertikale Verbreitungsgrenze giebt Gloger eine Meereshöhe von $4000 \mathrm{Fuss}$ an. Im Ricsengebirge lässt sich der Buchfink nach Gloger auch noch in den letzten Fichtenwälder'n sehr zahreich antretten, ohne dass man ihn das anstossende Knieholz jemals berühren sähe; dagegen zicht er sich bei schlechtem W Wetter mit beiden Bachstelzen, dem Wiesen- und Wasserpieper und der Ringdrossel bis dicht an die Hüuser auf die Miststïtten zurük. Neuerdings scheint übrigens sciu Bestand im Riesengebirge erheblich abgenommen zu haben. A. v. Hom eyer sah ihn am Ziegenrücken, im Elb- und Aupathale, auf der Tafelfichte, an den Schneegruben und selbst am Koppenkegel, Capek am Brunnenberge, Krezschmar an der Spindelbaude. 


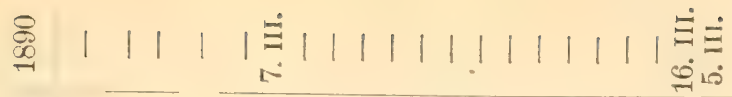

$$
\begin{aligned}
& \text { 兽 | | | | | | | | | }
\end{aligned}
$$

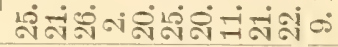

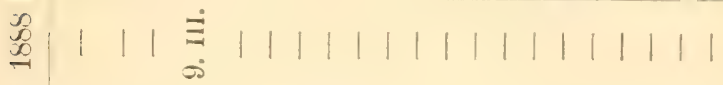

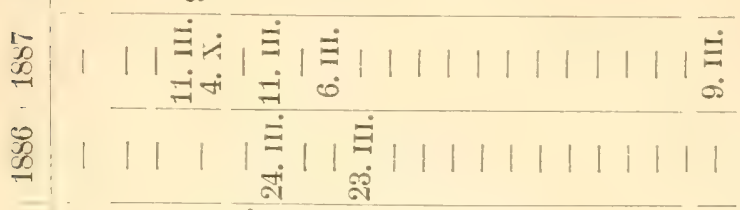

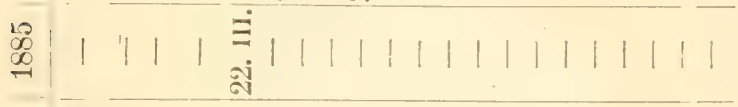

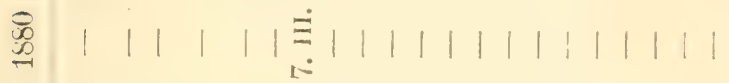

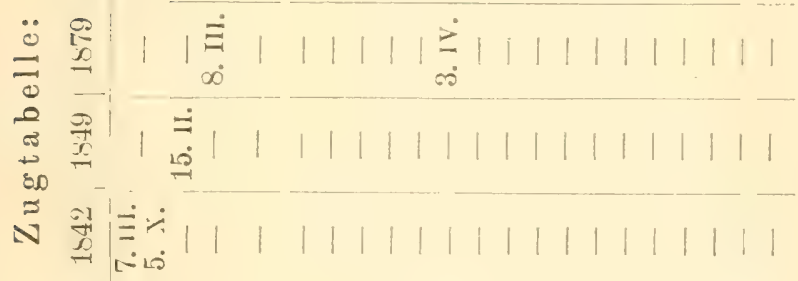

$$
\begin{aligned}
& \text { 焉 }
\end{aligned}
$$

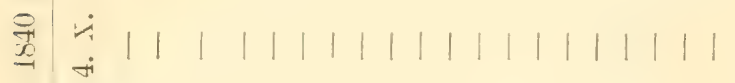

$$
\begin{aligned}
& \text { 象 }
\end{aligned}
$$

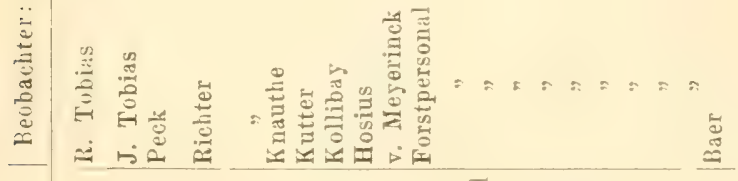

$$
\begin{aligned}
& \text { 落 }
\end{aligned}
$$


Viele Buchfinken überwintern auch bei uns, namentlich diejenigen, welche in den Gärten und öffeutlichen Anlagen heimisch sind. Es sind zwar überwiegend Männchen, aber auch zallhreiche Weibchen finden sich darunter. Es gewinnt den Anschein, als ob auch der Buchfink sich mehr und mehr zum Standvogel ausbilden wolle, wie ich dies in ähnlicher IVeise bei der Amsel und dem Star beobachten konnte. Meiner Ansicht nach hat Junghans sehr recht, wenn er mit Bezug hierauf (Ornithol. Monatsschrift, Bd. XVIII, Nr. 1, p. 13) sagt: ${ }_{n} J$ edenfalls vollzieht sich hier vor unseren Augen der bemerkenswerte Vorgang, dass gewisse Vogelarten den Wandertrieb melir und mehr unterdrücken, und vielleicht ist dies der Anfang einer langsamen aber schliesslich vollständigen Ausbildung der betretl. Vogelart zum Standvogel. Umgekehrt hat sich derselbe Togel gewiss vor Jahrtausenden mach und nach zum 'Lugrogel ausgebildet." Es ist sehr wahrscheinlich, dass der gesteigerte Ticrschutz unserer Zeit und die immer allgemeiner werdende Fütterung der Vögel im Winter hierbei eine treibende Rolle spielt, da es sich um lauter in der Nähe des Menschen lebende Vogelarten handelt. Der Buchfink ist ohnehin einer der zutraulichsten Tögel. Göller hatte bei Waldenburg ein Exemplar fürmlich ..in Freiheit dressirt". Die Buchfinken gehören zu denjenigen Arten, welche auf dem Zuge das schlesische Gebirge ohne weiteres ïburfliegen. A. v. H o me ye r hat dies airekt beobachtet: ${ }_{\pi}$ Am 26 . IX. war es an der Koppe klar, kalt und starker Nordwest. Dabei Buchfinken in grossen Scharen ziehend. Der Flug kam aus der Richtung Hirschberg, ging über den Koppenplan, also westlich der Koppe und am Ostabhange des Brumenberges vorbei, das Aupathal entlang. Die Flüge folgten sich ziemlich rasch, immer aus $50-100-100$ stück bestehend, und zogen mit dem WVinde, l, h. derselbe kam schräg von hintell. Am ㄴ. IX. waren vor Schmiedeberg auf den Aeckern viele tausende. Ich habe nie so viele gesehen." Auch $\mathbf{K} u$ tter beobachtete in der zweiten IIälfte des August bei Neustadt ${ }_{\text {Z Züge }}$ von ungeheurer Grösse". Ueber das Brutgeschäft liegen mir aus Schlesien sehr zahlreiche Nachrichten vor, dic aber nur selten von dem allgemein Bekannten abweichen und wenig Bemerkenswertes enthalten. In den letzten Tagen des April oder in den ersten des Mai pllegt das erste Gelege vollstäudig zu sein. Für das Jahr 1850 berichtet K u tter aus Neustadt: ${ }_{n}$ Währeud die gewöhnliche Eierzahl 5 , in seltenen Fällen 6 ist, wurden in diesem Jahre in vielen Nestern, die of nahe bei einander standen, nur 3 , noch dazu oft unbefruchtete Eier gefunden, manchmal auch ganze Nester voll toter Jungen." A. v. Homeyer fand Ende Mai 1867 bei Breslau ein Nest, welches innerhalb eines Hauses auf dem oberen Querbalken dicht unter dem Holzdache ganz so angebracht war, wie es Muscicapa grisola so gern zu thun pflegt. Kollibay 
erzählt von einem Neste, welches sich nur $1 \mathrm{~m}$ hoch am Ende eines schwanken Fichtenastes befand, der so weit über einen Feldweg hinwegragte, dass jeder voriiberfahrende Wagen daranstossen musste.

M a as e von 58 schlesischen Eiern in $\mathrm{mm}$ :

$\begin{array}{lccc} & \text { maximum } & \text { minimum } & \text { Durchschnitt } \\ \text { Länge: } & 19 & 17 & 17,5 \\ \text { Breite: } & 15 & 12,5 & 13,5\end{array}$

Die Farbe und Zeichnung der Eier variirt bekamntlich sehr' doch sind mir keine constanten Gesetze bekannt, auf' welche sich diese Abweichungen zurückführen liessen.

95. Fringilla montifringilla L. 175s. - Bergfink.

Synonyma: Fringilla lulensis L.; Struthus montifringilla Boie; Coelebs montifringilla Less.; Fringilla media Jaub.; Fringilla flammea Bes,; Fringilla septentrionalis et borealis Chr. Br.; Fringilla montifringilla L., Gim., Buft., Behst., Chr. Br., Naum., Glog., Gieb., Kays. u. Blas., A. Br., v. Hom., Hewes, Fridr., Radde, Hartert, Gätke, Jäckel.

Trivialnamen: Wald., Winter-, Tannen-, Gold-, Quetschund Laubfink, Gogler, Böhmer, Quäker, Queck, Quiecker, Finkenquäcker.

Kennzeichen der $\Delta \mathrm{rt}$ : Der gabelig ausgeschnittene Schwanz hat schwärzliche Federn von denen jederseits die erste einen weissen Keilfleck besitzt. Die 1. Schwinge ist grösser als die 4.

Heydrich besitzt einen Albino von montifingilla in seiner Sammlung:

Brütend ist der Bergfink in Sehlesien bisher noch nicht aufgefunden worden, obschon ich nicht zweitele, dass dies im Laufe der Jahre noch geschchen wird, da fast von allen nordischen Wintergïsten vereinzelte Exemplare den sommer über aus irgend welchen Gründen bei uns zurückgehalten werden und dann auch wohl unter günstigen Umständen ansnahmsiveise einmal zur Fortpflanzung schreiten mögen. Seidenschwänze und Leinzeisige sind bereits in Schlesien, Bergfinken in Sachsen, Weindrosseln in Thüringen mit Sicherheit beim Brutgeschäfte beobachtet worden, und ich möchte die Vermutung aussprechen, dass sich diese Fälle sehr bald mehren werden. Tewöhnlich erscheinen die Bergfinken im September und ziehen im April wieder ab, aber bereits li. Tobias hat noch im Juni einzelne innerhalb tiefer. Wälder angetrotten. Von allen nordischen Vögeln, welche den Winter bei uns verbringen, erscheint der Bergfink woh! am regelmïssigsten, wenn auch keines- 
wegs immer am zahlreichsten. Doch fehlt er in keinem Jahre gänzlich und ist in den meisten massenhaft vertreten.

96. Fringilla nivalis L. 1766. - Schneefin $\mathrm{k}$.

Synonyma: Plectrophanes fringilloides Boie; Montifringilla nivalis Chr. Br., A. Br., v. Hom; Leucosticte nivails Desm.; Orites nivalis Kays. u. Blas, Jïckel; Chionospiza nivalis Mewes; Montifringilla glacialis Chr. Brehm; Fringilla nivalis L., Gm., Bchst., Briss., Naum., Glog., Gieb., Fridr., Hart., Gätke.

Kennzeichen der Irt: Schwanz ziemlich gerade abgestutzt mit viel Weiss. Der spornartige Nagel der Hinterzehe ist nur wenig gebogen.

Schwenck feld beschreibt den Schneefink kurz aber kenntlich mit dem Zusatz: in montibus versatur." R. Tobias berichtet: "Wenn sich dieser Vogel auf Biume setzt, so kömnte ein Vogel, den ich im Winter $1527 / 28$ in einem kleinen Fuldholze unter Bergfinken sah, hierher gehören.“ Die To b i a s sche Notitz dürfte wohl auf eine Verwechslung hinauslaufen. Dagegen schreibt neuerdings $\mathrm{L}$ u $\mathrm{chs}$, dass micalis bisweilen in Hirschberger Thal erscheine. Jedenfalls ist der Vogel aber auch hier eine höchst seltene und ausnahmsweise Erscheinung. Auch Gericke führt den Schueefink als grosse Seltenheit mit auf, welche Angabe Kollibay (in litt.) wohl mit Recht bezweifelt.

G a t ung: Coccothraustes Briss. 1760 . - Kernbeis ser.

Der kreiselförmige Schnabel ist autfallend dick, plump und stark. Im Gaumen verlaufen :3 fein gerippte Längsriefen ; dahinter befindet sich eine knollige Erhöhung und derselben entsprechend im Unterkiefer eine grubenartige Vertiefung. Dic 2. Schwinge (bei der deutschen Art) am längsten. Die 5.-.9. Schwinge mit stumpfwinklig zugeschnittener Sjitze; jede Aussenfahne besitzt eine spitzwinklige Erweiterung, jede Lmmenfalme eine stumpfe Ausbuchtung. Schwanz kurz und seicht ausgeschnitten. Gefieder weich und seidenartig. beis ser.

97. Coccothraustes vulgaris Pall. 1811. - Kirschkern-

Synonyma: Fringilla coceothraustes Ill., Tem., Naum., Glog., Gätke; Loxia coccothraustes L., S'cop., Buff., Gm., Behst., Fridr.; Cocothraustes deformis Koch; Coccothraustes curopaeus et atrigularis Selby; Cocothraustes alpiuus Parz; Coccothraustes fagorum, C. cerasorum, C. planiceps, C. flaviceps, C. minor Chr. Br.; Coccothraustes coccothraustes 13p., Hart.; Coccothraustes vulgaris Pall., Kays. u. Blas., Gieb., A. Br., v. Hom., Mewes, Radde, Jäckel.

'Trivialnamen: Brauner Kernbeisser, Dickschnabel, Kirschfink, Kirschschneller, Bollenbeisser, Laske, Leske, Lysklicker. 
Kennzeichen der Art: Siehe die Gattungsmerkmale, da nur diese eine Art in Deutschland.

Maasse von 11 schlesischen Exemplaren in $\mathrm{cm}$ :

$\begin{array}{lccc} & \text { maximum } & \text { minimum } & \text { Durchschnitt } \\ \text { Länge: } & 17,6 & 17,3 & 17,4 \\ \text { Flugbreite: } & 32,4 & 31,7 & 32,0 \\ \text { Schwanz: } & 5,8 & 5,6 & 5,65 \\ \text { Schnabel : } & 2,0 & 2,0 & 2,0 \\ \text { Tarsus: } & 2,2 & 2,2 & 2,2\end{array}$

Die Kernbeisser sind ausserordentlich constante Vögel, welche mir in systematischer Hinsicht zu keinerlei Bemerkungen Veranlassung geben.

Der Kernbeisser bewohnt vorzugsweise die Laubholzwaldungen der Hügellandschaften und der Vorberge. In der Ebene ist er weit seltener und fehlt manchen Strichen ganz, und über sein Vorkommen im eigentlichen Gebirge habe ich gar keine Nachrichten. Eichenwaldungen giebt er den Vorzug vor allen anderen. Eigentlich bäufig ist er nur an den wenigsten Oertlichkeiten, so nach Sylaender bei Bolkenhayn. Obst- und Baumgärten besucht er nicht nur der Kirschen wegen, sondern er brütet auch gern in ihnen sowie auf Promenaden und Anlagen. So nistet der Kernbeisser mach $\mathrm{K} n$ a $\mathrm{u}$ the auf der Schweidnitzer Promenade und nach Kollibay vereinzelt in den Vorstädten von Neisse. Im Herbste wird der Bestand der einheimischen Brutvögel noch bedeutend verstärkt durch nordische Zuzügler, die sich aber in nichts von jenen unterscheiden. Kutter fand bei Neustadt am 25. Mai 18313 fertige Nester. Dieselben bestehen aus dïnuen Ruten, sind schlecht gebaut und deu Taubemnestern ähnlich.

Masse von 9 schlesischen Eiern in $\mathrm{mm}$ :

$\begin{array}{lccc} & \text { maximum } & \text { minimum } & \text { Durchschnitt } \\ \text { Länge: } & 24,5 & 23,5 & 23,75 \\ \text { Breite: } & 18 & 16,5 & 17,0\end{array}$

Gattung: Passer Briss. 1760. - Sperling.

Schnabel ziemlich stark, kolbig und spitz. An den kurzer Flügeln sind die 2.-4. Schwinge am längsten. Schwanz nur wenig ausgeschnitten. Kopf dick und flachstirnig. Gestalt und Wesen plump. Ein eigentlicher Gesang fehlt.

98. Passer petronius (L.) 1766. - St cins perling.

Synonyma: Fringilla petronia L., Belıst., Naum., Glog., Fridr.; Fringilla stulta, F. bononiensis, F. leucura Gm.; Fringilla diadema Müll.; Petronia marina Will. u. Ray; Petronia rupestris 
Bp., Boie; Petronia stulta Blyth, Mewes, A. Br.; Petronia saxorum, 1'. brachyrhynchus, P. macrorhynchus Chr. Br.; Petronia petronia Gray; l'yrgita rupestris, P. petronia Chr. Br.; Pyrgita petronia Kay.. u. Blas., A. Br., v. Hom., Radde, Jäckel; Coccothraustes petronia Cuv.; Passer silvestris Buff., Briss.; Passer petronius Koch, Degl., Gieb., Hartert.

Kennzeichen der Art: Schnabel sehr kräftig, Flügel ziemlich spitz. Dic 2. Schwinge am längsteu, die 2. und 3. auf der Aussenfahne deutlich, die 4. schwach verengt.

Gloger führt den steinsperling als nsehr selten" mit auf. In der Lausitz ist er cinmal mit Sicherheit nachgewiesen worden (Krezschmar) und soll wiederholt daselbst beobachtet worden sein, nameutlich in der Zittauer Gegend, wo er nach R. Tobias gebrütet haben dürfte. Ka $\mid$ u za nennt ihn einen seltenen Zugvogel". Aus der neueren Zeit liegen gar keine Nachrichten über sein Torkommen mehr vor. Nur zieht sich durch die ganze Litteratur die Angabe, dass der S'teinsperling auf dem Kynast brüte. Ich muss dies auf das bestimmteste in Abrode stellen und behaupte, rass eine Verwechslung mit Saxicolu oenanthe vorliegt, weleher im schlesischen Gebirge vielfach nteinsperling genannt wird. Dieser Fall zeigt uns so reeht eklatant, wie wichtig das planmässige Sammeh von Trivialnamen aus allen deutschen Gauen auch für die Wissenschaft Ornithologie ist!

\section{Passer montanus (L.) 175. - F eld sperling.}

śynonyma: Fringilla moutana L., Gm., Bechst., Naum., Fridr, Gätke; Fringilla campestris schranck, Glog.; Pyrgita montana Brie; Pyrgita campestris et septentrionalis Chr. Br.; Passer campestris Briss.; l'asser Hausmanni Bolle; Passer montaninus Pall.; P'asser hamburgensis Leach; Passer montanus Briss., Buff., Degl., Blyth, Koeh, Gieb., Kars, u. Blıs., A. Br., v. Hom., Mewes, Radde, Hartert, Jäckel.

Trivialnamen: It ald-, Baum-und Weidensperling, Ringelfink. Polnisch: Wrubel. Wendisch: Polsky Robel.

Kenuzeichen der Art: Schnabel mittelstark. Flügel ziemlich stumpt.' Sehwingen nicht verengt. Oberkopf und Nacken matt kupferrot. 2 weisse Flügelbinden.

II a a s e von 35 schlesischen Exemplaren in $\mathrm{cm}$ :

$\begin{array}{lccc} & \text { maximum } & \text { minimum } & \text { Durchschnitt } \\ \text { Länge: } & 14,9 & 13,1 & 14,2 \\ \text { Flugbreite: } & 23,4 & 21,5 & 22,4 \\ \text { Schwanz: } & 6,2 & 5,8 & 6,1 \\ \text { Schnabel: } & 1,2 & 1,0 & 1,15 \\ \text { Tarsus: } & 2,0 & 1,8 & 1,9\end{array}$


Die Feldsperlinge variiren in der (rrösse ziemlich; im allgemeinen pflegen die aus südlicheren Liinlern constant etwas kleiner zu sein. Doch machen anch enge Lokkalverhältnisse schon einen ziemlichen Untersehied je nach der Fruchtbarkeit und den landwirtschaftlichen Verhältnissen einer Gegend. - Im Breslauer Museum steht ein reiner Albino und noch ein zweites abnormes Exemplar, bei dem der ganze Körper weiss geffirbt ist, nur Stirn und Scheitel kastanienbraun; Kehı", Flügel und Rücken sind deutlich rostgelb gezeichnet.

Ich branche wohl kaum: zu erwähnen, dass anch in Schlesien der Feldsperling einer der allergemeinsten Tögel ist, das Gebirge natirlich ausgenommen. Im Sommer steht sein bestand dem vou clomesticus zwar nach, aber im Winter erhält er aus dem Norden noch so viel Zuzug, dass er alsdam pravalirt. Kolliba y notirte deu Feldsperling auch noch im Hirschberger Thal als überall häufigen Brutvogel; or hailt sich dort namentieh an die Chansseen.

Kopfweidenpflanzungen, Obstgïrten, F'eldhölzer und Auwilder mit hohlen Bïunen bilden während der Brutzeit dic Heimat der Feldsperlinge. Wohmungsmot macht anch diese Art oft zum grausamen Nesterplïnderer. Ieh beobachtete selbst, wie Feldsperlinge junge Kohl- und Blaumeisen aus dem Neste warfen. Ueberhaupt nimmt der Feldsperling bei uns immer meln die unangenehmen Eigensehaften seines Vetter's an und brandschatzt eben so erbarmungslos wie dieser die Itirsefelder, Kirsehbäume und Weinberge. Aehuliehes gilt anch von den Nistgewohnheiten. So berichtet Knathe: „o S!lu brïtete der Feldsperling melnrfach mitten im Dorfe, treibt sich anf den Misthaufen und F'utterplit zen der Hühner herum und schlïtt z. T. im Stroh der S'clemnen. Ein Iännchen schlief ständig in einem alten Finkenneste. Sobald es anfing, kälter zu werden, demolierte unser Held mit seiner Gemahlin dieses Bett und polsterte mit dessen Material ein Loh im Baum aus. Wieder andere haben sich die Kingehnester, die frïher ihr Vetter auf den Bäumen errichtete, zurechtgestutzt und näuhtigen darin." Ferner pflegen sie im Gebälk der stäle, in sicheunen, Hundehütten, Reisighaufen ete. zu schlafen. Im Whinter Is!h (r. baute nach $\mathrm{K} n \mathrm{n} u$ the ein Yärchen sein Winternest am Thor einer Scheune, in der täglich gearbeitet wurde. 1)as Brutgeschät ist allbekannt. Kollibay fand cimmal ein erbemgrosses spulci.

$\mathrm{M}$ a a s e von 25 schlesischen Eiern in $\mathrm{mm}$ :

$\begin{array}{lccc} & \text { maximum } & \text { minimum } & \text { Durchschnitt } \\ \text { Länge: } & 20 & 18,5 & 19,25 \\ \text { Breite: } & 14,5 & 13 & 13,75\end{array}$

100. Passer domesticus (L.) Tibs. - If a usperling. 
Synonyma: Fringilla domestica L., Buff., Gm., Bechst., Naum., Glog., Fridr., Gätke; Fringilla candida Sparrm.; Fringilla indica Licht.; Pyrgita domestica Boie, Chr. Br.; Pyrgita indica IIutt.; Passer nigripes Ehrbg.; Passer indicus Jord. und Selby; Passer cisalspinus Tem.; Passer Italiae Bp.; Passer caucasicus Bogd.; Passer cahirinus, P. pectoralis, P. castaneus, P. melanorhynchus IVürt.; Passer validıs, P. minor, P. pagorum, P. rusticus P. intercedens, P. brachyrhynchus, P. rufidorsalis Chr. Brehm; Passer domesticus Briss., Degl., Pall., Koch, Gieb., Kays. u. Blas., A. Br., v. Hom., Mewes, Radde, IIart., Jäckel; Passer domesticus indicus Hartert.

Trivialnamen: Spatz, Spatzker, sparg, Sperg, Sperlich, Dachsperling. Polnisch: Wrubel. Wendisch: Domjazy Robel.

Kennzeichen der Art: Schmabel mässig stark, Flügel ziemlich stumpf. Scheitel düster aschgrau oder braungrau. Eine gelblich-weisse Querbinde.

Ma as e von 32 schlesischen Exemplaren in $\mathrm{cm}$ :

$\begin{array}{lccc} & \text { maximum } & \text { minimum } & \text { Durchschnitt } \\ \text { Länge: } & 17,0 & 15,5 & 16,4 \\ \text { Flugbreite: } & 26,1 & 24,1 & 25,0 \\ \text { Schwanz: } & 6,5 & 5,8 & 6,15 \\ \text { Schnabel: } & 1,3 & 1,1 & 1,2 \\ \text { Tarsus: } & 2,2 & 1,9 & 2,0\end{array}$

In systematischer Hinsicht gilt ron tomestirus ganz dasselbe wiv von der vorigen Art, nur dass die betretfenden Verhältnisse hier in noch gesteigerten Maasse einwirken. Irgend welche Ankliinge an die ausserdentschen Formen habe ich bei den durch meine IIände gerangenen schlesischen sperlingen nicht finden kiininen. Terhälnismässig häufig kommen Farbenvarietäten vor. hin Breslauer Museum befinden sich folgende Stücke:

a. Unterseite weiss, Kehle und 'Teile der Brust licht braunschwarz, ganze Oberseite fahl lichtbraun, schnabel und Füsse gelb.

b. Gesamtfarbung sehr hell, anf jeder seite jo weisse Schwungfedern.

c. Ein Teil der Stirn- und Flügeldeckfedern weiss.

d. Unterseite ganz weiss, Oberseite licht rostfarben, auf Flügeln und Schwanz am hellsten.

e. Ueberall rein weiss. Rückenzeichnung kaum merklich braungrau angedeutet.

f. Weiss, aber mit deutlicher Zeichmung in Braun auf Rücken, Flügel und Stirn.

g. l. i. iuv. Reine Albinos. 
Auch in Ifeydrich's Sammlung steht ein reiner Albino. Kollibay benbachtete bei Neisse im Herbst 1891 cin junges Exemplar, an dem die Schwingen bis auf die mittelsten Federu weiss waren. In Breslau hielt sich einer Mitteilung Mohr's zilfolge von 1875-77 ein Weibchen auf, welches jeden Winter gauz weisse Schwungfedern bekam, während dieselben im Sommer nur eine Nuance heller waren als normale. Dieses Weibchen hatte sich einer ganz aussergewömlichen Aufmerksamkeit seitens der verliebten Mïnnchen zu erfreuen: eine positive Beobachtung, die für den Darwinisten voin hohem Werte sein dürfte.

Wo es menschliche Ackerwirtschaft giebt, da giebt es auch Spatzen in Unmassen. Nur in einsamen Valddörfern, die keinen Ackerbau treiben und wenig Verkehr nach aussen hin unterhalten, pflegt dieser Allerweltsvogel zu fehlen. Im Gebirge geht er bis zur Getreidegrenze hinauf und siedelt sich in den über derselben gelegenen Dörfern nur ausnahmsweise an, falls dieselben ctwa weitläuftigte Gürten besitzen oder einen grösseren Viehstand halten. Wenn sich die Verhältnisse irgendwo zu seinen Gunsten ändern, so stellt er sich sehr bald anch in Gegenden ein, die er bisher mied und macht sich hier gewöhnlich sehr rasch breit, demn er besitzt „Ellbogen", um einen menschlichen Ausdruck auf den Vogel zu übertragen. „Vor einigen Jahren“, so erzïhlt Kn a uthe, wurde mitten im Walde des Zobten, weitab von den Ortschatten, cine Försterei errichtet. Im Herbst 1886 bezog sie der Weidmam, frühzeitig 1887 fand sich auch der Spatz dort ein." Gewöhnlich vertreibt er dann sehr bald andere lieblichere und nützlichere Singrögel; der Spatz ist bei eintretender Wohnungsnot einer der rücksichtslosesten Nesterplünderer, welchen ich kenne. Mleines Erachtens wird dieser Umstand bei den zalillosen Debatten uiber Nutzen und Schaden des Sperlings noch viel zu wenig beriucksichtigt. Kna the sah, wie sie Mehlschwalben aus ihren halb fertigen Nestern vertrieben und selbst deren Eier hinauswarfen; ferner demolirten sie in seinem Garten Nester des grauen Fliegenschnäpper's und des Hausrotschwanzes. Achnliches beobachtete ich bei Blaumeisen. Ihr zänkisches Naturell tritt selbst viel grösseren Vögeln gegenüber zu Tage. Ein Trupp Sperlinge trieb in $\mathrm{K} n \mathrm{authe}$ 's Garten einen Griinspecht von Baum zu Baum, bis er endlich flüchtend das Gehöft verlassen musste. In dils Loblied, welches extreme Vogelschützler auf den Sperling zu singen pflegen, vermag ich durchaus nicht einzustimmen. Yichmehr wird der Vogel überall da, wo er sich übermässig vermehrt, zu einer wahren Landplage. Die Landleute sollten sich die fetten jungen Vögel im Spätsommer gut schmecken lassen; dann hätten sie die beste Gelegenheit, den Bestand der Sperlinge auf eine angenchme Weise in wohlthätigen Grenzen zu halten, ohne dass die Vögel deshalb ausgerottet oder auch nur zu sehr vermindert 
würden; denn dahin lässt es die Schlauheit des gefiederten Schelmes doch nicht kommen. Kn a the beobachtete ihn auch beim Fange kleiner Fischehen (Elritzen) und M üller benerkte, wie die Sperlinge in seinem Garten in Liegnitz massenhaft Crocus-Blüten zerzupften, um zu dem Honig zu gelangen. Anfangs machten sic dies recht tölpelhaft, später aber sehr geschickt. Seit dem Abnehmen der Schindeldächer bequemt sich der in allen Sätteln gerechte und veränderten Verhältuissen sich rasch anpassende Vogel vielfach dazu, scin lüderliches Nest frei auf Fichten oder andere astreiche Bäume zu bauen. "In einem 1 Morgen grossen Erlen- und Fichtengebüsch, wo die Fasanen gefüttert wurden, war den ganzen Trinter hindurch cin Trupp Haussperlinge, die schliesslich auch dort heckten und z. T. oflene Nester bauten" (K nathe). Diese freien Nester stehen meist colonieweise dicht bei einander. Bei Breslau dagegen brüten die Sperlinge noch fast aussehliesslich in Höhlungen. Freie Nester fanden insbesondere Knauthe bei Zobten, Kollibay bei Neisse, L. Tobias bei Neusalz und Grïncberg und R. Tobias bei Görlitz. Ausserdem errichten sich die Fïgel noch besondere Nester als Winterwolnungen und die Männchen auch im Sommer öfters eigene Spiel- und Schlafnester. Nach K na u the polstern sich viele Sperlinge zu Beginn des Winters die sichwalbennester mit Stroh und Federn zu warmen Betten aus. Bisweilen haben die Winternester vollständig Kugelform. Die kolossale Vermehrungsfähigkeit des ${ }_{n}$ Proletariers unter den Yögeh" ist bekannt. In allen Nonaten der warmen Jahreszeit findet man fertige und im Bau begrittene Nester, frische und bebrütete Eier, nackte oder bereits befiederte Junge. Kollibay berichtet, dass aus ein und derselben Nisthöhle unter einem Kirchendach in eiuer Woche dreimal Eier genonmen wurden, zusammen lo Stück. Der Spatz lässt sich durch solche Plünderungen oft herzlich wenig in seinem Tergnügen stören, sondern lıilt viclmehr mit grosser Zähigkeit an dem cinmal erwählten Brutplatz fest. Gar nicht selten findet man auch unter den Eiern allerlei Abnom mitiiten. In der ersten Woche nach dem Ausschlïpfen der Jungen füttern beide Eltcrn mit gleichem Eifer gemeinschaftlich, in der zweiten hingegen das Weibchen fast allein (R. Tobias). Das Männchen sieht sich inzwischen bereits nach einer anderen Lebensgefähntin um. Dic Singvögel bleiben also keineswegs alle lcbenslïnglich gepaart, wie man dies oft behauptet hat.

Ma a s e von 40 schlesischen Eiern in mm:

$\begin{array}{lccc} & \text { maximum } & \text { minimum } & \text { Durchschnitt } \\ \text { Länge: } & 24,5 & 19,5 & 22,5 \\ \text { Bleite: } & 16,5 & 15 & 15,75\end{array}$

Familie: Sturnidae, Stare. 
Mittelgrosse Vögel mit kopflangem, geradem und spitzigem Schnabel, mässig langem Schwanz und grossen, kräftigen, starkklauigen Füssen. In den ziemlich langen und spitzigen Fliggelı ist die 1. Schwinge selr kurz, die 2. und 3. am lïngsten.

Gattung: Sturnus L. 1758. - Star.

Sohnabel mindestens so lang als der Kopf, gerade, konisch zugespitzt und nach vorn etwas niedergedrückt. An der Schnabelwurzel keine Borstenfederchen. Die ovalen Nasenlöcher sind durch eine Hornhaut halb verschlossen. Lïufe vorn getäfelt. Die Federn der erwachsenen Vügel sind in eigentümiicher. Weise zugespitzt, hart und z. T. metallisch glänzend. Die 2. Schwinge am längsten.

\section{Sturuus vulgaris L. 1758. - star.}

Synonyma: Sturnus varius Meyer; Sturnus indicus Hodgs.; Sturnus unicolor Tem., Lamarm., Chr. Br.; Sturnus purpuraseens Gould; Sturnus nitens Hume, Chr. Brehm.; Sturnus Humei Brooks; Sturnus Poltoratzkyi Finsch; Sturnus domesticus, St. septentrionalis, St. silvestris, St. longirostris, St. tenuirostris Chr. Br.; Sturnus vulgaris Johnst., L., Gm., Behst., Naum., Chr. Br., Glog., Gieb., Kays. u. Blas., Koclr, A. Br., v. Hom., Mewes, Radde, Hart., Gätke, Jäcke].

Trivialnamen: Rinderstar, Spreche, Sprehe, Sprihm. Wendisch: Skurtz, Skortz.

Kennzeichen der Art: Siehe die Gattungsmerkmale, da nur diese eine Art in Deutschland.

Bereits früher (Ornithol. Jahrbuch III, p. 182) habe ich mich über die durch Sharpe angeregte Starenfrage ausgesprochen. Seitdem bin ich aber durch fortgesetzte Studien über diesen Gegenstand wesentlich anderer Meinung geworden und neige mich jetzt mehr und mehr der Ansicht von Radde zu, welcher nur eine Starenart annimmt, „mit verschieden schillerndem oder seltencr glanzlosem Grundton des Gefieders, die nur nach dor Jahreszeic ihr Kleid verändert und zwar vornehmlich dureh Abreiben der Flecken und z. T. auch durch ein lebhafteres Colorit im Frïhlinge". Speciell von dem systematischen Wert des Metallschiminer's im Vogelgefieder, welches Shar pe bei der Starenfrage besonders betont hat, halte ich nicht meln allzuviel, weil derselbe unter verschiedenen Verhältnissen doch gar zu veründerlich ist. Man hat neuerdings mit Recht darauf aufimerksam gemacht, dass es zunächst einer allgemein gültigen Norm belürfe, nach der die metallisch glänzenden Vogelfedern aus einer ganz bestinmten Lintfernung und unter einem ganz bestimmten Sehwinkel betrachtet werden müssteu, wenn man allgemein gültige Resultate erzielen wolle, Das ist durehans richtig und dringend zu beherzigen; es 
kommt hier aber noch ein anderer Faktor sehr schwerwiegend inbetracht, nämlich die Temperatur. Kleiuschmidt und ich haben in dieser Hinsicht neuerdings ganz überraschende Entdeckungen gemacht. In allgemeinen lässt sich sagen, dass metallisch glänzende Vogelfedern bei niedriger Temperatur mehr zur Purpurfarbe hinncigen, bei hoher 'Temperatur aber grünlich oder bläulich schimmern. Daraus erklärt es sich auch sehr einfach, dass die hierher gehörigen de uts e li en Vogelarten im Osten unseres Vaterlandes (also auch in Schlesien) viel mehr ins Purpurne spielen als in Westen, wo ein stahlgrüner oder bläulicher Metallglanz die Regel ist. Dies gilt nicht uur von den Staren, sondern anch vou den Kiebitzen, den Erpeln der Stockente u. s. w. Ein Entenkopf'z. B., den Kleinschmidt mehrere Tage im Winter vor's Fenster hing, schimmerte stark purpurn, und wenn er danu auf einige Zeit in der warmen stube gelassen wurde, erglänzte er wieder im reinsten Grün! Schon diese eine Beobachtung zeigt doch wohl hinlänglich, wie selı auch die Temperatur bei der Beurteilung des Metallschimmers im Vogelgefieder berücksichtigt werden muss, und wie gering der systematische Wert dieses so ¿usserst hinfälligen und leicht veränderlichen Glanzes ist. Die schlesischen Stare kann ich in keine der beiden S'har pe'schen Arten cinreihen, sondern sie stellen ebenso wie allen anderen vou mir untersuchten ostdeutsches Exemplare die intermediäre Zwischenform dar. Rücken und Bauch sind stahlgrün oder blau, Kopf und Kehle purpurn-violett, die Ohrdecken sehr verschieden.

$\mathrm{M}$ a asse von 44 schlesischen Exemplaren in $\mathrm{cm}$ :

$\begin{array}{lccc} & \text { maximum } & \text { minimum } & \text { Durchschnitt } \\ \text { Länge: } & 19,8 & 18,7 & 19,4 \\ \text { Flugbreite: } & 38,1 & 36,5 & 37,6 \\ \text { Schwanz: } & 6,2 & 5,9 & 6,1 \\ \text { Schnabel: } & 2,8 & 2,6 & 2,7 \\ \text { Tarsus: } & 2,5 & 2,4 & 2,45\end{array}$

Im Sommer 1890 beobachtete ich bei Breslau wiederholt ein Exemplar mit ganz weissem Schwanze. Im Breslauer Museum befindet sich ein reiner Albino, ebenso in der Sammlung $\mathrm{Heyd}$ rich s.

Der Bestand der Stare hat sich in Schlesien in den letzten Jahrzchnten ganz ausserordentlich gehoben, woran nicht zum mindesten das immer allgemeiner werdende Aushängen von Nistkïsten schuld haben mag. In der Lausitz und in Niederschlesien zwar war der star von jeher häufig, in gewissen Distrikten Mittelschlesiens aber und in fast ganz Oberschlesien noch vor 20 Jahren selten; ja grossen Landstrichen fehlte er gänzlich. Jetzt ist das anders geworden. Der Vogel hat sich auch in solchen Gegenden, 
die er früher kaum auf dem Zuge einmal aufsuchte, neuerdings fest angesiedelt und rasch vermehrt, vielfach sogar zu sich bereits unangenehm bemerkbar machenden Mengen. Uttendörfer schreibt mir aus Gnadenfeld bei Kosel: „War 1874 in einem Umkreis von etwa 2 Stunden noch nicht Brutvogel, hat sich aber seit 1888 immer mehr in der ummittelbaren Nähe angesiedelt." Am Zobten ist der Star nach Kna uthe erst seit 1857 Brutvogel. Ferner berichtet Richter aus Strehlen: "Selten; dürfte bis vor wenigen Jahren überhaupt getehlt haben wegen Mangels an hohlen Bäumen und infolge der Gleichgültigkeit der Menschen. Nistkästen lockten ihn bald an. In meinem ca. 1 Quadratmeile grossen Gebiet nicht mehr als 10 Pare." Und im folgenden Jahre (1855) schreibt derselbe Beobachter: "Noch selten und erst eingewandert, vermehrt sich aber zusehends." Auch bei Breslau waren die Stare keineswegs besonders zahlreich, aber gleichfalls in rascher Zunahme begritfen. Sehr gemein ist der Vogel dagegen in niederschlesischen Oderthal, in der Lausitz, in den Vorbergen und in der Bartschniederung. In Oberschlesien scheint er dagegen stellenweise noch inmer zu fehlen. Im Gebirge geht er so weit empor als sich Dörfer finden und ihm dort Nistkitsten ausgehängt werden, also nach Kollibay bis zu einer Höhe von etwa 3000 Fuss. v. Tsch us i traf (i Paare in Brutsïsten bei Sjundelmühl. Wohl keinen Vogel vermag man durch ausgehïingte Nistgelegenheiten, und seien sie auch noch so roh und scheinbar unpraktisch, so leicht anzulocken als den Star. Häufig genug ergreift derselbe auch von einem ihm geeignet erscheinenden Brutplatz Besitz, welcher ihm gar nieht zugedacht war. Die Frage über Nutzen und Schaden der Stare ist neuerdings von $\mathrm{K}$ oepert sehr ausführlich erörtert worden. Uass der Star für den Landmann ein recht nützlicher und deshalb zu schützender Vogel ist, unterliegt wohl keinem Zweifel. Wo er sich aber zu sehr vermehrt, vermag er stellenweise doch recht lästig zu werden, und erscheint es mir dann durchaus nicht unrecht, wemn die Landleute den Bestand durch Schiessen im Herbste in gewissen Grenzen halten. Dem Grüneberger Weinhau fïgen die Stare durch ihre uibergrosse Menge in der That empfindlichen Schaden zu (L. Tobias), ebenso dem für die Besitzer eine wertvolle Eimnahmequelle bildenden Rohr der Teiche der Bartschniederung, in dem sie im Sipätsommer und Herbst zu tausenden und abertausenden zu iibernachten pflegen, und endlich auch den Getreidefeldern der fruchtbaren niederschlesischen Ebene, von ihren kleinen Näschereien in den Obstgärten etc. ganz zu geschweigen. Wo sich dagegen die Stare nur in mässiger Zahl vorfinden, vermögen sie in keiner Weise wirklich lïstig zu werden und sind deshalb dort sorgfältigster Schonung und Beschützung zu empfehlen, zumal die munteren Burschen im März ja so viel dazu beitragen, unser Herz wit 


\begin{tabular}{|c|c|c|c|c|c|c|c|c|}
\hline Ort: & Beobaliter: & 1839 & 1840 & 1841 & 184: & 1849 & 1576 & 1877 \\
\hline Görlitz & R. Tobias & 15. II. & 24. 11. & $20 . \mathrm{II}$. & $\begin{array}{l}\text { 19. I1. } \\
11 . \mathrm{X} .\end{array}$ & 一 & - & - \\
\hline$"$ & $\begin{array}{l}\text { J. Tobias } \\
\text { Peck }\end{array}$ & - & - & - & - & 30. 1. & - & - \\
\hline " & Ricliter & - & - & - & - & - & - & 一 \\
\hline Strelilen & $\because$ & - & - & - & - & - & - & - \\
\hline Sprottau & Krezschimar & - & - & - & - & - & - & 一 \\
\hline Neustadt & Kutter & - & - & - & - & 一 & - & - \\
\hline & Kollibay & - & - & - & - & - & - & - \\
\hline $\begin{array}{l}\text { Randen } \\
\text { Canth }\end{array}$ & $\begin{array}{l}\text { Willimek } \\
\text { s. Meserinc }\end{array}$ & - & 一 & - & - & - & - & - \\
\hline $\begin{array}{l}\text { Canth } \\
\text { Goldberg }\end{array}$ & $\begin{array}{l}\text { 5. Meserinck } \\
\text { Emmrich }\end{array}$ & - & - & - & - & - & 24.11. & 19. II \\
\hline
\end{tabular}

Neurode

Alt-Hammer Forstpersunal

Friedrichsthal

Kl. Briesen

Kottwitz

Moselache

Nesselgrund

Paruschowitz

Proskau

Rogelwit?

Ullersdorf

Karlsberg

Zobten

Knauthe

Niesk y

Breslau

Bär U. Kramer

Floericke 
a belle.

\begin{tabular}{|l|l|l|l|l|l|l|l|l|l|l|l|}
1879 & 1840 & 1881 & 1882 & 1884 & 1885 & 1886 & 1887 & 1888 & 1889 & 1890 & 1891
\end{tabular} 15. 11. - 12. II. - 20. X.14. X. 6. III.

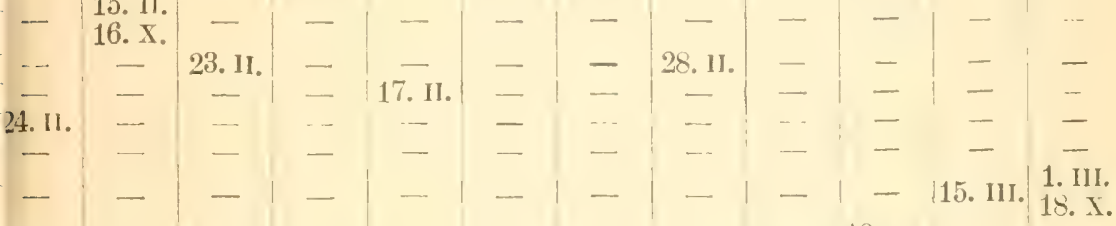
23. 11 12. III.

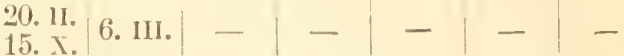

20. X. $\mid$ 14. X. $\mid$ 6. III. $|-|-\mid-1-$

15. 1I. 6. III. 25. II. 8. III. 9. III.

18. $x .15 . x .21 . x .20 . x .14 . x$.

19. IX. 19. MI. 13. 11. II. 9. III. 10. III.

15. $111 . \begin{aligned} & 12 . \\ & 6 . \mathrm{II} \\ & 17 .\end{aligned}$

1.111 .

17. II. 15. II. 27. II. 10. III. 12. III.

1. II. 13. HI. 26. II. 13. II. 10. III.

10. III. 25. II. 9. III. 28. II.

1. IX. 22. IX. 15. IX. 27. IX.

16. III. 3. III. 12. III.

28. III. 28. II. 5. III. 11. III. 15. III. 26. II.

24. 6. III. 12. 1II. 20. III.

10. X. T. X. 11. IX.

20. III. 26. II. $-\mid-24$. II. -

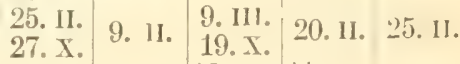
27. X. -19. III. 11. III. - 
Jubel über die Ankunft des Frühlings zu erfüllen. Der Star ist für Schlesien cin Zugrogel, welcher schon im Februar eintrifft und uns im Oktober wieder verlässt. R. To bi a s notirte von $1832-38$ für Görlitz als frühesten Ankunftstermin den 14. Februar, als spätesten den 6. März und als durchschnittlichen den 18. Februar.

Nïheres siehe auf der vorstehenden Zugtabelle!

Oefters bleibt ein kleiner Teil der alten Stare auch den Winter über bei uns und erhält damn wohl auch noch Zuzug aus nördlicheren Gegenden. So beobachtete ich den ganzen Winter $1589 / 90$ cinen Flug von etwa 30 Stück in der Strachate. Achnliche Nachrichten erbielt ich vielfach auch aus anderen Gegenden der Provinz, und es scheint, als ob ein solches Ueberwintern jetzt viel hänfiger und in ausgedehnterem Maasse stattfinde als früher. Aehnliche Beobachtungen machte $J u n g h$ a $n$ s für die Ungebung you Cassel. Tergl. las hierüber beim Buchfuk Gesagte. Tritt nach der Ankunt im Frühjahr nochmals winterliches Wetter ein, so entschliessen sich die Stare bisweilen zu einem Rückzug. Dies hat beispielsweise R i chter $1856^{\circ}$ für die Umgegend von Strehlen festgestellt. Es werden regelmässig '2 Bruten gemacht, von denen die erste Ende Mai, die zweite Mitte Juli ausfliegt. Beide Gatten brüten. Der Nestbau beginnt sehon Mitte April, und Ende dieses Monats findet man die ersten Eier. Ausser in die für ihn oder andere Höhlenbrüter aufgehängten Nistkisten baut der Star in Astlöcher, Spechthöhlen und Lücken im Gemäuer grösserer Gebäude.

Masse von 28 schlesischen Eiern in $\mathrm{mm}$ :

$\begin{array}{lccc} & \text { maximum } & \text { minimum } & \text { Durchschnitt } \\ \text { Länge: } & 29 & 27,7 & 28,5 \\ \text { Breite: } & 21 & 19 & 20,25\end{array}$

Gattung: Pastor Tem. 1815. - A mselstar.

Der zusammengedrückte und an der Spitze abwärts gebogene Schnabel ist von einzeluen Bartbor'sten umgebeu. Nasenlöcher eifömig. Schwanz mittellang und seicht ausgeschnitten. Die alten Vögel tragen auf dem Kopfe einen spitzen Federschopf.

102. Pastor roseus (L.) 1758. - Rosenstar.

Synouy ma: Turdus roseus L., Buft, Levaill., Klein, Behst.; Turdus seleucis et suratensis Gm,; Sturnus roseus Pall, Scop., Rehw., Gütke; Nerula rosea Bris., Koch, Naum., Jäckel; Acridotheres roseus Ranz.; Grieula rosea Cuv., Glog.; Boscis roseus Chr. Brehm; Thremmophilus roseus Macg.; Pastor peguanus Less.; Pastor rosens Tem., Gieb., A. Br., v. Hom., Mewes, Radde, Fridr., Hartert.

Trivialn a men: Rosendrossel. 
Kennzeichen der $\Lambda$ rt: Siehe die Gattungsmerkmale, da nur diese eine Art in Deutschland.

Dieser durch die Vertilg'ung der gefrässigen Heuschrecken so überans nützliche und in seiner Heimat deshalb für heilig gehaltene schöne Vogel bewohnt hauptsächlich Südosteuropa und das südwestliche Asien. Von hicr aus unternimmt er in manchen Jahren Vorstösse nach Westen oder Nordwesten, vou denen auch Schlesien mehr orler minder reichlich betroften zu werden pflegt. So ergoss sich im Jahre LSs! ein auf' 150-175 Stück zu sehiitzender Schwarm über minere I'rovinz. Ich hatte selbst das Glück, den ganzen geschlossenen Schwarm am 31). Mai cine Stunde südwestlich von Breslau zu beobachten, wo sich die Vügel auf den Wiesen vor der Strachate niedergelassen hatten und eifrig ihrer Nahrung nachgingen. Bei meiner Amuaherung erhoben sie sich und zogen, von neugierigen Kiebitzen gefolgt und umschwirmt, in westlicher Richtung über die Oder. Derselbe Schwarm wurde - Zcitungsnachrichten zufolge - in den nächsten Tagen noch mehrfach in der mittelschlesischen Ebene gesehen. Augenseheinlich waren dio Rosenstare aus den südrussischen Steppen gekommen und zogen nun langsam von Ost nath West dureh unsere Provinz, bis sie an den Fuss der Sudeten gelangten und sich hier in lanter kleine Trupps zersplitterten, die noch wochenlang in den Vorbergen und Gebirgsthïlern umherirrten und schliesslich ihres autfallenden Aussehens wegen meist anfgerieben wurden. Ich erhielt hierüber vielfach Nichrichten. So nerlegte am 8 . Juni der Forstassistent Baeh unweit des Dorfes Heinzendorf, Kr. Habelschwerdt, ein prächtig gefärbtes Miamnehen des Rosenstares, und zwar wurde der Yogel vou cinem Obstbanme hermutergeschossen, auf welehen sich derselbe mit noch etwa 15 Exemplaren seiner Gattung gesetzt hatte. Die Vögel hatten zuniehsst dureh ihr eigentümliches Gesehrei die Aufmerksamkeit des B. ant sich gelenkt und sehienen ziemlich ermattet zu sein, wie denn anch der erlegte Rosenstar sich in etwas abgemagertem Zustand befand." Bei (xablonz an der Neisse wurden nach Hirschenen 2 Exemplare gesehen und eins daron geschossen. Bei Bolkenhayn wurde nach Sylender ein Männchen gefangen, im Henscheuergebirge nach Asmus wiederholt Rosenstare beobachtet w. s. w. F'ast in allen an mich gelangten Nachrichten wurde die grosse und sichtliche Ermattung der Vügel betont, meines Erachtens ein Beweis mehr dafür, dass der gewaltige Querwall der Sudeten den nach Westen gerichteten Zug der Vögel irritirt und in planlos herumirrende Trupps zersprengt hatte. Auch aus früherer Zeit liegen mir mehrfach Nachrichten über das Vorkommen des Rosenstares in Schlesien vor. Weigel sagt: "sehr selten in Oberschlesien", und Endler erwähnt ein 1815 bei Neisse geschossenes Weibchen. R. Tobias erbentete am 19. Juni $1836^{\circ}$ bei Görlitz ein Mïunchen und erzühlt, dass 
auch noch ein schon früher erlegtes Exemplar sich in der dortigen Sanmlung befinde; später sah er noch 2 stück. Auch bei Hermsdorf ist der Vogel nach Brahts vorgekommen. 1856 erschien nach Baer ein Flug Rosenstare in Leopoldshain bei Görlitz, von denen einige erlegt wurden. Derselbe Gewälirsmann erwähnt auch noch ein am 28 . Mai 136 zu sohra bei Görlitz geschossenes Männchen. Im Mai 1876 endlich stellten sich bei Rotenburg ca. 100 Stück ein und richteten unter den dort massenhaft aufgetretenen Maikäfern grosse Verheerungen an.

Familie: Oriolidae, Pirole.

Der ziemlich stake', gestreckte und sanft grebogene sichuabel hat vorn einen schwachen Zahn. Die verkehrteiförmigen Nasenlöcher öttinen sich an der Unterseite einer starken Membran, liegen aber sonst ganz frei. Die Mittel- und Aussenzehe sind au der Basis etwas verwachsen, die Hinterzehe stark entwickelt. Die 1. Schwinge ist sehr kurz, die 3. am längsten. Das Getieder zeigt lebhafte Farben.

Gattung: Oriolus L. 1766. - Pirol.

Siehe die Familiencharaktere, da nu! diese eine Gattung in Deutschland.

\section{Oriolus galbula L. 1766. -- Pirol.}

Synonyma: Coracias oriolus Seop.; Coracias galbula Behst.; Turdus galbula Briss.; Oriolus aureus, O. garrulus Cir. Brehm; Oriolus galbula L., Gm., Niumn., Chr. Br., Clog., Gieb., Gould, Kays. u. Blas., A. Br., shar e, v. Hom., Mewes, Radde, Fridr., Hart., Gätke, Jäckel.

'Trivialnamen: Golddrossel, Goldamsel, Goldmeerle, Bierhole, Bierholt, Biereule, Bieroltt, Beerholdt, Kir'schvogel, Kirschhold, Kirschenspecht, Pirreule, Gottesrogel, Wittewale. Polnisch: Wilgwa Bozewoto. Wendisch: Dschaschuls.

Kennzeichen der Art: Siehe die Gattungsmerkmale, da nur diese eine Art in Deutschland.

$\mathrm{M}$ a asse von 18 schlesischen Exemplaren in $\mathrm{cm}$ :

$\begin{array}{lccc} & \text { maximum } & \text { minimum } & \text { Durchschnitt } \\ \text { Länge: } & 23,1 & 22,5 & 22,8 \\ \text { Flugbreite: } & 44,5 & 43,0 & 43,8 \\ \text { Schwanz: } & 8,6 & 8,3 & 8,5 \\ \text { Schnabel: } & 2,7 & 2,5 & 2,6 \\ \text { Tarsus: } & 2,7 & 2,5 & 2,6\end{array}$

Der Pirol ist im allgemeinen ein selr constanter Vogel, doch ändert der Farbenton der alten Männchen je nach dem Aufenthalts- 
ort etwas ab. Die Pirole der Nadelwälder sind schön goldgelb, sohr ins Rötliche spielend, die in den Laubwäldern dagegen mehr lichtgelb. Schon L. Tobias hat das richtig hervorgehoben.

Wohl nur in wenigen Gegenden Deutschlands dürfte es so viel Pirole geben wie in den Auwaldungen des schlesischen Oderthales. Der prächtig gelbe Geselle ist dort mit der erste Charaktervogel und belebt dic Laudschaft auf das aumutigste mit seinem weithin schallendeu l'fitl'. Uebrigens scheint auch die Stimme der Pirole nach ihrem Aufenthalte etwas verschicden zu sem. Auch im Hügellande und in der Lausitz ist der Pirol gemein, in Oberschlesien und in den Vorbergen schon erheblich sparsamer, und im eigentlichen Gebirge kommt er nur auf dem Zuge als Seltenheit vor. Laubwälder bevorzugt er entsehieden dem Nadelholz gegenüber. In der Görlitzer Heide und in den grossen Forsten Oberschlesiens finden sich deshalb nur relativ wenige. Allein aus dem nordwestlichen Winkel der Provinz wird von L. Tobias über Abnahme der Pirole geklagt, sonst in Gegenteil erfreulicher IVeise vielfach ein Heben des Bestandes constatirt, wie $z$. B. von $\mathrm{K} n$ a u the für die Umgebung des Zobten. In die Vorberge des Isergebirges ist der Pirol nach Menzel und Michel erst unlängst eingewandert. Kollibay fand ihn ancir im Hirschberger Thal melurfach brütend. Die Ankunft erfolgto nach R. Tobias von 1832-38 bei Görlitz frühesteus am 27. April, spätestens am 10. und im Durchschnitt an 3. Mai.

Näheres siehe auf umstehender Zugtabelle!

Während der Bruzeit hält sich der Pirol hauptsïchlich an waldbekrinzten Flussuferu, in gebüschreichen Laub-oder viel seltener Nadelwaldungen, in Feldhölzern und grossen Baumgärten auf, welche sich womöglich in der Nähe ron Wasser betinlen. Die Kürze seines sommeraufenthaltes bedingt nur eine Brut. Das Nest ist bekanntlich ein Kunstbau ersten Ranges. Kum Baumaterial eines solchen, welches Kutter am 4. Juni $15 s 1$ mit 4 Eiern m über dem Wasser auf einer Erle auttand, waren vielfach Kornähren verwendet. A. v. Homeyer controllirte 1 stiti bei Glogau 4 Nester, welche auttallend niedrig über dem Boden standen, wohl der Stürme und Windstüsse wegen. Volle Gelege fanden Wolf am 31. Mai, Practorius am 6., Thieman am 15. und ich selbst am 11. Juni. Lí Spätsommer gehen die Pirole nicht nur sehr eifrig an die Kirschen, sondern auch an Ebereschen, Birn- und Maulbeerbäume.

Masse von 9 schlesischen Eiern in $\mathrm{mm}$ :

$\begin{array}{lccc} & \text { maximum } & \text { minimum } & \text { Durchschnitt } \\ \text { Länge: } & 30,5 & 29,5 & 30,25 \\ \text { Breite: } & 21,5 & 21 & 21,25\end{array}$




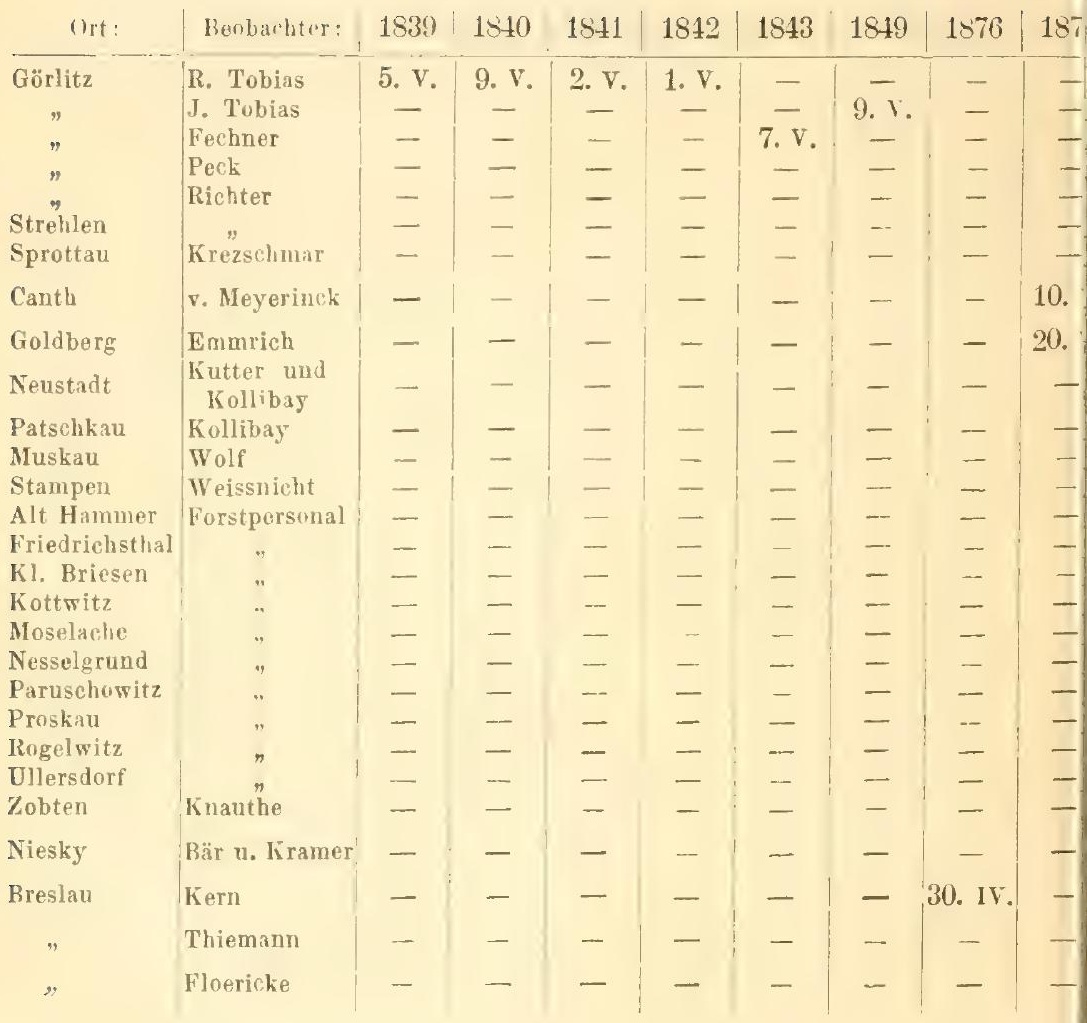


Familie: Corvidae, Raben.

Starke, mittelgrosse Vögel mit kräftigem, schwach gebogenem und scharfschneidigem Schnabel. Die rundlichen Nasenlöcher liegen nahe der Stirn und sind mit dichten Borstenfedern bedeckt, ebenso die Zügelgegend. Der vorn getäfelte Lauf ist stets länger als jede der völlig freien, scharfkralligen Zehen. Von den nach der Spitze zu verschmälerten Sch wingen ist meist die t, am längsten und die 1. stets mindestens halb so lang als die ?. Schwanz abgerundet, keil- oder stufenförmig. Dic Stimme ist rauh und der Singmuskelapparat nur schwach entwickelt. Es sind Allesfresser und meist kluge, derbe und räuberische Vögel.

Gattung: Pyrrhocorax Tunst. 1771. - Felsenrabe.

Pyrrhocorax alpinus Koch. 1816. - Alpendohle.

Nach Schwenckfeld war die Alpendohle früher im Riesengebirge heimisch: "In montibus altíssimis vivit, noctu clamore molestus." Er nonnt sie: Alp- und Waldrappe, Nacht- und Steinrabe. Aus neuerer Zeit liegen keine Nachrichten über das Vorkommen dieses schönen und in den Alpen heimischen Vogels in Schlesien mehr vor.

Gattung: Nucifraga Briss. 1760. - Nussheher.

Der mindestens kopflange rundliche Schnabel verläuft fast gerade und ist an der Spitze zu einem glatten Keil zusammengedrüekt. Auf der Imenseite des' Untersehnabels verläuft vous der Mitte bis zur Spitze ein wulstarliger Höcker. Die Füsse sind verhältnismässig schlank, das Gefieder locker. Die zusamengeleyten Flügel bedecken den sichwanz bis zur Hälfte. Die 4. und 5. Suluwinge sind am längsten, die $2 .--4$. aussen verengt.

101. Nucifraga caryocatactes (L.) 1758. - T'annenheher.

10ta. Nucifraga caryocatactes macrorhyncha Brehm. 1823. - Dünnschnäbliger Tannenheher.

Sy yonyma: l'ica guttata Frisc! ; Corvus nucifraga Nils; Corvus caryocatactes L., Scop., Gm., Behst., Naum., Glog., Gätke; Caryocatacies maculatus Koch; Caryocatactes nucifraga Cuv.; Caryocatacies caryocatactes schleg.; Nucifraga guttata Vieill.; Nucifmag carryocatactes Tem., Gray, Degl., Leach, Gieb., Kays. u. Blas., A. Br., v. Ilom., NIw, Fridr., Jickel; Nucifraga bracliyrhynchus, N. macrorhynchus, N. platyr hygnchus, N. minor, N. alpestris N. areuata Chr. Brehm; Nucifraga tenuirostris et crassirostris Hart.; Nucifraga caryocata ctes leptorhyncha et pachyrhyncha R. Blasius.

Trivialn amen: Gefleckter Nusshacker, Nusshecker, Nusspickcr, Nussbrceher, Nusskriahe, türkischer Holzschreier, Markward, Waldstarl, Tamnenelster, Nusshart, Nussert. Wendisch: Schkrikawa. 
Kennzeichen der Art: Siehe die Gattungsmerkmale, da nur diese eine Art in Deutschland. in $\mathrm{cm}$ :

Ma asse von 7 schlesischen Exemplaren (lauter Dickschnäbler)

$\begin{array}{lccc} & \text { maximum } & \text { minimum } & \text { Durchschnitt } \\ \text { Länge: } & 30,5 & 29,8 & 30,2 \\ \text { Flugbreite: } & 56,9 & 55,7 & 56,3 \\ \text { Schwanz: } & 11,5 & 11,2 & 11,3 \\ \text { Schnabel: } & 5,0 & 4,8 & 4,9 \\ \text { Tarsus: } & 4,2 & 4,2 & 4,2\end{array}$

Bekanntlich giebt es beim Tamnenheher 2 gut unterscheidbare, aber doch durch Uebergïnge mit cinander verbundene subspecies, welche man nach der Beschatenheit des Sichnabels als dickschnäblige und schlaukschuäblige 'Tamenheher bezeichnet hat. Nur die ersteren kommen als Brutrögel bei uns vor. Sie bewohmen den ganzen Sommer hindurch die Gebirgsivaldungen, aber es liält begreiflicherweise mngemein schwer den vollgültigen Beweis dafür zu erbringen, dass sie dort auch wirklich wisten. Endler hebt hervor, dass er den Vogel in der Grafschaft Glatz wiederholt im Sommer gesehen habe. Ebenso beobachteren Tannenheher während der Brutzeit A. v. Homeyer im Hochwald, A. E. Brehm an der Bismarkhöhe, R. Blasius am Hochstein und Zacharias an der Schlingelbaude. Häutig ist der Togel im Riesengebirge übrigens nicht und entzicht sich im Sonmer auch vielfach der Beobachtung, ist aber doch durch seine charakteristische Stimme und Erscheimung allbekamnt. Nach Gloger liegt der von ihm bewohnte Höhengürtel ziemlich tief, ja er geht nicht leicht über die bis zu 3.000 Fuss aufwirts reichenden Waldungen hinaus. Gloger ist noch der Meinumg, dass der Tannenheher aussehliesslich Höhlenbrüter sei und erwähnt selbst ein in einer Bammhöhle im Riesengebirge gefundeues Nest mit zerschlagenen Eiern, cin Irrtum, den bereits R. Tobias berichtet hat. Derselbe fiud 1840 ein gar nicht scheues Par bei Neusalz auf einer hohen Wiche brütend. Später entdeckte er noch rin zweites Nest im Petersdorfer Revier. Uasselbe stand chenfalls frei, hatte die Grüsse eines Ringeltanbennestes, war aber dichter gebaut. Nach v. Uechtritz nistet der Tamnenhelier auch im Queissthale. Kullibay hat es neuerdings sein wahrscheinlich gemacht, dass die dickschnäblige Varietät Brutvogel in Gesenke lïngs der selnlesischen Grenze ist. Förster Kramar z versicherte ihm, in seinem Revier Arnoldsdorf im Sommer wiederholt junge Taunenheher geschossen zu haben. Förster Karhan schuss bei Wildgrund im Mai 1055) ein Junges aul frischer Buchensat. Ton meinen Mitarbeitern führen sylaender (Bolkenhayn), Zi emer (Glograu), Brotke 
(Muskau), Titz (Sprottau) und Lange (Alt-Reichenau) den Tannenheher als wahrscheinlichen Brutvogel mit auf, welche Mitteilungen freilich noch alle des Beweises bedürfen. Im Herbst verstreichen die bei uns heimischen Tammenheher auch in Gegenden, wo sie sich sonst nicht blicken lassen. Die schlankschnäblige Form kommt nur auf dem Zuge zu uns. Vereinzelt erscheinen diese Vögel wohl alljährlich, bisweilen aber auch in grossen Massen, welche die ganze Provinz überschwemmen und dann vielfach im Dohnenstieg gefangen werden. Sie zeichmen sich vor ihren dickschnäbligen Vettern schon dureh eine auttallende Dummdreistigkeit aus. So erschienen die Tannenheher nach Hosius im Herbste 1855 im Riesengebirge sehr zahlreich und zeigten eine solche Sorglosigkeit, dass einzelne mit dem Stocke er'schlagen werden komnten. Besonders reich an Tannenhehern waren die Jahrgänge $1827,1836,1844,1875,1855$ und 1857. Inbezug auf die beiden letzten Invasionen liegen mir eine Unmasse Daten vor, welche aufzuzählen viel zu weit führen würde. In beiden Fällen kamen die Vögel im September an, zuerst vereinzelt, dann in ungeheuren Massen, welche sich aber alsbald auflösten und ziemlich gleichmässig über die ganze Provinz zerstrenten, soweit dieselbe einen ilmen zusagenden Landschaftscharakter besass. Anfangs zeigten sie sich sehr ermattet, suchten ängstlich im Pferdedünger der Landstrassen nach Nahrung und kamen doch vielfach 1 m (IV eiss); erst nach Verlauf mehrerer Tage waren sie imstande, wieder ihrer gewohnten Beschäftigung in den Wäldern nachzugehen. Im August 1525 erlegte Gloger ein Exemplar, dessen Magen fast ganz mit grossen Hornissen Ciabro) angefüllt war und ausserdem noch einige Käter und Tannensamen enthielt. Käfer findet man fast stets in ihrem Magen. Mit Vorliebe gehen die Tanuenheher an Haselnüsse, Ebereschen und Rhammus-Beeren.

\section{Gat tung: Garrulus Briss. 1760 . - Holzhe her.}

Der Oberschuabel ist vorn in einem kleinen Haken nach abwärts gekrümmt. Die 4. und j. Schwinge am längsten. Das Gefieder ist weitstrahlig and auf dem scheitel haubenartig verlängert.

105. Garrulus glandarius (L.) 1750. - Eich el heher.

sy no 1 y ma: Pica glandaria $\mid W a g l$; Lanius glandarius Nils.; Glandarius pictus Kon ; Corvus glandarius L., seop., Gm., Bchst., Buti., Levaill., Naum., Glog., Giitke; Garrulus glandarius Vieill., Degl., Schleg., Gieb., A. Bi., v. Hom., New., Fridr., Hart., Jäckel; Glaniarius germanieus, G. leucocephalus, G. robustus, G. septentrionalis, G. taeniurus Chr. Brehm.

Trivialluam en: Nussheher, -hecker, -hacker, -här, Holzschreier, Herrenvogel, Hehrsch, Buchner, Hätzler, Markolfus, 'Tatu, Buchelt, Bucholt, Eichelgabsch. Polnisch: Soika. Wendisch: Sehrikawa. 
M a a s e von 34 schiesischen Exemplaren in $\mathrm{cm}$ :

$\begin{array}{lcccc} & \text { maximum } & \text { minimum } & \text { Durchschnitt } & \text { Friderich } \\ \text { Länge: } & 37,5 & 33,0 & 35,2 & 32,2 \\ \text { Flugbreite: } & 57,0 & 54,2 & 55,6 & 53,5 \\ \text { Schwanz: } & 17,2 & 16,5 & 17,0 & 16,5 \\ \text { Schnabel: } & 3,1 & 2,6 & 2,8 & 2,4 \\ \text { Tarsus: } & 4,9 & 4,7 & 4,8 & 4,8\end{array}$

Wie man sicht, schwanken die Grössenverhältnisse bei den Ëichelhehern sehr und sind meine schlesischen Stücke im allgemeinen beträchtlich grösser als die west- und mittelitentschen! yon F riderich. Hand in Hand gehen auch noch andere Verschiedenheiten, welche die Tremung einer westlichen und östlichen subspecies rätlich erscheinen lassen. Kennzeichen für die letztere sind: Bedeutendere Grösse und viel Schwarz auf dem Scheitel auf grau-rötlichem Untergrunde. Für lie westliche Form dagegenn: Kleine Maasse, wenig Schwarz am scheitel auf' grau-weisslichem bis fast weissem Untergruude. Ausserdem ist bei ihr der Oberschnabel weit mehr über den Unterschnabel hinweg gebogen als bei der östlichen Subspecies. Ferner kommt noch die Nuancirung des Gesamtcolorits namentlich anf dem Rücken, die Dicke und Höhe des Schnabels sowie die Ausdehnung und Lebhaftigkeit der blanen Flügelspiegel in betracht. Alles dies sowie die Frage nach dem Einfluss der örtlichen Ungebung will ich hier unerörtert lassen, da Kleinschmidt demnächst die ornithologische Welt mit einer sehr eingehenden und trefflich illustrirten Monographie des Eichelhehers erfreuen wird. Ueberginge sind in allen nur denkbaren Schattirungen zahlreich vorhanden: wir haben es auch hier augenscheinlich mit einer erst im Eutstehen begriffenen Subspecies $\mathrm{zu}$ thun. In Schlesien, Posen und Ostpreussen überwiegt ganz entschiedon die dunkelköpfige Form, in Hessen und den liheingegenden die hellköpfige, und in Thüringen seheinen sich beide zu mischen. Die östliche Varietät wandert aber und zwar wahrscheinlich über die Brutplätze der westlichen hinweg noch weiter südwestlich. Daher werden auch in Westdeutschland auf dem Zuge vielfach dunkelköpfige Heher erlegt, besonder's im November und Februar. Sehon Gloger, der doeh bekanutlich sehr wenig von Lokalformen hich, hebt hervor, dass die schlesisehen Eichelheher sehr viel Schwarz auf Oberkopf und Scheitel zeigen. Brehms leucocephalus entspricht viclleich meiner westlichen Form. Moln berichtet: „Bei Breslau erschien Ende Oktober eine Herde ron 25 Stück. Das Blau an den Flügeh war ausgerlehnter und intensiver als sonst, der Hinterkopf mit dichten, zusammentlicssemen schwarzen Flecken besäet," Tom Eichelheher ist mir nur eine sclulesische Farbenvarietät (im Besitze des Breslaner Musemus) bekannt geworden. Die Grundfarbe dieses Exemplares ist iiber- 
all weiss, die Schwingen am Ende braun. Der blaue Spiegel ist schwach angedeutet, die Kopfzeichnung dagegen deutlich ausgeführt.

Der Eichelheher bewohnt alle gemischten und Fichtenwälder Schlesiens als ein häufiger Brutvogel, seltener die sandigen Kieferheiden. In den grossen Nadelwaldungen Oberschlesiens, der Vorberge und der Lausitz (namentlich auch in der Görlitzer Heide) ist er ausserordentlich gemein. Dabei ist sein Bestand vielfach noch im Heben begritten. In den Vorbergen ist er weit hänfiger als im cigentlichen Hochgebirge, aus dem er sich auch nach Beendigung des Brutgeschäftes sehr bald wieder thalwärts zu zichen ptlegt. Die Höhenlinie von $1150 \mathrm{~m}$ dürfte im allgemeinen scine Terbreitungsgrenze in vertikaler Richtung angeben (Seiffer t). Im Herbste stellen sich daun auch noch nordische Heher bei uns cin, die in kleinen Trupps umherschweifen und auch in die Gärten und Anlagen kommen. Oefters werden sie dam im Dohmenstiege gefangen, zumal wemm mit Eicheh geküdert wird. Kutter crwïhnt, dass bei Neustadt anf diese Weise in 4 Tagen 7 Stiuck crbeutet wurden. Den Bruten der kleinen Singrögel wird der Eichelheher schr schädlich, wovon ich mich mehrfach selbst zu überzengen Gelegenheit hatte. Knauthe beobachtete, wie sich dieser sehmucke Strauchdieb Krebse und Fische vortrefflich munlen liess. Kollibay fand eimmal ein Nest $20 \mathrm{~m}$ hoch auf einer schlanken Fichte; gewöhnlich baut der Vogel aber viel niedriger. Das Gelege besteht meist aus 7 Eiern. Volle Gelege sammelten Praetorius am 22. April und 29. Juni, Seiffert an 3., Kollibay am 12. und Baer am 15. Nai. seiffert traf ferner am 18. Mai nackte Junge an. Wohl 2 Bruten.

$\mathrm{M}$ a a s e von 14 schlesischen Eiern in $\mathrm{mm}$ :

$\begin{array}{lccc} & \text { maximum } & \text { minimum } & \text { Durchschnitt } \\ \text { Länge: } & 31 & 30 & 30,4 \\ \text { Breite: } & 23,5 & 23 & 23,25\end{array}$

106. Garrulus infaustus (L.) 1758. - Unglücksheher.

S'ynonyma: Lanius infaustus L., Gm., Bchst.; Pica infausta Wagl.; Corvus infaustus L., Gm., Brünn., Sparrm., Buff., Glog., Naum., Giatke; Corrus sibiricus et russicus Gm.; Corvus mimus Pall.; Dysornithia infaustus Swains.; Perisoreus infaustus Bp., Degl., A. Br., Mlewes; Garrulus infaustus Vieill., Schleg., Gieb., Boie, Kays, u. Blas., v. Hom., Fridr.

Kennzeichen der Art: Auf dem Flügel ein rostroter Spiegel.

Dieser hochnordische Heher ist für Schlesien ein äusserst seltener Irrgast. Doch hat Gloger einen sicheren Fall seines 
Vorkommens constatirt. Im Spätherbst 1824 nämlich wurde in Oberschlesien ein Exemplar im Dolinenstieg gefangen.

Gattung: Pica Briss. 1760. - Elster.

Der Schwanz ist länger als der Körper und keilförmig abgestuft. In den kurzen, runden Flügeln ist die 1. Schwinge klein und säbelförmig, die 5 . am längsten.

\section{Pica rustica (Scop.) 1769. - Elster.}

Synonyma: Garrulus picus Tem.; Corvus piea L., Gm., Bchst., Tem., Wils., Aud., Naum., Glog., Fridr., Güttke; Corvus rusticus Scop.; Corvus hudsonicus Sab., Firsch, Wied; Cleptes pica Cab.; Cleptes hudsonica Gamb.; Pica caudata Gessu., Aldr., Johnst., Will, u. Ray, Alb., L., Degl., Gicb., v. Hom., A. Birehm, Died., Radde, Jäckel; Piea melanolenca Vicill.; Pica eurupaea Boie; Pica albiventris Vieill.; Pica varia Schleg.; Pica germanica, P. hiemalis, P. pinetorum, P. lenconotus, P. septentrionalis Chr. Brehm; Pica bottanchsis Deless.; Pica butanensis, P. bactriana, P. japonica Bp.; Pica megaloptera Blyth; Pica tibetana Hodgs.; Pica vagabundus Pears.; Pica media Blyth; Piea sericea Goulda; Pica hudsonica Bp., Baird; Piea vulgaris Hemp.; Piea piea Sharpe, Hart.; Pica rustica Mewes.

Trivi a lnamen: Scholaster, Schalaster, Aglaster, Algaster, Algorte, Atzle, Egerste, Alaster, Sepalaster, Hetze. Polnisch: Stroká. Wendisch: Sroka.

Kenuzeichen der Art: Siehe die Gattungsmerkmale, da nur diese eine Art in Deutschland.

Die Elster gehört zu denjenigeu Vügeln, mit denen ich mich in systematischer Hinsieht mit am meisten beschäftigt habe, olme doch bis jetzt zu endgültigen und feststehenden Resultaten gelangi zu sein, zumal auch hier mein Studium manche unfreiwillige Unterbrechung erlitt. Wir haben in Dentschland entschieden zwei sehr differirende Subspecies, welche auch in Nestbau und inbezug von Form und Farbe der Eier versehieten sind, cine kurz- und eine langschwänzige. Ob wir es hier aber mit geographisehen líaçen oder mit an die lokalen Ungebungen gebundenen Varietäten zu thun haben, vermochte ich noch nicht zul constatiren und muss mir deshalb nähere Mitteilungen über alle diese Yerhältnisse für später vorbehalten. Nur das eine glanbe ich jetzt :chon mit Bestimmtheit behaupten zu können, diass die Elstern nach Norden und Osten zu ständig mehr. Weiss im Gefieder und namentlich an den Flügeln zeigen und sich so schon der asiatischen P. lenernteren nähern. Auch die Grösse nimmt in correspondirculem Matase zu. Schon die überaus grosse Verbreitung des Vogels lïsist von vorn herein auf Neigung zur Subspeciesbildung schliessen, und mïehte ich deshalb die Beobachter ganz besonder's auf unsere Sehalaster 
aufmerksam machen. Ueber die bekannten Abweichungen der Eier hat sich unter den schlesischen Forschern besonders Mo hr geäussert: „Die Eier sind verschieden gefärbt und geformt; während die einen die bekannte ziemlich rundliche Form haben, übertrifft der Längsdurchmesser anderer die gewöhnliche Länge beinahe um 2/3. Solche Eier nennt hier das Volk Scholaster-Sperlingseier. Sie sollen nämlich nach dem Volksglauben aus einer Verbastardirung von Sperlingsmännchen und Elsterweibchen hervorgegangen sein! Sie sind, wie gesagt, sehr lang, hellbraun gefleckt und finden sich nie mit der gewöhnlichen runden Form in einem Neste, auch nie in so hoher Anzahl, sondern böchstens 6 Eier in einem Nest."

Ma asse von 19 schlesischen Exemplaren in cm:

$\begin{array}{lccc} & \text { maximum } & \text { minimum } & \text { Durchschnitt } \\ \text { Långe: } & 44,4 & 42,8 & 43,8 \\ \text { Flugbreite: } & 58,1 & 56,0 & 57,3 \\ \text { Schwanz: } & 25,4 & 23,6 & 24,5 \\ \text { Schnabel: } & 3,8 & 3,6 & 3,7 \\ \text { Tarsus: } & 5,0 & 4,8 & 4,9\end{array}$

Ein partiell weisses Exemplar befindet sich in der Heydrich'schen Sammlung.

Die Elster findet sich am meisten in park- und auenartigen Gegenden, in Vorhölzern, Gärten und auf Wiesen, welche Gebüsch und einzelne hohe Bäume aufweisen können. Die Nähe des Menschen und seiner ländlichen Gehöfte liebt sie sehr, weil sie hier den ausgiebigsten Boden für ihre Räubereien findet. Gerade dies aber wird ihr zum Verderben. Denn sie macht sich auf den Hühnerhöfen und an den Ententeichen doch gar zu unangenehm bemerkbar und wird infolge dessen schonungslos verfolgt. Trotz ihrer walnhaft bewunderungswürdigen Schlauheit unterliegt sie in diesem Kampf ums Dasein und nimmt deshalb fast überall ständig ab, olme dass doch ihre gänzliche Ausrottung in absehbarer Zeit zu befürchten stände. Ich möchte sie den Fuchs unter den Vögeln nennen. In manchen Gegenden ist sie insofern besser daran, als Aberglaube die Landleute an der Zerstörung der Nester verhindert. Auch die Eichkätzchen thun ihr sehr erheblichen Abbruch und vernichten manche Brut. Bei Breslau fand ich die Elster aus allen diesen Gründen nur sehr spärlich vertreten. Am Zobten, in Oberschlesien und in der Lausitz ist sie noch häufiger. Nach Hosius siedelt sie sich neuerdings auch mehr am Nordfusse des Gebirges an und ist bei Hermsdorf erst seit 1885 Brutvogel. Die Elster ist der bei uns am zeitigsten heckende Vogel. Er beginnt schon im Februar mit dem Nestbau, und den ganzen März hindurch findet man Eier. Die rundlichen Eier sind gewöhnlich in 
grösserer Anzahl vorhand'n und liegen in niedriger gebauten offenen Nestern. Letztere stelien nach Mohr meist auf jungen Erlen, nach Kollibay gern auf Lürchen. Knauthe entdeckte ein Nest olme Haube ganz niedrig in einer Weissdornhecke. Das Gelege besteht aus 5-6 länglichen oder $8-10$, ja selbst 11 rundlichen Eiern. Volle Gelege fanden Praetorius am s. und Kutter am 13. April. Das zänkische Naturell der Elster tritt auch ihren Verwandten gegenüber zu tage. Nit comix liefert sie sich oft förmliche Schlachten. Richter sah, wie sich zu diesem Zweeke einmal 14 Elstern vereinigten. Auf den im Winter von Vogelfreunden hergerichteten Futierplatzen fällt die Elster oft räuberisch über Spatzen, Buchfinken und Goldammern her und zertrümmert denselben mit ihrem krä̈tigen Schnabel die Hiruschale (K nauthe). Ferner beobachtete sie $\mathrm{K} n \mathrm{n} u$ the beim Fressen von Krebsen und Fischen und sah ein Excmplar bei der Aufnahme eines angeschossenen Sperlings deutlich nrïtteln“. In der Gefangenschaft verträgt sie sich äbrigens mit ammähernd gleich starken und grossen Yögeln recht gut. Im allgemeinen ist die Elster ein ausgesprochener Standvogel, wenigstens bei uns. 1890 aber kamen nach $\mathrm{Kna}$ uthe die Elstem am Zobten mit den Kriahen auch auf dem Zuge durch, machten eine Weile die Aecker unsicher und verschwanden dam, gewöhnlich in Begleitmng jener, in östlicher oder westlichır Richtung, hüehst selten in nördlicher, der gewöhnlichen der Krähenzüge.

Ma asse von 2 fi schlesirchen Eiem in mm: (man achte auch hier auf die bedeutenden Grössendifferenzen.)

$\begin{array}{lccc} & \text { maximum } & \text { minimum } & \text { Durchschnitt } \\ \text { Länge: } & 38 & 32 & 34,5 \\ \text { Breite: } & 26 & 23 & 24,25\end{array}$

Gattung: Colaens Kaup. 1829. - Dohle.

Verbälnismässig kleine Rabenvögel mit starkem, kurzem und nur wenig gebogenem schmabel. Die :S. Schwinge ist am längsten; die Läufe vorn getäfelt.

108. Colaeus monedula (L.) 1758 - I o hle e.

S y non y ma: Corvus monectula L., Seop., Gm., Behst., Naum., Tem., Gould, Glog., Gieb., Kayss. u. Bliss., A. Br., Fridr., Radde, Jäckel, Gätke; Corvus cincreus Muill, Corrus spermolegus Vicill.; Corvus collaris Drumm.; Nonedula nigra Briss.; Monedula collaris Gray; Nonedula turrium, M. arborea, NI. septentrionalis Chr. Brr.; Lyeos monedula Boic, v. Ilum., Newers; Colaetes monedula Kaup, Hartert.

Trivialnamen: Thale, Thole, Tule, Aellse, Turmmabe. Polnisch: Kawka. Wendisch: Gauka. 
Kennzeichen der Art: Siehe die Gattungsmerkmale, da nur diesee eine Art in Deutschland.

Auch bei den Dohlen variirt hauptsächlich die Schwanzlänge, was aber bei meinen schlesischen Exemplaren weniger hervortritt. Nordische Vögel zeigen auch in Form und Stärke des Schnabels einige Abweichungen; solche Exemplare kommen aber nicht leicht bis nach Schlesien. Im Colorit stimmen die Schlesier ganz mit westdeutschen Stücken überein.

$\mathrm{M}$ a asse von 10 schlesischen Exemplaren in cm:

$\begin{array}{lccc} & \text { maximum } & \text { minimum } & \text { Durchschnitt } \\ \text { Länge: } & 34,8 & 31,2 & 32,9 \\ \text { Flugbreite: } & 65,1 & 67,1 & 67,6 \\ \text { Schwanz: } & 15,0 & 13,7 & 14,5 \\ \text { Schnabel: } & 3,2 & 3,1 & 3,1 \\ \text { Tarsus: } & 4,2 & 3,9 & 4,1\end{array}$

Im Breslauer Museum notirte ich 2) reine Albinos; auch im dortigen zoologischen Garten sail ich ein völlig weisses Exemplar.

Die Dohle ist fast iiberall in Schlesien recht häufig. Auf den Türmen beinahe aller schlesischen Städte findet sie sich regelmässig, falls man ihr nicht dureh eigens zu diesem Zwecke angebrachte Gitter den Zutritt verwehrt. Auf Sehlössern, Ruinen und einzelnen hohen Gebiiuden ist sie seltener und in kleinen Feldhölzern mit hohlen Bäumen fand ich sie in Schlesien weit weniger als in Westdeutschland. (Brehms arborea.) Gern halten sich die in Bäumen hausenden Dohlen in der Nähe der SaatkrähenColonien. Auf dem Striche kommen auch weiter nordwärts wohnende Dohlen in grosser Zahl zu uns. Obwohl die Dohle von alleu Rabenvögeln entschicden der harmloseste ist, werden doch auch von ihr allerlei schandthaten berichtet. Willimek z. B. beobachtete, wie sie eine brütende Fasanenheme angriff' und derselben einige Schwanzfedern auszog, um sie zum Verlassen ihrer leckeren Eier zu bewegen. Ferner erzihlt Kollibay: „Den kleinen Sängern wird sie schiddlich. Auf einer Linde in Patschkau befand sich ein Finkennest. Als die Jungen aungeschlüpft waren, zeigte sich wiederholt eine Dohle an Neste, wurde jedoch stets verjagt. Eines Tages indessen wurde beobachtet, dass sie wiederholt mit dem Schnabel in das Nest schllug. Auch diesmal wurde sie vertrieben. Bald darauf erschien sie wieder, nahm einen jungen Finken aus dem Nest, trug ihn auf ein benachbartes Dach, tötete ihn daselbst mit Schnabelhieben und flog sodann mit ihm weg. Da es bereits Mitte Mai war, so wird er sowie seine Geschwister, die sie sich auch noch holte, ihren Jungen zur Nahrung gedient haben. Auch das Nest einer Sylvia cinerea, welches gleichfalls auf eincr Linde stand, wurde von einer Dohle durch Hineinhacken 
zerstört, als es noch Eier enthielt." Der Nestbau beginnt Anfang April damit, dass die Dohlen zunächst Lehm zu Neste tragen; dann brechen sie Reiser von den Büumen und zwar nach Kollib a y auch vielfach von Obstbäumen. Kutter fand am 25. A pril volle Gelege, am 16. Mai nackte und Ende dieses Monats flügge Junge.

Masse von 25 schlesischen Eiern in $\mathrm{mm}$ :

$\begin{array}{cccc} & \text { maximum } & \text { minimum } & \text { Durchschnitt } \\ \text { Länge: } & 39,5 & 37,5 & 38,75 \\ \text { Breite: } & 26 & 24,5 & 25,25\end{array}$

Gattung: Corvus L. 1758. - Feldrabè.

Typische Rabenvögel mit sehwarzen sehnäbehn und Füssen und mässig langen Schwanz. Der Schnabel ist lïnger und stärker gekrümmt als bei den Dohlen.

109. Corvus frugilegus L. 1758 . - Sa a tk iähe.

Synonyma: Corvus agricola Friseh; Crous frugilegus L., Gm., Behst., Tem., Naum., Guuld, Sehleg., Glog., Gieb., Kays. u. Blas., A. Brehm, v. Hom., Rathle, Hart., Gätke, Jïcliel; Corrus pastinator Gould, Blyth; Corvus agrorum, C. mranorum, C. advena Chr. Brehm; Cornix frugilega Briss., Butì; Frugilegus frugilegus et pastinator Gray; Colaeus frugil(egus Kaup); Trypanacorax frugilegus Kaup, Loche, Mewes.

Trivialua men: Sehwarze Krähe, Kroë, Rooke, Rooche, Rouch, Ruck, Röck, Rorka, Ruch, Ruche, Rauch, Räche, Karachel, Kurak, Kranweitel, Grind- und Nacktschmabel, Haberkrah. Polnisch: Gawron.

Kennzeichen der Art: Länge unter $50 \mathrm{~cm}$. Die 1. Schwinge eben so lang als die 9.

Maasse von 12 schlesischen Exemplaren in cm:

$\begin{array}{lccc} & \text { maximum } & \text { minimum } & \text { Durchschnitt } \\ \text { Länge: } & 14,1 & 42,5 & 43,2 \\ \text { Flugbreite: } & 89,2 & 87,5 & 88,4 \\ \text { Schwanz: } & 27,8 & 27,3 & 27,6 \\ \text { Schnabel: } & 5,6 & 5,4 & 5,5 \\ \text { Tarsus: } & 5,2 & 4,9 & 5,0\end{array}$

Zwei abweichend gefirbte Exmplare, beide iuv, sah ich im Breslauer Mluseum, Bei a. ist der schnabel gelb, Kéhle, Augenstreif, 2 Sehwung-, dic wossen Flügeldeck- und die Schwanzfedern weiss. Bei b. ist der sumabel selwark, ein Fleck an der unteren Schnabelwuzel, die grussen Flïgehteck- und Sehwanzfedern weiss.

II a s sehie sagt ron der Salatkiähe: ,Nicht so häufig brütend wie in anderen deutschen Provinzen." Lir führt fulgende Colonien 
auf: Breslau, Wildschütz und Ottmachau (K e rn), Görlitz und Görlitzer Heide (Tobias), Brieg und Hünern (Hirsch), Casimir, Lenschütz, Urbankowitz und Zülz (Mitschke), Gutmannsdorf und Pitschenberg (A uras), Niederbrockendorf (M üller) und Tscheschkowitz (Zimmermann). Dazu kommen noch Ansiedlungen bei Niesky (Ba e r), Neisse, Patschkau und Schwammelwitz (Kollibay), Sprottau (Richter), Leuthen (Fritsch) und Lauban (Grosser). Am Zobten ist die Saatkrähe nach $\mathrm{K} n$ a uthe seit einigen Jahren als Brutvogel ausgerottet. Auch in der Bartschniederung muss sich cine Colonie befinden, die ich aber noch nicht auffinden konnte. Anderwärts kommt die Saatkrähe nur auf dem Zuge oder im Winter vor, dann aber oft sehr läufig. Die Vögel treiben sich dann mitten in den grossen Städten herum, namentlich an den Bahnhöfen. Uebrigens gehört auch die Saatkrähe zu denjenigen Arten, welche sich mehr und mehr zu Standvögeln ausbilden. Die bei uns nistenden Saatkrähen entfernen sich im Winter kaum noch aus der Provinz; die in grossen Zügen Durchpassirenden gehören nördlicheren oder östlicheren Gegenden an. März und Oktober sind die Hauptzugmonate. Das eigentliche Gebirge meidet die Saatkrïhe und geht als Brutvogel nur bis in die Torberge. Nach Gloger sieht main sie auf den obersten Bergwiesen ( 4300 Fuss und dariber) bisweilen noch herumschwärmen, doch nur in kleinen Gesellschaften von 12-20 Stück und als weit abgekommene Streifzüge. Im Gegensatz dazu versichert Kollibay, während eines viermonatlichen Aufenthaltes in Hirschberg trotz zahlreicher Excursionen niemals eine Saatkrähe gesehen zu haben, weder in der Thal- noch in der Waldregion noch gar auf dem Kamme. Mit welcher Zühigkeit diese Vögel an ihren eimmal crwählten und seit vielen Geschlechtern bewohnten Brutplätzen festhalten, und wie sehwer sie aus denselben zu vertreiben sind, ist allbekanut. Doch weiss ich gerade aus Schlesien davon mehrere Beispiele. So nisteten nach Fritsch in einem kleinen Kiefernwalde bei Leuthen jahrelang tausende von Saatkrähen, so dass sich auf mancher Kiefer bis 12 Nester vorfanden. 1883 haben sich dam die Vögel infolge des alljälırlich abgehaltenen Krähenschiessens sämtlich in einen $30 \mathrm{~km}$ entfernten Wald jenseits der Oder verzoger. Isolirt liegende Nadelwäldehen bewohnen die Saatkrihien iiberhaupt am allerliebsten. Andere und angenehmere Tögel freilich verdrüngen sie dann aus solchen fast gänzlich, wohl weniger durch Nesterplündereien als vielmehr durch ihr lärmendes Grbahren. Bei Saabor wurde in November $1 \$ t 5$ eiu Exemplar geschossen, ndessen verhärtete Zunge durch den Unter'schnabel guckte" (L. Tobias). Schuabeldeformitäten sind bei diesem Togel nicht allzu selten. In der Brutcolonie von Ransern bei Brcslau hatten die Krähen schon am 31. März 1889 vielfach gelegt. 
Masse von 30 schlesischen Eiern in $\mathrm{mm}$ :

$\begin{array}{lccc} & \text { maximum } & \text { minimum } & \text { Durchschnitt } \\ \text { Länge: } & 39 & 37,5 & 38,25 \\ \text { Breite: } & 28 & 26,5 & 27\end{array}$

\section{Corvus cornix L. 1758. - Nebelkrïh e.}

Synonyma: Cornix cinerea Briss.; Corone cornix Kaup ; Corvus cinereus Leach; Corvus subcornix, C. cincreus, C. tenuirostris Chr. Brehm; Corvus cornix L., Scop., Gm., Bchst., Tem., Naum., Gould, Schleg., Glog., Gieb., Kays, u. Blas., Midd., Sund., Degl., v. Heugl., Sevz, Gray, A. Brehm, v. Hom., Mewes, Radde, Hart., Gätke, Jäckel.

Trivialnamen: Kroë, Schildkrähe, Nebelkraye, Schild-, Winter-, Sattel- und Grakkrahe. Polnisch: Wrona. Wendisch: Gargona und Schüra Rona.

Kennzeichen der Art: Grösse unter $50 \mathrm{~cm}$. Die 1. Schwinge ist kürzer als die 9. Der Rumpf ist grösstenteils aschgrau gefärbt.

Masse von 8 schlesischen Exemplaren in $\mathrm{cm}$ :

$\begin{array}{lccc} & \text { maximum } & \text { minimum } & \text { Durchschnitt } \\ \text { Länge: } & 44,9 & 43,5 & 44,2 \\ \text { Flugbreite: } & 100,5 & 95,3 & 97,9 \\ \text { Schwanz: } & 18,5 & 17,8 & 18,1 \\ \text { Schnabel: } & 5,0 & 4,7 & 4,8 \\ \text { Tarsus: } & 6,2 & 5,9 & 6,0\end{array}$

Heydrich besitzt ein Exemplar mit ausgesprochenem Melanismus. Das Breslauer Museum weist folgende Farbenvarietäten auf:

a. Grauweiss, Kopf licht graubraun, Schnabel gelb, Füsse schwarz.

b. Die 7. Schwungfeder weiss.

c. Kopf, Kehle und Brust kastanienbraun, Flügeldeckfedern ebenso gerändert, sonst weiss. Schnabel und Füsse normal.

d. Kopf, Kehle und Brust lichtgrau, sonst schmutzig weiss.

e. Flügeldeckfedern rein weiss, im übrigen normal.

f. Kopf und Kelile braungrau, sonst schmutzig. Schnabel und Füsse normal.

g. Kopf und Kehle silbergran, sonst rein weiss. Schuabel und Füsse normal.

h. Wie c.

Cormix und corone stellen nach meiner Auttassung ebenfalls Formen dar, welche den Wert der Subspecies bereits überschritten haben und sich dem guter Arten nähern, als welche man sic am 
besten auch jetzt schon auffasst, obschon sie in noch sehr vielen Punkten völlig mit einander übereinstimmen. Im grossen und ganzen bildet für Deutschland die Elbe die Grenze zwischen den Brutbezirken der beiden For'men, d. h. die heller abgetönte Art bewohnt die deutsche Ebene, die ursprünglichere und dunkel ge. bliebene das deutsche Mittelgebirge. Schlesien weist fast ausschliesslich coinix als Brutrogel aut und nur im westlichsten Zipfel der Lausitz findet sich auch corone. Hier verläuft also die Grenze, welche ich auch auf der beigegebenen Karte eingezeichnet habe. Verbastardirungen jeden Grades sind in solchen Gegenden an der Tagesordnung. Bei Hoyerswerda findet sich nach Tobias uur cormix, aber das dürfte für Schlesien mit die üusserste Grenze ihres a uschliesslichen Torkommens sein. Bei Lohsa fand Tobias vielfach vermischte Pärchen und Bastarde. In ganz Mittel- und Niederschlesien ist die Nebelkrähe ausserordentlich gemein, und es ist mir vollkommen umverständlich, wie es im 1. Jahresbericht d. Aussch. f. Beub. Stat. d. Tögel Deutschlands heissen kann: "Bei Breslan im Sommer selten." Etwas anders liegen die Verhältnisse in Obersehlesien. Hier ist die Neljelkrähe infolge der unausgesetzten Nachstellungen in der Nähe der Fasanerien und auch mancher Teiche als Brutvogel vollstïndig ausgerottet, gewiss nicht zum schaden des W Wasserwildes, welches viel unter ihren Nesterplündereien zu leiden hat. Ich halte an vogelreichen 'Teichen die Krähe neben drm Ruhrweih für den schädlichsten Vogel, dessen rücksichtiloseste Verfolgung deshalb nur zu billigen ist. Auch Kollibay sagt: "Bei Neisse im Verbältnis zu fingilegus nur in versehwindend kleiner 'Lahl brïtend." In der Thal- und Waldregion des hiesengebirges kommt die Nebelkrähe nath demselben Forseher überall vor; nach Gloger bält sie sich dort hauptsächlich in den Vorbergen in einer Höhe von 2-3000 Fuss. A. v. Homeyer fand sie bei spindelmühl brïtend, Capek beobachtete eine Familie auf der Weissen Wiese und L. Tobias sah etliche auf dem Riesenkamm; Kramer notirte sie noch bei $1500 \mathrm{~m}$ Meereshöhe. In den Gegenden, wo sie nur spärlich nistet stellt sie sich damm wenigstens auf dem Striche zahlreich ein. Bei Schnee und Kailte kommt sie sogar bis mitten in die grossen Staidte. Fast alle meine Berichterstatter klagen über den durch die Krähen angerichteten schaden. In den Fasanerien sind sie die allerschlimmsten Gäste und gehen bei ihren Raubzügen mit einer Raffinirtheit zu Wrerke, die ihren geistigen Fähigkeiten alle Ehre macht. Kna the beobachtete, wie zwei Nebelkräben einen Grünspecht heftig und erfolgreich attaquirten. Ein anderer, der sich in eine Baumhöhle gerettet hatte, wurde von den Krïhen über eine Viertelstunde lang belagert. Am 25. November 1590 zertrümmerten 3 comix und 1 corone einem alten Rebhaln die Hirnschale. „Kurze Zeit später beobachtete ich 
(Knathe), wie ein Trupp Nebelkrähen über eine halb verhungerte Kette von \& Rebhühnern herfiel; die Tiere wehrten sich absolut nicht, weil sie dazu viel zu matt waren und wurden eine leckere Beute der Räuber. Im Sommer habe ich dagegen immer gesehen, dass die Rebhühner die Nebelkrähen heftig befehdeten und bald in die Flucht schlugen weun sie ihnen zu nahe kamen." Selbst alte Fasanenhähne lassen sich von dem Gesindel abwürgen. (Knauthe in litt.) Bei ihren Nesträubereien verfahren die Kräben förmlich nach gemeinschaftlicher Verabredung. Während die eine die besorgten Eltern im Schach hält, überfällt die andere hinterrücks das seiner Verteidiger entblösste Nest und plündert es aus. Kir a the beobachtete dies $z$. B. am Neste von Turdus viscivorus; meinen Erfahrungen nach weiss die Misteldrossel sich übrigens sehr mamhaft gegen solche Wegelagerer zu wehren. In milden Wintern kommen die Krïhen wenig auf die Gehöfte, sondern treiben sich mehr auf den Feldern herum, wo ihnen sehr viele ermattete Kleinvögel, angeschossene Hasen und Rebhühner zur Beute fallen. Emm r ich berichtet, dass sich die Krähen im Winter dutzendweise an seichten, fischreiche!n Gewässern aufhalten und hier ihren Unterhalt finden. Nach Kna u the fischen sie auch im Sommer an den Buhnen und gehen mit Vorliebe den Muschehn nach. Sie heben dieselben nieht nur auf, um sie dan! aus der Luft herabfallen zu lassen, sondern hacken auch sitzend Löcher in dieselben. Nach Kollibay gehen die Krähen gern an wilden Wein; ferner plündern sie die Getreidefeimen und reissen die Maispflanzen of nahezu säntlich heraus, um sie dann mit Strunk und Stiel zu verzehren ( $K$ na the). Durch ausgezeichnete Versuche bevies $\mathrm{K} n$ a u the, dass die Krïhen beim Autsuchen vou Aas lediglich durch das Gesicht geleitet werden, während der Geruch nur schlecht entwickelt ist. Stücke Fleisch, die mit einer dünnen Erdschicht überdeckt waren, blieben stets unbeachtet, während darauf liegende Nïuse gierig angenommen wurden. Ihre Nester legen die Nebelkrähen, oft auch gesellschaftsweise, in kleinen Feld- und Vorhölzeru an, auch in Parks und Alleen, seltener im Innern grosser Nadelwaldungen oder in weitläufigen Obstgärten. R. 'Tobias berichtet, dass sogar einmal ein Pärchen auf einem Kirchturm in Görlitz brütete. Ilitte April pllegt der Nestau vollendet zu sein. Tolle Gelege fanden Praetorius am 17., Baer am 22. und Kutter an 29. April, ich selbst zuerst am 20. April. Das Gelege besteht in der Regel aus 5 oft ziemlich variirenden Eiern.

Ma as e von 40 schlesischen Eiern in $\mathrm{mm}$ :

$\begin{array}{lccc} & \text { maximum } & \text { minimum } & \text { Durchschnitt } \\ \text { Länge: } & 44 & 41 & 42,2 \\ \text { Breite: } & 30 & 28 & 29,1\end{array}$


111. Corvus corone L. 1758. - Rabenkrähe.

Syuonyma: Corone sinensis Horsf; Corone corone Gray, Sharpe; Corvus subcorone, C. assimilis, C. hiemalis Chr. Brehm; Corvus corone L., Gm., Behst., Scop., Tem., Glog., Gieb., Kays. u. Blas., A. Brehm, v. Hom., Mewes, Fridr., Radde, Hart., Gätke, Jäckel.

Trivialnamen: Kroë. Wendisch: T'schorna Rona.

Kennzeichen der Art: Grösse unter $50 \mathrm{~cm}$. Die 1 . Schwinge kürzer als die 9. Tutalfärbung schwarz.

Durchschnitsmaasse von 5 schlesischen Exemplaren in $\mathrm{cm}$ : Totalliinge $=44,9$; Flügelspamung $=98,7$; Schwanzlïnge $=17,9 ;$ Schnabellänge $=5,0 ;$ Tarsus $=5,8$.

Die Rabenkrähe brütet nur im südwestlichsten Teile des Regierungsbezirkes Liegnitz. Görlitz liegt nach Tobias dicht an der Verbreitungsgrenze und kommen beide Arten vor, corritx aber überwiegend. Erst in der Gegend von Pulsnitz wird corone gewöhnlicher. Bei Breslau habe ich die Rabenkrähe im Sommer nie gesehen, während im 1. Jahresber, d. Aussch. f. Beob. Stat. d. Vügel Deutschl. behauptet wird, lass corone auch zur Brutzeit bei Breslau vorkomme. Ferner giebt Kna uthe an, dass die Rabenkrähe auf den beiderseitigen Ausläufern des Geiersberges sogar brüte, oft mit cornix zusammen, aber stets seltener als diese. Das wäre ein sehr bemerkenswerter und weit vorgeschobener Posten! Sonst kommt corrune in Sehlesien nur auf dem Striche vor und ist damn allerdings oft sehr hiaufig, insbesondere in harten Wintern in der Nähe der Städte. Auch im Riesengebirge wurde diese Krähe nach v. Tschusi schon erlegt. Das Breslauer Museum besitzt ein dicht bei der Stadt geschossenes Belegexemplar.

\section{Corvus corax L. 1758, - Kolkrabe.}

Synonyma: Corvus corvus L.; Corvus maximus Scop., Corvus elericus Sparrm., Sund, Corvus faroënsis Brunn.; Corvus carnivorus Bartram, Baird; Corvus leucophaeus Vieill.; Corvus calcalotl, C. leucomelas, C. sinuatus Wagl.; Corvus lugubris Ag.; Corvus montanus Tem.; Corvus thibetaus Hodgs.; Corvus nobilis Gould, Bp.; Corvus vociferus Cabot; Corvus corax littoralis Holb.; Corvus silvestris, C. littoralis, C. peregrinus, C. montanus Chr. Brehm; Corvus corax L., Gm., Behist., Naum., Schleg., Chr. Br., Glog., Gieb., Kays u. Blas., A. Br., v. Hom., Mewes., Fridr., Radde, Hart., Gätke, Jäckel.

Trivialnamen: Rabe, Kolrabe, Kolrappe, Kruk.

Kennzeichen der Art: Grösse über $50 \mathrm{~cm}$.

Durchschnittsmanse von 3 schlesischen Exemplaren in $\mathrm{cm}$ : Totalliange $=57,8$; Flügelspannung $=121,5$; Schnabel- 
länge (über den Bogen gemessen) $=7,2$; Schwanzlïnge $=12,6$; Tarsus $=7,1$. Sehwenckfeld erwähnt einen Albino.

Der stattliche Kolkrabe gehört mit zu denjenigen Vögchn, welchen das rastlose Vorwärtsschreiten der menschlichen Cultur am übelsten mitgespielt hat; doch unterliegt dor Vogel bei sciner sprichwörtlich gewordenen Schlauheit weniger den unausgeselzten Nachstellungen als vielmehr der Abholzung weit ausgedehnter uriger Bestïnde von riesigen, viele Jahrhunderte alten Kiefern und Fichten, wie sic früher in Schlesien nicht selten waren. Noch zu Anfang unseres Jahrhunderts müssen sehr viel Kolkraben in der Provinz gehaust haben. Endler schreibt: „Nicht selten, aber auch nicht so zahlreich als die beiden Krähen. Sie sollen sich seit der Zeit, als die grossen, dichten Wälder woniger geworden und ihre Federn zum Selureiben, Zeichnen und zu Klaviertangenten verwendet wurden, sehr vermindert haben. "Aher schon $R$. Tobias sagt, dass in der Lausitz nur noch selir wenige Paare horsten und zwar sowohl im Gebirge wie in den grossen Waldungen der Ebene. In der Muskauer Heide war der Kolkrabe bis 1 sito Brutvogel (Baer). Nenerdings ist corar. meines Wissens in der Lausitz nicht mehr horstend gefunden worden, doch ist es immerhin möglich, dass noch einige l'are im hmeren der Görlitzer Ifeide oder in abgelegeneu Gebirgsforsten einen Zufluchtsort gefunden haben, zumal im Winter fast stets Kolkraben aut der Bildfläche zu erscheinen pflegen. v. Ebert beobachtete einen solehen am 3. September lsus bei Jänkendurf. Im Herbst wandern manchmal kleine Gesellschaften ans dem Norden ein, die sich den ganzen W'inter über herumtreiben, aber sehon im E'ebruar wieder rerschwinden. L. Tobias fülırt den Kolkraben als vereinzelten Brutvogel für die Grünberger Gegend mit anf, und mach F'orstmeister Lipke nistet er noch jetzt bei Carrolath. Bei Breslau fand Praetorius noeh am 14. März 1572 einen mit 5 Eiern belegten Horst. Mir selbst war dieses Glüek zwar nicht beschieden, aber dafür beobachtete ich am 22. Februar 1890 ein wahrscheinlich schon gepartes Pärehen im Suchlosspark rou schleibitz und erlegte das Mïnnehen. Im Breslaucr Mnseum stehen ㄹ sehlesische Belegexemplare; ein 3. sah ich in der sammlung des Iluragos ron Ratibor in Raudten. Uttendürfer schreibt mir über den Kulk raben ans Kosel: „Brütete noch vor :3) Jahren in verschicalenen Wäldern und ist von den älteren Forstbeamlen of gesehnssen mier seiner Jungen beraubt worlen. Damu zeigten sich langu gar keine mehr. Erst vor wenigen Jahren wurden wieder 2 Lxemplite erlegt und das eine davon ausgestopft." Von meinen Mitarbeitern führen Abukir. (Carolath), Ziemer (Guhlan bei Glogant) und Helmich (Neurode bei Luiben) den Kolkraben als Brutrugel auf. Der Vogel brütet bekanntlich sehr zeitig. R. T'obia fimm schon am 3. April Junge. 


\section{Familie: Laniidae, W ï ger.}

Der starke Schnabel ist seitlich sehr zusammengedrückt, vorn mit hakiger spitze und scharfem Zahn, am Mundwinkel ron starren Borsten umstellt. Die rundlichen Nasenlöeher liegen nahe der sichualowwurzel und sind fast ganz vou Borstenfederchen verdeckt. Die Zehen sind völlig frei. Der lange Sehwanz ist am Eude algeruntet. In den kurzen Flügeln ist die 1. Schwinge sehr klein und die 3. und 4. am längsten.

Gat tung: Lanius L. 1758. - W ürger.

Siche die Familiencharaktere, da nur diese eine Gattung in Deutschland.

113. Lanius collurio L. 175s. - Rotrückiger Würger.

sy $n$ on yma: Emenetonus collurio Boie; Lanius spinitorquus Schwenckf,, Bchst.; Lanius dumetorum, L. cognatus, L. paradoxus Clr. Iir.; Lanius collurio L., Crm., Naum., Chr. Br., Glog., Gieb., Kirs. u. Blas, ג. Br., r. Hom., Fridr., Radde, Hartert, Gïtke, Jäckel.

Ty ivialnam en: Kleiner Neuntöter, Quarkringel, Diekkopf.

Kenuzeichender Art: An dem zusammengelegten Fligel ist linin weiwer Fleck sichtbar. Die -2. Sehwinge ist grösser als die อ. (selteu dieser gleich), aber kürzer als die 3.

M a asse von 533 schlesischen Exemplaren in em:

$\begin{array}{lccc} & \text { maximum } & \text { minimum } & \text { Durchschnitt } \\ \text { Länge: } & 18,9 & 17,5 & 18,1 \\ \text { Flugbreite: } & 29,6 & 28,2 & 29,0 \\ \text { Schivanz: } & 8,6 & 8,3 & 8,5 \\ \text { Schmabel: } & 1,4 & 1,2 & 1,3 \\ \text { Tarsus: } & 2,6 & 2,3 & 2,4\end{array}$.

Zn: abnorm gefarbte Exemplare des Breslauer Museums haben wacherelbe Fitsse und behnabel. I) as Gefieler ist rein wriss, auf dem lituken ctwas ins Itellgraue spielend; bei dem Cinen Silick habun cinge hüekenfedern rostgelbe Kanten. Zuweilen fimler matn anch bei collarin eincu kleinen weissen spiegelfleck, und hamblelt es sich hic möglicherweise um eine ständige subspecies.

Der rorürkge Würger ist in Schlesien die gemeinste Art

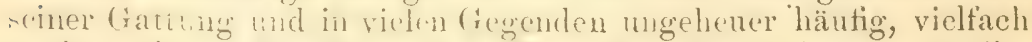
anch noch im \%unchmen burifien. Nur l)editius nennt ihn fïr die Lomgegent ron Nendlar selten; wahrseheinlich sind da irgend welche lokalen Terhältuisse schuld. Er findet sich ramentlich in lichen 1 äldern mit viel Unteriol\%, anf Triften und Wiesen mit lungen burnhedien und ausgedehisten Busehpartien, in verwilderton Anlagen und Obstgairten. Auch in den Vorbergen ist (') iihorall rahlireich. A. v. Homeyer traf ihn noch bei Hermsdorf' mol Ledersinef masconlaft, was ich ats eigener Erfahrung bestitign kamm. ('ollurio ist ein Zugvogel, weleher Anfangs Mai 
eintrifft und sich schon Ende August wieder auf die Wanderschaft begiebt. R. Tobias notirte von $1832-33$ für die Gegend von Görlitz als frühesten Ankunftstermin den 30. April, als spiitesten den 10. und als durchschnittlichen den 3. Mai.

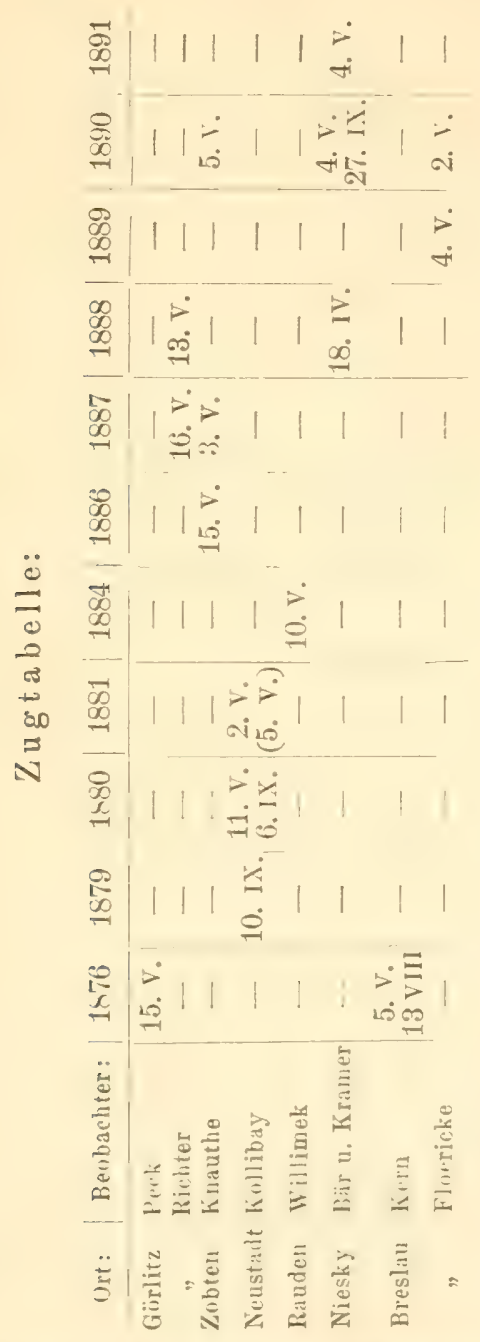

Kollib a y beobachtete diesen Würger beim Ausrauben cines Hanflingnestes. Sein eigenes Nest legt colluiv bei ums am liebsten 
in alten Akazien und Obstbäumen (Willimek) oder in Dornhecken an, selten in jungen Fichten (Mohr). Das erste Ei fand Kollibay am 18. Mai, volle Gelege am 5. und 8. Juni, nackte Junge am 20. Juni, ich selbst vollzählige Gelege am 2ð. und 30. Mai, an 4. und 7. Juni. Alle IVürger (vielleicht mit Ausnahme von excubitor) machen in Schlesien nur eine Brut.

Ma asse von 76 sehlesischen Eiern (davon 37 durch Kollibay gemessen) in $\mathrm{mm}$ :

$\begin{array}{lccc} & \text { maximum } & \text { minimum } & \text { Durchschnitt } \\ \text { Länge: } & 23,2 & 19,5 & 21,6 \\ \text { Breite: } & 17,2 & 15,1 & 16,3\end{array}$

114. Lanius senator L. I 15 s. - Rotköpfiger IVürger.

Sy non yma: Phoneus rufus Kaup; Phoneus senator Gray; Phoncis rutilans Gray; Enneoctonus rufus Bp.; Enneoctonus pomeranus Cab.; Enneoctonus senator Mewes; Enneoctonus frenatus Licht.; Enneoctonus rutilans Cab.; Emmeontonus peetoralis v. Müll.; Lanius rutus Briss, Naum., Chr. Br., v. Hom., Gätke, Jäakel; Lanius pmeranus sparm, Gm., Behst.; Lanins rutilus Lath., Butt,; Linius ruticeps Retz, Bohst., Glog., Radde; Lanius rutilans Tem, Buil; Lanin: melanotus, L. ruficep:i, L. paradoxus, L. cogratus Chti. Bretm; Lanius castaneus Haln; Lanius pectoralis v. IIcugl.; Lanius smator L., Levaill., A. Brehm, Fridr., Hartert; Lanius senator rutilans Hartert.

Kennzeichen der Art: Die 2. Schwinge gleich der 5 . Die reinhurn und die Ferlern über der Nasengrube sind weiss. Aut dem zusammengelegten Fliggel ist ein weisser Fleck sichtbar.

Ui s.p schön gezeichnete IVürgr. kommt in schlesien nur in

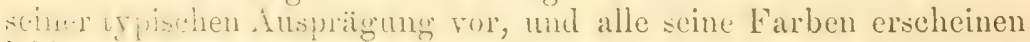
lebhaft und gesüttigt, nicht abgeblasst.

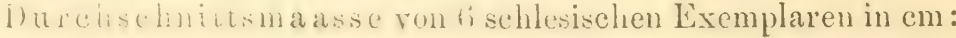

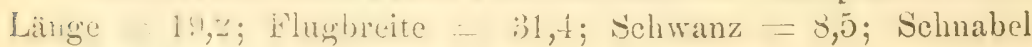
$=1,3$; Tarsus $=2,4$.

Sruntui ist wine mehr siidlich wohnende Art und deshalb in Schlesien nichi uben häufig zu finden, wenn anch gerade keine Seltenheis. Im gewöhnlichsten fiudet man den Rotkopf-Würger now im Ifügrllande sülwestlich ron Breslan, wo er strichweise recit zahlecich aufritt. Fermer brütet er in ziemlicher Anzahl in dor bartzchnir derung, weniger in dor Lausitz und in den

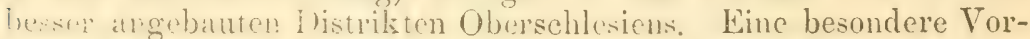
liehe hat dieser Troel tür Tiehtriften. Ferner liebt derselbe

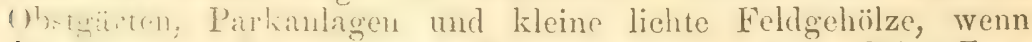

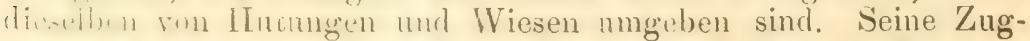
monatr sind ler April und der September. Nach R. Tobias 
erfolgte bei Görlitz von 1832 - 3s dic Ankunft frühestens :m -7. April, spätestens am 10. und im Mittel am 3. Mai. In den daranf folgenden nächsten 3 Jahren notirte Tobias den :2). April, den 1. Mai und den 29. April als Ankunfisdaten, fernel Peek den 26. April 1879. Die Eier variiren sehr (R. Tobias). Letzteres fand am 26. Mai das volle Gelege. Durchschnittsmaasse von 7 schlesischen Eiern in rnm: $22,6+17,4$.

\section{Lanins minor Gm. 17ss. - Graner W W r r ger.}

Synonyma: Collurio minor Balon, Ennenctunus minor ('ab. Boie, Mewes; Enneoctonus italicus Bp.; Lanius italicus Lath, Buff.; Lanius vigil Pall.; Lanius longipennis Blyth; Lanins tla vescens Ehrbg.; Lavius piuetorm, L. nigrifrons, L. eximius, L. sracuss Chr. Brehm; Lanius minor Gm., Bechst, Naum., Chr. Br., Glog., Gieb., Kays, u. Blas, A. Breim, v. Hom., Fridr., Fiahle, Hart., Gätke, Jäckel; Lanius minor obscurior Radde.

Trivialnamen: Klcine Krickelster. IV cndisch: Schuira Penza.

Kennzeichen der'Art: Die Feterehen über der Nasengrube sind schwarz. Länge unter 2:; cm. Anf len schwarzen Flügeln ein weisser Fleck. Die 1. Schwinge it nich halb so lang als die 2., diese gleich del !. Die 3 . ist am längtent.

Durehschnittsma asse von $i$ sehlesisehen Exemplaren in cm: Länge = 21,0; Flugbrcite - 31,!; Schwanz - 1,4 ; Schnabel $=1,3 ;$ Tarsus $=2,2$.

In manchen Gegenden Schlesiens ist winur durchaus nicht selten, in anderen aber fehlt e' nahezu gänzlich. Frïher war er häufiger, dem sein Bestand ist fast überall im Rückgang begriffen. So berichtet L. Tobia: für die Gegend von TeusalzGrüneberg: "War 1S50)-b(0) sehr häntig, nahm abur vou da auftallend $a b$, so dasio er selten wrute. Gloger nemut in ngemein" und R. Tobias sagt: "Ln mancheu Jahpen der gement? -te Würger." Beides trilit für heute kaum noeh irgendwo in suchlesicni zu,

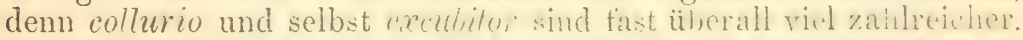
Verhältnismässig häutig trat ich minor in iler Barlechnialemung, bei Breslau dagegen nur vereinzelt (Nordwest:trand der Strachatr) und vermochte auch kein Nest voit ihm zu finden. Finaulhe nennt den Vogel nseltener als exthitui, ahor in Zumehmen we-

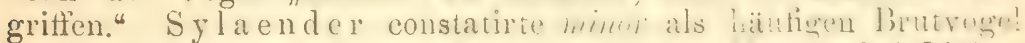
bei Bolkenhayn, v. Me y erinck hei Canth, N ciss bei Lipure.

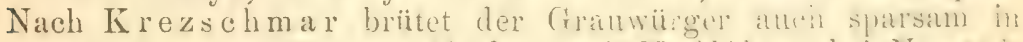
den Dörferu der Görlitzer Heide, nach Kollibas b) Neustait und nach TVolf im Schlosspark ron Maskan. Aueh A us as,

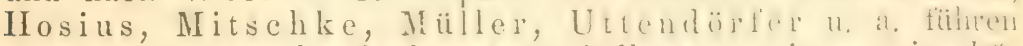
minor als Brutvogel auf', aber stets mit "zusit\% wic mereinzelu, "selten", "sparsam" u. derg]. Das Crebirge neilet der Grau- 
würger gänzlich. In der Ebene siedelt er sich namentlich in grossen parkähnlichen Gärten in Alleen, in gebüschreichen Baumgruppen und Feldhölzer’n an, ja sogar am Rande grösserer Waldungen, wenn dieselben an mit Gebüsch und einzelnen Bäumen besetztes Wiesenterrain stossen. Mai und August sind die Hauptzugmonate auch dieses Würgers. Bei Görlitz kam minor nach R. Tobias frühestens am 8., spätestens am 17. und durchschnittlich am 10. Mai an.

\section{Zugtabelle:}

\begin{tabular}{l|l|l|l|l|l|l|c} 
Ort: & Reobachter: & 1841 & 1880 & 1881 & 1889 & 1890 & 1891 \\
\hline Görlitz & $\begin{array}{l}\text { R. Tobias } \\
\text { Kutter und }\end{array}$ & 25. IV. & - & - & - & - & - \\
Neustadt & $\begin{array}{c}\text { Kullibay } \\
\text { Zobten }\end{array}$ & - & 11. V. & 5. V. & - & - & - \\
Niesky & Bär u. Kramer & - & - & - & - & - & 30 VIII \\
Breslau & Flooricke & - & - & - & 4. V. & 6. V. & -
\end{tabular}

Durchschnittsmaasse von 5 schles. Eiern in mm: $24,0+17,75$.

116. Lanius excubitor L. 1758. - Ra u bw ürger.

116a. Lanius excubitor maior Pall. 1811. - Oestlicher $\mathrm{R}$ a u bw ürger.

116b. Lanius excubitor Homeyeri Cab. 1823. - Homeyers Raubürger.

Synonyma: Pica cinerea Frisch; Ampelis coerulescens L.; Collyrio excubitor Gray; Lanius cinereus Briss., Leach; Lanius rapax Chr. Brehm; Lanius excubitor L., Gm., Lath., Bchst., Naun., Chr. Br., Glog., Gieb., Kays. u. Blas., A. Br., v. Hom., Mewes, Fridr., Radde, Hart., Gätke, Jäckel.

Trivialn a m en: Grosser Neuntöter, Waldherr, Waldhäher, Wamnengel, W arkrengel, IV urgengel, türkische Schalaster, Berg-, strauch- und Krickelster. Polnisch: Dziergwa.

Kennzeichen der Art: Ueber der Nasengrube schwarze Federchen. Den schwarzen Flügel zieren weisse Spiegel. Grösse uiber $22 \mathrm{~cm}$. Die 1. Schwinge ist halb so lang als die 2, diese gleich der 6.

Auf Tafel I sind die Flügel der drei verschiedenen Formen des exculitor dargestellt, ausserdem noch die weisseste Feder aus dem Flügel eines typischen Homeyeri. Neben der Verteilung der gratuen und weissen Farbe auf Bürzel und Kopf bildet bekanntlich die Ausdehnumg des oder der weissen Spiegel auf dem Flügel das hauptsächliche Unterscheidungsmerkmal zwischen den 3 Formen des Raubwürgers. Dies ist auf unserer Tafel deutlich zur Anschauung gebracht. Bei maior (a) findet sich auf dem zusammen- 
gelegten Flügel mur e in kleiner viereckiger, weisser F'leck, wialnend der typische excubitor sowie die Form Homeryeri z we i weisse Flügelspiegel besitzen. Es ist deshalb cin Unding, speciell die letztgenannte Subspecies als nzwcispiegeligen" liaubwïrger zu bezeichnen, wie dies seitens hervuragender Oruithologen ne-schehen

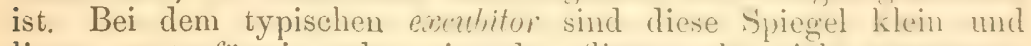
liegen rautenförmig neben einander, flicsen also nicht zusimmen, sondern sind scharf von cinander alugegrenzt (b). Carade entgegengesetzt verhält sich das bei Homeyeri (c), wo dic schn vergrösserten Spiegel vollständig zusammenflessen. I)ic meisten neueren Oruithologen führen maior und viele anch Inumeycit als selbststandige Art auf. Ich vermag mich dem keineswey anzuschliessen, sondern betrachte maior als östliche umr Itmmey i als südöstliche Subspecies cin und derselben Gruntform, ja als subspecies, die sich noch nicht einmal vollkommen heraturebildet haben, sondern teilweise noch im Entstehen begritien und jedenfalls trinär zu benennen sind. Uebergänge sind gar nicht sclten, wennschon es meiner Mcinung nach ausgeschlossen erscheint, lass man es hier etwa mit blosicen Altersversehiedenheiten zu thun hat. Im Herbst und Winter streichen die jungen Vïgel und rerwischen dadurch die Verbreitungsgrenzen. WVerden damm mulor mul Homeyeri in Gegenden betrolfen, wo sie sonst nicht vorkommen, so wird man es in den weitaus meisten Eillen mit jungen Exemplaren zu thun haben.

Ma asse von 11 schlesischen Exemplaren (lauter typische excubitor) in $\mathrm{cm}$ :

$\begin{array}{lccc} & \text { maximum } & \text { minimum } & \text { Durchschnitt } \\ \text { Länge: } & 25,2 & 24,3 & 24,6 \\ \text { Flugbreite: } & 36,7 & 35,5 & 36,0 \\ \text { Schwanz: } & 11,0 & 10,7 & 10,9 \\ \text { Schnabel: } & 1,8 & 1,8 & 1,8 \\ \text { Tarsus: } & 3,3 & 3,0 & 3,1\end{array}$

Als Brutvogel haben wir in Schlesien mu den typischen exerbitor. Im Winter aber komme anch maiur zu uns und in in manchen Jahren war nicht selten. Leh erhielt ihn mehriteh, so im Winter $1=89 / 90$ aus der strachate. Hemeyer dagenen ist auch zur Zugzeit eine seltene und ansmahmsweisu Ersehommeg. leh bekam diese Form nur eimmal in dem-eibun linter durein v. Fürstenmiihl aus dep fregend rom Lamderhut. Nericrlings soll dieselbe auch Jagdzeitumen zufulge bei IBnizlau rorge-

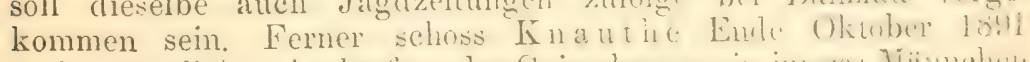

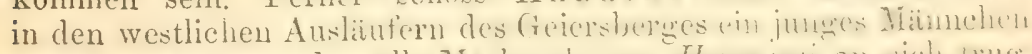
vom Grauwürger, das alle Merlimale ron Hone in an sich trug. Gegen fruher hat der Bestand unserer Raubwirger schr abgenommeu, aber noch jetzt felılt der schöne Voget wohl keiner 
Gegend völlig, wennschon er sich im Winter viel bemerklicher macht als wiihrend der Brutzeit. Er bewohnt dann Feldhölzer, Gärten und Gebüsche, am liebsten dicht bei den Dörfern. In vielen Strichen macht er sich durch Mäusefangen recht nützlich, in anderen (z. B. nach Mohr bei Breslau) frisst er während der Brutzeit fast ansschliesslich junge Vögel. Richter sagt ilım nach, dass er sogar vielfach junge Fasanen anfalle und denselben die Köpfe zerhacke. Das Nest steht gewöhnlich in Dornhecken und und enthailt 4-6 Eier. Praetorius fand am 21. April 187: cin Gelege bei Breslat, Baer 1890 eine Brut von 5 Jungen bei Niesky. Durehschnittsmaasse ron 6 schlesischen Eiern = $28,5+20 \mathrm{~mm}$.

\section{Familie: Muscicapidae, Fliegenfänger.}

Der gerade Schnabel ist an der Wrurzel breit und flach, vorn mit einer schwachen Hakenspitze versehen. Feine Borstenfedern bedecken die ovalen Nasenlöcher. Die Flügel sind ziemlich lang, die Füsse kurz. Die 2.-4. Schwinge am längsten. Das lockere Gefieder ist sehr zart and weich.

Gattung: Muscicapa Briss. 1760 . - Fliegenschnäpper Schmabel kurz, Füsse schwächlich, Rachen weit, am Munde mit steiten Bartborsten. Die 1. Schwinge ist ein wenig länger als die Handdecken, die 3. und 4. am längsten.

117. IIuscicapa parva Bchst. 1795. - Z wergfliegensehnäpper.

Śy no nym a: Erythrosterna parva Bp., Degl., Mewes, Radde; Synomis lencura Hodgs.; Muscicapa lais Hempr. und Ehrbg., v. Heugl.; Muscicapa rubecula Srains.; Nuscicapa rufogularis Chr. Brehm; Nuscicapa minuta IIorusch. 11. Schill.; Muscicapa parva Buhst., Tem., Naım., Clr. Brehm, Gloger, Gieb., Kays, u. Blas., A. Br., v. Hom., Fridr., Hart., Gätke, Jäckel.

Kennzeichen der Art: Flügel ohne Weiss. Die 2. Schwinge ist kürzer als die 5.

Dieser dureh sein laubsängerartiges Betrageu so sehr vor scinen Gattungsverwandten ausgezeichnete Fliegenschnäpper gehört zu de!ıjenigen Vögeln, welehe wahrscheinlich weit häufiger vorkommen als man annimmt, die sich aber durch ihre Lebensweise zu sehr der Beobachtung entziehen und deshalb dem Laien selten bekannt sind. Doch unterliegt es keinem Zweifel, dass para in den schönen Buchenwäldern der Grafschaft Glatz, des Hochwalds, des Eulen- und Heuschenergebirges brütet, wahrscheinlich auch noch anderwärts. Lübbert erhielt $185+5 \mathrm{Eier}$ aus Altheide, einer der bergigsten Landschaften von Glatz. Das Nest, welches in der Nähe eines Baches stand, wurde Mitte Mai 
gefunden. Anch Balıamus erhielt Eier aus Schlesien and H a r ter t besitzt ebenfalls solehe, die aus der Grafsehaft stammen. A. v. Hom eyer fand $1865 \mathrm{im}$ Buchenwald zwischen Heuschener und Cudowa i) Brutpare. In der Lausitz kommt das zierliche Vögelchen nur auf dem 1)urehzuge als Seltenheit vor, und beruht die Angabe $\mathrm{Naumanns}$.. brütet in Fichtenwäldern" augenscheinlich auf Irutum oder Verwechslung. Krezschmar erhielt ein Männchen aus der Zittauer Gegend, Fechner erwïhnt das gelegentliche Vorkommen des Vögeldens bei Hirschfelde und R. Tobias ein am 26. Mai 1839 T bei Görlitz geschossenes Männchen. Auch an anderen Punkten Schlusiens ist der Zwergfliegenfänger schon auf dem Zuge beobachtet worden. So hielten sich nach A. v. Hom ey er vom 8.-11. August 1 sit: mehrere Exemplare im Glacis der Festung Glogau aut, trieben sich oben in den Linden herum, waren gar nicht sehen, zuckten mit den Flügeln und schmarten fleissig. Derselhe Forscher beobachtete am 15. August $18703-4$ Zwergflegensehniaper in botanischen Garten von Breslau. Der Zwergfliegenschuipper hat uur ein kleines Jagdgobiet, treibt sich aber ruhelos in demselben umher und zwar meist to-6o Fuss hoch in dem grünen Blitterdach. Sein den Ornithologen jedemal hoch ertreuender Gesang ist glockenrein und nach $\AA$. V. H o me yer dem ron sibilator ähnlich, aber viel schöner. Es unterliegt für mich keinem Zweifel, dass parva demuächst noch öfters als Brutrogel in Schlesien wird nachgewiesen werden, wenn die lieobachter erst mehr auf ihn aufmerksam geworden sind und seine Stimme haben kennen lernen.

118. Muscicapa collaris Behst. 1745.-- Halsbancifliegens chnäpper.

Synonyma: Fieedula collaris M(wes; Muscicapa streptophora Vicill,; Muscicapa albifrons Chr. Brehm; Muscicapa melanoptera Heckel; Muscicapar albicollis T'm., Tamm., Gond., Swains., Chr. Br., Kays. u. Blas, v. Hom., Gätke, Jäckel; Mlucicapa collaris Bchst., Degl., Chr. Br., Glog., Gieb., Bp., Sund., (tray, A. Br., Radde, Hartert.

Trivialnamen: Wüstling.

Kennzeichen der Art: Flügel mit 2- weissen Schildern. Die 2. Schwinge grösser als die כ̃.

Der Halsbandllegenfinger ist eine der seltensien Erseheinumgen unserer Ornis und findet sich nu' in wenigen Lanbwählern, seheint aber doch bei Breslau ständig. vorzukommen, aus weleher Gegend das Universitätsmusenm $\ddot{B}$ Belegexemplare besitzt. Auch Endlel schoss hier ein Tarehen. r. Loebenstein erbentete in April 1837 ein Minnehen bei (rörlitz, bis jetze das einzige in der Lalusit\% nachgeviesene Exemplar. lch sah eimal' (rin Stück in einer Breslauer Vogelhandlung lebeud, ohne nïheres ïber seine Herkunft 
in Erfahrung bringen zu köunen und beobachtete am 24. Juni 1890 ein Pärchen in der Strachate, von dem ich das Männchen erlegte. Die Maasse desselben betrugen in $\mathrm{cm}$ : Länge $=13,4$; Flugbreite $=2 t, 4 ;$ Schwanz $=5,2 ;$ Schnabel $=1,0 ;$ Tarsus $=1,9$. Es ist ein mehr südlicher Vogel, der aber doch schon im benachbarten Mähren häufig ist.

119. Huscicapa atricapilla L. 1760 . - Trauerfliegenschnäpper.

Synonyma: Emberiza luctuosa Scop.; Sylvia melanoleuca Vieill.; Sylvia ficedula Lath.; Ficedula atricapilla Mewes; Motacilla fidecula L., Gm.; Muscicapa nigra Briss., Degl.; Muscicapa maculata Nüller; Muscicapa muscipeta Behst.; Muscicapa pectoralis Swains, Levaill.; MItuscica a alticeps, M. atrogrisea, M. fuscicapilla Chr. Brehm; Nuscicapa luctuosa Tem, Naum., Chr. Br., Glog., v. Hom., Gätke; Il uscicapa atricapilla L., Butf., Gm., Behst., Kays. u. Blas., Gieb., Fritsch, Heugl., A. Brehm, Fridr., Radde, Hart, Jäckel.

Trivialnamen: Nösseltink, Flicgenschnapfer, Trauer. und Totenvogel.

Kennzeichen der $₫ r t$ : Auf dem Flügel cin weisses Schild. Die 2. Schwinge kürzer als die 5 .

II a asse von 12 schlesischen Exemplaren in $\mathrm{cm}$ :

$\begin{array}{lccc} & \text { maximum } & \text { minimum } & \text { Durchschnitt } \\ \text { Länge: } & 13,5 & 13,1 & 13,35 \\ \text { Flugbreite: } & 23,1 & 22,6 & 22,9 \\ \text { Schwanz: } & 4,9 & 4,7 & 4,8 \\ \text { Schnabel: } & 1,0 & 0,9 & 0,95 \\ \text { Tarsus: } & 1,7 & 1,7 & 1,7\end{array}$

Der Trauerflegenfanger ist zwar bei weitem nieht so selten wie die beiden vorhergehenden Arten, gehört aber eben so wenig zu den besonders häufigen Yögeh. Inf dem Zuge ist er viel zahleeicher als während der Brutzeit. Lichte Lambwälder, parkartige Anlagen und grosse Gärten, denen es nicht an hohlen Bäumen fehlt, bililen seinen Aufenthaltsort. Ich sah ihu auf der Promenade von Breslau seine Junge fïttern, während hunderte geputzter und lïrnender Menselien dicht daran vorïber gingen. IV olf faul ilm bei Muskau, Krezsehnar bei Sprottau, Mohr bei Breslan und Michel im Isergebirge brütend; hier soll er seit cinigen Jahren sehr zugenommen haben. Auch Talsky beobachtete ein P'ärehen beim Anfticg auf den Ziegenücken. Die grosse Mehrahli der schilesischen Beobachter aber führt atricapilla nur als metir oder minder regehüssigen Passanten auf, der Ende April und Anfang Mrai und damn wieder Ende August und Anfang September bei uns durchzieht.

Siehe nebenstehende Tabelle! 


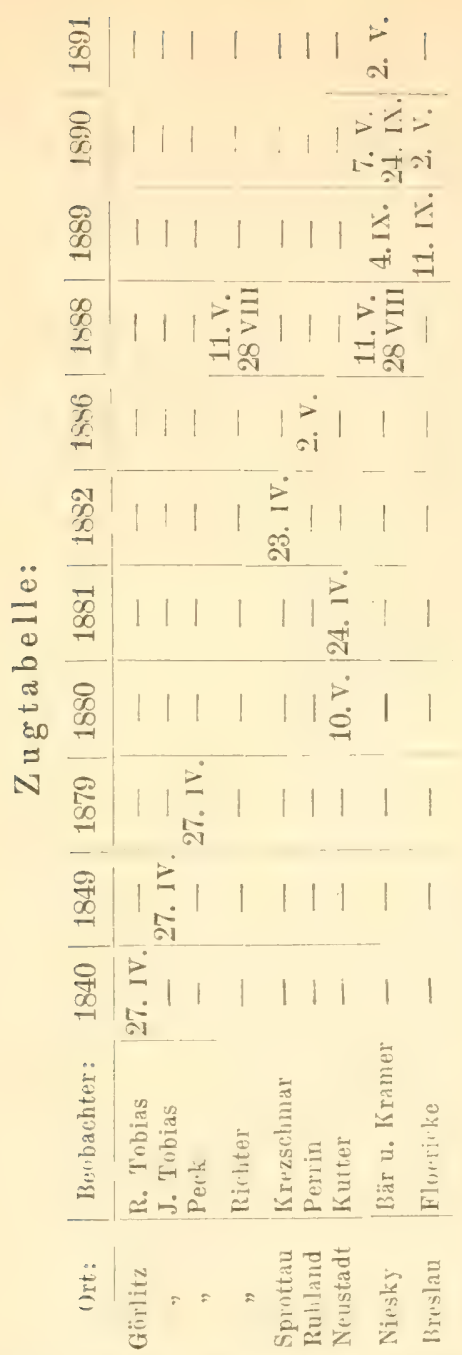

L. Tobias berichtet, dass ein Pairehen dieses Fliegenselmäpper's in einem vor einem Fenster aufgehängten hohlen Ast brütete. Während der Vogel sonst bekanntlich Höhlenbrüter ist, fand Wolf 1887 ein freistehendes Nest, dessen Unterlage und Aussenwand aus Stroh bestand, während die zweite Lage ans Birnbaumund Buchenblättern, feiner Kieferninde, Erdmoos und feinen Hobelspänen gebildet war. Die immere Ausfüterung bildeten zarte 
Würzelchen und Grasrispen olme Haare, Federn und sonstiges weiches Material. Durchschnittsmaasse von 6 schlesischen Eiern $=17,5+13,0 \mathrm{~mm}$.

120. Muscicapa grisola L. 1766. - Grauer Fliegenschnäpper.

Synonyma: Sylvia pestilencialis Klein; Butalis grisola Boie, Degl., Radde; Butalis griseosticta Swinh.; Butalis africana Bp.; Butalis montana, B. pinetorum, B. alpestris, B. domestica Chr. Brehm; Muscicapa latirostris Swains.; Muscicapa grisola L., Gm., Bchst., Buff., Tem., Naum., Chr. Br., Glog., Gieb., Kays. u. Blas., A. Br., v. Hom., Mew., Fridr., Hart., Gätke, Jäckel.

Trivialnamen: Sticherling, Fliegensehnapper, Fliegenschnaps, Fliegen- und Mückenstecher.

Kennzeichen der Art: Flügel ohne Weiss. Die 2. Schwinge grösser als die 5.

Ma asse von 14 schlesischen Exemplaren in $\mathrm{cm}$ :

$\begin{array}{lccc} & \text { maximum } & \text { minimum } & \text { Durchschnitt } \\ \text { Länge: } & 14,1 & 13,6 & 14,0 \\ \text { Flugbreite: } & 25,2 & 24,5 & 24,9 \\ \text { Schwanz: } & 5,6 & 5,4 & 5,5 \\ \text { Schnabel: } & 1,0 & 1,0 & 1,0 \\ \text { Tarsus: } & 1,4 & 1,4 & 1,4\end{array}$

Als Brutvogel ist grisola die bei weitem gemeinste Art seiner Gaitung und in lichten Baumwaldungen, Feldhölzern, Gärten, Anlagen und Kirchhöfen nirgends selten. Selbst auf den Blössen tief im Innern grosser Nadelwaldungen brütet er regelmässig, so nach Krezschmar in der Görlitzer Heide. In Oberschlesien und an den Teichen ist er etwas seltener und mehr auf dem Zuge zu finden. Im Gebirge geht der graue Fliegenschnäpper nach Gloger bis zu einer Mleereshöhe von 3500 Fuss empor. A. v. Homeyer fand ihn bei Cudowa und an der Josefinenhütte brïtend, desgleichen v. Tschusi auf einer jungen Fichte im Walde ron St. Peter. Capek traf obcrhalb Hohenelbe eben ausgeflogene Junge. Den Zobten selbst bewolint grisola nach Knauthe nicht, ist aber in der Umgegend sehr häufig. Es ist ein rechter Gartenvogel, der gern und ungescheut unter den Augen des Menschen sein harmloses Wesen treibt. Gloger beobachtete zur Zugzeit eine Familie von 6 Stück auf den Fenstersimsen der Breslauer Universität, mitten in der stadt und mehrere hundert Schritt von Bäumen entfernt. Der Zug gelıt hauptsächlich Ende April und Anfang September von statten. Auch bei diesem Yogel kommen die Wcibchen im Frühjahr einige Tage später als die Männchen. 


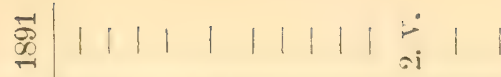

$$
\begin{aligned}
& \text { 事 } 11111111110 \\
& \text { 事 } 111111111111104
\end{aligned}
$$

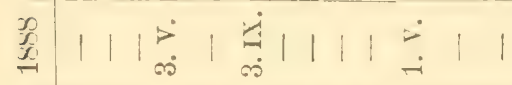

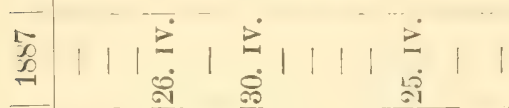

$$
\begin{aligned}
& \text { 墨11010 }
\end{aligned}
$$

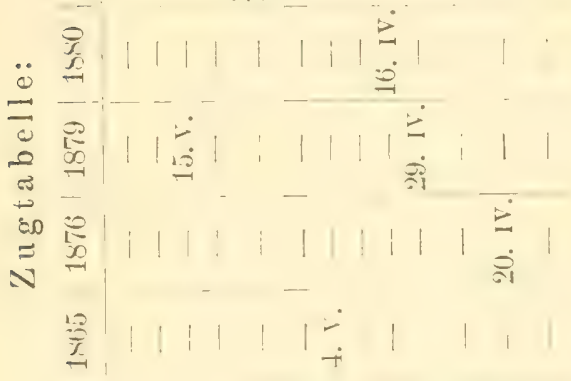

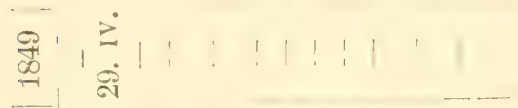

$$
\begin{aligned}
& \text { 悉 } \\
& \text { 嵒莣 }
\end{aligned}
$$

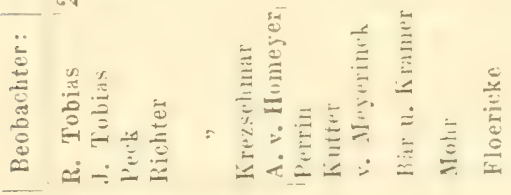

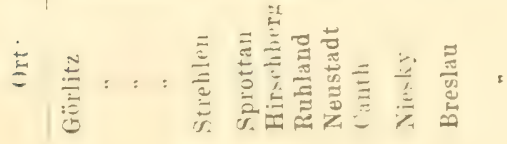


Die Imker führen vielfach Klage darüber, dass der graue Fliegenschuäpper den Bienen nachstelle. Es finden meist 2 Bruten statt, zu denen aber ein und dasselbe Nest benutzt wird. Kollibay beobachtete den Nestbau am 28. Mai und fand am 4. Juni auf dem Kirchhofe von Patschkau zivei Nester mit 3 und 5 frischen Eiern, das eine in einer Kopfrose, das andere in der ersten Gabelung eines frischen Fliederstrauches. Richter fand schon am 17., Kutter am 28. Mai, Perrin am 1. Juni und ich selbst am 27. Mai und 2. Juni volle Gelege. Das Austliegen der Jungen beobachtete Richter am 23. Juni und 4. Juli.

Ma asse von 24 schlesischen Eiern in $\mathrm{mm}$ :

$\begin{array}{lccc} & \text { maximum } & \text { minimum } & \text { Durchschnitt } \\ \text { Länge: } & 19,0 & 17,5 & 18,25 \\ \text { Breite: } & 14,5 & 13,0 & 13, \overline{0}\end{array}$

Gattung: Bombycilla Vieill. 1807. - Seidensehwanz.

Die 1. Schwinge der länglich zugespitzten Flügel ist verkümmert, die 2. und 3. am längsten; an den Spitzen der hinteren Schwingen befinden sich prachtvoll gefürbte Schaftfortsätze. Den Kopf ziert eine Federhaube. Das weiche und seidenartige Gefieder zeigt sebr zarte Farben.

121. Bombycilla garrula (L.) 175s. - Seidenschwanz.

synonyma: Lanius garrulus L.; Parus bombycilla Pall; Garrulus bohemicus Gessn.; Bombycivora poliocephala Meyer u. Wolf; Bombycivora garrula Tem.; Ampelis garrulus L., Gm., Bchst., A. Br., Mew., Fridr., Hart., Gïtke; Bombycilla brachyrhyncha Chr. Br.; Bombycilla bohemica Briss., Steph.; Bombycilla garrula Vieill., Naum., Chr. Br., Glog., Gieb., Kays. u. Blasius, v. Hom., Radde.

Trivialnamen: Wippsterz, Behmele, Frefe, Schneeleschke, Schneevogel.

Kennzeichen der Art: Siehe die Gattungsmerkmale, da nur diese eine Art in Deutschland.

Das Breslauer Museum besitzt einen sehr schünen Albino, der, wenn ich nicht sehr irre, von dem berühmten schlesischen und ein oftenes Herz für die Vogelwelt besitzenden Dichter Holtey stammt. Ferner wurde nach Endler im Frühjahr 1810 cine prachtvolle weissbunte Varietät bei Obornik gefangen. Inaube, Hinterkopf und Nacken waren hell rostfarben, die rote und gelbe Zeichnung lierrlich ausgeführt, Wangen, Stirn, Kehle, Flügel und Leib schneeweiss.

Der Seidenschwanz ist nicht nur im Sommer schon öfters in Schlesien geschen, sondern sogar einmal mit Sicherheit als Brutvogel festgestellt worden. Kläber, ein sehr tüchtiger Vogelkenmer, 
der u. a. zum ersten Male Corythus enucteator in der Gefangenschaft zïchtete, fand 1325 bei Festenberg ein Vest in dem Gabelzweig eines kleinen Birnbaums. Dassclbe war aus lieisig und Haaren verfertigt und enthielt 5 Eier. Der Gartner nahm letatere aus; da aber das brütende Weibehen darüber sehr böse wurde und ihn bis zu seiner Wohumg verfolgte, so legte er ¿ der Eier wieder ins Nest, welche auch ausgebrütet wurden. Beide Alten verweilten mit den Jungen bis zum Spätherbst in der Gegend, wo sie dann weiter zogen. Heydrich sah am 11. Juni(!) 185) eine kleine Gesellschatt Seidenschwinze bei Flinsberg, und ein mit Gloger befreundeter Forstmam beobachtete den prächtigen Vogel den ganzen sommer hindureh im Eulengebirge. Sonst ist der Seidenschwanz bei uns nur Wintergast, wemschon er oft ziemlich früh kommt und bis in den April hinein verweilt. Ganz fehlt er wohl in keinem Jahre, aber manchmal erseheint er nur sparsam and vereinzelt und dann wieder in grossen trehwirmen. Die Ebereschläume der Chansseen iiben eine besondere Anziehungskraft auf den gefrïsigen Gesellen aus. In den Gebirgslandschaften halten sie sich entschieden licber aut als in der Ébone. Von der Greuzbaudr aus wurden im Januar 1865 und lit nach A. r. Ho meyer sehr vide geschosen, in dex Lausitz waren sie 1843/44 nach R. Tobias zi tausenden und V. Loebenstein fing im Herbst $15 \pm 7$ in seinem lnohnenstieg allein iber 200 stiick.

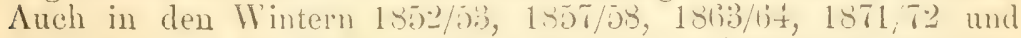
1877 is waren die sembenschwainze in schlesien besonders zahlreich, ebenso nach den mir zngegangenen Nachriohten in dem eben verflossenen Winter 1592/43. Ieh selbst habe den sehönen Voged oft in freier Natur beobachet mol mich dabei sehr mit ihm befireundet. Meiner Meinumg nach ist sein Vaturell in den ornithologischen Lehrbächern so unverteilhatt gesehildert und die (iefriissigkeit und Trigheit de: Tugels viel zu stark betont, wohl weil die betretienden Yerfassor zumedist nur nach in dere Cicfangenschaft gehaltenen Exemplaren urteilen konnten. Im Freien merkt man von diesen unangenehmen Eigenschaften so grut wie gar nichts, dann tritt die evig regame Fliegenschnäppernatur des Vugels viel mehr hervor und im Verein mit ihr kommt die nurerglede

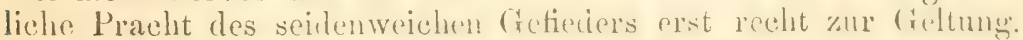
Familie: Hirundinidae, Sch wa $l$ b e n.

Der kurze, glatte, dreieckige mut an der Trurzel verbreiterte Schnabel führt in einen sehr grosinn Rachen. Die grisstenteils

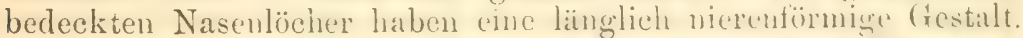
Die Mittel- und Aussenzehe der klemen, schwichlichen liüses sind fast bis zum ersten Gelenk verwachseu. Die sehr charakteristisch gebildeten Flügel sinel derl, schmal, lang und spitzige, die Armschwingen sehr viel kïrzer als die Handsehwingen. I)ie 1. Schwinger ist am längsten. 
Gattung: Chelidonaria Rehw. 1889. - Flaumfussschw a lbe.

Schwanz kulz gegabelt, Fuss weiss befiedert.

12.. Chelidonaria urbica (L.) 1758. - - M e h ls e h walbe.

Syuonyma: Hirundo lagopoda Pall.; Hirundo minor Briss.; Hirundo urbica L., scop., Gm., Behst., Buff., Kays. u. Blas., Gieb., v. Hom., Fridr., Gätke; Chelidon urbica Boie, Degl., Swinhoe, A. Brehm, Rehw., Mew., Radde, Jäckel; Chelidon tectorum, Ch. fenestrarum, Ch. rupestris Chr. Br.; Chelidonaria urbica Hartert.

Trivialnamen: Haus-, Fenster-, Dach-, Leim-, Lauben-, Kirch- und Mauerschwaibe. Wendisch: Wasstolza.

Kennzeichen der Art: Siehe die Gattungsmerkmale, da nur diese eine Art in Deutschland.

Ma asse von if schlesischen Exemplaren im Durchschnitt: Länge $=13,5 \mathrm{~cm} ;$ Flugbreite $-20,9 \mathrm{~cm} ; \mathrm{s} \cdot \mathrm{hwanz}=6,3 \mathrm{~cm}$; Schnabel $=0,7 \mathrm{~cm}$; Tarsus $=1,1 \mathrm{~cm}$.

Albinos sind nicht allzu seiten. Das Breslaner Museum besitzt deren drei, von denen las eine Exemplar ausser gelbem Schnabel und Füssen auch noch einen gelben Augenstreif hat.

Dic Mehlschwalbe ist in ganz Schlesien ein gemeiner Brutrogel, wenmgleich ihr Bestand fast überall hinter dem von rustica zurückbleibt. Im Gebirge ist mbica sehr verbreitet und steigt nach Kramer bis zu lo0U m Metreshöhe empor. Gloger giebt ihre vertikale Verbreitungsgrenze auf 3500 Fuss an, in welcher Höhe sie noch in grosser Anzahl an den Häusern nistet. Auf ihren Spazierflügen komm die Mehlschwalbe nach Gloger gesellschaftsweise bis zur Koppenkapelle, namentlich bei heiterem und schwïlem Wetter. Vor einem Gewitter sieht man sie stets in und uber den schneegruben. K r a mer fand die Mehlschwalbe in Schreiberhau und aut der l'etersbande, 'Talsky bei spindelmühl brütend, wo auch von T's ch u s i 50 - 60 und bei den Schlüsselbauden weitere 7 iarre constatirte. L. Tobias beobachtete viele Hausschwalben in Gr. und Kl. Is:r und Krezschmar bei Krummlübel und Kirche Wang. Nach Erlebach brütete 1878 zum crsten Male ein Päreheii aut der Elbfallbaude, 1879 2, 1883 6 bei so ungünstiger Witterung, dass die Jungen nicht gross wurden. $188 \pm$ kamen sie nicht wieder. Mehrfach wird über eine sich nach den ungünstigen Sommern der letzten Jahre immer mehr bemerklich machende Abnahme der Mehlschwalben geklagt.

Siehe nebenstehende Zugtabelle!

Wie man sieht, fällt der Zug hauptsächlich in die Monate April und September. R. Tobias notierte von 1832 - 35 für Görlitz als frühesten Ankunftstermin den 15́, als spätesten den 29. und als durchschnittlichen den 24. April. Klöber bemerkte 


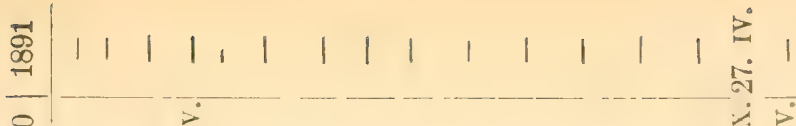

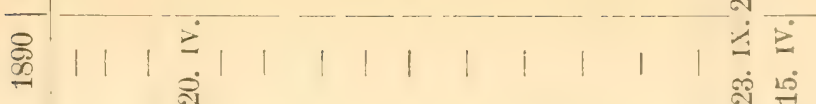

$$
\begin{aligned}
& \text { क }
\end{aligned}
$$

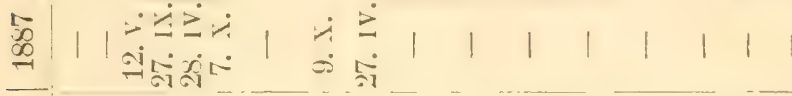

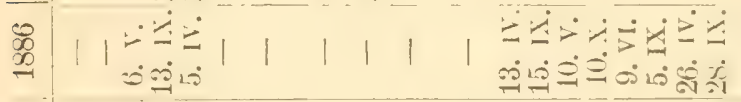

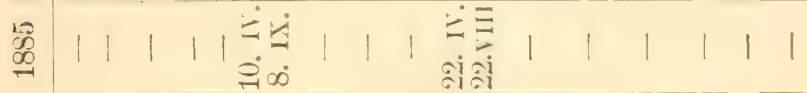

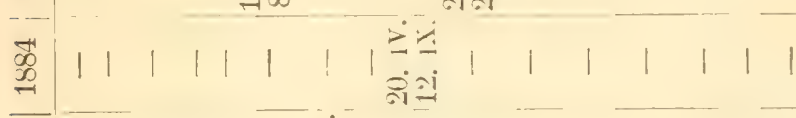

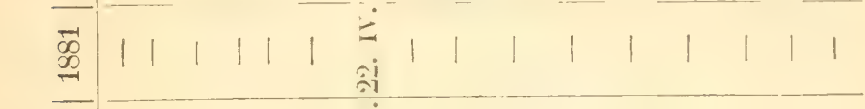

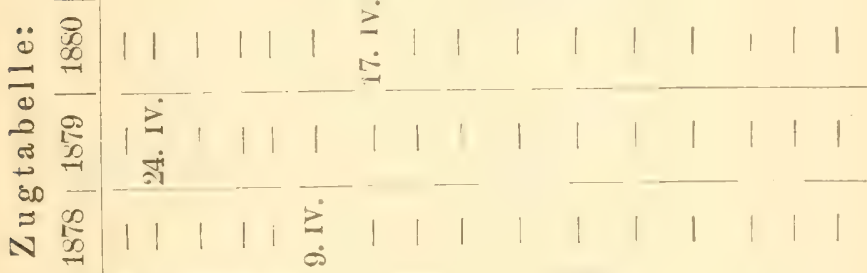

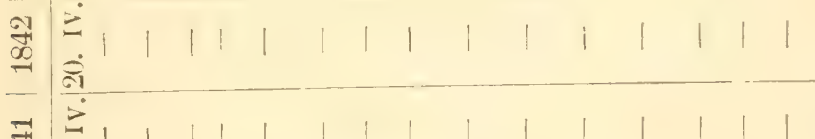

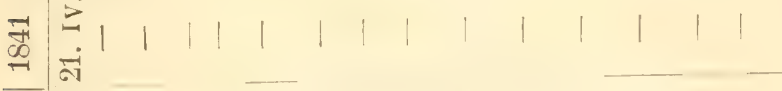

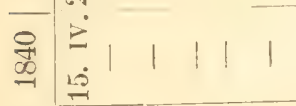

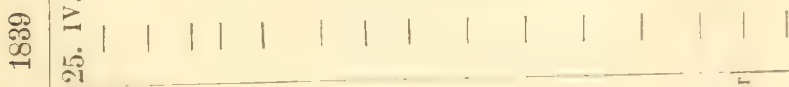

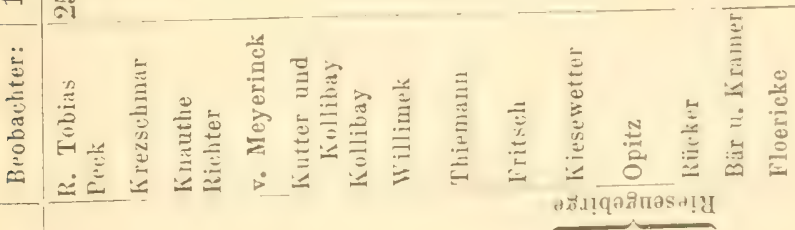

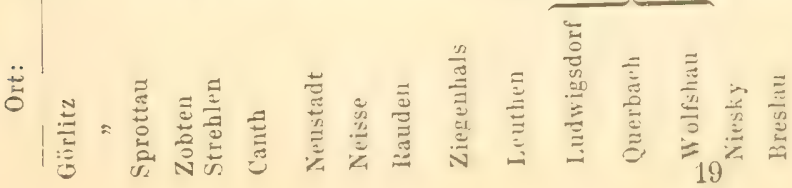


im Herbst 1826 bei Oppeln 7-8 Stück, welche zurückblieben, nachdem alle anderen schon fortgezogen waren. Es waren wahrscheinlich Alte mit den Jungen der ersten Brut, während die zweite noch im Nest sass. Am 3. Oktober verliessen sie dasselbe und am 7. zog der ganze Trupp ab. Aehnliches kommt übrigens öfters vor. Wenn der Herbst früh mit kalten Regengüssen hereinbricht, geraten die armen sichwalben of in grosse Not. Vom 2.- 4. September 10910 gingen nach Kuauthe viele bei anhaltendem Landreggen in den Nestern aus Nahrungsmangel zu grunde. Einige versuchten sich nach Art der Bienen an einander an die Wand zu hängen. Thiemann fand eimmal in einem alten Nest 15 Mehlschwalben, welche hier gemeinsam Schutz gesucht hatten. Bei Saabor sammeln sich die Nehlschwalben nach L. Tobias zur Abreise seit $18 \pm 1$ auf Bïumen und nicht mehr auf den Dächern. Ich weiss nicht, worauf dies zurückzuführen ist, und ob anderwärts ähnliche Beobachtungen gemacht worden sind. Von den Gebirgsłandschaften abgesehen macht urbica bei uns regelmässig 2 Bruten. Fritsch fand am 25. Mai cin Gelege. Kollibay beobachtete cinige Schwalben, welche ihre Jungen im Fluge fütterten. Im Nomente des Futterreichens flatterten der alte und der junge Vogel einen Augenblick Brust an Brust.

Ma as e von 19 schlesischen Eiern in $\mathrm{mm}$ :

$\begin{array}{lccc} & \text { maximum } & \text { minimum } & \text { Durchschnitt } \\ \text { Länge: } & 19 & 17 & 18,2 \\ \text { Breite: } & 14 & 12,5 & 13\end{array}$

G a t ung: Hiruudo L. 1758 . - H a us schwal be.

Die Füsschen besitzen ganz gespaltene Zehen und sind nicht befiedert. Die äusseren s'chwanzfedern sind zu einer spitzen Gabel ausgezogen.

12:3. Hirundo rustica L. 1759. - R a u chs chw albe.

Synonyma: Cecropis rustica Boie; Cecropis stabulorum, C. pagorum Chr. Br.; Hirundu domestica Pall., Briss.; Hirundo rustica L., Gm., Behst., Buff., Tem., Naum., Glog., Gieb., Kays. u. Blas., A. Br., r. Hom., Mewes, Radde, Hart., Gäitke, Jäckel.

Trivialnamen: Schwalmel, Gübelschwalm, Schwalm, Dorf-, Blut-, Stall-, Spiess- und Feuerschwalbe. Wendisch: WVasstolza und Jaschkolitzka. Polnisch: Jaskotka.

Kennzeichen der Art: Siehe die Gattungsmerkmale, da nur diese eine Art in Deutschland.

In systematischer Hinsicht habe ich über die schlesischen Ranchschwalben nur wenig zu bemerken. Die Farbe des Unterleibes wechselt allerdings selı, olne dass ich aber bei dem geringen durch meine Iände gegangenen Material etwas Genaueres darüber 
zu sagen wüsste. Anderen scheint es eben so zu gehen, demn A. v. Homeyer nennt die schlesischen Rauchschwalben ${ }_{\text {sehr }}$ weissbäuchigu und Gloger sagt ganz im Gegensatz dazu noft mit verdunkeltem Unterkörper." Im Breslaner Museum befinden sich folgende Farbenvarietäten:

a. S'chnabel und Füsse gelb, Kehle und Brustreif hell rostfarben, sonst weiss.

b. u. e. Ebeuso, jeloch der Brustring kaum angedeutet; Kopf, Nacken und Öberrücken hellgrau.

d. Ebenso mit grauen Flügeln.

e. Reiner Albino.

Masse von 13 schlesischen Exemplaren in $\mathrm{cm}$ :

$\begin{array}{lccc} & \text { maximum } & \text { minimum } & \text { Durchschnitt } \\ \text { Länge: } & 21,7 & 20,5 & 21,35 \\ \text { Flugbreite: } & 34,3 & 33,5 & 34,0 \\ \text { Schwanz: } & 12,3 & 11,9 & 12,1 \\ \text { Schnabel: } & 0,9 & 0,9 & 0,9 \\ \text { Tarsus: } & 1,1 & 1,1 & 1,1\end{array}$

Nur die typische rustica kommt in Schlesien vor; cahivica ist meines $W$ issens noch nie in der I'rovinz nachgewiesen worden. Dass die Rauchschwalbe auch bei uns allbekaunt und allverbreitet, der Liebling des Naturfremes und ler geheiligte schützling des Landmanus ist, bedarf wohl kaum besonderer Erwähnung. Im Gebirge geht rustica nistend noch etwas höher als aibica, streicht aber nicht so hoch. Gloger griebt t200 Fuss, Kramer $150 \mathrm{j}$ m als vertikale Verbreitungsgrenze an. Ein Laar versuchte nach Gloger 1526 in der Hampelsbaude (359:3 Fuss) mul ein anderes in der II iesenbaude (4:20U Fuss) Nester anzulegen, doch verloren sich die Vögel wieder beim Lintritt anhaltend rauher Witterung. Der Besitzer der Wiesenbaude versicherte (rloger, dass sie ror etwa 14 Jahren Junge ausgebracht hätten. Das scheint jedveh nur äuseerst selten nnd nur in einem solchen sommer möglich, der sich dureh rorzüglich andauernde IVirme auszeichmet. Mein Mitarbeiter simon schrieb mir, dass er mutrere Jahre hinter einander an der. Wisenbaude eine ziemlich starke und sich sichclich vermehrende Colonie angetrothen habe, bis lieselbe in vincm besonders rauhen Frahjahr aufgerieben wurde. In Kil. Lise haben sich die Rauchschwalben nach Michel erst seit isso ansïssign gemacht. Krezsehmar fand brütende Ranchsehwalben in der Elbbaude. Kramer fand rustice als Brutrogel in Sehreiberhan, jedoch bedeutend weniger zahlreich als urbica. 1)asselbe berichtet Talsky für Spindelmühl. In der Ebene sirdelt sich rustiru nicht nur in den Dörtern sundern auch in den stideden an. Lir Bestand schwankt übrigens sehr, da auch sie bui liunger an- 


\begin{tabular}{|c|c|c|c|c|c|c|c|c|c|}
\hline Ort: & Beobachter: & 1839 & 1840 & 1841 & $|1842|$ & 1849 & 1876 & 1878 & 1879 \\
\hline Görlitz & R. Tobias & 16. IV. & $\begin{array}{l}\text { 12. IV. } \\
\text { 28. x. }\end{array}$ & 12. IV & $\begin{array}{l}15 . \mathrm{IV}, \\
27 . \mathrm{x}\end{array}$ & - & - & - & - \\
\hline$"$ & $\begin{array}{l}\text { J. Tobias } \\
\text { Peck }\end{array}$ & $=$ & $=$ & $=$ & $=$ & 30. III. & $=$ & $=$ & 3. IV. \\
\hline$"$ & Richter & - & - & - & - & - & - & - & - \\
\hline Streblen & " & - & - & - & - & - & - & - & - \\
\hline Sprottau & Krezschmar & - & - & - & - & - & - & - & - \\
\hline Zobten & Knanthe & - & - & - & - & - & - & - & - \\
\hline Canth & v. Meyerinck & - & - & - & - & - & - & 15. IV & - \\
\hline Neristadt & $\begin{array}{c}\text { Kutter } \\
\text { Kollil }\end{array}$ & - & - & - & - & - & - & - & 18. $x$. \\
\hline $\begin{array}{l}\text { Neisse } \\
\text { Rauden }\end{array}$ & $\begin{array}{l}\text { Kollibay } \\
\text { Willimek }\end{array}$ & $=$ & $=$ & $\overline{-}$ & $=$ & $\overline{-}$ & $=$ & - & $=$ \\
\hline Karlsberg & Forstpersonal & - & - & - & - & - & - & - & - \\
\hline Friedrichsthal & ” & - & - & - & - & - & - & - & - \\
\hline Kottwitz & " & - & - & - & - & - & - & - & - \\
\hline Moselache & ", & - & - & - & - & - & - & - & - \\
\hline Nesselgrund & $"$ & - & - & - & - & - & - & - & - \\
\hline Paruschorritz. & , & - & - & - & - & - & - & - & - \\
\hline Proskan & " & - & - & - & - & - & - & - & - \\
\hline Rogel witz & " & - & - & - & - & - & - & - & - \\
\hline Ullersdorf & , & - & - & - & - & - & - & - & - \\
\hline Niesky & Bär u. Kramer & - & - & - & - & - & - & - & - \\
\hline Breslan & Mohr & - & - & - & - & - & 3. $x$. & - & - \\
\hline .. & Floerieke & - & - & - & - & - & - & - & - \\
\hline Lenczsok & , & - & - & - & - & - & - & - & - \\
\hline
\end{tabular}


Tabelle.

\begin{tabular}{|c|c|c|c|c|c|c|c|c|c|c|}
\hline 1880 & 1881 & 1882 & 1884 & 1885 & 1886 & 1857 & 1858 & 1889 & 1890 & 1891 \\
\hline - & - & - & - & - & - & - & - & - & - & - \\
\hline - & - & - & - & - & - & - & - & - & - & - \\
\hline- & - & - & & & - & & - & - & & \\
\hline- & - & - & - & - & - & $\begin{array}{l}\text { 7. IV. } \\
20 . \mathrm{IX} \text {. }\end{array}$ & 28. III. & - & - & - \\
\hline- & - & - & 3. IV. & $\begin{array}{l}\text { 14. IV. } \\
13 . \mathrm{x}\end{array}$ & 9. IV. & - & - & - & - & - \\
\hline- & - & 20. IV. & $12 . \mathrm{x}$ & 25. x. & $\begin{array}{l}\text { 4. IV. } \\
12 . \mathrm{X}\end{array}$ & 8.IV. & - & - & - & - \\
\hline- & - & - & - & - & 4. IV. & 27. IV. & - & - & $\begin{array}{l}28 . \text { III. } \\
30 . x .\end{array}$ & - \\
\hline- & 14. IV. & - & - & - & - & - & - & - & - & - \\
\hline 2. IV & 14. IV. & - & - & - & - & 26.x. & - & $\ldots$ & - & - \\
\hline - & $=$ & - & - & $=$ & I & 13. $1 \mathrm{~W}$ & $=$ & - & - & - \\
\hline- & - & - & - & - & 26. IV. & 29. IV. & 30. IV. & 25. IV. & - & -- \\
\hline- & - & - & - & & $\begin{array}{l}\text { 6. IV. } \\
14 . \mathrm{N}\end{array}$ & 22. & $\begin{array}{c}18 . \mathrm{IV} \\
2 . \mathrm{x}\end{array}$ & 13. 15 & - & - \\
\hline- & - & - & - & & $\begin{array}{l}1 \mathrm{l} . \\
12 \mathrm{x} .\end{array}$ & $\begin{array}{l}22.1 \mathrm{~V} . \\
28 \text {. }\end{array}$ & $\begin{array}{l}\text { S. IV. } \\
1 . x .\end{array}$ & $\begin{array}{l}15 . \mathrm{IV} \\
2.1 \mathrm{X}\end{array}$ & - & - \\
\hline - & & - & - & $\begin{array}{l}18 . \\
15 .\end{array}$ & $\begin{array}{l}26 . \\
20 .\end{array}$ & 14. IV. & . & - & - & - \\
\hline - & - & & - & 10. IV. & & & 18. $\mathrm{IV}$. & 1. $\mathrm{v}$ & - & - \\
\hline - & - & - & - & $30 . \mathrm{IX}$. & $\begin{array}{l}3 . \\
29 .\end{array}$ & $\begin{array}{c}7 . \\
29 .\end{array}$ & & $\begin{array}{l}11 . \text { IV. } \\
27 \text { IX. }\end{array}$ & - & - \\
\hline - & - & - & & $\begin{array}{l}12.1 \mathrm{~W} . \\
9.1 \mathrm{x}\end{array}$ & & $\begin{array}{c}11 . \\
15 \\
22\end{array}$ & $\begin{array}{r}5.1 \\
29 . \\
15 .\end{array}$ & $\begin{array}{l}\text { 8.IV. } \\
2 . \mathrm{X} \\
14 . \mathrm{IV}\end{array}$ & - & - \\
\hline - & - & - & - & -- & 28. & 18. IX. & & 16. IX. & - & - \\
\hline- & - & - & - & & & & $1 . \mathrm{x}$ & 21. IX. & $\begin{array}{c}1 . \mathrm{X} \\
25 \mathrm{x}\end{array}$ & \\
\hline - & - & - & - & - & - & $20 . \mathrm{x}$ & 16.x. & 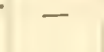 & $17 . \mathrm{X}$ & 7.11 \\
\hline - & - & - & - & - & - & - & $1-$ & $15-$ & - & - \\
\hline- & - & - & - & - & - & - & - & & 25. III. & - \\
\hline & & & - & - & - & - & - & - & - & 8.1 \\
\hline
\end{tabular}


haltender, nasskalter Witterung sehr zu leiden hat, wennschon sie eine kräftigere Natur besitzt als die vorige Art. Immerhin ist sie fast überall die gemeinste Schwalbe. Ilie Ankunft erfolgt bei Görlitz nach R. Tobias frühestens an 2, spätestens am 16. und in Nittel am : April, und zwar für die Jahre 1832-38 gerechnet.

Siehe vorstehende Zugtabelle!

Aus allen diesen Daten geht hervor, dass die Rauchschwalben meist Anfang April bei uns eintreflen und Anfang Oktober wieder abziehen, und dass sie in den Gebirgsgegenden erst später sich auf dem Brutplatze einstellen. Der auch für den Laien so auffällige Schwalbenzug mit seinen vielen Rätseln hat bekanntlich Veranlassung gegeben zu der Sage, dass die Schwalben überhaupt nicht nach dem süden zögen, sondern sich in hohle Bäume und ähnliche Schlupflöcher verkröchen, wo sie in eine Art von Winterschlaf vertielen. Mancherlei scheinbare Beweise werder dafür angeführt. So erzählt Richter folgendes verbürgtes Beispiel: "Im Winter 1868 wurde an dem Dorfe Thienendorf bei Niesky eine Lindenallee ausgerodet. Beim Zersägen und Zerhacken der einen grossen Linde, die völlig hoh! war und mehrere Zugänge (ausgefaulte Astlöcher) hatte, fand man in derselben 72 wohl erhaltene Exemplare der Rauchschwalbe!! Dieselben lagen jedoch nicht wirr durch einander, sondern lingen fest angeklammert am Baumstamm. Die Schuabel hatten sie fest zusammengepresst. In den ïbrigen z. T. ebenfalls hohlen Linden war nichts zu finden." Liebe giebt dafür wohl die richtigste und naturgemässeste Erklärung, wenn er meint, dass die betreftenden Schwalben beim Ausbruch eines Gewitters in der hohlen Linde Schutz gesucht hätten und hier durch einen leichten Blitzschlag getötet worden wären. Eine noch wunderbarere Geschichte berichten uns die "Breslauer Sammlungen" aus dem vorigen Jahrhundert. Im Monat Februar wurde bei Neumarkt der Landgraben gereinigt, wobei man gegen Mitternacht unter einem Erlenstock des Grabens cinen grossen Klumpen vom Umfang eines halben Breslaucr Schetiels in einander geschlungener Schwalben fand, welche tot zu sein sehienen. Als man aber einen Teil davon in die warme Stube gebracht hatte, wären sie lebendig geworden und herumgeflogen; die aber, so im Kalten blieben, wären gestorben. Kolliba y beobachtete einige Schwalben, welche cinen Personenzug der Sekundärbahn Hirschberg-Schmiedeberg mehrere Kilometer weit begleiteten und die von demselben aufgeschenchten Insekten fingen. Ferner salı er Schwalben, welche auf der äussersten Brüstung der Stallfenster sassen und Spinnen und Fliegen von der Mauer ablasen. S p eth erzïhlte mir, dass sich vor einigen Jahren, als die Strachate besonders von den Raupen des Eichenwicklers heimgesucht wurde, alle Rauchschwalben aus der Umgegend zu 
hunderten versammelten und die sich an ihren Fäden herablassenden Raupen im Fluge wegschnappten. In den ebenen Teilen der Provinz macht rustica regelmässig 2 Bruten, Nitte Mai und Anfang August (Mohr). Richter bemerkte ein Nest, welches in die Zinken cines aufgehängten alten Rechens gebaut war. Praetorius fand am 1. August 1872 ; 3 frische Eier, darunter ein auffallend rundliches, dessen Längsachse sich zur Querachse wie 4 zu 3 verhielt, und welches nur am stmmpfen Ende mit zwei grossen, rotbraunen, aschgrau umsäumten Flecken gezeichnet, sonst aber rein weiss war. Kollibay berichtet einen interessanten Fall, wo ein Rauchschwalbenpärchen zu den eigenen Jungen mit ins Nest gelegte junge Bachstelzen treulich gross zog.

Ma as e von 16 schlesischen Eiern in $\mathrm{mm}$ :

$\begin{array}{lccc} & \text { maximum } & \text { minimum } & \text { Durchschnitt } \\ \text { Länge: } & 20,2 & 19 & 19,6 \\ \text { Breite: } & 14 & 12,5 & 13,4\end{array}$

Gattung: Clivicola Forst. 1817. - Erdschwalbe.

Fusswurzel unbefiedert. Das Gefieder ist oben milusefarben, ohne jeden Metallglanz.

124. Clivicola riparia (L.) 1758 . - Ufersch w a l be.

Synonyma: Hirundo cinerea Tieill.; Hirundo rijaria L., Gm., Lath., Bchst., Butt., Wils., Naum., Chr. Brehm, Glog., Gieb., Kays. u. Blas., v. Hom., Fridr., Gätke; Cotyle litoralis Ehrbg.; Cotyle riparia Boie, v. Heugl., Rehw., New., Radde, Jickel; Cotyle fluviatilis et microrhynchus Chr. Brehn; Clivicola riparia Hartert.

Trivialnamen: Erdschwalbe, Rain- und Wassersehwalm.

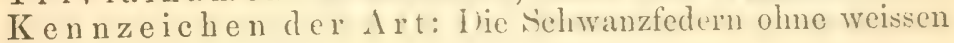
Fleck auf der Innenfahne.

M a a s e von 6 schlesischen Exemplaren in $\mathrm{cm}$ :

$\begin{array}{lccc} & \text { maximum } & \text { minimum } & \text { Durchschnitt } \\ \text { Länge: } & 12,9 & 12,6 & 12,8 \\ \text { Flügelbreite: } & 29,1 & 28,6 & 28,9 \\ \text { Schwanz: } & 5,3 & 5,0 & 5,1 \\ \text { Schnabel: } & 0,6 & 0,5 & 0,55 \\ \text { Tarsus: } & 1,0 & 1,0 & 1,0\end{array}$

Auch von dieser Art steht ein Abino im Breslaucr Musem. Dem Gebirge fehlt die Uferschwalbe völlig und ist anch sonst in Schlesien die seltenste Sehwalbenart, deren Bestand infolge der eigentümlichen Nistweise noch grösseren Sehwankungen unterworfen zu sein scheint als bei rutirk und uibira. Sie nistet an den sandigen Uferstellen der Oder und deren Nebenfluissen, aber dic Zahl der grossen Colonien schwindet immer mehr. Kleine Ansied- 
lungen fand ich auch mehrfach in Sand- und Lehmgruben, ziemlich weit vom IVasser entfernt. Die Ankunft erfolgte bei Görlitz von 183:--38 wach $R$. Tobias frühestens am 26. April, spätestens am 3. Mai und im Nittel am 27. April. Im übrigen liegen mir nur noch folgende Zugdaten vor:

\begin{tabular}{|c|c|c|c|c|c|c|}
\hline Ort: & Berbachter: & 1885 & 1886 & 1889 & 1890 & 1891 \\
\hline Canth & v. Meserinck & 10. IX. & - & - & - & - \\
\hline Ziegenhals & Thiemann & $\begin{array}{l}\text { 10. v. } \\
\text { 29.viII }\end{array}$ & - & - & 一 & - \\
\hline $\begin{array}{l}\text { Hermsdorf } \\
\text { Niesky }\end{array}$ & $\begin{array}{l}\text { Hosius } \\
\text { Kramer }\end{array}$ & 10. V. & 23. v. & - & - & 7. V. \\
\hline Breslau & Floericke & - & - & 6. V. & 27. IV. & - \\
\hline
\end{tabular}

Wie man sieht, kommt die Uferschwalbe auch noch bei Hermsdort' ror, ins eigentliche Gebirge aber geht sie nicht hinauf. Wenn es im 1. Jahresber. d. Aussch. f. Beob. Stat. der Vögel Deutschl. heisst, dass die Uferschwalbe der Breslauer Gegend gänzlich fehle, so muss ich dem entschieden widersprechen, da ich den Togel dort an zwei verschiedenen Punkten brïtend auffand, allerdings nur in geringer Anzahl. Der Vogel muss also erst neuerdings dort eingewandert sein, falls nicht ein Irrtum des betreffenden Beobachters vorliegt. Wenn ungünstige Witterung die erste Brut vernichtet und die Tügel sich deshalb zu einer zweiten entschliessen, so überrascht sie öfters der allmächtige Wandertrieb bereits wieder, ehe sie ilure Jumgen gross gezogen haben. In Liebe's „Ornitholog. Monatsschrif " habe ic! einen derartigen aus Schlesien stammenden Fall crzïhlt, in welchem die sonst so sehr an ihrer Brut hängenden Vögel die hilflosen Jungen schmählich verlassen und einem elenden Tode Preis gegeben hatten. Praetorius fand am 8. Juni und ich am 2. desselben Monats das volle Gelege.

Durchschnittsmaasse von 7 schlesischen Eiern $=16,75+$ $11,25 \mathrm{~mm}$.

II. Ordnung: Strisores, Schwirrvögel.

Kleine bis mittelgrosse Vögel ohne Singmuskelapparat, mit flachem, breitem Kopf, sehr kurzem, schwachem Schnabel, ungeheurem Rachen und ungemein kleinen Füsschen. Schwanz 10 federig:

Familie: Cypselidae, Segler.

Die sehr kurzen Füsse sind dennoch kräftig und haben die 4 zicmlich gleich langen, scharfklauigen Zehen sämtlich nach vorn gerichtet. Die langen sichelförmigen Flügel überragen weit den gabelförmig ausgeschnittenen Schwanz. Die 1. und 2. Schwinge sind am längsten, die 1. bis 3. säbelförmig gebogen und mit fischbeinartigen Federschäften versehen. Die nahe der Stirn liegenden und mit einer Haut umgebenen Nasenlöcher stellen länglich-ovale Ritzen dar. Der Magen besitzt nur eine schwache Muskulatur. Das Gefieder ist derb, der Gesamthabitus schwalbenartig. 
Gattung: Micropus Wolf 1810 . - S chwalbensegler.

Siehe die Familiencharaktere, da nur diese eine Gattung in Deutschland.

125. Micropus apus (L.) 175:- - Ma u ersegler.

Synonyma: Hirunds apus L., Gm., Behst., Buff.; Hirundo muraria Schwenckf.; Cypselus murarius T'em,; Cypselus vulgaris Steph.; Cypselus turrium, C. murinus Chr. Brehm; Cypselus apus Ill., Naum., Gould, Chr. Br., Glog., Gieb., Kays. 11. Blas., A. Br., v. Hom., Reichenow, Mewer, Fridr., Radde, Giatke, Jäckel; Apus murarius Less.; Nicropus murarius Heyer; Micropus apus Boie, Hartert.

Trivialnamen: Mauer-, Geyer-, Spyr- und Turmschwalbe. Polnisch: Murzina.

Kennzeichen der Art: Länge unter $20 \mathrm{~cm}$. Bauch braunschwarz.

M a as e von 13 schjesischen Exemplaren in $\mathrm{cm}$ :

$\begin{array}{lccc} & \text { maximum } & \text { minimum } & \text { Durchschnitt } \\ \text { Länge: } & 18,4 & 16,7 & 17,9 \\ \text { Flugbreite: } & 41,7 & 40,6 & 41,3 \\ \text { Schwanz: } & 8,0 & 7,7 & 7,9 \\ \text { Schnabel: } & 0,6 & 0,0 & 0,6 \\ \text { Tarsus: } & 1,1 & 1,1 & 1,1\end{array}$

Die Segler varimen zwar in les Grösse sehr und auch in der Nuancirung des Gefieder's einigumassen, aber angenscheiulich nur individuell, da man die Extreme in ein und derselben Colonie antrifft. Bei uns in sehlesien sind lie seghle überall recht liäufig und nisten auf allen Türmen und alten MIauern der Städte, in den Bastionen der Festungen, auf' den Kirchtürmen der loürfer, neuerdings vielfach in aufgehängten Starkïsten, selten in Felsspalten des Gebirges oder anch in Bammhöhlungen der Waldrinder. Selbst den einsamsten Heidedörfern fehlt der regsime Vogel wur selten. In den Häusern der Iser brütet er nach L. Tobias gleichfalls zahlreich und nach Kramer ebenso in schreiberhau. Im Riesengebirge sieht man den Segler oft auch an den lü̈ehsten Kämmen und über den äussersten Bergzipteh sehweluen; doch ist es noch immer fraglich, ob er im Hocligebirge auch wirklich nistet. R. Blasius sah im Juni $30-40$ siück am Koppensee, Ir ramer beobachtete ihm hoch ïber der schneekoppe fliegend, Capek erblickte 2 Segler über der Riesenbande (I fou m), Gloger grenzt die vertikale Verbreitung des Togels mit einer Meereshölne ron 4000 Fuss ab. In neu angelegten und nodernen stähten mit wenig altem Gemäuer findet sich der Sexhler viel seltener als in solehen, welche noch einen etwas mittelalterlichen Anstrich sich erhalten haben. 


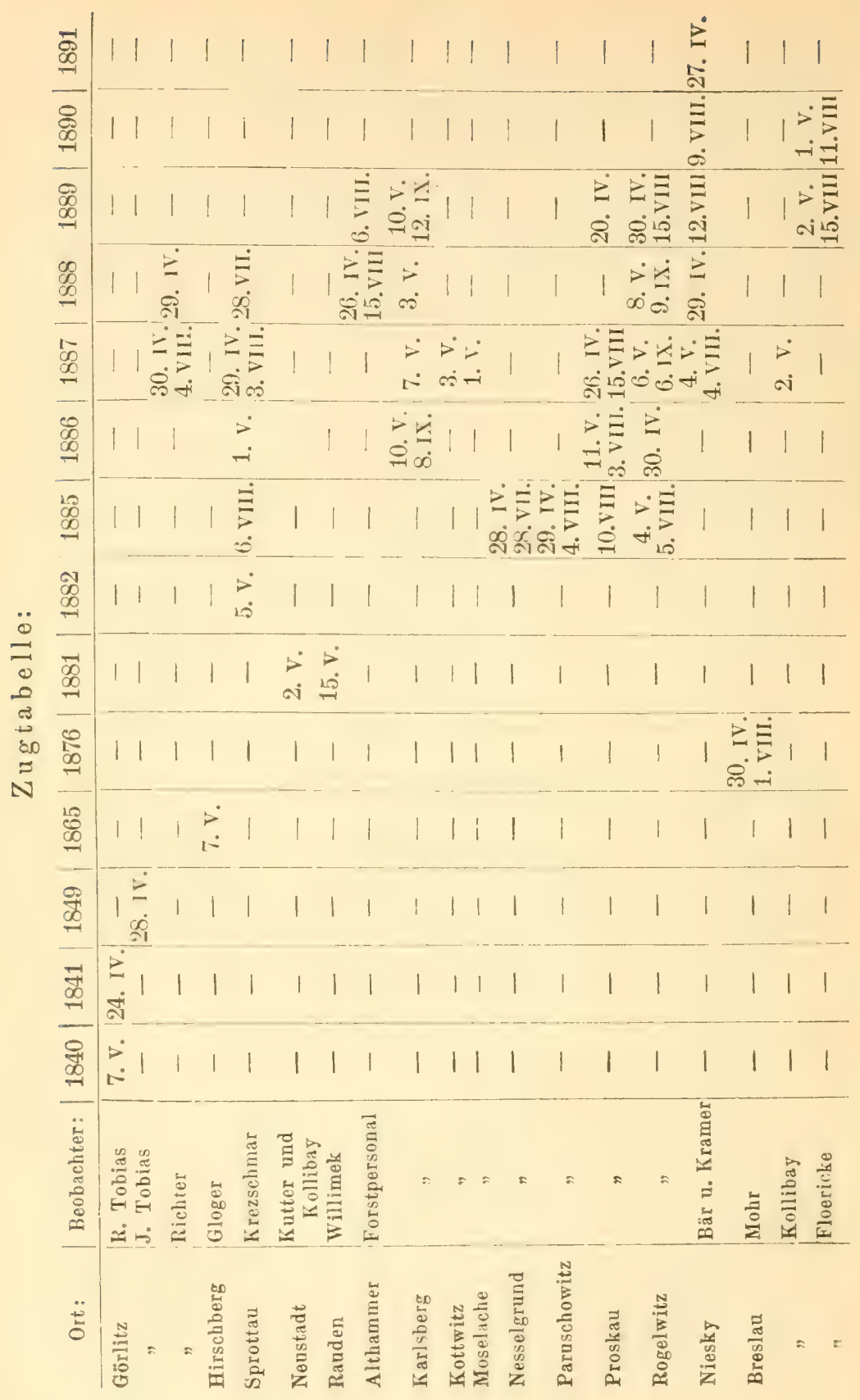


Aus dieser Tabelle ist ersichtlich, dass die Segler fast genau ein Vierteljalı bei uns zubringen. R. Tobias notirte für Görlitz von 1832-38 als frühesten Ankunftstermin den 2\%. April, als spätesten den 6. und als durchischmittlichen den 2. Mai. Bei Niesky erfolgt die Ankunft zwischen dem 29. April und 2. Nai, der Abzug zwischen dem t. mnd 12. August. Kolliba y beobachtete in einem Herbste, dass die Segler ver'schwanden, hicrauf nach einigen Tagen wieder kamen und dann erst definitiv abzogen. Mobr meint, dass die Segler in Breslau wohl 2) Bruten machten, was ich schon wegen der Kürze ihres Sommeraufenthaltes für sehr unwahrscheinlich halte; nur wenn die ersten Eier irgendwie zugruude gingen, mag sich das Pärchen zu einer zweiten Brut entschliessen. Ende Mai und Anfang Juni fand ich mehrfach Eier, Praetorius am 27. Mai volle Gelege und am 29. Juni nackte Junge. Im Breslauer Mluseum befindet sich ein Ei, welches bedeutend grösser als andere und anf grauem Grunde mit dunkelgraubraunen Flecken, Strichen und Punkten gezeichnet ist.

Ma as e von 22 schlesischen Eiern in mm:

$\begin{array}{lccc} & \text { maximum } & \text { minimum } & \text { Durchschnitt } \\ \text { Länge: } & 27 & 25,5 & 26,25 \\ \text { Breite: } & 17 & 15 & 15,75\end{array}$

\section{Micropus melba (L.) 1758. - Alpensegler.}

Synonyma: Hirundo maxima Edw., Klein; Hiruudo gularis Steph.; Hirundo melba L., Gm., Lath., Bechst.; Hirundo alpina Scop.; Apus melba Cuv.; Cypselus alpinus Tem.; Cypselus gutturalis Vieill.; Cypselus fuscicollis Chr. Brehm; Cypselus melba Ill, Naum. Gould, Chrr. Br., Glog., Gieb., Kays. u. Blas., A. Br., Rehw., v. Hom., Mewes, Radde, Fridr., Gütke, Jäckel; Micropus alpinus Meyer; Micropus melba Hartert.

Kennzeichen der Art: Grösse über 20 cm. Bauch weis:.

Gloger ist der Glückliche gewesen, der Alpensegler auf dem Riesengebirge beobachtet hat. Er schreibt: „Als ich am 12. Juni 1826 auf dem Ziegenrück (450) Fuss) war, zogen so hoch, dass mein Schuss ohne Erfolg blieb, aber doch nicht so hoch, das's nicht die ungewöhnliche Grösse und die weissen Bäuche das Erkennen vollkommen gesichert hätten, 3 Alpensegler still und meist ruhigg schwebend kurze Zeit über mir herum. Ich babe sie nirgends wieder gesehen; doch kömnten sie wohl in den Felsen westwirts vom Elbfalle, wohin ich nicht kam, ilneu eigentlichen Wohnsitz aufgeschlagen gehabt haben." Sunst ist dienel den Gebirgsländern des Mittelmeers angehörige Togul meines Wissens noch nicht in Schlesien vorgekommen. Allzu autiäligg kaun übrigens der von Gloger mitgeteilte Fall wicht erscheinen, da die Alpensegler be- 
kanntlich gern weite Streifzüge nach Norden zu unternehmen pflegen und auch schon anderwärts in Deutschland nachgewiesen worden sind.

\section{Familie: Caprimulgidae, $\mathrm{Nachtschwalben.}$}

Der Rachen ist von steifen Bartborsten umgeben. Nasenlöcher rund. Die kleinen Füsse haben 3 Zehen nach vorn (von denen die mittelste am längsten) und eine nach hinten gerichtet. Die Mittelzehe trägt einen kammartig gerieften Nagel und ist mit den beiden benachbarten durch eine breite Spannhaut verbunden. Die Hinterzehe ist wendbar und etwas höher eingelenkt. In den langen und schmalen Flügeln ist die 2. Schivinge am längsten und die 3 ersten gegen das Ende zu gezäbnelt; die Federschäfte sind sehr spröde. Das Gefieder ist locker und weich, der Schwanz abgerundet.

Gattung: Caprimulgus L. 1758. - Nachtschatten.

Siche die Familiencharaktere, da nur diese eine Gattung in Deutschland.

127. Caprimulgus europaeus L. 1758 . - Ziegenmelker.

Synonyma: Hirundo caprimulgus Pall.; Nyctichelidon europaeus Renn.; Caprimulgus vulgaris Vieill,; Caprimulgus punctatus Meyer; Caprimulgus maculatus et foliorum Chr. Brehm; Caprimulgus europaeus L., Gm., Lath., Bchst., Naum., Gould, Gloger, Gieb., Kays. u. Blas., A. Br., v. Hom. Mew., Fridr., Radde, Hart., Gätke, Jäckel.

Trivialnamen: Nachtschade, -schatten, -vogel, -rüblin, Tageschlïfer, Tagschlaf, Pfaff, Mulkedieb. Wendisch: Mata Szowa.

Kenuzeichen der Art: Siehe die Gattungsmerkmale, da nur diese eine Art in Deutschland.

Ma ase von 10 schlesischen Exemplaren in $\mathrm{cm}$ :

$\begin{array}{lccc} & \text { maximum } & \text { minimum } & \text { Durchschnitt } \\ \text { Länge: } & 28,4 & 27,2 & 27,9 \\ \text { Flugbreite: } & 55,1 & 54,2 & 5 \pm, 8 \\ \text { Schwanz: } & 15,9 & 15,1 & 15,4 \\ \text { Schnabel: } & 0,8 & 0,8 & 0,8 \\ \text { Tarsus: } & 1,9 & 1,9 & 1,9\end{array}$

Die schlesischen Ziegenmelker, namentlich die aus den grossen Nadelwäldern stammenden, gehören zu den grosswüchsigen und sind um eine Nuance dunkler als westdeutsche Exemplare. Im Breslaner Museum sah ich einen Albino mit gelbem Schnabel und Füssen und schwach angedeuteter Zeichnung. Der Ziegenmelker ist über ganz Schlesien verbreitet, wennschon in manchen Gegenden nur spärlich vertreten. Er hält sich mehr in der Ebene, obgleich 
er auch noch in der Waldregion des Riesengebirges brïtet, und liebt besonders die Blössen der Nadelwälder. Besonder's zahlreich traf ich ihn in den trockeneren und bewaldeten Teilen der Bartschniederung. Auf dem Zuge kommt dieser interessante Nachtvogel auch in die Obstgärten und sucht dann mit peinlicher Regelmässigkeit alljährlich dieselben Ruheplätzchen auf. Er zeigt dann eine gewisse Geselligkeit. A. v. Homeyer traf eimmal in Herbst 1875 am Fürstenstein 4 stiick nahe zusammen. Der Zug geht hauptsächlich in den Monaten Mai und September von statten.

\section{Zugtabelle:}

\begin{tabular}{|c|c|c|c|c|c|c|c|c|c|c|}
\hline Ort: & Beobachter: & 1811 & 1849 & $1870^{\circ}$ & 1879 & 1850 & 1881 & 1884 & 1889 & 1890 \\
\hline Görlitz & R. Tobias & 15. V. & $5, \mathrm{~V}$ & 二 & 二 & - & - & - & - & - \\
\hline Canth & v. Meyerinck & - & - & 一 & 6. v. & - & 9. V. & - & - & - \\
\hline Rauden & Willimek & - & - & - & - & - & - & 2. v. & - & - \\
\hline Neustadt & Kollibay & - & - & - & - & 25. IV. & - & - & - & - \\
\hline Breslau & Mohr & - & - & 24. IV. & - & $1-$ & - & - & - & - \\
\hline " & Floericke & - & - & - & - & - & - & 一 & $\begin{array}{l}6 . \mathrm{V} \\
10 . \mathrm{IS}\end{array}$ & 0.1 \\
\hline
\end{tabular}

Der Magen eines von Krezschmar untersuchten Exemplares enthielt 5Am 20. Mai 1839 fand ich ein Ei des Nachtschattens mitten auf einem IValdwege bei Breslau. Durchschnittsmaasse von 3 schlesischen Eiern in mm: $32+22$.

\section{II. Ordnung: Insessores, Sitzf üs sler.}

Kleine oder mittelgrosse Tögel ohne Singapparat ron sehr verschiedenartiger Gestaltung, welche durch kurze, vorn quergetäfelte, hinten nackte oder mit kleinen Schildchen bedeckte Läufe ausgezeichnet sind.

Familie: Coraciidae, $\mathrm{R}$ aken.

Der starke, gerade und beinahe kopflange Schnabel ist vorn in einem Haken nach abwärts gekrïmmt. Nasenlöcher ritzenförmig. Die bis zur. Wurzel gespaltenen Zehen sind sehr kur\%, namentlich die hintere. In den langen und spitzen Flügelu ist die 2. Schwinge am längsten. Schwanz l2fedrig. Gesamthabitus heherartig. Das Gefieder zeigt lebhafte Farben.

128. Coracias garrula L. 175j. - Blaurake.

Synonyma: Galgulus viridis Vieill.; Garrulus argentoratensis Aldr., Ray; Coracias virida Lath.; Coracins viridis Cuv., Reichb.; Coracias loquax Licht.; Coracias germanicus, C. planiceps, C. glancopterus Chr. Brehm; Coracias garrula(us) L., Scop., 
Gm., Behst., Brünn., Naum., Gould, Chr. Br., Glog., Gieb., Kays. u. Blas., A. Br., r. Hom., Radde, Fridr., Hart., Gätke, Jïckel.

Trivialnamen: Blaue Krähe, Holzkrahe, Deutscher Papagei, Rache, Golkregel, Galgenregel, Heiden- und Kugelelster. Polnisch: Kraezka. Wendisch: Dapernak, Räganer, Mudra Rona.

Kennzeichen der Art: Siehe die Gattungsmerkmale, da nur diese eine Art in Deutschland.

Maasse von 15 schlesischen Exemplaren in $\mathrm{cm}$ :

$\begin{array}{lccc} & \text { maximum } & \text { minimum } & \text { Durchschnitt } \\ \text { Länge: } & 32,0 & 31,5 & 31,8 \\ \text { Flugbreite: } & 71,3 & 70,7 & 71,1 \\ \text { Schwanz: } & 13,2 & 12,9 & 13,0 \\ \text { Schnabel: } & 3,3 & 2,6 & 2,9 \\ \text { Tarsus: } & 2,4 & 2,4 & 2,4\end{array}$

Auftallend ist bei der Nandelkriihe das starke Variiren in der Länge des Schnabels, welehes aber lediglich ron dem melir oder minder hohen Grade der Abuutzung desselben abhängig zu sein scheint. Im allgemeinen kounte ich die Beobachtung machen, dass die in Höhlungen brütenden Blauraken dickere und kürzere Schnäbel haben als diejenigen, welche in alten Krähennestern ihre Eier ablegen, was in Schlesien nicht allzu selten der Fall ist.

Dieser durch seine tropische Farbenpracht so auffallende Vogel gehört ausschliesslich den ebenen Teilen der Provinz an, während er das Gebirge völlig meidet und auch sehon in den Landstrichen vor demselben selten ist. In der Lausitz und auf dem linken Oderufer Mittel. und Oberschlesiens ist die Mandelkrähe schon häufiger und auf dem rechten Oderufer geradezu gemein. Sie liebt die Blössen grosser aber nicht allzu dichter Waldungen sowie auch Viehweiden und Triften mit einzeln stehenden hohlen Bäumen, welche nicht weit vom nïchsten Waldrande entfernt sind. Zwischen Laub- und Nadehö̈lzern macht sie keinen Unterschied. Dagegen scheint sie eine grosse Vorliebe für Sandboden zu haben, weshalb man sie im Lublinitzer und Rosenberger Kreise ganz besonders häufig findet. Auch in grösseren Parkanlagen fehlt der schö̈ne Vogel nicht. Immerhin macht sich auch in Schlesien eine fortdanernde Abnahme der Blauraken geltend. So war sie im Beobachtungsbezirke Richter's bis vur 12 Jahren noch häufig, ist aber seitlem völlig versehwunden. Ich schiebe diese Abnalne sowohl bei der Blaurake wie bei manehen anderen Vögeln weniger auf ndie ekle Somntagsjägerei, die ihre vandalische Zersiörungslust gerade an schönsten mit Vorliebe befriedigt", wie es Diederich und Friderich thun, denn dieser wissen sich die klugen Vögel schon zu entziehen, als vielmehr auf den 
sich immer empfindlicher bemerkbar machenden Mangel an geeigneten Niststätten. Deshalb empfiehlt sich gerade hier das Inbringen von praktischen Nistkïsten: meines Erachtens iberhaupt die einzig wirksame Art und Weise vernünftigen Vogelschutzes. Und der Erfolg hat gezeigt, dass wir damit in der That unserer Heimat eine so hervorragende Zierde der Vogelwelt zu erhalten vermögen. Liebe, wohl unbestritten die erste Autorität auf diesen Gebiete, schreibt: "In einem grossen Waldrevier Oberschlesiens wurde eine Forstabteilung, auf welcher viele alto Eichen und Buchen stehen, in denen Tauben und Mandelkrähen alljährlich bräten, zu dem Versuch gewählt. Da die Abteilung geschlagen wurde, so standen im Winter 1890/91 hohle gefällte Bäume zur Verfügung, welehe gleich an Ort und Stelle zu Nistkästen verarbeitet wurden, wie sie in den "Winken* für Tauben und Raken angegeben sind. Auch wurde gleich von dem entstandenen Sägemehl eingefüllt. Die Kasten wurden nun $\checkmark$ m hoch an der Sonnenseite des Schlages angebracht, und nahmen bald eintreftende Dohlen, Tauben und nachweislich ein Par. Mandelkrähen dieselben als Nisthöhlen an. Die Bruten kamen glücklich auf.“ $\mathrm{Krezschmar}$ berichtet, dass die Mandelkrähen in der Görlitzer Heide sogar in grossen Starkiisten nisten. Die Ankunft erfolgt meist in der ersten Hälfte des Mai, der Wegzug vollzieht sich im September. Nacb R. T'obias kamen die Mandelkriben von 1832-38 bei Görlitz frühestens am 30. April, spaitestens am 15. und durchschnittlich am 5. Mai an.

\section{Zugt a b elle:}

\begin{tabular}{l|l|l|l|l|l|l|l|}
\multicolumn{1}{c}{ Ort: } & Beobachter: & 1839 & 1842 & 1880 & 1885 & 1886 & 1891 \\
\hline Görlitz & R. Tobias & 20.1V.23. IV. & - & - & - & - & - \\
Muskau & Wolf & - & - & - & - & $16 . \mathrm{V}$. & - \\
Niesky & Kramer & - & - & - & - & - & 2. V. \\
Canth & v. Meyerinck & - & - & - & 1. V. & - & - \\
Neustadt & Kutter & - & - & 11. V. & - & - & -
\end{tabular}

Das vollständige Gelege cuthält $4-5$ Eier. IV olf fand ein solches am 3. Juni. Die Nisthöhlen entwickehn nach $K$ na u the einen sehr üblen Geruch, ähneln also in dieser. Hinsicht deneu des Wiedehopfs. Durchschnittsmaasse ron 4 schlesischen Lien $37,75+28 \mathrm{~mm}$.

\section{Familie: Upupidae, Hop fe.}

Der gebogene Schmabel ist sehr lang und zart. Die ovalen Nasenlöcher liegen frei an seinem Grunde. Füsse kurz und stämmig, die beiden äusseren Zehen bis ans Gelenk mit einander verwachsen, die Hinterzehe mit ziemlich geradem Nagrol. In den grossen, breiten und abgerundeten Flügch ist die 1. Sctnwinge kaum halb 
so lang als die 2., die 4. und כ̌. am längsten. Der breite 10 fedrige Schwanz ist gerade. Auf dem Kopfe ein fächerförmiger Federbusch. Gefieder weich und bunt.

Gattung: Upupa L. 1758. - Wied ehopf.

Siehe die Familiencharaktere, da nur diese eine Gattung in Deutschland.

\section{Upupa epops L. 1758. - IV i ed e h opf.}

Synonyma: Upupa vulgaris Pall.; Upupa indica Hodgs.; Upupa rubbola Storr.; Upupa maculigera Rchb.; Upupa bifasciata, U. macrorhyncha, U. brachyrhyncha, U. exilis, U. maior Chr. Br.; Upupa epops L., Gm., Bchst., Chr. Br., Naum., Glog., Gieb., Kays. u. Blas., A. Br., v. Hom., Mewes, Radde, Hart., Gätke, Jäckel.

Trivialnamen: IViedehuppe, Hupper, Huphup, Kothahn, Kuckuckslakey, -küster. Polnisch: Dudek. Wendisch: Huppak.

Kennzeichen der. Art: Siehe die Gattungsmerkmale, da nur diese eine Art in Deutschland.

Masse von 9 schlesischen Exemplaren in $\mathrm{cm}$ :

$\begin{array}{lccc} & \text { maximum } & \text { minimum } & \text { Durchschnitt } \\ \text { Länge: } & 26,0 & 25,5 & 25,7 \\ \text { Flugbreite: } & 50,0 & 46,4 & 46,7 \\ \text { Schwanz: } & 9,6 & 9,4 & 9,5 \\ \text { Schnabel: } & 5,1 & 4,9 & 4,95 \\ \text { Tarsus: } & 2,2 & 2,2 & 2,2\end{array}$

Wie schon Gloger hervorhebt, findet man bei schlesischen Wiedehopfen oft eine zweite Querbiude auf dem Schwanze angedeutet ( $\mathrm{Brehms}$ bifas:iata). Zur Zurzeit ist der Wiedehopf in Schlesien überall noch eine hiutige Erscheinung, aber als Brutvogel wird auch er mehr und mehr zurückgedrängt, obschon an manchen Punkten auch ein Heben seiries Bestandes zu verzeichnen ist, so nach $\mathrm{Kn}$ a uthe am Zobten, wo der Wiedehopf überhaupt gemein ist. In den Auwaldungen der Oder fand ich den anziehenden Vogel ebenfalls noch recht zahlreich, und auch in der Bartschniederung hörte ich oftmals sein fröhliches ${ }_{n}$ Huphup . Ebenso ist er nach Kollibay in den Auen des Neisseflusses nicht selten. Bacr traf ihn ungemein häufig bei Neusalz. In der Nadelwaldregion Oberschlesiens, in den Vorbergen und im grössten Teil der Lausitz ist er dagegen iecht sparsam vertreten, und dem Gebirge fehlt er völlig. Er liebt vorzüglich kleine, feuch te Feldhölzer mit hohlen Bäumen oder Waldränder, welche an Hutungen stossen, auch die umbuschten Dämme der Teichgegenden. Im Herbst sieht man ihn of gesellschaftsweise in den Kartoffeläckern (L. Tobias).

Siehe nebenstehende Zugtabelle! 


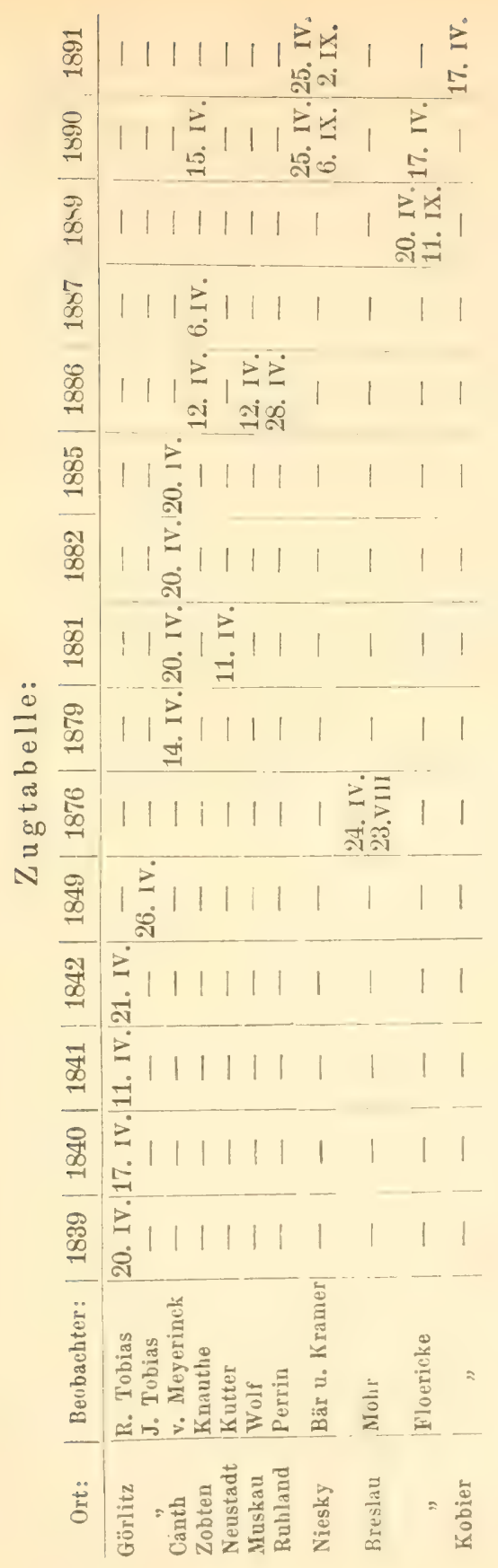


Bei Görlitz erfolgte die Ankunft nach R. Tobias rou 1832-33 frühestens am 13. April, spätestens am 3. Mai und im Mittel am 24. April. Bei den grossen Pferderennen in Scheitnig sah ich wiederholt Wiedehopfe, welche ängstlich und ratlos auf der von tausenden von Zuschauern eingefassten Arena herumflatterten. Die armen Vögel hatten vollständig den Kopf verloren über dem sie umgebenden Lärm und Getöse. Wahrscheinlich hatten sie sich ihrer Gewohnheit gemäss im Anfang gedrückt und waren darüber vollständig eingeschlossen worden. Nur einmal beobachtete ich, wie ein Wiedehopf sich hoch in die Luft erhob und entfloh; seine Kameraden kamen wahrscheinlich eben so elend ums Leben wie die „Manöverhasen“ bei ähnlichen Gelegenheiten. Das Nest steht in Baumhöhlen, Spechtlöchern, alten Kopfweiden, nach L. Tobias selbst in Erlenstöcken auf der Erde. Praetorius fand schon am 2. Mai das volle Gelege und am 21. nackte Junge. Ich selbst traf am 30. Juni eben dem Ausfliegen nahe Junge. Durchschnittsmaasse von 6 schlesischen Eiern $=24,5+17,5 \mathrm{~mm}$.

\section{Familie: Meropidae, Bienenfresser.}

Schlanke, prachtvoll gefärbte Vögel mit scharfschneidigem, mehr als kopflangem, sanft gebogenem Schnabel. Die rundlichen Nasenlöeher werden von Borstenfederchen überdeckt. Die Mittelzehe der sehr kleinen Füsse ist bis zum zweiten Gelenk mit der Aussen- und bis zum ersten mit der Innenzehe verwachsen. In den spitzen Flügeln ist die 1. Schwinge sehr klein, die 2. am längsten. Der lange Schwanz ist 12 fedrig.

Gattung: Merops L. 1768. - S schwalbenspint.

siehe die Familiencharaktere, da nur diese eine Gattung in Dentschland.

130. Merops apiaster L. 175\%. - Bienenfresser.

ś y no 11 y ma: Ispida merops L.; A piaster icterocephalus Briss.; Merops Shateghagi Forsk; Nerops galileus Hasselqu; Merops conger et chry socephalus Gm.; Merops brevirostris Rehbeh.; Merops Ifungariae et clegans Chr. Brehm; Mcrops apiaster L., Scop., Gm., Behst., Chr. Brehm, Naum., Gould, Glog., Gieb., Kays. u. Blas., A. Br., y. Hom., Mew., Fridr., Radde, Hart., Gättke, Jäckel.

Trivialnamen: Heumöher.

Kennzeichen der Art: Siehe die Gattungsmerkmale, da nur diese eine Art in Deutschland.

l)er prachtvolle, in Sïdeuropa heimische Bienenfresser ist schin melirfach in schlesien vorgekommen und hat sogar in zwei Fällen nachweisslich bei uns gebrütet. In den Jahren des furchtbaren Raupenfrasses im Anfang unseres Jahrhunderts wurde nach B ratlıs ein kleiner Flug Bienenfresser auf Trebuher Revier bei Niesky gesehen und ein Exemplar dvaon geschossen. Feruer 
wurden nach R. Tobias im Juli 18303 Stück an einer nach Görlitz führenden Obstbaumallee beobachtet. Hnd ler berichtet: „Im Sommer 1792 zeigten sich mehrere Bienenfresser in Schlesien, von denen auch einige geschossen und ausgestopft wurden. Ich überzeugte mich sogar, dass sie am Obleflusse unweit der Stadt Ohlau genistet hatten, denn ich bekam von dort her einen sehr jungen, noch nicht befiederten Bienenfresser zugeschickt, welchen ich mit Fliegen und Mehlwürmern auffütterte." Ganz an derselben Stelle brütete 1824 wieder ein Pärchen der farbenschönen Fremdlinge (Gloger). Ohlau dürfte also neben Ziegenhain in Hessen der nördlichste bisher bekannte Brutplatz des Bienenfressers sein. Luchs behauptet, dass der Bienenfresser alljälurlich zwischen Hirschberg und Warmbrunn erscheine, welche Ängabe ich denn doch mit einem Fragezeichen versehen möchte.

F a milie: Alcedinidae, E is vögel.

Dickköpfige, schön gefärbte Vögel mit langem, starkem, geradem, vierkantigem, allmählich zugespitztem Schnabel und sehr kleinen Füsschen, an denen die Mittel- und Aussenzehe bis zum zweiten Gelenk verwachsen sind. Die durch eine Haut verschliessbaren Nasenlöcher sind klein und ritzenförmig. In den kurzen, stumpfen Flügeln sind die aussen verengte 2 . und 3 . Schwinge am längsten. Der ungemein kurze Schwanz ist 12fedrig:

Gattung: Alcedo L. 1758. - Eisvogel.

Siehe die Familiencharaktere, da nur diese eine Gattung in Deutschland.

\section{Alcedo ispida L. 1758. - E is vogel.}

Synonyma: Corvus aegyptius Hasselqu.; Gracula atthis Gm.; Sturnus attis Daud.; Alcedo cristata Sand.; Alcedo aegyptia Vieill.; Alcedo bispida Less.; Alcedo Pallasii Reichb.; Alcedo subispida, A. advena, A. brachyrhynchus Chr. Brehm; Alcedo bengalensis Gml.; Alcedo ispida L., Scop., Gm., Bchst., Chr. Br., Naum., Gould, Glog., Gieb., Kays. u. Blas., A. Br., v. Hom., Mew., Fridr., Radde, Hart., Gätke, Jäckel.

Trivia In a men: Blauer Wasserspecht, seeschwalne, Eissengart, Wassertiintin. Polnisch: Zelony, Rybiorez.

Kennzeichen der Art: Siche die Gattungsmerkmale, da nur diese eine Art in Deutschland.

Masse von 's schlesischen Exemplaren in cm:

$\begin{array}{lccc} & \text { maximum } & \text { minimum } & \text { Durchschnitt } \\ \text { Länge: } & 17,6 & 17,1 & 17,4 \\ \text { Flugbreite: } & 28,2 & 27,6 & 27,9 \\ \text { Schwanz: } & 4,2 & 4,0 & 4,1 \\ \text { Schnabel: } & 4,0 & 3,8 & 3,9 \\ \text { Tarsus: } & 2,1 & 2,0 & 2,05\end{array}$


Die schlesischen Eisvögel stellen grosswüchsige und sehr typische ispita dar, ohne alle Anklänge an bengalensis, den ich nur als Subspecies gelten lassen mag, da Uebergänge keineswegs selten sind.

Wenige Vögel sind in ihrem Bestande während der letzten Jahre so zurückgegangen wie der farbenprächtige Eisvogel. Die das Wasser der Bäche vergiftenden Fabriken, die Fischereien mit ihrer übertriebenen Verfolgungswut und ihren Schiessprämien und sich gern knallen hörende Sonntagsjäger haben den "tliegenden Edelstein “ unserer Gewässer auf dem Gewissen. Daneben vernichtet auch das Hochwasser viele Bruten und trägt dadurch sehr zum Schwanken des Bestandes bei. In vielen Gegenden ist der Eisvogel völlig ausgestorben oder doch in Aussterben begriffeu $(z, B, a m$ Zobten), in den meisten schon recht selten geworden und nur in wenigen noch häufig zu nennen. Bei Breslau traf ich ihn nur ganz vereinzelt; weiter oderabwärts soll er nach L. Tobias zahlreicher sein. Im Gebirge ist er nirgends mehr häufig, eher noch an den linken Nebenflüssen der Oder, soweit diese durch die Vorberge und das Hügelland fliessen. In den Teichlandschaften ist er 'zwar' ein regelmaissiger Gast zur Zugzeit, brütet aber kaum daselbst. Sylaender in Bolkenhayn ist der einzige von meinen Mitarbeitern, welcher den Eisvogel häufig nemnt, obschou ihn fast alle mit aufzählen. Im Winter müssen die Eisvögel noch ron auswärts Zuzug erhalten, da man dann viel mehr sieht. Der Schaden, welchen das Vögelchen der Fischerei zufügt, wird meist sehr übertrieben dargestellt. An Bächen, in denen Forellenzucht betrieben wird, ist er allerdings nicht zu dulden, sonst sollte man ihn aber unter Berücksichtigung seiner Seltenheit und seines ästhetischen Wertes gewähren lassen, zumal ja schon sein ungeselliges und einsiedlerisches Wesen seine Ueberhandnahme in ciner bestimmten Gegend ausschliesst. Praetorius fand am 22. Mai 1 s 22 bei Breslau ein Gelege von 9 Eiern in einer $23 / 4$ Fuss langen Röhre ohne jede Unterlage. Sonderbarer Weise wird im 1. Jahresbericht d. Aussch. f. Beob. Stat.d. Vögel Dentschlands, das Brüten des Eisvogels bei Breslau gänzlich geleugnet. Ich fand selbst an einem alten Wassergraben in der Strachate eine Niströhre, aus der ich die Jungen auskommen liess. Hübsche Beobachtungen über das Brutgeschäft des Eisvogels haben $\mathrm{K} u \mathrm{t}$ t e $\mathrm{r}$ und Kolli b a y bei Neustadt gemacht. Am 22 . April 1881 fanden dieselben ein $i$ Tage lang bebrütetes Gelege von 7 Eiern, am 17. Ilai ein eben so grosses und sehr stark bebrütetes Gelege, aber am 30. desselben Monats wieder 6 frische Eier. Der Vogel war dort ziemlich häufig.

M a asse von 12 schlesischen Eiern in mm:

$$
\text { maximum minimum Durchschnitt }
$$

Länge :

Breite:

22

19

17,5 22,5

18,5 
IV. Ordnung: Scansores, Klettervögel.

Kleine oder mittelgrosse Vögel ohne Singmuskelapparat, mit kurzen Füssen, an denen 2 Zehen nach vorn und zwei (oder eine) nach hinten gerichtet sind. Schwanz 10- oder 12 fedrig. Die 3. oder 4. Schwinge am längsten.

Familie: Picidae, Spechte.

Schnabel ziemlich kopflang, hart, gerade, meisselartig. Die eirunden Nasenlöeher liegen nahe der stim. Die oft auffallend lange, wurmförmige und an der Vorderspitze mit Widerhäkchen versehene Zunge kann curch die um den ganzen Kopf herum bis zur Nasenwurzel verlaufenden Zungenbeimmuskelı plötzlich vorgeschnellt und dann wieder in eine besondere Scheide zurückgezogen werdell. Die nach hinten gerichtete Aussenzche ist die grösste, die beiden Vorderzehen sind bis zur Hälfte des 1. Gliedes verwachsen; alle tragen starke, sehr gebogene Krallen. Die 1. Schwinge ist stets kürzer als die Armschwingen. Der zur Unterstützung beim Klettern dienende Schwanz hat 12 Federn mit sehr elastischen, fischbeinartigen und ohne Fahnen endigenden Schäften. Doch ist das äusserste Schwanzfederupaar unter den Deckfedern verborgen.

Gattung: Picus L. 1758. - Erdspecht.

Die Zunge ist ungefähr dreimal so lang als der Schmabel. Das Gefieder ist in der Hauptsache grünlich gefärbt. Sie halten sich zur Nahrungssuche mehr auf der Erde und weniger auf Bäumen auf als andere Spechte.

\section{Picns viridis L. 1758. - Grünspecht.}

Synonyma: Gecinus viridis Boie, Kays. u. Blas, v. Hom. Mew., Radde, Jäckel; Gecinus Sharpei Saund,; Gecinus Saundersi Tacz,; Gecinus Vaillanti Nal.; Gecinus pinctorum, Cr. frondium, G. virescens, G. brachyrhynchus Chr. Brehm; Brachylophus viridis Swains.; Chloropicus viridis Malh.; Picus semirostris L.; Picus viridis L., Gm., Bchst., Chr. Brehn, Naum., Gould, Lilog., Gieb., A. Br., Fridr., Hart., Gätke.

Trivialnamen: Grasspecht, grüner Bamblacker, grüner Holzhacker. ITendisch: Pujak. Polnisch: Zanna.

Kenuzeichen der Art: Simtliche Schwanzfedern sind bandirt.

M a as e von 14 schlesischen Exemplaren in cm:

$\begin{array}{lccc} & \text { maximum } & \text { minimum } & \text { Durchschnitt } \\ \text { Länge: } & 31,9 & 31,1 & 31,6 \\ \text { Flugbreite: } & 51,2 & 50,5 & 50,9 \\ \text { Schwanz: } & 11,4 & 11,1 & 11,2 \\ \text { Schnabel: } & 4,4 & 4,1 & 4,3 \\ \text { Tarsus: } & 2,9 & 2,7 & 2,85\end{array}$


In den Auwaldungen des Oderthales ist der Grünspecht sehr häufig, und gerade bei Breslau fand ich ihn zahlreich, während ihn Mohr dort nur zweimal beobachtet haben will. Der Vogel müsste demnach erst neuerdings dort eingewandert sein oder sich sehr vermehrt haben, was nicht eben viel Wahrscheinlichkeit für sich hat. Auch in der Bartschniederung begegnete ich ihm vielfach auf den Teichdämmen wie am Rande und auf den Blössen des Waldes. Laubhölzer bewohnt er mit Vorliebe, auch gemischte Waldungen ganz gern und nur die tiefen Nadelwaldungen meidet er fast gänzlich. Deshalb ist er auch in Oberschlesien verhältnismässig selten, in den anderen Teilen der Provinz dagegen so häufig wie in wenigen Gegenden Deutschlands. Knauthe führt ihn mit der Bezeichnung "massenhaft" auf und Richter nennt ilın geradezu den gemeinsten Specht. In den Vorbergen kommt er vor, fehlt aber dem eigentlichen Gebirge. Doch beobachtete ihn A. v. Hom e yer bein Aufstieg auf die Tafelfichte. Im Winter kommt der Grünspecht ungescheut bis in die Gärten selbst grosser Städte. Den Bienenstöcken thut er alsdann bisweileu grossen Schaden, indem er sowohl die Bienen als den Honig verzehrt. v. M e y erinck stellte fest, dass ein einziger Grünspecht auf diese Weise 12 Bienenstöcke gänzlich zerstörte. Praetorius fand das volle Gelege am 2. Mai 1872 bei Breslau. Durchschnittsmaasse von 4 schlesischen Eiern $=3,0+2,3 \mathrm{~cm}$.

133. Picus viridicanus Wolf. 1810 . - Gra uspecht.

Synonyma: Chloropicus canus Malb.; Brachylophus canus Swains.; Gecinus canus Boie, Degl.., Kays, u. Blas., v. Hom., Mew., Radde, Jäckel; Gecinus viridicanus et caniceps Chr. Br.; Picus canus Gm., Bchst., Naum., Glog., Gieb., A. Brehm; Picus norvegicus Lath., Vieill.; Picus viridis Scop.; Picus chloris Pall.; Picus caniceps Nils.; Picus viridicanus Meyer, Hartert.

Kenuzeichen der Art: Nur die beiden mittelsten Federn des Schwanzes sind gebändert.

Durchsehnittsma asse von 3 schlesischen Exemplaren in $\mathrm{cm}$ : Länge - 30,3; Flugbreite = 46,4; Schwanz $=10,8$; Schnabel $=3,1 ;$ Tarsus $=2,4$.

Der Grauspecht ist in Schlesien ungleich seltener als die vorige Art und felilt den Landstrichen rechts der Oder wohl völlig, ist auch in der Ebene auf dem anderen Ufer eine sehr seltene Erscheinung. Auch die Lausitz beherbergt ihn nur spärlich. Nach dem Gebirge zu wird er häufiger und ist am zablreichsten noch in den grossen Laubwäldern der Vorberge und der niedrigeren Teile der Sudeten zu finden. In dem Höhengürtel von 2000-2500 Fuss dürfte er bei uns sein Verbreitungsmaximum erreichen. Das Breslauer Museum besitzt 2 schlesische Belegexemplare. Von meinen Mitarbeitern führen Baer, Sylaeuder und Emmrich 
ihn als Brutvogel auf. II a asse von einem schlesischen $\mathrm{Ei}=$ $25+20 \mathrm{~mm}$.

Gattung: Picoides Lac. 1801. - Stumnelspecht.

Die eigentliche Hinterzehe ist bei diesen Spechten ganz in Wegfall gekommen.

134. Picoides tridactylus (L.) 1758 . - Dreizehenspecht.

Synonyma: Picus tridactylus L., Edw., Gm., Bchst., Gieb., Kays. u. Blas, Fridr.; Picus hirsutus Vieill.; Dendrocopus tridactylus Koch; Dryobates tridactylus Boie; Tridactylia tridactylus Mew.; Tridactylia hirsuta Steph., Cab.; Pipodes tridactylus (rlog.; Apternus tridactylus Gould, Rehw., Jickel; Apternus longirostris, A. montanus, A. septentrionalis Chr. Brelım; Picoides variegatus Val.; Picoides europaens Less., Malh.; Picoides alpinus, P. montanus, P. septentrionalis Chr. Br.; Picoides tridactylus Lac., Chr. Brehm, A. Brehm, v. Hom., Hartert.

Trivi 1 n a men: Starspecht.

Kennzeichen der Art: Siehe die Gattungsmerkmale, da nur diese eine Art in Deutschland.

Der Dreizehenspecht gehört zwar auch in Schlesien zu den Seltenheiten, aber doch nicht in dem Grade wie in den ïbrigen Provinzen der preussischen Monarchie. Gloger sagt von ihm: "Gehört weder tief im Riesengebirge noch im Gesenke und Altvater zu den Seltenheiten und ist dort allgemein bekannt." Ias Breslauer Museum besitzt "2 schlesische Belegexemplare, lcider ohne alle näheren Daten. Auch in der Sammlung Heydrichs befinden sich 2 bei Schreiberhan erlegte Dreizehenspechte, von denen der eine 1880 geschossen wurde. Aus der Lausitz sind ebenfalls 2 bei Zittau und bei Hirschfelde erlegte Exemplare bekannt geworden. L. Tobias berichtet von einem cinmaligen Vorkommen des tridactylus bei Neusalz; doch erseheint dieser Fall nicht ganz sicher. Kramer beobachtete den Dreizehenspecht 1890 am Reifträger und ich selbst beim Autstieg zur Sohmeegrube. Ob der Vogel in Schlesien brütet ist immer noch eine ottene Frage. A. v. Homeyer nennt ihn zwar einen nseltenen Brutvogel im Isergebirge", erbringt aber eben so wenig Beweise datïr wie diverse andere Beobachter.

Gattung: Dendrocopus Koch. 1s16. -- Buntspecht.

Die Buntspechte sind oben schwarz und weiss gefleckt und gebändert. Nur die $4-6$ mittelsten Schwanzfedern sind zugespitzt und fischbeinartig.

135. Dendrocopus minor (L.) 1758. - 'Lwergspectit.

Sy n on yma: Picus minor L., Gm., Behst., Butf., Naum, Gould, Mall., Glog., Gieb., Kays. u. Blas., A. Br., v. Hom., Fridr., 
Radde, Jäckel; Picus pipra Pall.; Picus striatus Macg.; Picus hortorum, P. herbarum, P. crassirostris, P. pusillus Chr. Brehm; Picus kamtschkadensis Sand.; Picus minor quadrifasciatus Radde; Picus pusillus Chr. Br.; Dryobates minor Boie; Hylocopus minor Mewes; Pipripicus minor Bp.; Hylocopus minor Cab.; Dendrocopus minor Koch, Hartert.

Trivialnamen: Grasespecht. Wendisch: Maty Düpürnak. Polnisch heissen alle Buntspechte Dziendziol.

Kennzeichen der Art: Grösse unter $16 \mathrm{~cm}$.

$\mathrm{M}$ a a s e von 10 schlesischen Exemplaren in $\mathrm{cm}$ :

$\begin{array}{lccc} & \text { maximum } & \text { minimum } & \text { Durchschnitt } \\ \text { Länge: } & 14,6 & 14,3 & 14,4 \\ \text { Flugbreite: } & 28,0 & 27,4 & 27,7 \\ \text { Schwanz: } & 5,6 & 5,4 & 5,5 \\ \text { Schnabel: } & 1,5 & 1,3 & 1,4 \\ \text { Tarsus: } & 1,4 & 1,4 & 1,4\end{array}$

Der niedliche Zwergspecht, einer meiner ganz besonderen Lieblinge aus der Vogelwelt, ist ebenfalls ein Charaltervogel der schönen Laubwälder des Oderthales. Hier ist er verhältnismässig häufig und hält sich auch in Parkanlagen und grossen Gärten bisweilen ziemlich zahhreich auf. Mohr sagt zwar „bei Breslau nie gesehen", ich sah hingegen dort mehrmals an einem Tage wohl bei Dutzend und schätze allein in der Strachate auf alle 20-30 Morgen ein Brutpar. Auch in der Bartschniederung traf ich den Vogel ziemlich zahlreich, ebenso L. Tobias bei Neusalz. In Oberschlesien und in der Lausitz ist er weniger häutig und lommt in vielen Gegenden nur auf dem Striche vor. In der dem Sudetenzuge vorgelagerten Hügellandschaft tritt el wieder zahlreicher auf, aber dem eigentlichen Gebirge scheint er gänzlich zu fehlen. Wolf (Muskau), Kollibay (Neustadt), Sylaender (Bolkenhayn), v. Meyerinck (Canth) und Emmrich (Neurode) fülıren ihn als sicheren Brutvogel auf. Oefters als andere Buntspechte sah ich diese Art ganz niedrig über oder selbst auf dem Boden, woraus sich auch sein schlesischer Volksname "Grasespecht" ableiten mag. Oft sah es in der That aus, als ob der ganz niedrig an einem jungen Stämmchen kletternde Specht in dem hohen umgebenden Grase herumhüpfe. A. v. Homeyer beobachtete am 15. Juni 1866 eben flügge gewordene junge Zwergspechte an einem nach Nordwesten gerichteten Nistloche. Durchschnittsmaase von 2 schlesischen Eiern = $17,75+13,25 \mathrm{~mm}$.

136. Dendrocopus medius (L.) 1758. - Mittels pecht.

Synonyma: Picus medius L., Gm., Bchst., Naum., Gould, Malh., Glog., Gieb., Kays. u. Blas., A. Br., v. Hom., Fridr,, Radde, 
Jäckel; Picus varius Briss, Butl.; Picus cynaedus Pall.; Picus quercuum, P. roseiventris, P. meridonalis Chr. Br.; Pieus Saneti Johannis Blanf; P'ipripicus medius Bp.; Dendrocoptes medius Cab., Mewes; Dendrocopus medius Koch, Hartert.

Trivialnamen: Rotspecht.

Kennzeichen der Art: Grösse über $16 \mathrm{~cm}$. Bürzel schwarz, welche Farbe dem Gesicht fehlt. Unterleib und After rosenrot.

M a as e von 20 schlesischen Exemplaren in $\mathrm{cm}$ :

$\begin{array}{lccc} & \text { maximum } & \text { minimum } & \text { Durchschnitt } \\ \text { Länge: } & 19,8 & 19,4 & 19,5 \\ \text { Flugbreite: } & 38,0 & 37,4 & 37,6 \\ \text { Schwanz: } & 8,4 & 8,2 & 8,3 \\ \text { Schnabel: } & 2,6 & 2,3 & 2,4 \\ \text { Tarsus: } & 2,3 & 2,3 & 2,3\end{array}$

Im Breslauer Museum befindet sich ein ganz weisses Exemplar mit einigen blutroten Schulterfedern.

Der Mittelspecht, welcher in vielen Gegenden Deutschlands bekanntlich recht selten ist, ist in Schlesien eine sehr gewöhnliche Erscheinung. Namentlich das Oderthal beherbergt ihn in grosser Menge in seinen schören Auluölzern, und der Bestand von medius steht dort hinter dem von maior nur wenig oder gar nicht zurück, übertrifft ihn sogar in einigen Gegenden. Was letzte berichtet auch Wo lf für Muskau. Flussufer und überhaupt Gewässer liebt der Mittelspecht sehr. Das Laubholz, namentlich lichte Eichenund Buchenwälder zieht or gemischten Beständen vor und die grossen Nadelwälder meidet er so gut wie günzlich. Aus diesem Grunde giebt es auch in Oberschlesien, im Gebirge und in der Lausitz ungleich weniger Mittelspechte. I)oeh soll der Vogel mach $\mathrm{H}$ osius sogar bei Hermsdorf noch vereinzelt brïten. In der Görlitzer Heide kommt er nach Krezschmar gar nicht vor. Ein interessantes Begegnis mit dem Mittelspecht hatte ich am 2. April 18.0 im Schleipitzer Schlosspark. Ein brünstiges Spechtmännchen trieb in der bekannten stürmischen und hitzigen IV eise ein mir anders vorkommendes Weibchen durch die holien Wipfel der alten Eichen, holte es schlicsslich cin und zwang es zur Begattung. In diesem Noment holte ich beide durch einen Schuss herunter und hielt einen Augenblick später das Männchen von mertius und das Weibchen von maior in der Hand! Durchschittsmaasse von 4 schlesischen Eiern $=21+17 \mathrm{~mm}$.

137. Dendrocopus leuconotus (Bchst.) 1s02. - We issrückiger Buntspecht.

Synonyma: Picus leuconotus Bchst., Tieill., Chr. Br., Naum., Gould, Malh., Glog., Gieb., Kays. u. Blas., A. Br., Fridr., Radde, 
Gätke, Jäckel; Picus cirris Pallas; Picus uralensis Malh.; Pipripicus uralensis et leuconotus Bp.; Dendrodromas leuconotus Kaup, Cab., Mewes; Dendrocopus leuconotus Koch, Hartert.

Trivialnamen: Elsterspecht.

Kennzeichen der Art: Grösse über $16 \mathrm{~cm}$. Bürzel weiss, Bauch und After roseniot.

Ich möchte vermuten, dass leuconotus in Schlesien gar nicht so sehr selten ist als man bisher angenommen hat. Schon Kaluza war dieser Ansicht, denn er sagt: "Nicht sehr selten, wird aber liäufig mit medius verwechselt." Es ging eben damals wie heute: es fehlte weniger an seltenen Vögeln als an kundigen und eifrigen Beobachtern. Das Breslauer Museum enthält 2 schlesische Stücke. Auch in der Sammlung der "Senckenbergischen naturf. Gesellsch." in Frankfurt a. M. befindet sich ein junges Männchen des Elsterspechtes, welches nach $\mathrm{Hartert}$ autrallend alten Datums sein muss und auffallend viel Weiss zeigt. Mir selbst kam der Vogel bei Breslau zweimal in den Oderwaldungen südöstlich der Stadt zu Gesicht und erlegte das cine Exemplar für moine Sammlung. In beiden Fällen fielen mir die Vögel sehr durch ihre grosse Zutraulichkeit auf.

138. Dendrocopus maior (L.) 1758. - Grosser Buntspecht.

Synonyma: Picus maior L., Gm., Behst., Naum., Gould, Malh., Chr. Br., Glog., Gieb., Kays. u. Blas., A. Br., v. Hom., Fridr., Radde, Gätke, Jäckel; Picus cissa Pall.; Picus pipra Macg., Picus baskiriensis $\mathrm{B}_{\mathrm{p}}$.; Pieus brevirostris, P. presospilus, P. alpestris Rchbch.; Picus lucorum, P. sordidus, P. pinetorum, P. pityopicus P. montanus, P. frondium Chr. Brehm; Dryobates maior Boie Dendrocopus maior Koch, Cab., Hartert.

Trivialn a m e n: Boomhacker, Gesprengelter Specht, Elster-, Weiss-, Rot- und Bandspecht. IVendisch: Wulki Düpuirnak.

Kenuzeichen der Art: Grösse über $16 \mathrm{~cm}$. Bürzel schwarz. Das schöne Rot des Afters dehnt sich nicht auf den Unterleib aus. Vom Mundwinkel aus erstreckt sich ein schwarzer Streif nach dem Halse zu.

$\mathrm{M}$ a a s e von 22 schlesischen Exemplaren in $\mathrm{cm}$ :

$\begin{array}{lccc} & \text { maximum } & \text { minimum } & \text { Durchschnitt } \\ \text { Länge: } & 23,6 & 21,8 & 23,1 \\ \text { Flugbreite: } & 44,8 & 43,5 & 44,2 \\ \text { Schwanz: } & 9,5 & 9,1 & 9,3 \\ \text { Schnabel: } & 2,6 & 2,5 & 2,5 \\ \text { Tarsus: } & 2,5 & 2,4 & 2,4\end{array}$

Die anscheinend bedeutenden Grössenverschiedenheiten erklären sich dadurch, dass die Weibchen ständig und erheblich 
kleiner sind als die Mäunchen, worauf' schon Radde aufmerksam gemacht hat. Die Abtönung der Unterseite variirt ebenfalls sehr, was mit dem Alter und der Lebensweise, auch mit dem Aufenthalte zusammen zu hängen scheint. Im Breslauer Museum notirte ich einen reinen Albino.

In den meisten Gegenden Schlesiens ist der grosse Buntspecht der gemeinste Specht. Dies gilt namentlich von der Lausitz, den Sudeten und Oberschlesien, üherhaupt von denjenigen Landstrichen, in welchen der Nadelwald prävalirt. Fast einstimmig melden die Beobachter ein starkes Abnehmen des Buntspechtes, welches mit der heutigen Forstwirtschaft zusammenhängen dürfte. Auch im Riesengebirge kommt diese Art zahlreich vor und ist namentlich in dem Waldgürtel von $7-900 \mathrm{~m}$ Meereshöhe so recht heimisch. Durchschnittsmaasse von 6 schlesischen Eiern $=-25,5$ $+19,75 \mathrm{~mm}$.

Gattung: Dryocopus Boie. 1826 - Schwarzspeht.

Grosse Spechte mit vorwiegend schwarzem Gefieder.

139. Dryocopus martius (L.) 1758. - Schwarzspecht.

Synonyma: Picus niger L.; Picus maior Briss.; Picus martius L., Gm., Bchst., Buff., Naum., Gould, Chr. Br., Glog., Gieb., Kays. u. Blas., A. Br., Fridr.; Carbonarius martius Kaup; Dryotomus martius Swains.; Dryopicus martius Mall.; Dendrocopus martius, D. pinetorum, D. alpinus, D. niger Chr. Brehm; Dryocopus martius Boie, Cab., Radde, Hart., Jäckel.

Trivialnamen: Waldpferd, Holzkrähe, Holzkrahe, Holzhuse, Krahspecht. Wendisch: Kanja. Polnisch: Zanna.

Kennzeichen der Art: Siehe die Gattungsmerkmale, da mur diese eine Art in Deutschland.

$\mathrm{M}$ a asse von 6 schlesischen Exemplaren in $\mathrm{cm}$ :

$\begin{array}{lccc} & \text { maximum } & \text { minimum } & \text { Durchschnitt } \\ \text { Länge: } & 41,1 & 40,2 & 40,7 \\ \text { Flugbreite: } & 74,9 & 74,1 & 74,6 \\ \text { Schwanz: } & 16,8 & 16,5 & 16,7 \\ \text { Schnabel: } & 5,5 & 5,4 & 5,5 \\ \text { Tarsus: } & 3,7 & 3,6 & 3,6\end{array}$

Auch hier sind die Weibchen merklich kleiner.

Der herrliche Schwarzspecht, diese stolze Zierde unserer alten Hochwaldbestände, der in den meisten Gegenden Deutsch. lands leider schon so selten geworden ist, hat in einigen Strichen unserer Provinz, wo der Grossgrundbesitz noch über weite und ruhige Forsten gebietet, glïcklicherweise noch einen schützenden Zufluchtsort gefunden und ist deshalb verhältnismiissig häufig. In der Bartschniederung $z$. B. sah und hörte ich ihn fast täglich 
und erhielt mehrere sehr schöne Exemplare. Ebenso ist er in den grossen Waldungen Oberschlesiens, des Glatzer-, Eulen-, Riesenund Isergebirges ein regelmässiger, wenn auch spärlich auftretender Brutvogel, und daselbe gilt von der Lausitz. Den Bestand der Görlitzer Heide schätzt A. v. Homeyer auf 10-15 Brutpare. Meine Mitarbeiter führen den Schwarzspecht fast sämtlich mit auf, namentlich die Oberschlesier. Der stattliche Vogel liebt insbesondere die ältesten gemischten Hochwaldreviere, während er krüppelhafte und mit Flechteu überkleidete Nadelhölzer nicht gern bewohnt. Auf dem Striche kommt er auch in die Parkanlagen, nach Kuauthe selbst in grosse Obstgärten. Im Gebirge steigt er ziemlich hoch empor. Zacharias beobachtete ihn häufig noch oberhalb der Schlingelbaude (11184 m). Nach Kollibay liatte ein Schwarzpecht bei Wolfshau an einer ganz gesunden, mittelstarken Buche seine Bruthöhle gezimmert, nachdem er den Baum schon vorher an einer anderen Stelle angegriffen hatte. Am 27. Juli erhielt Kolli b a y ein noch nicht ausgefiedertes Junge. Durchschnittsmaasse von 3 schlesischen Eiern $=30, \overline{5}+21 \mathrm{~mm}$.

Familie: Indicatoridae, S päh ög el.

Siehe die Charaktere der einzigen deutschen Gattung!

Gattung: Jynx L. 1758. - Wendehals.

Der spitzige und kegelförmige Schnabel ist kürzer als der Kopf. Die nahe an cinander gerückten Nasenlöcher liegen dicht vor der Stirn. Die ungemein lange, wurnförmige und vorschnellbare Zunge endet vorn in cine kleine Hornspitze ohne Widerhaken. Der lofedrige Schwanz ist abgerundet und weich und hat unter sich noch 2 sehr verkümmerte Seitenfedern. Die 1. Schwinge ist rudimentär, die 3. am längsten und nebst der t. aussen verengt. Das Gefieder ist sehr locker und zeigt zarte Baumrindenfarben.

140. Jynx torquilla L. 1758 . - Wendehals.

Syno nyma: Cuculus subgrisea et jyux L.; Picus jynx Pall.; Torquilla striata Briss.; Jynx torquilla L., Gm., Bchst., Naum., Gould, Malh., Chr. Br., Glog., Gieb., Kays, u. Blas., A. Br., v. Hom., Hew., Fridr., Hart, Jïckel; Jynx punctata, J. arborea, J. maior Chr. Brehm.

Trivia ln a men: Drehschlunk, Drehhals, Windhals, Weibermann, Natterwendel, verdrehtes Wagenrad.

Kennzeichen der Art: Siehe die Gattungsmerkmale, da nur diese eine Art in Deutschland. 
Ma asse von 18 schlcsischen Exemplaren in $\mathrm{cm}$ :

$\begin{array}{lccc} & \text { maximum } & \text { minimum } & \text { Durchschnitt } \\ \text { Länge: } & 18,1 & 17,7 & 18,0 \\ \text { Flugbreite: } & 28,0 & 27,4 & 27,8 \\ \text { Schwanz: } & 6,0 & 6,0 & 6,0 \\ \text { Schnabel : } & 1,2 & 1,2 & 1,2 \\ \text { Tarsus: } & 1,6 & 1,6 & 1,6\end{array}$

Der Wendehals ist in den Laubwaldungen Mittelschlesiens ungemein häufig, so z. B. bei Breslau. Namentlich liebt er alte Eichenbestände mit recht vielen Ameisenhaufen. Auch in gemischten Beständen findet man ihn vielfach, nie aber in blossen Nadelwaldungen. In kleinen Feldhölzern, Anlagen, Baumpflanzungen und Gärten ist der WVendehals eine sehr gewöhnliche Erscheinung. In Gegenden, wo sich auf weithin mu Nadelholz findet, stellt er sich nur auf dem Zuge ein. Lieser fillt in die zweite Hälfte des April und in den September.

Siehe umstehende Zugtabelle!

R. T'obias notirte bei Görlitz von $1332-33$ als frühesten Ankunftstermin den 21., als spätesten den 27. und als Durchschnitt den 24. April. Nach Baer findet ur eine Brut statt. Tolle Gelege fanden Praetorius am 16, und Thiemann am 28. Mai. Kutter traf am 26). Juni flügge Junge. Wiederbolt habe ich Wendehälse im Kätig gehalten, aber trotz ihres drolligen Gesichterschueidens und ihrer Anspruchlosigkeit wenig Freudo an ihnen erlebt.

Ma as se von 10 schlesischen Eiern in $\mathrm{mm}$ :

$\begin{array}{lccc} & \text { maximum } & \text { minimum } & \text { Durchschnitt } \\ \text { Länge: } & 21 & 19,5 & 20,25 \\ \text { Breite : } & 16 & 14,5 & 15,25\end{array}$

Familie: Cuculidae, Kuckucke.

Der etwas gebogene, schwache, aber scharfschneidige Schuabel ist nicht so lang wie der Kopf und hat kreisrunde, von einem hervorstehenden Rande umgebene Nasenlücher. Die Länfe sind sehr kurz, die äussere Hinterzehe eine Wendezehe. In den langen, schmalen und spitzigen Flügeh ist die 1. Suhinge gleich der 8. , die 3. am längsten. Der lange 10 fedrige Schwanz ist stufig abgerundet. Alle Federn sitzen sehr lose. Inbezug auf das Brutgeschäft sind viele Kuckucke Parasiten.

Gattung: Cuculus L. 1750. - Ba umkuckuck.

Die 2. Schwinge fast gleich der 4. Kopf ohne Federhaube.

141. Cuculus canolus L. 1755 . - Ku $\mathrm{ckuck}$. 


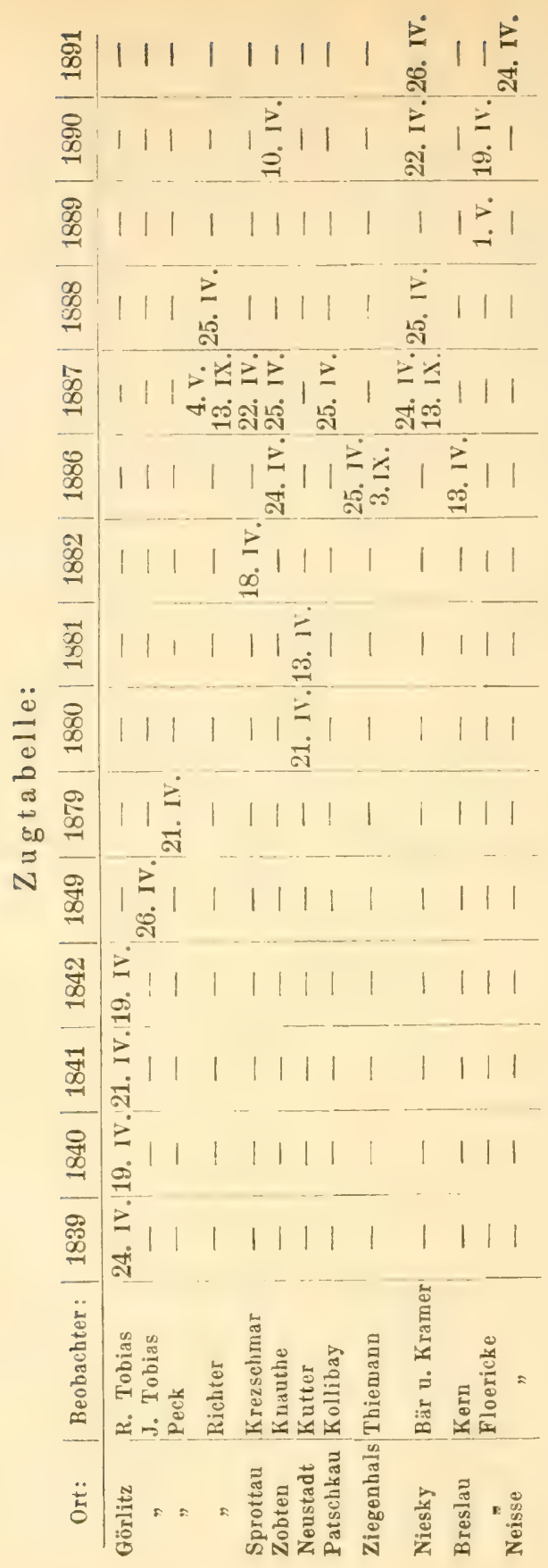


Synonyma: Cuculus hepaticus Sparrm.; Cuculus rufus Bchst., Herm.; Cuculus borealis Pall.; Cuculus tristis Iferm.; Cuculus tinereus Chr. Brehm; Cuculus indicus Cab.; Cuculus himalayanus Gould, Blyth; Cuculus telephonus Heine; Cuculus cuculus L.; Cuculus canorus L., Scop., Noz., Gm., Bchst., Chr. Br., Naum., Gould, Schleg., Gieb., Sylkes, Kay's. u. Blas., A. Br., v. Hom., Mew., Fridr., Radde, Hart., Gätke, Jäckel, Bald., Rey.

Trivialnamen: Guckauch, Gucker. Polnisch: Kulkowka. Wendisch: Kokula, Kokler, Kokla.

Kennzeichen der Art: Siehe die Gattungsmerkmale, da nur diese eine Art in Deutschland.

Maasse von 21 schlesischen Exemplaren in cm:

$\begin{array}{lccc} & \text { maximum } & \text { minimum } & \text { Durchschnitt } \\ \text { Länge : } & 31,4 & 29,9 & 31,1 \\ \text { Flügelbreite: } & 61,5 & 59,9 & 61,3 \\ \text { Sch.wanz: } & 17,3 & 16,9 & 17,0 \\ \text { Schnabel: } & 2,1 & 2,0 & 2,1 \\ \text { Tarsus: } & 1,6 & 1,6 & 1,6\end{array}$

Rotbraune Kuckucke kommen in Schlesien nur äusserst selten vor; ich sah nie einen. Der Kuckuck ist im grössten Teile Schlesiens ein ausserordentlich gemeiner Vogel und in manchen Auwäldern der Oder, Ohle, Buber, Neisse, Weistritz und anderer Flüsse sowie in den Erlenbrüchen der Bartschniederung findet man ihn in oft fabelhafier Menge. Dabei ist der Vogel fast überall noch im Zunehmen begriften. Auch im Gebirge ist er häufig und bewohnt noch die letzten Fichtenwälder des Riesengebirges in einem Höhengürtel von t:00 Fuss in sehr beträchtlicher Mlenge. Im Krummholz sah ihn r. T's ch us i noch vieltach, namentlich am Ziegenrücken. E. v. 'L 1 me yer' f'and ihn an der Elbbaude (3727 Fuss) und Kollibay am kleinen Teich ( 3650 Fuss), wo das Brutgebiet des WVasserpieper's beginnt, dessen Nester also der Kuckuck wahrscheinlich auch zum Ablegen seiner Eier benützt, obgleich mir noch kein diesbezügliches Gelege bekannt geworden ist. Z Z els arias erzählt sogar von einem Kuckucke, welcher sich 1890 an der 'Telegraphenleitung' auf der Schneekoppe (-1931 Fuss) tot geflogen hatte. Dieser t'all dürte beweisen, dass der Kuckuck auf seinen Wanderungen das Riesengebirge olme weiteres überfliegt und dasselbe für ihn kein Hindernis bildet. Nur grosse, geschlossene Nadelwaldungen wie z. B. die Gürlitzer Heide, meidet der Kuckuck fast gänzlich, bewohnt aber doch ihre Ränder und Vorhölzer. In den letzten Tagen des April pflegt der erste Kuckucksruf bei uns zu erschallen. Nach R. Tobias war dies von 1832-30 bei Gürlitz frühestens am 2:3. April, spätestens am 3. Mai und in Durehschnitt an 30. April der Fall.

Siehe umstehende Zugtabelle! 


$$
\begin{aligned}
& \text { 兽 }|1| 1|1| 1|1| 1|1| 1|1| 1|1| \frac{1}{8} \mid 1
\end{aligned}
$$

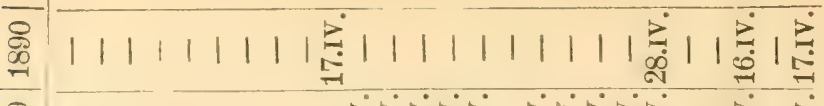

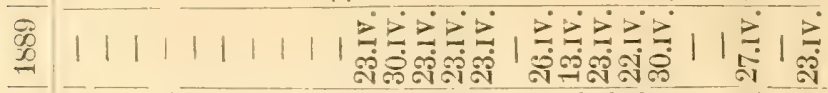

$$
\begin{aligned}
& \text { 要 | | | } \\
& \text { 年 | | 1 }
\end{aligned}
$$

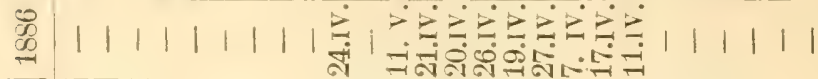

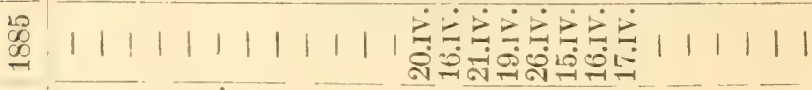

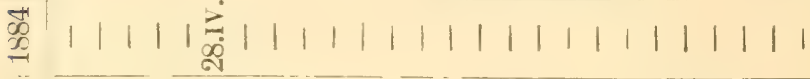

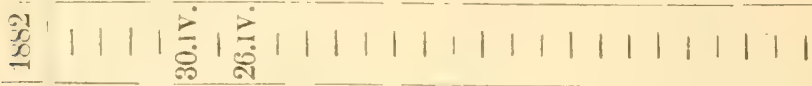

$$
\begin{aligned}
& . \text { 要 }
\end{aligned}
$$

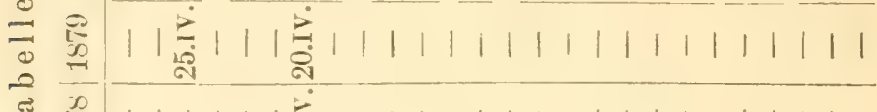

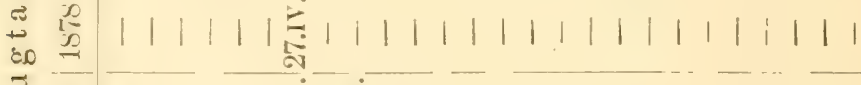

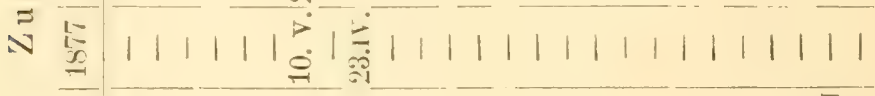

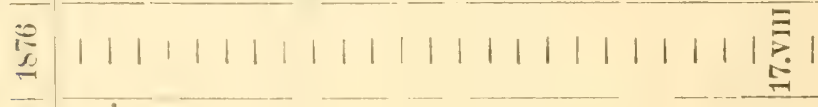

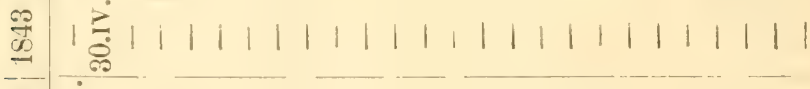

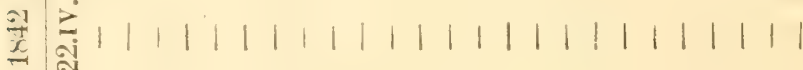

$$
\begin{aligned}
& \text { 尊度111111111111111111111111 } \\
& \text { 莺富 }
\end{aligned}
$$

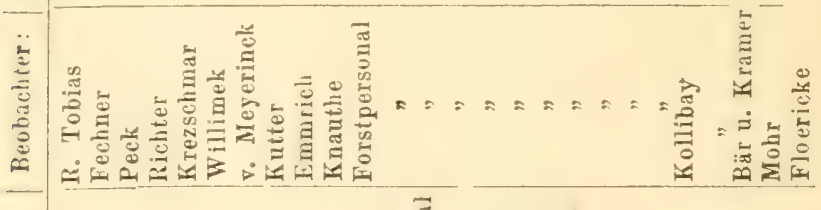

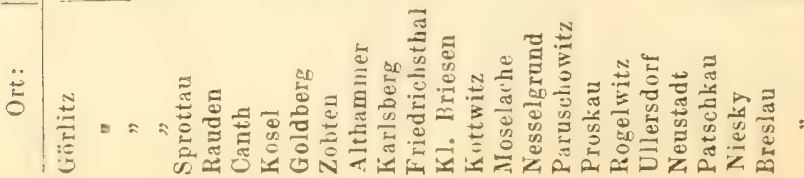


Ende Juni hört man nur noch ganz vereinzelte Kuckucksrufe, aber erst zu Beginn des September erfolgt der eigentliche Abzug. Vor demselben bekommt man die Vögel öfters als sonst zu sehen, denn sie kommen dann ans den Wäldern heraus auf die Landstrassen, wo sie auf den Birken und Pappeln sich allerlei Larven aufsuchen (z. B. von Cimlser variabilis und Tenthredo septentrionalis). Die Weibchen legen auch einen T(il ihrer Scheu ab, wenn es sich darum handelt, ihr Li in fremde Nester einzuschmuggeln; sie kommen dann selbst in kleinere Gärten. Noch mehr lassen die hitzigen Männchen bei ihren eifersüchtigen Zänkereien die sonstige Vorsicht ausser acht, Zwei solcher verliebter Cumpane balgten sich einmal keine 10 schritt vor mir auf einer kleinen und ganz frei an der Landstrasse stehenden Birke herum. Der mich begleitende Förster trat zurück und schoss den einen herunter, worauf der andere zunächst fortflng, aber gleich darauf wiederkehrte, wütend nach seinem eben gefallenen Gegner spähte und nun ebenfalls sein Leben lassen musste. Aus schlesien sind bisher folgende Pflegeeltern des Kuckucks mit Sicherheit bekannt geworden: Ruticilla phoenicura (Oberschlesien), Saxicola ocnanthe, Erithacus ruberulus, Hypolais philomela, Sylcia ruta, S. atricapilla, S. hortensis, S. niscria, Acroceplutus streperus und arundinaceus (Lausitz und Breslau), Motarilla alle und melanope und Anthus compestris (Neusalz). Kutter fand am 1. und 15. Juni Kuckuckseier bei Syleia hurtensis, die wohl von demselben Weibchen herrührten, da sie sich in demselben kleinen Gehölze vorfanden und einander sehr ämlich waren. Kollibay erbeutete am 8. Juni ein Kuckucksei mit 5 Nesteiern von Sylvia rufa. Während die Nesteier zu der dunklen Varietät gehörten, welche sich durch grosse aschgraue und ölbraume, an stumpfen Eude zusammentretende Flecke auszeichnet, ähnelte das Kuckucksei mehr der lichten Abart, bei welcher die weissliche Grundfarbe mur wenig durch punktartige Zeichung verdeckt wird.

In meinem ersten Verzeichnis schlesischer Vögel in Cabanis Journal hatte ich irrtümlicherweise auch den $\mathrm{H}$ eherkuckuck (Coccystes glandarius) mit aufgeführt. Freumdlichen Mitteilungen der Herren Dr. Reichenow und Baer zufolge wurden aber die betreffenden Stücke nicht imerhalb mserer Provinz, sondern a uf brandenburgischem resp. sächsischem Gebiet unweit der schlesischen Grenze erlegt, so dass ich diesen seltenen Irrgast wieder aus meiner Liste streichen musste. 




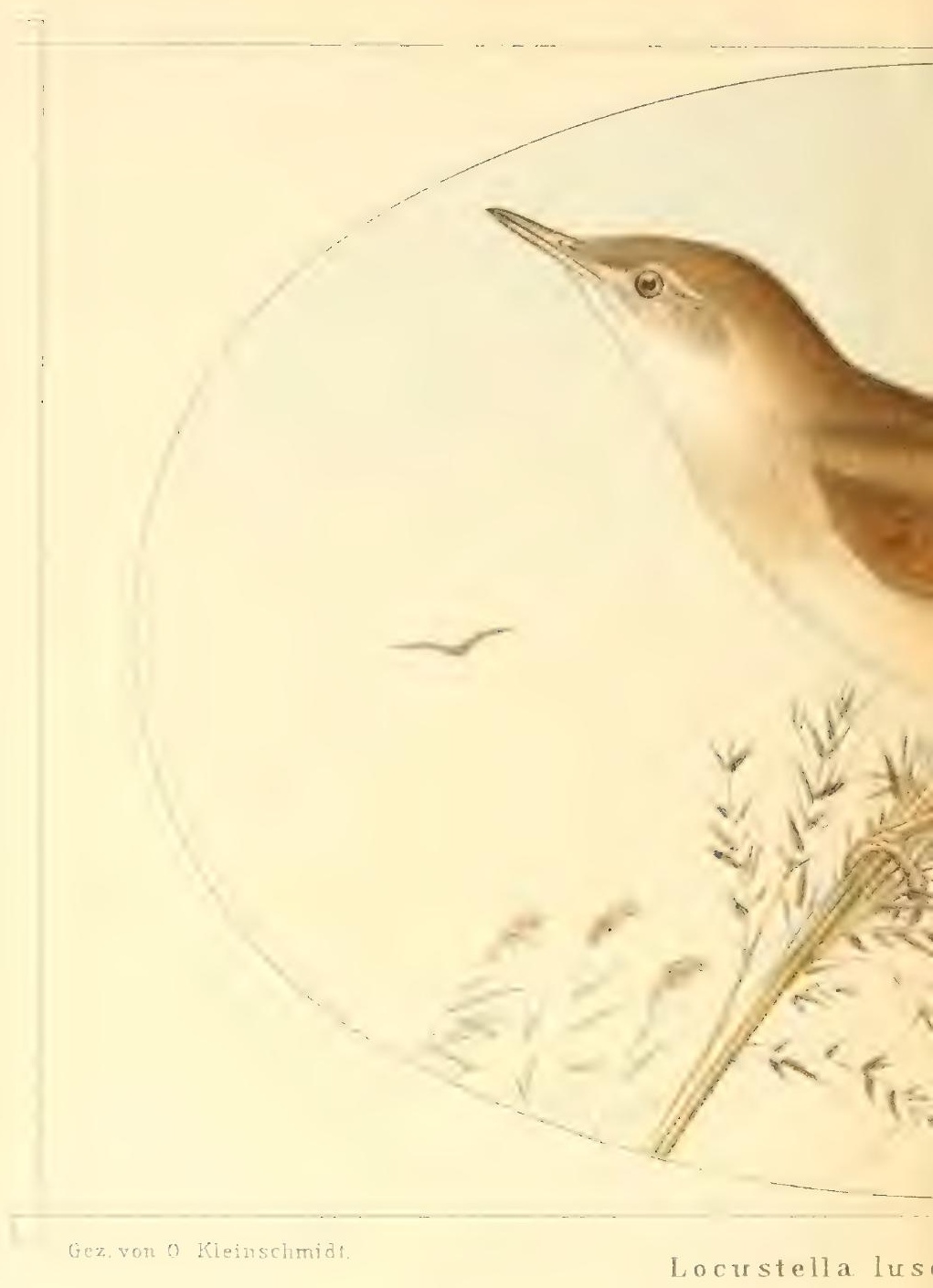




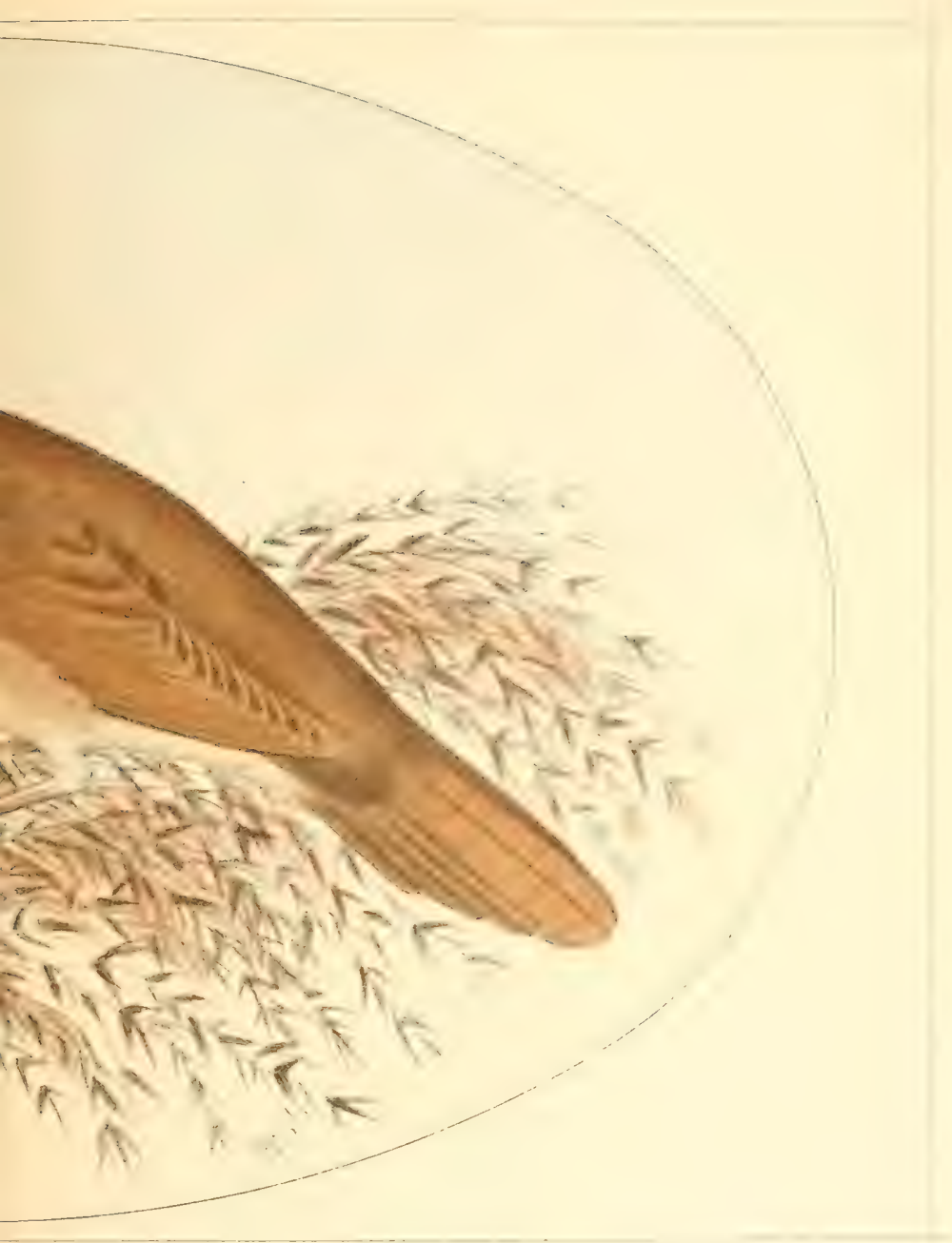

oides (Savi) 




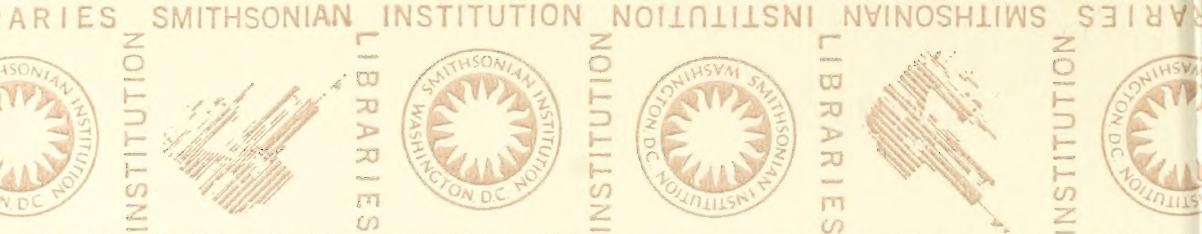

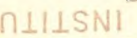
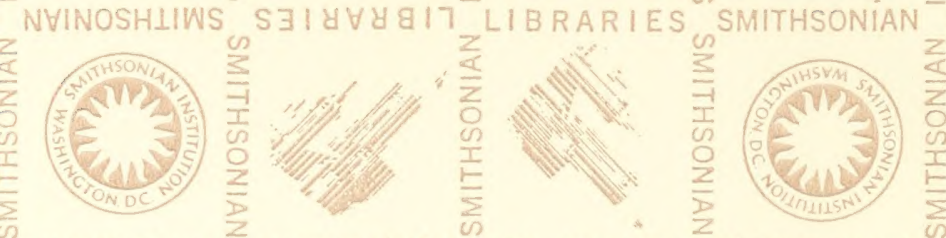

INSTITL ARIES SMITHSONIAN

INSTITUTION
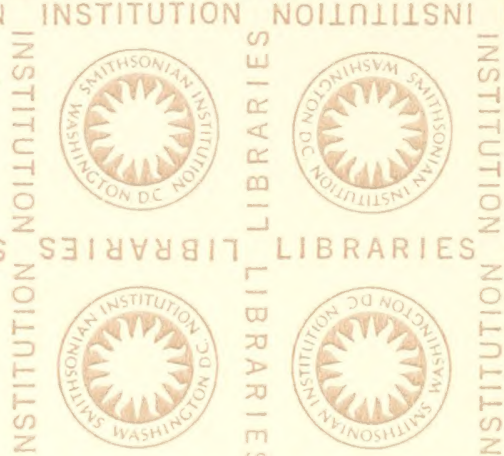
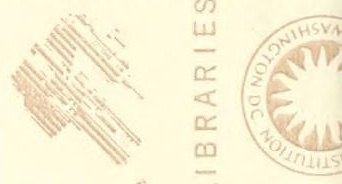

SMITHSONIAN

INSTITL
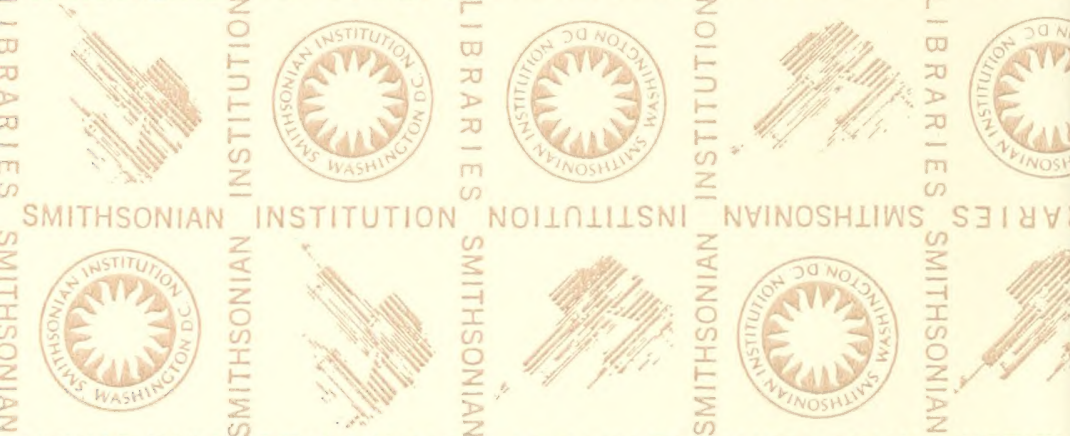

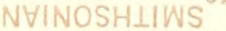
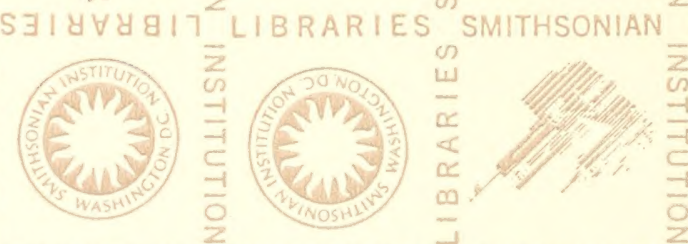

INSTITL

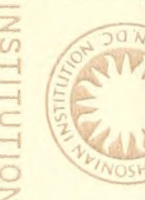

SMITHSONIAN
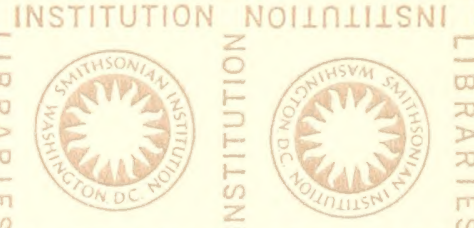

NVINOSHIIWS

$S \exists I d V$

2

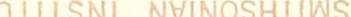
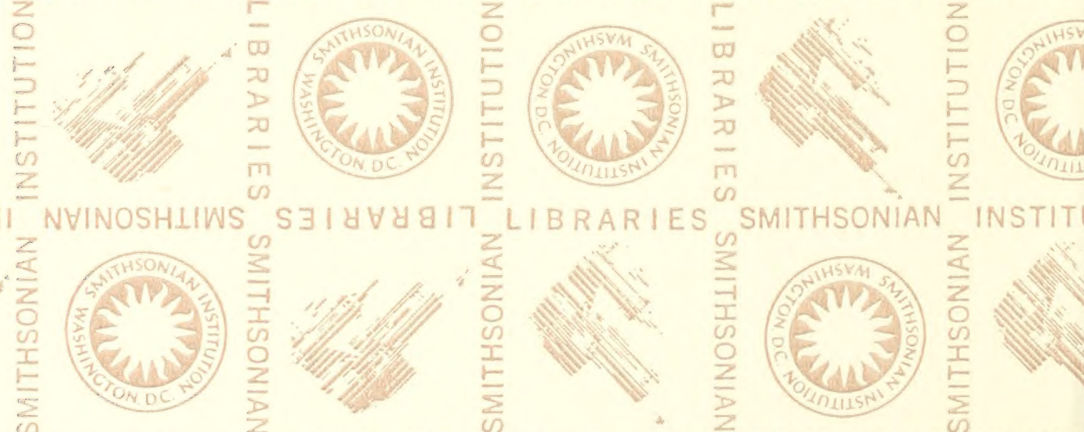

INSTITUTION NOIINIIISNI NVINOSHLIWS 


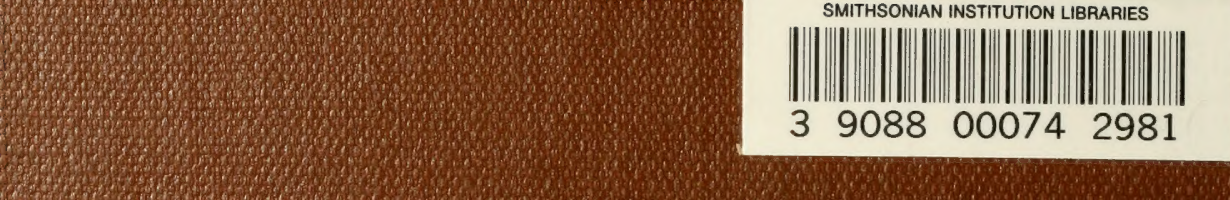

